\title{
SYNTHESIS AND BIOLOGICAL EVALUATION OF TREHALOSE GLYCOLIPIDS
}

by

Ashna Ashneen Khan

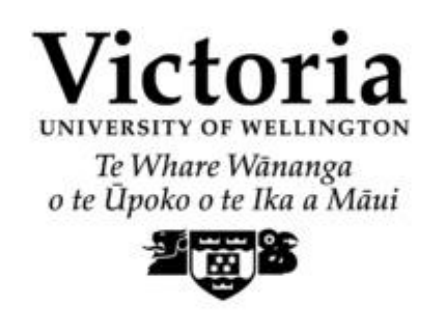

A thesis

submitted to Victoria University of Wellington in fulfilment of the requirements for the degree of Doctor of Philosophy

VICTORIA UNIVERSITY OF WELLINGTON 



\section{Abstract}

Numerous $\alpha$, $\alpha$-trehalose diesters have been isolated from bacteria such as Mycobacteria and Corynebacteria, and more recently from Caenorhabditis elegans dauer larvae. Although these glycolipids are thought to confer protection to the bacteria and larvae against harsh environmental conditions, it is the biological activities of these compounds, including anti-tumour and adjuvant activities, which have been of major interest to scientists over recent years.

In this thesis, three different aspects relating to the synthesis and testing of defined trehalose glycolipids will be presented. First, the synthesis of a variety of fatty acid trehalose diesters (TDEs) with varying lipid lengths was performed and the ability of these glycolipids to activate macrophages was studied. Two different synthetic strategies were employed to attain the TDEs of interest and it was observed that lipid lengths of more than 18 carbons were required for macrophage activation. Furthermore, the C22 fatty acid trehalose monoester (TME) and the C26 TME were also synthesised and interestingly they both showed macrophage activation abilities, with subsequent studies indicating that like TDEs, the TMEs were also ligands for mincle, a C-type lectin found on macrophages. This is the first time that TMEs have been tested for their ability to activate macrophages via Mincle. The cytotoxicity of these compounds and subsequent anti-tumour activity of a few selected compounds were also studied and although the TDEs and TMEs did not exhibit any significant cytotoxicity, in in vivo models the C10 TDE and C22 TDE both showed anti-tumour activity. This depicts that the mechanism for anti-tumour activity of these compounds is not due to cytotoxicity but due to as yet unidentified pathway.

Methodology that can be applied to the synthesis of more complex trehalose glycolipids, such as trehalose dicorynomycolates (TDCMs, isolated from Corynebacteria) and trehalose dimycolates (TDMs, isolated from Mycobacteria) was also explored. One of the key steps frequently used in the synthesis of these glycolipids is the Fráter-Seebach alkylation. To improve the efficacy of this methodology allylic iodides, rather than alkyl iodides were used for the $\alpha$-alkylation of $\beta$-hydroxy esters. Our results showed that for all substrates studied, the yield of the $\alpha$-alkylation was greatly improved when the allylic, rather that the alkyl halide 
was used. The use of this methodology in the synthesis of trehalose monocorynomycolate (TMCM) was also investigated.

The third aspect of this thesis focuses on the use of Affinity Based Proteome Profiling (AfBPP) for elucidating the receptors that TDMs bind to upon interacting with host cell. AfBPP focuses on using small molecules which mimic the natural substrate for a particular protein and through the use of 'trap' and 'tag' groups on the molecule the identity of the protein/receptors can be determined. The synthesis of a TDM probe containing a benzophenone 'trap' group and an alkyne 'tag' group will be discussed. 


\section{Acknowledgements}

My $\mathrm{PhD}$ has been an amazing and fulfilling journey with its own share of ups and downs. There are a lot of people who have stayed with me through it all and to whom I am extremely grateful for their support.

To begin with, I would like to thank my supervisors, Drs. Mattie Timmer and Bridget Stocker for all the guidance and support you have provided me over the past years. Thanks for teaching me how to write and helping me solve so many of my chemistry problems.

A big thank you to the past and present Immunoglycomics team, Lynton, Ben, Emma, Anna, Greg, Janice, Chris, Emily, Janelle, Hilary, Stefan, Gert, Amy, Jessie and Steph. Thanks for all the talks, laughters and for making the lab such an awesome place to work in. Special thanks to Steph for helping me with the biological assays and taking time out for celebrating all the little achievements.

Thanks to James for doing the cytotoxicity testing, Rene and Dr. Jacquie Harper for helping with the cytokine analysis, Dr. Faustin Kamena who helped me set up the macrophage assay and for doing biological testing on the trehalose glycolipids. Thanks also to Sabine for doing the in vivo tumour work.

I would also like to thank VUW, Curtis-Gordon Research Scholarship and Claude McCarthy Fellowship for funding throughout my $\mathrm{PhD}$ studies. Thanks to all the staff of Malaghan Institute of Medical Research and School of Chemical and Physical Sciences who have provided assistance and support to me in so many ways.

Finally I have to thank my family for supporting me through the past few years. My mum and dad, for believing in me and providing me with constant encouragement. My brothers Azwal and Amaan for being there for me, helping me out financially and for giving me their love and support. Last but not the least my husband, Razeen, who has been a pillar of strength throughout my studies. Thanks for putting up with my moods and taking time out to listen to my chemistry problems (which you knew nothing about!). Your support and encouragement over the past 4 years has been phenomenal, and without you my dreams would not have been possible. This $\mathrm{PhD}$ is as much a part of you as it is of me. 



\section{Table of Content}

CHAPTER 1: Introduction

1.1 Mycobacteria in the treatment of disease 1

1.2 Overview 3

1.3 Mycobacterium tuberculosis and related mycobacteria 3

$\begin{array}{ll}1.4 \text { Mycobacterial cell wall components } & 7\end{array}$

$\begin{array}{ll}1.5 \text { Trehalose 6,6'-diesters } & 14\end{array}$

1.6 Fráter-Seebach alkylation in TDCM and TDM syntheses 32

1.7 Trehalose diester probes to study trehalose immunology 39

1.8 Thesis outline 49

CHAPTER 2: TDE Synthesis

2.1 Introduction 58

2.2 TDE Synthesis $\quad 59$

2.3 Conclusion $\quad 72$

2.4 Experimental Section $\quad 72$

CHAPTER 3: TDE Biological Testing

3.1 Introduction $\quad 90$

3.2 Results and Discussion $\quad 92$

$\begin{array}{ll}3.3 \text { Conclusion } & 112\end{array}$

$\begin{array}{ll}3.4 \text { Experimental } & 113\end{array}$

CHAPTER 4: An Improved Fráter-Seebach Alkylation

$\begin{array}{ll}4.1 \text { Introduction } & 119\end{array}$

$\begin{array}{ll}4.2 \text { Results and Discussion } & 121\end{array}$

$\begin{array}{ll}4.3 \text { Conclusion } & 135\end{array}$

$\begin{array}{ll}4.4 \text { Experimental } & 135\end{array}$

CHAPTER 5: TMCM Synthesis

$\begin{array}{ll}5.1 \text { Introduction } & 153\end{array}$

5.2 TMCM and TDCM Synthesis 154

$\begin{array}{ll}5.3 \text { Conclusion and Future Work } & 161\end{array}$

$\begin{array}{ll}5.4 \text { Experimental } & 161\end{array}$ 
CHAPTER 6: AfBP Probe Synthesis and Biological Testing

$\begin{array}{ll}6.1 \text { Introduction } & 169\end{array}$

$\begin{array}{lr}\text { 6.2 TDM Probe Synthesis } & 170\end{array}$

$\begin{array}{lr}6.3 \text { Biological Testing } & 185\end{array}$

$\begin{array}{lr}6.4 \text { Future Work } & 187\end{array}$

$\begin{array}{lr}6.5 \text { Conclusion } & 189\end{array}$

$\begin{array}{lr}6.6 \text { Experimental } & 189\end{array}$

CHAPTER 7: Summary and Future Prospects

$\begin{array}{ll}7.1 \text { Summary } & 203\end{array}$

$\begin{array}{ll}\text { 7.2 Future Prospects } & 205\end{array}$

$\begin{array}{ll}\text { List of Publication } & 207\end{array}$

Appendix

${ }^{1} \mathrm{H}$ and ${ }^{13} \mathrm{C}$ NMR spectra of synthesised compounds 208 


\section{List of Figures}

\section{CHAPTER 1}

1. Taxonomic classification of bacteria 5

2. Respiratory system. 6

3. Cartoon of M. $t b$ cell wall $\quad 7$

4. Structure of PIMs (1) 8

5. $\operatorname{LM~(2)~and~LAM~(3)~structures~} \quad 10$

6. $\quad$ PDIM (4) from M. $t b \quad 11$

7. Stereochemistry of esters in PDIM from various mycobacterial 11 species

8. $\quad$ PGL from M. leprae and $M . t b \quad 12$

9. TDMs (10) and mycolic acids (11) 13

$\begin{array}{ll}\text { 10. Sulfolipids } & 14\end{array}$

11. TDEs (14) and maradolipids (15) 15

12. Cartoon of Mincle interacting with TDM and TDB 16

13. Representative maradolipid 20

14. Lipid composition of maradolipids 20

15. Trehalose dicorynomycolate 23

16. Representative cartoon of Activity/Affinity Based Proteome 40 Probe

17. ABPP vs AfBPP 41

18. Common reporter tags used in ABP and AfBP probes 42

19. Ligation methods for azide and alkyne coupling 43

20. Examples of common trap systems for AfBP probes 44

21. Aryl azide and diazirines based AfBPs 46

22. Benzophenone based AfBP probes 47

23. CC-based AfBP probes $\quad 48$

24. TDEs 50

25. TMCM analogue 51

26. AfBPP probe 51

\section{CHAPTER 2}

1. Target TDEs $1 \quad 59$

2. ${ }^{1}$ H NMR spectrum of C26 TME (9g) 68

3. ${ }^{13} \mathrm{C}$ NMR spectrum of C26 TME (9g) 69

4. ${ }^{1} \mathrm{H}$ NMR spectrum of C26 TDE (1g) $\quad 70$

5. ${ }^{13} \mathrm{C}$ NMR spectrum of C26 TDE (1g) 71 


\section{CHAPTER 3}

1. $\quad$ TDM (1), TDEs (2) and TMEs (3) 91

2. NO production by TDB-treated BMM 94

3. NO production by TDB-treated BMM following IFN- $\gamma$ priming 95 at different concentrations

4. Cytokine production by TDB-treated BMM 96

5. NO production by TDE-treated BMM 97

6. Cytokine production by TDE-treated BMM 98

7. NO and cytokines IL-6 and IL-1 $\beta$ production by TDB/TME- 102 treated BMM

8. NO production from TDE/TME-treated BMM derived from 105 $\mathrm{Mincle}^{-/-}, \mathrm{TLR} 2 / 4^{-/-}$and wild type mice

9. The effect of priming with IFN- $\gamma$ on BMM stimulated with TDB 107

10. Cytotoxicities of TMEs and TDEs against HepG cell line 110

\section{CHAPTER 4}

1. TDM (1) and TDCM (2) 120

2. ${ }^{1} \mathrm{H}$ NMR spectrum of product $\mathbf{5 j} \quad 131$

3. ${ }^{13} \mathrm{C}$ NMR spectrum for product $\mathbf{5} \mathbf{j} \quad 132$

4. $\quad{ }^{1} \mathrm{H}$ NMR spectrum of product $\mathbf{5 k} \quad 133$

5. $\quad{ }^{13} \mathrm{C}$ NMR spectrum of product $\mathbf{5 k} \quad 134$

\section{CHAPTER 5}

1. TDCM (1), TMCM analogue (2) and TDCM analogue (3) 154

\section{CHAPTER 6}

1. Proposed AfBP Probe 1 170

2. ${ }^{1}$ H NMR spectrum of benzophenone $6 \quad 173$

3. $\quad{ }^{1} \mathrm{H}$ NMR spectra of compounds $\mathbf{1 8}$ and $\mathbf{1 9} \quad 177$

4. ${ }^{1} \mathrm{H}$ NMR spectrum of AfBP probe 1

5. ${ }^{13} \mathrm{C}$ NMR spectrum of AfBP probe $1 \quad 184$

6. $\quad \mathrm{NO}$ production by BMM treated with AfBP probe $\mathbf{1} 186$

7. AfBP probe $\mathbf{1}$ in Affinity Based Profiling 188 


\section{List of Schemes}

\section{CHAPTER 1}

1. Trehalose dipalmitate synthesis 18

2. Maradolipid synthesis 22

3. Corynomycolic acid synthesis 24

4. Synthesis of TDCM 26

5. TDCM synthesis via Noyori's asymmetric reduction 27

6. Retrosynthesis of $\alpha$-TDM $10 \quad 30$

7. Fráter's alkylation 33

8. Seebach's alkylation 33

9. Fráter-Seebach alkylation in mycolic acid synthesis 35

10. Chain-elongation methodology in mycolic acid synthesis 36

11. Fráter-Seebach alkylation in corynomycolic acid and analogues 37 syntheses

12. Alternate route for C20 TDCM analogue synthesis 38

13. Chemistry of benzophenone after photolysis 45

14. Improved methodology for Fráter-Seebach alkylation 50

\section{CHAPTER 2}

1. Initial synthetic strategy 60

2. Reaction mechanism for BSA mediated silylation of trehalose 63

3. Alternate synthetic strategy used 65

\section{CHAPTER 3}

1. Griess reaction 93

2. MTT reduction 109

\section{CHAPTER 4}

1. Transition state for allyl halide substitution via an $\mathrm{S}_{\mathrm{N}} 2$ reaction 120

$\begin{array}{ll}\text { 2. Proposed Fráter-Seebach alkylation } & 121\end{array}$

3. Synthesis of representative allylic iodides 122

4. Mechanism for the $S_{N} 2$ reaction 123

5. Hydrogenation of $\alpha, \beta$-unsaturated esters 127

$\begin{array}{ll}\text { 6. Hydrolysis of product } \mathbf{5 b} & 128\end{array}$

7. Confirming the stereochemistry of the alkylated products 128

8. Explanation of stereoselectivity in the Fráter-Seebach alkylation 129 


\section{CHAPTER 5}

1. Retrosynthesis for TDCMs $\mathbf{1}$ and $3 \quad 155$

2. $\quad$ Synthesis of epoxide $7 \quad 156$

3. Synthesis of TBS protected corynomycolic acid 5 159

4. Synthesis of protected TMCM analogue 15 160

\section{CHAPTER 6}

1. Retrosynthesis of target AfBP probe 1

2. Synthesis of benzophenone $6 \quad 172$

$\begin{array}{lll}3 . & \text { Synthesis of iodide } 7 & 175\end{array}$

4. Zipper reaction for isomerisation of triple bonds 176

5. Synthesis of benzophenone building block $3 \quad 179$

6. Total synthesis of AfBP probe 1 


\section{List of Tables}

\section{CHAPTER 2}

1. Formation of TDEs 61

2. Attempted debenzylation conditions 62

3. Esterification reaction using diol $6 \quad 66$

\section{CHAPTER 4}

1. Alkylation Conditions and Yields 125

\section{CHAPTER 5}

1. Copper mediated Grignard reaction

\section{CHAPTER 6}

1. Alkylation conditions for coupling benzophenone $\mathbf{6}$ and iodide $\mathbf{7}$

178 


\section{List of Abbreviations}

\begin{tabular}{|c|c|c|c|}
\hline $\mathrm{AcOH}$ & acetic acid & IFN & interferon \\
\hline $\mathrm{ABP}$ & activity based proteome & IL & interleukin \\
\hline $\mathrm{A} f \mathrm{BP}$ & affinity based proteome & IMDM & Iscove's Modified \\
\hline ABPP & $\begin{array}{l}\text { activity based proteome } \\
\text { profiling }\end{array}$ & Imid. & $\begin{array}{l}\text { Dulbecco's Medium } \\
\text { imidazole }\end{array}$ \\
\hline $\mathrm{A} f \mathrm{BPP}$ & affinity based proteome profiling & IR & infrared spectroscopy \\
\hline APC & antigen presenting cell & $J$ & coupling constant \\
\hline aq. & aqueous & LAM & lipoarabinomannan \\
\hline BCG & Bacillus Calmette-Guérin & LC/MS & liquid chromatography \\
\hline BINAP & $\begin{array}{l}\text { 2,2'-bis(diphenylphosphino)- } \\
\text { 1,1'-binaphthyl }\end{array}$ & LDA & $\begin{array}{l}\text { mass spectrometry } \\
\text { lithium diisopropylamide }\end{array}$ \\
\hline BMM & bone marrow macrophages & LM & lipomannan \\
\hline BMS & borane dimethyl sulfide & LPS & lipopolysaccharide \\
\hline $\mathrm{Bn}$ & benzyl & $\mathrm{m}$ & multiplet \\
\hline $\begin{array}{l}\text { BSA } \\
\text { Calcd. }\end{array}$ & $\begin{array}{l}\mathrm{N}, \mathrm{O} \text {-bis-trimethylsilylacetamide } \\
\text { calculated }\end{array}$ & $\mathrm{MCP}$ & $\begin{array}{l}\text { monocyte chemoattractant } \\
\text { protein }\end{array}$ \\
\hline $\mathrm{CC}$ & click chemistry & MS & mass spectrometry \\
\hline $\mathrm{CD}$ & cluster of differentiation & $\mathrm{Me}$ & methyl \\
\hline $\begin{array}{l}\text { COSY } \\
d\end{array}$ & $\begin{array}{l}\text { Correlation spectroscopy } \\
\text { doublet }\end{array}$ & $\mathrm{MHC}$ & $\begin{array}{l}\text { major histocompatibility } \\
\text { complex }\end{array}$ \\
\hline $\mathrm{dd}$ & doublet of doublets & $\mathrm{MHz}$ & megahertz \\
\hline DC & dendritic cell & MIC & minimum inhibitory \\
\hline DCC & $N, N^{\prime}$-dicyclohexylcarbodiimide & & concentration \\
\hline DCM & dichloromethane & $\min$. & minutes \\
\hline DIAD & diisopropyl azodicarboxylate & Mincle & macrophage inducible C-type \\
\hline DIPT & diisopropyl tartrate & & lectin \\
\hline DMAP & 4-(dimethyl)-aminopyridine & MIP & macrophage inflammatory \\
\hline DMF & $N, N$-dimethylformamide & & protein \\
\hline DMSO & dimethyl sulfoxide & MMP & matrix metalloproteinases \\
\hline EDCI & 1-ethyl-3-(3- & $\mathrm{Mp}$ & melting point \\
\hline & dimethylaminopropyl) & $m / z$ & mass to charge ratio \\
\hline & carbodiimide & M. $t b$ & Mycobacterium tuberculosis \\
\hline eq. & equivalent & MyD & myeloid differentiation \\
\hline ESI & electrospray ionisation & NADPH & nicotinamide adenine \\
\hline $\mathrm{Et}$ & ethyl & & dinucleotide phosphate \\
\hline GMCSF & granulocyte macrophage colony & NK & natural killer \\
\hline & stimulating factor & NMR & nuclear magnetic \\
\hline HepG2 & human hepatocellular carcinoma & & resonance \\
\hline HDAC & histone deactylases & $\mathrm{NO}$ & nitric oxide \\
\hline HMBC & $\begin{array}{l}\text { heteronuclear multiple } \\
\text { bond correlation }\end{array}$ & NOD & $\begin{array}{l}\text { nucleotide oligomerisation } \\
\text { domain }\end{array}$ \\
\hline HMPA & hexamethylphosphoric triamide & Obsd. & observed \\
\hline HRMS & $\begin{array}{l}\text { high-resolution mass } \\
\text { spectrometry }\end{array}$ & PAMP & $\begin{array}{l}\text { pathogen associated molecular } \\
\text { pattern }\end{array}$ \\
\hline HSQC & heteronuclear single & PBS & phosphate-buffered saline \\
\hline & quantum coherence & PCC & pyridinium chlorochromate \\
\hline
\end{tabular}




$\begin{array}{llll}\text { PDIM } & \text { phthiocerol dimycocerosate } & \text { TDM } & \text { trehalose dimycolate } \\ \text { PGL } & \text { phenolic glycolipid } & \text { TES } & \text { triethylsilane } \\ \text { ppm } & \text { parts per million } & \text { TFA } & \text { trifluoroacetic acid } \\ \text { PRR } & \text { pathogen recognition receptor } & \text { Tf } & \text { trifluoromethanesulfonyl } \\ p \text { TsOH } & \text { para-toluenesulfonic acid } & \text { THF } & \text { tetrahydrofuran } \\ \text { r.t. } & \text { room temperature } & \text { THP } & \text { tetrahydropyran } \\ \text { s } & \text { singlet } & \text { TLC } & \text { thin layer chromatography } \\ \text { sat. } & \text { saturated } & \text { TLR } & \text { toll-like receptor } \\ \text { SDS- } & \text { sodium dodecyl sulfate } & \text { TMCM } & \text { trehalose monocorynomycolate } \\ \text { PAGE } & \text { polyacrylamide gel } & \text { TME } & \text { trehalose monoester of fatty } \\ & \text { electrophoresis } & & \text { acid } \\ \text { SL } & \text { sulfolipid } & \text { TMS } & \text { trimethyl silyl } \\ \text { t } & \text { triplet } & \text { Tr } & \text { tumour necrosis factor } \\ \text { TAM } & \text { tumour associated macrophage } & \text { triphenylmethyl } \\ \text { TB } & \text { tuberculosis } & \text { VEGF } & \text { vascular endothelial } \\ \text { TBAF } & \text { tetrabutyl ammonium fluoride } & & \text { growth factor } \\ \text { TBDPS } & \text { tert-butyldiphenylsilyl } & & \\ \text { TBS } & \text { tert-butyldimethylsilyl } & & \\ \text { TDB } & \text { trehalose dibehenate } & & \\ \text { TDCM } & \text { trehalose dicorynomycolate } & & \\ \text { TDE } & \text { trehalose diester of fatty acid } & & \end{array}$





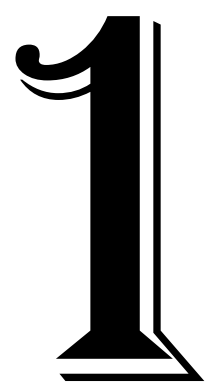

\section{General}

\section{Introduction}

\subsection{Mycobacteria in the treatment of disease: $A$ historical perspective}

The use of bacteria in the treatment of disease has been a topic of much interest to the scientific community for over 100 years. In the late 1800s, William Coley was the first to illustrate that bacteria have the potential to be used in the treatment of cancer. In his seminal work, Coley injected streptococcal bacteria into a cancer patient and noted a reduction in the tumour burden. ${ }^{1}$ Although this result was encouraging, subsequent injections with streptococcal bacteria alone sometimes resulted in fatalities. Accordingly, Coley switched to using a tumour vaccine containing Streptococcal pyogenes and Serratia marcescens. This concoction, known as 'Coley's toxins', turned out to be more effective in treating malignant tumors. ${ }^{1,2}$

Over the next 40 years, Coley treated more than 1000 patients, however, his work was often criticised due to poor documentation and follow up of patients, variability 
in the modes of administration, and the inconsistencies in Coley's Toxin preparation. There were 13 different toxin preparations reported, of which some were more effective than others. ${ }^{3}$ Because of this, Coley's experiments were largely ignored until the late $20^{\text {th }}$ century.

Science has progressed significantly since Coley's original experiments and now it is widely acknowledged that bacteria and bacterial components can be used in disease treatment and in vaccination programmes. For example, inactive and dried Mycobacterium tuberculosis $(M . t b)$ is a major component of Freund's complete adjuvant system which has proved to be effective in disease treatments. It has shown potential to prevent juvenile-onset diabetes in mouse models ${ }^{4}$ and its use in Parkinson's disease treatments in rat models has also been explored. ${ }^{5}$ However, the use of this adjuvant in humans is forbidden due to its toxicity. ${ }^{6}$

Bacillus Calmette-Guérin (BCG) is the current vaccine in use for tuberculosis (TB) and is made up of attenuated live bovine tuberculosis bacillus, Mycobacterium bovis, which has lost its virulence in humans. BCG was first formulated by Calmette and Guérin in $1920{ }^{7}$ given to a human infant in 1921 , and to date, has been administered to four billion people making it the most widely used vaccine in the world. ${ }^{8}$ Although the vaccine is effective against childhood tuberculosis, meningitis, and miliary tuberculosis, the efficacy of the vaccine is questionable in adult pulmonary tuberculosis where variable results have been obtained. ${ }^{9}$ This could be due to the inability of BCG to impart a memory $\mathrm{T}$ cell response which is vital for long-term immunity to TB. To address this problem, adjuvants could be incorporated into vaccines. Currently bacterial cell components known to induce $\mathrm{T}$ cell immunity are being tested in vaccine programmes to deduce if they boost the response of the vaccine over a long period of time. ${ }^{10} \mathrm{BCG}$ is also used as a standard therapy in the treatment of bladder cancer. ${ }^{11}$

Of particular interest to us is the potential use of mycobacterial cell wall components, from $M . t b$ and related mycobacteria, in the treatment of disease. While there is much evidence to suggest that such cell wall components have important immunomodulatory effects, ${ }^{12}$ to date, the immunomodulatory properties of distinct (homogenous) cell wall constituents has been poorly documented. Moreover, the 
mechanism of action of individual mycobacterial cell wall components is not fully understood.

\subsection{Overview}

The objective of this thesis is to better understand the immunomodulatory properties of distinct mycobacterial cell wall components with a view that this may lead to better therapies and vaccination protocols against tuberculosis. In particular, the focus of my research relates to the effects of trehalose diesters (which are the major cell wall components of $M$. $t b$ ) on the immune response. This may be achieved via the synthesis of distinct trehalose diesters of differing lipid lengths using novel Fráter-Seebach alkylation methodology, and the subsequent testing of these glycolipids in a number of biological assays. In addition, modified trehalose dimycolate (TDM) containing functionalised traps (e.g. benzophenone, azides) will be prepared so that the proteins that bind to TDM can be elucidated via Affinity Based Proteome Profiling (A $f$ BPP). ${ }^{13}$ The context of this TDM work will be discussed following a brief discussion of $M$. $t b$ and the variety of cell wall constituents that the bacterium contains.

\subsection{Mycobacterium tuberculosis and related mycobacteria}

$M . t b$ is a wax-coated rod-shaped bacillus discovered by Robert Koch in $1882 .{ }^{14}$ It is a slow growing, aerobic, acid-fast, non-motile, obligate intracellular pathogen that can infect several animal species, as well as humans. The bacterium divides every 15 to 20 hours which is quite slow compared to majority of other bacteria (Escherichia coli divides every 20 minutes). ${ }^{8} M$. $t b$ belongs to the Mycobacterium family in the Corynebacterinae sub-group of the Actinomycete line (Figure 1). The class Actinobacteria under phylum Actinobacteria comprises of Gram positive bacteria with high guanine and cytosine content. Although $M$. $t b$ does not stain with Gram 
staining, it is classified under this class due to lack of an outer cell membrane (as in Gram negative bacteria). The sub-order Corynebacteria contains most of the acid fast bacteria like Mycobacteriaceae, Nocadiaceae and Corynebacterineae. Bacteria classified under genus Mycobacterium in the Mycobacteriaceae family have a characteristic cell wall which is thicker than those found in other bacteria. In addition, the cell wall is hydrophobic, waxy and rich in mycolic acids and mycolates. The cell wall structure of Mycobacterium will be discussed in more detail in section 1.4 . 


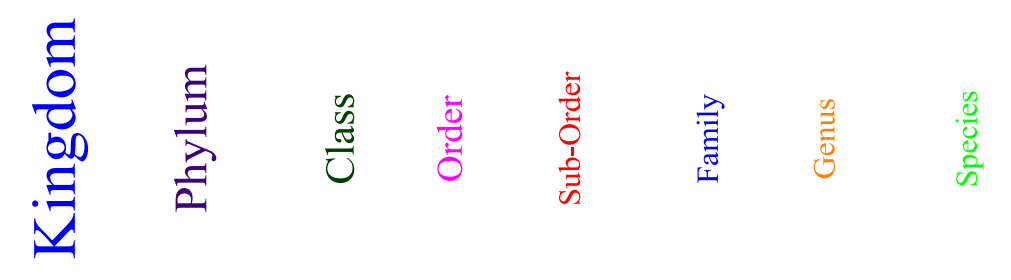

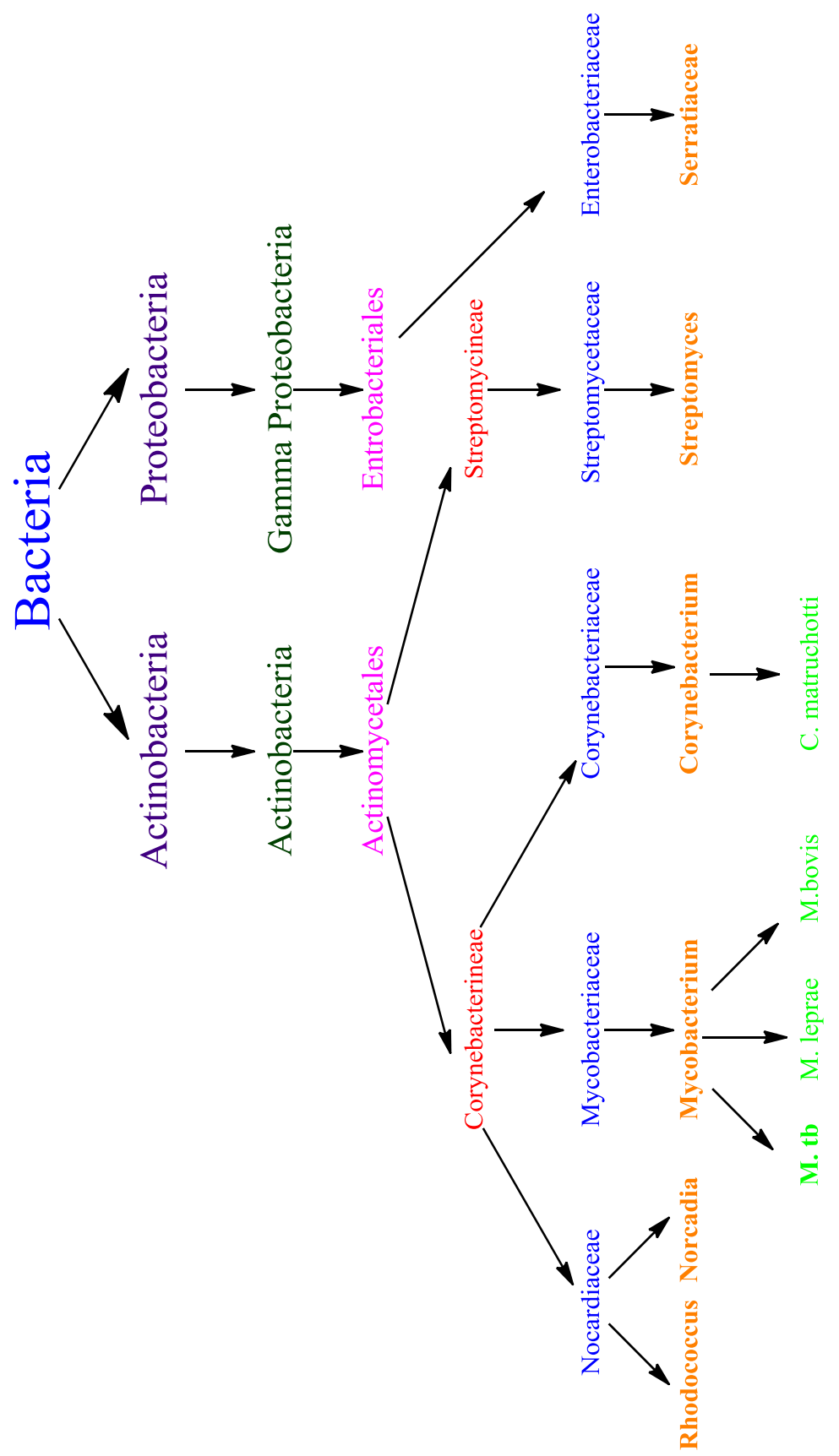

Figure 1. Taxonomic classification of bacteria. 
$M$. $t b$ is responsible for causing TB, a pernicious disease that affects the respiratory system (Figure 2). One third of the world's population is infected by this bacteria ${ }^{15}$ that kills about 1.7 million people every year. The occurrence of TB strongly correlates with reduced socio-economic status making TB more prominent in developing countries in Asia and Africa. M. $t b$ is also an opportunistic pathogen which is quite prominent in people who are HIV positive, for whom TB is a leading cause of death. In order to treat TB, a cocktail of drugs is required along with very lengthy treatment regimes. In addition, due to the marginal efficacy of the BCG vaccine, the vaccination against $M$. $t b$ has been discontinued in many countries, including NZ, except for those deemed to be in high risk groups. It is hoped that by understanding more about the immunomodulatory effects of the cell wall components of $M$. $t b$, better TB vaccines can be developed and novel drug targets identified.

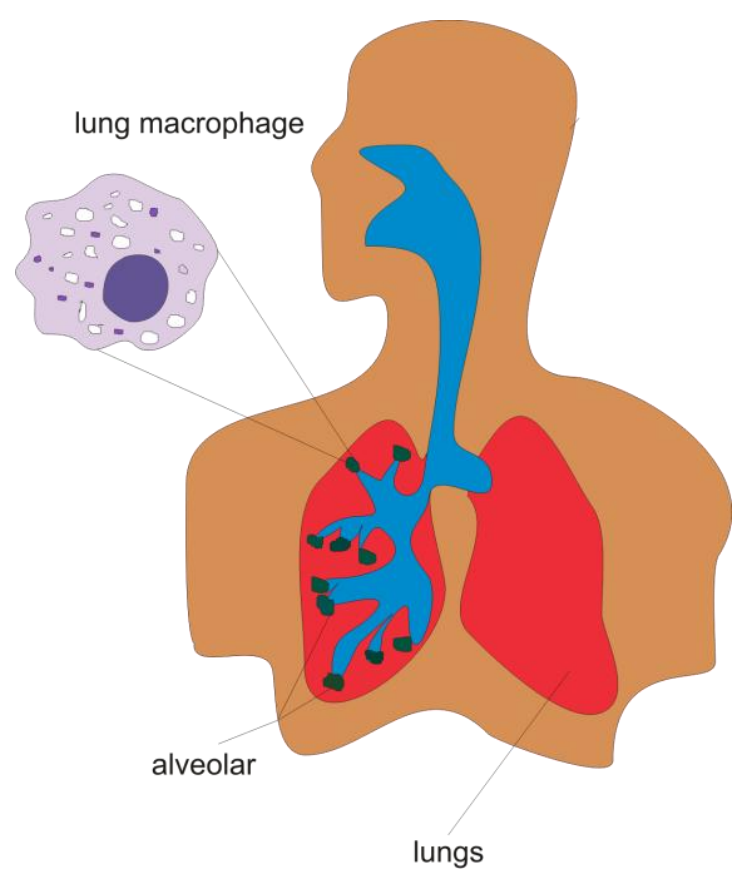

Figure 2. Respiratory system. 


\subsection{Mycobacterial cell wall components}

The ability of $M . t b$ to remain in a dormant state in the host organism and evade destruction from drug treatment, chemical injury and the host immune system has been attributed to the outer cell wall structure of $M$. $t b$ that has been deemed crucial in the survival of the bacteria. ${ }^{16}$ Made up of various types of lipids, the cell wall structure of $M . t b$ is highly complex and contains several key features (Figure 3). ${ }^{17,18}$ Closest to the plasma membrane is the peptidoglycan layer comprising of a highly cross-linked polymer of amino acids, like alanine and glutamic acid, and amino sugars. Protruding from the peptidoglycan layer are arabinogalactan saccharides which contain linear galactan and branched arabinose motifs. The arabinose chains are then linked to mycolic acids which are primarily present in two forms in the cell wall: covalently bonded to arabinogalactan, and as esters of trehalose giving rise to trehalose dimycolate (TDM), the most abundant glycolipid present in the cell wall of M. $t b$. The cell wall also contains phthiocerol dimycocerosate (PDIM) and phenolic glycolipids (PGL) (not shown), along with lipoarabinomannan (LAM) which consists of a phosphoryl-inositol-mannose (PIM) anchor and a polysaccharide backbone. The individual cell wall glycoconjugates are discussed in more details as follows.

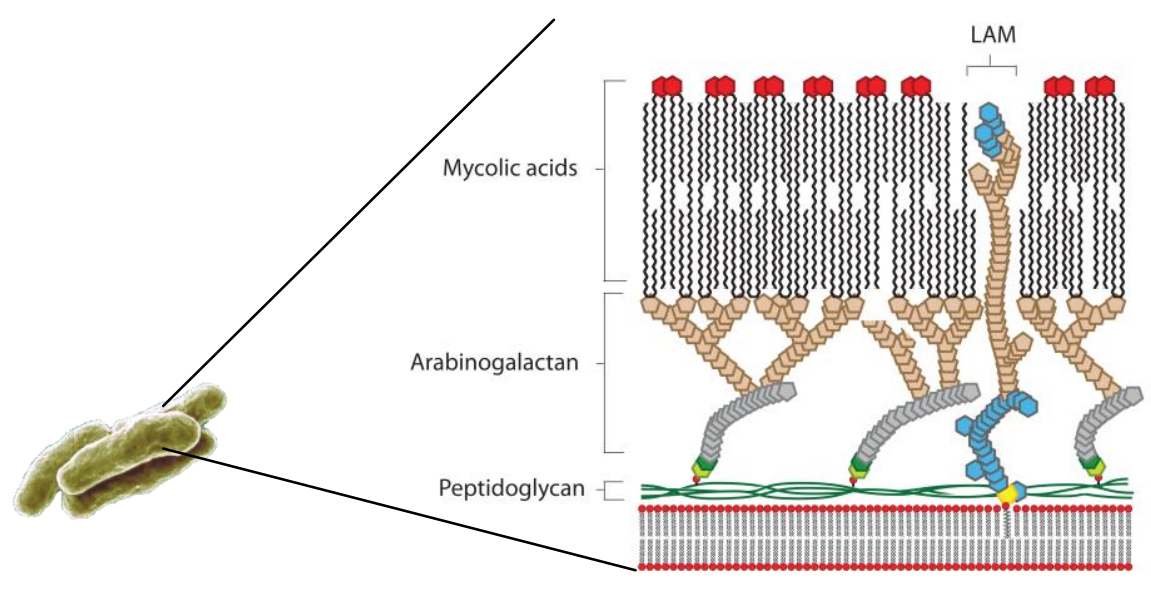

Figure 3. Cartoon of $M$. $t b$ cell wall. 


\subsubsection{Phosphoryl-inositol-mannosides (PIMs)}

M. $t b$ contains several phosphoryl-inositol-mannosides (PIMs) structures (1, Figure 4) including PIM $_{1}$ (where the inositol residue of PI [phosphatidyl-myo-inositol] is mannosylated at the C-2 position), $\mathrm{PIM}_{2}$ (where $\mathrm{PIM}_{1}$ is further mannosylated at C-6 of inositol). ${ }^{19}$ Further $\alpha-1,6$ mannosylation of $\mathrm{PIM}_{2}$ gives rise to $\mathrm{PIM}_{3}$ and $\mathrm{PIM}_{4}$ the common precursor of $\mathrm{PIM}_{5}$ and $\mathrm{PIM}_{6}$ (made by further $\alpha-1,2$ mannosylation of $\mathrm{PIM}_{4}$ ). In addition, the core PI unit is found as a unique entity on its own. The synthesis of naturally occurring PIMs and analogues has been undertaken and many elegant syntheses have been reported. (For a recent review see ref. ${ }^{20}$ )

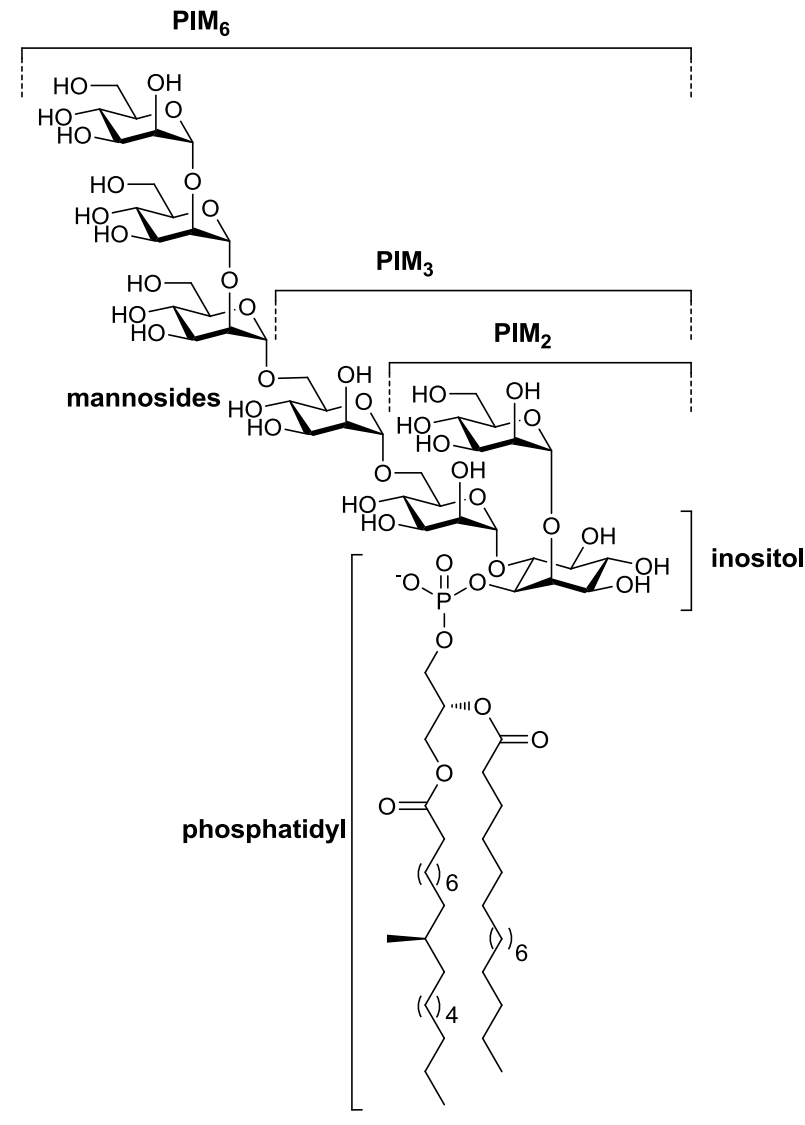

1

Figure 4. Structure of PIMs (1).

PIMs exhibit both immunosuppressive and adjuvant activities. The ability of PIMs to induce cell mediated immunity, particularly, a Th1 type immune response illustrates 
their potential to be used as adjuvants in sub-unit vaccines. ${ }^{21,22}$ In a study by Painter and co-workers, a synthetic analogue of $\mathrm{PIM}_{6}$ was shown to induce DC-mediated suppression of human $\mathrm{CD}^{+} \mathrm{T}$ cell proliferation, which can enhance the survival of M. $t b$ when resident in the host cell. ${ }^{23} \mathrm{PIM}_{6}$ has also been found to interact with DCSIGN, a receptor on dendritic cells. DC-SIGN has also been shown to be regulated following host infection with $M$. $t b$, thus suggesting that PIMs could potentially be involved in the virulence and pathogenesis of $M . t b .^{24}$

\subsubsection{Lipoarabinomannan (LAMs)}

PIMs are common precursors for more complex mycobacterial cell wall components like lipomannan (LM, 2, Figure 5), lipoarabinomannan (LAM, 3) and mannan capped lipoarabinomannan (ManLAM). $\mathrm{PIM}_{4}$ is the key biosynthetic intermediate whereby $\alpha-1,6$ linked mannose to the $\mathrm{PIM}_{4}$ backbone leads to mature branched lipomannan, which undergoes subsequent arabinoyslation to form lipoarabinomannan and further mannosylation of LAM leads to ManLAM. ${ }^{25}$ The use of LAM as a diagnostic tool for tuberculosis was investigated by Sada et al., whereby they noted the presence of LAM in the serum of most patients with pulmonary tuberculosis, indicating that the detection of LAM is an accurate diagnostic tool for pulmonary tuberculosis. ${ }^{26}$ In another study, purified LM, LAM and $\mathrm{PIM}_{1}$ from a cell wall fraction of $M$. bovis BCG Tokyo-172 strain were examined for their ability to induce differentiation of human peripheral blood naive CD4 T cells into Th1 and Th2 cells. ${ }^{27}$ The results showed that LAM/LM enhanced T cell differentiation under both Th1 and Th2 conditions, since both Th1 [e.g. interleukin (IL)-2, tumour necrosis factor (TNF)- $\alpha$, interferon (IFN)- $\gamma$ ] and Th2 (e.g. IL-4, IL-5) cytokines were observed, indicating that LAM/LM possess a potent modulating activity in human systems and could thus be used in vaccine development for both Th1 and Th2 diseases. 


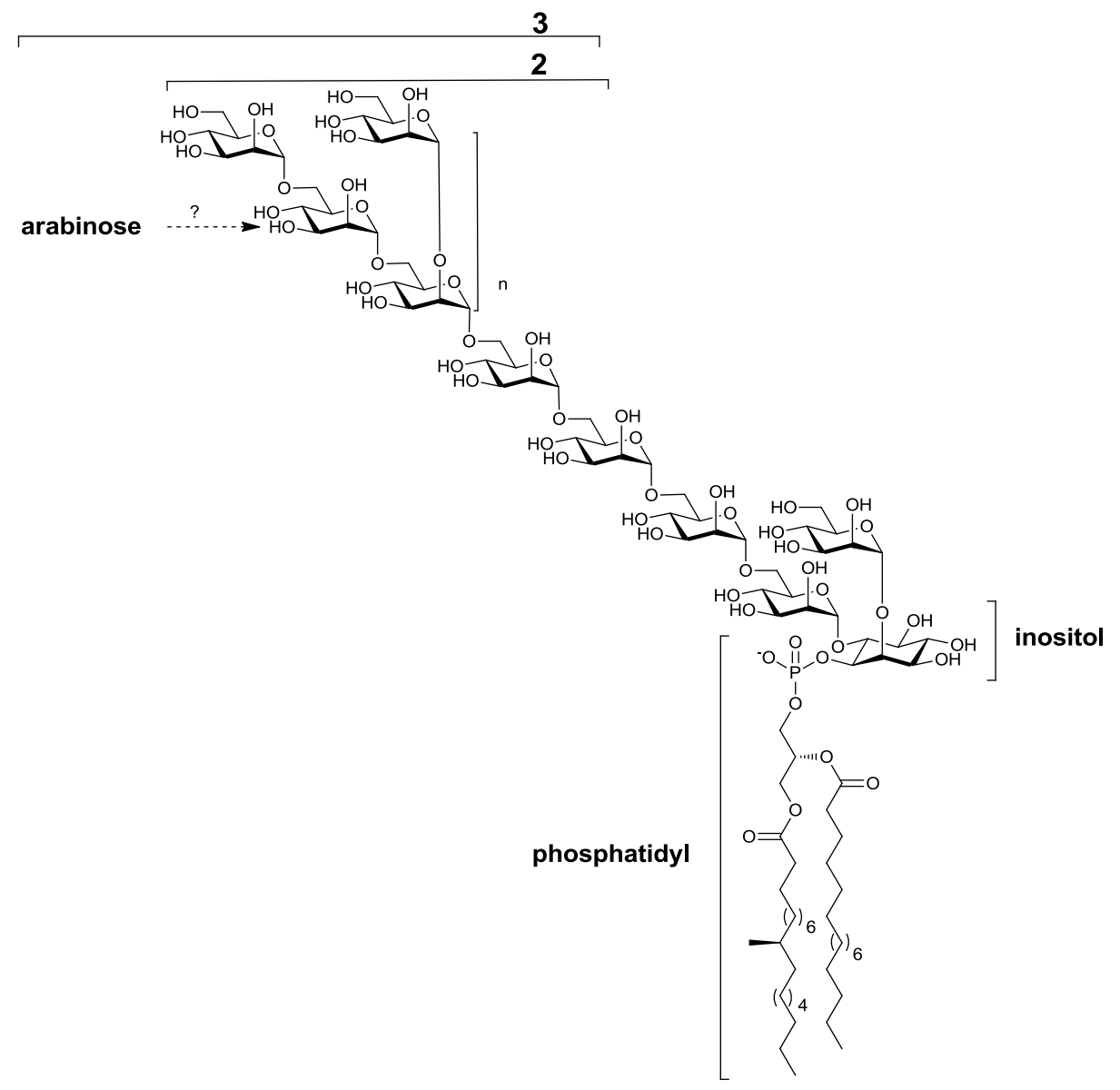

Figure 5. LM (2) and LAM (3) structures.

\subsubsection{Phthiocerol dimycocerosate (PDIMs)}

Phthiocerol dimycocerosate (PDIM) (4, Figure 6) and its derivatives consist of a long chain $\beta$-diol (phthiocerol), which occurs naturally as diesters of polymethyl branched fatty acids (mycocerosic acid), and have been found in all pathogenic Mycobacteria except M. gastri. $^{28}$ The methylated branched asymmetric centres can be of L or D configuration depending on the strain of mycobacterium. For instance, in $M$. marinum, the configuration of the asymmetric centres is L, whereas in M. leprae and $M . t b$ they are of the D configuration. ${ }^{29}$ 


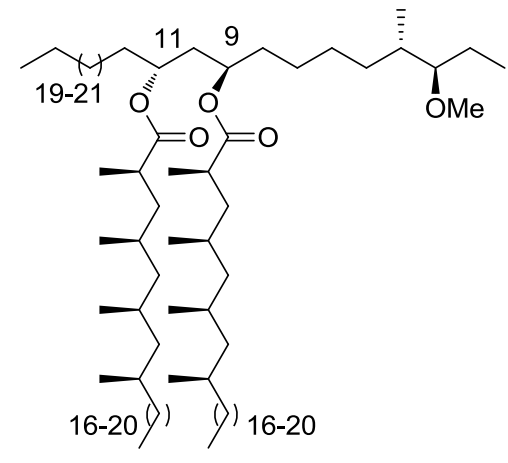

4

Figure 6: PDIM (4) from $M . t b$.

The ester groups present at carbons 9 and 11 in PDIMs can have either an anti or syn relationship, again depending on the mycobacterial strain. For PDIMs isolated from M. tb, M. leprae, M. bovis and M. kansasii the esters are anti to each other (5), whereas those obtained from M. marinum (6) and M. ulcerans (7) display a syn relationship (Figure 7). ${ }^{30}$ PDIMs have also been found to be involved in the pathogenesis of $M$. $t b$, as illustrated by mutant strains of $M$. $t b$ without PDIMs in the cell wall which exhibit higher cell permeability, thus making them more vulnerable to detergents and the host immune response. ${ }^{31}$
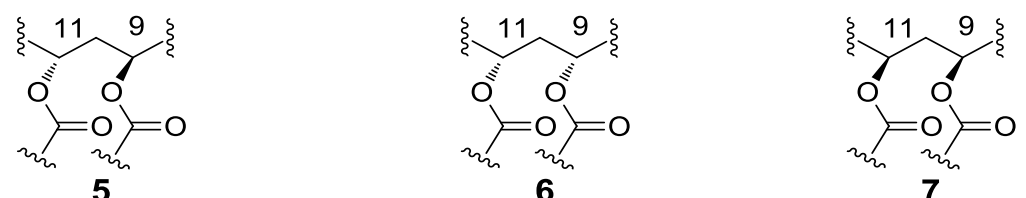

Figure 7: Stereochemistry of esters in PDIM from various mycobacterial species.

\subsubsection{Phenolic glycolipids (PGLs)}

Structurally related to PDIMs are phenolic glycolipids (PGLs) where the lipid core is $\omega$-terminated by an aromatic nucleus, which in turn is glycosylated by different saccharide units leading to a variety of phenolic glycolipids. The structures of PGLs from different mycobacterial species differ in the sugar moiety attached to the 
aromatic nucleus. ${ }^{30}$ PGL (8) from $M$. leprae and PGL (9) from $M$. $t b$ each contain trisaccharide sugar units (Figure 8). Similarly, PGL from M. bovis and M. marinum both have a single rhamnose sugar that only differs in its methylation pattern. PGLs from $M . t b$ have been shown to inhibit the innate immune response in the host organism and thus play an important role in the virulence of TB. ${ }^{32}$

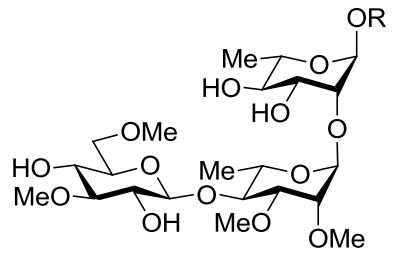

8

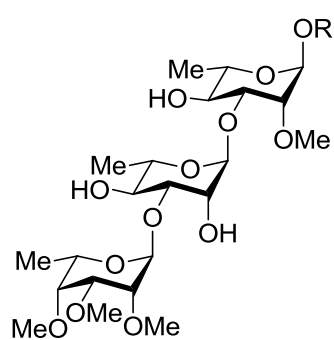

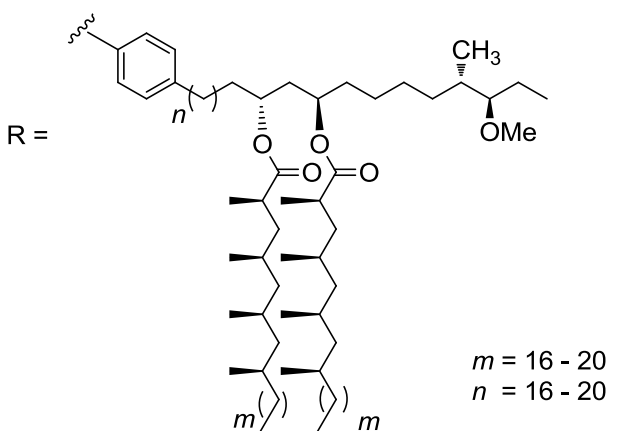

Figure 8: PGL from M. leprae and $M$. $t b$.

\subsubsection{Trehalose dimycolates (TDMs)}

As alluded to before, trehalose dimycolates (TDMs, 10, Figure 9) are the most abundant glycolipids found on the cell wall of $M . t b$ and were first discovered in the bacterium in the early 1950s when it was observed that virulent strains of $M . t b$ expressed a material named "cord factor" which was essential for the pathogenesis of the bacteria. ${ }^{33}$ It was not until 1956, that "cord factors" were characterised as TDMs and since then a vast number of studies have looked at the structural requirements and biological activities of this class of compounds. ${ }^{12,34,35}$

Amongst the different mycobacterial species, the variability of these glycolipids is apparent both in terms of the type and the amount of individual TDMs present. ${ }^{34}$ TDMs are characterised by the presence of a mycolic acid (11, Figure 9) and a trehalose moiety, with the mycolic acid consisting of at least two chiral centres, $\alpha$ and $\beta$ to the carboxylate, both of $R$ configuration. ${ }^{36,37}$ The lipid chain $\alpha$ to the carboxylate is known as the $\alpha$ branch, while the other portion of the mycolic acid is termed the meromycolate. Among different TDMs, the $\alpha$ branch of the mycolic acid varies only in the number of carbons present. The meromycolate region, however, is 
more variable with different functionalities present. ${ }^{38}$ Mycolic acids are generally divided into two groups - the $\alpha$-mycolates, which have no oxygenated functional groups, and the oxygenated mycolates. The most common mycolic acids are the $\alpha$ mycolates in which cis-cyclopropanes are present in the meromycolate branch. The oxygenated mycolates include methoxy mycolates, keto mycolates and epoxy mycolates. ${ }^{18}$ The biological activity and synthesis of TDMs and related trehalose 6,6'-diesters will be discussed in more detail later (Section 1.5.3).

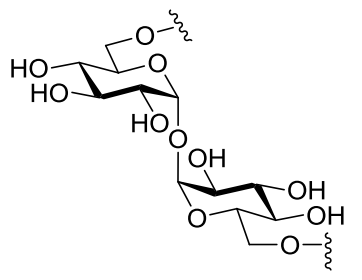

Trehalose

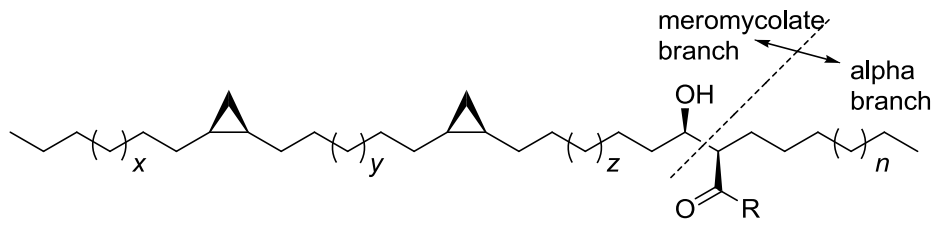

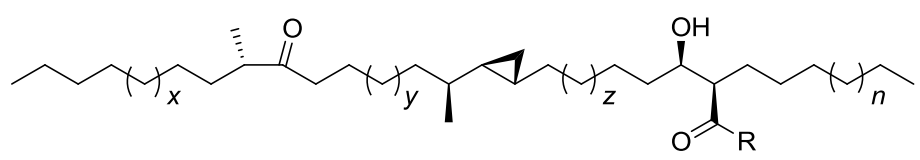

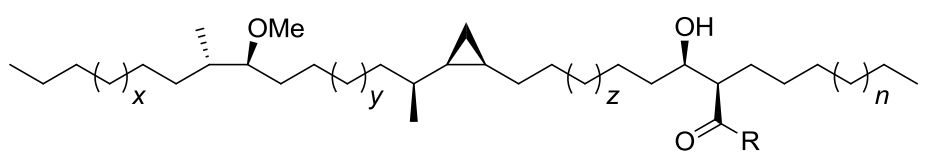

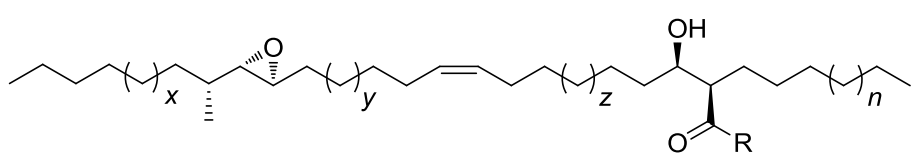

10, TDMs, where $\mathrm{R}=$ trehalose

11, Mycolic acids, where $\mathrm{R}=\mathrm{OH}, x, y, z$ : total chain length is $\mathrm{C}_{60^{-}} \mathrm{C}_{90}, n=13-19$

Figure 9. TDMs (10) and mycolic acids (11).

\subsubsection{Other Trehalose Glycolipids}

A second class of trehalose glycolipids found in virulent strains of mycobacteria are termed sulfolipids (e.g. SL-1, 12, Figure 10), to account for the presence of sulfate esters. ${ }^{39}$ Although first isolated in 1959, the structure of these sulfolipids was not elucidated until 1970 when Goren et al. characterised them as 2,3,6,6'-tetraesters of trehalose-2'-sulfate. ${ }^{40}$ It was not until 2004 that diacyltrehalose sulfates (13), the biosynthetic precursors for SL-1, were isolated from $M$. $t b$ independently by Domenech et al. $^{41}$ and Gilleron et al.. ${ }^{42}$ 


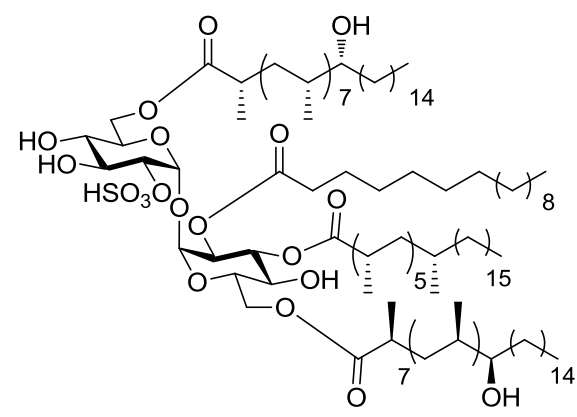

12

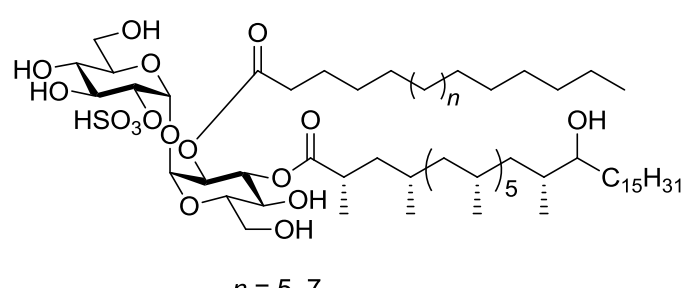

13

Figure 10. Sulfolipids.

\subsection{Trehalose 6,6'- diesters}

\subsubsection{Overview}

In addition to TDMs, sulfolipids, and diacyl trehalose sulfates found in mycobacteria, a number of other trehalose diesters have been observed in other bacterial species, and recently in Caenorhabditis elegans. Notably, these include the trehalose diesters of fatty acids (TDEs) (including maradolipids) and the trehalose dicorynomycolates (TDCMs). Collectively, these can be defined as trehalose 6,6'diesters, whereby two esters are present on the 6 and 6'-positions of the trehalose moiety, as opposed to the 2,3-trehalose diesters (as in the case of diacyl trehalose sulfates) or the 2,3,6,6'-tetraesters (SL-1). The focus of this thesis concerns the synthesis and biological activity of trehalose 6,6'-diesters, which will be discussed in more detail below. 


\subsubsection{Trehalose diesters of fatty acids (TDEs)}

\subsection{2a Introduction}

Trehalose diesters of fatty acids (TDEs) (14, Figure 11) are the simplest glycolipids found in the trehalose 6,6'-diester series and can be differentiated by lipid length and the branching of the fatty acids. Historically, linear TDEs have been studied for their anti-tumor ${ }^{43-47}$ and anti-bacterial activities, ${ }^{48,49,50}$ however, it is only in recent years that the presence of these compounds has been detected in the animal kingdom. ${ }^{51}$ The isolation of the palmitic acid diester of trehalose $(14, n=14)$, from Mycobacterium fortuitum was also reported in the 1960s. ${ }^{52}$ Branched TDEs form an intergral part of the diacyl trehalose isolated from dauer larvae of C. elegans (commonly known as maradolipids, 15), while linear TDEs and cyclopropanated trehalose diesters are also found in maradolipid extracts, albeit in smaller quantities. $^{51}$
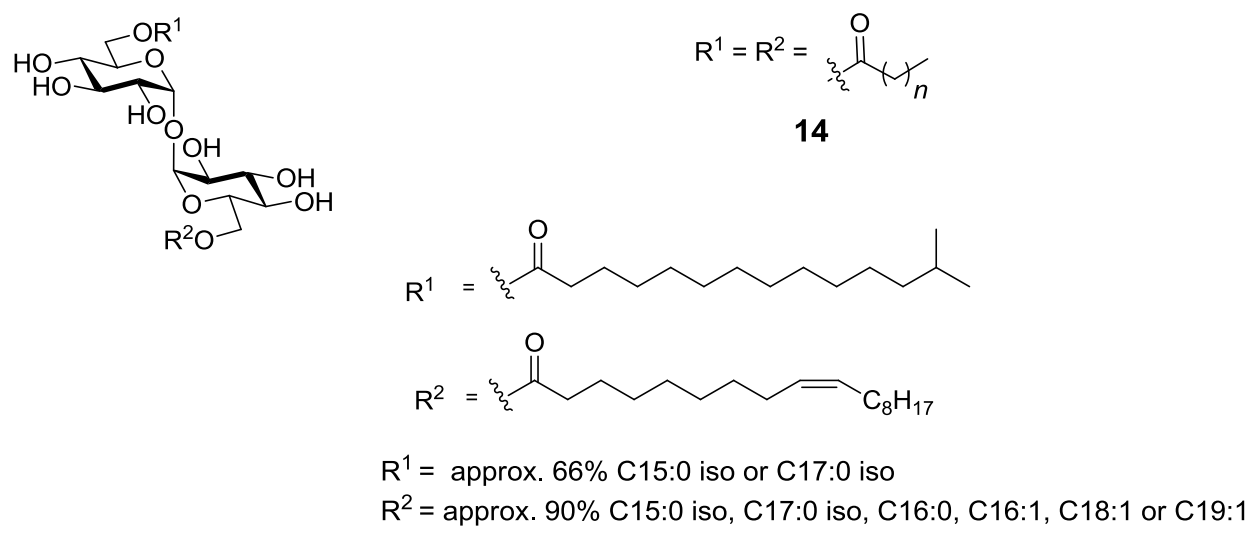

15

Figure 11. TDEs (14) and maradolipids (15).

Of the TDEs, perhaps the most noteworthy family member is the C22 homologue, trehalose dibehenate (TDB), which has recently been shown to bind to and activate macrophages in a similar way to its more complex counterpart, TDM. TDB binds to Macrophage Inducible C-type Lectin (mincle, Figure 12), a calcium dependent receptor that posseses a carbohydrate identifying domain in its extracellular 
region, ${ }^{53,54}$ and activates macrophages through a FcRgamma-Syk-Card9-dependant pathway. These studies have important implications as they provide insight into the mechanism of action of TDEs, which in turn will aid in the development of better therapeutics for cells of the myeloid lineage. Toll-like receptor (TLR)-2 and dectin-1 are examples of other surface membrane receptors found on immune cells which recognise certain bacteria, fungi and exogenous substances.

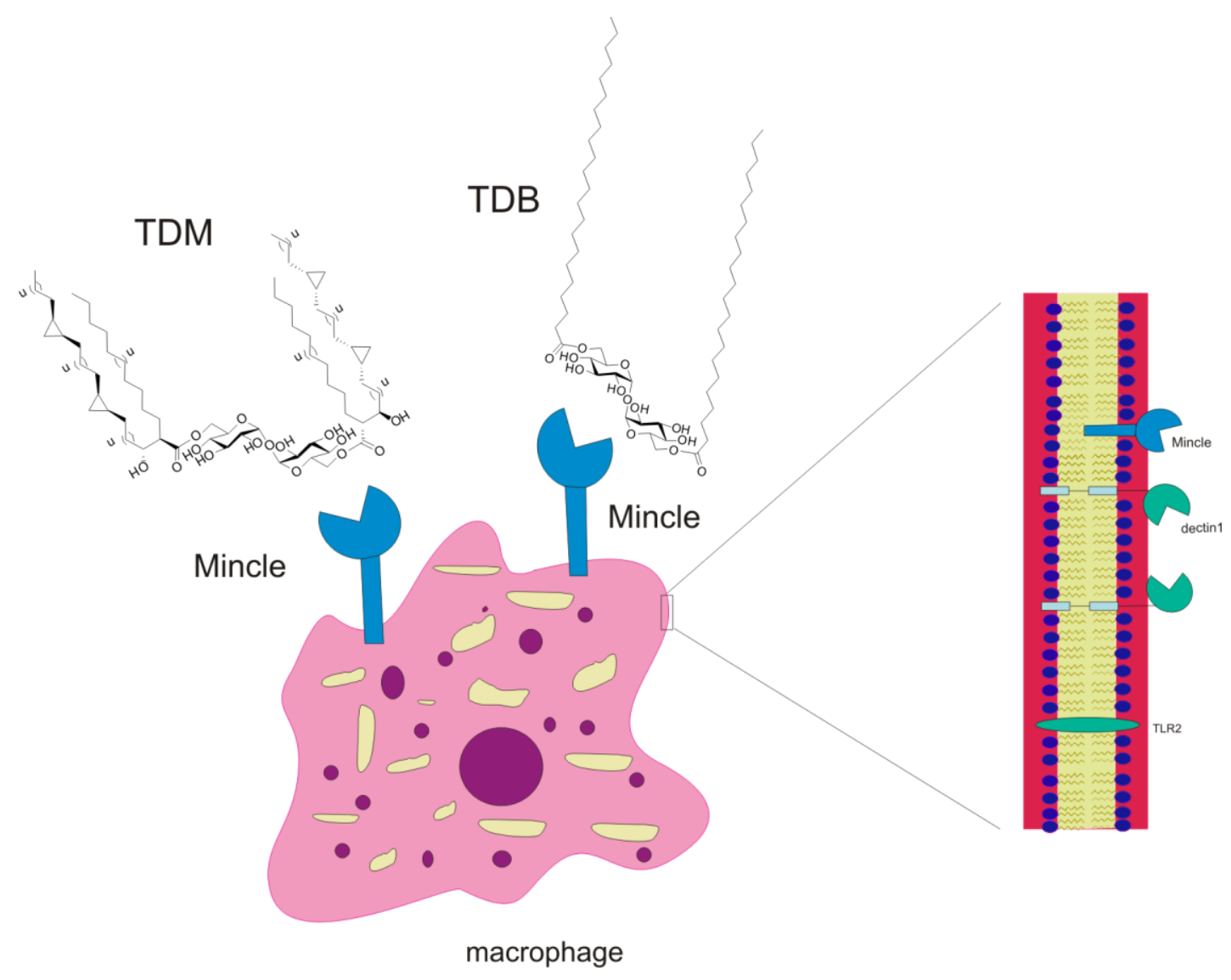

Figure 12. Cartoon of Mincle interacting with TDM and TDB.

\subsection{2b Linear TDE syntheses}

Various synthetic methodologies for TDE syntheses have been developed over time to gain access to these intriguing diesters. One of the first synthetic methods reported was the potassium carbonate mediated trans-esterification of fatty acid methyl esters with trehalose. ${ }^{55}$ This reaction, however, was not selective with various other mono, di- and tri-esters also being formed. The synthesis of TDEs has also been reported 
whereby 6,6'-ditosylate trehalose was subjected to esterification conditions with the potassium salt of palmitic acid, ${ }^{56}$ based on methodology developed previously. ${ }^{57}$ This synthetic strategy posed a few difficulties including the formation of 3,6-anhydrotrehalose products and other by-products that were difficult to separate from the desired TDEs. ${ }^{58}$ Toccane ${ }^{59}$ and Toubiana et al. ${ }^{60}$ independently proposed the use of a 6,6'-dihalo-6,6'-dideoxy trehalose derivative for the synthesis of trehalose diesters to eliminate these side reactions. The esterification reaction could also be improved by using $2,2^{\prime}, 3,3^{\prime}, 4,4^{\prime}$-hexa- $O$-benzyl-trehalose as an intermediate. ${ }^{58}$

In 1983, Bottle and Jenkins reported on a new method for the synthesis of TDEs via the reaction of trehalose with fatty acids in the presence of diisopropyl azodicarboxylate (DIAD) and triphenyl phosphine under exceptionally mild conditions. ${ }^{61}$ In their seminal work, unprotected trehalose and palmitic acid were subjected to the Mitsunobo reaction ${ }^{62}$ to yield 6,6'-trehalose dipalmitate in 59\% yield. ${ }^{61}$ Later, Jenkins and Goren extended this methodology for the synthesis of more complex TDMs. ${ }^{63}$

In the continual search for the optimum conditions for the synthesis of TDEs, the use of 2,2',3,3',4,4'-hexa- $O$-trimethylsilyl trehalose as an intermediate for the synthesis of dipalmitate trehalose was reported. ${ }^{64}$ This intermediate was appealing due to the ease in which labile trimethylsilyl (TMS) protecting groups could be removed after the esterification reaction. In the initial studies by Toubiana et al., hexa- $O$-trimethylsilyl trehalose was synthesised in 2 -steps from commercially available $\alpha, \alpha$-trehalose, while in the later work by Johnson, an elegant 2-step, one pot synthesis of hexatrimethylsilyl trehalose was developed, ${ }^{65}$ and later used for the synthesis of trehalose dipalmitate 14a (Scheme 1). ${ }^{66}$ Here, $\alpha, \alpha$-trehalose (16) was persilylated using $N, O$ bis(trimethylsilyl)acetamide (BSA) and tetra-butylammonium fluoride (TBAF) and the more labile primary TMS ethers were removed via the addition of potassium carbonate to the same reaction vessel to give 17 in good (85\%) yield. Diol 17 was then converted to triflate $\mathbf{1 8}$ and condensed with the potassium salt of the acid to give the fully protected diacyl trehalose 19a, which was deprotected under acidic conditions to provide trehalose dipalmitate $\mathbf{1 4 a}$ in good overall yield. 


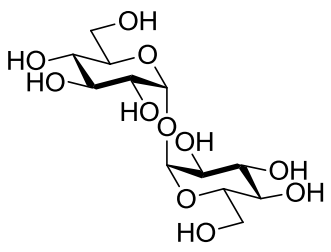

16
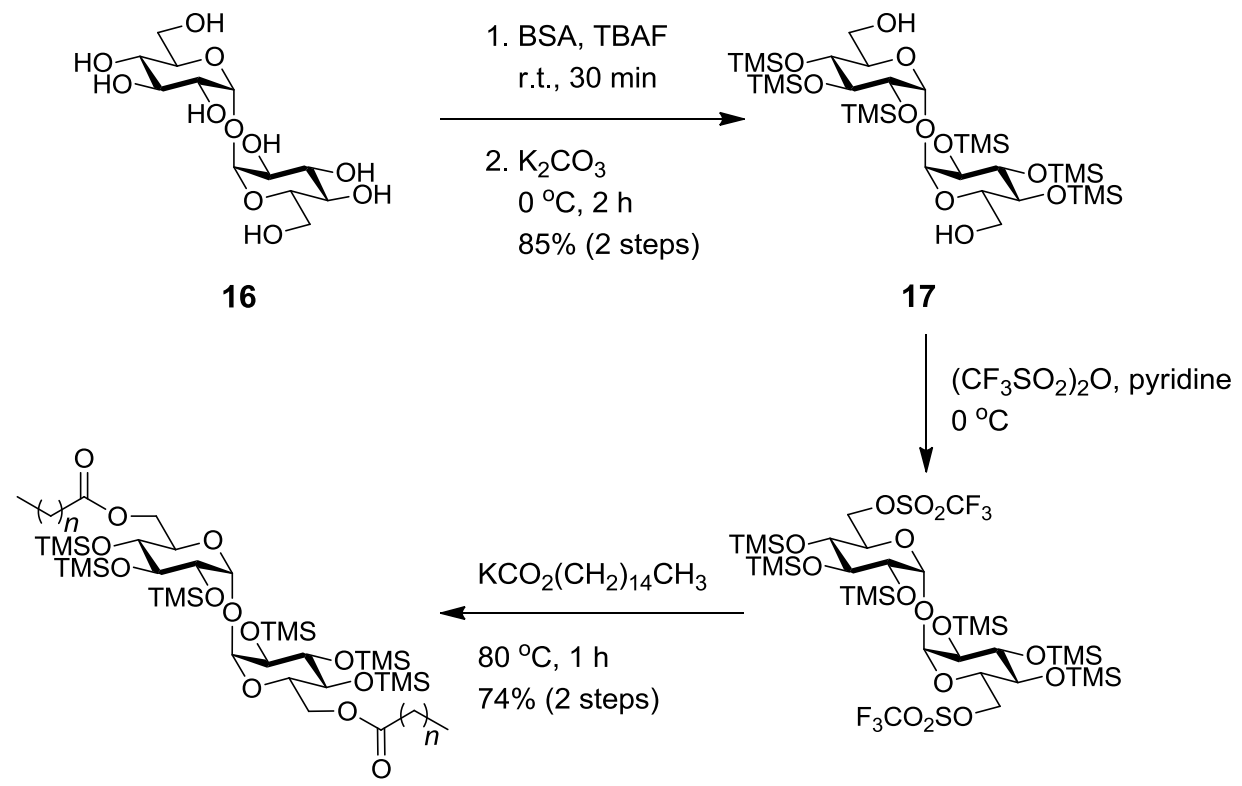

$19 a$
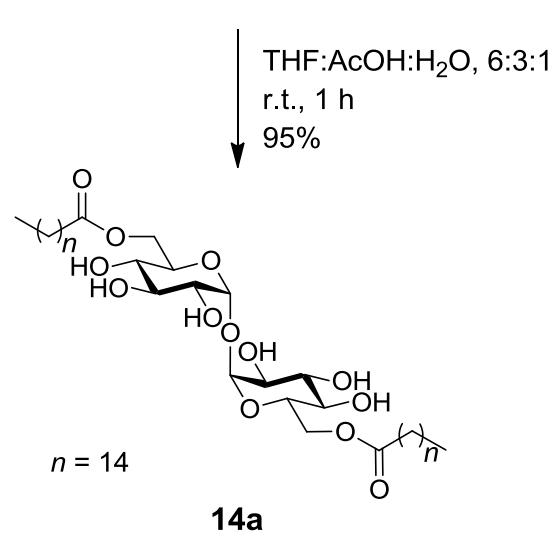

Scheme 1. Trehalose dipalmitate synthesis. ${ }^{66}$

\subsection{2c Biological Activity of linear TDEs}

The anti-tumour activity of TDEs has been studied for many years and though it is difficult to deduce with certainity which factors are responsible for good anti-tumour activity due to the different ways in which the assays were performed, several general conclusions can be drawn. Lipopolysaccharide (LPS) has been shown to enhance the anti-tumour activity of the linear TDMs in in vivo tumour assays, ${ }^{44-47}$ and the co-presence of an oil vehicle also appears to enhance the response. ${ }^{67-70}$ The importance of the acyl chain length was seen in an in vivo tumour assay, where an 
acyl chain of more than 10 carbons was essential to induce anti-tumour activity in an Ehlrich ascites carcinoma model. ${ }^{43}$ The most common tumour model employed in these studies was the rat hepatoma cell line.

The anti-bacterial activity of linear TDEs has also been studied by several groups and varying results obtained depending on the bacterial strain used. When tested against Klebsiella pneumoniae and Listeria monocytogenes in mice, the $\mathrm{C} 22$ diester as well as the $\mathrm{C} 16$ diester did not confer any protection. ${ }^{48}$ However, when tested on Schistosoma mansoni, the C16 diester conferred protection, whereas no protection was seen with the $\mathrm{C} 22$ diester. ${ }^{49}$ Similarly, the $\mathrm{C} 16$ diester and monoester were seen to confer protection against Salmonella typhi and Salmonella typhimurium. ${ }^{50}$ In all studies, the glycolipids were formulated in oil and adminstered to the mice as an emulsion. In the case of Schistosoma mansoni and Salmonella challenges, the mice were pre-treated with the TDEs before being challenged with the bacteria, whereas, in the $K$. pneumoniae and L. monocytogenes studies, the mice were first challenged with the infection and then the TDEs were introduced. C16 and C22 diesters of trehalose have also shown potential to be used in the serodiagnosis of tuberculosis. ${ }^{71}$

The singularly most studied glycolipid in the TDE family is the C22 diester of trehalose, TDB. In addition to the aforementioned anti-tumour and anti-bacterial studies, TDB has been combined with dimethyldioctadecylammonium bromide (DDA), a cationic surfactant to produce a liposome adjuvant system which induces a strong cell-mediated and antibody response, ${ }^{72}$ and thus could be an effective adjuvant in $M . t b$ subunit vaccines. ${ }^{73}$ Indeed, such cationic liposomes are now in Phase I clinical trials for their use during $\mathrm{TB}$ vaccination. ${ }^{74}$

\subsection{2d Maradolipid Syntheses}

Maradolipids are diacyltrehalose glycolipids containing linear, branched and cyclopropanated fatty acid chains, observed in the dauer larvae of C. elegans. ${ }^{51}$ The lipid composition and the relative abundances of the lipids of the dauer larvae were analysed using extensive NMR spectroscopy and mass spectrometric analysis and it 
was revealed that the major TDE was maradolipid (15, Figure 13) which is an acylated trehalose containing a branched fatty acid moiety at position 6 and either a mono-unsaturated or saturated linear fatty acid at the 6 ' position. MS/MS analysis revealed that $40 \%$ of the fatty acid moieties were 15:0 and 17:0 fatty acid (FA) (Figure 14) and about $60 \%$ of the maradolipids were found to have a branched fatty acid chain. The presence of cyclopropanated lipids was also found on the maradolipids. ${ }^{51}$ As the first diacyl trehalose glycolipid found in the animal kingdom, the discovery of maradolipids represents a first step in understanding stress related lipid composition changes in cells.

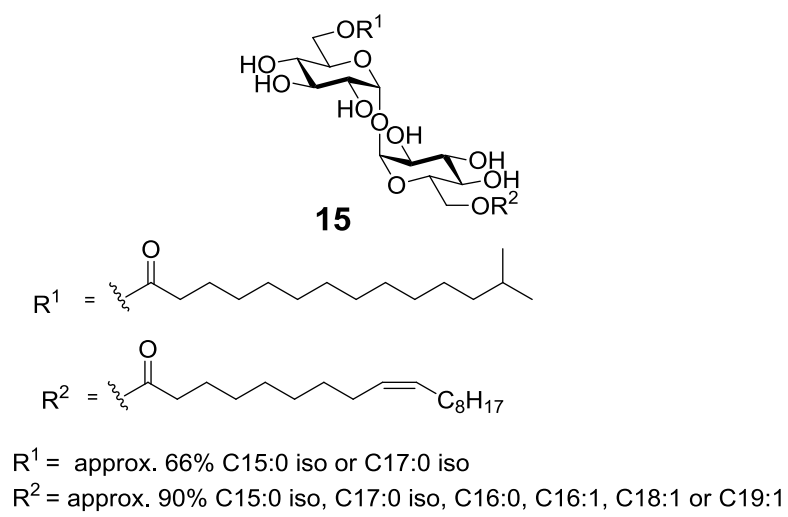

Figure 13. Representative maradolipid.
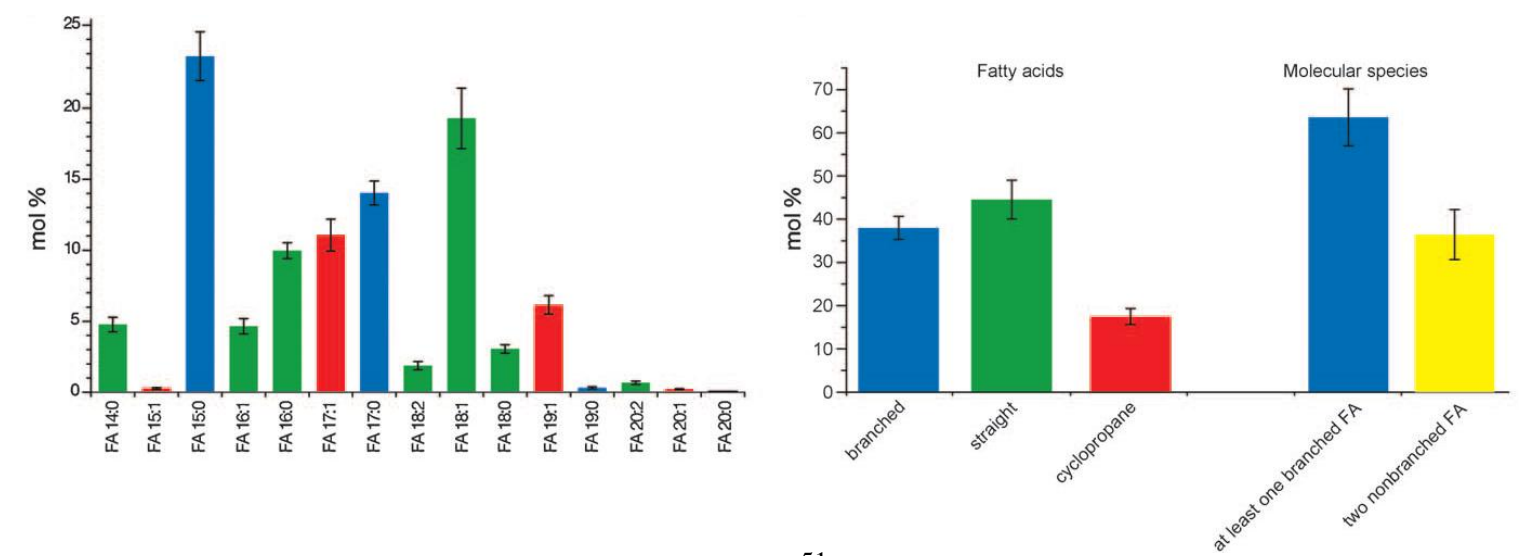

Figure 14. Lipid composition of maradolipids. ${ }^{51}$ 
Two syntheses of the major maradolipids from $C$. elegans were reported simultaneously in 2011 by the groups of Sarpe and Kulkarni ${ }^{75}$ (Scheme 2) and Knölker and colleagues. ${ }^{76}$ In the former synthesis, $\alpha, \alpha$-trehalose (16) was transformed into diol 17 using similar methodology as that developed by Johnson, ${ }^{65}$ and the diol was then subjected to esterification with oleic acid (1 equiv.) in the presence of $N, N^{\prime}$-dicyclohexylcarbodiimide (DCC) and 4-dimethylaminopyridine (DMAP) to give mono-ester 20. A further esterification with 13-methylmyristic acid using the same coupling conditions then gave the fully protected diester $\mathbf{2 1}$, which was deprotected in the presence of acidic dowex to yield maradolipid $\mathbf{1 5}$ in $46 \%$ yield (five steps). To date, there have been no biological activities reported on the maradolipids aside from those saturated derivatives discussed in section 1.5.2c above. 


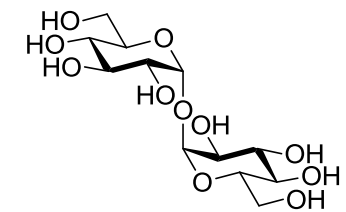

16

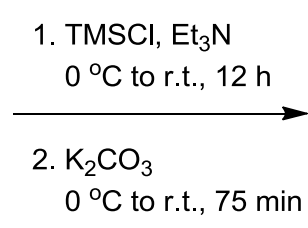

$92 \%$ (2 steps)

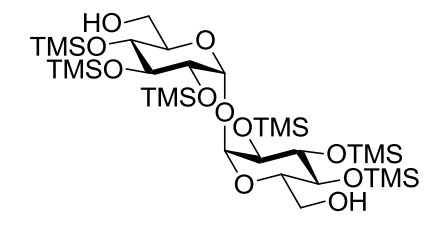

17
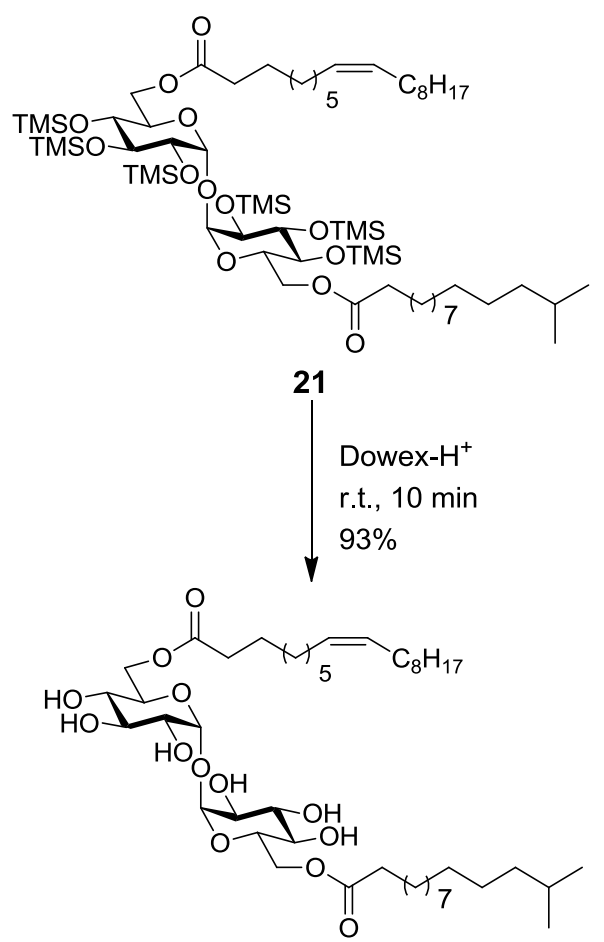

15 13-methylmyristic acid DCC, DMAP

r.t., $8 \mathrm{~h}$ $89 \%$

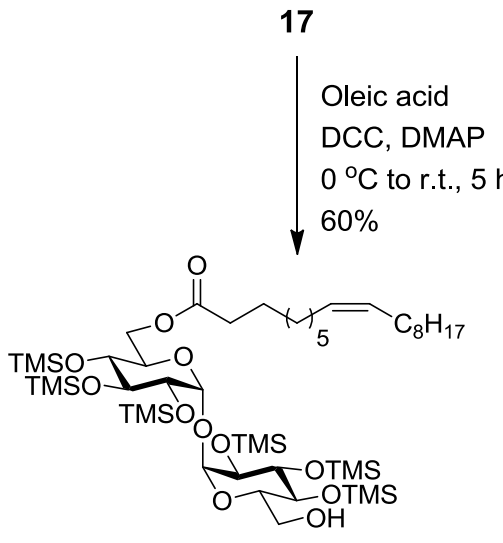

20

Scheme 2. Maradolipid synthesis. ${ }^{75}$

\subsubsection{Trehalose Dicorynomycolate (TDCM)}

\subsection{3a Introduction}

Trehalose dicorynomycolates (TDCMs) are found in Corynebacteria and consist of a trehalose carbohydrate group esterified at the 6 and 6' position with corynomycolic acid. The major TDCM (22, Figure 15) contains a C32 corynomycolic acid, however, TDCMs with shorter acid chains (C24-C30) have also been found in Corynebacteria. TDCMs were first isolated in $1963,{ }^{77}$ and later found to be a mixture 
of three components: dicorynomycolate, monocorynomycolatemono(dehydrocorynomycolate) and the bis(dehydrocorynomycolate) ${ }^{78,79}$ which were separable once converted to their trimethylsilyl derivatives. ${ }^{78}$ In more recent years, the isolation, and characterisation of TDCM (22) and mono-corynomycolate from Corynobacterium matruchotti using ${ }^{1} \mathrm{H}$ NMR spectroscopy has been reported by Datta and Takayama. ${ }^{80}$ The stereochemistry of the two chiral centres in TDCMs lipid chain have been shown to be $R, R^{36}$

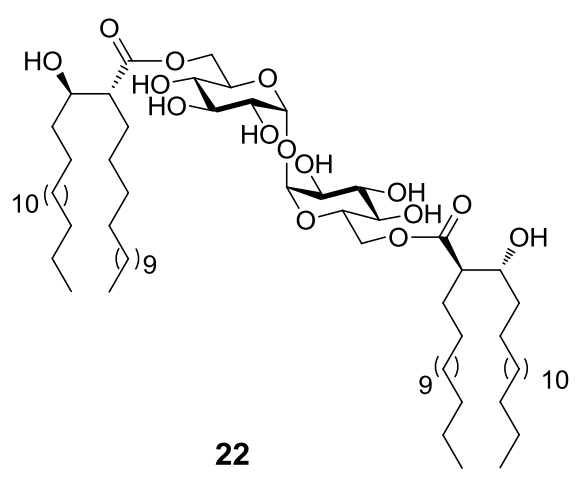

Figure 15. Trehalose dicorynomycolate (22).

\subsection{3b TDCM Syntheses}

Most earlier syntheses of TDCMs were reported by Liav et al. whereby the synthesis of this glycolipid along with analogues of TDCM with different carbohydrate groups (e.g. dimannosides, digalactosides), and the synthesis of mono-esterified compounds were undertaken in order to correlate the structure to the biological activities of these compounds. ${ }^{81-86}$ In these earlier reactions, the racemic corynomycolic acid was synthesised using Lederer and Polonsky's method ${ }^{87}$ which involved the self condensation of methyl palmitate, subsequent reduction of the keto ester using sodium borohydride $\left(\mathrm{NaBH}_{4}\right)$, and then hydrolysis of the methyl ester in $10 \%$ potassium hydroxide $(\mathrm{KOH})$ to give the crystalline potassium corynomycolate as the product.

It was not until 1985, that the synthesis of optically pure corynomycolic acid was reported by Sato and co-workers. Here, corynomycolic acid was synthesised in nine 
steps starting from $n$-tetradecyl iodide. ${ }^{88}$ Later, Ukata reported a more efficient six step synthesis of (+)-corynomycolic acid from 3-oxo-octadecanoic acid using an asymmetric reduction mediated by fermenting baker's yeast (Scheme 3 ). ${ }^{89}$ In their synthesis, methyl 3-oxo-octadecanoate (23) prepared from methyl acetoacetate and $n$-tetradecyl iodide in $75 \%$ yield, was hydrolysed and subsequently subjected to enzymatic reduction to form hydroxy acid $\mathbf{2 4}$. The acid was then methylated using diazomethane and subjected to alkylation via treatment with lithium diisopropylamide (LDA) and $n$-tetradecyl iodide in the presence of hexamethylphosphoric triamide (HMPA) to form methyl corynomycolate 25. Finally, hydrolysis of the methyl ester led to the single enantiomer of corynomycolic acid (26) in $13 \%$ overall yield.

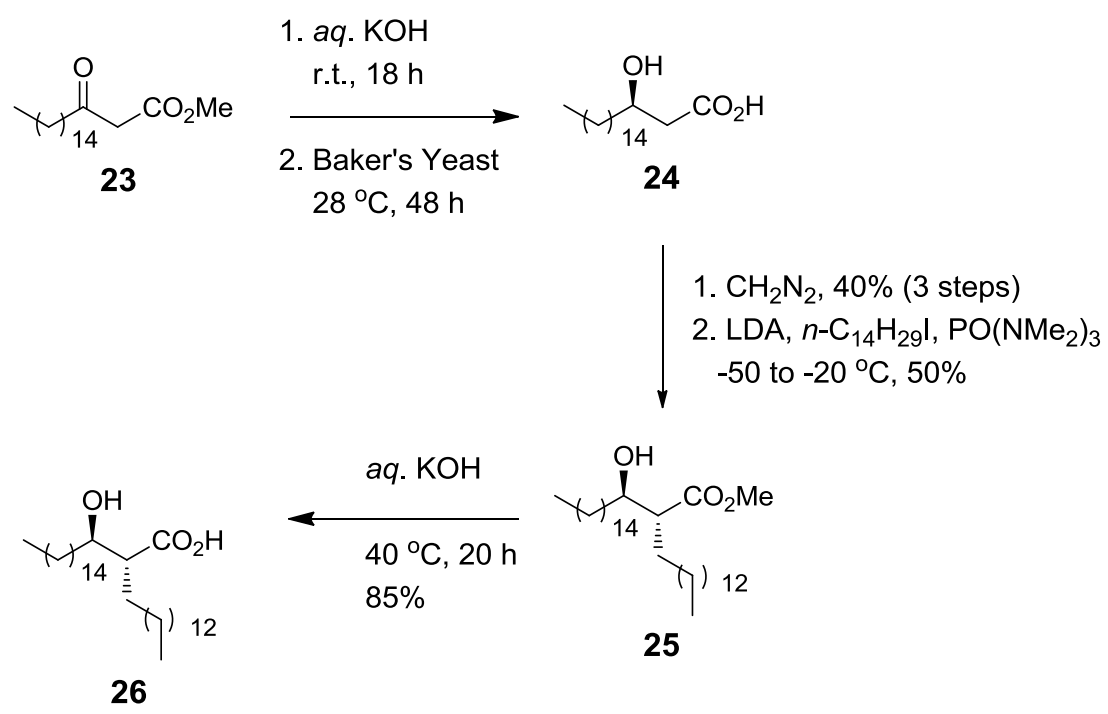

Scheme 3. Corynomycolic acid synthesis. ${ }^{89}$

The first total synthesis of naturally occurring TDCM, the 6,6'-trehalose diester of $(2 R, 3 R)$-corynomycolic acid, was reported by Nishizawa et al. in 1994 (Scheme 4). ${ }^{90}$ The required stereochemistry at the 2- and 3-positions was installed using a KatsukiSharpless catalytic asymmetric epoxidation ${ }^{91}$ of 2-octadecenol (27) using D-(-)diisopropyl tartrate (DIPT) in $\mathrm{CH}_{2} \mathrm{Cl}_{2}$ to give epoxide (+)-28 in quantitative yield. Protection of the free hydroxyl in $\mathbf{2 8}$ as the $p$-methoxybenzyl (PMB) ether, followed by epoxide ring opening with allylmagnesium bromide resulted in the formation of 
alcohol 29 in combination with the undesired regioisomeric ring-opened product in a 38:62 ratio. Benzylation of the alcohol and cleavage of the double bond by LemieuxJohnson oxidation ${ }^{92}$ provided aldehyde 30, which was then subjected to a Wittig reaction with the ylide derived from triphenyldodecylphosphonium bromide, followed by removal of the PMB protective group to give $\mathbf{3 1}$ as a mixture of $E$ and $Z$ isomers. Subsequent $\mathrm{Swern}^{93}$ and $\mathrm{NaClO}_{2}$ oxidations of $\mathbf{3 1}$ resulted in the protected cornynomycolic acid 32, ready for coupling with the selectively protected trehalose 33. Three other stereoisomers of 32, the $(2 R, 3 S)-,(2 S, 3 R)-$, and $(2 S, 3 S)$-isomers, were also prepared in analogous fashion. Coupling of the corynomycolates with hexa-benzyl trehalose derivative 33, followed by global deprotection by Pd-catalysed hydrogenation, with concommitant reduction of the double bond, provided the target TDCM 22 in excellent yield. 


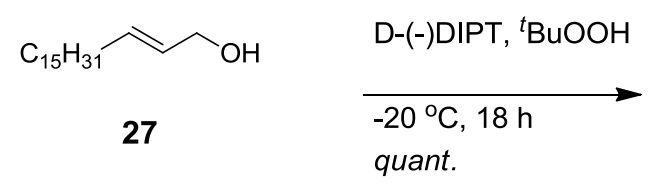

$\overbrace{30}^{C_{15} H_{31}} \overbrace{\text { 妾 }}^{O B n}$ OPMB

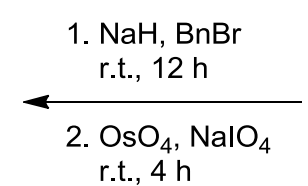

1. $\left(\mathrm{Ph}_{3} \mathrm{PCH}_{2} \mathrm{C}_{11} \mathrm{H}_{23}\right) \mathrm{Br}$

BuLi, -78 to $0^{\circ} \mathrm{C}, 2 \mathrm{~h}$

2. $\mathrm{DDQ}$, r.t., $2 \mathrm{~h}$

$60 \%$ (4 steps)<smiles>CCCCCCCCCCCCCO</smiles>

$(+)-28$

1. $\mathrm{o}-\mathrm{MeOC}_{6} \mathrm{H}_{4} \mathrm{CH}_{2} \mathrm{Cl}$

$\mathrm{NaH}$, r.t., 7 h, $80 \%$

2. $\mathrm{CH}_{2}=\mathrm{CHCH}_{2} \mathrm{MgBr}$

v -78 to $0^{\circ} \mathrm{C}, 6 \mathrm{~h}, 38 \%$<smiles>C=CC[C@H](CO[Na])C(O)c1ccccc1</smiles>

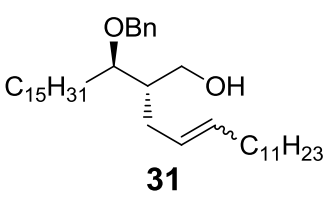

31

1. $(\mathrm{COCl})_{2}, \mathrm{DMSO}, \mathrm{Et}_{3} \mathrm{~N}$ $-78^{\circ} \mathrm{C}, 1.5 \mathrm{~h}$

2. $\mathrm{NaClO}_{2}, \mathrm{NaH}_{2} \mathrm{PO}_{4}$ 2-methyl-2-butene r.t., $30 \mathrm{~min}$ $50 \%$ (2 steps)

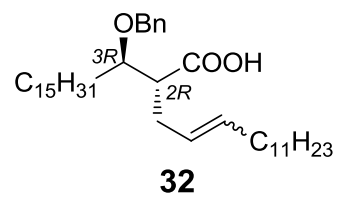

1. 33, DCC, DMAP.HCl $99 \%$

2. $\mathrm{H}_{2}, \mathrm{Pd}(\mathrm{OH})_{2}$ quant.
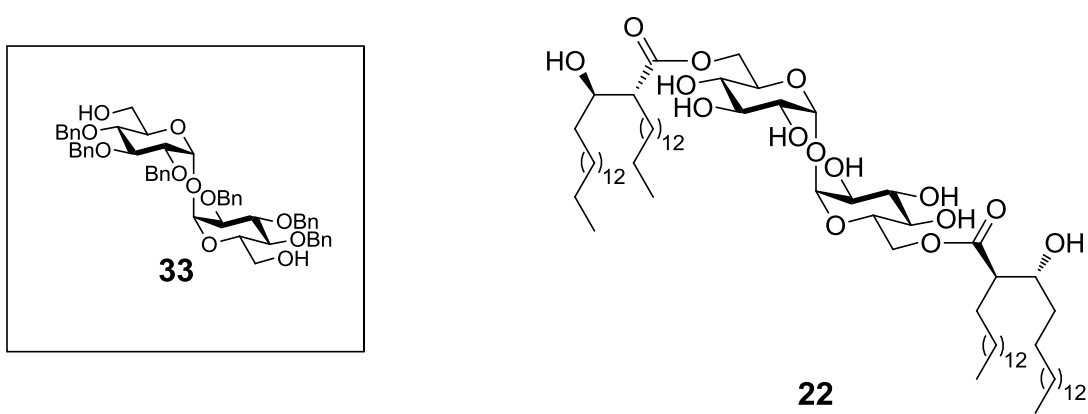

Scheme 4. Synthesis of TDCM. ${ }^{90}$

Nishizawa et al. also reported on a more efficient route to corynomycolic acids that makes use of Noyori's 2,2'-bis(diphenylphosphino)-1,1'-binaphthyl (BINAP)-Rucatalysed asymmetric reduction, ${ }^{94}$ in the dynamic kinetic resolution of $\alpha$-palmitylbutyrolactone. ${ }^{95}$ This reduction was later used in the synthesis of corynomycolic acid analogues, whereby a tert-butyl acylacetate was stereoselectively reduced (Scheme 
$5) .{ }^{96}$ In order to form the natural $(2 R, 3 R)$-TDCM isomer 22, the dianion of tert-butyl acetoacetate (34) was generated with $\mathrm{NaH}$ and $n$-BuLi, and subsequently treated with $n$-tetradecyl iodide to form the $\gamma$-alkylated product 35. Stereoselective reduction of the ketone in $\mathbf{3 5}$ using $(R)$-BINAP- $\mathrm{RuCl}_{2}$ and hydrogen then gave $(R)$-hydroxy ester 36 in an excellent yield of $94 \%$ and more than $98 \%$ ee. Subsequent Fráter-Seebach alkylation $^{97,98,99}$ of $\mathbf{3 6}$ with tetradecyl iodide introduced the second stereocentre, again with excellent selectivity (>99\% de, 37). Next, reductive etherification and ester cleavage led to the benzyl protected corynomycolic acid 38, which was then coupled to the hexa-benzyl protected trehalose derivative 33. Again global deprotection using catalytic hydrogenation led to the target TDCM 22 in a highly efficient seven step synthesis. In addition, further stereoisomers and branched chain TDCM analogues were produced using the same strategy, but using (S)-BINAP$\mathrm{RuCl}_{2}$ for the stereoselective reduction, and a variety of alkylating reagents in the $\gamma$ alkylation of the acetoacetate and Fráter-Seebach alkylation.

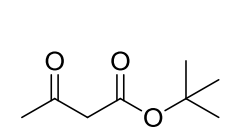

34

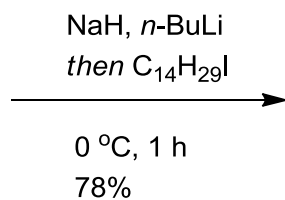

$78 \%$

\section{LDA, HMPA}

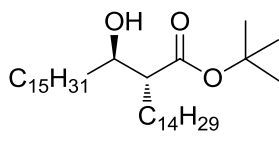

37
$\mathrm{C}_{14} \mathrm{H}_{29} \mathrm{I}$

$-48{ }^{\circ} \mathrm{C}, 7 \mathrm{~h}$

$55 \%$

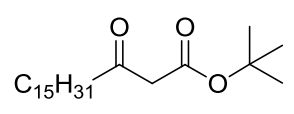

35

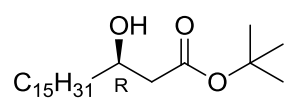

36

1. $\mathrm{TMSCl}, \mathrm{Et}_{3} \mathrm{~N}$

r.t., $30 \mathrm{~min}$

2. benzaldehyde, $\mathrm{TMSOTf} \mathrm{Et}_{3} \mathrm{SiH}$

r.t., $2 \mathrm{~h}$

v $96 \%(2$ steps $)$

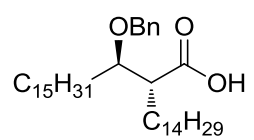

38
1. 33, EDCI, DMAP r.t., $7 \mathrm{~h}$ $50 \%$

2. $\mathrm{Pd}(\mathrm{OH})_{2}, \mathrm{H}_{2}$ r.t., $7 \mathrm{~h}$ $92 \%$

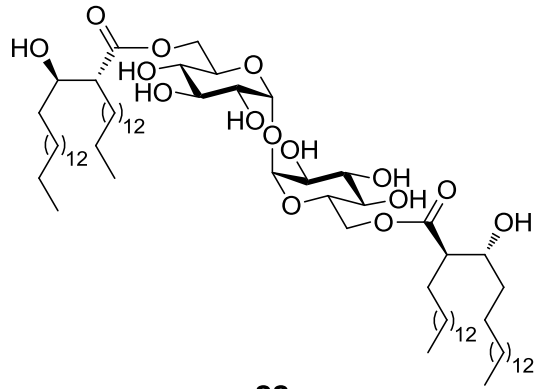

22

Scheme 5. TDCM synthesis via Noyori's asymmetric reduction. ${ }^{95}$ 


\subsection{3c TDCM Biological Activity}

Over the years, TDCMs isolated from the cell wall of Corynebacterium have been shown to have a variety of biological activities, including acting as agonists for macrophage activation during in vivo studies. ${ }^{100}$ In combination with monophosphoryl lipid A, TDCMs form an integral part of the Ribi Adjuvant system which has shown to be effective in Leshmania ${ }^{101}$ and $M$. $t b$ vaccine formulations. ${ }^{102}$ The tumour regression property of synthetic racemic TDCMs has also been reported whereby the TDCMs were injected intralesionally as an oil emulsion in mice with fibrosarcoma. ${ }^{100}$

The first testing on homogenous TDCMs, was carried out in 1996 when four TDCMs synthesised by Nishizawa et al. were tested individually for their biological activity. ${ }^{103}$ In the study, the immunoadjuvant activity of the TDCMs was analysed, by considering the cytolytic activity of peritoneal macrophages obtained from mice treated peritoneally with TDCM, to Lewis lung carcinoma cells. The results indicated that all four diastereomeric TDCMs had adjuvant activities, however, the natural $(2 R, 3 R)$ and its enantiomer $(2 S, 3 S)$ were more potent than the $2 R, 3 S$ and the $2 S, 3 R$ isomers in terms of stimulating the cytolytic activity of the macrophages. Subsequent invivo studies showed that all four TDCMs were effective in prophylactically, as well as therapeutically, inhibiting lung metathesis produced by the highly metastatic tumour cells, colon 26-M3.1 carcinoma and B16-BL6 melanoma. The compounds were injected intravenously into mice as oil emulsions and again the $2 R, 3 R$-TDCM and $2 S, 3 S$-TDCM were shown to be most effective at inhibiting metathesis. The antimetastatic effects of TDCMs were seen to be much higher than that of TDMs. Furthermore, it was shown that the lethal toxicity of TDMs, apparent in mice, was not exhibited by the TDCMs thereby making TDCMs better candidates for future biological studies. ${ }^{104}$

The effect of TDCMs on the production of IL-6 in in vivo murine models has also been explored. ${ }^{96}$ TDCMs induced a more potent immune response than the monoesters; the natural TDCM with $2 R, 3 R$ stereochemistry and a C14 lipid on the fatty acid residue was the most active (based on IL-6 accumulation in mice serum). This is 
an important observation and provides further evidence for the potential use of natural TDCM in the treatment of cancer and other diseases.

\subsubsection{TDM- Reported Synthesis and Biological Activity}

\subsection{4a Introduction}

TDMs are the most complex form of 6,6'-diesters isolated from mycobacterial species. For isolation and characterisation of TDMs see section 1.4.5. The complexity of TDMs has presented many challenges during their synthesis, though much elegant work has been achieved in this field, particularly by Baird and coworkers whose initial work focussed on the synthesis of various mycolic acids, ${ }^{105-113}$ and more recently extended to the synthesis of individual TDMs. ${ }^{114}$

\subsection{4b TDM synthesis}

One of the first mycolic acids prepared by Baird and co-workers was $\alpha$-mycolate (39, Scheme 6) ${ }^{106}$ which they later transformed into $\alpha$-TDM 10. ${ }^{114}$ The key steps in the synthesis included esterification between mycolic acid 39 and TMS trehalose 17 (obtained from $\alpha, \alpha$-trehalose following Johnson's procedure), ${ }^{65}$ with mycolic acid 39 obtained from Julia reaction ${ }^{115}$ between aldehyde $\mathbf{4 0}$ and cyclopropane building block 41. Aldehyde 40, in turn, was synthesised via Fráter-Seebach alkylation between THP-ether 42 and tetracosanoyl iodide (43). THP-ether 42 was accessed from epoxide 44, itself obtained from aspartic acid. ${ }^{116}$ The cyclopropyl building block 41 was prepared via Julia reaction between cyclopropyl building blocks 45 and 46, whereby both intermediates were synthesised from the same common precursor $47 .^{117}$ 


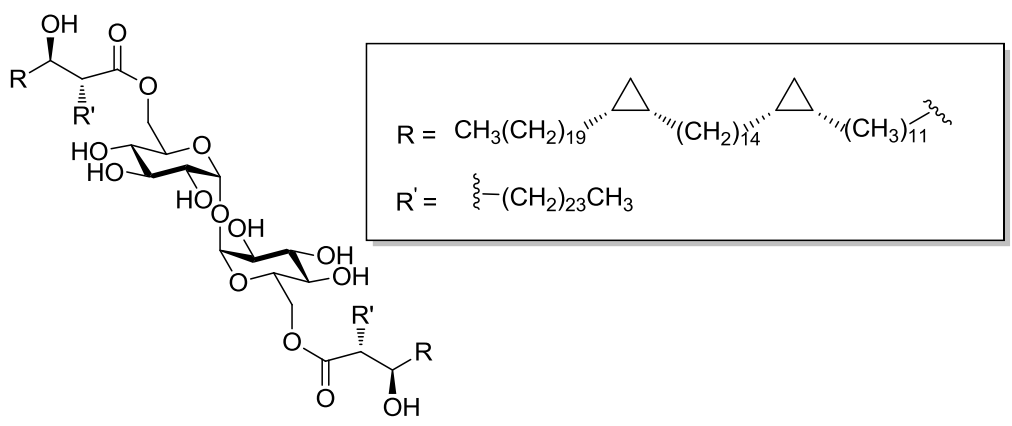

10
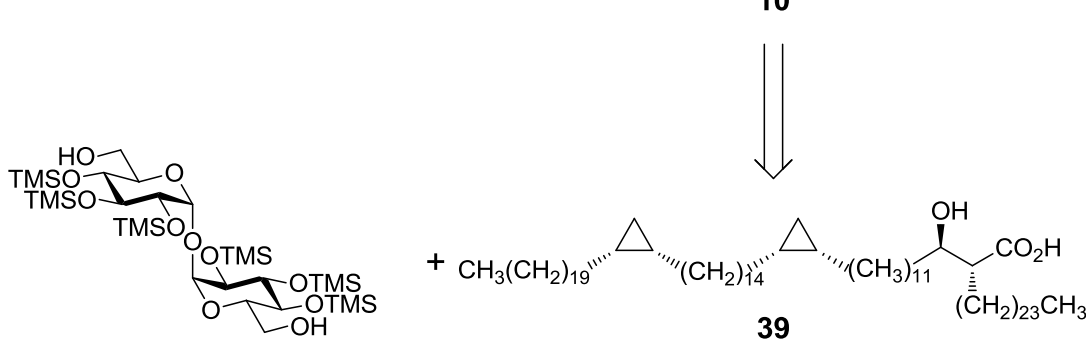

17

40

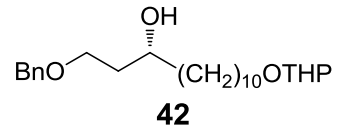

42
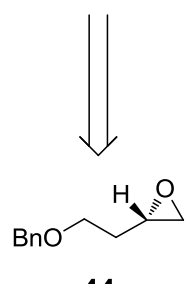

44

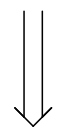

43

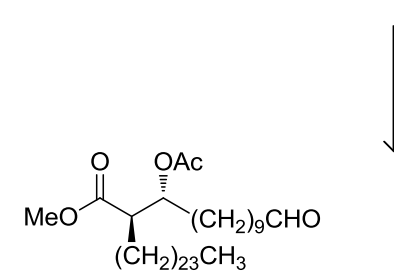

$+\quad \mathrm{C}_{24} \mathrm{H}_{49} \mathrm{l}$
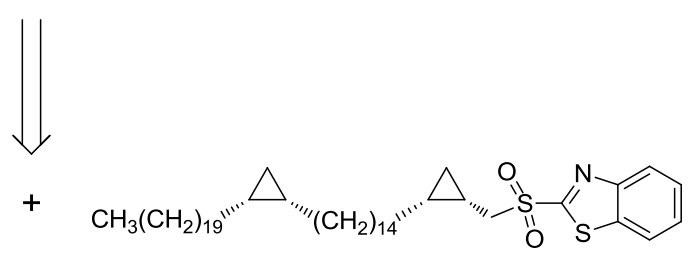

41

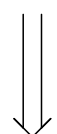

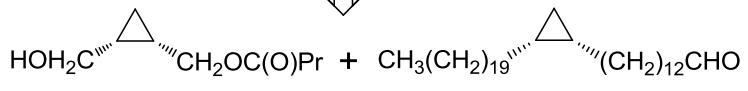

45

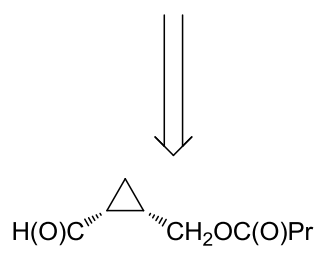

47

Scheme 6. Retrosynthesis of $\alpha$-TDM 10. 


\subsection{4c TDM Biological activity}

Although TDMs have been shown to play a role in the pathogenesis of $M$. $t b$ by conferring protection to the bacteria against harsh environmental conditions, ${ }^{17,18,118,119}$ it is the biological activity of TDMs, which have been of much interest over the past years. TDMs exhibit anti-tumour activity, ${ }^{120,121}$ adjuvant activity, ${ }^{73}$ anti-bacterial properties, ${ }^{122,123}$ and have the ability to induce granuloma formation ${ }^{124-127}$ and angiogenesis. ${ }^{128}$

TDMs exhibit anti-tumour activity, through tumour prevention, tumour regression and immunisation. A number of studies have been conducted to illustrate the effect of TDM on various tumour cells. In a study by Yarkoni et.al., prior injection of TDMs in mice was shown to suppress the growth of Ehrlich Ascites tumour cells. ${ }^{129}$ The tumour regression property of TDMs was demonstrated in a study where the growth of an ascetic rat hepatoma was suppressed in a mouse model following injection of TDM as an emulsion in peanut oil. ${ }^{130}$ In another study, administration of TDMs as liposomes led to activation of macrophages, subsequent nitric oxide (NO) production, and the development of anti-tumour activity against synergenic P77 fibrohistiocytoma tumour cells. ${ }^{120}$

TDMs exhibit adjuvant activity, as seen by Bekierkunst et al., ${ }^{131}$ where it was found that pre-injection of TDMs followed by injection of antigen into the same footpad of mice induced a high antibody production, whereas injection of antigen alone into contralateral footpads resulted in a lower antibody production. A number of studies have also shown induction of IL-4, IL-6 and IL-10 production after exposure of mice cells to TDMs, indicating that TDM could potentially enhance antibody production. ${ }^{36}$ In another study, it was found that TDMs caused a significant increase in IFN- $\gamma$ production, which was accompanied by the expansion of natural killer (NK) cells and upregulation of MHC class II on macrophages. ${ }^{132}$ The increased proportion of Th1 cells evident after 3 weeks suggest that TDMs could be potentially used as the adjuvant component of Th1 vaccines (e.g. cancer vaccines).

TDMs have also been shown to produce granulomas similar to those formed during mycobacterial infection. ${ }^{133}$ The purpose of granulomas is to contain the mycobacterium in distinct foci preventing the spread of infection and making 
destruction of the bacterium by cell-mediated immunity easier. However, it also serves to protect the bacterium from the host organism's natural defence system and allow the bacterium to multiply inside host cells.

Inflammatory granulomas are usually associated with angiogenesis, and several studies have been conducted to determine the effects that TDMs have on granuloma formation and angiogenesis. ${ }^{128,134,135}$ The production of vascular endothelial growth factor (VEGF) and IL-8, which are crucial for angiogenesis, were initiated in the presence of TDMs in macrophages indicating that TDMs play a major role in angiogenesis by inducing the production of cytokines required for this process.

Cord factors have also been shown to stimulate non-specific resistance against bacterial infections and parasites. Mice injected with TDMs were protected against Salmonella typhi strain Ty2 or Salmonella typhi strain SR11. ${ }^{136}$ Similar studies found that TDMs induce non-specific response against $K$. pneumoniae and $L$. monocytogenes. ${ }^{123}$

\subsection{Fráter-Seebach alkylation in TDCM and TDM syntheses}

\subsubsection{The Fráter-Seebach alkylation}

As highlighted previously in $1.5 .3 \mathrm{~b}$ and $1.5 .4 \mathrm{~b}$ one of the key steps in TDCM and TDM synthesis is the Fráter-Seebach alkylation. Defined as a highly efficient means of diastereoselectively introducing $\alpha$-substituents to chiral $\beta$-hydroxy-esters, this methodology was proposed by Fráter in 1979. He reported that by utilising LDA as a base, ethyl (S)-3-hydroxybutyrate (48) could be alkylated with methyl, allyl, butyl and benzyl bromide to give the corresponding (2S, 3S)-alkylated products 49a-c in good yield and excellent diastereoselectivity (Scheme 7). ${ }^{98,99}$ Similar methodology was also used for the alkylation of ethyl $(R)$-3-hydroxyvalerate using propyl iodide as the electrophile. ${ }^{137}$ 


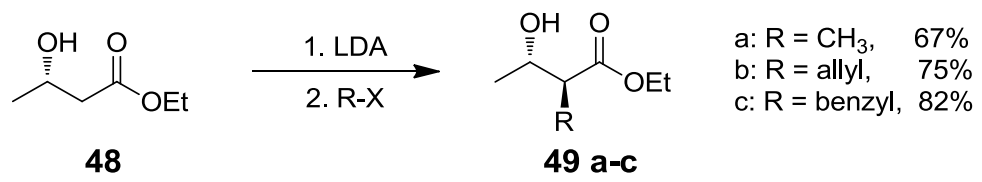

anti:syn 19:1

Scheme 7. Fráter's alkylation. ${ }^{98,99}$

At approximately the same time as Fráter, Seebach also performed pioneering studies in this field, as illustrated by the alkylation of diethyl malate $\mathbf{5 0}$ with methyl, allyl and benzyl halides to yield the alkylated product 51a-c (Scheme 8). ${ }^{97}$ Again, excellent diastereoselectivities, in favour of the anti-isomer, and good yields were reported for the $\alpha$-alkylations. To recognise the contributions by both research groups to this field, the $\alpha$-alkylation of $\beta$-hydroxy-esters is thus referred to as the FráterSeebach alkylation.

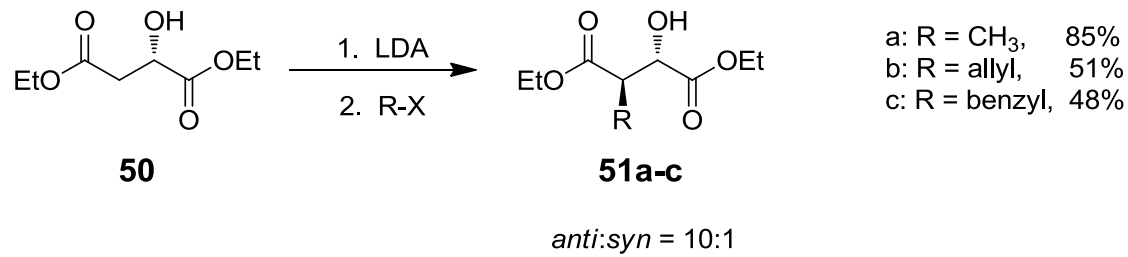

Scheme 8. Seebach's alkylation. ${ }^{97}$

Over the years, the Fráter-Seebach alkylation has formed a crucial step in the preparation of a variety of biologically important compounds including natural products ${ }^{138,139,140}$ and derivatives thereof, ${ }^{141,142,143}$ enzyme inhibitors, ${ }^{144}$ and other key chiral building blocks. ${ }^{145}$ The methodology has also been modified by the addition of HMPA to the reaction vessel so as to enhance the efficacy of the reaction. Despite the versatility of the Fráter-Seebach alkylation in organic synthesis, the extension of this methodology to longer chain alkyl halides, however, has been met with mixed success. ${ }^{96,105,106}$ 


\subsubsection{Scope and limitations of the Fráter-Seebach alkylation in the synthesis of trehalose glycolipids}

During their initial syntheses of mycolic acids en route to the preparation of TDMs, Baird and co-workers used the Fráter-Seebach alkylation for the introduction of the $\alpha$-chain of the mycolic acid. ${ }^{105,106}$ The synthesis of the $\alpha$-alkyl- $\beta$-hydroxy fragment started with a Grignard type ring-opening of epoxide $\mathbf{4 4}$ to produce alcohol $\mathbf{5 2}$ as a single enantiomer (Scheme 9). Alcohol 52 was then transformed into diol 53 in four steps, after which selective protection of the primary hydroxyl in $\mathbf{5 3}$ as the tertbutyldiphenylsilyl (TBDPS) ether, followed by Fráter-Seebach alkylation using tetracosanyl iodide $\mathbf{4 3}$ furnished hydroxy-ester 54, albeit in modest (31\%) yield. Protection of the secondary alcohol in $\mathbf{5 4}$ as an acetate, followed by deprotection of the primary hydroxyl, and subsequent oxidation then yielded aldehyde $\mathbf{4 0}$, the core fragment of mycolic acid. 


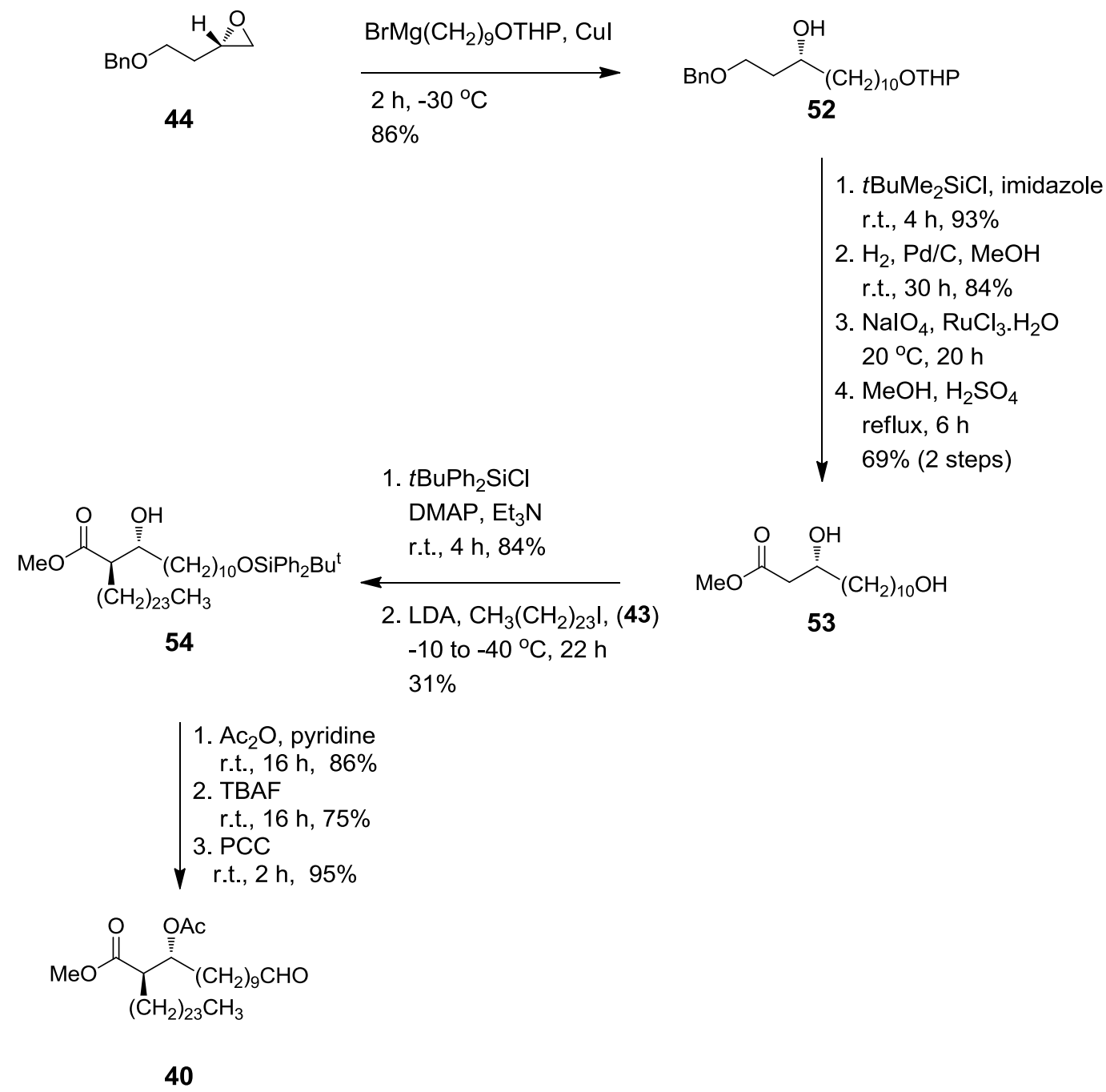

Scheme 9. Fráter-Seebach alkylation in mycolic acid synthesis. ${ }^{105,106}$

To circumvent the low yield of $\alpha$-alkylation with tetracosyl iodide, Baird and coworkers later developed a chain-elongation strategy ${ }^{112}$ in order to install the required lipid at the $\alpha$-position (Scheme 10). Here, hydroxy ester 55 was subjected to the Fráter-Seebach reaction with allyl iodide in the presence of HMPA to yield the $\alpha$ alkylated ester 56 in an improved 62\% yield. The $\alpha$-alkylated ester 56 was further derivatised to oxo-ester $\mathbf{5 7}$ via protection of the hydroxyl as the TBDMS ether followed by oxidation of the alkene to the corresponding aldehyde. Elongation of the $\alpha$-position in $\mathbf{5 7}$ was achieved via Julia olefination with tetrazole 58, followed by subsequent removal of the TBDMS group and hydrogenation of the double bond to yield hydroxy ester 59. Although this methodology led to an increased yield for the 
Fráter-Seebach reaction, additional steps were required to generate the desired alkyl length at the $\alpha$-position.

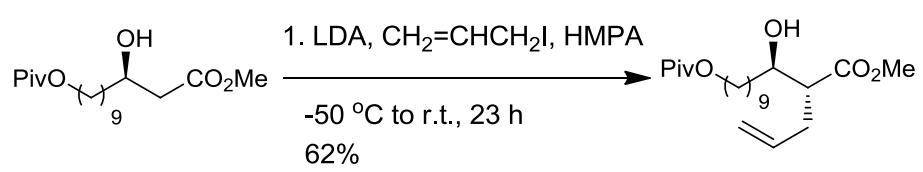

55

56

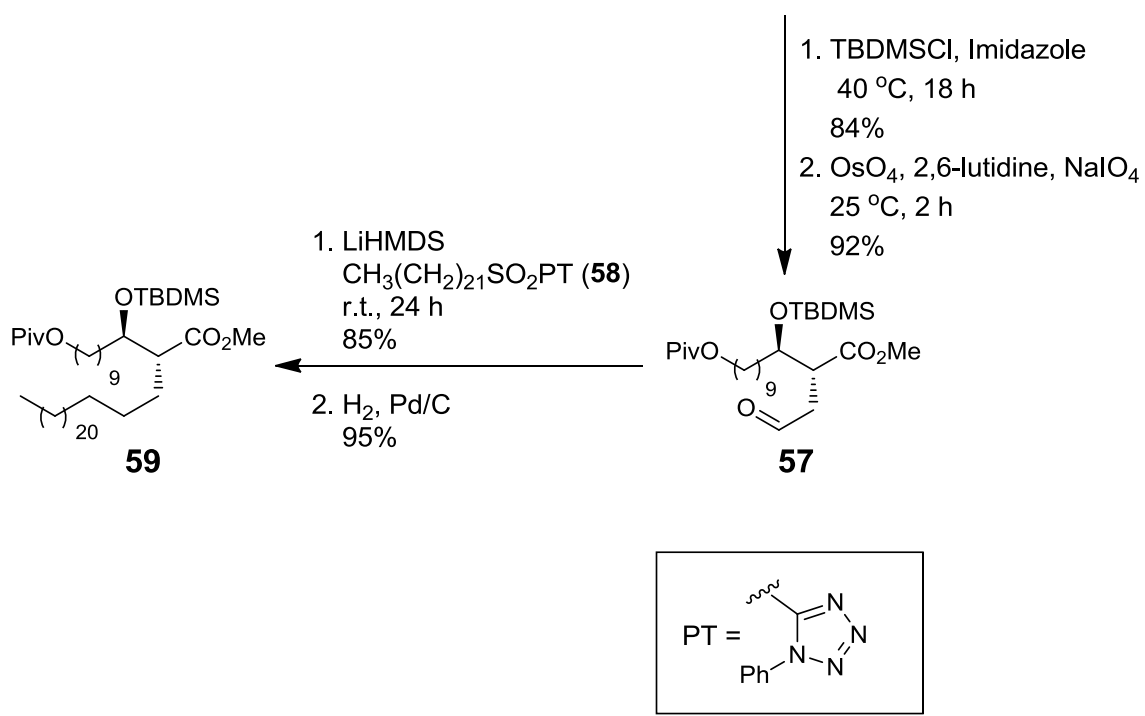

Scheme 10. Chain-elongation methodology in mycolic acid synthesis. ${ }^{112}$

In their synthesis of TDCM and analogues, Nishizawa et al. noted similar difficulties when performing a Fráter-Seebach alkylation with long chain alkyl (eicosanyl) iodide. ${ }^{96}$ Although the synthetic strategy was successful for the synthesis of natural TDCM and analogues with shorter corynomycolic chains (e.g. 37a-c) (Scheme 5), TDCM analogues with the C20 alkyl chain (e.g. 37d) could not be synthesised via a Fráter-Seebach alkylation of tetracosanoyl $\beta$-hydroxy functionalised ester $\mathbf{3 6}$ with eicosanyl iodide (Scheme 11). 


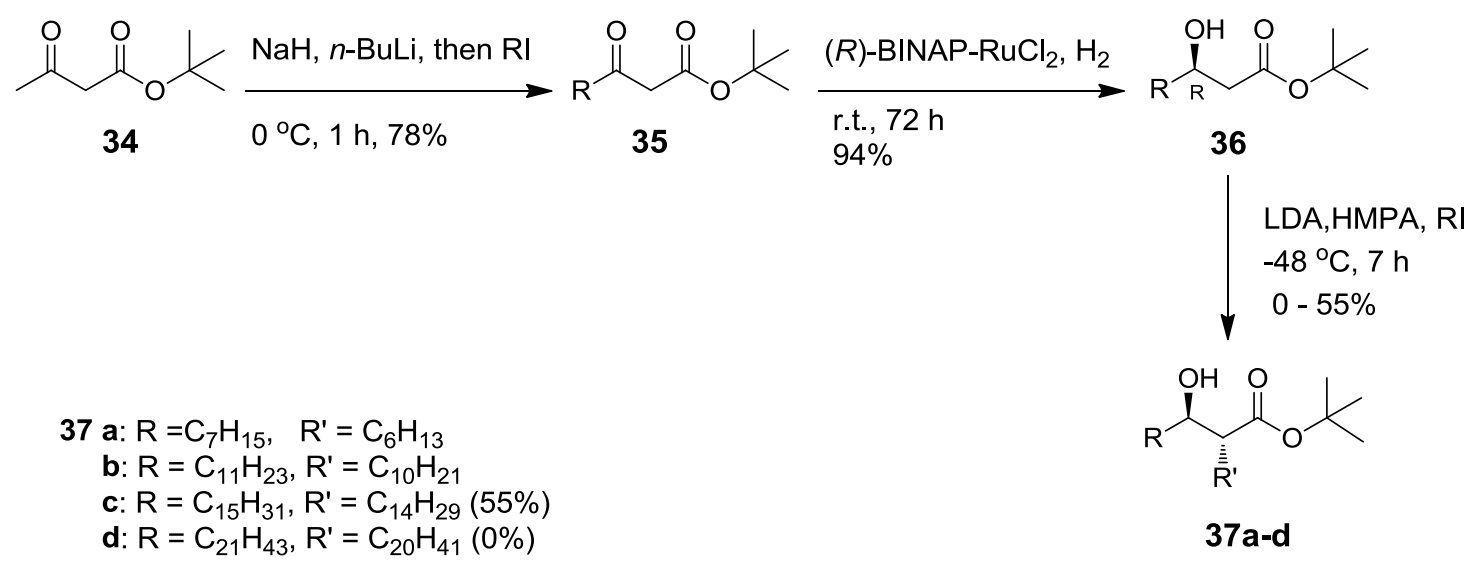

Scheme 11. Fráter-Seebach alkylation in corynomycolic acid and analogues syntheses. ${ }^{96}$

To accomplish the synthesis of the C20 TDCM analogue, 22, the authors thus resorted to a different strategy involving the $\gamma$-alkylation of tert-butyl acetoacetate (34) with bis-homoprenyl iodide 60 to form ester 61 (Scheme 12). Stereoselective reduction of the ketone in $\mathbf{6 1}$ using $(R)$ - BINAP- $\mathrm{RuCl}_{2}$ and hydrogen gave hydroxy ester 62, which was subjected to a Fráter-Seebach alkylation using eicosanyl iodide to form product 63 in $55 \%$ yield. Here, the presence of a shorter lipid on ester 62 was thought to facilitate the Fráter-Seebach alkylation by increasing the solubility of the substrate. Reductive etherification of $\mathbf{6 3}$ then afforded benzyl ether 64, which was subjected to ozonolysis, followed by Wittig reaction and subsequent treatment with TMSOTf, to liberate mycolic acid $\mathbf{6 5}$. Finally, acid $\mathbf{6 5}$ was coupled to the hexabenzyl protected trehalose derivative 33 , followed by hydrogenation of the benzyl groups and reduction of the double bond to yield the desired C20 TDCM 22. 


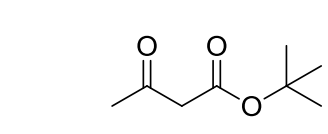

34
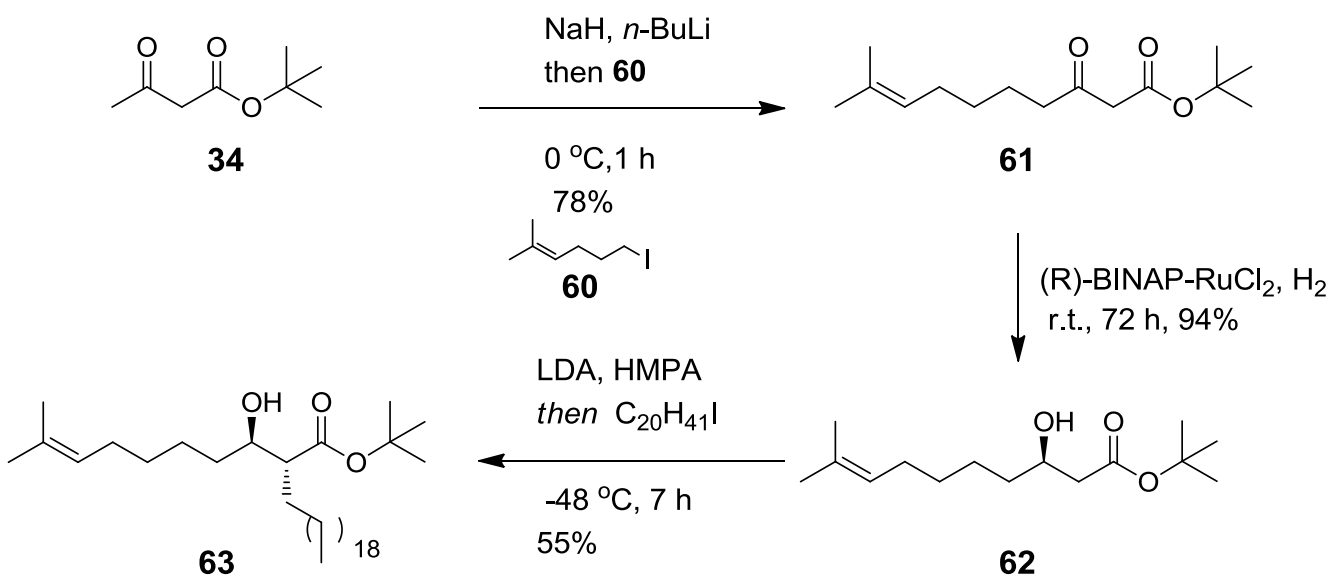

62

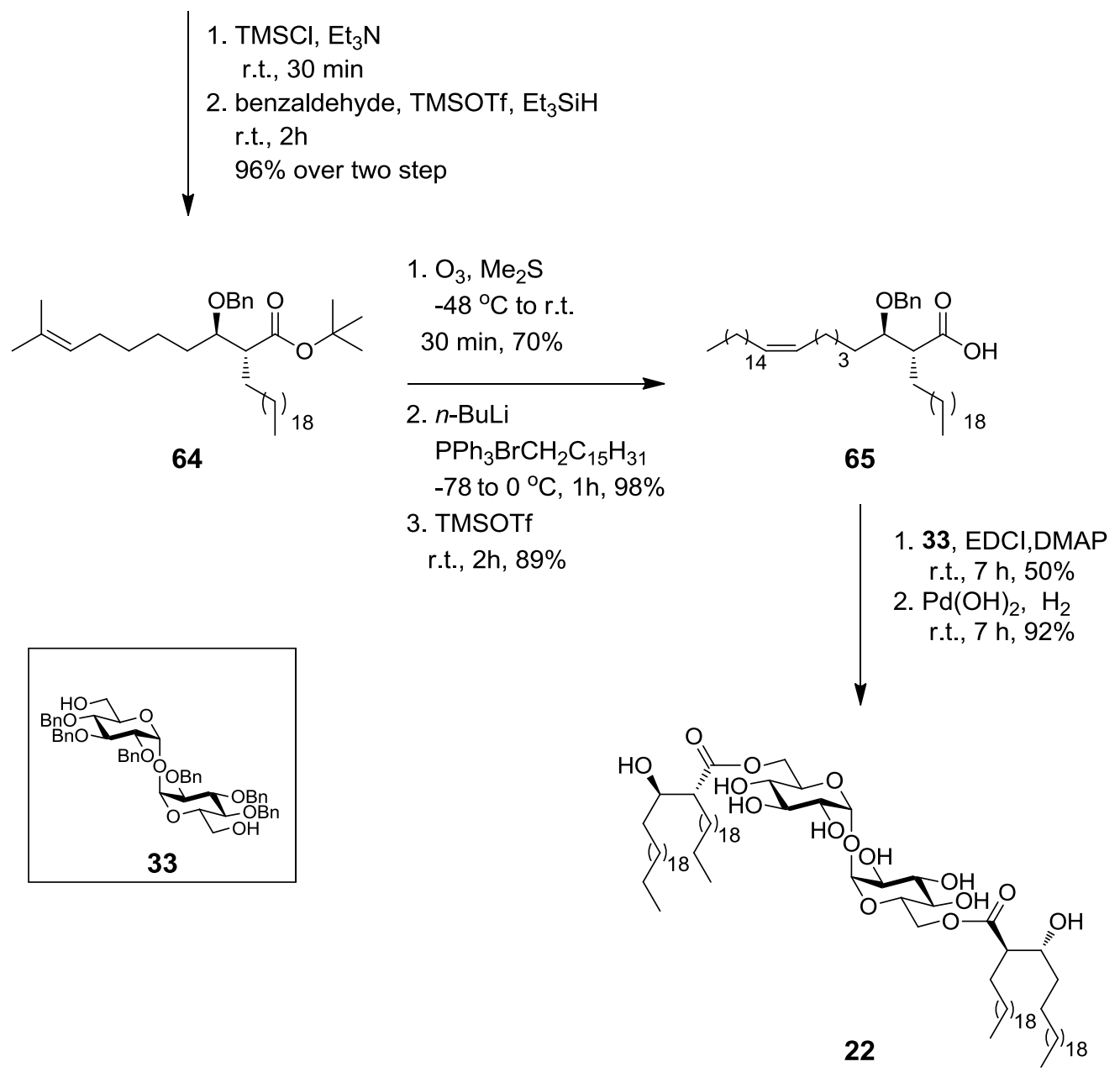

Scheme 12. Alternate route for C20 TDCM analogue synthesis. ${ }^{96}$ 


\subsection{Trehalose diester probes to study trehalose immunology}

\subsubsection{Introduction}

To date, aside from Mincle, there are no other known receptors for TDMs (and associated linear analogues such as TDB). One way to determine potential proteins that trehalose diesters bind to and interact with, is through the development of trehalose-diester probes, for use in affinity based proteome profiling (AfBPP). This, in turn, will aid in our understanding of the mechanism of action of this intriguing class of bio-molecules.

\subsubsection{Affinity Based Proteome Profiling (AfBPP)}

\subsection{2a Overview}

Proteomic research focuses on the study of proteins, their functions, and subsequent interactions with other bio-molecules in complex biological systems. Instead of studying individual proteins separately, proteomic research allows for the study of distinct proteins expressed at the same time by an organism or cell type. Traditionally, proteins were separated using techniques such as 1D/2D gelelectrophoresis and isotope coded affinity tagging (ICAT), followed by determination of the relative abundance. ${ }^{146}$ An alternate strategy that is now commonly employed is activity or affinity based proteome profiling (ABPP or AfBPP). ABPP and AfBPP use site-directed chemical probes to elucidate the functional state of enzymes in complex biological systems. They use relatively small organic molecules to label specific enzymes at their active site (and not their inactive precursor or inhibitor-bound forms). ${ }^{146}$ These methods are better since they can detect important post-translational forms of protein regulation like those mediated by protein-protein and/or protein-small molecule interactions. ${ }^{147}$ To date, probes have been developed for a number of enzyme classes, and these have provided a means of 
elucidating enzyme functions, and understanding enzyme activity in specific physiological and pathological processes.

\subsection{2b Basic Technology of AfBP Probes}

To ensure selective binding of activity and affinity based proteome (ABP and AfBP) probes to proteins and prevent cross reactivity with other proteins in the proteome, most probes consist of a combination of binding and reactive groups that target conserved mechanistic or structural features in a protein's active site. The probe contains three major elements: the recognition group, the reactive group, and the tag. The recognition group directs the $\mathrm{ABP}$ probe and $\mathrm{A} f \mathrm{BP}$ probe to the target protein and is designed in a way to resemble the natural substrate of the target protein. Closely attached to the recognition group is the reactive group ('trap') that reacts with amino acids in the proteins active site and thus forms a bond between the probe and protein. The recognition and reactive group are linked most often via a spacer unit to a tag which allows for visualisation and/or purification of the bound protein (Figure 16). ${ }^{148}$

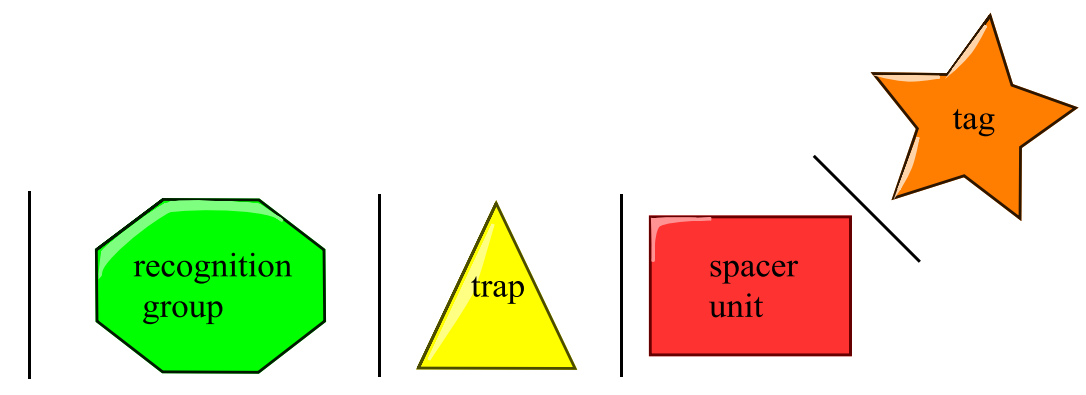

Figure 16. Representative cartoon of Activity/Affinity Based Proteome Probe. 


\subsection{2c AfBPP vs ABPP}

The difference between $\mathrm{ABPP}$ and $\mathrm{A} f \mathrm{BPP}$ arises from the different reactive groups employed by the two profiling methods. ${ }^{13}$ In ABP probes, electrophilic traps are present which are suited for proteins that contain a nucleophilic amino acid side chain residue (e.g. serine, cysteine, threonine) in their active site such as: cysteine proteases, serine hydrolases, and proteasome subunits. ABP probes thus involve a directed approach in which individual probes are designed to target specific proteins (Figure 17A). In contrast, AfBP probes employ the use of photoreactive trap groups and are commonly used for proteins not relying on nucleophilic residues in their active site, for example, metalloproteases and histone deacetylases. Most photoreactive groups are used to label proximal resides in the proteins active site following irradiation with light (Figure 17B). The use of AfBP probes offer a nondirected way of profiling proteins from several different classes, and in many cases are commonly used to profile proteins not accessible by ABP probes.

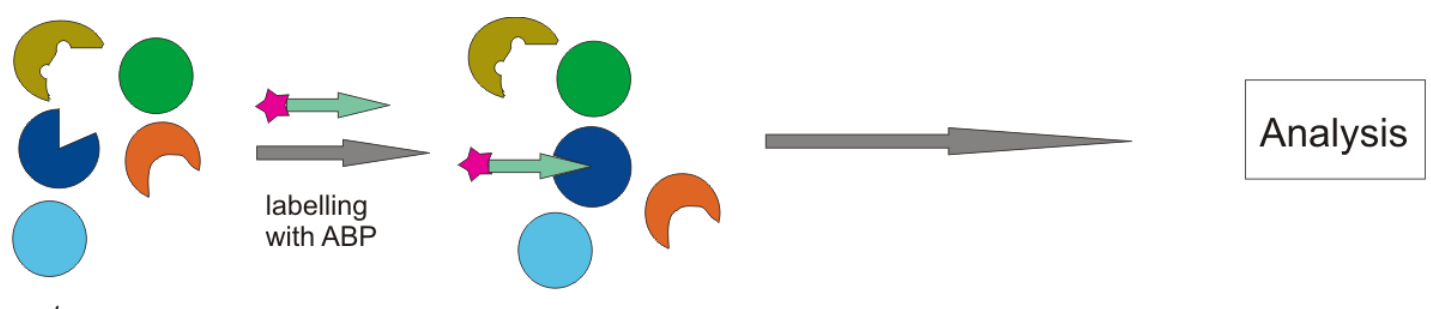

proteome

A
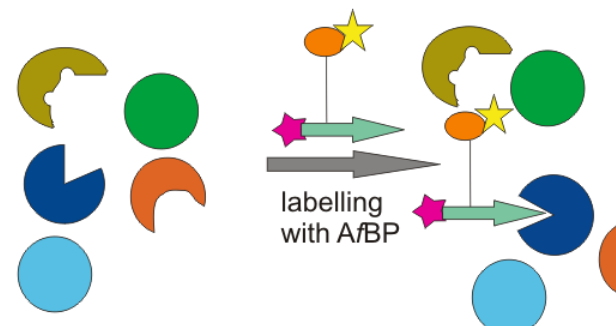

proteome

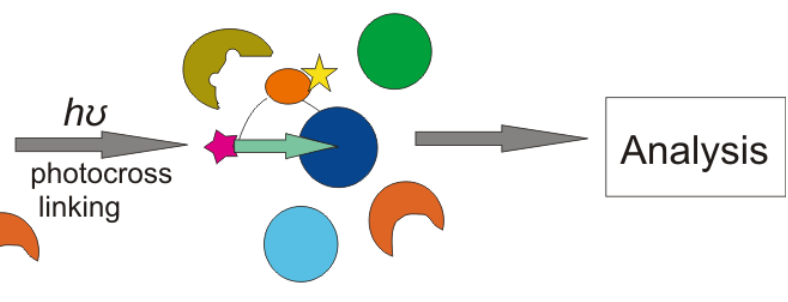

B

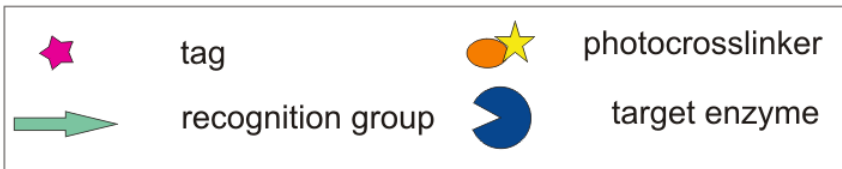

Figure 17. $\mathrm{ABPP}(\mathrm{A})$ vs $\mathrm{A} f \mathrm{BPP}(\mathrm{B})$. 


\subsection{2d Tag Groups}

The tag group on a probe is used to facilitate the characterisation of the target protein. Some tags that are commonly used include fluorophores [(e.g. rhodamine, 66)], biotin (67) and latent analytical handles like azides and alkynes (68) (Figure 18). ${ }^{149,150}$

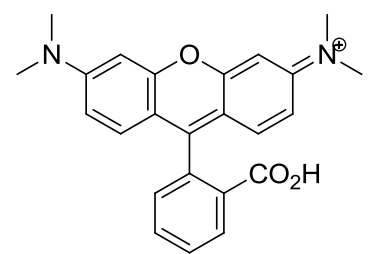

66

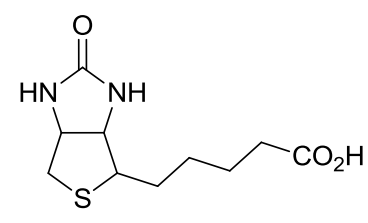

67

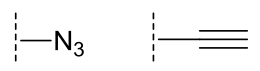

68

Figure 18. Common reporter tags used in $\mathrm{ABP}$ and $\mathrm{A} f \mathrm{BP}$ probes.

The use of azides and alkynes to visualise protein targets post-labelling overcomes the problem of the bulkiness associated with fluorophores which can influence the uptake of the probe into the cells. In this approach (known as a two step labelling process), the $\mathrm{ABP}$ or $\mathrm{A} f \mathrm{BP}$ probes tag is replaced by a ligation handle, which can be connected to the reporter group after the protein is captured. The most common ligation reactions used are Huisgen 2,3-dipolar cycloaddition or 'click' reactions. These can be copper catalysed (I) ${ }^{151}$ or strain-promoted (II) (Figure 19). ${ }^{152}$ Recently a new reagent has been reported by Boons and co-workers to promote a strainpromoted click reaction after irradiation with light. ${ }^{153}$ This has been termed the 'photoclick' reaction (III). 

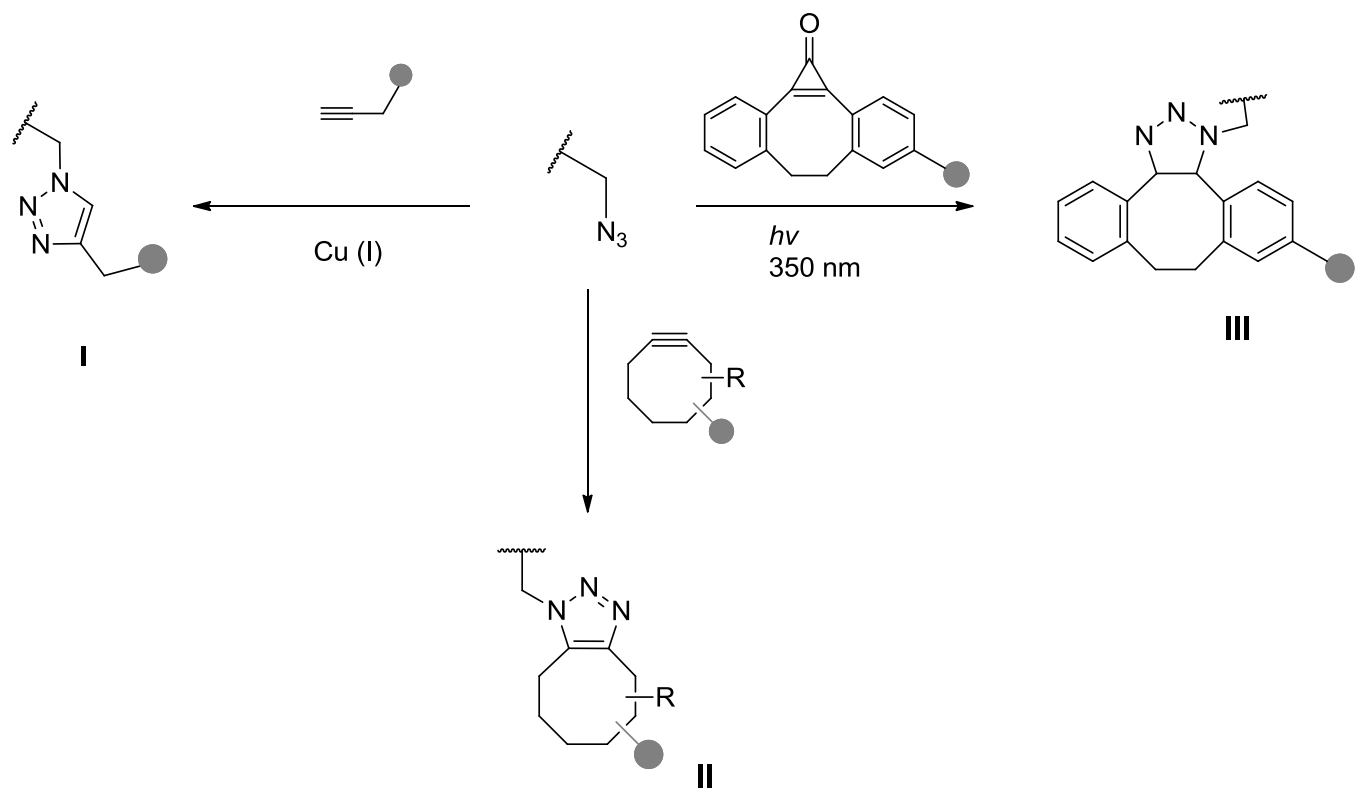

III

Figure 19. Ligation methods for azide and alkyne coupling.

\subsection{2e Reactive Groups}

To be used in AfBP probes, a photoreactive group needs to meet certain criteria. First, they need to be activated only upon irradiation with light of a specific wavelength which will not damage biological systems $\left(\lambda_{\text {act }}>300 \mathrm{~nm}\right) .{ }^{154}$ Second, the generated reactive species should have a shorter life span than the lifetime of the studied protein-substrate complex in order to limit non-specific labelling. It is also important that the activated species reacts with any chemical entity in close proximity to form a stabile covalent adduct. Finally, the photoreactive group should be small in order to minimise its influence on the binding mode and activity of the $\mathrm{A} f \mathrm{BP}$ probe towards the protein.

The use of photoreactive groups was first reported by Westheimer and co-workers in 1962 whereby they used a diazoacetyl group to deactivate chymotrypsin via photolysis. ${ }^{155}$ Over the years, many photoreactive groups have been developed but only few meet the requirements set out above. The common trap systems used today for probes are benzophenones (69, first reported in 1973), ${ }^{156}$ aryl azides (70) ${ }^{157}$ and diazirines (71) (Figure 20). ${ }^{158}$ 


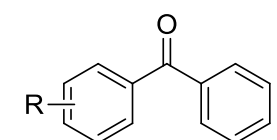

69

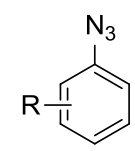

70

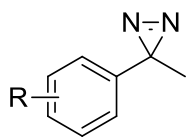

71

Figure 20. Examples of common trap systems for AfBP probes.

A major advantage of using benzophenones and diazirines, as opposed to aryl azides, is that they can be excited at wavelengths of $350-360 \mathrm{~nm}$, and therefore no significant damage to the biological system occurs. Aryl azides have their maximum absorption wavelength below $300 \mathrm{~nm}$; however this could be improved by using an electron withdrawing substituent (e.g. nitro, hydroxyl, and acyl groups) on the phenyl group. The major advantage of using aryl azides, is their small size which allows for easy incorporation into natural biological compounds without too much alteration of the original structure.

Unlike diazirines and aryl azides, most benzophenone building blocks are commercially available and in recent years, many examples of $\mathrm{A} f \mathrm{BP}$ probes containing benzophenone have been reported. ${ }^{159,160,161}$ Although, the benzophenone group might seem like an ideal photo-crosslinking reagent, it has drawbacks such as being relatively bulky, which may influence the interaction between the enzyme and substrate and lead to non-specific labelling. Benzophenones also need prolonged time for irradiation (>30 minutes) to result in reasonable cross-linking. The mechanism of cross-linking of the benzophenones to proteins can be explained as depicted in Scheme 13. ${ }^{162}$ After irradiation of benzophenone, the triplet diradical 72 is formed which abstracts a hydrogen atom from the $\alpha$-centre of a nearby amino acid 73 to form a ketyl radical (74) and an amino acid alkyl radical (75). These radical species then rapidly combine to form the desired cross-linked species, benzhydrol $\mathbf{7 6}$. In the presence of a glycine amino acid residue $\left(R^{\prime}=H\right)$, there is the possibility of water eliminating from bezhydrol (76) resulting in olefin $\mathbf{7 7}$, detection of which can be used to elucidate the presence of glycine in the active site of the protein. If diradical $\mathbf{7 2}$ reacts with water, the corresponding hydrate $\mathbf{7 8}$ forms, which rapidly loses water to form the starting benzophenone. One possible side reaction that can 
take place is homodimerisation of the ketyl $\mathbf{7 4}$ to form benzopinacol 79, however due to the relative large difference between hydrogen abstraction and recombination to form the benzhydrol 76, only a small amount of this by-product is formed.

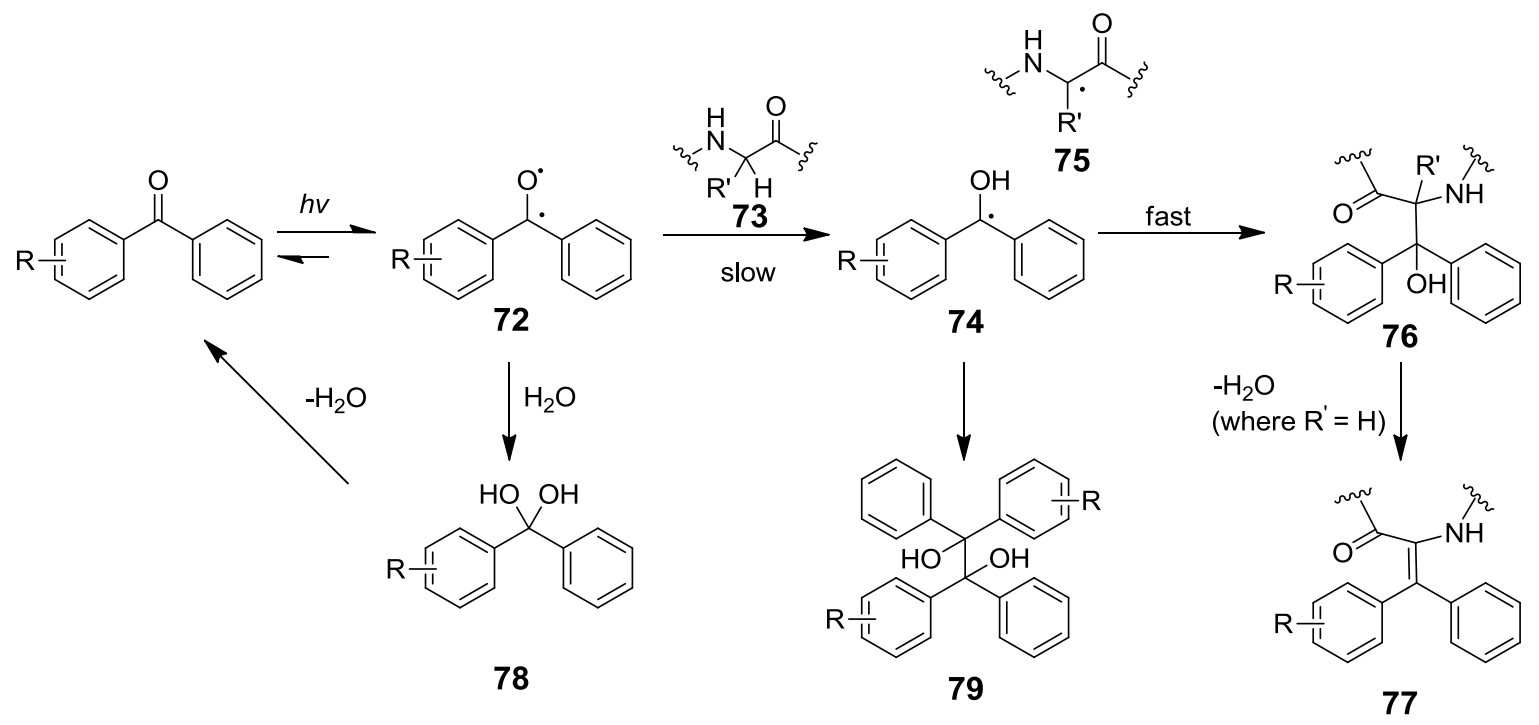

Scheme 13. Chemistry of benzophenone after photolysis.

\subsection{2f Applications and Synthesis of AfBP probes}

Over the years, many aryl azide based AfBP probes have been developed which can target various classes of enzymes and enhance our understanding of the mechanistic and functional states of these enzymes. In one such study, Dive and co-workers synthesised $\mathrm{A} f \mathrm{BP}$ biotinylated probe $\mathbf{8 0}$ and $\mathrm{ABP}$ biotinylated probe $\mathbf{8 1}$ to study matrix metalloproteinases (MMPs) from tumour extracts (Figure 21). ${ }^{163}$ 


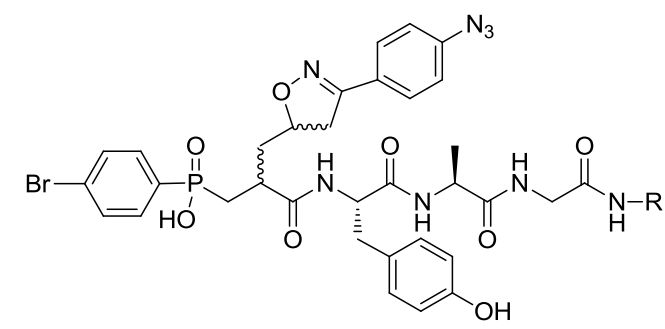

80

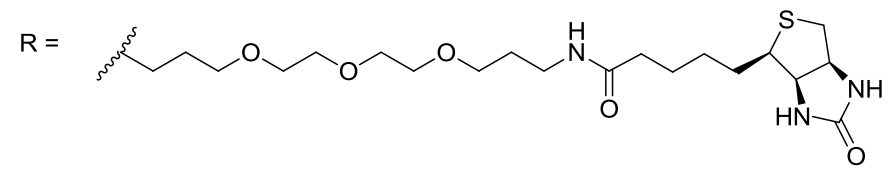<smiles>CC1(C[C@H](N)C(=O)O)N=N1</smiles>

82<smiles>[R]NCC(C)OCCOCCOc1cc(C2(C(F)(F)F)N=N2)ccc1CNCC(=O)Nc1cccnc1C(=O)Nc1nccs1</smiles>

$84 \mathrm{R}=$ biotin

$85 R \stackrel{R^{5}}{=} \prod_{0}^{5^{5}} \mathrm{~N}_{3}$<smiles>CC1(CC[C@H](N)C(=O)O)N=N1</smiles>

83

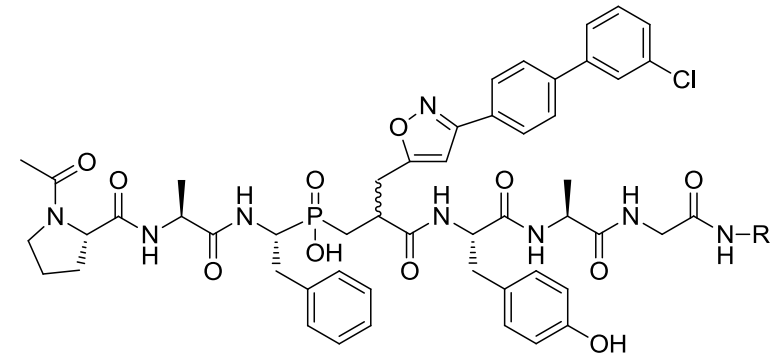

81

Figure 21. Aryl azide and diazirines based AfBPs.

There are also a number of interesting AfBP probes containing diazirines as 'traps', and these include photo-leucine (82) and photo-methionine (83), synthesised in 2005 by Thiele and co-workers, which were used as photoactivatable amino acids to study protein-protein interactions in living cells. ${ }^{164}$ Here, it was shown that both photoactivatable amino acids could be readily incorporated into proteins, and protein-protein interactions not identified previously were detected using these traps. Qui et al. reported on the synthesis of L288-probes $\mathbf{8 4}$ and $\mathbf{8 5}$, and analysed them for their ability to label methionine aminopeptidases (MetAPs). ${ }^{165}$ L288 (86) is a potent inhibitor of type I MetAP, an enzyme that is a potential target for new anti-bacterial 
and anti-fungal therapeutics. Both ABPs $\mathbf{8 4}$ and $\mathbf{8 5}$, were able to bind MetAP, with probe $\mathbf{8 5}$ being more selective for MetAP protein labelling.

There are many examples of $\mathrm{A} f \mathrm{BP}$ probes containing benzophenone groups reported in literature. To study histone deactylases (HDACs), a key regulator of gene expression that assembles into larger protein complexes, Salisbury and Cravatt reported the synthesis of SAHA-Bryne 87 (Figure 22). ${ }^{159}$ This probe contains the important structural elements of HDAC inhibitor suberoylanilide hydroxamic acid [SAHA, (88)] as well as benzophenone and alkyne moieties for targeting the HDACs. SAHA-Bryne 87 demonstrated good HDAC binding specificity and could also be used to measure HDAC content in different forms of cancer. Results indicated that SAHA was quite selective for HDACs and thus could be a valuable tool for profiling both the activity of HDAC proteins, and the binding proteins that regulate their function, particularly in cancer. ${ }^{159}$ Benzophenone based ABPs have also been used for targeting metalloproteases. For example, GM600 (89) a matrix metalloprotease inhibitor, was converted to photoaffinity probe $\mathbf{9 0}$ by incorporating a benzophenone building block and a fluorophore. ${ }^{160}$ This probe could then be used to covalently label and visualise several active MMPs in complex proteomes.

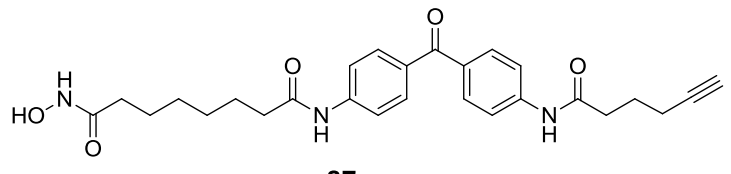<smiles>O=C(CCCCCCCC(=O)Nc1ccccc1)NO</smiles>

88<smiles>CNC(=O)C(CC(=O)C(CC(=O)NO)CC(C)C)Cc1cc2ccccc2[nH]1</smiles>

89<smiles>CC(C)C[C@@H](C(=O)NO)C(=O)N[C@@H](Cc1ccc(C(=O)c2ccccc2)cc1)C(=O)NCCCCc1cn(CCCN[18CH])nn1</smiles>

Figure 22. Benzophenone based AfBP probes. 


\subsection{2g Click chemistry based AfBP probes}

In recent years, the use of click chemistry (CC) in proteomic research has significantly increased. Earlier designs of $\mathrm{A} f \mathrm{BP}$ probes used $\mathrm{CC}$ as a mode of introducing the linker unit. Due to the high specificity of this reaction, functional group protection and deprotection was not required and the trizole ring, formed after ligation, was thought to facilitate some protein-binding interactions. CC probes are commonly used since the 'reporter' group in this case is either the alkyne or azide moiety, which is much smaller than other reporter groups (e.g. biotin, fluorophores) and thus does not hamper the interaction between the probe and protein. Fuwa et al. used CC to synthesise a diazirine based benzodiazepine probe 91 (Figure 23), in order to study the enzyme $\gamma$-secretase. ${ }^{166} \mathrm{CC}$ was also used by Yao and co-workers, to synthesise probe $\mathbf{9 2}$ for the detection of all four plasmesins in the malarial parasite Plasmodium falciparum. ${ }^{167}$
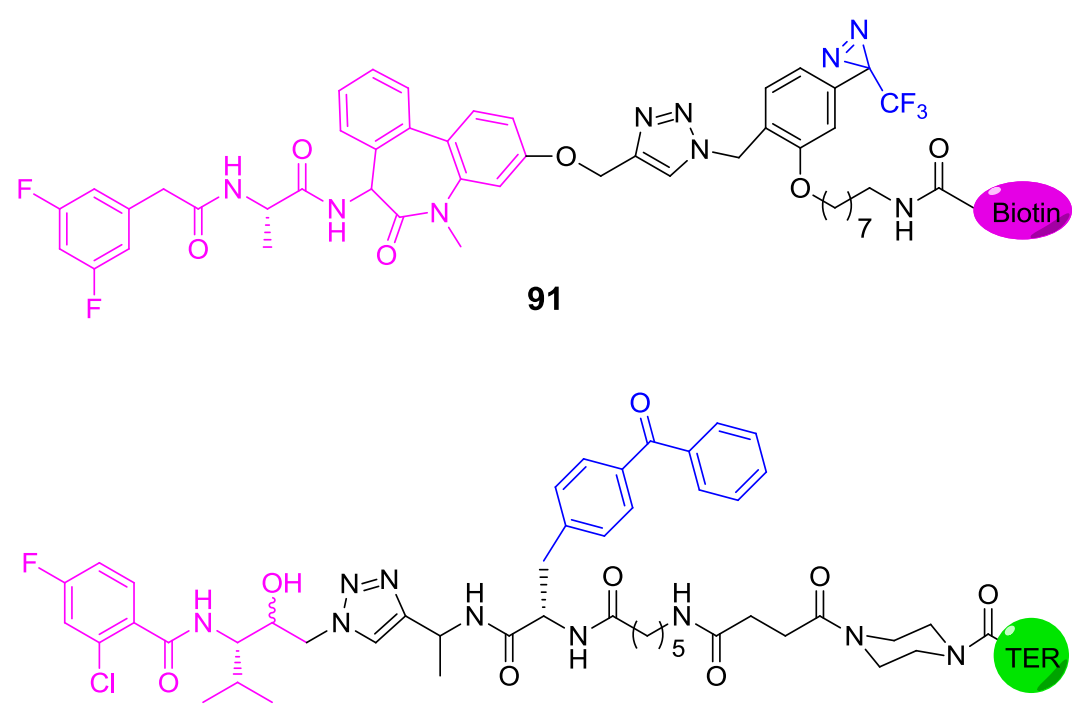

92

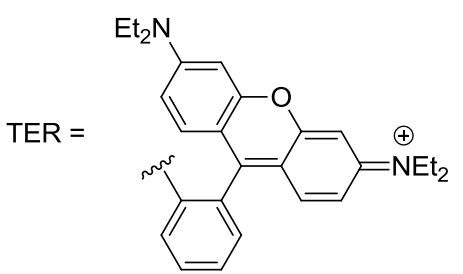

Figure 23. CC-based AfBP probes. 


\subsubsection{Elucidation of bound enzymes}

Once the proteins have been 'trapped' by the probe, the complex is isolated, digested using trypsin and the peptide fragments are characterised using analytical platforms like gel electrophoresis (e.g. SDS-PAGE) and liquid chromatography-mass

spectrometry (LC-MS). ${ }^{146}$ Trypsin is commonly used for peptide digestion as it is known to cleave peptide chains at the carboxyl side of lysine and arginine residues specifically, except when they are attached to a proline residue. In gel electrophoresis, the probe-treated proteome is first resolved using one- (1D) or twodimensional (2D) polyacrylamide gel electrophoresis (PAGE), which differentiates peptide fragments based on their molecular weights, and the labelled proteins are visualised by in-gel fluorescence scanning (for fluorescent probes) or avidin blotting (for biotinylated probes). In LC-MS analysis, after digestion with trypsin, the streptavidin enriched peptides are analysed using LC-MS/MS.

\subsection{Thesis Outline}

The work described in this thesis focuses on trehalose glycolipids, particularly the synthesis and biological testing of these compounds. In Chapter 2, investigations into the synthesis of trehalose diesters of fatty acids (TDEs, 14, Figure 24) with varying lipid lengths and a discussion on the different synthetic strategies employed in order to obtain all required compounds will be presented. This will be followed by the biological evaluation of TDEs by way of macrophage activation studies and subsequent investigation of structural requirements of trehalose glycolipids for the activation of macrophages in Chapter 3. The effect of TDEs on cytotoxicity would also be analysed and correlations made to the previously observed anti-tumour activity of these compounds. 

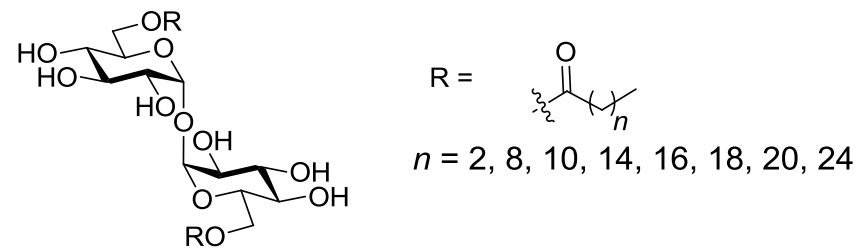

14

Figure 24. TDEs

In Chapter 4, the development of an improved method for the $\alpha$-alkylation of $\beta$ hydroxy-esters will be presented (Scheme 14). Here, it will be illustrated that diethyl malate (50) is more effectively alkylated using allylic iodides, 93, to yield $\alpha$ alkylated- $\beta$-hydroxy esters, 94, when compared to alkyl iodides, in the FráterSeebach alkylation methodology. This method is commonly used in the synthesis of TDMs and TDCMs and thus our methodology could lead to more effective synthesis of these glycolipids. This will be followed by the use of this improved methodology for the synthesis of a trehalose monocorynomycolate (TMCM) analogue (95, Figure 25) in Chapter 5 in order to set the conditions required for the synthesis of other TMCMs and related TDCM glycolipids.

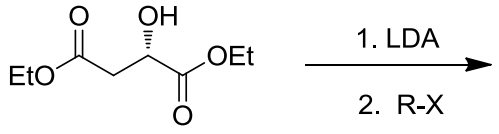

50
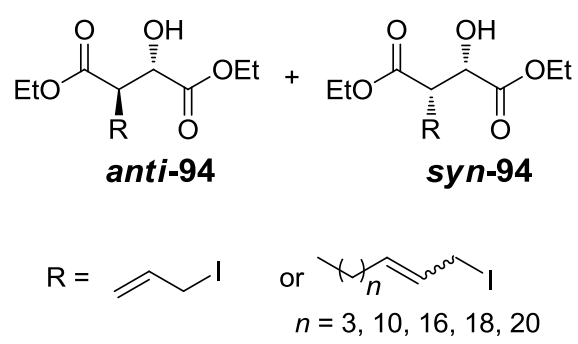

93

Scheme 14. Improved methodology for Fráter-Seebach alkylation 


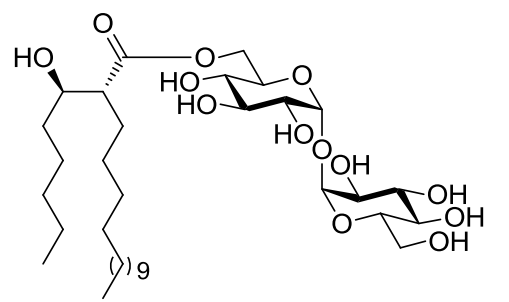

95

Figure 25. TMCM analogue

Chapter 6 would focus on the synthesis of an AfBPP probe (96, Figure 26), which can be used to elucidate the proteins that TDMs bind to upon interaction with host cells. The probe will consists of a benzophenone trap and an alkyne tag group and together with the reactive trehalose moiety has all the components needed in an $\mathrm{A} f \mathrm{BP}$ probe.

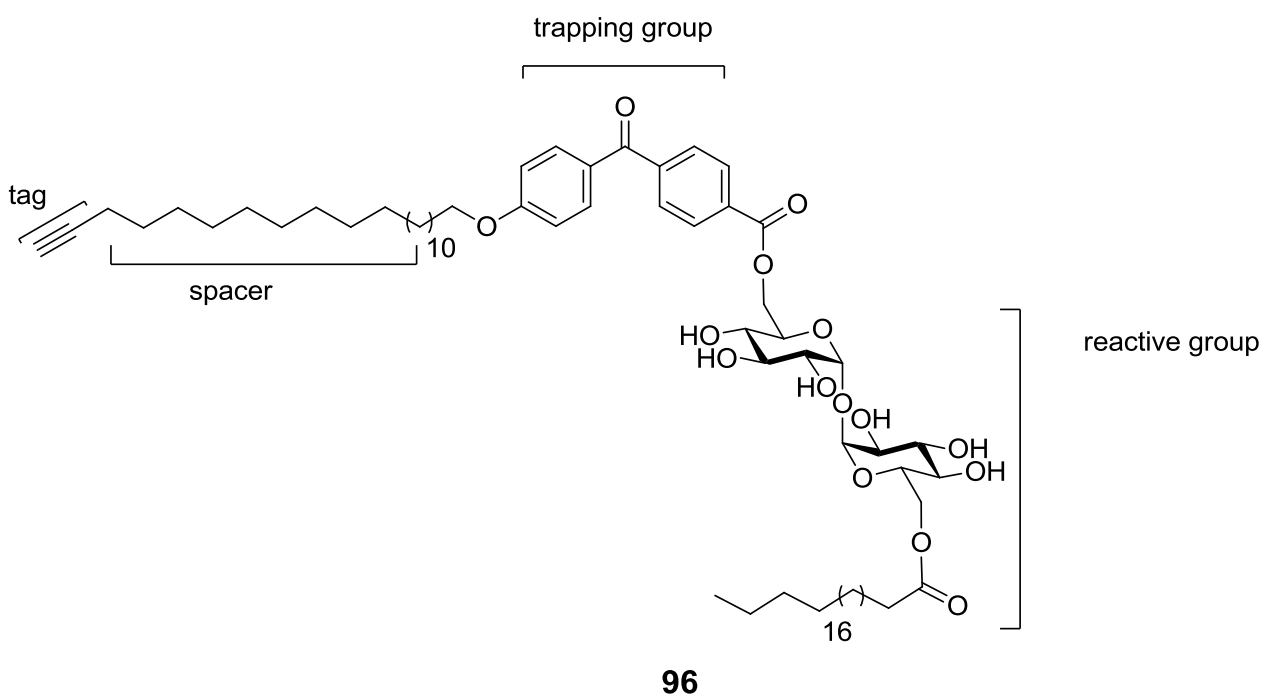

Figure 26. A $f \mathrm{BPP}$ probe

Chapter 7 would comprise of a summary of this thesis and some of the future work which will be carried out. Unless otherwise stated, all work was performed by the candidate. 


\section{Reference}

(1) Coley, W. B. Am. J. Med. Sci. 1893, 105, 487- 511.

(2) Coley, W. B. Proc. R. Soc. Med. 1910, 3, 1-48.

(3) McCarthy, E. F. Iowa Orthop. J. 2006, 26, 154-158.

(4) Qin, H.-Y.; Sadelain, M. W. J.; Hitchon, C.; Lauzon, J.; Singh, B. J. Immunol. 1993, 150, 2072-2080.

(5) Armentero, M.-T.; Levandis, G.; Nappi, G.; Bazzini, E.; Blandini, F. Neurobiol. Dis. 2006, 24, 492-505.

(6) Oscherwitz, J.; Hankenson, F. C.; Yu, F.; Cease, K. B. Vaccine 24, 30183025.

(7) Calmette, A.; Guèrin, C. Ann. Inst. Pasteur. 1920, 34, 553-560.

(8) Lawn, S. D.; Zumla, A. I. Lancet 2011, 378, 57-72.

(9) Trunz, B. B.; Fine, P.; Dye, C. Lancet 2006, 367, 1173-1180.

(10) Young, D. B.; Perkins, M. D.; Duncan, K.; Barry III, C. E. J. Clin. Invest. 2008, 118, 1255-1265.

(11) Herr, H. W.; Schwalb, D. M.; Zhang, Z. F.; Sogani, P. C.; Fair, W. R.; Whitmore, W. F. J.; Oettgen, H. F. J Clin Oncol 1995, 13, 1404-1408.

(12) Ryll, R.; Kumazawa, Y.; Yano, I. Microbiol. Immunol. 2001, 45, 801-811.

(13) Kalesh, K. A.; Shi, H. B.; Ge, J. Y.; Yao, S. Q. Org. Biomol. Chem. 2010, 8, 1749-1762.

(14) Koch, R. Br. Med. J. 1891, 2, 125-127.

(15) Russell, D. G. Nat. Rev. Microbiol. 2007, 5, 39- 47.

(16) Bhowruth, V.; Alderwick, L.; Brown, A.; Bhatt, A.; Besra, G. Biochem. Soc. Trans. 2008, 36, 555-564.

(17) Brennan, P. J.; Nikaido, H. Annu. Rev. Biochem. 1995, 64, $29-63$.

(18) Chatterjee, D. Curr. Opin. Chem. Biol. 1997, 1, 579-588.

(19) Liu, X.; Stocker, B. L.; Seeberger, P. H. J. Am. Chem. Soc. 2006, 128, 36383648.

(20) Cao, B.; Williams, S. J. Nat. Prod. Rep. 2010, 27, 919-947.

(21) Parlane, N. A.; Denis, M.; Severn, W. B.; Skinner, M. A.; Painter, G. F.; La Flamme, A. C.; Ainge, G. D.; Larsen, D. S.; Buddle, B. M. Immunol. Invest. 2008, 37, 129-142.

(22) Denis, M.; Ainge, G. D.; Larsen, D. S.; Severn, W. B.; Painter, G. F. Immunopharmacol. Immunotoxicol. 2009, 31, 577-582.

(23) Ainge, G. D.; Compton, B. J.; Hayman, C. M.; Martin, W. J.; Toms, S. M.; Larsen, D. S.; Harper, J. L.; Painter, G. F. J. Org. Chem. 2011, 76, 4941-4951.

(24) Driessen, N. N.; Ummels, R.; Maaskant, J. J.; Gurcha, S. S.; Besra, G. S.; Ainge, G. D.; Larsen, D. S.; Painter, G. F.; Vandenbroucke-Grauls, C. M. J. E.; Geurtsen, J.; Appelmelk, B. J. Infect. Immun. 2009, 77, 4538-4547.

(25) Boonyarattanakalin, S.; Liu, X.; Michieletti, M.; Lepenies, B.; Seeberger, P. H. J. Am. Chem. Soc. 2008, 130, 16791-16799.

(26) Sada, E.; Aguilar, D.; Torres, M.; Herrera, T. J. Clin. Microbiol. 1992, 30, 2415-2418.

(27) Ito, T.; Hasegawa, A.; Hosokawa, H.; Yamashita, M.; Motohashi, S.; Naka, T.; Okamoto, Y.; Fujita, Y.; Ishii, Y.; Taniguchi, M.; Yano, I.; Nakayama, T. Int. Immunol. 2008, 20, 849-860.

(28) Constant, P.; Perez, E.; Malaga, W.; Laneelle, M.-A.; Saurel, O.; Daffé, M.; Guilhot, C. J. Biol. Chem. 2002, 277, 38148-38158. 
(29) Daffe, M.; Laneelle, M.-A. J. Gen. Microbiol. 1988, 134, 2049-2055.

(30) Onwueme, K. C.; Vos, C. J.; Zurita, J.; Ferreras, J. A.; Quadri, L. E. N. Prog. Lipid Res. 2005, 44, 259-302.

(31) Camacho, L. R.; Constant, P.; Raynaud, C.; Lanèelle, M.-A.; Triccas, J. A.; Gicquel, B.; Daffé, M.; Guilhot, C. J. Biol. Chem. 2001, 276, 19845-19854.

(32) Reed, M. B.; Domenech, P.; Manca, C.; Su, H.; Barczak, A. K.; Kreiswirth, B. N.; Kaplan, G.; Barry III, C. E. Nature 2004, 431, 84-87.

(33) Bloch, H. J. Exp. Med. 1950, 91, 197-218.

(34) Lemaire, G.; Tenu, J.-P.; Petit, J.-F. Med. Res. Rev. 1986, 6, 243-274.

(35) Lederer, E. Chem. Phys. Lipids 1976, 16, 91-106.

(36) Barry III, C. E.; Lee, R. E.; Mdluli, K.; Sampson, A. E.; Schroeder, B. G.; Slayden, R. A.; Yuan, Y. Prog. Lipid Res. 1998, 37, 143-179.

(37) Minnikin, D. E.; Polgar, N. Chem. Commun. 1966, 648-649.

(38) Minnikin, D. E.; Polgar, N. Tetrahedron Lett. 1966, 7, 2643-2647.

(39) Middlebrook, G.; Coleman, C. M.; Schaefer, W. B. Proc. Natl. Acad. Sci. 1959, 45, 1801-1804.

(40) Goren, M. B.; Brokl, O.; Roller, P.; Fales, H. M.; Das, B. C. Biochemistry 1976, 15, 2728-2735.

(41) Domenech, P.; Reed, M. B.; Dowd, C. S.; Manca, C.; Kaplan, G.; Barry III, C. E. J. Biol. Chem. 2004, 279, 21257-21265.

(42) Gilleron, M.; Stenger, S.; Mazorra, Z.; Wittke, F.; Mariotti, S.; Böhmer, G.; Prandi, J.; Mori, L.; Puzo, G.; De Libero, G. J. Exp. Med. 2004, 199, 649-659.

(43) Nishikawa, Y.; Katori, T.; Kukita, K.; Ikekawa, T. Nippon Kagaku Kaishi 1982, 10, 1661-1666.

(44) Toubiana, R.; Ribi, E.; McLaughlin, C.; Strain, S. M. Cancer Immunol. Immunother. 1977, 2, 189-193.

(45) Kamiya, S. Hirosaki Igaku 1986, 38, 712-719.

(46) Yarkoni, E.; Rapp, H. J.; Polonsky, J.; Lederer, E. Int. J. Cancer 1978, 22, 564-569.

(47) Satoh, K. Hirosaki Igaku 1991, 42, 455-464.

(48) Parant, M.; Audibert, F.; Parant, F.; Chedid, L.; Soler, E.; Polonsky, J.; Lederer, E. Infect. Immun. 1978, 20, 12-19.

(49) Olds, G. R.; Chedid, L.; Lederer, E.; Mahmoud, A. A. F. J. Infect. Dis. 1980, 141, 473-478.

(50) Yarkoni, E.; Bekierkunst, A. Infect. Immun. 1976, 14, 1125-1129.

(51) Penkov, S.; Mende, F.; Zagoriy, V.; Erkut, C.; Martin, R.; Pässler, U.; Schuhmann, K.; Schwudke, D.; Gruner, M.; Mäntler, J.; Reichert-Müller, T.; Shevchenko, A.; Knölker, H.-J.; Kurzchalia, T. V. Angew. Chem. Int. Ed. 2010, 49, 9430-9435.

(52) Vilkas, E.; Rojas, A. Bull. Soc. Chim. Biol. 1964, 46, 689- 701.

(53) Schoenen, H.; Bodendorfer, B.; Hitchens, K.; Manzanero, S.; Werninghaus, K.; Nimmerjahn, F.; Agger, E. M.; Stenger, S.; Andersen, P.; Ruland, J.; Brown, G. D.; Wells, C.; Lang, R. J. Immunol. 2010, 184, 2756- 2760.

(54) Ishikawa, E.; Ishikawa, T.; Morita, Y. S.; Toyonaga, K.; Yamada, H.; Takeuchi, O.; Kinoshita, T.; Akira, S.; Yoshikai, Y.; Yamasaki, S. J. Exp. Med. 2009, 206, 2879-2888.

(55) Toubiana, R.; Toubiana, M. J. Biochimie 1973, 55, 575-578.

(56) Polonsky, J.; Soler, E.; Varenne, J. Carbohydr. Res. 1978, 65, 295-300. 
(57) Polonsky, J.; Ferréol, G.; Toubiana, R.; Lederer, E. Bull. Soc. Chim. Fr. 1956, 1471-1477.

(58) Liav, A.; Goren, M. B. Chem. Phys. Lipids 1980, 27, 345-352.

(59) Tocanne, J.-F. Carbohydr. Res. 1975, 44, 301-307.

(60) Toubiana, R.; Das, B. C.; Defaye, J.; Mompon, B.; Toubiana, M.-J. Carbohydr. Res. 1975, 44, 308-312.

(61) Bottle, S.; Jenkins, I. D. J. Chem. Soc., Chem. Commun. 1983, 385.

(62) Mitsunobu, O. Synthesis 1981, 1981, 1-28.

(63) Jenkins, I. D.; Goren, M. B. Chem. Phys. Lipids 1986, 41, 225-235.

(64) Toubiana, R.; Toubiana, M.-J.; Das, B. C.; Richardson, A. C. Biochimie 1973, $55,569-573$.

(65) Johnson, D. Carbohydr. Res. 1992, 237, 313-318.

(66) Johnson, D. A.; Livesay, M. T. J. Carbohydr. Chem. 1998, 17, 969-974.

(67) Ishii, F.; Takano, S.; Kohya, H.; Ishida, N. Gan To Kagaku Ryoho 1984, 11, 1629-1634.

(68) Kohya, H.; Ishii, F.; Takano, S.; Katori, T.; Ebina, T.; Ishida, N. Gan To Kagaku Ryoho 1986, 13, 1897-1904.

(69) Kohya, H.; Ishii, F.; Takano, S.; Katori, T.; Ebina, T.; Ishida, N. Jpn. J. Cancer Res. 1986, 77, 602-609.

(70) McLaughlin, C. A.; Ribi, E. E.; Goren, M. B.; Toubiana, R. Natl. Inst. Allergy Infect. Dis. 1978, 4, 109-113.

(71) Laszlo, A.; Baer, H. H.; Goren, M. B.; Handzel, V.; Papa, F. Res. Microbiol. 1994, 145, 563-572.

(72) Davidsen, J.; Rosenkrands, I.; Christensen, D.; Vangala, A.; Kirby, D.; Perrie, Y.; Agger, E. M.; Andersen, P. Biochim. Biophys. 2005, 1718, 22-31.

(73) Holten-Andersen, L.; Doherty, T. M.; Korsholm, K. S.; Andersen, P. Infect. Immun. 2004, 72, 1608-1617.

(74) Henriksen-Lacey, M.; Devitt, A.; Perrie, Y. J. Control. Release 2011, 154, 131-137.

(75) Sarpe, V. A.; Kulkarni, S. S. J. Org. Chem. 2011, 76, 6866-6870.

(76) Pässler, U.; Gruner, M.; Penkov, S.; Kurzchalia, T. V.; Knölker, H.-J. Synlett 2011, 2482-2486.

(77) Ioneda, T.; Lenz, M.; Pudles, J. Biochem. Biophys. Res. Commun. 1963, 13, 110-114.

(78) Puzo, G.; Tissié, G.; Aurelle, H.; Lacave, C.; Prome, J.-C. Eur. J. Biochem. 1979, 98, 99-105.

(79) Senn, M.; Ioneda, T.; Pudles, J.; Lederer, E. Eur. J. Biochem. 1967, 1, 353356.

(80) Datta, A. K.; Takayama, K. Carbohydr. Res. 1993, 245, 151-158.

(81) Liav, A.; Goren, M. B. Carbohydr. Res. 1980, 81, C1-C3.

(82) Liav, A.; Das, B. C.; Goren, M. B. Carbohydr. Res. 1981, 94, 230-235.

(83) Liav, A.; Goren, M. B. Carbohydr. Res. 1984, 125, 323-328.

(84) Liav, A.; Flowers, H. M.; Goren, M. B. Carbohydr. Res. 1984, 133, 53-58.

(85) Liav, A.; Goren, M. B. Carbohydr. Res. 1984, 129, 121-129.

(86) Liav, A.; Goren, M. B. Carbohydr. Res. 1986, 155, 229-235.

(87) Polonsky, J.; Lederer, E. Bull. Soc. Chim. Fr. 1954, 504-510.

(88) Kitano, Y.; Kobayashi, Y.; Sato, F. J. Chem. Soc. Chem. Commun. 1985, 498 499. 
(89) Utaka, M.; Higashi, H.; Takeda, A. J. Chem. Soc. Chem. Commun. 1987, 1368-1369.

(90) Nishizawa, M.; Minagawa, R.; Garcia, D. M.; Hatakeyama, S.; Yamada, H. Tetrahedron Lett. 1994, 35, 5891-5894.

(91) Katsuki, T.; Sharpless, K. B. J. Am. Chem. Soc. 1980, 102, 5974-5978.

(92) Pappo, R.; Allen Jr., D. S.; Lemieux, R. U.; Johnson, W. S. J. Org. Chem. 1956, 21, 478-479.

(93) Omura, K.; Swern, D. Tetrahedron 1978, 34, 1651-1660.

(94) Noyori, R.; Ikeda, T.; Ohkuma, T.; Widhalm, M.; Kitamura, M.; Takaya, H.; Akutagawa, S.; Sayo, N.; Saito, T.; Taketomi, T.; Kumobayashi, H. J. Am. Chem. Soc. 1989, 111, 9134-9135.

(95) Nishizawa, M.; Garcia, D. M.; Minagawa, R.; Noguchi, Y.; Imagawa, H.; Yamada, H.; Watanabe, R.; Yoo, Y. C.; Azuma, I. Synlett 1996, 452-454.

(96) Nishizawa, M.; Yamamoto, H.; Imagawa, H.; Barbier-Chassefiére, V.; Petit, E.; Azuma, I.; Papy-Garcia, D. J. Org. Chem. 2007, 72, 1627-1633.

(97) Seebach, D.; Wasmuth, D. Helv. Chim. Acta 1980, 63, 197-200.

(98) Fráter, G. Helv. Chim. Acta 1979, 62, 2825 -2828.

(99) Fráter, G.; Muller, U.; Gunther, W. Tetrahedron 1984, 40, 1269-1277.

(100) Yarkoni, E.; Rapp, H. J.; Polonsky, J.; Varenne, J.; Lederer, E. Infect. Immun. 1979, 26, 462- 466.

(101) Ravindran, R.; Bhowmick, S.; Das, A.; Ali, N. BMC Microbiol. 2010, 10, 181-191.

(102) Hovav, A.-H.; Fishman, Y.; Bercovier, H. Infect. Immun. 2005, 73, 250-257.

(103) Nishizawa, M.; Garcia, D. M.; Minagawa, R.; Noguchi, Y.; Imagawa, H.; Yamada, H.; Watanabe, R.; Yoo, Y. C.; Azuma, I. Synlett 1996, 452-454.

(104) Watanabe, R.; Yoo, Y. C.; Hata, K.; Mitobe, M.; Koike, Y.; Nishizawa, M.; Garcia, D. M.; Nobuchi, Y.; Imagawa, H.; Yamada, H.; Azuma, I. Vaccine 1999, 17, 1484-1492.

(105) Al Dulayymi, R. A.; Baird, M. S.; Roberts, E. Chem. Commun. 2003, 228229.

(106) Al Dulayymi, J. R.; Baird, M. S.; Roberts, E. Tetrahedron 2005, 61, 1193911951.

(107) Al Dulayymi, J. R.; Baird, M. S.; Roberts, E.; Minnikin, D. E. Tetrahedron 2006, 62, 11867-11880.

(108) Al-Dulayymi, J. R.; Baird, M. S.; Mohammed, H.; Roberts, E.; Clegg, W. Tetrahedron 2006, 62, 4851-4862.

(109) Al Dulayymi, J. R.; Baird, M. S.; Roberts, E.; Deysel, M.; Verschoor, J. Tetrahedron 2007, 63, 2571-2592.

(110) Koza, G.; Theunissen, C.; Al Dulayymi, J. R.; Baird, M. S. Tetrahedron 2009, 65, 10214-10229.

(111) Al Kremawi, D. Z.; Al Dulayymi, J. R.; Baird, M. S. Tetrahedron Lett. 2010, $51,1698-1701$.

(112) Toschi, G.; Baird, M. S. Tetrahedron 2006, 62, 3221-3227.

(113) Driver, C.; Balogun, M. O.; Toschi, G.; Verschoor, J. A.; Baird, M. S.; Pilcher, L. A. Tetrahedron Lett. 2010, 51, 1185-1186.

(114) Al Dulayymi, J. R.; Baird, M. S.; Maza-Iglesias, M.; Beken, S. V.; Grooten, J. Tetrahedron Lett. 2009, 50, 3702-3705.

(115) Baudin, B. J.; Hareau, G.; Julia, S. A.; Ruel, O. Tetrahedron Lett. 1991, 32 , $1175-1178$. 
(116) Frick, J. A.; Klassen, J. B.; Bathe, A.; Abramson, J. M.; Rappoport, H. Synthesis 1992, 621-623.

(117) Grandjean, D.; Pale, P.; Chuche, J. Tetrahedron 1991, 47, 1215-1230.

(118) Indrigo, J.; Hunter Jr, R. L.; Actor, J. K. Microbiology 2003, 149, 2049-2059.

(119) Rajni; Rao, N.; Meena, L. S. Biotechnol. Res. Int. 2011, Article ID 274693, 7 pages.

(120) Nolibe, D.; Masse, R.; Tenu, J.-P.; Lepoivre, M.; Petit, J.-F. Cancer Immunol. Immunother. 1986, 23, 200-206.

(121) Mclaughlin, C. A.; Strain, S. M.; Bickel, W. D.; Goren, M. B.; Azuma, I.; Milner, K.; Cantrell, J. L.; Ribi, E. Cancer Immunol. Immunother. 1978, 4, 61-68.

(122) Yarkoni, E.; Bekierkunst, A. Infect. Immun. 1976, 14, 1125- 1129.

(123) Parant, M.; Parant, F.; Chedid, L.; Drapier, J. C.; Petit, J. F.; Wietzerbin, J.; Lederer, E. J. Infect. Dis. 1977, 135, 771-777.

(124) Yamagami, H.; Matsumoto, T.; Fujiwara, N.; Arakawa, T.; Kaneda, K.; Yano, I.; Kobayashi, K. Infect. Immun. 2001, 69, 810-815.

(125) Bekierkunst, A. J. Bacteriol. 1968, 96, 958-961.

(126) Guidry, T. V.; Hunter Jr, R. L.; Actor, J. K. Microbiology 2007, 153, 33603369.

(127) Hunter, R. L.; Olsen, M.; Jagannath, C.; Actor, J. K. Am. J. Pathol. 2006, 168, 1249-1261.

(128) Saita, N.; Fujiwara, N.; Yano, I.; Soejima, K.; Kobayashi, K. Infect. Immun. 2000, 68, 5991-5997.

(129) Yarkoni, E.; Wang, L.; Bekierkunst, A. Infect. Immun. 1974, 9, 977- 984.

(130) Pimm, M. V.; Baldwin, R. W.; Polonsky, J.; Lederer, E. Int. J. Cancer 1979, 24, 780-785.

(131) Bekierkunst, A.; Yarkoni, E.; Flechner, I.; Morecki, S.; Vilkas, E.; Lederer, E. Infect. Immun. 1971, 4, 256-263.

(132) Ryll, R.; Watanabe, K.; Fujiwara, N.; Takimoto, H.; Hasunuma, R.; Kumazawa, Y.; Okada, M.; Yano, I. Microbes Infect. 2001, 3, 611-619.

(133) Ryll, R.; Kumazawa, Y.; Yano, I. Microbiol. Immunol. 2001, 45, 801-811.

(134) Sakaguchi, I.; Ikeda, N.; Nakayama, M.; Kato, Y.; Yano, I.; Kaneda, K. Infect. Immun. 2000, 68, 2043-2052.

(135) Yoshida, S.; Ono, M.; Shouno, T.; Izumi, H.; Ishibashi, T.; Suzuki, H.; Kuwano, M. Mol. Cell Biol. 1997, 17, 4015-4023.

(136) Yarkoni, E.; Bekierkunst, A. Infect. Immun. 1976, 14, 1125-1129.

(137) Fráter, G. Helv. Chim. Acta 1979, 62, 2829- 2832.

(138) Heathcock, C. H.; Kath, J. C.; Ruggeri, R. B. J. Org. Chem. 1995, 60, 11201130.

(139) Eggen, M.; Mossman, C. J.; Buck, S. B.; Nair, S. K.; Bhat, L.; Ali, S. M.; Reiff, E. A.; Boge, T. C.; Georg, G. I. J. Org. Chem. 2000, 65, 7792-7799.

(140) Mori, K.; Kuwahara, S. Tetrahedron 1986, 42, 5539-5544.

(141) Crimmins, M. T.; O’Bryan, E. A. Org. Lett. 2010, 12, 4416-4419.

(142) Raghavan, S.; Ramakrishna Reddy, S. Tetrahedron Lett. 2004, 45, 5593-5595.

(143) Raghavan, S.; Rathore, K. Tetrahedron 2009, 65, 10083-10092.

(144) Duan, J. J.-W.; Chen, L.; Xue, C.-B.; Wasserman, Z. R.; Hardman, K. D.; Covington, M. B.; Copeland, R. R.; Arner, E. C.; Decicco, C. P. Bioorg. Med. Chem. Lett. 1999, 9, 1453-1458.

(145) Kraft, P.; Tochtermann, W. Tetrahedron 1995, 51, 10875-10882. 
(146) Cravatt, B. F.; Wright, A. T.; Kozarich, J. W. Annu. Rev. Biochem. 2008, 77, 383-414.

(147) Adam, G. C.; Burbaum, J.; Kozarich, J. W.; Patricelli, M. P.; Cravatt, B. F. J. Am. Chem. Soc. 2004, 126, 1363- 1368.

(148) Timmer, M. S. M.; Stocker, B. L.; Seeberger, P. H. Curr. Opin. Chem. Biol. 2007, 11, 59-65.

(149) Speers, A. E.; Adam, G. C.; Cravatt, B. F. J. Am. Chem. Soc. 2003, 125, 4686-4687.

(150) Speers, A. E.; Cravatt, B. F. Chem. Biol. 2004, 11, 535-546.

(151) Rostovtsev, V. V.; Green, L. G.; Fokin, V. V.; Sharpless, K. B. Angew. Chem. Int. Ed. 2002, 41, 2596-2599.

(152) Baskin, J. M.; Prescher, J. A.; Laughlin, S. T.; Agard, N. J.; Chang, P. V. ; Miller, I. A.; Lo, A.; Codelli, J. A.; Bertozzi, C. R. Proc. Natl. Acad. Sci. 2007, 104, 16793-16797.

(153) Poloukhtine, A. A.; Mbua, N. E.; Wolfert, M. A.; Boons, G. J.; Popkin, V. V. J. Am. Chem. Soc. 2009, 131, 15769-15776.

(154) Vodovozova, E. L. Biochemistry-Moscow 2007, 72, 1-20.

(155) Singh, A.; Thornton, E. R.; Westheimer, F. H. J. Biol. Chem. 1962, 237, 3006-3008.

(156) Galardy, R. E.; Craig, L. C.; Printz, M. P. Nature 1973, 242, 127-128.

(157) Fleet, G. W. J.; Porter, R. R.; Knowles, J. R. Nature 1969, 224, 511-512.

(158) Smith, R. A. G.; Knowles, J. R. J. Am. Chem. Soc. 1973, 95, 5072-5073.

(159) Salisbury, C. M.; Cravatt, B. F. Proc. Natl. Acad. Sci. 2007, 104, 1171-1176.

(160) Saghatelian, A.; Jessani, N.; Joseph, A.; Humphrey, M.; Cravatt, B. F. Proc. Natl. Acad. Sci. 2004, 101, 10000-10005.

(161) Völkert, M.; Uwai, K.; Tebbe, A.; Popkirova, B.; Wagner, M.; Kuhlmann, J.; Waldmann, H. J. Am. Chem. Soc. 2003, 125, 12749-12758.

(162) Geurink, P. Synthetic tools to illuminate matrix metalloproteinase and proteasome activities, 2010, p. 20.

(163) Bregant, S.; Devel, L.; Beau, F.; Thai, R.; Czarny, B.; Yiotakis, A.; Dive, V. J. Proteome Res. 2009, 2484-2494.

(164) Suchanek, M.; Radzikowska, A.; Thiele, C. Nature Methods 2005, 1-7.

(165) Qiu, W.-W.; Xu, J.; Li, J.-Y.; Li, J.; Nan, F.-J. ChemBioChem 2007, 8, 13511358 .

(166) Fuwa, H.; Takahashi, Y.; Konno, Y.; Watanabe, N.; Miyashita, H.; Sasaki, M.; Natsugari, H.; Kan, T.; Fukuyama, T.; Tomita, T.; Iwatsubo, T. ACS Chem. Biol. 2007, 2, 408-418.

(167) Liu, K.; Shi, H.; Xiao, H.; Chong, A. G. L.; Bi, X.; Chang, Y.-T.; Tan, K. S. W.; Yada, R. Y.; Yao, S. Q. Angew. Chem. Int. Ed. 2009, 48, 8293-8297. 



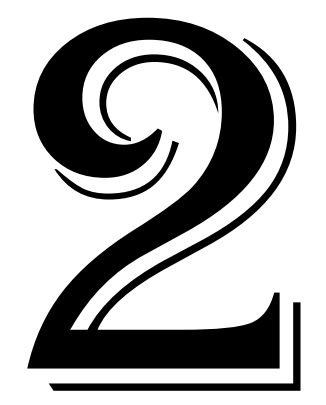

\section{TDE \\ Synthesis ${ }^{1}$}

\subsection{Introduction}

Trehalose diesters of fatty acids (TDEs, 1, Figure 1) are the simplest form of trehalose glycolipids that have been studied for many decades for their biological activities such as anti-tumour, anti-bacterial and macrophage activation properties. ${ }^{2,3,4}$ Perhaps the most well known member of the TDE family is the C22 diester, trehalose dibehenate (TDB) that has shown comparable macrophage activation properties to the more complex trehalose dimycolates (TDMs). ${ }^{5}$ This observation has renewed interest in these glycolipids and one area of interest for us was to investigate the effect that lipid length has on the ability of TDEs to activate macrophages and lead to subsequent activation of the immune system.

To correlate the lipid length to the biological activity of these glycolipids (see Chapter 3 for biological analysis), we planned to synthesise TDEs containing short 
(C4), medium (C7, C10), long (C18, C20 and C22) and very long (C26) aliphatic lipid chains (Figure 1).
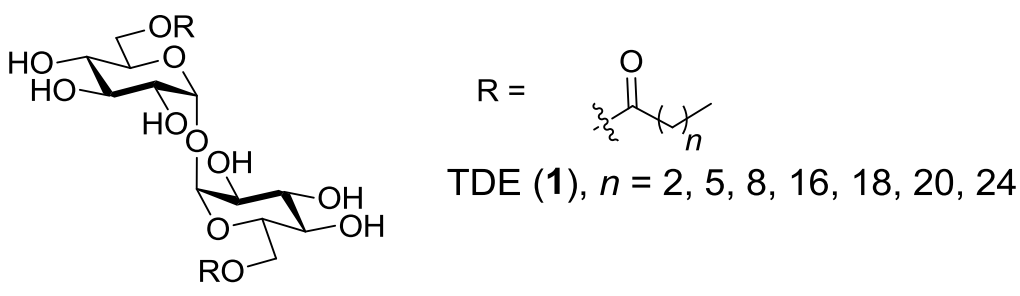

Figure 1. Target TDEs 1

\subsection{TDE Synthesis}

\subsubsection{Initial Strategy}

In order to synthesise a range of TDEs, we envisaged a single synthetic strategy that could be used for the synthesis of all these related compounds. To this end, commercially available $\alpha, \alpha^{\prime}$-D-trehalose (2) was selectively tritylated at the 6 and $6^{\prime}$ positions using trityl chloride and pyridine, ${ }^{6}$ perbenzylated $^{7}$ using benzyl bromide and sodium hydride to form the fully protected compound $\mathbf{3}$ in $85 \%$ over two steps (Scheme 1). The trityl groups were subsequently removed using trifluoroacetic acid (TFA) and triethylsilane resulting in diol 4 in good (80\%) yield. Diol 4 was then subjected to esterification with various fatty acids using 1-ethyl-3-(3dimethylaminopropyl)carbodiimide (EDCI) and 4-dimethylamino-pyridine (DMAP) to form the fully protected diacyl trehaloses 5a-g. Most of the carboxylic acids were sourced commercially, except for docosanoic acid which was obtained after Jones oxidation of docosanol. ${ }^{8}$ The optimum conditions for the esterification reaction were found to be 1 equiv. of diol 4, 4.4 equiv. of the acid, 6.6 equiv. of EDCI, and 0.15 equiv of DMAP with the reaction being stirred overnight. However, it was noted that longer reaction times were required for the longer lipids (Table 1). With the protected diacyl trehaloses $\mathbf{5}$ in hand, attempts were then made to remove the benzyl protecting groups so as to generate the target TDEs 1. Initially, $\mathrm{Pd} / \mathrm{C}$ in $\mathrm{CHCl}_{3}: \mathrm{MeOH}$ (3:2) was used for the reaction; however, no product formation was 
seen with only starting material retrieved from the reaction mixture. Next, catalytic $\mathrm{Pd}(\mathrm{OH})_{2}$ was used and the debenzylation proceeded uneventfully for the C4-C18 derivatives (5a-d, Table 1, Entries 1-4). Unfortunately, the extension of this methodology to the C20-C26 homologues (5e-g, Entries 5-7) was unsuccessful and only product degradation was observed.

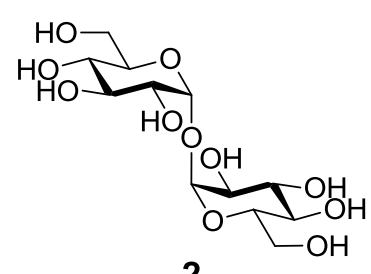

2
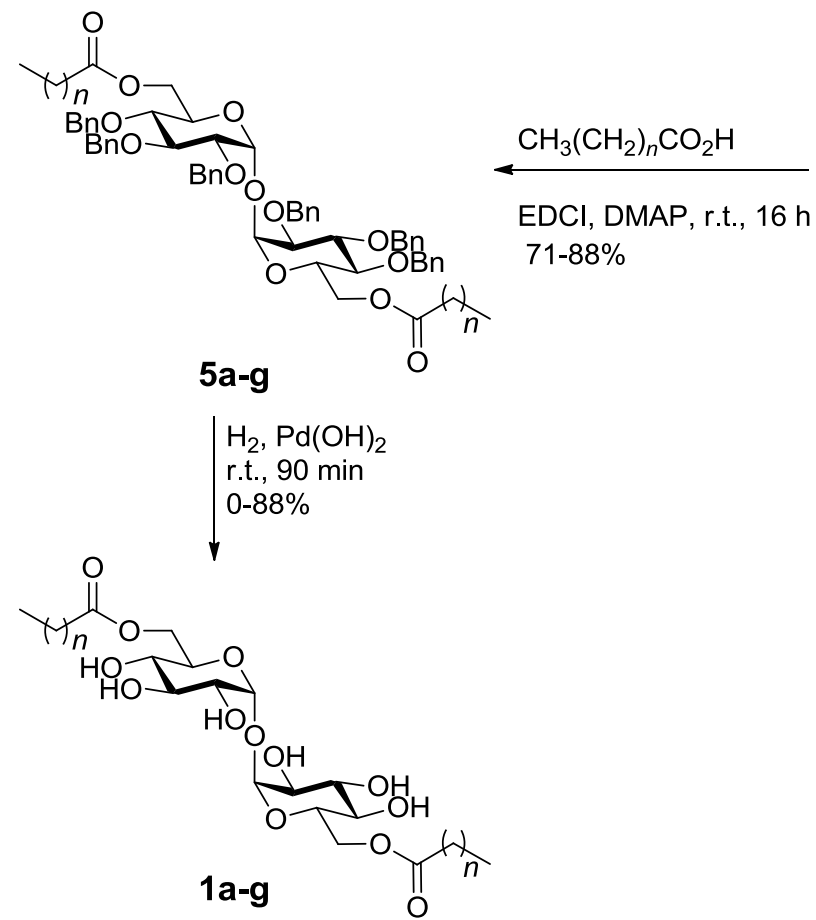

1. $\mathrm{TrCl}$, pyridine r.t., $16 \mathrm{~h}$

2. $\mathrm{BnBr}, \mathrm{NaH}$, r.t., $16 \mathrm{~h}$ $85 \%$ (2 steps)

$\mathrm{CH}_{3}\left(\mathrm{CH}_{2}\right)_{n} \mathrm{CO}_{2} \mathrm{H}$

EDCI, DMAP, r.t., $16 \mathrm{~h}$ $71-88 \%$

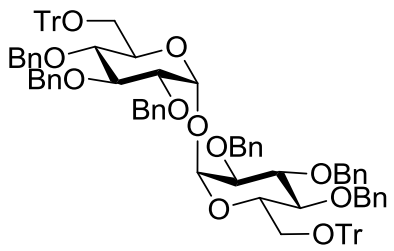

3

TFA, $\mathrm{Et}_{3} \mathrm{SiH}$ r.t., $30 \mathrm{~min}$ $80 \%$

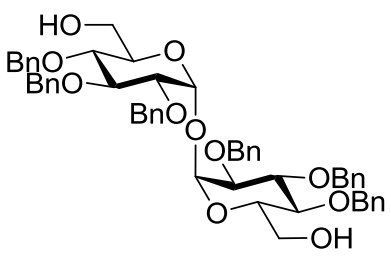

4 a, $n=2$

b, $n=5$

c, $n=8$

d, $n=16$

e, $n=18$

f, $n=20$

g, $n=24$

Scheme 1. Initial synthetic strategy 
Table 1. Formation of TDEs

\begin{tabular}{|c|c|c|c|c|c|c|}
\hline \multirow[t]{2}{*}{ Entry } & \multirow[t]{2}{*}{$\mathbf{C}_{n}$} & \multirow{2}{*}{$\begin{array}{l}\text { Coupling } \\
\text { Conditions } \\
\text { EDCI }=6.6 \text { equiv., } \\
\text { DMAP }=0.15 \text { equiv } \\
\mathrm{CH}_{2} \mathrm{Cl}_{2}\end{array}$} & \multirow{2}{*}{$\begin{array}{l}\text { Yield- } \\
\text { Coupling } \\
(\%)\end{array}$} & \multicolumn{2}{|c|}{$\begin{array}{l}\text { Debenzylation } \\
\text { Conditions }\end{array}$} & \multirow{2}{*}{$\begin{array}{l}\text { Yield- } \\
\text { Debenzylation } \\
(\%)\end{array}$} \\
\hline & & & & & & \\
\hline 1 & 2 & $\begin{array}{l}\mathrm{C} 4 \text { acid }=4.4 \text { equiv., } \\
\text { overnight, r.t. }\end{array}$ & 88 & $\begin{array}{l}\mathrm{Pd}(\mathrm{OH})_{2}, \\
\mathrm{CHCl}_{3}: \mathrm{MeOH} \\
1 \mathrm{~atm}\end{array}$ & $3: 2$ & 62 \\
\hline 2 & 5 & $\begin{array}{l}\text { C7 acid }=4.4 \text { equiv., } \\
\text { overnight, r.t. }\end{array}$ & 85 & $\begin{array}{l}\mathrm{Pd}(\mathrm{OH})_{2}, \\
\mathrm{CHCl}_{3}: \mathrm{MeOH} \\
1 \mathrm{~atm}\end{array}$ & $3: 2$ & 67 \\
\hline 3 & 8 & $\begin{array}{l}\mathrm{C} 10 \text { acid }=4.4 \text { equiv., } \\
\text { overnight, r.t. }\end{array}$ & 83 & $\begin{array}{l}\mathrm{Pd}(\mathrm{OH})_{2}, \\
\mathrm{CHCl}_{3}: \mathrm{MeOH} \\
1 \mathrm{~atm}\end{array}$ & $3: 2$ & 63 \\
\hline 4 & 16 & $\begin{array}{l}\mathrm{C} 18 \text { acid }=4.4 \text { equiv., } \\
\text { overnight, r.t. }\end{array}$ & 85 & $\begin{array}{l}\mathrm{Pd}(\mathrm{OH})_{2}, \\
\mathrm{CHCl}: \mathrm{MeOH} \\
1 \text { atm }\end{array}$ & $3: 2$ & 88 \\
\hline 5 & 18 & $\begin{array}{l}\mathrm{C} 20 \text { acid }=4.4 \text { equiv., } \\
\text { overnight, r.t. }\end{array}$ & 80 & $\begin{array}{l}\mathrm{Pd}(\mathrm{OH})_{2}, \\
\mathrm{CHCl}_{3}: \mathrm{MeOH} \\
1 \text { atm }\end{array}$ & $3: 2$ & 0 \\
\hline 6 & 20 & $\begin{array}{l}\mathrm{C} 22 \text { acid }=4.4 \text { equiv., } 2 \\
\text { days, r.t. }\end{array}$ & 78 & Various (see Ta & le 2) & 0 \\
\hline 7 & 24 & $\begin{array}{l}\mathrm{C} 26 \text { acid }=4.4 \text { equiv., } 7 \\
\text { days, r.t. }\end{array}$ & 71 & Various (see $\mathrm{T}$ & le 2) & 0 \\
\hline
\end{tabular}

The key reason for the low reactivity of the longer chain TDEs was attributed to the low solubility of these compounds leading to reduced reactivity. Hence different catalysts, solvent systems, reaction temperatures and pressures were used, but at best, only minor amounts of partially debenzylated products were observed (Table 2). This result was disappointing, however, the sluggish hydrogenation of benzyl protected long-chain glycolipids has been reported previously. ${ }^{9}$ The lack of reactivity of the long chain diacyl trehaloses 5e-g towards hydrogenation led us to adopt an alternative approach for the preparation of the C20-C26 TDEs focusing on using another protecting group for the trehalose unit. 
Table 2. Attempted debenzylation conditions

\begin{tabular}{|c|c|c|c|}
\hline Entry & $\mathbf{C}_{n}$ & Debenzylation Conditions & Results \\
\hline 1 & 20 & $\begin{array}{l}\mathrm{Pd}(\mathrm{OH})_{2}, \mathrm{CHCl}_{3}: \mathrm{MeOH} 3: 2,1 \text { atm at } \\
\text { r.t. over } 3 \text { days }\end{array}$ & $\begin{array}{l}\text { Degradation (loss of lipid chain) and } \\
\text { starting material }\end{array}$ \\
\hline 2 & 20 & $\begin{array}{l}\mathrm{Pd}(\mathrm{OH})_{2}, \mathrm{CHCl}_{3}: \mathrm{MeOH} 3: 2,15 \text { psi at } \\
\text { r.t. overnight }\end{array}$ & Degradation \\
\hline 3 & 20 & $\begin{array}{l}\mathrm{Pd} / \mathrm{C}, \quad \text { EtOH:EtOAc: } \mathrm{CHCl}_{3} \quad 1: 1: 1, \\
15 \text { psi at r.t. overnight }\end{array}$ & partially-debenzylated products \\
\hline 4 & 20 & $\begin{array}{l}\mathrm{Pd} / \mathrm{C}, \mathrm{THF}: \text { EtOH:EtOAc } 1: 1: 1,1 \mathrm{~atm} \\
\text { at } 50^{\circ} \mathrm{C} \text {, over } 2 \text { days }\end{array}$ & Degradation \\
\hline 5 & 24 & $\begin{array}{l}\mathrm{Pd}(\mathrm{OH})_{2}, \mathrm{CHCl}_{3}: \mathrm{MeOH} 3: 2,1 \mathrm{~atm} \text { at } \\
\text { r.t. over } 3 \text { days }\end{array}$ & Degradation \\
\hline 6 & 24 & $\begin{array}{l}\mathrm{Pd} / \mathrm{C}, \mathrm{THF}: \mathrm{EtOH}: \mathrm{EtOAc} 1: 1: 1,1 \mathrm{~atm} \\
\text { at } 50{ }^{\circ} \mathrm{C} \text { over } 4 \text { days }\end{array}$ & Degradation \\
\hline
\end{tabular}

\subsubsection{Alternate Synthetic Strategy}

With a view to using protecting groups that could be more readily removed at the final stage in the synthesis, we employed the strategy of Toubiana and co-workers to prepare 2,2',3,3',4,4'-hexa- $O$-trimethylsilyl- $\alpha, \alpha$-trehalose. ${ }^{10}$ This elegant two-step one-pot synthesis of hexa-silylated trehalose was proposed by Johnson ${ }^{11}$ and the reaction proceeds through per-silylation of the trehalose moiety followed by the removal of the more labile primary trimethylsilyl (TMS) ethers using potassium carbonate. The reaction is initiated with the attack on the silyl atom in $\mathrm{N}, \mathrm{O}$-bistrimethylsilylacetamide (BSA) (I) by the fluoride anion of tetra-butylammonium fluoride (TBAF), generating intermediate II (Scheme 2). The preference for attack on this silyl group is due to the stability of the resulting intermediate II, attributed to resonance stabilization of the negative charge on the oxygen in II by the nitrogen as 
shown in intermediate III. The negatively charged nitrogen in intermediate III abstracts a proton from one of the trehalose hydroxyls. The resulting negatively charged oxygen in IV then attacks the silyl group in another molecule of BSA (I) leading to the formation of a TMS ether (V) and regeneration of the BSA intermediate (II).

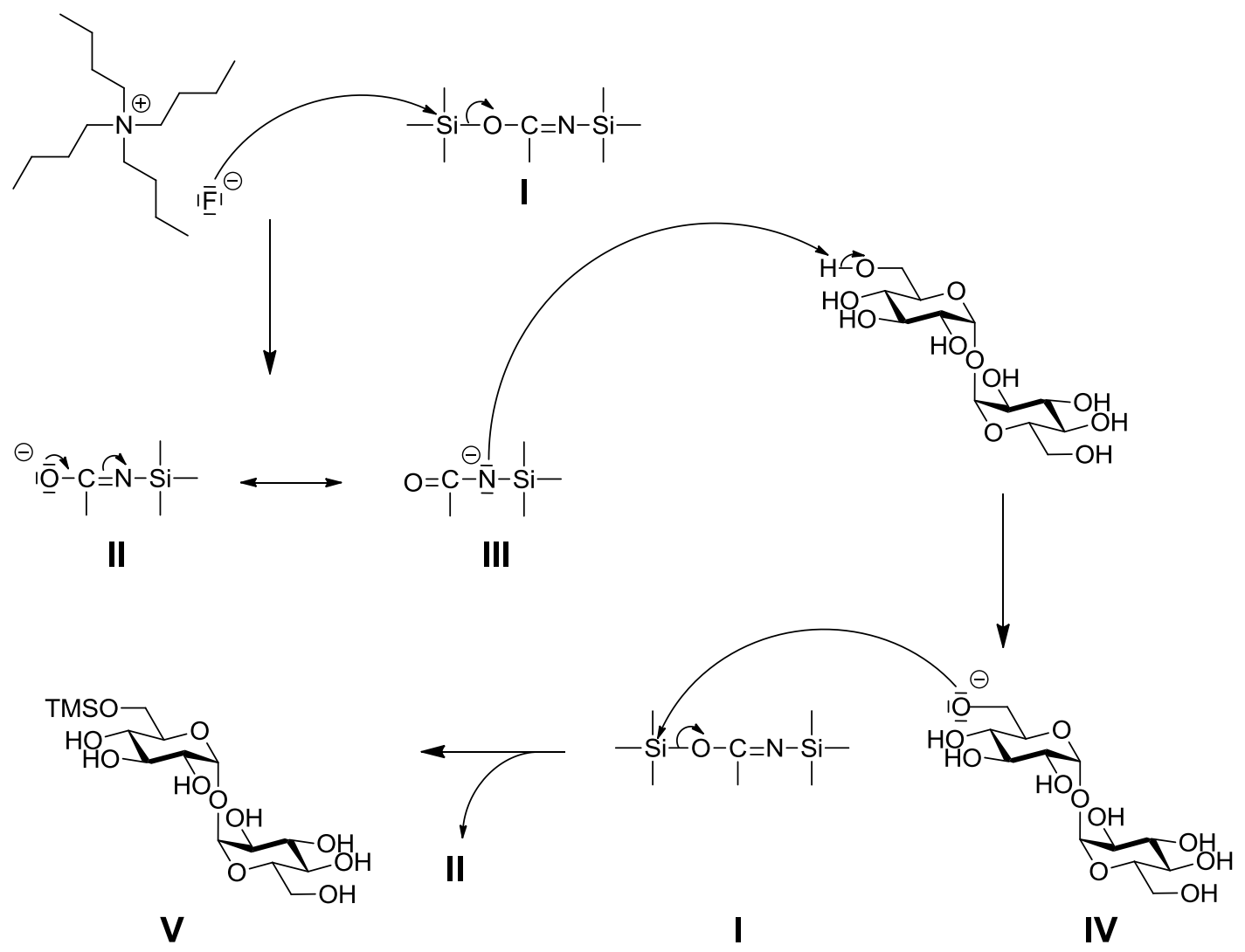

Scheme 2. Reaction mechanism for BSA mediated silylation of trehalose

Accordingly, $\alpha, \alpha$-D-trehalose (2) was treated with BSA and catalytic TBAF, followed by $\mathrm{K}_{2} \mathrm{CO}_{3}$ to generate diol 6 in a good (85\%) yield over two steps (Scheme $3)$. Diol 6 was then coupled to the longer chain carboxylic acids using the protocols outlined in Table 3. Formation of the C20 trehalose diester $(n=18)$ proceeded uneventfully mediated by EDCI and DMAP in $\mathrm{CH}_{2} \mathrm{Cl}_{2}$ to give trehalose diester $7 \mathbf{e}$ in 93\% yield (Table 3, Entry 1). Surprisingly, extension of this methodology to the C22 homologue proved unsuccessful with none of the desired trehalose diester $7 \mathbf{f}$ 
observed even after the use of excess acid, the addition of further equivalents of EDCI and DMAP, or refluxing of the reaction mixture (Entries 2-5). In all instances, only minor $(<40 \%)$ amounts of the corresponding mono-ester were observed. Although, a change of solvent to dimethylformamide (DMF) did not lead to any improvement (Entries 4 and 5), the use of toluene and heating the reaction at $70{ }^{\circ} \mathrm{C}$ for 2 days saw complete conversion of starting material and the desired trehalose diester $7 f$ was isolated in $86 \%$ yield (Entry 6). These conditions were then used for the synthesis of the $\mathrm{C} 26$ trehalose diester $\mathbf{7 g}$, which was formed in a respectable $(60 \%)$ yield although a longer reaction time (6 days) was required to see complete consumption of starting material (entry 7). The TMS-groups were then readily removed following subjection of the diesters to Dowex $-\mathrm{H}^{+}$resin to yield the target TDEs (1e-g) in $80 \%, 80 \%$ and $70 \%$ yield, respectively. 


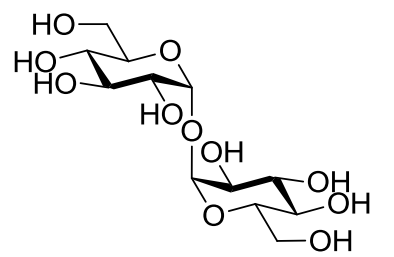

2

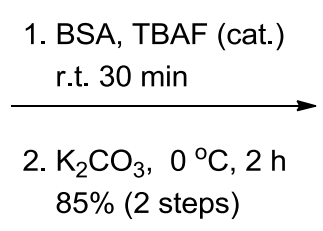

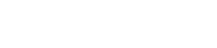

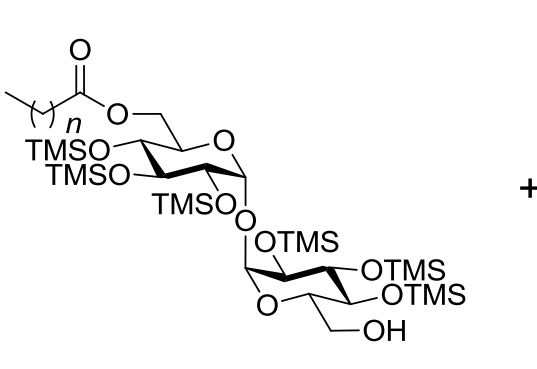

\section{8f-g}

Dowex- $\mathrm{H}^{+}$

$\mathrm{rt}, 30 \mathrm{~min}$

$\checkmark 96-97 \%$

e, $n=18$

f, $n=20$

g, $n=24$

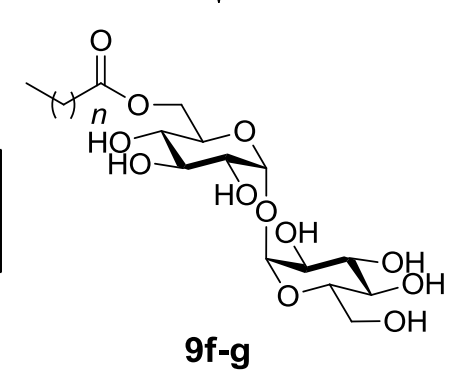

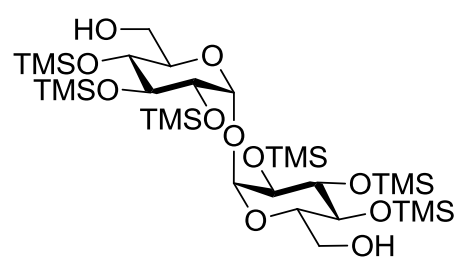

6

$\mathrm{CH}_{3}\left(\mathrm{CO}_{2}\right)_{n} \mathrm{CO}_{2} \mathrm{H}$

EDCI, DMAP

r.t. to $70^{\circ} \mathrm{C}, 2-6$ days

$60 \%-93 \%(7 e-7 g)$

$12 \%-20 \%(8 f-8 g)$

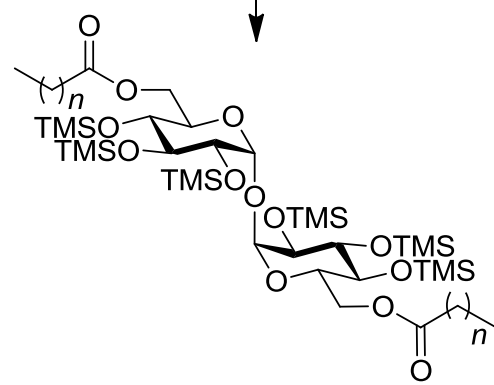

7e-g

Dowex- $\mathrm{H}^{+}$

r.t., $30 \mathrm{~min}$

$70-80 \%$

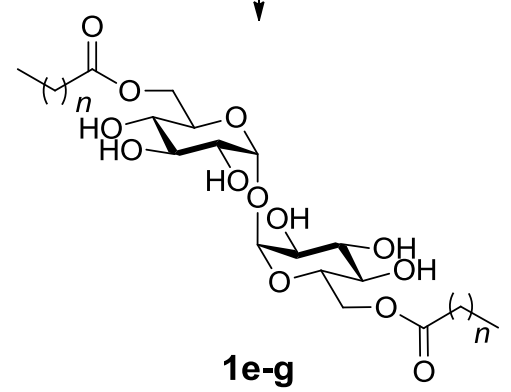

Scheme 3. Alternate synthetic strategy used 
Table 3. Esterification reaction using diol 6

\begin{tabular}{|c|c|c|c|c|}
\hline Entry & $\mathrm{Cn}$ & $\begin{array}{l}\text { Conditions } \\
\text { EDCI ( } 6.6 \text { equiv.), DMAP ( } 0.15 \text { equiv.), }\end{array}$ & Product & Yield $^{[\mathrm{a}]}$ \\
\hline 1 & 18 & $\mathrm{CH}_{3}\left(\mathrm{CH}_{2}\right)_{18} \mathrm{CO}_{2} \mathrm{H}$ (4.4 equiv.), $\mathrm{CH}_{2} \mathrm{Cl}_{2}, \mathrm{rt}, 18 \mathrm{~h}$ & $7 e$ & $93 \%$ \\
\hline 2 & 20 & $\mathrm{CH}_{3}\left(\mathrm{CH}_{2}\right)_{20} \mathrm{CO}_{2} \mathrm{H}$ (4.4 equiv.), $\mathrm{CH}_{2} \mathrm{Cl}_{2}, \mathrm{rt}, 18 \mathrm{~h}$ & $7 f$ & $0 \%{ }^{[b]}$ \\
\hline 3 & 20 & $\mathrm{CH}_{3}\left(\mathrm{CH}_{2}\right)_{20} \mathrm{CO}_{2} \mathrm{H}$ (4.4 equiv.), $\mathrm{CH}_{2} \mathrm{Cl}_{2}$, reflux, $48 \mathrm{~h}$ & $7 f$ & $0 \%{ }^{[\mathrm{b}]}$ \\
\hline 4 & 20 & $\mathrm{CH}_{3}\left(\mathrm{CH}_{2}\right)_{20} \mathrm{CO}_{2} \mathrm{H}$ (4.4 equiv.), DMF, rt, $48 \mathrm{~h}$ & $7 f$ & $0 \%{ }^{[\mathrm{b}]}$ \\
\hline 5 & 20 & $\mathrm{CH}_{3}\left(\mathrm{CH}_{2}\right)_{20} \mathrm{CO}_{2} \mathrm{H}$ (4.4 equiv.), DMF, $50{ }^{\circ} \mathrm{C}, 48 \mathrm{~h}$ & $7 f$ & $0 \%{ }^{[\mathrm{b}]}$ \\
\hline 6 & 20 & $\mathrm{CH}_{3}\left(\mathrm{CH}_{2}\right)_{20} \mathrm{CO}_{2} \mathrm{H}$ (4.4 equiv.), toluene, $70{ }^{\circ} \mathrm{C}, 48 \mathrm{~h}$ & $7 f$ & $86 \%$ \\
\hline 7 & 24 & $\mathrm{CH}_{3}\left(\mathrm{CH}_{2}\right)_{24} \mathrm{CO}_{2} \mathrm{H}$ (4.4 equiv.), toluene, $70{ }^{\circ} \mathrm{C}, 6$ days & $7 \mathrm{~g}$ & $60 \%$ \\
\hline
\end{tabular}

[a] Isolated yield

[b] Only monoester (12-40\%) was observed.

In addition to the protected TDEs, the esterification reaction also yielded about 12$20 \%$ of the protected trehalose monoesters of fatty acids (TMEs, $\mathbf{8 f}$ and $\mathbf{8 g}$ ). Both the protected TMEs were more polar than the corresponding trehalose diesters $7 \mathbf{f}$ and $\mathbf{7 g}$, making it possible to separate the monoesters from the diesters through silica gel flash chromatography. The protected TMEs were then deprotected using Dowex $-\mathrm{H}^{+}$ resin to yield the target TMEs $9 f$ and $9 \mathrm{~g}$ in good yields.

\subsubsection{Isolation of final compounds and characterisation}

For C4-C22 TDEs, the compounds were readily purified using silica gel flash chromatography, with the compounds eluting in $1-3 \% \mathrm{MeOH}$ in EtOAc. For the purification of C26 TME (9g) and TDE (1g) silica gel chromatography was not ideal for the separation of compounds from impurities. Reversed phase chromatography gave better results with the $\mathrm{C} 26 \mathrm{TME}$ eluting in $\mathrm{MeOH}$, however, the $\mathrm{C} 26 \mathrm{TDE}$ 
could only be eluted using pyridine in reversed phase chromatography. The final compounds were obtained as white solids and NMR analyses of the glycolipids comprising of 18 carbon lipid chains or lower were carried out in a mixture of deuterated chloroform and methanol. For the longer TDEs and TMEs, pyridine was used as the NMR solvent.

The TDEs and TMEs were characterised based on NMR and mass spectral analysis. For the C26 TME (9g, Figure 2 and 3), the chemical shifts for the anomeric protons were different in the ${ }^{1} \mathrm{H}$ NMR spectrum, with two doublet resonances observed at $5.84(J=3.9 \mathrm{~Hz})$ and $5.82 \mathrm{ppm}(J=3.9 \mathrm{~Hz})$, indicating that the trehalose molecule was no longer symmetrical. In addition, the protons at 6 and 6 positions had very different chemical shifts indicative of different groups attached to the carbons at these positions. Integral comparison of the $\alpha$-protons of the lipid chain and the anomeric protons indicated a 1:1 ratio. An HMBC correlation was found between the carbonyl carbon at $173.8 \mathrm{ppm}$ and the protons at the 6 position but not at the $6^{\prime}$ position and this together with the mass spectral analysis [HRMS(ESI) $m / z$ calcd. for $\left[\mathrm{C}_{38} \mathrm{H}_{72} \mathrm{O}_{12}+\mathrm{Na}\right]^{+}:$743.4916, obsd.: 743.4907$]$ unequivocally established that only one of the primary positions in the trehalose moiety was esterified. On the other hand, for the C26 TDE (1g, Figure 4 and 5), the ${ }^{1} \mathrm{H}$ NMR spectrum showed only one doublet resonance at $5.78 \mathrm{ppm}(J=3.7 \mathrm{~Hz})$ for the anomeric protons and using COSY correlations the resonances for the protons at $6 \mathrm{a} / 6 \mathrm{a}^{\prime}$ and $6 \mathrm{~b} / 6 \mathrm{~b}^{\prime}$ positions were found to being $4.87 \mathrm{ppm}(\mathrm{m})$ and $4.82 \mathrm{ppm}(\mathrm{dd}, J=11.7 \mathrm{~Hz}, J=5.4 \mathrm{~Hz}$,) with both showing HMBC correlations to the carbonyl carbon at $173.8 \mathrm{ppm}$. Here, integral comparison of the $\alpha$-protons of the lipid chain and the anomeric protons clearly indicated a 2:1 ratio indicating that lipid chains were attached at both the 6 and 6' position of the trehalose. Mass spectral analysis of the product was in agreement with the expected mass [HRMS(ESI) $\mathrm{m} / \mathrm{z}$ calcd. for $\left[\mathrm{C}_{64} \mathrm{H}_{122} \mathrm{O}_{12}+\mathrm{Na}\right]^{+}:$1121.8783, obsd.:1121.8764]. Full assignments for all the compounds were made on the basis of 2D NMR (COSY, HSQC and HMBC) (see experimental for full assignment). 


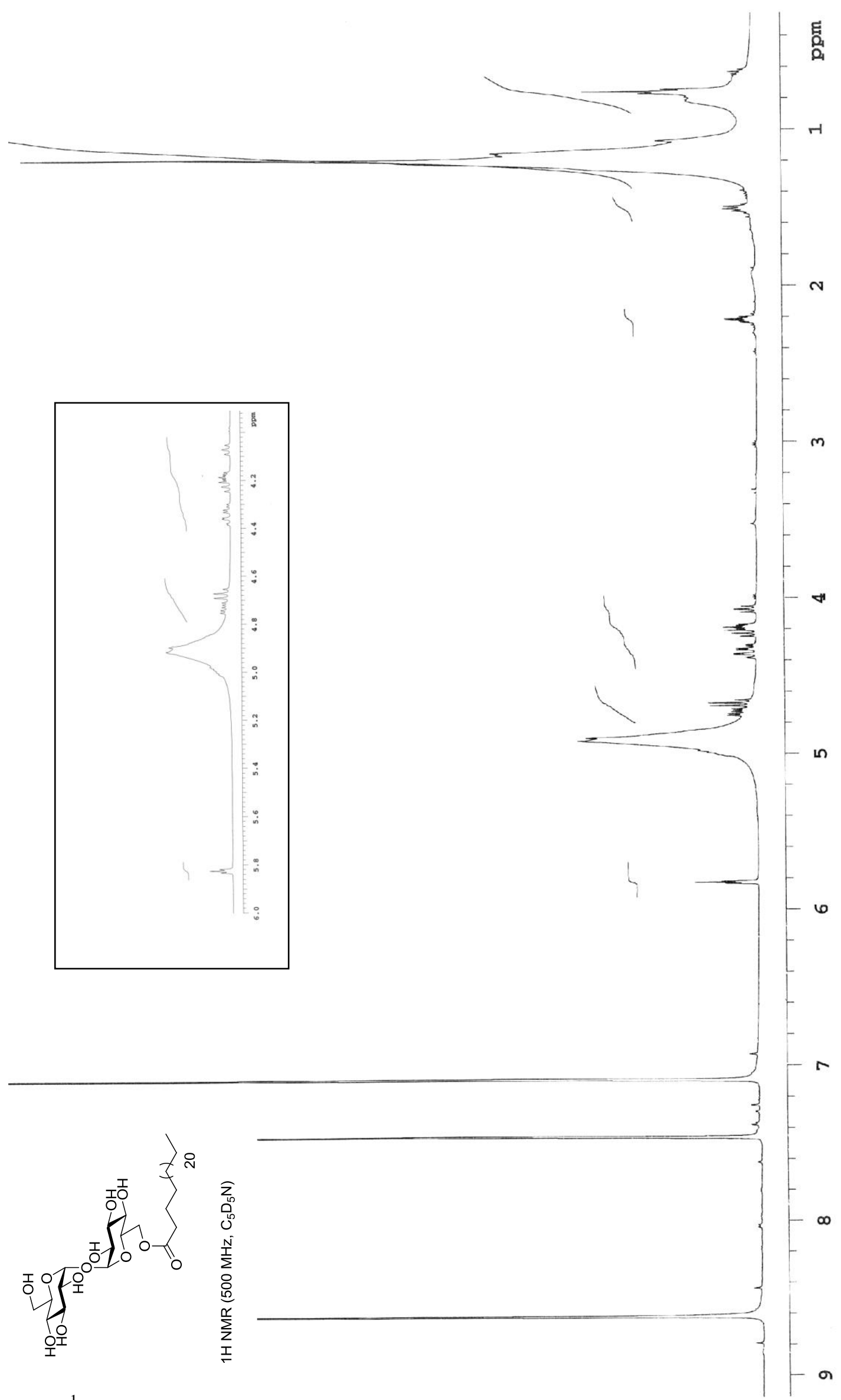

Figure 2. ${ }^{1} \mathrm{H}$ NMR spectrum of C26 TME (9g) 


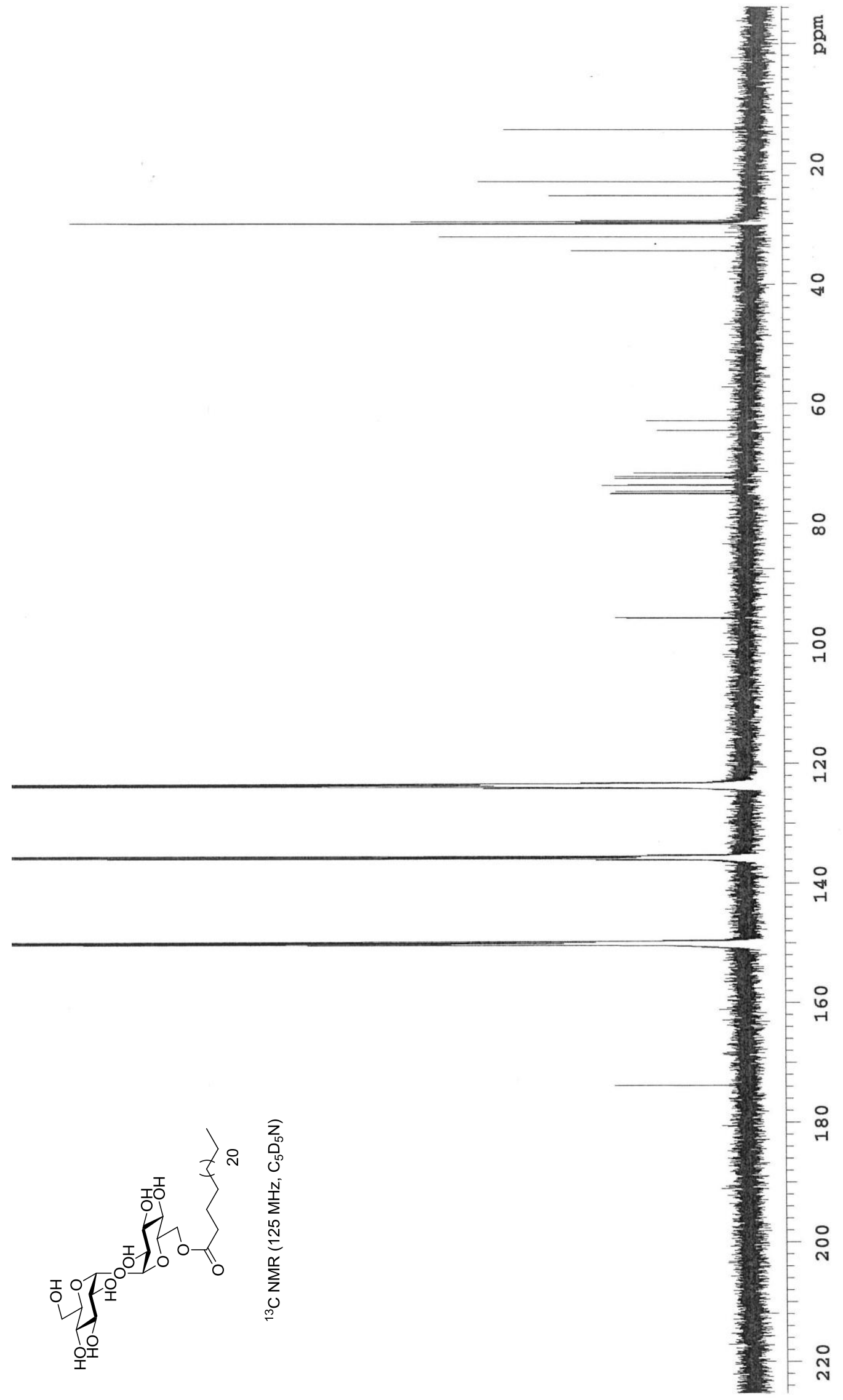

Figure 3. ${ }^{13} \mathrm{C}$ NMR spectrum of C26 TME (9g) 


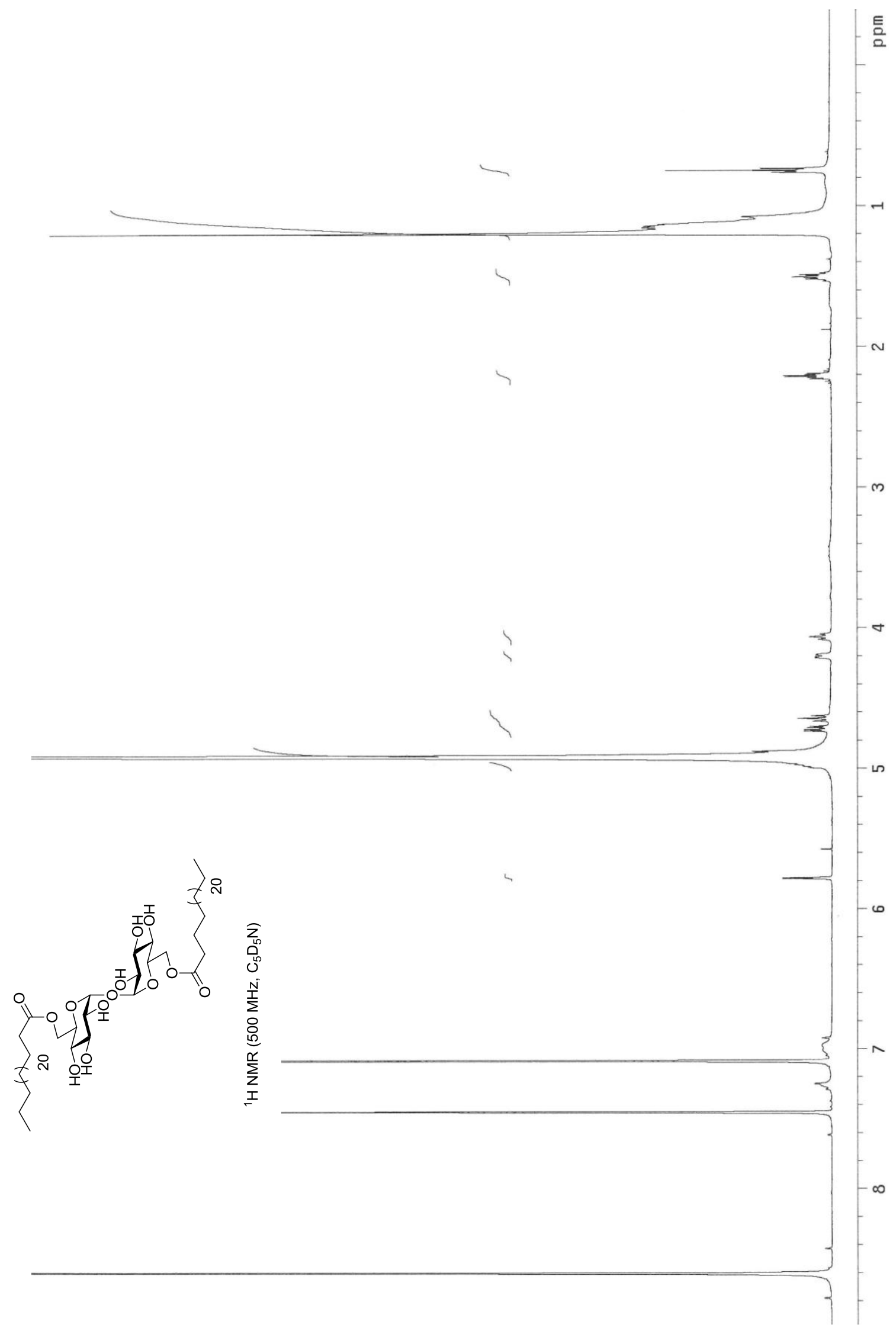

Figure 4. ${ }^{1} \mathrm{H}$ NMR spectrum of C26 TDE (1g) 


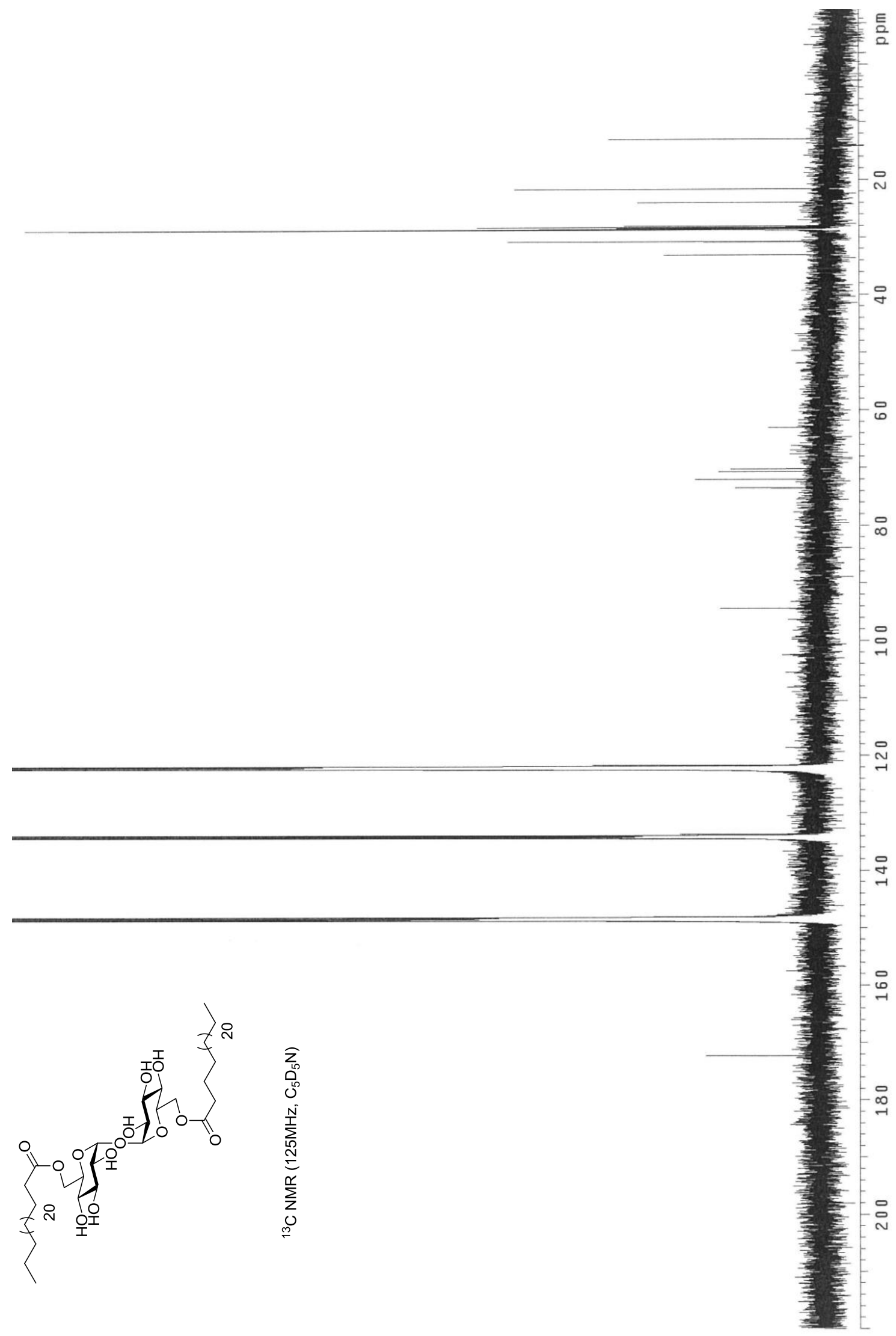

Figure 5. ${ }^{13} \mathrm{C}$ NMR spectrum of C26 TDE (1g) 


\subsection{Conclusion}

In this work, 7 TDEs ranging from $\mathrm{C} 4-\mathrm{C} 26$ were prepared, along with the $\mathrm{C} 22$ and C26 TMEs. Two different synthetic strategies were used to obtain these final compounds with the use of TMS protecting groups deemed more favourable in the synthesis of these trehalose glycolipids.

\subsection{Experimental Section}

Unless otherwise stated, all reactions were performed under $\mathrm{N}_{2}$. Prior to use, pyridine was dried and stored over $4 \AA$ molecular sieves (4 $\AA \mathrm{MS}$ ), $\mathrm{CH}_{2} \mathrm{Cl}_{2}$ was distilled from $\mathrm{P}_{2} \mathrm{O}_{5}$ and toluene was dried and stored under $\mathrm{Na}$ wire. D-(+)-Trehalose dihydrate (Sigma), trityl chloride (Acros), anhydrous DMF (Acros), TBAI (Riedel-de Haen), $\mathrm{NaH}$ (Avocado Research Chemicals, 60\% dispersion in mineral oil), $\mathrm{Et}_{3} \mathrm{SiH}$ (Sigma), TFA (Aldrich), EDCI (Aldrich), DMAP (Merck), n-butyric acid (BDH), heptanoic acid (BDH), decanoic acid (Merck), stearic acid (ICN Pharmaceuticals), arachidic acid (Sigma), 1-docosanol (Fluka), hexacosanoic acid (Acros), $\mathrm{Pd}(\mathrm{OH})_{2} / \mathrm{C}$ (Aldrich, $20 \mathrm{wt} \%$ ), TBAF (Aldrich), N,O-bis(trimethylsilyl)acetamide (Fluka), Dowex- $\mathrm{H}^{+}$ (Supelco), anhydrous $\mathrm{Et}_{2} \mathrm{O}$ (Biolab), EtOAc (Panreac), petroleum ether (Pure Science), anhydrous $\mathrm{MeOH}$ (Panreac), isopropanol (Pure Science), $\mathrm{CHCl}_{3}$ (Panreac), $\mathrm{NaHCO}_{3}$ (Pure Science), $\mathrm{K}_{2} \mathrm{CO}_{3}$ (Pure Science), $\mathrm{MgSO}_{4}$ (Pure Science) and $\mathrm{NaCl}$ (Panreac) were used as received. All solvents were removed through evaporation under reduced pressure. Reactions were monitored by TLC analysis on MachereyNagel silica gel coated plastic sheets $\left(0.20 \mathrm{~mm}\right.$ with fluorescent indicator $\left.\mathrm{UV}_{254}\right)$ via detection by UV-absorption $(254 \mathrm{~nm})$ and by dipping in $10 \% \mathrm{H}_{2} \mathrm{SO}_{4}$ in EtOH followed by charring at $150{ }^{\circ} \mathrm{C}$. Column chromatography was performed using Pure Science silica gel $(40-63 \mu \mathrm{m})$. AccuBOND II ODS-C18 (Agilent) was used for reversed phase chromatography. High resolution mass spectra were recorded on a Waters Q-TOF Premier ${ }^{\mathrm{TM}}$ Tandem Mass Spectrometer using positive electro-spray ionisation. Optical rotations were recorded on a Perkin-Elmer 241 polarimeter or Autopol II (Rudolph Research Analytical) at $589 \mathrm{~nm}$ (sodium D-line). Infrared spectra were recorded as thin films using a Bruker Tensor 27 FTIR spectrometer equipped with an Attenuated Total Reflectance (ATR) sampling accessory and are 
reported in wave numbers $\left(\mathrm{cm}^{-1}\right)$. Nuclear magnetic resonance spectra were at $20{ }^{\circ} \mathrm{C}$ in $\mathrm{C}_{5} \mathrm{D}_{5} \mathrm{~N}, \mathrm{CD}_{3} \mathrm{OD}$ or $\mathrm{CDCl}_{3}$ using a Varian INOVA operating at $500 \mathrm{MHz}$. Chemical shifts are given in ppm $(\delta)$ relative to solvent residual peak. NMR peak assignments were made using COSY, HSQC and HMBC 2D experiments. Melting points were obtained using a Gallenkamp Melting Point Apparatus.

\section{2,2',3,3',4,4'-Hexa-O-benzyl-6,6'-di- $O$ -}

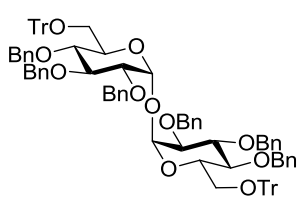

trityl- $\alpha, \boldsymbol{\alpha}^{\prime}$-D-trehalose (3). $\alpha, \alpha^{\prime}$-Trehalose $2(5.26 \mathrm{~g}, 14.6$ mmol) was co-evaporated with pyridine $(3 \times 20 \mathrm{~mL})$ and then dissolved in $30 \mathrm{~mL}$ of pyridine. Trityl chloride (28.5 g, 102.2 mmol) was added and the resulting mixture stirred at $40{ }^{\circ} \mathrm{C}$ under nitrogen for $16 \mathrm{~h}$ after which dry methanol $(40 \mathrm{~mL})$ was added and the reaction stirred for a further 0.5 $\mathrm{h}$. The solvent was removed under reduced pressure to give a pale yellow solid. Diethyl ether $(100 \mathrm{~mL})$ was added to the crude product and the resulting suspension filtered through a Büchner filter. The solid product was repeatedly washed with diethyl ether until free from triphenylmethyl chloride, as gauged by TLC. The solid was then washed with $3 \% \mathrm{NaHCO}_{3}$ and dried under vacuum and stored in a dessicator.

6,6'-Di- $O$-trityl-trehalose $(2.57 \mathrm{~g}, 3.12 \mathrm{mmol})$ was co-evaporated with anhydrous DMF (3 x $5 \mathrm{~mL}$ ) and dissolved in $15 \mathrm{~mL}$ of DMF. Catalytic TBAI (103 mg, 0.28 mmol) was added and the resulting solution cooled down to $0{ }^{\circ} \mathrm{C}$. Benzyl bromide (3.14 $\mathrm{mL}, 28.1 \mathrm{mmol}$ ) was added slowly to the reaction mixture followed by portionwise addition of sodium hydride (60\% dispersion in mineral oil) (1.86 g, $46.7 \mathrm{mmol}$ ), and the reaction was allowed to warm up to room temperature. After stirring for $2 \mathrm{~h}$, the reaction was quenched with $\mathrm{MeOH}(30 \mathrm{~mL})$, stirred vigorously for $10 \mathrm{~min}$ and concentrated in vacuo. The resulting crude mixture was dissolved in $\mathrm{Et}_{2} \mathrm{O}(200 \mathrm{~mL})$, washed with water $(3 \times 50 \mathrm{~mL})$ and brine $(50 \mathrm{~mL})$, dried $\left(\mathrm{MgSO}_{4}\right)$, filtered and concentrated in vacuo. The title compound was obtained after silica gel flash chromatography eluting in 15:1 (v/v) Pet. Ether/EtOAc, as a white crystals (3.62 g, $2.65 \mathrm{mmol}, 85 \%$ over 2 steps). Mp 91.0-94.0 ${ }^{\circ} \mathrm{C} ; \mathrm{R}_{f}=0.5(4 / 1, \mathrm{PE} / \mathrm{EA}, \mathrm{v} / \mathrm{v}) ;[\alpha]^{23}{ }_{\mathrm{D}}=$ $+60.5\left(c=1.0 \mathrm{CHCl}_{3}\right.$ ); IR (film): 3019, 2878, 2212, 1265, 1214, 744, $668 \mathrm{~cm}^{-1} ;{ }^{1} \mathrm{H}$ 
NMR (500 MHz, $\left.\mathrm{CDCl}_{3}\right) \delta$ 6.76-7.42 (m, 60H, $\left.\mathrm{H}_{\text {arom }}\right), 5.47\left(\mathrm{~d}, J_{1,2}=3.7 \mathrm{~Hz}, 2 \mathrm{H}, \mathrm{H}-\right.$ 1), $4.92\left(\mathrm{~d}, J_{\mathrm{a}, \mathrm{b}}=10.7 \mathrm{~Hz}, 2 \mathrm{H}, \mathrm{CH}-\mathrm{a}, 3-O-\mathrm{Bn}\right), 4.80\left(\mathrm{~d}, J_{\mathrm{a}, \mathrm{b}}=10.7 \mathrm{~Hz}, 2 \mathrm{H}, \mathrm{CH}-\mathrm{b}, 3-\right.$ $O-\mathrm{Bn}), 4.72\left(\mathrm{~d}, J_{\mathrm{a}, \mathrm{b}}=10.3 \mathrm{~Hz}, 2 \mathrm{H}, \mathrm{CH}-\mathrm{a}, 4-O-\mathrm{Bn}\right), 4.67\left(\mathrm{~d}, J_{\mathrm{a}, \mathrm{b}}=11.9 \mathrm{~Hz}, \mathrm{CH}-\mathrm{b}, 2-\right.$ $O$-Bn), $4.66\left(\mathrm{~d}, J_{\mathrm{a}, \mathrm{b}}=11.9 \mathrm{~Hz}, 2 \mathrm{H}, \mathrm{CH}-\mathrm{a}, 2-O-\mathrm{Bn}\right), 4.23\left(\mathrm{~d}, J_{\mathrm{a}, \mathrm{b}}=10.3 \mathrm{~Hz}, 2 \mathrm{H}, \mathrm{CH}-\mathrm{a}\right.$, 4-O-Bn), 4.17 (bd, $\left.J_{4,5}=9.6 \mathrm{~Hz}, 2 \mathrm{H}, \mathrm{H}-5\right), 3.97$ (t, $\left.J_{2,3}=J_{3,4}=9.6 \mathrm{~Hz}, 2 \mathrm{H}, \mathrm{H}-3\right), 3.87$ $\left(\mathrm{t}, J_{3,4}=J_{4,5}=9.6 \mathrm{~Hz}, 2 \mathrm{H}, \mathrm{H}-4\right), 3.72\left(\mathrm{dd}, J_{2,3}=9.6 \mathrm{~Hz}, J_{1,2}=3.7 \mathrm{~Hz}, 2 \mathrm{H}, \mathrm{H}-2\right), 3.33$ $\left(\mathrm{dd}, J_{6 \mathrm{a}, 6 \mathrm{~b}}=10.3 \mathrm{~Hz}, J_{5,6 \mathrm{a}}=2.7 \mathrm{~Hz}, 2 \mathrm{H}, \mathrm{H}-6 \mathrm{a}\right), 3.06\left(\mathrm{dd}, J_{6 \mathrm{a}, 6 \mathrm{~b}}=10.3 \mathrm{~Hz}, J_{5,6 \mathrm{~b}}=1.7\right.$ $\mathrm{Hz}, 2 \mathrm{H}, \mathrm{H}-6 \mathrm{~b}) ;{ }^{13} \mathrm{C}$ NMR $\left(125 \mathrm{MHz}, \mathrm{CDCl}_{3}\right) \delta 143.8,138.7,138.2,138.0(\mathrm{C} i$-Tr and Bn), 128.9, 128.4, 128.2, 128.1, 128.1, 127.8, 127.6, 127.5, 127.1, 126.9, 126.8 $\left(\mathrm{CH}_{\text {arom}}\right), 94.9$ (C-1), 81.8 (C-3), 80.3 (C-2), 77.8 (C-4), $75.9\left(\mathrm{CH}_{2}, 3-\mathrm{O}-\mathrm{Bn}\right), 75.1$ $\left(\mathrm{CH}_{2}, 4-\mathrm{O}-\mathrm{Bn}\right), 72.5\left(\mathrm{CH}_{2}, 2-\mathrm{O}-\mathrm{Bn}\right), 70.7$ (C-5) and $62.2(\mathrm{C}-6)$; HRMS(ESI) $\mathrm{m} / \mathrm{z}$ calcd. for $\left[\mathrm{C}_{92} \mathrm{H}_{86} \mathrm{O}_{11}+\mathrm{Na}\right]^{+}$: 1389.6068 , obsd.: 1389.6072 .

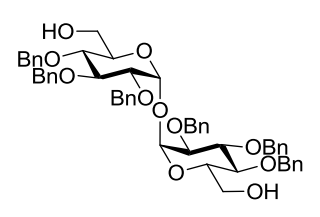

\section{$2,2^{\prime}, 3,3 ', 4,4^{\prime}$-Hexa- $O$-benzyl- $\alpha, \alpha^{\prime}-\mathrm{D}-$} trehalose (4). $\mathrm{Et}_{3} \mathrm{SiH}(0.75 \mathrm{~mL}, 4.74 \mathrm{mmol})$ was added to the hexa- $O$-benzyl-di- $O$-trityl-trehalose $(3.24 \mathrm{~g}, 2.37 \mathrm{mmol})$ (coevaporated $3 \mathrm{x}$ with toluene) in dry $\mathrm{CH}_{2} \mathrm{Cl}_{2}(30 \mathrm{~mL}) .10 \%$

TFA solution was then added drop-wise to the reaction mixture until the yellow colour no longer appeared. The reaction was completed in $30 \mathrm{~min}$, (as determined via TLC monitoring) after which $\mathrm{MeOH}(6 \mathrm{~mL})$, saturated $\mathrm{NaHCO}_{3}(20 \mathrm{~mL})$ and brine (20 mL) was added. The aqueous layer was extracted with $\mathrm{CH}_{2} \mathrm{Cl}_{2}(2 \times 50 \mathrm{~mL})$ and the combined organic layer was dried $\left(\mathrm{MgSO}_{4}\right)$, filtered and concentrated in vacuo. The residue was subjected to silica gel flash chromatography and eluted with 1:1 $(\mathrm{v} / \mathrm{v})$ Pet. Ether/EtOAc to afford the title compound $\mathbf{4}$ as a colourless viscous oil $(1.675 \mathrm{~g}, 1.90 \mathrm{mmol}, 80 \%) . \mathrm{R}_{f}=0.38(\mathrm{PE} / \mathrm{EA}, 1 / 1, \mathrm{v} / \mathrm{v}) ;[\alpha]^{23} \mathrm{D}=+68.0(c=1.0$, $\mathrm{CHCl}_{3}$ ); IR (film): 3465, 3067, 3016, 2928, 2875, 1360, 1215, 1155, 1095, 1068 , $1027 \mathrm{~cm}^{-1} ;{ }^{1} \mathrm{H} \mathrm{NMR}\left(500 \mathrm{MHz}, \mathrm{CDCl}_{3}\right) \delta 7.27-7.53\left(\mathrm{~m}, 30 \mathrm{H}, \mathrm{H}_{\text {arom }}\right), 5.13\left(\mathrm{~d}, J_{1,2}=\right.$ $3.6 \mathrm{~Hz}, 2 \mathrm{H}, \mathrm{H}-1), 5.01\left(\mathrm{~d}, J_{\mathrm{a}, \mathrm{b}}=11.0 \mathrm{~Hz}, 2 \mathrm{H}, \mathrm{CH}-\mathrm{a}, 3-O-\mathrm{Bn}\right), 4.89\left(\mathrm{~d}, J_{\mathrm{a}, \mathrm{b}}=11.0 \mathrm{~Hz}\right.$, $2 \mathrm{H}, \mathrm{CH}-\mathrm{b}, 3-O-\mathrm{Bn}), 4.88\left(\mathrm{~d}, J_{\mathrm{a}, \mathrm{b}}=11.0 \mathrm{~Hz}, 2 \mathrm{H}, \mathrm{CH}-\mathrm{a}, 4-O-\mathrm{Bn}\right), 4.72\left(\mathrm{~d}, J_{\mathrm{a}, \mathrm{b}}=11.7\right.$ $\mathrm{Hz}, 2 \mathrm{H}, \mathrm{CH}-\mathrm{a}, 2-O-\mathrm{Bn}), 4.67$ (d, $\left.J_{\mathrm{a}, \mathrm{b}}=11.7 \mathrm{~Hz}, 2 \mathrm{H}, \mathrm{CH}-\mathrm{b}, 2-O-\mathrm{Bn}\right), 4.65$ (d, $J_{\mathrm{a}, \mathrm{b}}=$ $11.0 \mathrm{~Hz}, 2 \mathrm{H}, \mathrm{CH}-\mathrm{b}, 4-\mathrm{O}-\mathrm{Bn}), 4.08$ (m, 4H, H-3 and H-5), 3.55-3.60 (m, 6H, H-4 and H-6a,b), 3.54 (dd, $\left.J_{2,3}=10.0 \mathrm{~Hz}, J_{1,2}=3.6 \mathrm{~Hz}, 2 \mathrm{H}, \mathrm{H}-2\right) ;{ }^{13} \mathrm{C}$ NMR $(125 \mathrm{MHz}$, 
$\left.\mathrm{CDCl}_{3}\right) \delta 138.8(\mathrm{C}-i, 3-O-\mathrm{Bn}), 138.2(\mathrm{C}-i, 4-O-\mathrm{Bn}), 138.0(\mathrm{C}-i, 2-O-\mathrm{Bn}), 128.9$, 128.5, 128.4, 128.1, 127.9, 127.7, 127.6, $127.5\left(\mathrm{CH}_{\text {arom }}\right), 94.1$ (C-1), $81.6(\mathrm{C}-3), 79.5$ (C-2), $77.3(\mathrm{C}-4), 75.6\left(\mathrm{CH}_{2}, 3-O-\mathrm{Bn}\right), 75.1\left(\mathrm{CH}_{2}, 4-O-\mathrm{Bn}\right), 73.0\left(\mathrm{CH}_{2}, 2-O-\mathrm{Bn}\right)$, $71.3(\mathrm{C}-5)$ and $61.5(\mathrm{C}-6)$; HRMS(ESI) $\mathrm{m} / \mathrm{z}$ calcd. for $\left[\mathrm{C}_{54} \mathrm{H}_{58} \mathrm{O}_{11}+\mathrm{Na}\right]^{+}: 905.3877$, obsd.: 905.3881 .

General Procedure for Esterification. To a solution of diol 4 (1 mmol, 1 equiv.) in DCM $(10 \mathrm{~mL})$ the carboxylic acid $(4.4 \mathrm{mmol}, 4.4$ equiv.), EDCI $(6.6 \mathrm{mmol}, 6.6$ equiv.) and DMAP (0.15 mmol, 0.15 equiv.) were added. The reaction was stirred at room temperature overnight, after which the resulting precipitate was removed from the mixture by filtration and washed with cold DCM. The combined organic layers were washed with water $(30 \mathrm{~mL})$, dried $\left(\mathrm{MgSO}_{4}\right)$, filtered and concentrated in vacuo. The residue was purified using silica gel flash chromatography and the eluent given.

\section{$2,2^{\prime}, 3,3^{\prime}, 4,4^{\prime}$-Hexa-O-benzyl-}

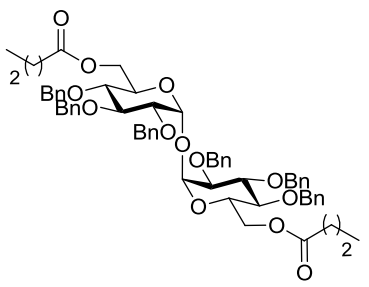
6,6'-di-O-butanoyl- $\boldsymbol{\alpha}, \boldsymbol{\alpha}^{\prime}$-D-trehalose (5a). By subjecting diol 4 (100 mg, $0.11 \mathrm{mmol}$ ), butyric acid (44 mg, 0.50 mmol), EDCI (143 mg, $0.73 \mathrm{mmol})$ and DMAP (2.06 mg, $0.002 \mathrm{mmol}$ ) to the general procedure for esterification, the title compound was obtained (eluting with 5:1 (v/v) Pet. Ether/EtOAc) as a colourless oil (101.8 mg, $\left.0.097 \mathrm{mmol}, 88 \%) . \mathrm{R}_{f}=0.76(\mathrm{PE} / \mathrm{EA}, 1 / 1, \mathrm{v} / \mathrm{v})\right) ;[\alpha]^{18}=$ +90.25 ( $c=1.0, \mathrm{CHCl}_{3}$ ); IR (film): 3028, 2934, 1733, 1497, 1454, 1359, 1215, 1158 , 1070, 1028, 995, 747, 697, $667 \mathrm{~cm}^{-1}$; ${ }^{1} \mathrm{H}$ NMR (500 MHz, $\left.\mathrm{CDCl}_{3}\right) \delta 7.25-7.38(\mathrm{~m}$, $\left.30 \mathrm{H}, \mathrm{H}_{\text {arom }}\right), 5.17\left(\mathrm{~d}, J_{1,2}=3.5 \mathrm{~Hz}, 2 \mathrm{H}, \mathrm{H}-1\right), 5.01\left(\mathrm{~d}, J_{\mathrm{a}, \mathrm{b}}=10.5 \mathrm{~Hz}, 2 \mathrm{H}, \mathrm{CH}-\mathrm{a}, 3-O-\right.$ $\mathrm{Bn}), 4.87\left(\mathrm{~d}, J_{\mathrm{a}, \mathrm{b}}=10.5 \mathrm{~Hz}, 2 \mathrm{H}, \mathrm{CH}-\mathrm{b}, 3-O-\mathrm{Bn}\right), 4.87\left(\mathrm{~d}, J_{\mathrm{a}, \mathrm{b}}=10.6 \mathrm{~Hz}, 2 \mathrm{H}, \mathrm{CH}-\mathrm{a}, 4-\right.$ $O-\mathrm{Bn}), 4.72\left(\mathrm{~d}, J_{\mathrm{a}, \mathrm{b}}=11.9 \mathrm{~Hz}, 2 \mathrm{H}, \mathrm{CH}-\mathrm{a}, 2-O-\mathrm{Bn}\right), 4.69\left(\mathrm{~d}, J_{\mathrm{a}, \mathrm{b}}=11.9 \mathrm{~Hz}, 2 \mathrm{H}, \mathrm{CH}-\mathrm{b}\right.$, 2-O-Bn), $4.52\left(\mathrm{~d}, J_{\mathrm{a}, \mathrm{b}}=10.6 \mathrm{~Hz}, 2 \mathrm{H}, \mathrm{CH}-\mathrm{b}, 4-O-\mathrm{Bn}\right), 4.23\left(\mathrm{bd}, J_{4,5}=9.5 \mathrm{~Hz}, 2 \mathrm{H}, \mathrm{H}-\right.$ 5), $4.15\left(\mathrm{dd}, J_{6 \mathrm{a}, 6 \mathrm{~b}}=12.2 \mathrm{~Hz}, J_{5,6 \mathrm{a}}=3.4 \mathrm{~Hz}, 2 \mathrm{H}, \mathrm{H}-6 \mathrm{a}\right), 4.06\left(\mathrm{dd}, J_{6 \mathrm{a}, 6 \mathrm{~b}}=12.2 \mathrm{~Hz}, J_{5,6 \mathrm{~b}}\right.$ $=2.4 \mathrm{~Hz}, 2 \mathrm{H}, \mathrm{H}-6 \mathrm{~b}), 4.05\left(\mathrm{t}, J_{2,3}=J_{3,4}=9.3 \mathrm{~Hz}, \mathrm{H}-3\right), 3.55\left(\mathrm{dd}, J_{2,3}=9.3 \mathrm{~Hz}, J_{1,2}=\right.$ $3.5 \mathrm{~Hz}, \mathrm{H}-2), 3.53$ (t, $\left.J_{3,4}=J_{4,5}=9.5 \mathrm{~Hz}, 2 \mathrm{H}, \mathrm{H}-4\right), 2.24$ (t, $\left.J_{8,9}=6.9 \mathrm{~Hz}, 4 \mathrm{H}, \mathrm{H}-8\right)$, 1.63-1.60 (m, 4H, H-9), 0.91 (t, $\left.J_{9,10}=7.3 \mathrm{~Hz}, 6 \mathrm{H}, \mathrm{H}-10\right) ;{ }^{13} \mathrm{C}$ NMR (125 MHz, 
$\left.\mathrm{CDCl}_{3}\right) \delta 173.3(\mathrm{C}-7), 138.6(\mathrm{C}-i, 3-O-\mathrm{Bn}), 137.8(\mathrm{C}-i, 4-O-\mathrm{Bn}), 137.8(\mathrm{C}-i, 2-O-$ $\mathrm{Bn}), 128.53,128.5,128.1,128.0,127.8,127.7,127.5\left(\mathrm{CH}_{\text {arom }}\right), 94.0(\mathrm{C}-1), 81.6(\mathrm{C}-$ 3), $79.3(\mathrm{C}-2), 77.5(\mathrm{C}-4), 75.7\left(\mathrm{CH}_{2}, 3-O-\mathrm{Bn}\right), 75.2\left(\mathrm{CH}_{2}, 4-O-\mathrm{Bn}\right), 72.9\left(\mathrm{CH}_{2}, 2-O-\right.$ Bn), 69.1 (C-5), 62.5 (C-6), 36.0 (C-8), 18.4 (C-9), 13.6 (C-10); HRMS(ESI) m/z calcd for $\left[\mathrm{C}_{62} \mathrm{H}_{70} \mathrm{O}_{13}+\mathrm{Na}\right]^{+}:$1045.4714, obsd.: 1045.4720 .

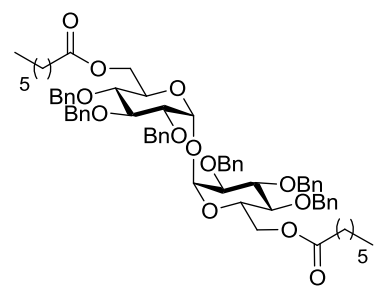

$2,2^{\prime}, 3,33^{\prime}, 4,4^{\prime}-$-Hexa- $O$ benzyl-6,6'-di- $O$-heptanoyl- $\alpha, \alpha^{\prime}$-D-trehalose (5b). By subjecting diol 4 (0.41 g, $0.46 \mathrm{mmol})$, heptanoic acid (0.29 mL, $2.02 \mathrm{mmol})$, EDCI (0.58 g, 3.03mmol) and DMAP $(0.008 \mathrm{~g}, 0.07 \mathrm{mmol})$ to the general procedure for esterification, the title compound was obtained (eluting in 10:1 (v/v) Pet. Ether/EtOAc) as a colourless oil (0.43 g, $0.39 \mathrm{mmol}, 85 \%) . \mathrm{R}_{f}=0.8$ (PE/EA, 1/1, $\mathrm{v} / \mathrm{v}) ;[\alpha]^{18}{ }_{\mathrm{D}}=+69.8\left(c=1.0, \mathrm{CHCl}_{3}\right)$; IR (film): 3018, 2981, 1732, 1454, 1215, 1159 , 1069, 996, 747, 697, $667 \mathrm{~cm}^{-1} ;{ }^{1} \mathrm{H}$ NMR (500 MHz, $\left.\mathrm{CDCl}_{3}\right) \delta 7.25-7.38(\mathrm{~m}, 30 \mathrm{H}$, $\left.\mathrm{H}_{\text {arom}}\right), 5.17\left(\mathrm{~d}, J_{1,2}=3.6 \mathrm{~Hz}, 2 \mathrm{H}, \mathrm{H}-1\right), 5.01$ (d, $\left.J_{\mathrm{a}, \mathrm{b}}=10.7 \mathrm{~Hz}, 2 \mathrm{H}, \mathrm{CH}-\mathrm{a}, 3-O-\mathrm{Bn}\right)$, $4.87\left(\mathrm{~d}, J_{\mathrm{a}, \mathrm{b}}=10.7 \mathrm{~Hz}, 2 \mathrm{H}, \mathrm{CH}-\mathrm{b}, 3-O-\mathrm{Bn}\right), 4.87\left(\mathrm{~d}, J_{\mathrm{a}, \mathrm{b}}=10.5 \mathrm{~Hz}, 2 \mathrm{H}, \mathrm{CH}-\mathrm{a}, 4-O-\right.$ $\mathrm{Bn}), 4.72\left(\mathrm{~d}, J_{\mathrm{a}, \mathrm{b}}=11.9 \mathrm{~Hz}, 2 \mathrm{H}, \mathrm{CH}-\mathrm{a}, 2-O-\mathrm{Bn}\right), 4.69\left(\mathrm{~d}, J_{\mathrm{a}, \mathrm{b}}=11.9 \mathrm{~Hz}, 2 \mathrm{H}, \mathrm{CH}-\mathrm{b}\right.$, 2-O-Bn), 4.52 (d, $\left.J_{\mathrm{a}, \mathrm{b}}=10.5 \mathrm{~Hz}, 2 \mathrm{H}, \mathrm{CH}-\mathrm{b}, 4-O-\mathrm{Bn}\right), 4.23$ (bd, $J_{4,5}=9.6 \mathrm{~Hz}, 2 \mathrm{H}, \mathrm{H}-$ 5), $4.15\left(\mathrm{dd}, J_{6 \mathrm{a}, 6 \mathrm{~b}}=12.5 \mathrm{~Hz}, J_{5,6 \mathrm{a}}=3.5 \mathrm{~Hz}, 2 \mathrm{H}, \mathrm{H}-6 \mathrm{a}\right), 4.06\left(\mathrm{dd}, J_{6 \mathrm{a}, 6 \mathrm{~b}}=12.5 \mathrm{~Hz}, J_{5,6 \mathrm{~b}}\right.$ $=2.4 \mathrm{~Hz}, 2 \mathrm{H}, \mathrm{H}-6 \mathrm{~b}), 4.05\left(\mathrm{t}, J_{2,3}=J_{3,4}=9.6 \mathrm{~Hz}, \mathrm{H}-3\right), 3.58\left(\mathrm{dd}, J_{2,3}=9.6 \mathrm{~Hz}, J_{1,2}=\right.$ $3.6 \mathrm{~Hz}, \mathrm{H}-2), 3.54\left(\mathrm{t}, J_{3,4}=J_{4,5}=9.6 \mathrm{~Hz}, 2 \mathrm{H}, \mathrm{H}-4\right), 2.25$ (t, $\left.J_{8,9}=7.1 \mathrm{~Hz}, 4 \mathrm{H}, \mathrm{H}-8\right)$, 1.60-1.56 (m, 4H, H-9), 1.29-1.22 (m, 12H, H-10-H-12), 0.86 (t, J12,13 = 6.6 Hz, 6H, $\mathrm{H}-13) ;{ }^{13} \mathrm{C}$ NMR $\left(125 \mathrm{MHz}, \mathrm{CDCl}_{3}\right) \delta 173.5$ (C-7), 138.6 (C-i, 3-O-Bn), 137.9 (C-i, 4-O-Bn), 137.8 (C-i, 2-O-Bn), 128.53, 128.5, 128.1, 128.0, 127.8, 127.7, 127.5 $\left(\mathrm{CH}_{\text {arom}}\right), 94.0$ (C-1), 81.6 (C-3), 79.3 (C-2), 77.5 (C-4), $75.7\left(\mathrm{CH}_{2}, 3-O-\mathrm{Bn}\right), 75.2$ $\left(\mathrm{CH}_{2}, 4-\mathrm{O}-\mathrm{Bn}\right), 72.9\left(\mathrm{CH}_{2}, 2-O-\mathrm{Bn}\right), 69.1$ (C-5), 62.5 (C-6), 34.1 (C-8), 28.8, 24.8 22.5, 18.4 (C-9-C-12), 14.0 (C-13); HRMS(ESI) $m / z$ calcd. for $\left[\mathrm{C}_{68} \mathrm{H}_{82} \mathrm{O}_{13}+\mathrm{Na}\right]^{+}$: 1129.5653, obsd.:1129.5646. 


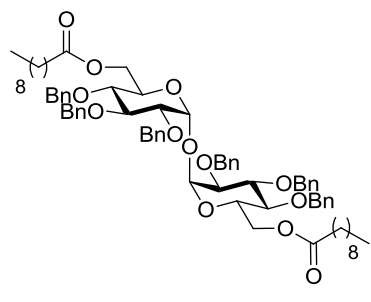

$2,2^{\prime}, 3,3^{\prime}, 4,4^{\prime}$-Hexa- $O$ benzyl-6,6'-di- $\boldsymbol{O}$-decanoyl- $\boldsymbol{\alpha}, \boldsymbol{\alpha} \boldsymbol{\alpha}^{\prime}$-D-trehalose $(\mathbf{5 c})$. Вy subjecting diol 4 (0.47 g, $0.53 \mathrm{mmol})$, decanoic acid $(0.40 \mathrm{~g}, 2.35 \mathrm{mmol})$, EDCI $(0.68 \mathrm{~g}, 3.52 \mathrm{mmol})$ and DMAP $(0.01 \mathrm{~g}, 0.08 \mathrm{mmol})$ to the general procedure for esterification, the title compound was obtained (eluting in 10:1 (v/v) Pet. Ether/EtOAc) as a yellow oil $(0.53 \mathrm{~g}, 0.45 \mathrm{mmol}, 83 \%) . \mathrm{R}_{f}=0.74(\mathrm{PE} / \mathrm{EA}, 1 / 1, \mathrm{v} / \mathrm{v}) ;[\alpha]^{18}{ }_{\mathrm{D}}=+70.0(c=1.0$, $\mathrm{CHCl}_{3}$ ); IR (film): 2927, 1732, 1454, 1215, 1157, 1070, 996, 747, 697, $667 \mathrm{~cm}^{-1} ;{ }^{1} \mathrm{H}$ NMR (500 MHz, $\left.\mathrm{CDCl}_{3}\right) \delta 7.38-7.26\left(\mathrm{~m}, 30 \mathrm{H}, \mathrm{H}_{\text {arom }}\right), 5.17\left(\mathrm{~d}, J_{1,2}=3.4 \mathrm{~Hz}, 2 \mathrm{H}, \mathrm{H}-\right.$ 1), $5.01\left(\mathrm{~d}, J_{\mathrm{a}, \mathrm{b}}=10.7 \mathrm{~Hz}, 2 \mathrm{H}, \mathrm{CH}-\mathrm{a}, 3-O-\mathrm{Bn}\right.$ and), $4.88\left(\mathrm{~d}, J_{\mathrm{a}, \mathrm{b}}=10.7 \mathrm{~Hz}, 2 \mathrm{H}, \mathrm{CH}-\mathrm{b}\right.$, $3-O-\mathrm{Bn}), 4.86\left(\mathrm{~d}, J_{\mathrm{a}, \mathrm{b}}=10.8 \mathrm{~Hz}, 2 \mathrm{H}, \mathrm{CH}-\mathrm{a}, 4-O-\mathrm{Bn}\right), 4.72\left(\mathrm{~d}, J_{\mathrm{a}, \mathrm{b}}=11.8 \mathrm{~Hz}, 2 \mathrm{H}, \mathrm{CH}-\right.$ a, 2-O-Bn), $4.68\left(\mathrm{~d}, J_{\mathrm{a}, \mathrm{b}}=11.8 \mathrm{~Hz}, 2 \mathrm{H}, \mathrm{CH}-\mathrm{b}, 2-O-\mathrm{Bn}\right), 4.52\left(\mathrm{~d}, J_{\mathrm{a}, \mathrm{b}}=10.8 \mathrm{~Hz}, 2 \mathrm{H}\right.$, CH-b, 4- $O-\mathrm{Bn}), 4.24-4.21(\mathrm{~m}, 2 \mathrm{H}, \mathrm{H}-5), 4.15\left(\mathrm{dd}, J_{6 \mathrm{a}, 6 \mathrm{~b}}=12.2 \mathrm{~Hz}, J_{5,6 \mathrm{a}}=3.7 \mathrm{~Hz}\right.$, $2 \mathrm{H}, \mathrm{H}-6 \mathrm{a}$ ), 4.05 (dd, $\left.J_{6 \mathrm{a}, 6 \mathrm{~b}}=12.2 \mathrm{~Hz}, J_{5,6 \mathrm{~b}}=3.1 \mathrm{~Hz}, 2 \mathrm{H}, \mathrm{H}-6 \mathrm{~b}\right), 4.04$ (t, $J_{2,3}=J_{3,4}=9.3$ $\mathrm{Hz}, \mathrm{H}-3$ ), 3.57 (dd, $\left.J_{2,3}=9.3 \mathrm{~Hz}, J_{1,2}=3.4 \mathrm{~Hz}, \mathrm{H}-2\right), 3.54\left(\mathrm{t}, J_{3,4}=J_{4,5}=9.3 \mathrm{~Hz}, 2 \mathrm{H}\right.$, $\mathrm{H}-4), 2.25$ (t, $\left.J_{8,9}=7.3 \mathrm{~Hz}, 4 \mathrm{H}, \mathrm{H}-8\right), 1.58-1.55$ (m, 4H, H-9), 1.29-1.22 (m, 24H, H10-H-15), 0.87 (t, $\left.J_{15,16}=7.0 \mathrm{~Hz}, 6 \mathrm{H}, \mathrm{H}-16\right) ;{ }^{13} \mathrm{C}$ NMR $\left(125 \mathrm{MHz}, \mathrm{CDCl}_{3}\right) \delta 173.5$ (C-7), 138.6 (C-i, 3-O-Bn), 137.9 (C-i, 4-O-Bn), 137.8 (C-i, 2-O-Bn), 128.53, 128.5, 128.1, 128.0, 127.8, 127.7, $127.5\left(\mathrm{CH}_{\text {arom }}\right), 94.0$ (C-1), 81.6 (C-3), 79.3 (C-2), 77.5 (C-4), $75.7\left(\mathrm{CH}_{2}, 3-O-\mathrm{Bn}\right), 75.2\left(\mathrm{CH}_{2}, 4-O-\mathrm{Bn}\right), 72.9\left(\mathrm{CH}_{2}, 2-O-\mathrm{Bn}\right), 69.1(\mathrm{C}-5)$, 62.5 (C-6), 34.1 (C-8), 31.8, 29.4, 29.2, 29.1, 24.9, 22.7(C-9-C-15) and 14.1 (C-16); HRMS(ESI) $m / z$ calcd. for $\left[\mathrm{C}_{74} \mathrm{H}_{94} \mathrm{O}_{13}+\mathrm{Na}\right]^{+}: 1213.6592$, obsd.:1213.6591.

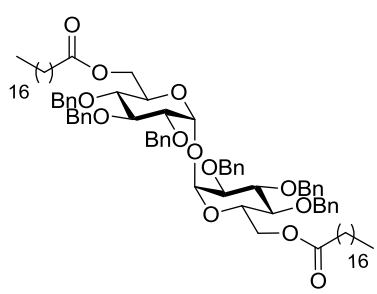

\section{$2,2^{\prime}, 3,33^{\prime}, 4,4^{\prime}$-Hexa-O-benzyl-} 6,6'-di- $O$-stearoyl- $\alpha, \boldsymbol{\alpha}^{\prime}$-D-trehalose (5d). By subjecting diol 4 (0.21 g, $0.24 \mathrm{mmol})$, stearic acid (0.31 g, 1.07 $\mathrm{mmol})$, EDCI (0.31 g, $1.61 \mathrm{mmol})$ and DMAP (0.005 g, $0.04 \mathrm{mmol}$ ) to the general procedure for esterification, the title compound was obtained (eluting in 10:1 (v/v)

Pet. Ether/EtOAc) as a colourless oil $(0.30 \mathrm{~g}, 0.21 \mathrm{mmol}, 85 \%) . \mathrm{R}_{f}=0.79$ (PE/EA, $2 / 1, \mathrm{v} / \mathrm{v}) ;[\alpha]_{\mathrm{D}}^{18}=+61.8\left(c=1.0, \mathrm{CHCl}_{3}\right)$; IR (film): 3055, 2926, 2855, 1732, 1455, 
1265, 1157, 1071, 998, 896, 733, 701, $669 \mathrm{~cm}^{-1} ;{ }^{1} \mathrm{H}$ NMR $\left(500 \mathrm{MHz}, \mathrm{CDCl}_{3}\right) \delta 7.38-$ $7.26\left(\mathrm{~m}, 30 \mathrm{H}, \mathrm{H}_{\text {arom }}\right), 5.17\left(\mathrm{~d}, J_{1,2}=3.4 \mathrm{~Hz}, 2 \mathrm{H}, \mathrm{H}-1\right), 5.01\left(\mathrm{~d}, J_{\mathrm{a}, \mathrm{b}}=10.9 \mathrm{~Hz}, 2 \mathrm{H}\right.$, $\mathrm{CH}-\mathrm{a}, 3-O-\mathrm{Bn}), 4.87\left(\mathrm{~d}, J_{\mathrm{a}, \mathrm{b}}=10.9 \mathrm{~Hz}, 2 \mathrm{H}, \mathrm{CH}-\mathrm{b}, 3-O-\mathrm{Bn}\right), 4.87\left(\mathrm{~d}, J_{\mathrm{a}, \mathrm{b}}=10.5 \mathrm{~Hz}\right.$, $2 \mathrm{H}, \mathrm{CH}-\mathrm{a}, 4-O-\mathrm{Bn}), 4.72\left(\mathrm{~d}, J_{\mathrm{a}, \mathrm{b}}=11.8 \mathrm{~Hz}, 2 \mathrm{H}, \mathrm{CH}-\mathrm{a}, 2-O-\mathrm{Bn}\right), 4.69$ (d, $J_{\mathrm{a}, \mathrm{b}}=11.8$ $\mathrm{Hz}, 2 \mathrm{H}, \mathrm{CH}-\mathrm{b}, 2-O-\mathrm{Bn}$ ), 4.52 (d, $\left.J_{\mathrm{a}, \mathrm{b}}=10.5 \mathrm{~Hz}, 2 \mathrm{H}, \mathrm{CH}-\mathrm{b}, 4-O-\mathrm{Bn}\right), 4.23$ (bd, $J_{4,5}=$ $9.2 \mathrm{~Hz}, 2 \mathrm{H}, \mathrm{H}-5), 4.16\left(\mathrm{dd}, J_{6 \mathrm{a}, 6 \mathrm{~b}}=12.4 \mathrm{~Hz}, J_{5,6 \mathrm{a}}=3.7 \mathrm{~Hz}, 2 \mathrm{H}, \mathrm{H}-6 \mathrm{a}\right) 4.05$ (dd, $J_{6 \mathrm{a}, 6 \mathrm{~b}}=$ $\left.12.4 \mathrm{~Hz}, J_{5,6 \mathrm{~b}}=2.1 \mathrm{~Hz}, 2 \mathrm{H}, \mathrm{H}-6 \mathrm{~b}\right), 4.06\left(\mathrm{t}, J_{2,3}=J_{3,4}=9.2 \mathrm{~Hz}, \mathrm{H}-3\right), 3.57$ (dd, $J_{2,3}=$ $\left.9.2 \mathrm{~Hz}, J_{1,2}=3.4 \mathrm{~Hz}, \mathrm{H}-2\right), 3.54\left(\mathrm{t}, J_{3,4}=J_{4,5}=9.2 \mathrm{~Hz}, 2 \mathrm{H}, \mathrm{H}-4\right), 2.24\left(\mathrm{t}, J_{8,9}=7.3 \mathrm{~Hz}\right.$, $4 \mathrm{H}, \mathrm{H}-8), 1.59-1.56$ (m, 4H, H-9), 1.31-1.23 (m, 56H, H-10-H-23), 0.88 (t, J23,24= $7.0 \mathrm{~Hz}, 6 \mathrm{H}, \mathrm{H}-24) ;{ }^{13} \mathrm{C} \mathrm{NMR}\left(125 \mathrm{MHz}, \mathrm{CDCl}_{3}\right) \delta 173.5(\mathrm{C}-7), 138.6(\mathrm{C}-i, 3-O-\mathrm{Bn})$, 137.9 (C-i, 4-O-Bn), 137.9 (C-i, 2-O-Bn), 128.5, 128.4, 128.1, 128.0, 127.8, 127.5 $\left(\mathrm{CH}_{\text {arom}}\right), 94.1$ (C-1), $81.6(\mathrm{C}-3), 79.3$ (C-2), $77.5(\mathrm{C}-4), 75.7\left(\mathrm{CH}_{2}, 3-O-\mathrm{Bn}\right), 75.2$ $\left(\mathrm{CH}_{2}, 4-\mathrm{O}-\mathrm{Bn}\right), 72.9\left(\mathrm{CH}_{2}, 2-\mathrm{O}-\mathrm{Bn}\right), 69.1$ (C-5), 62.5 (C-6), 34.1 (C-8), 31.9, 30.9, 29.7, 29.6, 29.5, 29.4, 29.3, 29.2, 29.1, 24.8, 22.7(C-9-C-23) and 14.1 (C-24); HRMS(ESI) $m / z$ calcd. for $\left[\mathrm{C}_{90} \mathrm{H}_{126} \mathrm{O}_{12}+\mathrm{Na}\right]^{+}:$1437.9096, obsd.: 1437.9098 .

General procedure for debenzylation. $\mathrm{Pd}(\mathrm{OH})_{2}(2.5 \mathrm{~mol} \%)$ was added to a solution of the benzylated trehalose diesters $(1 \mathrm{mmoL})$ in a mixture of $\mathrm{CHCl}_{3} / \mathrm{MeOH}(10 \mathrm{~mL}$, $3 / 2, \mathrm{v} / \mathrm{v}$ ) and stirred at room temperature under a steam of $\mathrm{H}_{2}$ (gas) at $1 \mathrm{~atm}$ for $7 \mathrm{~h}$. The reaction mixture was then filtered through Celite, the Celite washed thoroughly with $\mathrm{CHCl}_{3} / \mathrm{MeOH}(20 \mathrm{~mL}, 3 / 2, \mathrm{v} / \mathrm{v})$ and the filtrate concentrated in vacuo. The product was purified using silica gel flash chromatography and the eluent given.

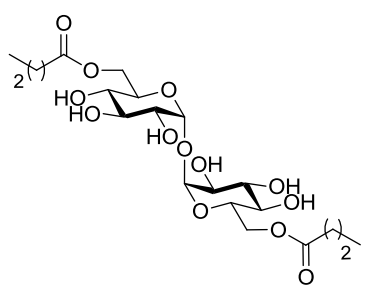

6,6'-Di-O-butanoyl-a, $\alpha^{\prime}$-Dtrehalose (1a). By subjecting dibutyl trehalose 5a (180 $\mathrm{mg}, 0.17 \mathrm{mmol}$ ) to the procedure for debenzylation, trehalose diester 1a was obtained (eluting in 95:5 (v/v) EtOAc/MeOH) as a white powder $(52.9 \mathrm{mg}, 0.10 \mathrm{mmol}$, $62 \%) . \mathrm{R}_{f}=0.2(\mathrm{EtOAc}) ;[\alpha]_{\mathrm{D}}^{24}=+132.75(c=1.0$, $\mathrm{MeOH}$ ); IR (film): 3318, 2943, 2832, 1732, 1449, 1114, $1022 \mathrm{~cm}^{-1} ;{ }^{1} \mathrm{H}$ NMR (500 $\left.\mathrm{MHz}, \mathrm{CD}_{3} \mathrm{OD}\right) \delta 5.04\left(\mathrm{~d}, J_{1,2}=3.6 \mathrm{~Hz}, 2 \mathrm{H}, \mathrm{H}-1\right), 4.36\left(\mathrm{dd}, J_{6 \mathrm{a}, 6 \mathrm{~b}}=11.9 \mathrm{~Hz}, J_{5,6 \mathrm{a}}=2.0\right.$ 
$\mathrm{Hz}, 2 \mathrm{H}, \mathrm{H}-6 \mathrm{a}), 4.20\left(\mathrm{dd}, J_{6 \mathrm{a}, 6 \mathrm{~b}}=11.9 \mathrm{~Hz}, J_{5,6 \mathrm{~b}}=5.1 \mathrm{~Hz}, 2 \mathrm{H}, \mathrm{H}-6 \mathrm{~b}\right), 4.04-4.00(\mathrm{~m}$, $2 \mathrm{H}, \mathrm{H}-5), 3.78\left(\mathrm{t}, J_{2,3}=J_{3,4}=9.2 \mathrm{~Hz}, \mathrm{H}-3\right), 3.46\left(\mathrm{dd}, J_{2,3}=9.2 \mathrm{~Hz}, J_{1,2}=3.6 \mathrm{~Hz}, 2 \mathrm{H}\right.$, H-2), $3.35\left(\mathrm{t}, J_{3,4}=J_{4,5}=9.2 \mathrm{~Hz}, 2 \mathrm{H}, \mathrm{H}-4\right), 2.33\left(\mathrm{t}, J_{8,9}=7.3 \mathrm{~Hz}, 4 \mathrm{H}, \mathrm{H}-8\right), 1.65$ (pentet, $\left.J_{\alpha, \beta}=J_{\beta, \gamma}=7.3 \mathrm{~Hz}, 4 \mathrm{H}, \mathrm{H}-9\right), 0.96\left(\mathrm{t}, J_{9,10}=7.3 \mathrm{~Hz}, 6 \mathrm{H}, \mathrm{H}-10\right) ;{ }^{13} \mathrm{C} \mathrm{NMR}$ (125 MHz, CD 3 OD) $\delta 173.9$ (C-7), 93.9 (C-1), 73.1 (C-3), 71.7 (C-2), 70.4 (C-4), 70.1 (C-5), 62.9 (C-6), 36.8 (C-8), 18.0 (C-9), 12.5 (C-10); HRMS(ESI) m/z calcd. for $\left[\mathrm{C}_{20} \mathrm{H}_{34} \mathrm{O}_{13}+\mathrm{Na}\right]^{+}$: 505.1897, obsd.: 505.1891.

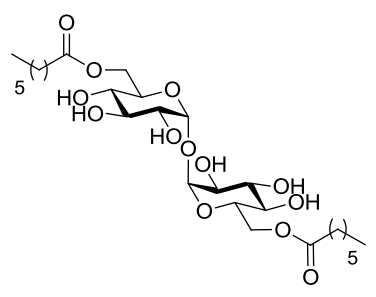

6,6'-Di- $O$-heptanoyl- $\alpha, \alpha^{\prime}-\mathrm{D}-$ trehalose

(1b). By subjecting diheptyl trehalose $\mathbf{5 b}(105.6 \mathrm{mg}, 0.096 \mathbf{m m o l})$ to the general procedure for debenzylation, trehalose diester 1b was obtained (eluting in 95:5 (v/v) EtOAc/MeOH) as a white solid $(35.9 \mathrm{mg}, 0.064 \mathrm{mmol}$, $67 \%) . \mathrm{R}_{f}=0.75(\mathrm{EtOAc} / \mathrm{MeOH}, 9 / 1, \mathrm{v} / \mathrm{v}) ;[\alpha]_{\mathrm{D}}^{24}=+70.8(c=1.0, \mathrm{EtOH}) ; \mathrm{IR}($ film$)$ : 3319, 2943, 2831, 1735, 1448, 1113, $1022 \mathrm{~cm}^{-1} ;{ }^{1} \mathrm{H}$ NMR (500 MHz, CD 3 OD) $\delta$ $5.04\left(\mathrm{~d}, J_{1,2}=3.1 \mathrm{~Hz}, 2 \mathrm{H}, \mathrm{H}-1\right), 4.36\left(\mathrm{dd}, J_{6 \mathrm{a}, 6 \mathrm{~b}}=11.7 \mathrm{~Hz}, J_{5,6 \mathrm{a}}=2.0 \mathrm{~Hz}, 2 \mathrm{H}, \mathrm{H}-6 \mathrm{a}\right)$, $4.20\left(\mathrm{dd}, J_{6 \mathrm{a}, 6 \mathrm{~b}}=11.7 \mathrm{~Hz}, J_{5,6 \mathrm{~b}}=4.9 \mathrm{~Hz}, 2 \mathrm{H}, \mathrm{H}-6 \mathrm{~b}\right), 4.03-4.00(\mathrm{~m}, 2 \mathrm{H}, \mathrm{H}-5), 3.88(\mathrm{t}$, $\left.J_{2,3}=J_{3,4}=9.3 \mathrm{~Hz}, \mathrm{H}-3\right), 3.47\left(\mathrm{dd}, J_{2,3}=9.3 \mathrm{~Hz}, J_{1,2}=3.1 \mathrm{~Hz}, 2 \mathrm{H}, \mathrm{H}-2\right), 3.34\left(\mathrm{t}, J_{3,4}=\right.$ $\left.J_{4,5}=9.3 \mathrm{~Hz}, 2 \mathrm{H}, \mathrm{H}-4\right), 2.35$ (t, $J_{8,9}=7.4 \mathrm{~Hz}, 4 \mathrm{H}, \mathrm{H}-8$ ), 1.62 (pentet, $J_{\alpha, \beta}=J_{\beta, \gamma}=7.3$ $\mathrm{Hz}, 4 \mathrm{H}, \mathrm{H}-9), 1.36-1.32$ (m, 12H, H-10-H-12), 0.96 (t, $\left.J_{12,13}=7.3 \mathrm{~Hz}, 6 \mathrm{H}, \mathrm{H}-13\right)$; ${ }^{13} \mathrm{C}$ NMR (125 MHz, CD $\left.3 \mathrm{OD}\right) \delta 174.1$ (C-7), 93.8 (C-1), 73.1 (C-3), 71.7 (C-2), 70.5 (C-4), 70.1 (C-5), 63.0 (C-6), 33.6 (C-8), 31.3, 28.5, 24.6, 22.2 (C-9-C-12), 13.0 (C13); HRMS(ESI) $m / z$ calcd. for $\left[\mathrm{C}_{26} \mathrm{H}_{46} \mathrm{O}_{13}+\mathrm{Na}\right]^{+}:$589.2836, obsd.: 589.2837.

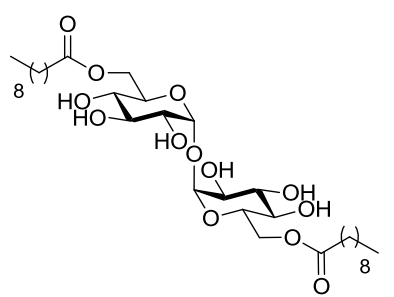

6,6'-Di- $\boldsymbol{O}$-decanoyl- $\boldsymbol{\alpha}, \boldsymbol{\alpha}$ '-D-trehalose (1c). By subjecting didecanoyl trehalose $5 \mathbf{c}(119 \mathrm{mg}, 0.10 \mathrm{mmol})$ to the general procedure for debenzylation, trehalose diester 1c was obtained (eluting in 95:5 (v/v) EtOAc/MeOH) as a white solid (40.9 $\mathrm{mg}, 0.063 \mathrm{mmol}, 63 \%) . \mathrm{R}_{f}=0.5$

$(\mathrm{EA} / \mathrm{MeOH}, 9 / 1, \mathrm{v} / \mathrm{v}) ;[\alpha]^{24}{ }_{\mathrm{D}}=+111.3(c=1.0, \mathrm{EtOH}) ; \mathrm{IR}($ film): 3320, 2973, 2882, 1736, 1379, 1275, 1088, 1046, $880 \mathrm{~cm}^{-1} ;{ }^{1} \mathrm{H}$ NMR (500 MHz, $\left.\mathrm{CD}_{3} \mathrm{OD}\right) \delta 5.05\left(\mathrm{~d}, J_{1,2}\right.$ 
$=3.9 \mathrm{~Hz}, 2 \mathrm{H}, \mathrm{H}-1), 4.35\left(\mathrm{dd}, J_{6 \mathrm{a}, 6 \mathrm{~b}}=11.9 \mathrm{~Hz}, J_{5,6 \mathrm{a}}=2.0 \mathrm{~Hz}, 2 \mathrm{H}, \mathrm{H}-6 \mathrm{a}\right), 4.20(\mathrm{dd}$, $\left.J_{6 \mathrm{a}, 6 \mathrm{~b}}=11.9 \mathrm{~Hz}, J_{5,6 \mathrm{~b}}=5.1 \mathrm{~Hz}, 2 \mathrm{H}, \mathrm{H}-6 \mathrm{~b}\right), 4.05-4.01(\mathrm{~m}, 2 \mathrm{H}, \mathrm{H}-5), 3.78\left(\mathrm{t}, J_{2,3}=J_{3,4}\right.$ $=9.1 \mathrm{~Hz}, \mathrm{H}-3), 3.47\left(\mathrm{dd}, J_{2,3}=9.1 \mathrm{~Hz}, J_{1,2}=3.9 \mathrm{~Hz}, 2 \mathrm{H}, \mathrm{H}-2\right), 3.34\left(\mathrm{t}, J_{3,4}=J_{4,5}=9.1\right.$ $\mathrm{Hz}, 2 \mathrm{H}, \mathrm{H}-4), 2.35$ (t, $J_{8,9}=7.5 \mathrm{~Hz}, 4 \mathrm{H}, \mathrm{H}-8$ ), 1.62 (pentet, $J_{\alpha, \beta}=J_{\beta, \gamma}=7.1 \mathrm{~Hz}, 4 \mathrm{H}$, H-9), 1.33-1.30 (m, 24H, H-10-H-15), 0.90 (t, $J_{15,16}=7.3 \mathrm{~Hz}, 6 \mathrm{H}, \mathrm{H}-16$ ); ${ }^{13} \mathrm{C}$ NMR (125 MHz, CD $\left.{ }_{3} \mathrm{OD}\right) \delta 174.1$ (C-7), 93.8 (C-1), 73.1 (C-3), 71.2 (C-2), 70.5 (C-4), 70.1 (C-5), 63.0 (C-6), 33.7 (C-8), 31.7, 29.2, 29.0, 28.8, 24.7, 22.3 (C-9-C-15), 13.1 (C-16); HRMS(ESI) $m / z$ calcd. for $\left[\mathrm{C}_{32} \mathrm{H}_{58} \mathrm{O}_{13}+\mathrm{Na}\right]^{+}:$673.3775, obsd.: 673.3773 .

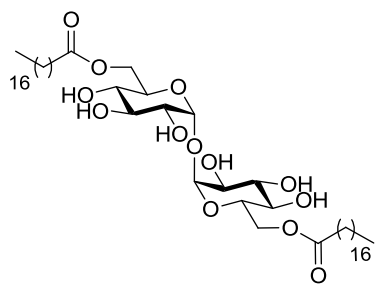

6,6'-Di- $\boldsymbol{O}$-stearoyl- $\boldsymbol{\alpha}, \boldsymbol{\alpha}^{\prime}$-D-trehalose (1d). By subjecting distearoyl trehalose $\mathbf{5 d}(112.1 \mathrm{mg}, 0.079 \mathrm{mmol})$ to the general procedure for debenzylation, trehalose diester 1d was obtained after silica gel chromatography eluting in 95:5 (v/v) EtOAc/MeOH as a white solid $(60.9 \mathrm{mg}$, $0.070 \mathrm{mmol}, 88 \%) . \mathrm{R}_{f}=0.64(\mathrm{EA} / \mathrm{MeOH}, 9 / 1, \mathrm{v} / \mathrm{v}) ;[\alpha]_{\mathrm{D}}^{22}=+16.0(c=1.0, \mathrm{EtOH})$; IR (film): 3330, 2919, 2850, 2835, 1660, 1453, 1109, $697 \mathrm{~cm}^{-1} ;{ }^{1} \mathrm{H}$ NMR (500 MHz, $\left.\mathrm{CD}_{3} \mathrm{OD}\right) \delta 5.06\left(\mathrm{~d}, J_{1,2}=3.7 \mathrm{~Hz}, 2 \mathrm{H}, \mathrm{H}-1\right), 4.35\left(\mathrm{dd}, J_{6 \mathrm{a}, 6 \mathrm{~b}}=11.4 \mathrm{~Hz}, J_{5,6 \mathrm{a}}=2.0 \mathrm{~Hz}\right.$, $2 \mathrm{H}, \mathrm{H}-6 \mathrm{a}), 4.21\left(\mathrm{dd}, J_{6 \mathrm{a}, 6 \mathrm{~b}}=11.4 \mathrm{~Hz}, J_{5,6 \mathrm{~b}}=5.1 \mathrm{~Hz}, 2 \mathrm{H}, \mathrm{H}-6 \mathrm{~b}\right), 4.02-3.98$ (m, 2H, H5), $3.77\left(\mathrm{t}, J_{2,3}=J_{3,4}=9.3 \mathrm{~Hz}, \mathrm{H}-3\right), 3.48\left(\mathrm{dd}, J_{2,3}=9.3 \mathrm{~Hz}, J_{1,2}=3.7 \mathrm{~Hz}, 2 \mathrm{H}, \mathrm{H}-2\right)$, $3.34\left(\mathrm{t}, J_{3,4}=J_{4,5}=9.3 \mathrm{~Hz}, 2 \mathrm{H}, \mathrm{H}-4\right), 2.34\left(\mathrm{t}, J_{8,9}=7.4 \mathrm{~Hz}, 4 \mathrm{H}, \mathrm{H}-8\right), 1.62$ (pentet, $\left.J_{\alpha, \beta}=J_{\beta, \gamma}=7.1 \mathrm{~Hz}, 4 \mathrm{H}, \mathrm{H}-9\right), 1.32-1.27(\mathrm{~m}, 56 \mathrm{H}, \mathrm{H}-10-\mathrm{H}-23), 0.89$ (t, $J_{23,24}=7.3$ $\mathrm{Hz}, 6 \mathrm{H}, \mathrm{H}-24) ;{ }^{13} \mathrm{C}$ NMR (125 MHz, $\left.\mathrm{CD}_{3} \mathrm{OD}\right) \delta 174.2$ (C-7), 93.7 (C-1), 73.2 (C-3), 71.7 (C-2), 70.4 (C-4), 70.0 (C-5), 63.1 (C-6), 33.8 (C-8), 31.7, 29.5, 29.4, 29.3, 29.1, 29.1, 28.9, 24.7, 22.4 (C-9-C-23), 13.1 (C-24); HRMS(ESI) m/z calcd. for $\left[\mathrm{C}_{48} \mathrm{H}_{90} \mathrm{O}_{13}+\mathrm{Na}\right]^{+}:$897.6279, obsd.: 897.6279.

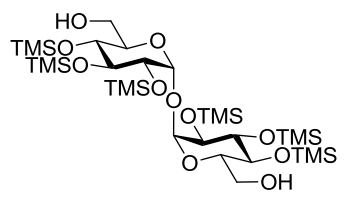

$2,2^{\prime}, 3,3$ ',4,4'-Hexa- $O$-trimethylsilyl- $\alpha, \alpha^{\prime}$-D-trehalose (6). $\alpha, \alpha$-D-Trehalose dihydrate $2(0.25 \mathrm{~g}, 0.66 \mathrm{mmol})$ was coevaporated with anhydrous DMF (3 x $5 \mathrm{~mL}$ ) and then dissolved in DMF $(1 \mathrm{~mL})$. To this solution, $\mathrm{N}, \mathrm{O}$ bis(trimethylsilyl)acetamide $(1.4 \mathrm{~mL}, 5.70 \mathrm{mmol})$ and TBAF $(0.04 \mathrm{~mL}, 0.04 \mathrm{mmol})$ 
were added and the reaction stirred at room temperature for $1.5 \mathrm{~h}$. The reaction was quenched with $0.25 \mathrm{~mL}$ iso-propanol and the resulting solution was diluted with 15 $\mathrm{mL} \mathrm{MeOH}$ and cooled down to $0{ }^{\circ} \mathrm{C} . \mathrm{K}_{2} \mathrm{CO}_{3}$ solution $(0.091 \mathrm{~g}$ in $20 \mathrm{~mL} \mathrm{MeOH})$ was added to the reaction mixture and stirring at $0{ }^{\circ} \mathrm{C}$ was continued for $2 \mathrm{~h}$. The reaction mixture was concentrated in vacuo and the resulting residue partitioned between ether and brine. The aqueous layer was extracted twice more with diethyl ether (30 $\mathrm{mL}$ x 2) and the combined organic layer dried $\left(\mathrm{MgSO}_{4}\right)$ and concentrated in vacuo. Flash chromatography of the crude product gave diol 6, eluting in $4: 1(\mathrm{v} / \mathrm{v})$ Pet. Ether/EtOAc, as a white solid (0.43 g, $0.56 \mathrm{mmol}, 85 \%) . \mathrm{R}_{f}=0.29(\mathrm{PE} / \mathrm{EA}, 3 / 1, \mathrm{v} / \mathrm{v})$; $[\alpha]_{\mathrm{D}}^{18}=+109\left(c=1.0, \mathrm{CHCl}_{3}\right), \mathrm{Lit}^{11}[\alpha]_{\mathrm{D}}^{25}=+103$; IR (film): 3628, 3019, 2958, 1558, 1541, 1387, 1250, 1215, 1166, 1109, 1075, $1005 \mathrm{~cm}^{-1} ;{ }^{1} \mathrm{H}$ NMR (500 MHz, $\left.\mathrm{CDCl}_{3}\right) \delta 4.91\left(\mathrm{~d}, J_{1,2}=3.1 \mathrm{~Hz}, 2 \mathrm{H}, \mathrm{H}-1\right), 3.90\left(\mathrm{t}, J_{2,3}=J_{3,4}=9.0 \mathrm{~Hz}, 2 \mathrm{H}, \mathrm{H}-3\right), 3.88$ $3.84(\mathrm{~m}, 2 \mathrm{H}, \mathrm{H}-5), 3.72\left(\mathrm{dd}, J_{6 \mathrm{a}, 6 \mathrm{~b}}=11.8 \mathrm{~Hz}, J_{5,6 \mathrm{a}}=2.7 \mathrm{~Hz}, 2 \mathrm{H}, \mathrm{H}-6 \mathrm{a}\right), 3.70$, (dd, $\left.J_{6 \mathrm{a}, 6 \mathrm{~b}}=11.8 \mathrm{~Hz}, J_{5,6 \mathrm{~b}}=3.9 \mathrm{~Hz} 2 \mathrm{H}, \mathrm{H}-6 \mathrm{~b}\right), 3.49\left(\mathrm{t}, J_{3,4}=J_{4,5}=9.1 \mathrm{~Hz}, 2 \mathrm{H}, \mathrm{H}-4\right), 3.42$ $\left(\mathrm{dd}, J_{2,3}=9.0 \mathrm{~Hz}, J_{1,2}=3.1 \mathrm{~Hz}, 2 \mathrm{H}, \mathrm{H}-2\right), 0.17,0.15,0.13\left(3 \mathrm{~s}, 54 \mathrm{H}, \mathrm{CH}_{3}, \mathrm{TMS}\right) ;{ }^{13} \mathrm{C}$ NMR (125 MHz, $\left.\mathrm{CDCl}_{3}\right) \delta 94.6$ (C-1), 73.3 (C-3), 73.0 (C-2), 72.8 (C-5), $71.4(\mathrm{C}-4)$, 61.7 (C-6), 1.0, 0.8, 0.07 (TMS); HRMS(ESI) $m / z$ calcd. for $\left[\mathrm{C}_{30} \mathrm{H}_{70} \mathrm{O}_{11} \mathrm{Si}_{6}+\mathrm{Na}\right]^{+}$: 797.3431, obsd.:797.3424.

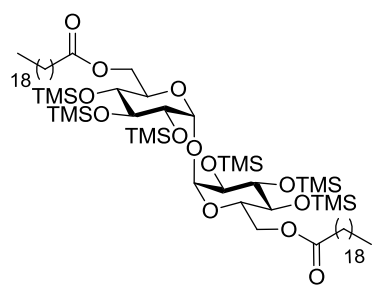

$2,2^{\prime}, 3,3^{\prime}, 4,4^{\prime}$-Hexa- $O$-trimethylsilyl-6,6'-di- $O$ eicosanoyl- $\alpha, \alpha^{\prime}$-D-trehalose (7e). To a solution of diol 6 (37.6 $\mathrm{mg}, 0.049 \mathrm{mmol})$ and arachidic acid $(84.6 \mathrm{mg}, 0.22$ mmol) in anhydrous $\mathrm{CH}_{2} \mathrm{Cl}_{2}(3 \mathrm{~mL})$ was added EDCI (61.4 $\mathrm{mg}, 0.32 \mathrm{mmol})$ and DMAP $(8.8 \mathrm{mg}, 0.001 \mathrm{mmol})$ and the reaction stirred at room temperature for 2 nights. The resulting precipitate was removed by filtration and washed thoroughly with EtOAc $(2 \times 10 \mathrm{~mL})$. The combined organic layers were washed with water $(20 \mathrm{~mL})$, brine $(20 \mathrm{~mL})$, dried $\left(\mathrm{MgSO}_{4}\right)$, filtered and concentrated in vacuo. Purification of the crude product by silica gel flash chromatography gave the title compound 7e, eluting in 50:1 (v/v) Pet. Ether/EtOAc, as pale yellow oil (61.5 mg, $0.045 \mathrm{mmol}, 93 \%) . \mathrm{R}_{f}=0.83$ (PE/EtOAc, 5/1, v/v); $[\alpha]^{18}{ }_{\mathrm{D}}=+45.0\left(c=0.1 \mathrm{CHCl}_{3}\right)$; IR (film): 3016, 2970, 2924, 2853, 1739 , 1010, 966, $843 \mathrm{~cm}^{-1} ;{ }^{1} \mathrm{H}$ NMR $\left(500 \mathrm{MHz}, \mathrm{CDCl}_{3}\right) \delta 4.92\left(\mathrm{~d}, J_{1,2}=3.2 \mathrm{~Hz}, 2 \mathrm{H}, \mathrm{H}-1\right)$, 
$4.28\left(\mathrm{dd}, J_{6 \mathrm{a}, 6 \mathrm{~b}}=12.0 \mathrm{~Hz}, J_{5,6 \mathrm{a}}=2.2 \mathrm{~Hz}, 2 \mathrm{H}, \mathrm{H}-6 \mathrm{a}\right), 4.06\left(\mathrm{dd}, J_{6 \mathrm{a}, 6 \mathrm{~b}}=12.0 \mathrm{~Hz}, J_{5,6 \mathrm{~b}}=\right.$ $4.4 \mathrm{~Hz}, 2 \mathrm{H}, \mathrm{H}-6 \mathrm{~b}$ ), 4.06-3.99 (m, 2H, H-5), 3.90 (t, $J_{2,3}=J_{3,4}=9.0 \mathrm{~Hz}, 2 \mathrm{H}, \mathrm{H}-3$ ), $3.49\left(\mathrm{t}, J_{3,4}=J_{4,5}=9.0 \mathrm{~Hz}, 2 \mathrm{H}, \mathrm{H}-4\right), 3.45\left(\mathrm{dd}, J_{2,3}=9.0 \mathrm{~Hz}, J_{1,2}=3.2 \mathrm{~Hz}, 2 \mathrm{H}, \mathrm{H}-2\right)$, $2.37\left(\mathrm{dt}, J_{8 \mathrm{a}, 8 \mathrm{~b}}=13.7 \mathrm{~Hz}, J_{8 \mathrm{a}, 9}=7.6 \mathrm{~Hz}, 2 \mathrm{H}, \mathrm{H}-8 \mathrm{a}\right), 2.36\left(\mathrm{dt}, J_{8 \mathrm{a}, 8 \mathrm{~b}}=13.7 \mathrm{~Hz}, J_{8 \mathrm{~b}, 9}=\right.$ $7.5 \mathrm{~Hz}, 2 \mathrm{H}, \mathrm{H}-8 \mathrm{~b}), 1.66-1.60$ (m, 4H, H-9), 1.30-1.26 (m, 64H, H-10-H-25), 0.89 (t, $\left.J_{25,26}=7.1 \mathrm{~Hz}, \mathrm{H}-26\right), 0.16,0.141,0.137$ (3 s, 54H, $\left.\mathrm{CH}_{3}, \mathrm{TMS}\right) ;{ }^{13} \mathrm{C}$ NMR $(125$ $\mathrm{MHz}, \mathrm{CDCl}_{3}$ ) $\delta 173.4$ (C-7), 94.4 (C-1), 73.5 (C-3), 72.6 (C-2), 71.9 (C-4), 70.7 (C5), 63.3 (C-6), 34.2 (C-8), 31.9, 29.71, 29.67, 29.5, 29.4, 29.3, 29.2, 29.1, 24.8, 22.7 (C-9-C-25), 14.1 (C-26), 1.1, 0.9, 0.2 (TMS) HRMS(ESI) $\mathrm{m} / z$ calcd. for $\left[\mathrm{C}_{70} \mathrm{H}_{146} \mathrm{O}_{13} \mathrm{Si}_{6}+\mathrm{Na}\right]^{+}$: 1385.9277, obsd.:1385.9282.

General Procedure for Esterification in Toluene. To a solution of diol 6 (1 mmol, 1 equiv.) and the carboxylic acid ( $4.4 \mathrm{mmol}, 4.4$ equiv.) in dry toluene (5 mL), EDCI (6.6 mmol, 6.6 equiv.) and DMAP (0.15 mmol, 0.15 equiv.) were added. The reaction was stirred at $70{ }^{\circ} \mathrm{C}$ until analysis by TLC showed no further formation of product. The resulting precipitate was removed by filtration and the precipitate washed thoroughly with EtOAc $(2 \times 50 \mathrm{~mL})$. The combined organic layers were washed with water $(50 \mathrm{~mL})$ and brine $(40 \mathrm{~mL})$, dried $\left(\mathrm{MgSO}_{4}\right)$, filtered and concentrated in vacuo. The product was purified by silica gel flash chromatography using the eluent given.

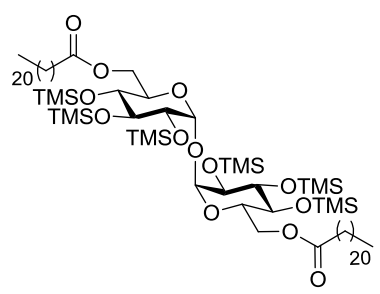

2,2',3,3',4,4'-Hexa-O-trimethylsilyl-6,6'-di- $O$ docosanoyl- $\alpha, \boldsymbol{\alpha}^{\prime}$-D-trehalose (7f). By subjecting diol 6 (106.1 mg, $0.14 \mathrm{mmol}$ ), docosanoic acid (205 mg, 0.60 $\mathrm{mmol}), \mathrm{EDCI}$ (177 mg, $0.92 \mathrm{mmol}$ ) and DMAP (2.5 mg, $0.02 \mathrm{mmol})$ to the general procedure for esterification $(2$ days), the title compound 7f was obtained (eluting in 50:1 (v/v) Pet. Ether/ EtOAc) as a white solid (170 mg, $0.12 \mathrm{mmol}, 86 \%) . \mathrm{R}_{f}=0.84(\mathrm{PE} / \mathrm{EA}, 5 / 1, \mathrm{v} / \mathrm{v}) ;[\alpha]^{18}{ }_{\mathrm{D}}=$ +46.1 ( $c=0.1 \mathrm{CHCl}_{3}$ ); IR (film): 2970, 2926, 2854, 1737, 1046, 1032, 993, 755, 704 $\mathrm{cm}^{-1} ;{ }^{1} \mathrm{H}$ NMR $\left(500 \mathrm{MHz}, \mathrm{CDCl}_{3}\right) \delta 4.93\left(\mathrm{~d}, J_{1,2}=2.9 \mathrm{~Hz}, 2 \mathrm{H}, \mathrm{H}-1\right), 4.29\left(\mathrm{dd}, J_{6 \mathrm{a}, 6 \mathrm{~b}}=\right.$ $\left.11.9 \mathrm{~Hz}, J_{5,6 \mathrm{a}}=2.2 \mathrm{~Hz}, 2 \mathrm{H}, \mathrm{H}-6 \mathrm{a}\right), 4.07\left(\mathrm{dd}, J_{6 \mathrm{a}, 6 \mathrm{~b}}=12.0 \mathrm{~Hz}, J_{5,6 \mathrm{~b}}=4.7 \mathrm{~Hz}, 2 \mathrm{H}, \mathrm{H}-\right.$ 
6b), 4.02-3.98 (m, 2H, H-5), $3.91\left(\mathrm{t}, J_{2,3}=J_{3,4}=9.0 \mathrm{~Hz}, 2 \mathrm{H}, \mathrm{H}-3\right), 3.49\left(\mathrm{t}, J_{3,4}=J_{4,5}=\right.$ $9.0 \mathrm{~Hz}, 2 \mathrm{H}, \mathrm{H}-4), 3.45\left(\mathrm{dd}, J_{2,3}=9.0 \mathrm{~Hz}, J_{1,2}=2.9 \mathrm{~Hz}, 2 \mathrm{H}, \mathrm{H}-2\right), 2.37\left(\mathrm{dt}, J_{8 \mathrm{a}, 8 \mathrm{~b}}=\right.$ $\left.13.1 \mathrm{~Hz}, J_{8 \mathrm{a}, 9}=7.3 \mathrm{~Hz}, 2 \mathrm{H}, \mathrm{H}-8 \mathrm{a}\right), 2.36\left(\mathrm{dt}, J_{8 \mathrm{a}, 8 \mathrm{~b}}=13.1 \mathrm{~Hz} J_{8 \mathrm{~b}, 9}=7.4 \mathrm{~Hz}, 2 \mathrm{H}, \mathrm{H}-8 \mathrm{~b}\right)$, $1.64-1.58$ (m, 4H, H-9), 1.34-1.22 (m, 72H, H-10-H-27), 0.89 (t, J27,28 $=6.8$ Hz, H28), 0.16, 0.141, 0.137 (3 s, 54H, $\left.\mathrm{CH}_{3}, \mathrm{TMS}\right) ;{ }^{13} \mathrm{C} \mathrm{NMR}\left(125 \mathrm{MHz}, \mathrm{CDCl}_{3}\right) \delta 173.8$ (C-7), 94.4 (C-1), 73.5 (C-3), 72.6 (C-2), 71.9 (C-4), 70.7 (C-5), 63.8 (C-6), 34.2 (C8), 31.9, 29.71, 29.67, 29.6, 29.5, 29.4, 29.3, 29.2, 24.8, 22.7 (C-9-C-27), 14.1 (C28), $1.1,0.9,0.2$ (TMS); HRMS (ESI) $m / z$ calcd. for $\left[\mathrm{C}_{74} \mathrm{H}_{154} \mathrm{O}_{13} \mathrm{Si}_{6}+\mathrm{Na}\right]^{+}$: 1441.9903, obsd.: 1441.9901.

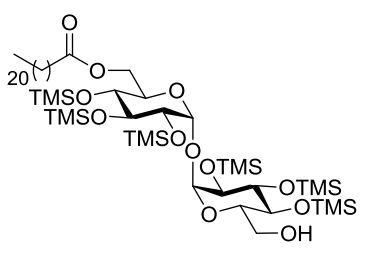

2,2',3,3',4,4'-Hexa- $O$-trimethylsilyl-6-docosanoyl-6'hydroxy- $\boldsymbol{\alpha}, \boldsymbol{\alpha}^{\prime}$-D-trehalose (8f). The title compound $\mathbf{8 f}$ was obtained (eluting in Hex: EtOAc 20:1) as a white solid (20 mg, $0.018 \mathrm{mmol}, 12 \%) . \mathrm{R}_{f}=0.55$ (PE/EA, 5/1, $\mathrm{v} / \mathrm{v}) ;[\alpha]_{\mathrm{D}}{ }^{18}=+20.2\left(c=1.0, \mathrm{CHCl}_{3}\right)$; IR (film): 3017, 2923, 2852, 1737, 1372, 1250, 1076, 1007, 965, $\mathrm{cm}^{-1} ;{ }^{1} \mathrm{H}$ NMR $\left(500 \mathrm{MHz}, \mathrm{CDCl}_{3}\right) \delta$ $4.94\left(\mathrm{~d}, J_{1 / 1^{\prime}, 2 / 2^{\prime}}=3.5 \mathrm{~Hz}, 1 \mathrm{H}, \mathrm{H}-1 / 1^{\prime}\right), 4.92\left(\mathrm{~d}, J_{1 / 1^{\prime}, 2 / 2^{\prime}}=3.7 \mathrm{~Hz}, 1 \mathrm{H}, \mathrm{H}-1 / 1^{\prime}\right), 4.30(\mathrm{dd}$, $\left.J_{6 \mathrm{a}, 6 \mathrm{~b}}=12.0 \mathrm{~Hz}, J_{5,6 \mathrm{a}}=2.2 \mathrm{~Hz}, 1 \mathrm{H}, \mathrm{H}-6 \mathrm{a}\right), 4.07\left(\mathrm{dd}, J_{6 \mathrm{a}, 6 \mathrm{~b}}=12.0 \mathrm{~Hz}, J_{5,6 \mathrm{~b}}=4.6 \mathrm{~Hz}\right.$, $1 \mathrm{H}, \mathrm{H}-6 \mathrm{~b}), 4.03-4.00$ (m, 1H, H-5), $3.92\left(\mathrm{t}, J_{2 / 2^{\prime}, 3 / 3^{\prime}}=J_{3 / 3^{\prime}, 4 / 4^{\prime}}=8.8 \mathrm{~Hz}, 1 \mathrm{H}, \mathrm{H}-3 / 3^{\prime}\right)$, $3.91\left(\mathrm{t}, J_{2 / 2^{\prime}, 3 / 3^{\prime}}=J_{3 / 3^{\prime}, 4 / 4^{\prime}}=9.0 \mathrm{~Hz}, 1 \mathrm{H}, \mathrm{H}-3 / 3^{\prime}\right), 3.85\left(\mathrm{dt}, J_{4^{\prime}, 5^{\prime}}=9.5 \mathrm{~Hz}, J_{5^{\prime}, 6 \mathrm{a}^{\prime}}=J_{5^{\prime}, 6 \mathrm{~b}^{\prime}}=\right.$ $\left.3.5 \mathrm{~Hz}, 1 \mathrm{H}, \mathrm{H}-5^{\prime}\right), 3.86-3.83$ (m, 2H, H-6a' and H-6b'), 3.49 (t, $J_{3,4}=J_{4,5}=9.0 \mathrm{~Hz}$, $1 \mathrm{H}, \mathrm{H}-4), 3.47\left(\mathrm{t}, J_{3^{\prime}, 4^{\prime}}=J_{4^{\prime}, 5^{\prime}}=9.0 \mathrm{~Hz}, 1 \mathrm{H}, \mathrm{H}-4^{\prime}\right), 3.44\left(\mathrm{dd}, J_{2,3 / 2^{\prime}, 3^{\prime}}=9.0 \mathrm{~Hz}, J_{1,2 / 1^{\prime}, 2^{\prime}}=\right.$ $\left.3.5 \mathrm{~Hz}, 1 \mathrm{H}, \mathrm{H}-2 / 2^{\prime}\right), 3.43\left(\mathrm{dd}, J_{2,3 / 2^{\prime}, 3^{\prime}}=9.0 \mathrm{~Hz}, J_{1,2 / 1^{\prime}, 2^{\prime}}=3.5 \mathrm{~Hz}, 1 \mathrm{H}, \mathrm{H}-2 / 2^{\prime}\right), 2.35$ (dt, $\left.J_{8 \mathrm{a}, 8 \mathrm{~b}}=13.2 \mathrm{~Hz}, J_{8 \mathrm{a}, 9}=7.3 \mathrm{~Hz}, 1 \mathrm{H}, \mathrm{H}-8 \mathrm{a}\right), 2.34\left(\mathrm{dd}, J_{8 \mathrm{a}, 8 \mathrm{~b}}=13.2 \mathrm{~Hz}, J_{8 \mathrm{~b}, 9}=7.4 \mathrm{~Hz}\right.$, $1 \mathrm{H}, \mathrm{H}-8 \mathrm{~b}), 1.66-1.57$ (m, 2H, H-9), 1.34-1.26 (m, 36H, H-10-H-27), 0.89 (t, J27,28 = $7.1 \mathrm{~Hz}, 3 \mathrm{H}, \mathrm{H}-28), 0.17,0.16,0.15,0.14,0.13$ (6 s, 54H, $\left.\mathrm{CH}_{3}, \mathrm{TMS}\right) ;{ }^{13} \mathrm{C} \mathrm{NMR}(125$ $\mathrm{MHz}, \mathrm{CDCl}_{3}$ ) 1173.8 (C-7), 94.5 (C-1/1'), 94.4 (C-1/1'), 73.5 (C-3/3'), 73.3 (C-3/3'), 72.9 (C-2/2'), 72.8 (C-5'), 72.6 (C-2/2'), 71.9 (C-4), 71.4 (C-4'), 70.8 (C-5), 63.3 (C6), 61.7 (C-6'), 34.2 (C-8), 31.9, 29.70, 29.66, 29.60, 29.5, 29.4, 29.3, 29.2, 24.8, 22.7 (C-9-C-27), 14.1 (C-28), 1.04, 1.00, 0.89, 0.85, 0.14, 0.10 (TMS) HRMS (ESI) $m / z$ calcd. for $\left[\mathrm{C}_{52} \mathrm{H}_{112} \mathrm{O}_{12} \mathrm{Si}_{6}+\mathrm{Na}\right]^{+}: 1119.6662$, obsd.: 1119.6667 . 


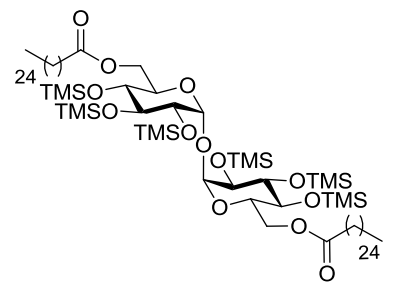

2,2',3,3',4,4'-Hexa-O-trimethylsilyl-6,6'-di- $O$ hexacosanoyl- $\alpha, \alpha^{\prime}$-D-trehalose $(7 \mathrm{~g})$. By subjecting diol 6 (17 mg, $0.022 \mathrm{mmol})$, hexacosanoic acid (37.9 mg, 0.096 mmol), EDCI (27.7 mg, $0.14 \mathrm{mmol})$ and DMAP (0.39 $\mathrm{mg}, \quad 0.003 \mathrm{mmol}$ ) to the general procedure for esterification (6 days), the title compound $\mathbf{7 g}$ was obtained (eluting in 50:1 (v/v) Pet. Ether/ EtOAc) as a white solid (20 mg, $0.013 \mathrm{mmol}, 60 \%) . \mathrm{R}_{f}=0.83$ (PE/EA, 5/1, $\mathrm{v} / \mathrm{v}) ;[\alpha]^{18}=+43.2\left(c=1.0, \mathrm{CHCl}_{3}\right)$; IR (film): 3016, 2970, 2919, 2851, 1739, 966, 899, $760 \mathrm{~cm}^{-1}$; ${ }^{1} \mathrm{H}$ NMR $\left(500 \mathrm{MHz}, \mathrm{CDCl}_{3}\right) \delta 4.92\left(\mathrm{~d}, J_{1,2}=2.9 \mathrm{~Hz}, 2 \mathrm{H}, \mathrm{H}-1\right), 4.28$ $\left(\mathrm{dd}, J_{6 \mathrm{a}, 6 \mathrm{~b}}=11.7 \mathrm{~Hz}, J_{5,6 \mathrm{a}}=2.2 \mathrm{~Hz}, 2 \mathrm{H}, \mathrm{H}-6 \mathrm{a}\right), 4.06\left(\mathrm{dd}, J_{6 \mathrm{a}, 6 \mathrm{~b}}=11.7 \mathrm{~Hz}, J_{5,6 \mathrm{~b}}=4.7\right.$ Hz, 2H, H-6b), 4.02-3.98 (m, 2H, H-5), 3.91 (t, $J_{2,3}=J_{3,4}=9.0 \mathrm{~Hz}, 2 \mathrm{H}, \mathrm{H}-3$ ), 3.48 (t, $\left.J_{3,4}=J_{4,5}=9.0 \mathrm{~Hz}, 2 \mathrm{H}, \mathrm{H}-4\right), 3.45\left(\mathrm{dd}, J_{2,3}=9.0 \mathrm{~Hz}, J_{1,2}=2.9 \mathrm{~Hz}, 2 \mathrm{H}, \mathrm{H}-2\right), 2.36(\mathrm{dt}$, $\left.J_{8 \mathrm{a}, 8 \mathrm{~b}}=13.6 \mathrm{~Hz}, J_{8 \mathrm{a}, 9}=7.3 \mathrm{~Hz}, 2 \mathrm{H}, \mathrm{H}-8 \mathrm{a}\right), 2.34\left(\mathrm{dt}, J_{8 \mathrm{a}, 8 \mathrm{~b}}=13.6 \mathrm{~Hz}, J_{8 \mathrm{~b}, 9}=7.0 \mathrm{~Hz}, 2 \mathrm{H}\right.$, H-8b), 1.64-1.60 (m, 4H, H-9), 1.34-1.18 (m, 88H, H-10-H-31), 0.89 (t, $J_{31,32}=6.7$ $\mathrm{Hz}, \mathrm{H}-32), 0.16,0.14,0.137$ (3 s, 54H, $\left.\mathrm{CH}_{3}, \mathrm{TMS}\right) ;{ }^{13} \mathrm{C} \mathrm{NMR}\left(125 \mathrm{MHz}, \mathrm{CDCl}_{3}\right.$ ) 8174.0 (C-7), 94.4 (C-1), 73.5 (C-3), 72.6 (C-2), 71.9 (C-4), 70.7 (C-5), 63.3 (C-6), 34.2 (C-8), 31.9, 29.71, 29.67, 29.6, 29.5, 29.4, 29.31, 29.28 29.2, 24.8, 22.7 (C-9-C31), 14.1 (C-32), $1.1, \quad 0.9, \quad 0.2 \quad$ (TMS); HRMS (ESI) $\mathrm{m} / \mathrm{z}$ calcd. for $\left[\mathrm{C}_{82} \mathrm{H}_{170} \mathrm{O}_{13} \mathrm{Si}_{6}+\mathrm{Na}\right]^{+}:$1554.1155, obsd.: 1554.1166 .

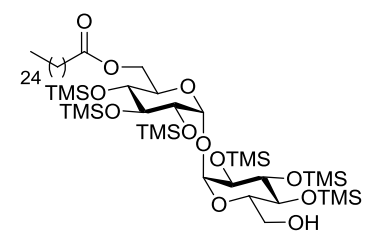

2,2',3,3',4,4'-Hexa-O-trimethylsilyl-6-hexacosanoyl-6'hydroxy- $\boldsymbol{\alpha}, \boldsymbol{\alpha}^{\prime}$-D-trehalose (8g). The title compound was obtained after (eluting in Hex: EtOAc 20:1) a colourless oil (5 mg, $0.005 \mathrm{mmol}, 20 \%) . \mathrm{R}_{f}=0.61(\mathrm{PE} / \mathrm{EA}, 5 / 1, \mathrm{v} / \mathrm{v})$; $[\alpha]_{\mathrm{D}}{ }^{18}=23.2\left(c=1.0 \mathrm{CHCl}_{3}\right)$; IR (film): 3400, 2920, 2851, 1739, 1457, 1166, 1077, $1008,843,760 \mathrm{~cm}^{-1} ;{ }^{1} \mathrm{H}$ NMR $\left(500 \mathrm{MHz}, \mathrm{CDCl}_{3}\right) \delta 4.93\left(\mathrm{~d}, J_{1 / 1^{\prime}, 2 / 2^{\prime}}=3.5 \mathrm{~Hz}, 1 \mathrm{H}, \mathrm{H}-\right.$ $\left.1 / 1^{\prime}\right), 4.92\left(\mathrm{~d}, J_{1 / 1^{\prime}, 2 / 2^{\prime}}=3.5 \mathrm{~Hz}, 1 \mathrm{H}, \mathrm{H}-1 / 1^{\prime}\right), 4.30\left(\mathrm{dd}, J_{6 \mathrm{a}, 6 \mathrm{~b}}=11.7 \mathrm{~Hz}, J_{5,6 \mathrm{a}}=2.2 \mathrm{~Hz}\right.$, $1 \mathrm{H}, \mathrm{H}-6 \mathrm{a}), 4.07$ (dd, $J_{6 \mathrm{a}, 6 \mathrm{~b}}=11.7 \mathrm{~Hz}, J_{5,6 \mathrm{~b}}=4.7 \mathrm{~Hz}, 1 \mathrm{H}, \mathrm{H}-6 \mathrm{~b}$ ), 4.03-3.99 (m, 1H, H5), $3.91\left(\mathrm{t}, J_{2 / 2^{\prime}, 3 / 3^{\prime}}=J_{3 / 3^{\prime}, 4 / 4^{\prime}}=9.0 \mathrm{~Hz}, 1 \mathrm{H}, \mathrm{H}-3 / 3^{\prime}\right), 3.90\left(\mathrm{t}, J_{2 / 2^{\prime}, 3 / 3^{\prime}}=J_{3 / 3^{\prime}, 4 / 4^{\prime}}=9.0 \mathrm{~Hz}\right.$, 
$\left.1 \mathrm{H}, \mathrm{H}-3 / 3^{\prime}\right), 3.85\left(\mathrm{dt}, J_{4^{\prime}, 5^{\prime}}=9.6 \mathrm{~Hz}, J_{5^{\prime}, 6 \mathrm{a}^{\prime}}=J_{5^{\prime}, 6 \mathrm{~b}^{\prime}}=3.4 \mathrm{~Hz}, 1 \mathrm{H}, \mathrm{H}-5^{\prime}\right), 3.71\left(\mathrm{dd}, J_{6 \mathrm{a}^{\prime}, 6 \mathrm{~b}^{\prime}}=\right.$ $\left.11.7 \mathrm{~Hz}, J_{5^{\prime}, 6 \mathrm{a}^{\prime}}=3.0 \mathrm{~Hz}, 1 \mathrm{H}, \mathrm{H}-6 \mathrm{a}^{\prime}\right), 3.69\left(\mathrm{dd}, J_{6 \mathrm{a}^{\prime}, 6 \mathrm{~b}^{\prime}}=11.7 \mathrm{~Hz} J_{5^{\prime}, 6 \mathrm{~b}^{\prime}}=3.9 \mathrm{~Hz}, 1 \mathrm{H}, \mathrm{H}-\right.$ $\left.6 b^{\prime}\right), 3.49\left(\mathrm{t}, J_{3,4}=J_{4,5}=9.0 \mathrm{~Hz}, 1 \mathrm{H}, \mathrm{H}-4\right), 3.48\left(\mathrm{t}, J_{3^{\prime}, 4^{\prime}}=J_{4^{\prime}, 5^{\prime}}=9.0 \mathrm{~Hz}, 1 \mathrm{H}, \mathrm{H}-4^{\prime}\right), 3.44$ $\left(\mathrm{dd}, J_{2,3 / 2^{\prime}, 3^{\prime}}=9.0 \mathrm{~Hz}, J_{1,2 / 1^{\prime}, 2^{\prime}}=3.5 \mathrm{~Hz}, 1 \mathrm{H}, \mathrm{H}-2 / 2^{\prime}\right), 3.43\left(\mathrm{dd}, J_{2,3 / 2^{\prime}, 3^{\prime}}=9.0 \mathrm{~Hz}, J_{1,2 / 1^{\prime}, 2^{\prime}}=\right.$ $\left.3.5 \mathrm{~Hz}, 1 \mathrm{H}, \mathrm{H}-2 / 2^{\prime}\right), 2.36\left(\mathrm{dt}, J_{8 \mathrm{a}, 8 \mathrm{~b}}=12.5 \mathrm{~Hz}, J_{8 \mathrm{a}, 9}=7.1 \mathrm{~Hz}, 1 \mathrm{H}, \mathrm{H}-8 \mathrm{a}\right), 2.34\left(\mathrm{dt}, J_{8 \mathrm{a}, 8 \mathrm{~b}}\right.$ $=12.5, J_{8 \mathrm{~b}, 9}=7.0 \mathrm{~Hz}, 1 \mathrm{H}, \mathrm{H}-8 \mathrm{~b}$ ), 1.63 (pentet, $J_{\alpha, \beta}=J_{\beta, \gamma}=6.8 \mathrm{~Hz}, 2 \mathrm{H}, \mathrm{H}-9$ ), 1.38 1.20 (m, 44H, H-10-H-31), 0.89 (t, $J_{31,32}=6.8$ Hz, 3H, H-32), 0.17, 0.16, 0.15, 0.14, 0.13 (5 s, 54H, $\left.\mathrm{CH}_{3}, \mathrm{TMS}\right) ;{ }^{13} \mathrm{C} \mathrm{NMR}\left(125 \mathrm{MHz}, \mathrm{CDCl}_{3}\right) \delta 173.8$ (C-7), 94.5 (C1/1'), 94.4 (C-1/1'), 73.5 (C-3/3'), 73.3 (C-3/3'), 72.9 (C-2/2'), 72.8 (C-5'), 72.6 (C2/2'), 71.9 (C-4), 71.4 (C-4'), 70.8 (C-5), 63.3 (C-6), 61.7 (C-6'), 34.2 (C-8), 31.9, 31.4, 30.3, 30.2 29.70, 29.68, 29.67, 29.60, 29.5, 29.4, 29.3, 29.2 , 24.8, 22.7 (C-9-C31), 14.1 (C-32), 1.05, 1.00, 0.89, 0.85, 0.14, 0.10 (C-TMS); HRMS(ESI) $\mathrm{m} / z$ calcd. for $\left[\mathrm{C}_{56} \mathrm{H}_{120} \mathrm{O}_{12} \mathrm{Si}_{6}+\mathrm{Na}\right]^{+}:$1175.7288, obsd.: 1175.7285 .

General Procedure for Desilylation. To a solution of the trehalose diester $\mathbf{7 e - 7} \mathbf{g}$ or trehalose monoester $\mathbf{8 f - 8 g}(1 \mathrm{mmol})$ in $5 \mathrm{~mL} \mathrm{CH}_{2} \mathrm{Cl}_{2}: \mathrm{MeOH}$ mixture $(3 / 1, \mathrm{v} / \mathrm{v})$ Dowex $-\mathrm{H}^{+}(10 \%$ by weight $)$ was added and the reaction stirred at room temperature. After $30 \mathrm{~min}$, the reaction mixture was filtered and concentrated in vacuo, and the resulting residue subjected to column chromatography (straight phase or reverse phase) using the eluent given in order to obtain the fully deprotected compounds.

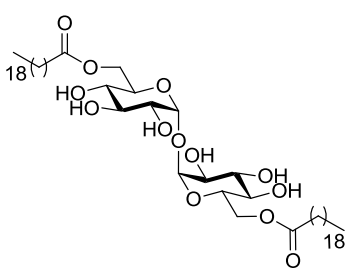

6,6'-Di-O-eicosanoyl- $\alpha, \alpha^{\prime}$-D-trehalose (1e). Ву subjecting trehalose diester $7 \mathrm{e}(13 \mathrm{mg}, 0.010 \mathrm{mmol})$ to the general procedure for desilylation, the title compound 1e was obtained after silica gel flash chromatography eluting in 98:2 (v/v) EtOAc/MeOH as a white solid (7.5 $\mathrm{mg}, 0.008 \mathrm{mmol}, 80 \%) . \mathrm{R}_{f}=0.47(\mathrm{EA} / \mathrm{MeOH}, 95 / 5, \mathrm{v} / \mathrm{v}) ;[\alpha]_{\mathrm{D}}^{18}=+29.8(c=0.1$, $\mathrm{C}_{5} \mathrm{H}_{5} \mathrm{~N}$ ); IR (film); 3567, 3459, 2967, 2926, 1737, 1016, 846, $750 \mathrm{~cm}^{-1} ;{ }^{1} \mathrm{H}$ NMR $\left(500 \mathrm{MHz}, \mathrm{C}_{5} \mathrm{H}_{5} \mathrm{~N}\right) \delta 5.79\left(\mathrm{~d}, J_{1,2}=3.6 \mathrm{~Hz}, 2 \mathrm{H}, \mathrm{H}-1\right), 5.00-4.97$ (m, 2H, H-5), 4.90 $(\mathrm{m}, 2 \mathrm{H}, \mathrm{H}-6 \mathrm{a}), 4.72\left(\mathrm{dd}, J_{6 \mathrm{a}, 6 \mathrm{~b}}=11.7 \mathrm{~Hz}, J_{5,6 \mathrm{~b}}=5.4 \mathrm{~Hz}, 2 \mathrm{H}, \mathrm{H}-6 \mathrm{~b}\right), 4.64\left(\mathrm{t}, J_{2,3}=J_{3,4}\right.$ $=9.0 \mathrm{~Hz}, 2 \mathrm{H}, \mathrm{H}-3), 4.20\left(\mathrm{bd}, J_{2,3}=9.0 \mathrm{~Hz}, 2 \mathrm{H}, \mathrm{H}-2\right), 4.07\left(\mathrm{t}, J_{3,4}=J_{4,5}=9.0 \mathrm{~Hz}, 2 \mathrm{H}\right.$, 
$\mathrm{H}-4), 2.22\left(\mathrm{dt}, J_{8 \mathrm{a}, 8 \mathrm{~b}}=12.2 \mathrm{~Hz}, J_{8 \mathrm{a}, 9}=7.9 \mathrm{~Hz}, 2 \mathrm{H}, \mathrm{H}-8 \mathrm{a}\right), 2.20\left(\mathrm{dt}, J_{8 \mathrm{a}, 8 \mathrm{~b}}=12.2 \mathrm{~Hz}\right.$, $J_{8 \mathrm{~b}, 9}=7.3 \mathrm{~Hz}, 2 \mathrm{H}, \mathrm{H}-8 \mathrm{~b}$ ), 1.51 (pentet, $J_{\alpha, \beta}=J_{\beta, \gamma}=7.3 \mathrm{~Hz}, 4 \mathrm{H}, \mathrm{H}-9$ ), 1.19-1.09 (m, $64 \mathrm{H}, \mathrm{H}-10-\mathrm{H}-25), 0.75$ (t, $\left.J_{25,26}=6.8 \mathrm{~Hz}, 6 \mathrm{H}, \mathrm{H}-26\right) ;{ }^{13} \mathrm{C} \mathrm{NMR}\left(125 \mathrm{MHz}, \mathrm{C}_{5} \mathrm{H}_{5} \mathrm{~N}\right)$ 8173.7 (C-7), 95.9 (C-1), 75.0 (C-3), 73.5 (C-2), 72.2 (C-4), 71.7 (C-5), 64.5 (C-6), 34.5 (C-8), 32.2, 30.09, 30.05, 30.0, 29.9, 29.7, 29.5, 25.4, 23.0 (C-9-C-25), 14.3 (C26); HRMS(ESI) $m / z$ calcd. for $\left[\mathrm{C}_{52} \mathrm{H}_{98} \mathrm{O}_{13}+\mathrm{Na}\right]^{+}: 953.6905$, obsd.:953.6904.

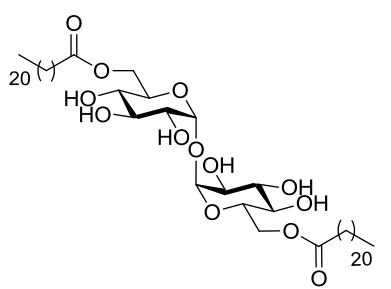

6,6'-Di- $O$-docosanoyl- $\alpha, \alpha^{\prime}$-D-trehalose (1f). By subjecting trehalose diester $7 \mathbf{f}(42 \mathrm{mg}, 0.030 \mathrm{mmol})$ to the general procedure for desilylation, the title compound 1f was obtained after silica gel flash chromatography eluting in 98:2 (v/v) EtOAc/MeOH as a white solid (23.3 mg, $0.024 \mathrm{mmol}, 80 \%) \mathrm{R}_{f}=0.52(\mathrm{EA} / \mathrm{MeOH}, 95 / 5, \mathrm{v} / \mathrm{v}) ;[\alpha]^{25}=$ $+1.3\left(c=0.1 \mathrm{C}_{5} \mathrm{H}_{5} \mathrm{~N}\right)$; IR (film): 3324, 2944, 2832, 1737, 1449, 1216, 1114, 1022 , $737 \mathrm{~cm}^{-1} ;{ }^{1} \mathrm{H}$ NMR $\left(500 \mathrm{MHz}, \mathrm{C}_{5} \mathrm{H}_{5} \mathrm{~N}\right) \delta 5.78\left(\mathrm{~d}, J_{1,2}=3.4 \mathrm{~Hz}, 2 \mathrm{H}, \mathrm{H}-1\right), 5.00-4.97$ (m, 2H, H-5), 4.89 (m, 2H, H-6a), $4.73\left(\mathrm{dd}, J_{6 \mathrm{a}, 6 \mathrm{~b}}=11.7 \mathrm{~Hz}, J_{5,6 \mathrm{~b}}=5.3 \mathrm{~Hz}, 2 \mathrm{H}, \mathrm{H}-\right.$ $6 \mathrm{~b}), 4.64\left(\mathrm{t}, J_{2,3}=J_{3,4}=9.6 \mathrm{~Hz}, 2 \mathrm{H}, \mathrm{H}-3\right), 4.20\left(\mathrm{bd}, J_{2,3}=9.6 \mathrm{~Hz}, 2 \mathrm{H}, \mathrm{H}-2\right), 4.07$ (t, $\left.J_{3,4}=J_{4,5}=9.6 \mathrm{~Hz}, 2 \mathrm{H}, \mathrm{H}-4\right), 2.22\left(\mathrm{dt}, J_{8 \mathrm{a}, 8 \mathrm{~b}}=11.7 \mathrm{~Hz}, J_{8 \mathrm{a}, 9}=7.5 \mathrm{~Hz}, 2 \mathrm{H}, \mathrm{H}-8 \mathrm{a}\right), 2.18$ $\left(\mathrm{dt}, J_{8 \mathrm{a}, 8 \mathrm{~b}}=11.7 \mathrm{~Hz}, J_{8 \mathrm{~b}, 9}=7.2 \mathrm{~Hz}, 2 \mathrm{H}, \mathrm{H}-8 \mathrm{~b}\right.$ ), 1.51 (pentet, $J_{\alpha, \beta}=J_{\beta, \gamma}=7.1 \mathrm{~Hz}, 4 \mathrm{H}$, H-9), 1.20-1.14 (m, 72H, H-10-H-27), 0.76 (t, $\left.J_{27,28}=6.8 \mathrm{~Hz}, 6 \mathrm{H}, \mathrm{H}-28\right) ;{ }^{13} \mathrm{C} \mathrm{NMR}$ (125 MHz, $\left.\mathrm{C}_{5} \mathrm{H}_{5} \mathrm{~N}\right) \delta 173.8$ (C-7), 95.9 (C-1), 75.0 (C-3), 73.5 (C-2), 72.1 (C-4), 71.7 (C-5), 64.5 (C-6), 34.5 (C-8), 32.3, 30.14, 30.09, 30.0, 29.9, 29.72, 29.69, 29.5, 25.4, 23.0 (C-9-C-27), 14.4 (C-28); $\operatorname{HRMS}(\mathrm{ESI}) \mathrm{m} / \mathrm{z}$ calcd. for $\left[\mathrm{C}_{56} \mathrm{H}_{106} \mathrm{O}_{13}+\mathrm{Na}\right]^{+}$: 1009.7531, obsd.: 1009.7532.

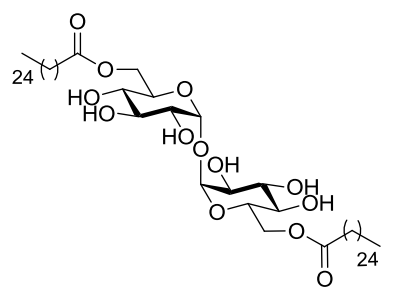

6,6'-Di- $O$-hexacosanoyl- $\alpha, \alpha^{\prime}$-D-trehalose (1g). Вy subjecting trehalose diester $7 \mathrm{~g}$ ( $3 \mathrm{mg}, 0.002 \mathrm{mmol})$ to the general procedure for desilylation, the title compound 1g was obtained after reverse phase chromatography eluting in pyridine as a white solid $(1.53 \mathrm{mg}, 0.0014 \mathrm{mmol}, 70 \%) . \mathrm{R}_{f}=0.52(\mathrm{EA} / \mathrm{MeOH}, 95 / 5, \mathrm{v} / \mathrm{v}) ;[\alpha]^{25}{ }_{\mathrm{D}}=+0.7(c=$ 
$0.1, \mathrm{C}_{5} \mathrm{H}_{5} \mathrm{~N}$ ); IR (film) $\mathrm{cm}^{-1} 3361,2923,2851,2215,1733,1181,1107,1022 ;{ }^{1} \mathrm{H}$ NMR (500 MHz, $\left.\mathrm{C}_{5} \mathrm{H}_{5} \mathrm{~N}\right) \delta 5.78\left(\mathrm{~d}, J_{1,2}=3.7 \mathrm{~Hz}, 2 \mathrm{H}, \mathrm{H}-1\right), 4.98-4.96$ (m, 2H, H-5), 4.87 (m, 2H, H-6a), $4.72\left(\mathrm{dd}, J_{6 \mathrm{a}, 6 \mathrm{~b}}=11.7 \mathrm{~Hz}, J_{5,6 \mathrm{a}}=5.4 \mathrm{~Hz}, 2 \mathrm{H}, \mathrm{H}-6 \mathrm{~b}\right), 4.64$ (t, $J_{2,3}=$ $\left.J_{3,4}=9.0 \mathrm{~Hz}, 2 \mathrm{H}, \mathrm{H}-3\right), 4.21\left(\mathrm{dd}, J_{2,3}=9.0 \mathrm{~Hz}, J_{1,2}=3.7 \mathrm{~Hz}, 2 \mathrm{H}, \mathrm{H}-2\right), 4.01\left(\mathrm{t}, J_{3,4}=\right.$ $\left.J_{4,5}=9.0 \mathrm{~Hz}, 2 \mathrm{H}, \mathrm{H}-4\right), 2.23\left(\mathrm{dt}, J_{8 \mathrm{a}, 8 \mathrm{~b}}=12.2 \mathrm{~Hz}, J_{8 \mathrm{a}, 9}=7.5 \mathrm{~Hz}, 2 \mathrm{H}, \mathrm{H}-8 \mathrm{a}\right), 2.17(\mathrm{dt}$, $J_{8 \mathrm{a}, 8 \mathrm{~b}}=12.2 \mathrm{~Hz}, J_{8 \mathrm{a}, 9}=7.5 \mathrm{~Hz}, 2 \mathrm{H}, \mathrm{H}-8 \mathrm{~b}$ ), 1.50 (pentet, $J_{\alpha, \beta}=J_{\beta, \gamma}=7.4 \mathrm{~Hz}, 4 \mathrm{H}, \mathrm{H}-9$ ), 1.26-1.04 (m, 88H, H-10-H-31), 0.73 (t, $\left.J_{31,32}=6.8 \mathrm{~Hz}, 6 \mathrm{H}, \mathrm{H}-32\right) ;{ }^{13} \mathrm{C}$ NMR $(125$ $\left.\mathrm{MHz}, \mathrm{C}_{5} \mathrm{H}_{5} \mathrm{~N}\right) \delta 173.8(\mathrm{C}-7), 95.9$ (C-1), 75.0 (C-3), 73.5 (C-2), 72.1 (C-4), 71.7 (C5), 64.5 (C-6), 34.5 (C-8), 32.2, 30.17, 30.16, 30.12, 30.07, 30.04, 29.9, 29.74, 29.72, 29.5, 25.4, 23.0 (C-9-C-31), 14.4 (C-32); HRMS(ESI) $m / z$ calcd. for $\left[\mathrm{C}_{64} \mathrm{H}_{122} \mathrm{O}_{12}\right.$ $+\mathrm{Na}]^{+}: 1121.8783$, obsd.:1121.8764.

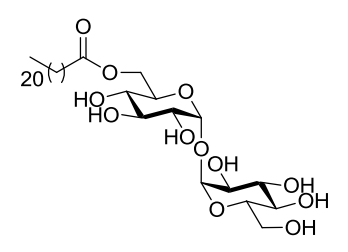

6-O-Docosanoyl- $\boldsymbol{\alpha}, \boldsymbol{\alpha}^{\prime}-\mathrm{D}-$-trehalose (9f). By subjecting trehalose monoester $8 \mathbf{8}(5.6 \mathrm{mg}, 0.005 \mathrm{mmol})$ to the procedure described above, the title compound $9 f$ was obtained after flash chromatography (eluting in $2 \% \mathrm{MeOH}$ ) as a white solid (3.2 mg, $0.0048 \mathrm{mmol}, 96 \%) . \mathrm{R}_{f}=0.37(5 \%$ $\mathrm{MeOH}$ in EtOAc); $[\alpha]_{\mathrm{D}}^{23}=0.6\left(c=0.1, \mathrm{C}_{5} \mathrm{H}_{5} \mathrm{~N}\right)$; IR (film) IR (film); 3350, 2917, 2926, 1642, 1443, 1021, $942 \mathrm{~cm}^{-1} ;{ }^{1} \mathrm{H}$ NMR $\left(500 \mathrm{MHz}, \mathrm{C}_{5} \mathrm{H}_{5} \mathrm{~N}\right) \delta 5.84\left(\mathrm{~d}, J_{1 / 1^{\prime}, 2 / 2^{\prime}}=\right.$ $\left.3.7 \mathrm{~Hz}, 1 \mathrm{H}, \mathrm{H}-1 / 1^{\prime}\right), 5.83\left(\mathrm{~d}, J_{1 / 1^{\prime}, 2 / 2^{\prime}}=3.7 \mathrm{~Hz}, 1 \mathrm{H}, \mathrm{H}-1 / 1^{\prime}\right), 5.04-5.00$ (m, 1H, H-5), $4.91\left(\mathrm{dd}, J_{6 \mathrm{a}, 6 \mathrm{~b}}=11.7 \mathrm{~Hz}, J_{5,6 \mathrm{a}}=1.7 \mathrm{~Hz}, 1 \mathrm{H}, \mathrm{H}-6 \mathrm{a}\right), 4.87-4.84(\mathrm{~m}, 1 \mathrm{H}, \mathrm{H}-5$ '), 4.73 $\left(\mathrm{dd}, J_{6 \mathrm{a}, 6 \mathrm{~b}}=11.7 \mathrm{~Hz}, J_{5,6 \mathrm{~b}}=5.1 \mathrm{~Hz}, 1 \mathrm{H}, \mathrm{H}-6 \mathrm{~b}\right), 4.71\left(\mathrm{t}, J_{2 / 2^{\prime}, 3 / 3^{\prime}}=J_{3 / 3^{\prime}, 4 / 4^{\prime}}=9.5 \mathrm{~Hz}, 1 \mathrm{H}\right.$, H-3/3'), $4.69\left(\mathrm{t}, J_{2 / 2^{\prime}, 3 / 3^{\prime}}=J_{3 / 3^{\prime}, 4 / 4^{\prime}}=9.0 \mathrm{~Hz}, 1 \mathrm{H}, \mathrm{H}-3 / 3^{\prime}\right), 4.39\left(\mathrm{dd}, J_{6 \mathrm{a}^{\prime}, 6 \mathrm{~b}^{\prime}}=12.0 \mathrm{~Hz}, J_{5^{\prime}, 6 \mathrm{a}^{\prime}}\right.$ $\left.=2.7 \mathrm{~Hz}, 1 \mathrm{H}, \mathrm{H}-6 \mathrm{a}^{\prime}\right), 4.31\left(\mathrm{dd}, J_{6 \mathrm{a}^{\prime}, 6 \mathrm{~b}^{\prime}}=12.0 \mathrm{~Hz}, J_{5^{\prime}, 6 \mathrm{a}^{\prime}}=4.9 \mathrm{~Hz}, 1 \mathrm{H}, \mathrm{H}-6 \mathrm{~b}^{\prime}\right), 4.20(\mathrm{dd}$, $\left.J_{2,3 / 2^{\prime}, 3^{\prime}}=9.5 \mathrm{~Hz}, J_{1,2 / 1^{\prime}, 2^{\prime}}=3.7 \mathrm{~Hz}, 1 \mathrm{H}, \mathrm{H}-2 / 2^{\prime}\right), 4.19\left(\mathrm{dd}, J_{3^{\prime}, 4^{\prime}}=J_{4^{\prime}, 5^{\prime}}=9.5 \mathrm{~Hz}, 1 \mathrm{H}, \mathrm{H}-\right.$ $\left.4^{\prime}\right) 4.18\left(\mathrm{dd}, J_{2,3 / 2^{\prime}, 3^{\prime}}=9.5 \mathrm{~Hz}, J_{1,2 / 1^{\prime}, 2^{\prime}}=3.2 \mathrm{~Hz}, 1 \mathrm{H}, \mathrm{H}-2 / 2^{\prime}\right), 4.08\left(\mathrm{t}, J_{3^{\prime}, 4^{\prime}}=J_{4^{\prime}, 5^{\prime}}=9.5\right.$ $\mathrm{Hz}, 1 \mathrm{H}, \mathrm{H}-4), 2.24$ (dt, $\left.J_{8 \mathrm{a}, 8 \mathrm{~b}}=11.4 \mathrm{~Hz}, J_{8 \mathrm{a}, 9}=7.5 \mathrm{~Hz}, 1 \mathrm{H}, \mathrm{H}-8 \mathrm{a}\right), 2.23$ (dt, $J_{8 \mathrm{a}, 8 \mathrm{~b}}=$ $11.4 \mathrm{~Hz}, J_{8 \mathrm{~b}, 9}=7.4 \mathrm{~Hz}, 1 \mathrm{H}, \mathrm{H}-8 \mathrm{~b}$ ), 1.52 (pentet, $J_{\alpha, \beta}=J_{\beta \gamma}=7.6 \mathrm{~Hz}, 2 \mathrm{H}, \mathrm{H}-9$ ), 1.20 1.08 (m, 36H, H-10-H-27), 0.73 (t, $\left.J_{27,28}=7.1 \mathrm{~Hz}, 3 \mathrm{H}, \mathrm{H}-28\right) ;{ }^{13} \mathrm{C}$ NMR $(125 \mathrm{MHz}$, $\left.\mathrm{C}_{5} \mathrm{H}_{5} \mathrm{~N}\right) \delta 173.9(\mathrm{C}-7), 95.9$ (C-1/1'), 95.7 (C-1/1'), 75.1 (C-3/3'), 74.9 (C-3/3'), 74.6 (C-5'), 73.6 (C-2/2'), 73.5 (C-2/2'), $72.4\left(\mathrm{C}-4^{\prime}\right), 72.1$ (C-4), 71.5 (C-5), 64.5 (C-6), 
62.8 (C-6'), 34.4 (C-8), 32.3, 30.7, 28.62, 28.57, 28.52, 28.36, 28.20, 28.19, 27.98, 23.88, (C-9-C-27), 14.4 (C-28); HRMS(ESI) $\mathrm{m} / \mathrm{z}$ calcd. for $\left[\mathrm{C}_{34} \mathrm{H}_{64} \mathrm{O}_{12}+\mathrm{Na}\right]^{+}$: 687.4290, obsd.: 687.4287 .

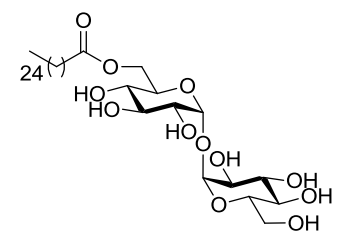

6-O-Hexacosanoyl- $\boldsymbol{\alpha}, \boldsymbol{\alpha}^{\prime}-\mathrm{D}-$ trehalose $(\mathbf{9 g})$. By subjecting trehalose monoester $\mathbf{8 g}$ ( $5 \mathrm{mg}, 0.004 \mathrm{mmol})$ to the procedure described above, the title compound $\mathbf{9 g}$ was obtained after reverse phase chromatography (eluting in $\mathrm{MeOH}$ ) as a white solid (3 mg, $0.004 \mathrm{mmol}, 97 \%) \mathrm{R}_{f}=0.38(5 \% \mathrm{MeOH}$ in EtOAc); $[\alpha]_{\mathrm{D}}{ }^{25}=2.0\left(c=0.1, \mathrm{CHCl}_{3}\right)$; IR (film) 3322, 2917, 2932, 1659, 1449, 1022, $736 \mathrm{~cm}^{-1} ;{ }^{1} \mathrm{H}$ NMR $\left(500 \mathrm{MHz}, \mathrm{C}_{5} \mathrm{H}_{5} \mathrm{~N}\right) \delta 5.84\left(\mathrm{~d}, J_{1 / 1^{\prime}, 2 / 2^{\prime}}=3.9 \mathrm{~Hz}, 1 \mathrm{H}, \mathrm{H}-1 / 1^{\prime}\right), 5.82$ $\left(\mathrm{d}, J_{1 / 1^{\prime}, 2 / 2^{\prime}}=3.9 \mathrm{~Hz}, 1 \mathrm{H}, \mathrm{H}-1 / 1^{\prime}\right), 5.01-5.91(\mathrm{~m}, 1 \mathrm{H}, \mathrm{H}-5), 4.89\left(\mathrm{dd}, J_{6 \mathrm{a}, 6 \mathrm{~b}}=11.5 \mathrm{~Hz}\right.$, $\left.J_{5,6 \mathrm{a}}=1.9 \mathrm{~Hz}, 1 \mathrm{H}, \mathrm{H}-6 \mathrm{a}\right), 4.89-4.86\left(\mathrm{~m}, 1 \mathrm{H}, \mathrm{H}-5{ }^{\prime}\right), 4.73\left(\mathrm{dd}, J_{6 \mathrm{a}, 6 \mathrm{~b}}=11.5 \mathrm{~Hz}, J_{5,6 \mathrm{~b}}=\right.$ $5.2 \mathrm{~Hz}, 1 \mathrm{H}, \mathrm{H}-6 \mathrm{~b}), 4.70\left(\mathrm{t}, J_{2 / 2^{\prime}, 3 / 3^{\prime}}=J_{3 / 3^{\prime}, 4 / 4^{\prime}}=8.9 \mathrm{~Hz}, 1 \mathrm{H}, \mathrm{H}-3 / 3^{\prime}\right), 4.68\left(\mathrm{t}, J_{2 / 2^{\prime}, 3 / 3^{\prime}}=\right.$ $\left.J_{3 / 3^{\prime}, 4 / 4^{\prime}}=8.9 \mathrm{~Hz}, 1 \mathrm{H}, \mathrm{H}-3 / 3^{\prime}\right), 4.37\left(\mathrm{dd}, J_{6 \mathrm{a}^{\prime}, 6 \mathrm{~b}^{\prime}}=11.7 \mathrm{~Hz}, J_{5^{\prime}, 6 \mathrm{a}^{\prime}}=2.5 \mathrm{~Hz}, 1 \mathrm{H}, \mathrm{H}-6 \mathrm{a}^{\prime}\right)$, $4.31\left(\mathrm{dd}, J_{6 \mathrm{a}^{\prime}, 6 \mathrm{~b}^{\prime}}=11.7 \mathrm{~Hz}, J_{5^{\prime}, 6 \mathrm{a}^{\prime}}=4.9 \mathrm{~Hz}, 1 \mathrm{H}, \mathrm{H}-6 \mathrm{~b}^{\prime}\right), 4.22\left(\mathrm{dd}, J_{2,3 / 2^{\prime}, 3^{\prime}}=9.4 \mathrm{~Hz}\right.$, $\left.J_{1,2 / 1^{\prime}, 2^{\prime}}=3.9 \mathrm{~Hz}, 1 \mathrm{H}, \mathrm{H}-2 / 2^{\prime}\right), 4.19\left(\mathrm{dd}, J_{3^{\prime}, 4^{\prime}}=J_{4^{\prime}, 5^{\prime}}=9.4 \mathrm{~Hz}, 1 \mathrm{H}, \mathrm{H}-4^{\prime}\right), 4.18(\mathrm{dd}$, $\left.J_{2,3 / 2^{\prime}, 3^{\prime}}=9.4 \mathrm{~Hz}, J_{1,2 / 1^{\prime}, 2^{\prime}}=3.9 \mathrm{~Hz}, 1 \mathrm{H}, \mathrm{H}-2 / 2^{\prime}\right), 4.08\left(\mathrm{t}, J_{3^{\prime}, 4^{\prime}}=J_{4^{\prime}, 5^{\prime}}=9.4 \mathrm{~Hz}, 1 \mathrm{H}, \mathrm{H}-4\right)$, $2.22\left(\mathrm{dt}, J_{8 \mathrm{a}, 8 \mathrm{~b}}=11.5 \mathrm{~Hz}, J_{8 \mathrm{a}, 9}=7.4 \mathrm{~Hz}, 1 \mathrm{H}, \mathrm{H}-8 \mathrm{a}\right), 2.21\left(\mathrm{dd}, J_{8 \mathrm{a}, 8 \mathrm{~b}}=11.5 \mathrm{~Hz}, J_{8 \mathrm{~b}, 9}=\right.$ $7.4 \mathrm{~Hz}, 1 \mathrm{H}, \mathrm{H}-8 \mathrm{~b}$ ), 1.51 (pentet, $J_{\alpha, \beta}=J_{\beta \gamma}=7.3 \mathrm{~Hz}, 2 \mathrm{H}, \mathrm{H}-9$ ), $1.27-1.06$ (m, 36H, H$10-\mathrm{H}-31), 0.74\left(\mathrm{t}, J_{31,32}=7.1 \mathrm{~Hz}, 3 \mathrm{H}, \mathrm{H}-32\right) ;{ }^{13} \mathrm{C} \mathrm{NMR}\left(125 \mathrm{MHz}, \mathrm{C}_{5} \mathrm{H}_{5} \mathrm{~N}\right) \delta 173.8$ (C-7), 95.8 (C-1/1'), 95.7 (C-1/1'), 75.1 (C-3/3'), 74.9 (C-3/3'), 74.6 (C-5'), 73.7 (C2/2'), 73.5 (C-2/2'), 72.4 (C-4'), 72.1 (C-4), 71.6 (C-5), 64.5 (C-6), 62.9 (C-6'), 34.5 (C-8), 32.2, 30.1, 30.1, 30.04, 30.01, 29.9, 29.71, 29.69, 29.48, 25.4, 23.0 30.7, 28.62, 28.57, 28.52, 28.36, 28.20, 28.19, 27.98, 23.88 (C-9-C-31), 14.4 (C-32); HRMS(ESI) $m / z$ calcd. for $\left[\mathrm{C}_{38} \mathrm{H}_{72} \mathrm{O}_{12}+\mathrm{Na}\right]^{+}:$743.4916, obsd.: 743.4907 . 


\section{References}

(1) Khan, A. A.; Chee, S. H.; McLaughlin, R. J.; Harper, J. L.; Kamena, F.; Timmer, M. S. M.; Stocker, B. L. ChemBioChem 2011, 3, 2572-2576.

(2) Ryll, R.; Kumazawa, Y.; Yano, I. Microbiol. Immunol. 2001, 45, 801-811.

(3) Lemaire, G.; Tenu, J.-P.; Petit, J.-F. Med. Res. Rev. 1986, 6, 243-274.

(4) Asselineau, C.; Asselineau, J. Prog. Chem. Fats Other Lipids 1978, 16, 59-99.

(5) Ishikawa, E.; Ishikawa, T.; Morita, Y. S.; Toyonaga, K.; Yamada, H.; Takeuchi, O.; Kinoshita, T.; Akira, S.; Yoshikai, Y.; Yamasaki, S. J. Exp. Med. 2009, 206, 2879-2888.

(6) Laï, R. Inorg. Chim. Acta 2003, 350, 568-576.

(7) Hui, Y.; Chang, C.-W. T. Org. Lett. 2002, 4, 2245-2248.

(8) Whitson, E. L.; Ratnayake, A. S.; Bugni, T. S.; Harper, M. K.; Ireland, C. M. J. Org. Chem. 2009, 74, 1156-1162.

(9) Lederer, E. Chem. Phys. Lipids 1976, 16, 91-106.

(10) Toubiana, R.; Das, B. C.; Defaye, J.; Mompon, B.; Toubiana, M.-J. Carbohydr. Res. 1975, 44, 308-312.

(11) Johnson, D. Carbohydr. Res. 1992, 237, 313-318. 


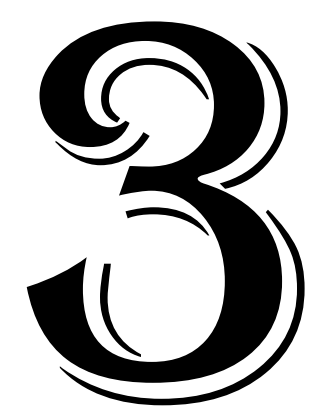

\section{TDE Biological}

\section{Testing}

\subsection{Introduction}

Although the biological properties of trehalose dimycolates (TDMs, 1, Figure 1) and trehalose diesters of fatty acids (TDEs, 2) have been studied for many years, it was only in 2009 that TDM and its simpler analogue, trehalose dibehenate (TDB, 2f), were found to activate macrophages via the Macrophage Inducible C-type Lectin 'Mincle'. 1,2,3 It has been suggested that Mincle binds to the ester and carbohydrate groups in trehalose derivatives, ${ }^{1,4}$ however, to date, no comprehensive structureactivity studies have been performed. In view of this, we were interested in determining the structural requirements of trehalose glycolipids for the activation of macrophages by way of the Mincle receptor. We were also interested in investigating how TDE structure influences cytotoxicity and whether this correlates to the previously observed anti-tumour activity of these compounds..$^{5-9}$ 

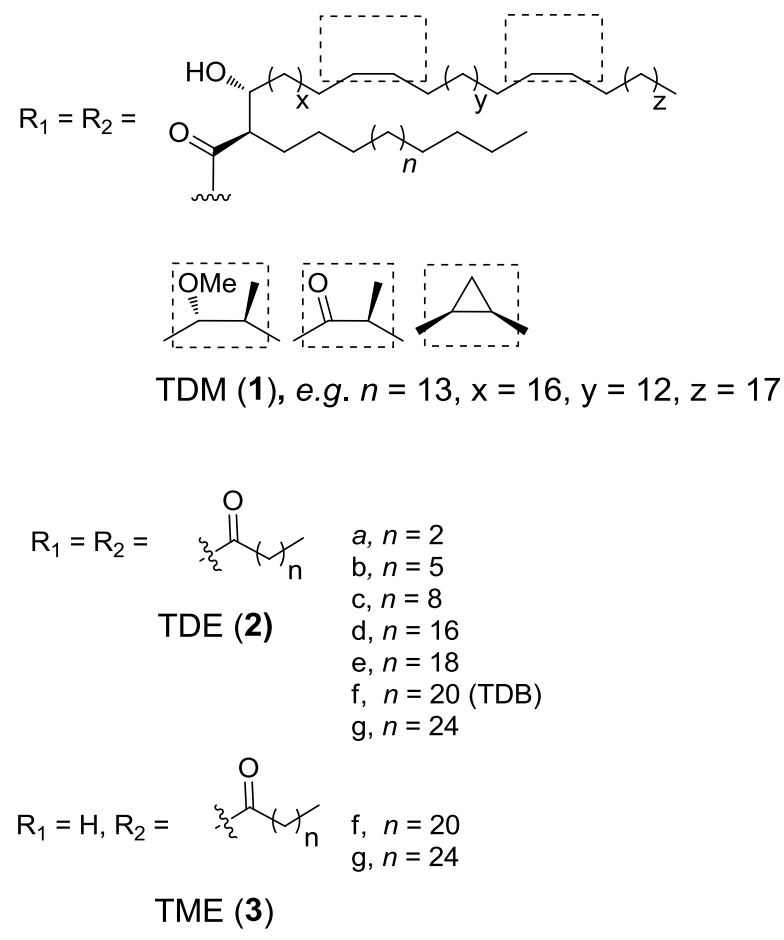

Figure 1. TDM (1), TDEs (2) and TMEs (3)

To meet the aforementioned objectives, TDEs of different lipid length (2a-g, Figure 1) were tested for their ability to activate macrophages, as evidenced by nitric oxide (NO) and cytokine production [interleukin (IL)-6 and IL-1 $\beta$ ]. ${ }^{10,11}$ The mechanism of activation was then explored by determining whether Mincle ${ }^{-/-}$or specific Toll-likereceptor $(\mathrm{TLR})^{-/-}$macrophages are activated in the presence of TDEs 2a-g. In addition to these studies, the requirements for Mincle binding were further probed by testing trehalose monoesters of fatty acids (TMEs), such as 3f-g, in similar macrophage activation assays. Finally, the cytotoxicity of each TDE was determined and two representative TDEs were subsequently tested in an in vivo tumour model. The results of these studies and their implications are discussed in this chapter. 


\subsection{Results and Discussion}

\subsubsection{Bone Marrow Macrophage (BMM) Assay Optimisation}

Macrophages are the first line of defense for the host organism against bacterial infection. ${ }^{12,13}$ Since TDB (2f) has been shown to bind to Mincle on macrophages and lead to macrophage activation we wanted to investigate if other TDEs can also lead to macrophage activation as evidenced by the production of NO and cytokines such as IL-6 and IL-1 $\beta$. NO is commonly produced by activated macrophages and is the radical responsible for cytotoxic effects. ${ }^{14,15}$ Macrophages release IL-6 in response to specific microbial molecules known as pattern associated molecular patterns (PAMPs) for example, trehalose glycolipids, which are recognised by pattern recognition receptors. IL-6 can act both as a pro-inflammatory and anti-inflammatory cytokine. IL- $1 \beta$ is produced by activated macrophages as a pro-protein which is processed to its active form by caspase 1. It is an important mediator of the inflammatory response and has been shown to be involved in cell proliferation and differentiation. Thus using NO and cytokine IL- 6 and IL-1 $\beta$ readouts, the activation state of macrophages can be deduced. Initial experiments were done using TDB as a model compound to set up the parameters for analysis of these glycolipids in a bone marrow macrophage (BMM) assay.

NO production is commonly analysed using Griess assay, which is a chemical test that detects the amount of nitrite present by spontaneous oxidation of NO under physiological conditions. ${ }^{16,17}$ Griess reagent consists of $\mathrm{N}$-(1naphthyl)ethylenediamine (4) and sulfanilic acid (5) (Scheme 1). The sulfanilic acid in the presence of nitrite anion forms the diazonium salt, $\mathbf{6}$ which further reacts with $N$-(1-naphthyl)ethylenediamine (4) to form the azo dye 7, detectable at $548 \mathrm{~nm}$. 


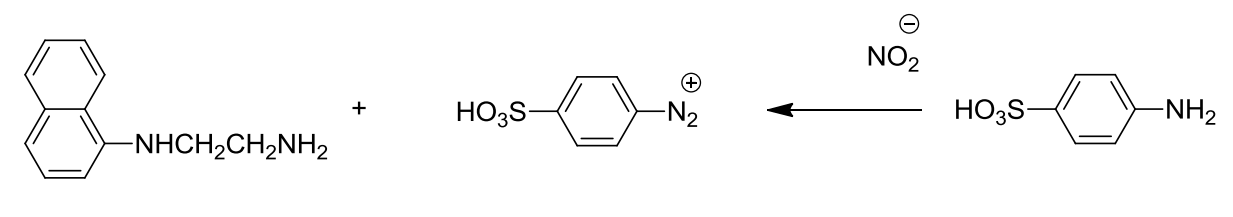

4

6

5

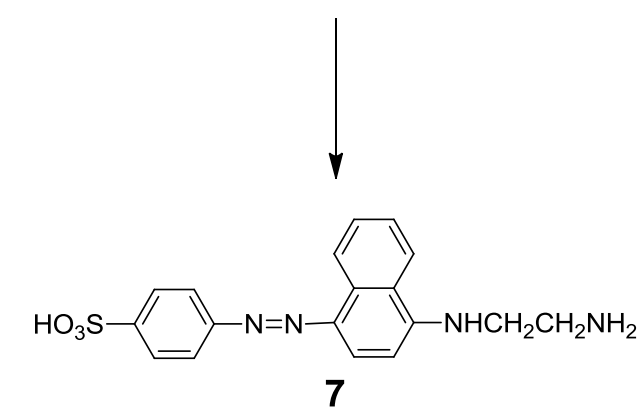

Scheme 1. Griess reaction

The first parameter to establish was the number of bone marrow (BM) cells required to be derivatised into macrophages in order to get a response from these compounds. To this end, BM cells were isolated from C57BL/6 mice, plated out in 24-well plates at $2.5 \times 10^{5}$ cell $/ \mathrm{mL}, 5 \times 10^{5}$ cells $/ \mathrm{mL}, 1 \times 10^{6}$ cells $/ \mathrm{mL}$ and $2 \times 10^{6}$ cells $/ \mathrm{mL}$ to a total of $1 \mathrm{~mL}$ in each well, and differentiated into macrophages over 10 days (see experimental section for more details). On day 10, the BMM were primed with IFN- $\gamma$ $(10 \mathrm{ng} / \mathrm{mL}$ ) for 3 hours after which time they were incubated with TDB at four concentrations (50, 10, 2 and $0.4 \mu \mathrm{g} / \mathrm{mL}$ ), and lipopolysaccharide (LPS, $100 \mathrm{ng} / \mathrm{mL}$ ) which was used as positive control. IFN- $\gamma$ priming is commonly used to skew naïve macrophages more towards a Th1 phenotype (classically activated macrophages). ${ }^{18,19}$ As the TDEs and TMEs are similar to the bacterial cell wall component TDMs, a Th1 response is more akin to that which would be observed when considering the immune response to the whole bacteria. ${ }^{20}$ The supernatants were analysed for NO production using Griess assay at 96 hours (Figure 2). In all cases, good dose response curves were observed when starting with the four different concentrations of cells. We opted for the lower number of cells (250 000) because this enabled more assays to be performed per animal. 


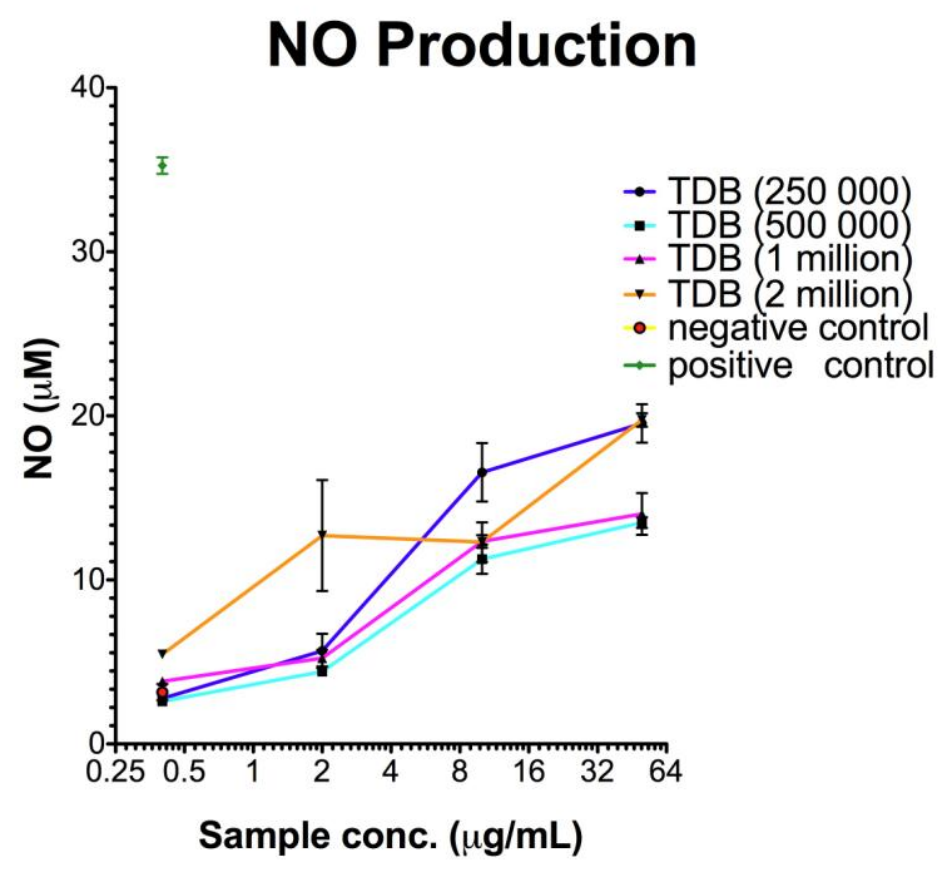

Figure 2. NO production by TDB-treated BMM. Bone marrow cells were plated out at four different concentrations, differentiated into macrophages over 10 days, primed with $10 \mathrm{ng} / \mathrm{mL}$ IFN- $\gamma$ and stimulated with TDB $(50,10,2$ and $0.4 \mu \mathrm{g} / \mathrm{mL})$ or LPS (100 ng/mL) for $96 \mathrm{~h}$, after which levels of NO production in the supernatants were analysed.

The next parameters analysed were the amounts of IFN- $\gamma$ and TDB required to activate macrophages. Thus BMM were cultured, incubated with IFN- $\gamma$ at $10 \mathrm{ng} / \mathrm{mL}$ and $20 \mathrm{ng} / \mathrm{mL}$ for 3 hours, after which time they were incubated with TDB at six concentrations $(80,40,20,10,5$ and $2.5 \mu \mathrm{g} / \mathrm{mL})$ and LPS (100 ng/mL). The supernatants were analysed after 96 hours and as illustrated in Figure 3, more consistent NO readings were obtained when the macrophages were primed with 10 $\mathrm{ng} / \mathrm{mL}$ IFN- $\gamma$ followed by stimulation with TDB at either 20 or $40 \mu \mathrm{g} / \mathrm{mL}$. Thus future experiments were performed using $10 \mathrm{ng} / \mathrm{mL}$ IFN- $\gamma$ for priming and samples at 20 and $40 \mu \mathrm{g} / \mathrm{mL}$. 


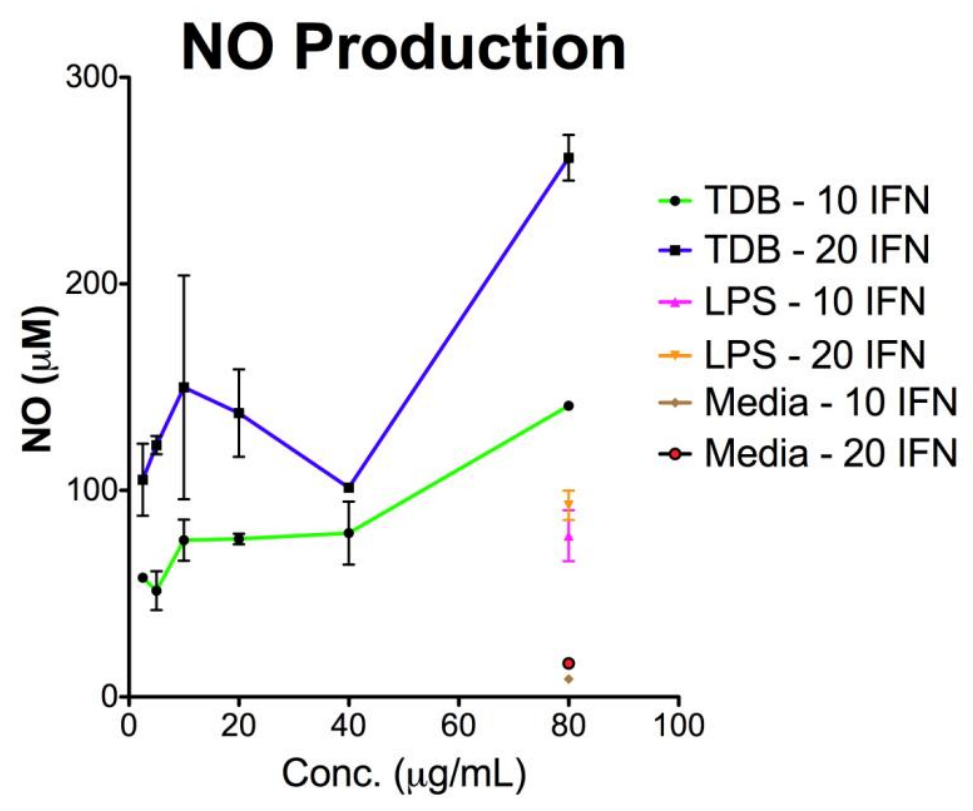

Figure 3. NO production by TDB-treated BMM following IFN- $\gamma$ priming at different concentrations. BMM were primed with IFN- $\gamma(10$ or $20 \mathrm{ng} / \mathrm{mL})$, followed by stimulation with TDB $(80,40,20,10,5$ and $2.5 \mu \mathrm{g} / \mathrm{mL})$ or LPS $(100 \mathrm{ng} / \mathrm{mL})$ and the supernatants analysed for NO production after $96 \mathrm{~h}$.

In order to determine the optimum time-point for cytokine read-outs, a time-course experiment for cytokine analysis was undertaken. To this end, BMM were stimulated with TDB $(20 \mu \mathrm{g} / \mathrm{mL})$ and the supernatants analysed for IL-1 $\beta$ and IL-6 production at 24, 48, 72 and 96 hours by enzyme-linked immunosorbent assay (ELISA) [Cytokine analysis was performed by Rene McLaughlin, a PhD student in Dr Jacquie Harper's group at MIMR]. The induction of IL- 6 and IL-1 $\beta$ by TDB (2f) reached a plateau at $72 \mathrm{~h}$ (Figure 4A and 4B). As with NO production, TDB (2f) induced production of IL-6 and IL-1 $\beta$, exhibited delayed kinetics and was weaker than LPS induced production. 


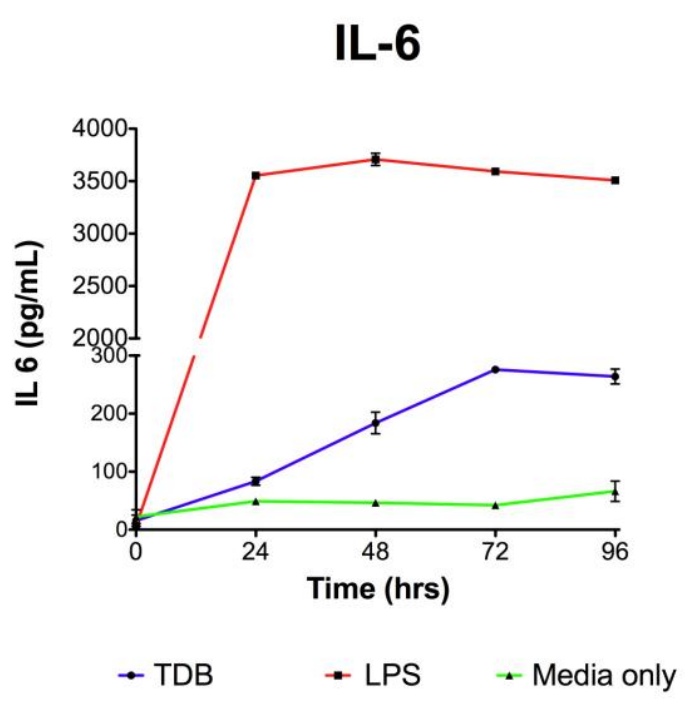

A
IL-1 $\beta$

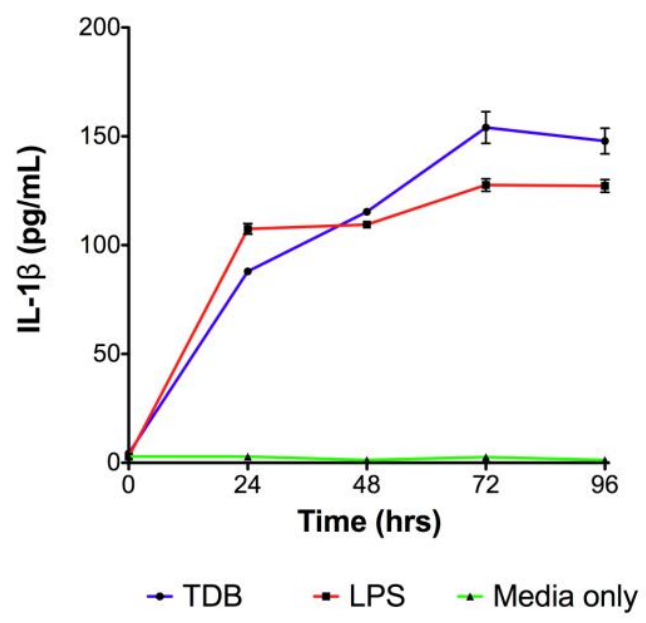

B

Figure 4. Cytokine production by TDB-treated BMM. BMM were treated with TDB $(20 \mu \mathrm{g} / \mathrm{mL})$ or LPS $(100 \mathrm{ng} / \mathrm{mL})$. At $24,48,72$ and $96 \mathrm{~h}$ the supernatants were analysed for A) IL-6 and B) IL-1 $\beta$ levels by ELISA.

\subsubsection{Understanding how trehalose lipid length affects}

\section{macrophage activation}

With the BMM assay set-up, all the synthesised TDEs were tested for their ability to activate macrophages. Here, IFN- $\gamma$ primed BMM were treated with $20 \mu \mathrm{g} / \mathrm{mL}$ of TDEs, and at different time points supernatants were collected for NO analysis (Figure 5A). Trehalose and the uncoupled C22 (behenic) acid were used as controls in the experiment. The longer chain TDEs 2e-g all induced NO production, with NO levels reaching a plateau at $96 \mathrm{~h}(\mathrm{C} 22>\mathrm{C} 20>\mathrm{C} 26)$. The shorter TDEs $(\mathrm{C} 4-\mathrm{C} 10)$ were inactive. The $\mathrm{C} 18$ analogue led to a small but significant $(\mathrm{p}<0.05)$ increase in NO production. Trehalose and the uncoupled C22 (behenic) acid showed no activity. To determine the influence of TDE concentration on NO production, BMM were then incubated with $20 \mu \mathrm{g} / \mathrm{mL}$ and $40 \mu \mathrm{g} / \mathrm{mL}$ of each compound and NO production measured at $96 \mathrm{~h}$ (Figure 5B). For those TDEs that stimulated BMM (2e-g), there was a modest increase in NO production with increased glycolipid concentration. 


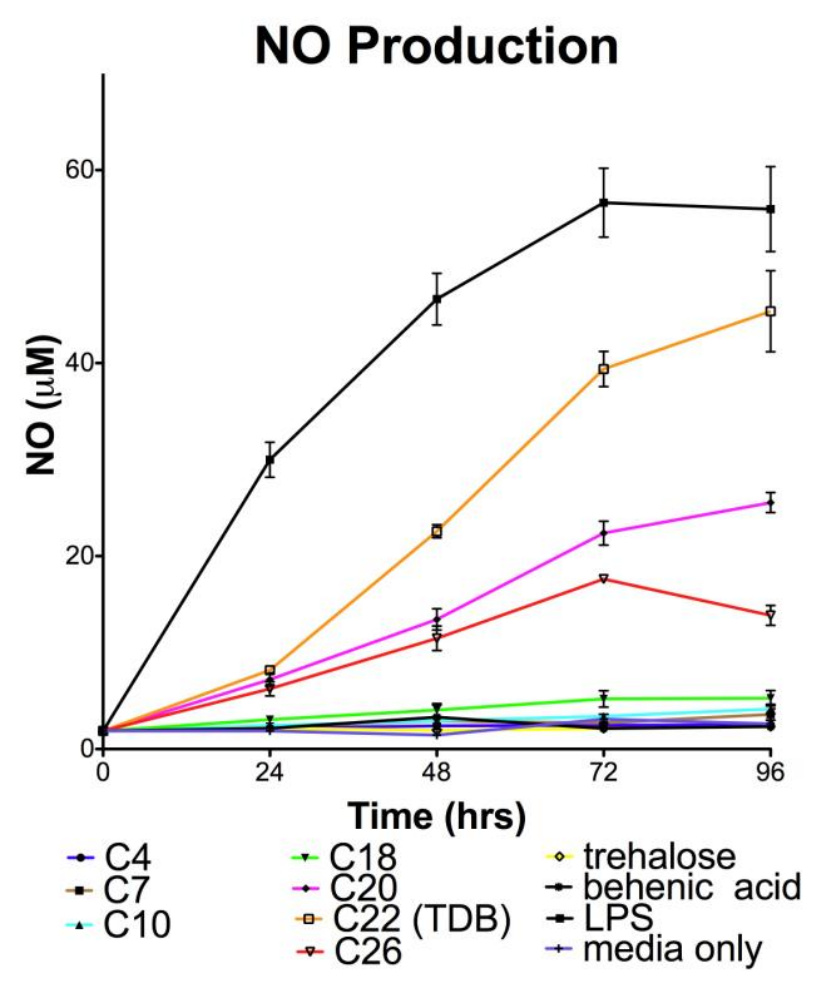

A
NO Production

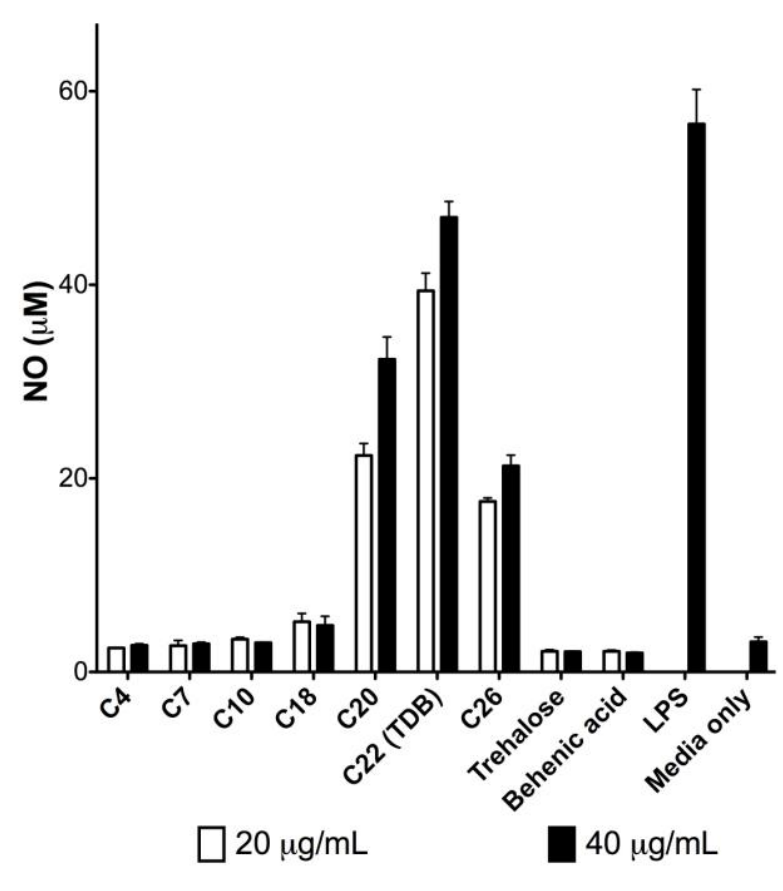

B

Figure 5. NO production by TDE-treated BMM. A) BMM were stimulated with TDEs $(20 \mu \mathrm{g} / \mathrm{mL})$ or with LPS $(100 \mathrm{ng} / \mathrm{mL})$. At $24,48,72$ and $96 \mathrm{~h}$ the supernatants were analysed for NO production using Griess assay. B) BMM were treated with TDEs, trehalose or behenic acid $(40 \mu \mathrm{g} / \mathrm{mL}$ and $20 \mu \mathrm{g} / \mathrm{mL})$ or with LPS (100 $\mathrm{ng} / \mathrm{mL})$ and NO production was determined at $96 \mathrm{~h}$. The mean and SD of triplicate samples from a represenative experiment of two are shown.

The levels of IL- 6 and IL- $1 \beta$ production were also measured at 96 hours for all the TDEs. In both cases, only the longer TDEs (C22 C26>C20) induced significant cytokine production (Figure 6A and 6B). TDEs induced lower levels of IL-6 production by the BMMs when compared to LPS. The shorter lipid chain analogues (C4-C10) showed no activity. 


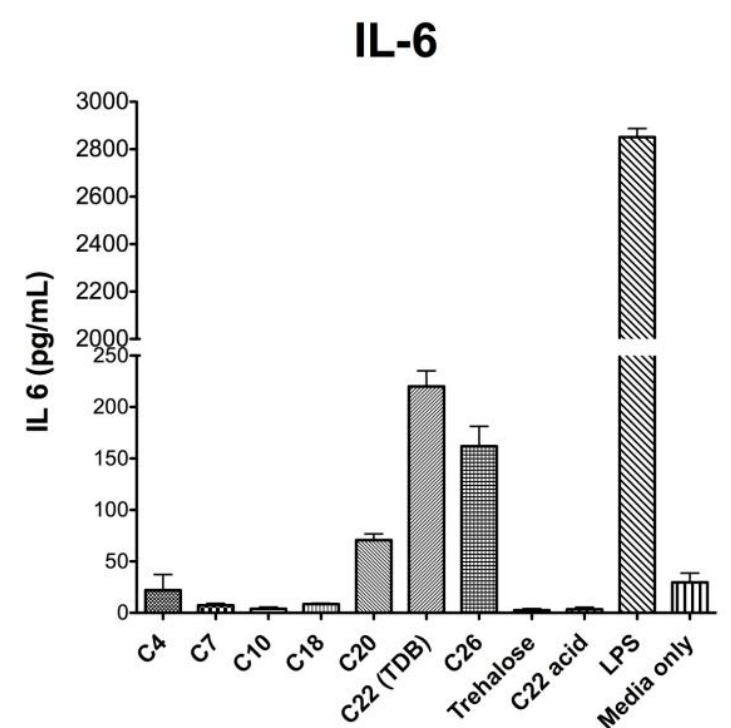

A

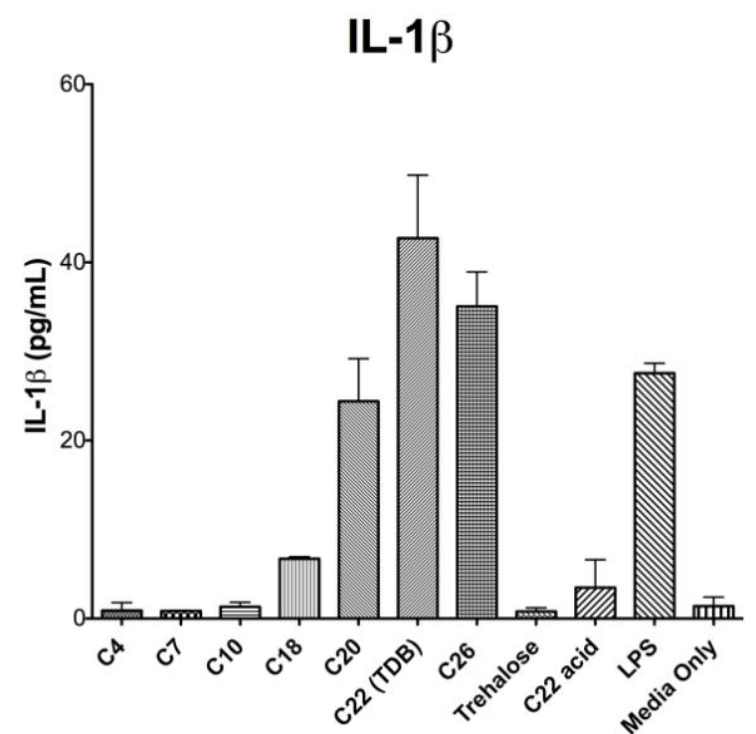

B

Figure 6. Cytokine production by TDE-treated BMM. BMM were stimulated with TDEs $(20 \mu \mathrm{g} / \mathrm{mL})$ or with LPS $(100 \mathrm{ng} / \mathrm{mL})$ for $96 \mathrm{~h}$, and the supernatants were analysed for the accumulation of A) IL- 6 and B) IL- $1 \beta$ by ELISA. The mean and SD of triplicate samples from a representative experiment of two are shown.

In this work, the importance of the lipid chain length on trehalose in inducing macrophage activation is clearly emphasised. Taken as a whole, these results indicate that longer lipids $(\geq \mathrm{C} 18)$ are required for the activation of macrophages by diacyltrehalose glycolipids whereas TDEs with short chain lipids $(<\mathrm{C} 18)$ are inactive. In addition to the lipid length, the ester linkage was also found to be an important moiety required for the recognition of trehalose glycolipids by macrophages since both trehalose and behenic acid on their own were unable to induce macrophage activation. These observations are interesting as they provide insight into why $M$. $t b$, which expresses long lipid chain TDMs, triggers an innate immune response in the host upon invasion. 


\subsubsection{On One Leg: Trehalose Mono-Esters (TMEs) Activate Macrophages in a Mincle-Dependant Manner}

As highlighted previously, diacyltrehalose glycolipids, in the form of trehalose 6,6'dimycolates [TDMs (1), Figure 1], are the most abundant cell surface glycolipid from $M . t b$ and related mycobacteria, and have important immunomodulatory functions in $M . t b$ pathogenicity. ${ }^{21,22,23,24}$ In particular, the pivotal role of TDMs in granuloma formation and in the prevention of phagosome-lysosome fusion, thus facilitating bacterial survival within the host macrophages ${ }^{25,26}$ has led to much interest in the mechanism by which TDMs interact with macrophages. Initially it was proposed that TDMs regulate the immune response by binding to the cluster of differentiation (CD) 1 isoform CD1d on macrophages, thus allowing for subsequent glycolipid presentation to Natural Killer (NK) T cells, ${ }^{27,28}$ however, further studies using $\mathrm{CD}_{1 \mathrm{~d}}{ }^{-/}$mice revealed that the activity of TDMs was independent of CD1d interaction. ${ }^{29}$ It was not until 2009 that Ishikawa and co-workers ${ }^{1}$ and Lang and coworkers $^{2}$ independently identified Mincle as a receptor for TDMs. Lang then followed on from these studies to illustrate that TDM-Mincle interaction induces a SyK-Card9-Bcl1-Malt1 signalling pathway, ${ }^{3}$ and furthermore, that the simple straight-chain TDM analogue TDB (2f) also activates macrophages in a manner similar to the parent esters. This work proved revolutionary, not only because the binding of TDMs/TDB to Mincle provides insight into the mechanisms by which $M$. tb interacts with its host cell, but also because the Th-1 type cytokine response generated by macrophages upon stimulation with trehalose glycolipids may be better harnessed in the development of $M . t b$ vaccine adjuvants ${ }^{30,31}$ if more knowledge about the requirements of TDM-Mincle binding are known. To date, however, the limited availability of the appropriate $\mathrm{Mincle}^{-/-}$murine models has meant that much in this field remains unanswered.

Mincle, (also known as Clec4e and Clecf9) $)^{32,33}$ is a trans-membrane protein found on cells of the myeloid lineage (predominantly macrophages) and was discovered just over ten years ago by Akira and co-workers. ${ }^{34}$ Mincle has an extracellular $\mathrm{Ca}^{2+}$ dependent carbohydrate recognition domain and is highly conserved between mice and humans with $85 \%$ protein similarity, ${ }^{34}$ however, to date, no tertiary structure is 
known. In addition to the trehalose diesters, Mincle is also a receptor for Candida albicans $^{35}$ and the pathogenic fungus Malassezia. ${ }^{36}$ It has been proposed that Mincle binds to $\alpha$-linked mannose containing glycolipids in these organisms, although no specific agonists were identified. Moreover, Mincle does not recognise $\alpha-1,2$ mannose containing glycolipids from mycobacterium cell wall extracts. ${ }^{3,4}$

To better understand the influence that trehalose diesters have on the immune response, and in particular, the manner in which they bind to macrophages the structural requirements for TDE/Mincle binding was explored. In the earlier studies reported here, it has been shown how lipid length affects the innate immune response of macrophages to trehalose diesters and observed that long lipids $(\geq \mathrm{C} 18)$ are required for the activation of macrophages. ${ }^{37}$ The mechanism of activation, however, was not investigated, although others have suggested that trehalose diesters bind to Mincle via their carbohydrate and ester groups. ${ }^{3,4}$ Herein, the structural requirements for the binding of TDEs with Mincle, including unprecedented insight into the number of esters required for macrophage activation and the mechanisms of activation is reported.

\subsection{3a Trehalose mono-esters of carbon length $\geq \mathrm{C20}$ activate macrophages}

To understand more about the structural requirements for the binding of trehalose esters to Mincle, the ability of trehalose mono-esters of fatty acids (TMEs, 3, Figure $1)$ to activate macrophages was investigated. Given that long lipids ( $\geq \mathrm{C} 18)$ are required for macrophage activation, ${ }^{37}$ C22 TMEs (3f) and C26 TME (3g), and along with C22 TDE (TDB, 2f, as positive control) were prepared and the ability of each of these glycolipids to activate BMMs derived from C57BL/6 mice, as determined by NO and cytokine production (Figure 8) was explored. As illustrated, NO production by the BMMs in response to C22 TME (3f) and C26 TME (3g) $(20 \mu \mathrm{g} / \mathrm{mL})$ increased over the $96 \mathrm{~h}$ time period, although at a much slower rate when compared to the tolllike receptor (TLR) 4 ligand, LPS (Figure 7A). At 24 h, C22 TMEs (3f) and C26 TME (3g) and TDB (2f) all induced similar levels of NO, however by $96 \mathrm{~h}$, levels of this intracellular mediator were lower for C22 TME (3f) and C26 TME (3g) (with 
$\mathbf{3 g}<\mathbf{3 f}$ ). The influence of glycolipid concentration on NO production was then investigated and BMMs were incubated with 20 and $40 \mu \mathrm{g} / \mathrm{mL}$ of the TMEs/TDB and NO levels recorded at $96 \mathrm{~h}$. As illustrated (Figure 7B), a modest increase in NO production with increased glycolipid concentration was observed for both the monoand di-esters. 


\section{NO Production}

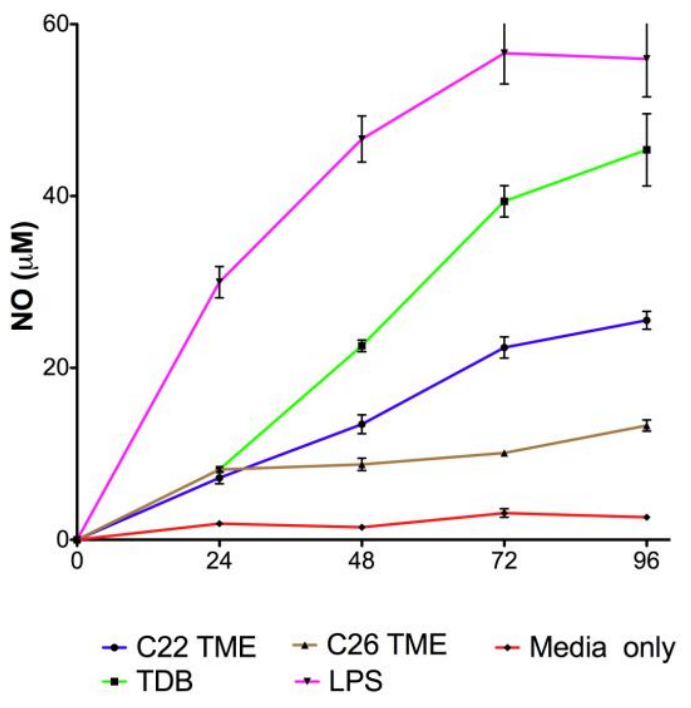

A

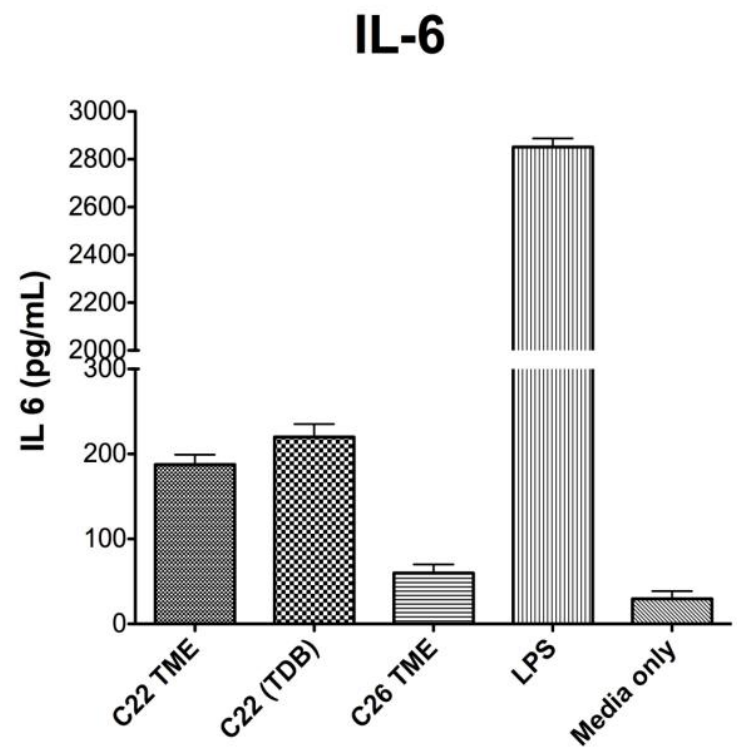

$\mathrm{C}$
NO Production

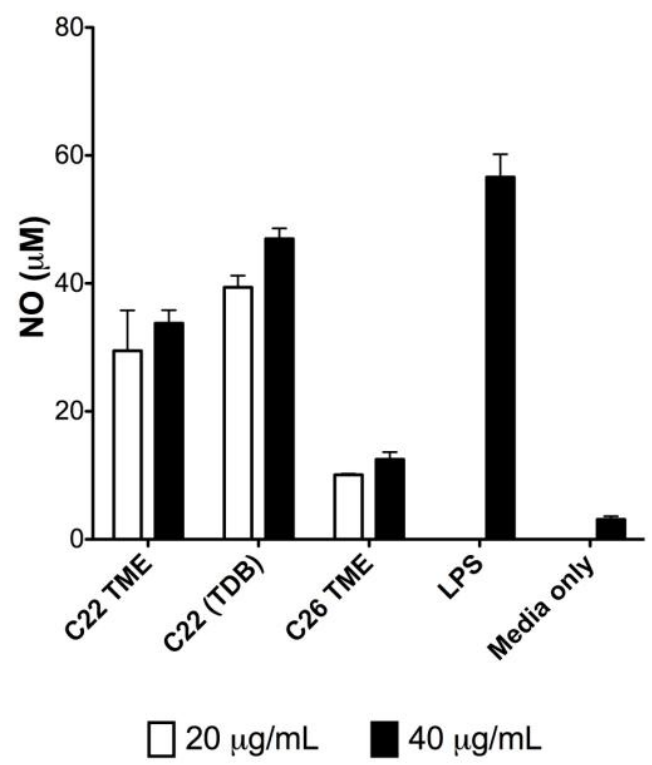

B

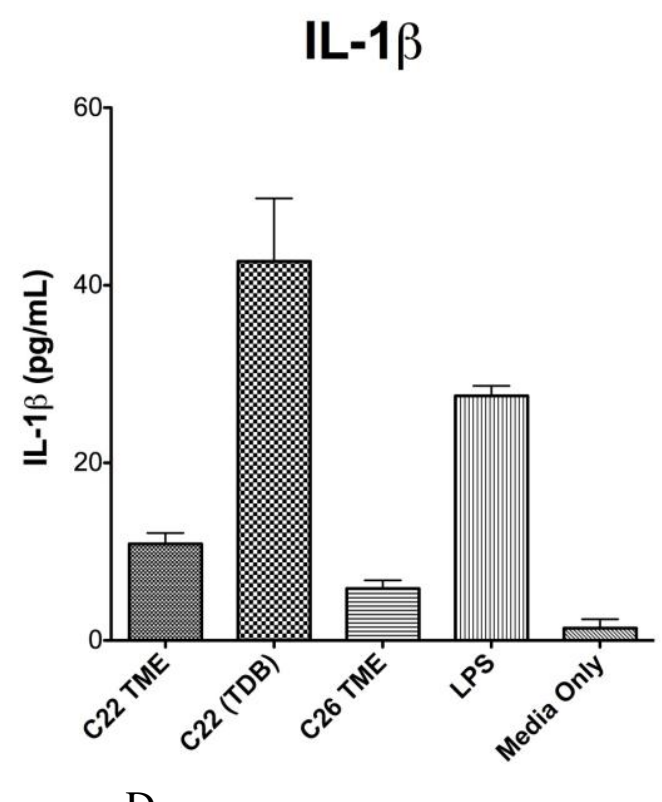

Figure 7. NO and cytokines IL-6 and IL- $1 \beta$ production by TDB/TME-treated BMM. A) BMM were stimulated with TMEs, TDB $(20 \mu \mathrm{g} / \mathrm{mL})$ or with LPS $(100 \mathrm{ng} / \mathrm{mL})$. At 24, 48, 72 and $96 \mathrm{~h}$ the supernatants were analysed for NO accumulation. B) BMM were treated with TMEs, TDB $(40 \mu \mathrm{g} / \mathrm{mL}$ or $20 \mu \mathrm{g} / \mathrm{mL})$ or with LPS (100 $\mathrm{ng} / \mathrm{mL}$ ) and NO production was determined at $96 \mathrm{~h}$. BMM were stimulated with TMEs, TDB $(20 \mu \mathrm{g} / \mathrm{mL})$ or LPS $(100 \mathrm{ng} / \mathrm{mL})$ for $96 \mathrm{~h}$, and the supernatants were analysed for the accumulation of C) IL-6 and D) IL- $1 \beta$ by ELISA. For all graphs, the mean and SD of triplicate samples from a representative experiment of two are shown. 
Having established that C22 and C26 TMEs (3f and 3g), stimulate the production of NO by BMMs, the effect of these mono-esters on the production of the intracellular cytokines, IL- 6 and IL-1 $\beta$ was then investigated. To this end, BMMs were stimulated with the trehalose esters and the levels of each cytokine measured at $96 \mathrm{~h}$, which was previously determined as being the optimum time-point. ${ }^{37}$ Surprisingly, levels of IL6 were similar for C22 TME (3f) and the corresponding C22 TDE (2f), while treatment of the BMMs with C26 TME (3g) also led to IL-6 production, albeit at lower levels (Figure 7C). Production of IL-1 $\beta$ was slightly lower for C22 and C26 TME (3f and 3g), when compared to both TDB (2f) and LPS (Figure 7D). Taken as a whole, these observations are interesting and suggest that trehalose structure can influence the relative ratios of cytokines produced. Moreover, the first evidence to suggest that trehalose mono-esters also activate macrophages is provided, which is surprising and contrary to current ideas about the requirements for trehalose glycolipid/Mincle interactions. ${ }^{1,4}$

\subsection{3b Mincle is a key cellular mediator in the activation of macrophages by trehalose mono- and di-esters}

In the earlier studies the effect of lipid length on the activation of BMMs by TDEs was demonstrated; however, no insight was provided for the mechanism of this phenomenon. ${ }^{37}$ Although one could assume that all linear trehalose diesters that activate BMMs do so via Mincle [as established by Lang and co-workers for TDB (2f) $],{ }^{2}$ this hypothesis needs to be explored. Similarly, the manner by which trehalose C22 and C26 TME, (3f and 3g), activate BMMs also needs to be determined. To this end, the ability of C20 and C22 TDEs (2e and $\mathbf{2 f}$ ) and C22 and C26 TMEs (3f and 3g) to activate Mincle ${ }^{-/-}$BMMs was investigated. Given that other C-type lectins, such as Dectin-1, act synergistically with other receptors (e.g., TLR2 and TLR4), ${ }^{38}$ we also explored the ability of the trehalose esters to activate TLR2/4 ${ }^{-/-}$BMMs. This work was carried out by Dr. Faustin Kamena at Max Plank Institute, Berlin, Germany.

Using the NO BMM assay developed above, C22 and C26 TMEs (3f and 3g), and C20 TDE (2e), C22 TDE (2f) and C4 TDE, (2a, as a negative control), ${ }^{37}$ were tested 
for their ability to activate BMMs (Figure 8). In this experiment, the C20 TDE (2e) did not lead to the generation of NO by wild-type BMMs, however, TDB (2f) did. What is more important, however, is that both C22 (3f) and C26 (3g) TMEs were able to activate wild-type BMMs but not Mincle $^{-/-}$BMMs, thus highlighting the importance of this receptor for the activation of macrophages by trehalose monoesters. The ability of C22 and C26 TMEs, (3f and $\mathbf{3 g}$ ), and TDB (2f) to activate TLR $2 / 4^{-/-}$macrophages, also suggests that neither of these TLRs binds to the trehalose glycolipids. This finding is supported by Lang's earlier studies where it was illustrated that both TDM and TDB were able to activate BMMs from MyD88 ${ }^{-/-}$ mice, as measured by NO and cytokine production. ${ }^{2}$ Here, it should be noted however, that care needs to be taken in the interpretation of our TLR2 data because the control (PamCys - a TLR2 ligand) led to the activation of TLR2/4 ${ }^{-/-}$BMMs. This unusual result could either be due to too high levels of PamCys being used in the assay or the PamCys being contaminated. These assays will be repeated in due course to better explain this phenomenon. 


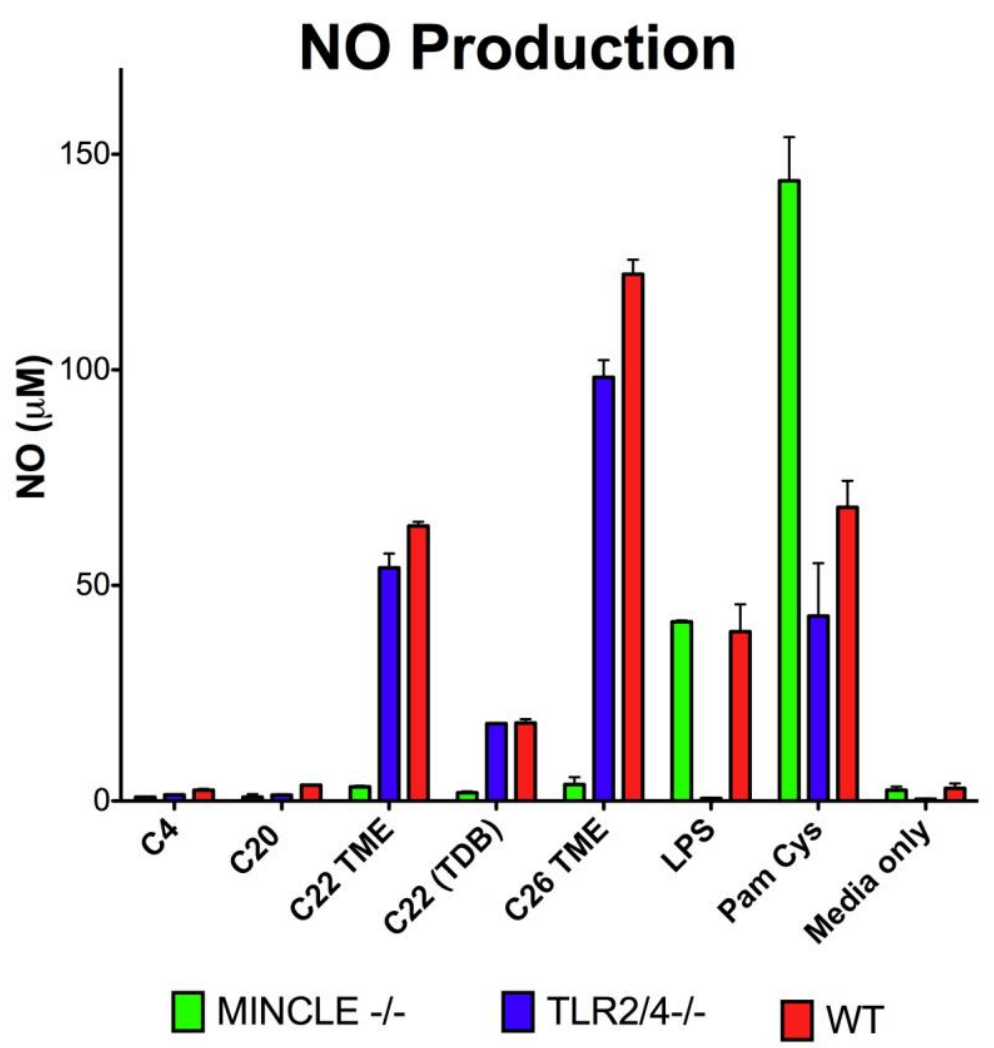

Figure 8. NO production from TDE/TME-treated BMM derived from Mincle $^{-/}$, TLR $2 / 4^{-/-}$and wild type mice. BMM were primed with IFN- $\gamma(10 \mathrm{ng} / \mathrm{mL})$ and stimulated with C4 TDE (2a), C20 TDE (2e), C22 TDE (2f) C22 TME (3f), and C26 TME (3g) at $40 \mu \mathrm{g} / \mathrm{mL}$, LPS $(10 \mathrm{ng} / \mathrm{mL})$ or PamCys $(10 \mathrm{ng} / \mathrm{mL})$ and NO measured after $72 \mathrm{~h}$.

Although there are still a number of experiments to be performed using the trehalose mono- and di-esters (including the testing of further analogues in the BMM assays), results obtained to date, point to a number of interesting facts. First, the ability of trehalose diesters to activate BMMs appears to be a general phenomenon of all diesters which have a lipid length $\geq \mathrm{C} 20$, with the mechanism of macrophage activation being Mincle, but not TLR, dependent. While earlier studies by Giesel et $a l .{ }^{39}$ and Bowdish et $a .^{40}$ had implicated TLRs (including TLR2) in TDM-binding and recognition, the studies by Ishikawa, ${ }^{1}$ Lang, ${ }^{2}$ and now the results obtained during this research, point to a mechanism of macrophage activation by TDEs that is independent of TLRs. To add to this argument, the ability of the TDEs and TMEs to 
activate BMMs in the absence of other TLRs (e.g. by using TLR9 ${ }^{-/}$, Myd88 $8^{-/-} \mathrm{BMMs}$ etc.) will be further explored.

In addition to providing insight into the mechanism of action for a range of TDE's, we have also illustrated that C22 and C26 TMEs ( $\mathbf{3 f}$ and $\mathbf{3 g}$ ) activate macrophages via Mincle. Although, it is generally thought that the induction of intracellular signalling by macrophages in response to trehalose esters requires two esters to bind to and activate Mincle, ${ }^{3,4}$ through this work, however, it has been demonstrated that only one ester group is necessary, and by doing so, a new sub-class of Mincle ligands have been uncovered, which will provide potential for the future development of agonists for this receptor.

\subsection{3c Trehalose diesters (TDEs) can prime macrophages}

To engage a full immune response, macrophages are typically primed prior to the addition of any subsequent immunomodulatory compound. Priming of macrophages is often performed using IFN- $\gamma$, which causes an increase in antigen presentation and lysosome activity of macrophages and skews naïve macrophages towards a Th1

phenotype (classically activated macrophages). ${ }^{18,19}$ The TLR4 ligand LPS has also shown potential to be used as a priming agent for macrophages, making macrophages sensitive to induction of pro-inflammatory cytokines in the presence of secondary stimuli. $^{41}$ The identification of a new class of compounds that can prime macrophages in a TLR-independent manner, however, provides a new way to enhance the immune response and may lead to the identification of new combinations of therapies to generate the desired immunological response.

To this end, the ability of TDE's to activate macrophages with different levels of IFN- $\gamma$ priming was explored. Preliminary work in this area was performed by Lang and co-workers, ${ }^{2}$ whereby BMMs were incubated with TDM and TDB $(20 \mu \mathrm{g} / \mathrm{mL})$ and found to produce NO, albeit at a lower level than the IFN- $\gamma$ primed $(20 \mathrm{ng} / \mathrm{mL})$ BMMs. In the current study, however, the ability of unprimed BMMs to generate NO and cytokines (e.g. IL-6) upon exposure to a variety of TDE's was investigated. Accordingly, BMMs were stimulated with different concentrations of IFN- $\gamma(0,10$ 
and $20 \mathrm{ng} / \mathrm{mL}) 3 \mathrm{~h}$ prior to the addition of TDB (2f) and the supernatant analysed for NO and IL-6. As illustrated (Figure 9A), in the absence of IFN- $\gamma$ priming, there was no NO production by the BMMs in response to TDB (2f), however, IL-6 production for the unprimed BMMs was similar to that for BMMs primed with $10 \mathrm{ng} / \mathrm{mL}$ of IFN- $\gamma$ (Figure 9B).

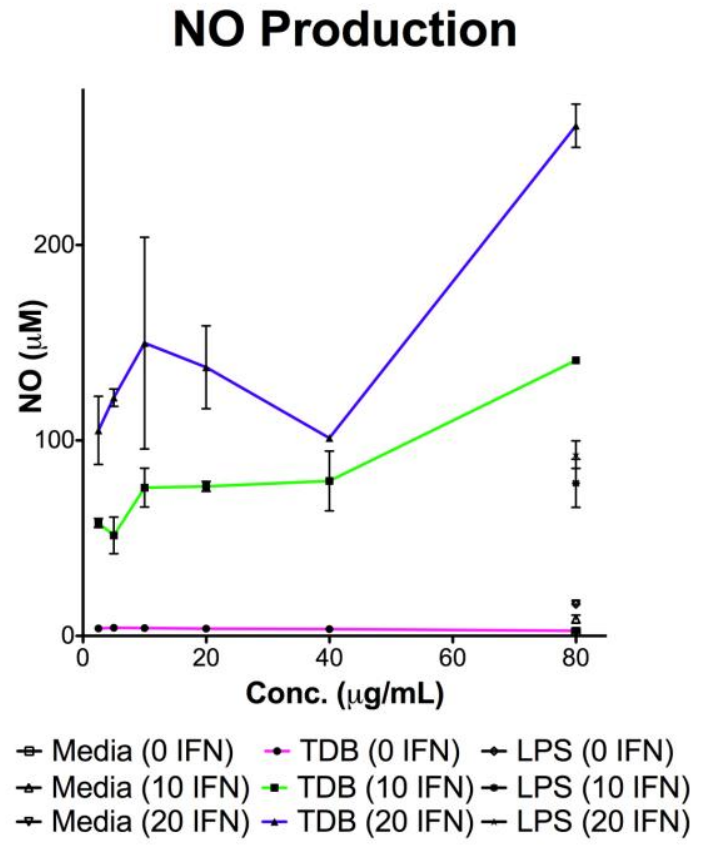

A

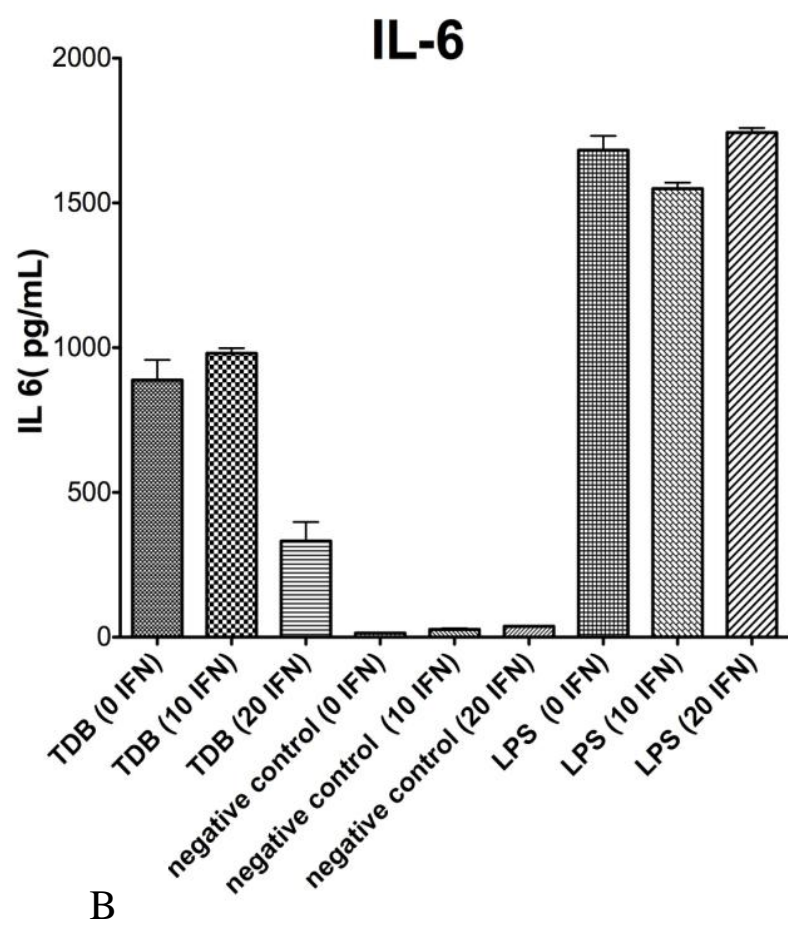

Figure 9. The effect of priming with IFN $-\gamma$ on BMM stimulated with TDB. BMM were primed with IFN- $\gamma(0,10$ or $20 \mathrm{ng} / \mathrm{mL})$ for $3 \mathrm{~h}$ followed by stimulation with TDB $(80,40,20,10,5,2.5 \mu \mathrm{g} / \mathrm{mL})$ or LPS (100 ng/mL); A) The supernatants were analysed for NO production after $96 \mathrm{~h}$. B) The supernatants from BMM stimulated with TDB $(20 \mu \mathrm{g} / \mathrm{mL})$, LPS $(100 \mathrm{ng} / \mathrm{mL})$ were analysed for IL-6 production at $96 \mathrm{~h}$.

From the above preliminary results, it is apparent that TDB (2f) is able to activate macrophages independent of IFN- $\gamma$ priming. There are, however, some differences between the results reported here and those obtained by Weringhaus et al. who showed that in the absence of IFN- $\gamma$ priming, macrophages were able to induce modest NO production in response to $20 \mu \mathrm{g} / \mathrm{mL}$ of TDB (2f). ${ }^{2}$ That said, no investigations into the levels of cytokines produced by unprimed macrophages in response to TDB (2f) were reported. ${ }^{2}$ 
To further explore the potential of trehalose diesters as priming agents, there are a number of experiments that should follow. First, a variety of TMEs and TDEs should be tested for their ability to activate BMMs (without priming) to determine whether this is a response unique to TDB (2f) or more widely applicable. Moreover, it should be determined whether BMMs treated with LPS show greater activity following priming with TDB (2f). By performing this assay, the potential of trehalose glycolipids to act as priming agents can be more readily assessed. Indeed, if increased BMM activation is observed following TDB priming, a variety of other immunostimulatory molecules could then be tested following TDB (or similar trehalose glycolipid) priming, thus opening-up a whole new avenue of research and means by which to generate an enhanced immune response.

\subsubsection{Application of TMEs and TDEs in cancer therapy}

It has been known for some time that trehalose glycolipids have potential in the treatment of solid tumours, ${ }^{5-9}$ however, the mechanism of action and the means by which to develop an optimum anti-tumour response are poorly understood. This is in part due to the variety of assays that have been performed, which involve either intravenous (i.v.), intra-tumoural, subcutaneous or oral administration of different trehalose diesters $(\mathrm{C} 2-\mathrm{C} 22)$ in different vehicles (e.g. as saline solutions or as oil emulsions with or without the addition of LPS), and in different tumour models., ${ }^{5,9,43-47}$ From an analysis of the literature, it would appear as though use of an oil vehicle leads to a better anti-tumour effect, ${ }^{42,44}$ as does the addition of LPS, ${ }^{7,9,45}$ however, these conclusions can only be reached by considering experiments that were performed using similar assays and where only one variable was altered at a time. Given this, it is difficult to determine whether there is a particular trehalose lipid length that leads to an optimum anti-tumour response. For example, trehalose diesters with lipids of lengths C8, C10, C18, C22 have all shown anti-tumour potential, depending on the assay used. Moreover, it is not known whether the antitumour effect of the trehalose esters is due to their cytotoxic or immunomodulatory effects (or both). Given that previously it has been observed that only trehalose esters with lipid length $\geq \mathrm{C} 18$ were able to activate $\mathrm{BMMs},{ }^{37}$ the mechanism by which 
trehalose esters exert their anti-tumour activity was explored next, particularly since solid tumours contain large numbers of the immunosuppressive tumour associated macrophages (TAMs). ${ }^{46}$

To determine whether the anti-cancer activities of trehalose esters are due to general cytotoxicity, the compounds were tested in an in vitro MTT viability assay using a human hepatocellular carcinoma (HepG2) cell line. HepG2 is a liver cancer cell line commonly used to study liver metabolism and toxicity. The MTT assay assesses cell viability by determining whether the yellow tetrazolium salt MTT (3-(4,5dimethylthiazol-2-yl)-2,5-diphenyl-tetrazolium bromide (8) is reduced to the purple formazan product 9 by NADPH in the presence of dehydrogenase, which occurs during normal cellular respiration (Scheme 2). In the presence of a cytotoxic agent however, cellular growth is suppressed and no or limited colour change of the dye occurs. Cell viability is than expressed in a percentage of MTT reduction with respect to an untreated control.

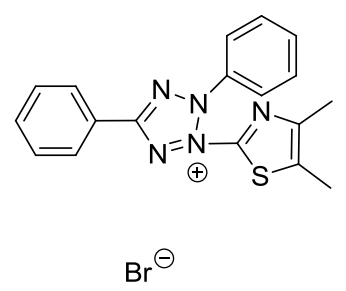

8

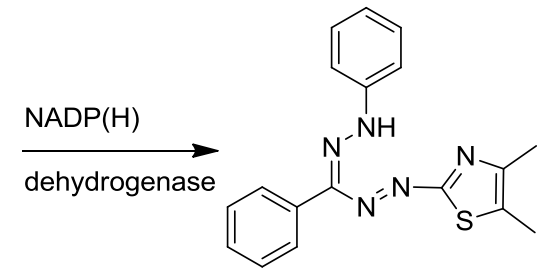

9

Scheme 2. MTT reduction

The results of the MTT assay are depicted in Figure 10 [Assays performed by Dr James Baty, MIMR]. None of the tested trehalose glycolipids showed appreciable cytotoxicity at concentration under $50 \mu \mathrm{M}$ (data not shown). At the two highest concentrations (50 and $150 \mu \mathrm{M}$ ), however, the more lipophilic compounds, the C26 monoester and the C20, C22 and C26 diesters of trehalose, appeared to be slightly cytotoxic, in a concentration dependant manner. Interestingly, the C22 TME did not follow this trend, as it did not show any cytotoxicity at the concentrations tested. 


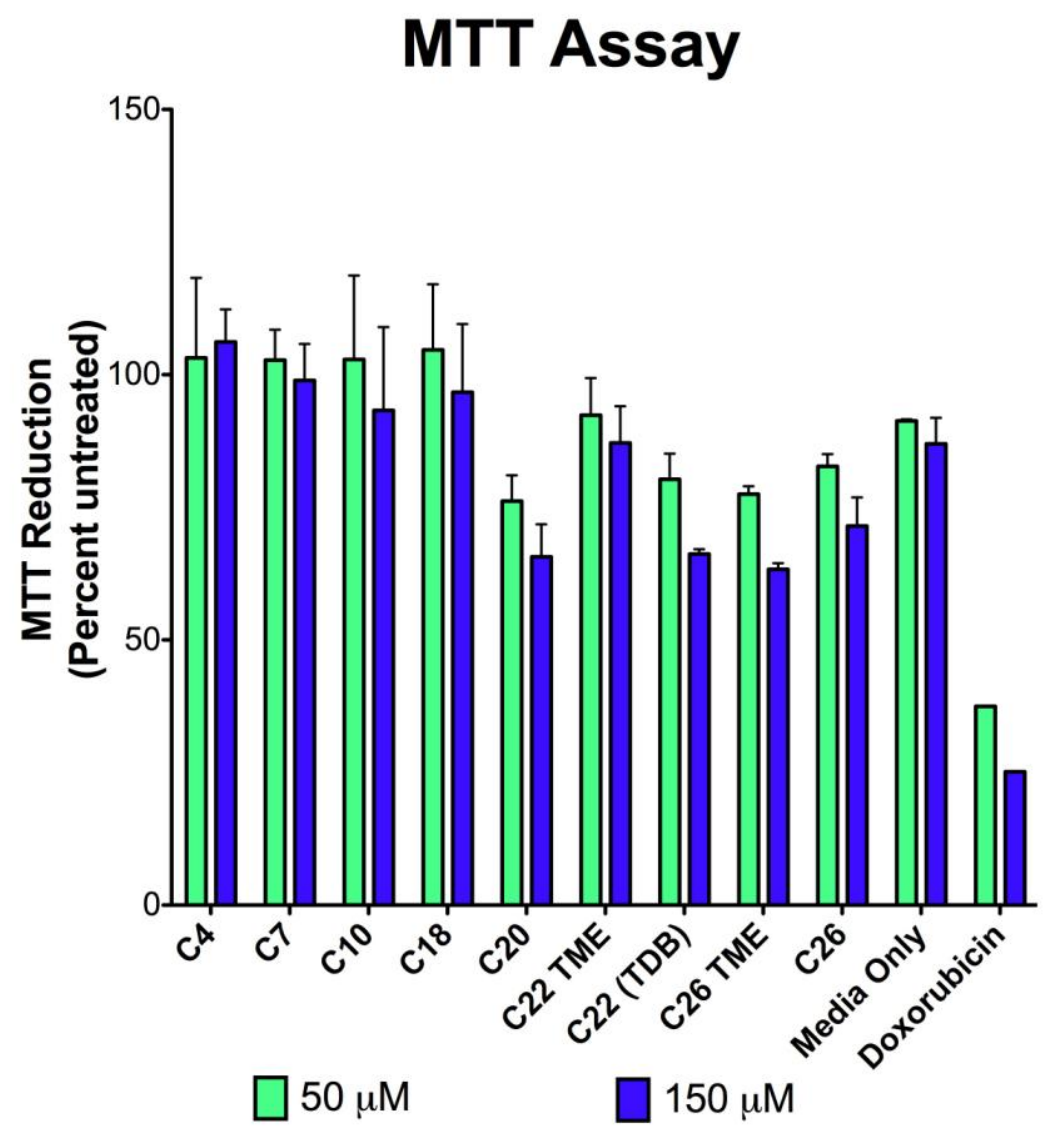

Figure 10. Cytotoxicities of TMEs and TDEs against HepG cell line. HepG cells were stimulated with TDEs, TMEs, Doxorubicin (positive control) at 50 and $150 \mu \mathrm{M}$ for 2 days after which time $20 \mu \mathrm{L}$ MTT was added, followed by addition of SDS lysing buffer after 2 hours. The cells were incubated a further overnight and absorbance were measured in a FLUOstar OPTIMA plate reader at $570 \mathrm{~nm}$.

\section{Future Directions}

Though investigations into understanding the mechanism by which trehalose diesters exert their anti-cancer activity is very much in its infancy, from the analysis it is apparent that when the trehalose esters are administered in PBS they exhibit poor cytotoxicities therefore direct killing of cancer cells by the TDMs is unlikely. It has, however, been shown that the same TDEs are able to activate BMMs, leading to the generation of NO and cytokines (such as IL-1 $\beta$ and IL-6), which suggests an ability to induce a Th1 immune response in macrophages. Given this, one could suggest that 
the anti-tumour activity of the trehalose diesters is due to the ability of the compounds to invoke the systemic activation of macrophages, which could lead to tumour regression, or potentially switch the phenotype of the immunosuppressive TAMs to that of the tumour suppressive M1 phenotype (a phenotypic 'switch' known to occur via the agency of Th-1 cytokines such as tumour necrosis factor (TNF)- $\alpha$ and IL-12. ${ }^{46,47}$ Indeed, if this is true, then improved anti-tumour immunomodulators may be generated through the development of trehalose esters that lead to an optimum 'Th-1' response.

To further substantiate this hypothesis, however, numerous other experiments need to be performed. First, the cytotoxicity of the trehalose esters should be determined when administered in an oil vehicle. Perhaps the cytotoxicity of the compounds depends on the mode of administration, as has been suggested in earlier studies whereby the co-presence of an oil vehicle was necessary for anti-tumour activity. ${ }^{42,44}$ It has also been suggested that oil primarily functions as a carrier of the glycolipids to the tumour site, ${ }^{44}$ and that the lack of activity of trehalose diesters when administered in aqueous media is due to micelle formation, thus rendering the trehalose esters biologically inert. ${ }^{43}$ During the course of this thesis, however, some provisional in vivo results were obtained which suggest that the trehalose diesters (when administered as a solution in 2\% DMSO and PBS) do exhibit an ability to reduce tumour growth [Assay performed by Sabine Kuhn, MIMR]. As this experiment was only performed once, it is too premature to present the work here, however, as some tumour regression was observed, it would therefore be instructive to determine the critical micelle concentration of our diesters. This can readily be achieved by fluorescent measurements of the trehalose glycolipids at $25^{\circ} \mathrm{C}$, using pyrene or pyrene-3-carboxaldehyde as the probe. ${ }^{48}$ Following on from this, the in vivo assays can then be repeated using a selection of trehalose glycolipids. Here, a number of variables can be considered including glycolipid concentration, tumour type, ${ }^{5}$ and the co-administration of LPS. ${ }^{7,9,45,49}$ If significant tumour regression is observed using any one combination of reagents, this experiment could then be repeated using Mincle $^{-/-}$mice to understand more about the mechanism of action. 
Finally, whether trehalose esters have the ability to switch the phenotype of macrophages, for example from TAM to M1 (thus leading to better tumour regression), ${ }^{46,47,50,51}$ could be investigated by following the protocols of Duluc et al. ${ }^{52}$ and Eriksson et al.. ${ }^{47}$ Here, TAMs would be generated from naïve macrophages (obtained from BM cells) by culturing them form 48 hours in complete medium containing 30\% medium from tumour cultures. Subsequent treatment with the TDEs followed by analysis of immunosuppressive and pro-tumoural mediators [e.g. IL-10, Vascular endothelial growth factor (VEGF) and Chemokine ligand (CCL) 18] would then be used to determine if phenotype switching occurs. Should macrophage phenotype switching be observed, these studies can then be repeated using Mincle $^{-/-}$ mice to understand more about the mechanism of action.

\subsection{Conclusion}

From the first part of this work, it is clearly evident that long chain trehalose diesters ( $\geq \mathrm{C} 18)$ are required to activate macrophages. The activation of macrophages was measured using NO and cytokine IL- 6 and IL-1 $\beta$ read-outs. In addition the C22 and C26 TMEs were also shown to activate macrophages, thus unveiling a new sub-class of compounds which have macrophage activation abilities. The work with Mincle $^{-/-}$ and TLR2/4 ${ }^{-{ }_{-}}$BMM clearly showed that Mincle is the key receptor on macrophages for TDEs and TMEs binding. The recognition of TDEs and TMEs is independent of TLR2 and 4 receptors and further testing using other $\mathrm{TLR}^{-/-}$and MyD88 ${ }^{-/-} \mathrm{BMM}$ needs to be performed to rule out involvement of other TLR receptors. TDB has also shown potential to be used as a priming agent, leading to the discovery of a new class of compounds, independent of TLR binding, that can be used to generate an enhanced immune response.

The anti-tumour activity of the TDEs and TMEs was also probed and results from the cytotoxicity assay using HepG2 cell line showed that these compounds were only slightly cytotoxic; however, preliminary in-vivo results showed that both the C10 and C22 TDE have anti-tumour activities. Thus the mechanism by which the trehalose glycolipids exert anti-tumour activity needs to be further investigated. 


\subsection{Experimental}

Material and methods for Biological Assays: C57BL/6 male mice were bred and housed in a conventional animal facility at the Malaghan Institute of Medical Research, Wellington, New Zealand. All animals used for the experiments were aged between 8-10 weeks. All experimental procedures were approved by the Victoria University Animal Ethics Committee in accordance with their guidelines for the care of animals. All synthetic compounds were confirmed to be free of endotoxin, at a sensitivity of $\leq 0.125 \mathrm{EU} / \mathrm{mL}$ by testing them in Limulus amebocyte lysate (LAL) assay using an endotoxin kit (Pyrotell, Limulus Amebocyte Lysate).

Generation of bone marrow derived macrophages (BMMs): Bone marrow cells were collected from the tibia and femur of C57BL/6, $\mathrm{Mincle}^{-/-}$or TLR2/4 ${ }^{-/-}$mice and were cultured (250 000 cells $/ \mathrm{mL}$ ) in Iscove's Modified Dulbecco's Media (IMDMGibco) supplemented with 5\% FBS (Gibco), 1\% Penicillin streptomycin (Gibco) and $55 \mu \mathrm{M}$ 2-mercaptoethanol (Invitrogen) containing $10 \mathrm{ng} / \mathrm{mL}$ GM-CSF (clone $\mathrm{X} 63 / \mathrm{GM}-\mathrm{CSF}$ murine cells). Cells were incubated at $37{ }^{\circ} \mathrm{C}\left(5 \% \mathrm{CO}_{2}\right)$ and the media changed on days 2, 5 and 7. On day 10, the media was removed and the BMM were primed with $10 \mathrm{ng} / \mathrm{mL}$ IFN- $\gamma$ (Peprotech) for $3 \mathrm{~h}$ prior to the addition of the compounds. $^{2}$

BMM Assay: TDEs, TMEs, trehalose, and docasonoic acid stock solutions were prepared $\left(2.5 \mathrm{mg} / \mathrm{mL}\right.$ in PBS containing $2 \%$ DMSO), vortexed and warmed to $50{ }^{\circ} \mathrm{C}$ for $30 \mathrm{~min}$ ( $\mathrm{x}$ 3) to ensure complete solubilisation of the compounds prior to administration to BMM cultures. BMM cultures were then treated with 20 or 40 $\mu \mathrm{g} / \mathrm{mL}$ of TDE, TMEs, trehalose, or behenic acid, with LPS (100 $\mathrm{ng} / \mathrm{mL})$ as a positive control and media only as a negative control for the times indicated. Supernatants were collected and tested immediately for $\mathrm{NO}$ levels or stored at $-80{ }^{\circ} \mathrm{C}$ for subsequent cytokine analysis. 
NO and cytokine analysis: NO levels in supernatants were determined using the Griess assay. Levels of IL-6 and IL-1 $\beta$ cytokine in the supernatants sandwich ELISA (R\&D Systems and BD Biosciences respectively), as per manufacturer's instructions.

HepG2 cell culture: HepG2 cells were maintained in RPMI supplemented with $10 \%$ (v/v) fetal calf serum (FCS), $2 \mathrm{mM}$ glutamate, $100 \mathrm{U} / \mathrm{mL}$ penicillin, and $100 \mu \mathrm{g} / \mathrm{mL}$ streptomycin and were kept at $37{ }^{\circ} \mathrm{C}$ in a humidified incubator maintained at $5 \%$ $\mathrm{CO}_{2}$.

Cell Metabolism MTT assay: Cell metabolism activity was measured using the 2day MTT assay as previously described and reviewed. ${ }^{53,54}$ Doxorubicin was used as a positive control in these experiments. HepG2 cells were plated into 96-well plates in the presence of different concentration of the TDEs and TMEs (final cell concentration $=0.1 \times 10^{6}$ cells $/ \mathrm{mL}$ in complete RPMI $)$ and incubated for $48 \mathrm{~h}\left(37^{\circ} \mathrm{C}\right.$, $\left.5 \% \mathrm{CO}_{2}\right) .20 \mu \mathrm{L}$ of MTT $(2.5 \mathrm{mg} / \mathrm{mL}$ in HBSS $)$ was then added to each well and the cells incubated for $2 \mathrm{~h}$ before adding $100 \mu \mathrm{L}$ of SDS lysing buffer (10\%)w/v SDS, $45 \% \mathrm{v} / \mathrm{v}$ dimethylforamide $/ \mathrm{H}_{2} \mathrm{O}, \mathrm{pH}$ 4.7) and further overnight incubation. The absorbance at $570 \mathrm{~nm}$ was measured in a FLUOstar OPTIMA plate reader (BMG Labtechnologies Pty. Germany). All assays were performed in triplicate and the mean result recorded.

Murine tumour and compound preparation: EG.7-OVA (thymoma) cells were cultured and washed with PBS and resuspended in PBS to a final concentration of 1 x $10^{6}$ cell/mL. C10 and C22 TDEs stock solutions were prepared $(3.0 \mathrm{mg} / \mathrm{mL}$ in PBS containing $2 \%$ DMSO), vortexed and warmed to $50{ }^{\circ} \mathrm{C}$ for $30 \mathrm{~min}$ (x3) to ensure complete solubilisation of the compounds prior to administration. 
Treatment of mice with established tumour transplants: On day 1 groups of 5 mice received $100 \mu \mathrm{L}$ of viable thymoma cells subcutaneously, followed by $50 \mu \mathrm{L}$ of TDEs, 2\% DMSO in PBS (negative control) or $2 \times 10^{6}$ CFU M. smegmatis (positive control). At day 2, 4, 6 and 8 thereafter, the same groups were given intra-tumoural injection of TDEs, $2 \%$ DMSO in PBS or $2 \times 10^{6}$ CFU M. smegmatis.

Evaluation of tumour growth: The tumour size for individual mice were measured (using calipers) every 2 days until the tumour reached $150 \mathrm{~mm}^{2}$

Statistical Analysis: Statistical significance was determined by student's t-test. 


\section{References}

(1) Ishikawa, E.; Ishikawa, T.; Morita, Y. S.; Toyonaga, K.; Yamada, H.; Takeuchi, O.; Kinoshita, T.; Akira, S.; Yoshikai, Y.; Yamasaki, S. J. Exp. Med. 2009, 206, 2879-2888.

(2) Werninghaus, K.; Babiak, A.; Groß, O.; Hölscher, C.; Dietrich, H.; Agger, E. M.; Mages, J.; Mocsai, A.; Schoenen, H.; Finger, K.; Nimmerjahn, F.; Brown, G. D.; Kirschning, C.; Heit, A.; Andersen, P.; Wagner, H.; Ruland, J.; Lang, R. J. Exp. Med. 2009, 206, 89-97.

(3) Schoenen, H.; Bodendorfer, B.; Hitchens, K.; Manzanero, S.; Werninghaus, K.; Nimmerjahn, F.; Agger, E. M.; Stenger, S.; Andersen, P.; Ruland, J.; Brown, G. D.; Wells, C.; Lang, R. J. Immunol. 2010, 184, 2756- 2760.

(4) Matsunaga, I.; Moody, D. B. J. Exp. Med. 2009, 206, 2865-2868.

(5) Nishikawa, Y.; Katori, T.; Kukita, K.; Ikekawa, T. Nippon Kagaku Kaishi 1982, 10, 1661-1666.

(6) Numata, F.; Nishimura, K.; Ishida, H.; Ukei, S.; Tone, Y.; Ishihara, C.; Saiki, I.; Sekikawa, I.; Azuma, I. Chem. Pharm. Bull. 1985, 33, 4544-4555.

(7) Toubiana, R.; Ribi, E.; McLaughlin, C.; Strain, S. M. Cancer Immunol. Immunother. 1977, 2, 189-193.

(8) Pimm, M. V.; Baldwin, R. W.; Polonsky, J.; Lederer, E. Int. J. Cancer 1979, 24, 780-785.

(9) Yarkoni, E.; Rapp, H. J.; Polonsky, J.; Lederer, E. Int. J. Cancer 1978, 22, 564-569.

(10) MacMicking, J.; Xie, Q. -w.; Nathan, C. Annu. Rev. Immunol. 1997, 15, 323350.

(11) Eder, C. Immunobiology 2009, 214, 543 -553.

(12) Russell, D. G. Nat. Rev. Microbiol. 2007, 5, 39- 47.

(13) Flynn, J. L.; Chan, J. Annu. Rev. Immunol. 2001, 19, 93 -129.

(14) Bogle, R. G.; Baydoun, R.; Pearson, J. D.; Moncada, S.; Mann, G. E. Biochem. J 1992, 284, 15-18.

(15) Fang, F. C.; Vazquez-Torres, A. Am. J. Physiol. Lung Mol. Physiol. 2002, 282, L941-L943.

(16) Ignarro, L. J.; Buga, G. M.; Wood, K. S.; Byrns, R. E.; Chaudhuri, G. Proc. Natl. Acad. Sci. 1987, 84, 9265-9269.

(17) Stuehr, D. J.; Nathan, C. F. J. Exp. Med. 1989, 169, 1543-1555.

(18) Classen, A.; Lloberas, J.; Celada, A. Methods Mol. Biol. 2009, 531, 29-43.

(19) Schroder, K.; Hertzog, P. J.; Ravasi, T.; Hume, D. A. J. Leukocyte Biol. 2004, 75, 163-189.

(20) Loke, P.; Nair, M. G.; Parkinson, J.; Guiliano, D.; Blaxter, M.; Allen, J. E. BMC Immunol. 2002, 3, 7-11.

(21) Brennan, P. J.; Nikaido, H. Annu. Rev. Biochem. 1995, 64, $29-63$.

(22) Chatterjee, D. Curr. Opin. Chem. Biol. 1997, 1, 579-588.

(23) Indrigo, J.; Hunter Jr, R. L.; Actor, J. K. Microbiology 2003, 149, 2049-2059.

(24) Rajni; Rao, N.; Meena, L. S. Biotechnol. Res. Int. 2011, Article ID 274693, 7 pages.

(25) Guidry, T. V.; Hunter Jr, R. L.; Actor, J. K. Microbiology 2007, 153, 33603369. 
(26) Hunter, R. L.; Olsen, M.; Jagannath, C.; Actor, J. K. Am. J. Pathol. 2006, 168, 1249-1261.

(27) Ryll, R.; Watanabe, K.; Fujiwara, N.; Takimoto, H.; Hasunuma, R.;

Kumazawa, Y.; Okada, M.; Yano, I. Microbes Infect. 2001, 3, 611-619.

(28) Sada-Ovalle, I.; Chiba, A.; Gonzales, A.; Brenner, M. B.; Behar, S. M. PLoS Pathog. 2008, 4, e1000239.

(29) Actor, J. K.; Olsen, M.; Hunter, R. L.; Geng, Y.-J. J. Interferon Cytokine Res. 2001, 21, 1089-1096.

(30) Davidsen, J.; Rosenkrands, I.; Christensen, D.; Vangala, A.; Kirby, D.; Perrie, Y.; Agger, E. M.; Andersen, P. Biochim. Biophys. 2005, 1718, 22-31.

(31) Holten-Andersen, L.; Doherty, T. M.; Korsholm, K. S.; Andersen, P. Infect. Immun. 2004, 72, 1608-1617.

(32) Osorio, F.; Reis e Sousa, C. Immunity 2011, 34, 651- 663.

(33) Balch, S. G.; Greaves, D. R.; Gordon, S.; McKnight, a J. Eur. J. Immunogenet. 2002, 29, 61-4.

(34) Matsumoto, M.; Tanaka, T.; Kaisho, T.; Sanjo, H.; Copeland, N. G.; Gilbert, D. J.; Jenkins, N. A.; Akira, S. J. Immunol. 1999, 163, 5039-5048.

(35) Wells, C. A.; Salvage-Jones, J. A.; Li, X.; Hitchens, K.; Butcher, S.; Murray, R. Z.; Beckhouse, Anthony, G.; Lo, Y.-L.-S.; Manzanero, S.; Cobbold, C.; Schroder, K.; Ma, B.; Orr, S.; Stewart, L.; Lebus, D.; Sobieszczuk, P.; Hume, D. A.; Stow, J.; Blanchard, H.; Ashman, R. B. J. Immunol. 2008, 180, 74047413.

(36) Yamasaki, S.; Matsumoto, M.; Takeuchi, O.; Matsuzawa, T.; Ishikawa, E.; Sakuma, M.; Tateno, H.; Uno, J.; Hirabayashi, J.; Mikami, Y.; Takeda, K.; Akira, S.; Saito, T. Proc. Natl. Acad. Sci. 2009, 106, 1897- 1902.

(37) Khan, A. A.; Chee, S. H.; McLaughlin, R. J.; Harper, J. L.; Kamena, F.; Timmer, M. S. M.; Stocker, B. L. ChemBioChem 2011, 3, 2572-2576.

(38) Ferwerda, G.; Meyer-Wentrup, F.; Kullberg, B.-J.; Netea, M. G.; Adema, G. J. Cell. Microbiol. 2008, 10, 2058-2066.

(39) Geisel, R. E.; Sakamoto, K.; Russell, D. G.; Rhoades, E. R. J. Immunol. 2005, 174, 5007-5015.

(40) Bowdish, D. M. E.; Sakamoto, K.; Kim, M.-J.; Kroos, M.; Mukhopadhyay, S.; Leifer, C. A.; Tryggvason, K.; Gordon, S.; Russell, D. G. PLoS Pathog. 2009, 5, e1000474.

(41) Pestka, J.; Zhou, H.-R. Toxicol. Sci. 2006, 92, 445-455.

(42) Kohya, H.; Ishii, F.; Takano, S.; Katori, T.; Ebina, T.; Ishida, N. Jpn. J. Cancer Res. 1986, 77, 602-609.

(43) Retzinger, G. S.; Meredith, S. C.; Hunter, R. L.; Takayama, K.; Kezdy, F. J. J. Immunol. 1982, 129, 735-744.

(44) Barclay, W. R.; Anacker, R.; Brehmer, W.; Ribi, E. J. Bacteriol. 1967, 94, 1736-1745.

(45) Kamiya, S. Hirosaki Igaku 1986, 38, 712-719.

(46) Palma, M. D.; Lewis, C. E. Nature 2011, 472, 303-304.

(47) Eriksson, F.; Tsagozis, P.; Lundberg, K.; Parsa, R.; Mangsbo, S. M.; Persson, M. A. A.; Harris, R. A.; Pisa, P. J. Immunol. 2009, 182, 3105-3111.

(48) Ananthapadmanabhan, K. P.; Goddard, E. D.; Turro, N. J.; Kuo, P. L. Langmuir 1985, 1, 352-355. 
(49) Fukushi, K. Antitumor formulation containing lipopolysaccharide with trehalose derivatives 1986, 4.

(50) Koto, K.; Murata, H.; Kimura, S.; Horie, N.; Matsui, T.; Nishigaki, Y.; Ryu, K.; Sakabe, T.; Itoi, M.; Ashihara, E.; Maekawa, T.; Fushiki, S.; Kubo, T. Oncol. Rep. 2010, 24, 233-239.

(51) Coscia, M.; Quaglino, E.; Iezzi, M.; Curcio, C.; Pantaleoni, F.; Riganti, C.; Holen, I.; Mönkkönen, H.; Boccadoro, M.; Forni, G.; Musiani, P.; Bosia, A.; Cavallo, F.; Massaia, M. J Cell. Mol. Med. 2010, 14, 2803-2815.

(52) Duluc, D.; Corvaisier, M.; Blanchard, S.; Catala, L.; Descamps, P.; Gamelin, E.; Ponsoda, S.; Delneste, Y.; Hebbar, M.; Jeannin, P. Int. J. Cancer 2009, 125, 367-373.

(53) Berridge, M. V.; Herst, P. M.; Tan, A. S. Biotechnol. Annu. Rev. 2005, 11, 127-152.

(54) Berridge, M. V.; Tan, A. S. Arch. Biochem. Biophys. 1993, 303, 474-482. 



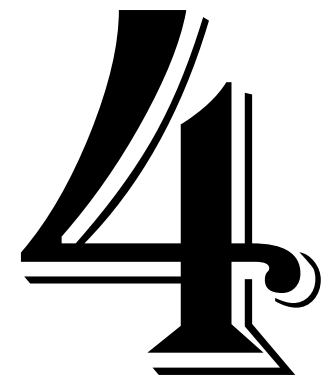

\section{An Improved Fráter-Seebach Alkylation 1}

\subsection{Introduction}

Fráter-Seebach alkylation is a key step commonly used in the synthesis of trehalose dimycolates (TDMs, 1, Figure 1) and trehalose dicorynomycolate (TDCM, 2) to install the $\alpha$-chain in the mycolic acid and corynomycolic acid fragments, respectively. However, using this methodology for installing long alkyl chains at the $\alpha$-position of $\beta$-hydroxy esters has been met with mixed success. In order to improve the efficacy of this reaction for the installation of long alkyl chains, we developed a strategy whereby allyl halides are used as electrophiles. 


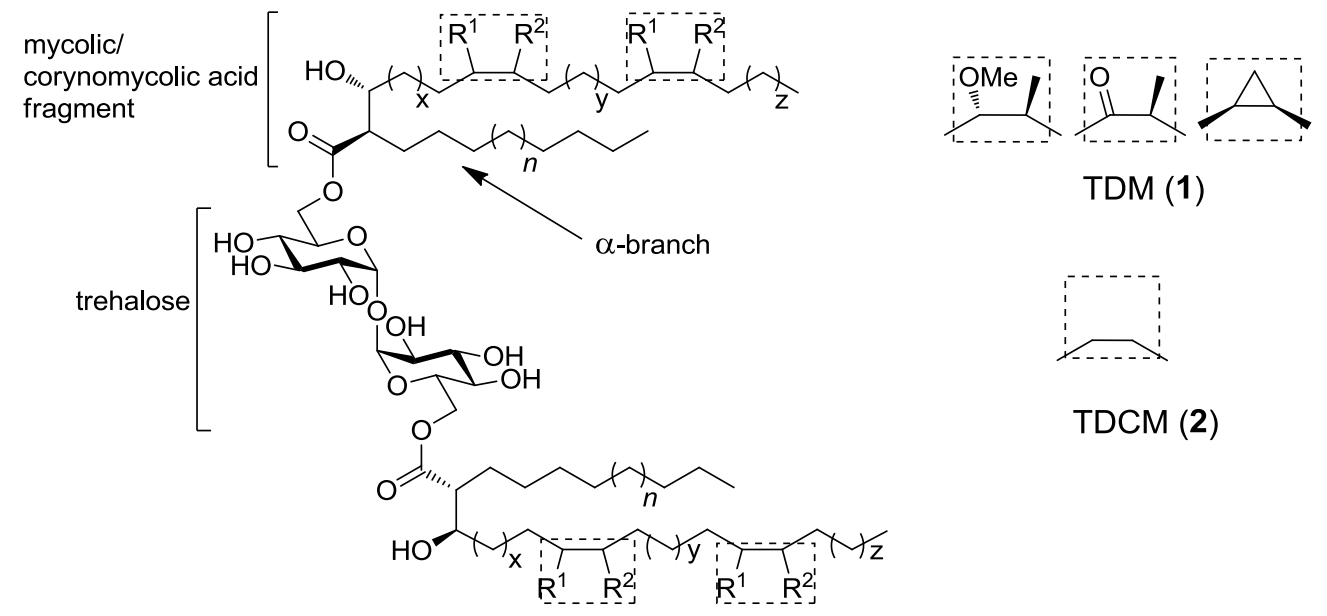

Figure 1. TDM (1) and TDCM (2)

Allyl halides are known to have excellent reactivity, which arises from stereoelectronic interactions between the $\sigma^{*}{ }_{\mathrm{C}-\mathrm{X}}$ orbital and the adjacent $\pi$ system. ${ }^{2,3}$ In the transition state for the $S_{N} 2$ reaction of an allylic halide (I, Scheme 1), the overlap between the p orbital developed on the carbon at which displacement occurs and the p orbitals of the conjugated double bond allows for electron density of the $\pi$ system to be delocalised over the three carbon atoms involved in the allylic system (II). This, in turn, leads to a lower transition state energy when compared to that of the corresponding saturated halide, resulting in higher yield of the product (III).

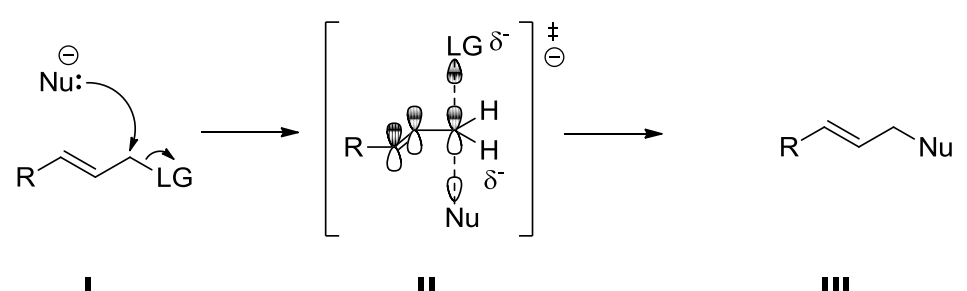

Scheme 1. Transition state for allyl halide substitution via an $S_{N} 2$ reaction

Accordingly, we proposed that a Fráter-Seebach alkylation using highly reactive long chain allylic iodides would lead to more efficient $\alpha$-alkylations when compared to the alkyl halide counterpart. The hydroxy-ester of choice was diethyl malate (3) which could be derivatised at a later stage to form the corynomycolic or mycolic 
acids for the synthesis for TDCMs and TDMs respectively. A range of allylic iodides (4) were used to form alkylated esters 5 of varying lipid lengths (Scheme 2).

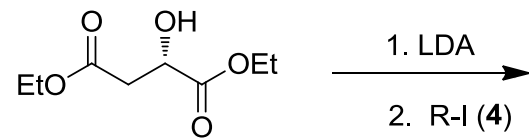

3<smiles>[R]C(C(=O)OCC)[C@@H](O)C(=O)OCC[CH2+]</smiles>

5-anti

5-syn

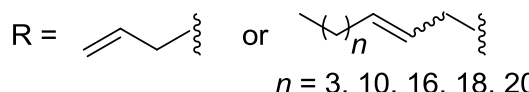

Scheme 2. Proposed Fráter-Seebach alkylation

\subsection{Results and Discussion}

\subsubsection{Synthesis of allylic iodides}

To prepare the required allylic iodides, an efficient two-step strategy was proposed, that first involved the Grignard addition of vinyl magnesium bromide to an aldehyde ${ }^{3}$ and a subsequent $\mathrm{S}_{\mathrm{N}} 2^{\prime}$ substitution of the in situ generated alkoxytriphenylphosphonium iodide intermediate (Scheme 3$){ }^{4}$ The starting aldehydes, pentanal $\mathbf{6 a}$ and dodecanal $\mathbf{6 b}$, were sourced commercially, while octadecanal 6c, eicosanal 6d, and docosanal 6e were prepared via a pyridinium chlorochromate (PCC) oxidation of the corresponding alcohols. ${ }^{5}$ In case of pentanal and dodecanal, the Grignard reaction was carried out smoothly in THF with $1 \mathrm{M}$ vinyl magnesium bromide solution, to give the corresponding allylic alcohols $\mathbf{7 a - b}$ in good yields. However, when longer aldehydes $\mathbf{6 c - 6 e}$ were used, the yield for this reaction was quite low, with reduction of the aldehyde to the corresponding alcohols also observed. In order to reduce this by-product formation, the solvent was replaced with toluene, which had been previously reported to minimise aldehyde reduction. ${ }^{6}$ Indeed, a small improvement in product yield was observed, however, the by-product was still present. Other reasons for this by-product formation were attributed to the lower reactivity of long chain aldehydes, and the quality of the reagents used. Thus, in an attempt to improve the latter, vinyl magnesium bromide was prepared in situ ${ }^{7}$ and the reaction was performed at $0{ }^{\circ} \mathrm{C}$ in toluene, which did indeed lead to improved yields (71-89\%) of the allylic alcohols 7c-7e. 


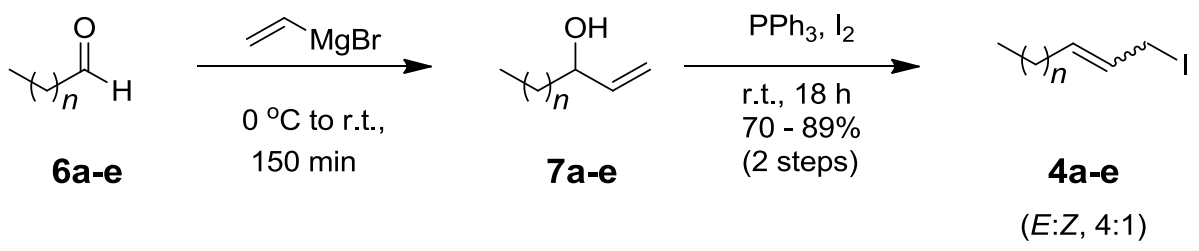

$n=3,10,16,18,20$

Scheme 3. Synthesis of representative allylic iodides

The intermediate allylic alcohols 7a-e were then subjected to a short silica gel plug and used immediately in the iodination reaction, as they are prone to decomposition. ${ }^{4}$ Treatment of each alcohol with a solution of triphenylphosphine and iodine in THF gave the corresponding allylic iodides, $4 \mathbf{a}(n=3), \mathbf{4 b}(n=10), \mathbf{4 c}(n=16), \mathbf{4 d}(n=$ $18)$ and $4 \mathbf{e}(n=20)$ in $89 \%, 81 \%, 70 \%, 71 \%$ and $73 \%$ yield, respectively, over two steps. As anticipated, each of the allylic iodides 4a-e were found to be an inseparable isomeric mixture consisting mainly of the $E$-isomer $(E: Z \mathrm{ca} .4: 1)$, as determined by the $18.6 \mathrm{~Hz}$ vs $8.5 \mathrm{~Hz}$ coupling constant for the alkene protons in the ${ }^{1} \mathrm{H}$ NMR of the crude reaction mixtures. Spectroscopically, a very minor $(<5 \%)$ amount of the corresponding 1,3-diene elimination product was also observed during the reaction.

The iodination of allylic alcohol 4a-e could be asserted to occur via a $\mathrm{S}_{\mathrm{N}} 2^{\prime}$ mechanism (Scheme 4). ${ }^{3}$ Here, the in situ generated iodophosphonium iodide (IV), undergoes a nucleophilic attack by alcohol $\mathbf{V}$, which results in the generation of an alkoxytriphenylphosphonium iodide (VI). $\mathrm{S}_{\mathrm{N}} 2^{\prime}$ attack of the iodide then leads to the generation of the desired internal alkene (VII), with triphenylphosphine oxide (VIII) being generated as a by-product. 


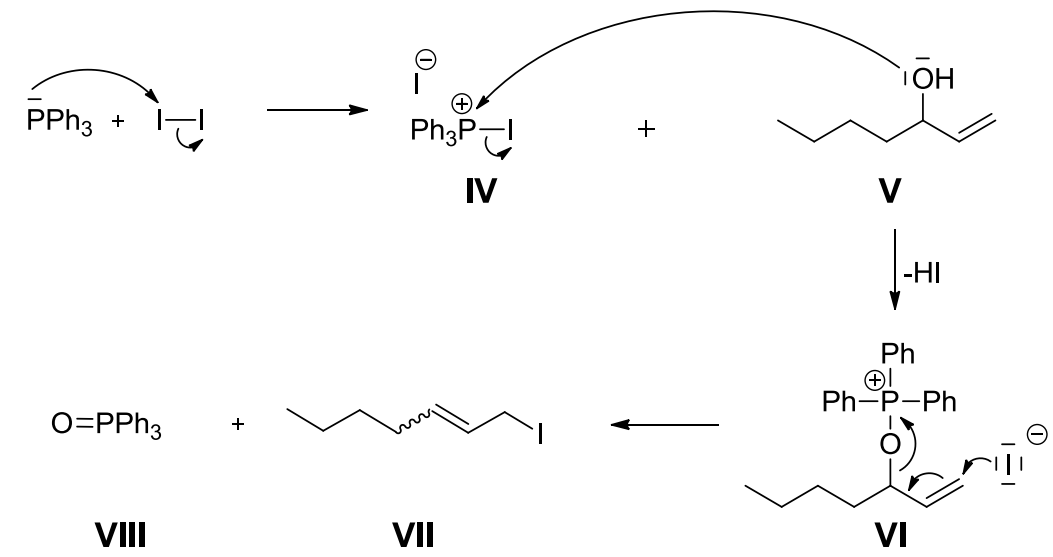

Scheme 4. Mechanism for the $S_{N} 2$ reaction

\subsubsection{Fráter-Seebach Alkylation}

With the necessary allylic halides in hand, we set out to investigate their potential in a Fráter-Seebach alkylation. Thus, diethyl malate 3, was prepared via esterification of the commercially available L-malic acid in a good (95\%) yield, ${ }^{8}$ and then alkylated with the allylic halides or their saturated counterparts (Table 1). The saturated alkyl iodides were prepared via the iodination of the corresponding alcohols or, in the case of iodo-tetradecane, via cross halogenation of bromo-tetradecane. Overall yields were, in general, similar to those for the preparation of the allylic iodides. The alkylations were performed in THF using 2.5 equivalents of lithium diisopropylamide (LDA, generated in situ at $-78{ }^{\circ} \mathrm{C}$ ), to which was added 1 equivalent of diethyl malate 3 , followed by 1.5 equivalents of the alkyl or alkenyl halide.

Our first study involved the alkylation of diethyl malate $\mathbf{3}$, using either allyl bromide (entry 1), or allyl iodide (entry 2), in the absence of hexamethylphosphoramide (HMPA). As illustrated, both reactions proceeded smoothly to give anti-5a as the predominant diastereomer in respectable yield. Use of heptyl iodide, however resulted in a decreased yield with $\mathbf{5 b}$ being obtained in $37 \%$ following purification by flash column chromatography (entry 3). There was no other identifiable product obtained from the reaction, and although excess alkyl halide could be recovered from the reaction mixture, diethyl malate $\mathbf{3}$ had decomposed. On the other hand, 
alkylation with the C7 allylic iodide, 1-iodo-hept-2-ene (4a), resulted in an improved (55\%) yield of the desired $\alpha$-alkylated $\beta$-hydroxy ester with a diastereoselectivity of 9:1; anti:syn (entry 4). This result was encouraging and demonstrated the improved reactivity of the allylic system. 
Table 1. Alkylation Conditions and Yields

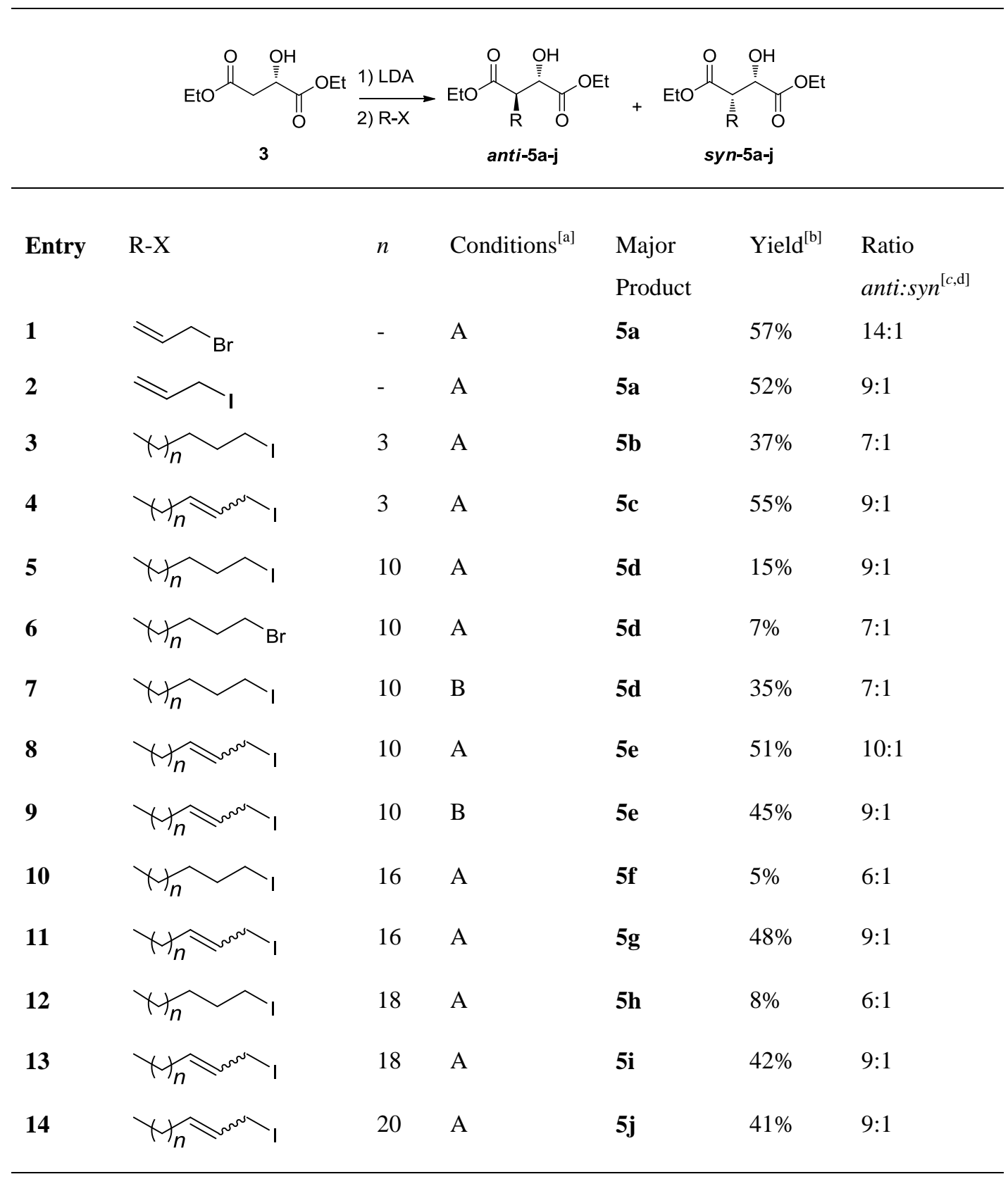

[a] A. LDA (2.5 equiv.), 3 (1 equiv.), R-X (1.5 equiv.), THF; B. As in A, but with the addition of HMPA (HMPA:THF; 1:1).

[b] Isolated yield following purification by flash chromatography

[c] Determined by ${ }^{1} \mathrm{H}$ NMR (in case of the allylic compounds after hydrogenation) of the crude reaction mixture

[d] Used as a mixture of isomers $(E: Z c a .4: 1)$ 
When either 1-iodotetradecane or 1-bromotetradecane was used as the electrophile, very poor yield of the corresponding $\alpha$-alkylated ester $\mathbf{5 d}$ was observed (entries 5 and 6). In an attempt to improve these yields, HMPA was added to the reaction vessel as a co-solvent. HMPA has been shown to enhance $S_{N} 2$ reactions via its ability to strongly solvate cations, and has been used by Utaka et al. ${ }^{9}$ and Fujisawa et $a l .{ }^{10}$ to perform $\alpha$-alkylations using 1 -iodotetradecane. Indeed, we also observed an improvement in reaction yield (35\%) when HMPA was added (entry 7). These results were then compared to similar reactions using the corresponding C14 allylic iodide. In the absence of HMPA, the use of 1-iodotetradec-2-ene (entry 8) gave an improved 51\% yield of ester 5e ( $c f$. entry 5). Surprisingly, the addition of HMPA to the reaction mixture (entry 9) did not further improve the yield ( $c f$. entry 8). In view of the toxicity of this reagent and the lack of improvement in reaction yield, HMPA was not used in subsequent alkylations.

The difficulties in obtaining good yields when using long chain alkyl iodides in the Fráter-Seebach alkylation was further demonstrated when attempts were made to alkylate diethyl malate 3 using 1-iodoeicosane (entry 10). In our hands, this reaction resulted in a dismal 5\% yield. The general problem we encountered when performing this $\alpha$-alkylation was that the reaction was very slow and required the gradual warming of the reaction mixture from $-78{ }^{\circ} \mathrm{C}$ to $0{ }^{\circ} \mathrm{C}$ for any product formation to be observed via TLC. Unfortunately, the temperature at which the reaction commenced ( ca. $-20{ }^{\circ} \mathrm{C}$ ) was also the temperature at which diethyl malate $\mathbf{3}$ began to decompose. Many changes to solvent, reaction time, and equivalents of reagents were then made in an attempt to improve this yield, but without success. A change to iodo-eicos-2ene, however, gave the desired $\alpha$-alkylated ester $\mathbf{5 g}$ in a much improved $49 \%$ yield (entry 11). Although some decomposition of diethyl malate $\mathbf{3}$ was observed, we were satisfied with the final yield of the ester anti-5g, given the difficulty of this $\alpha$ alkylation. Attempts at performing the Fráter-Seebach alkylation using 1iododocosane gave a mere $8 \%$ yield of $\mathbf{5 h}$ (entry 12 ), while the use of iodo-docos-2ene as an electrophile improved the yield of the alkylation to $42 \%$ (entry 13). The methodology was then used to synthesise ester anti-5j, which contains the most common mycolic acid $\alpha$-chain length. Gratifyingly, the yield for this reaction was a respectable $41 \%$ (entry 14 ). In all examples, the diastereoselectivity of the allylic 
alkylations was excellent (ca. 9:1, anti:syn), and was higher than those observed for the corresponding saturated alkyl halides.

\subsubsection{Hydrogenation}

Having demonstrated the benefit of allylic halides in the Fráter-Seebach alkylation, we then set about to hydrogenate the $\alpha, \beta$-unsaturated esters (Scheme 4). The mixtures of diastereomers anti:syn $(n=3,10,16,18,20)$ were thus hydrogenated in the presence of catalytic (5 wt\%) $\mathrm{Pd} / \mathrm{C}$ (Scheme 5). Following hydrogenation, the diastereomers were readily separable by flash column chromatography and the desired esters anti-5b $(n=3)$, anti-5d $(n=10)$, anti-5f $(n=16)$, anti-5h $(n=18)$ and anti-5k $(n=20)$ were isolated as pure compounds in excellent yields $(90-91 \%)$.<smiles>C[CH+]/C=C/C[C@H](C(=O)OCC)[C@@H](O)C(=O)OCC</smiles>

$5 c, e, g, i, j$

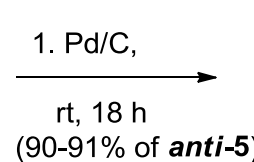

(90-91\% of anti-5)<smiles></smiles>

anti-5b,d,f,h, $\mathrm{k}$

Scheme 5. Hydrogenation of $\alpha, \beta$-unsaturated esters

\subsubsection{Diastereoselectivity}

In an attempt to prove that the major diastereomer obtained from the Fráter-Seebach reaction was indeed the anti-isomer, we set about hydrolysising ester anti-5b to form the di-acid 8. This could potentially be crystallised, enabling the use of X-ray crystallography to determine the absolute stereochemistry of the compound. We opted to use this method as crystallisation of the hydrolysed product of malic ester $\mathbf{5 a}$ had been reported in Seebach's earlier work. ${ }^{11}$ To this end, ester anti-5b (obtained after hydrogenation of $\mathbf{5 c}$ ) was subjected to hydrolysis with potassium carbonate in $\mathrm{MeOH}: \mathrm{H}_{2} \mathrm{O}$ (1:1) in order to form di-acid 8 (Scheme 6). The crude product was obtained as a white solid, however, despite several attempts, compound $\mathbf{8}$ could not be crystallised, with a waxy solid being obtained in most instances. This may be due 
to the lipid chain at the $\alpha$-position of the molecule, and thus another method of distereoselectivity determination was investigated.
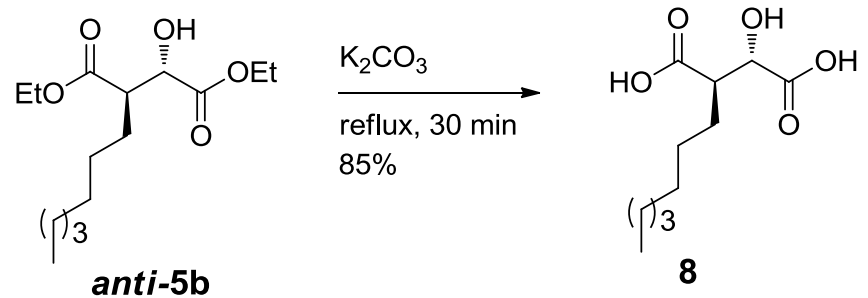

Scheme 6. Hydrolysis of product $\mathbf{5 b}$

We envisaged using cross metathesis as a means of deducing the stereochemistry of the alkylated compounds. Thus, Grubbs cross metathesis reaction ${ }^{12}$ was performed between allylic ester anti-5a (of known $2 S, 3 R$ stereochemistry), ${ }^{11}$ and 1-tridecene to give the unsaturated ester anti-5e in $41 \%$ yield and in an $E: Z$ ratio of $4: 1$ (Scheme 7). In addition, the homo-dimerisation product of 1-tridecene was observed along with unreacted allylic ester anti-5a, which accounted for the remainder of the material. Hydrogenation of ester anti-5e then gave a product that exhibited spectral data consistent with those obtained from the direct alkylation of ethyl $(S)$-malate 5 with 1iodotetradecane (Table 1). This unequivocally established that the major isomer from the allylic alkylation was the anticipated $2 S, 3 R$-ester.

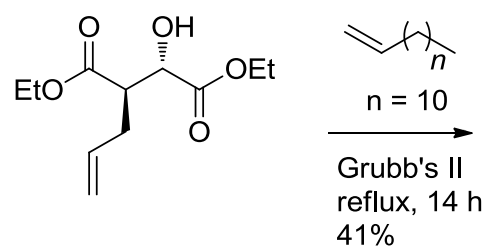

anti-5a

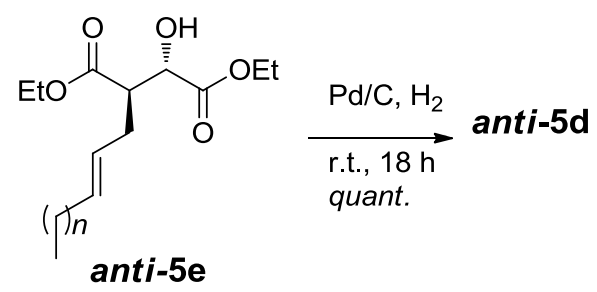

Scheme 7. Confirming the stereochemistry of the alkylated products

To explain the preferential formation of the $2 S, 3 R$ diastereomer, the rigid cyclic intermediate that is formed during the course of reaction needs to be considered (Scheme 8). More than two equivalents of LDA are added to the $\beta$-hydroxy ester, 
whereby, one equivalent is used to deprotonate the hydroxyl, which results in the formation of a monoanion where the negatively charged oxygen is countered by the lithium cation, while the second equivalent of LDA leads to the formation of an ester enolate where the lithium cation bridges the two negative charges via a sixmembered cyclic intermediate IX. Regeneration of the carbonyl then allows the enolate $\mathbf{X}$, to attack the alkyl halide, $\mathrm{R}-\mathrm{X}$, at the face opposite to the ester which is adjacent to the $\beta$-hydroxyl substituent due to steric hindrance thus leading to the antidiastereomer XI ${ }^{13}$ It should also be noted that greater reactivity of the allylic system leads to higher diastereoselectivities, due to the ability of the reactions to be performed at lower temperatures.

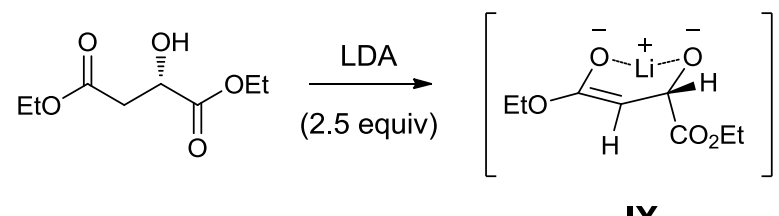

IX<smiles>[R]C(C(=O)OCC)[C@@H](O)C(=O)OCC</smiles>

$\mathbf{X} \mathbf{I}$

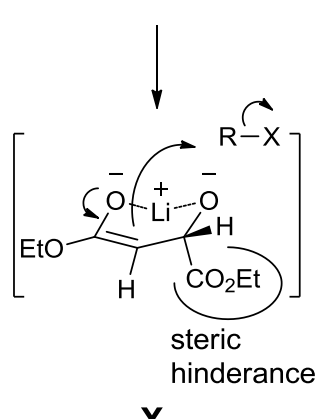

$\mathbf{x}$

Scheme 8. Explanation of stereoselectivity in the Fráter-Seebach alkylation

\subsubsection{Product Characterisation}

The Fráter-Seebach reaction products were characterised by NMR and mass spectral analyses. As shown for compound 5j (Figure 2 and 3), the distinct resonance for the alkylated products included peaks at $5.56 \mathrm{ppm}(\mathrm{dt}, J=15.1 \mathrm{~Hz}, J=6.8 \mathrm{~Hz})$ and 5.39 ppm (dt, $J=15.1 \mathrm{~Hz}, J=6.5 \mathrm{~Hz}$ ) for the alkene protons. In addition, the resonance at $2.91 \mathrm{ppm}(\mathrm{ddd}, J=9.1 \mathrm{~Hz}, J=9.1 \mathrm{~Hz}, J=3.2 \mathrm{~Hz})$ intergrated for one proton and had COSY correlations to $\alpha$-protons of the lipid chain at $2.58-2.53 \mathrm{ppm}(\mathrm{m})$ and at 2.38 ppm (ddd, $J=14.3 \mathrm{~Hz}, J=8.3 \mathrm{~Hz}, J=8.3 \mathrm{~Hz}$ ), indicating that alkylation has occured at the desired position. Furthmore, the different signals for the two $\alpha$-protons of the 
lipid chain were indictive of an adjacent chiral centre. A clear HMBC between the resonance at $5.39 \mathrm{ppm}$ and $\mathrm{C}-3$ at $48.6 \mathrm{ppm}$, establised the postion of the respective allylic protons. Mass spectral analysis of the product was in agreement the expected mass; [HRMS(ESI) $m / z$ calcd. for $\left[\mathrm{C}_{32} \mathrm{H}_{60} \mathrm{O}_{5}+\mathrm{Na}\right]^{+}:$547.4338, obsd.: 547.4344.] and full assignment was made on the basis of 2D NMR (COSY, HSQC and HMBC) (see experimental for full assignment). With the saturated alkylated products as shown for 5k (Figure 4 and 5), key peaks in the ${ }^{1} \mathrm{H}$ NMR included resonance at $2.84(\mathrm{td}, J=7.3$ $\mathrm{Hz}, J=3.7 \mathrm{~Hz}$ ) intergrating for one proton and the protons from the $\alpha$-chains at 1.83 (ddt, $J=13.9 \mathrm{~Hz}, J=7.6 \mathrm{~Hz}, J=7.6 \mathrm{~Hz})$, and $1.66 \mathrm{ppm}(\mathrm{ddt}, J=13.9 \mathrm{~Hz}, J=7.1 \mathrm{~Hz}$, $J=7.1 \mathrm{~Hz}$ ). HMBC correlation between the $\alpha$-protons and carbonyl peak at 172.9 ppm establised the resonances for one of the carbonyl carbons. Mass spectral analysis of the product was in agreement with the expected mass; [HRMS(ESI) m/z calcd. for $\left[\mathrm{C}_{32} \mathrm{H}_{62} \mathrm{O}_{5}+\mathrm{Na}\right]^{+}:$549.4495, obsd.: 549.4490] ${ }^{+}$and full assignment was made on the basis of 2D NMR (COSY, HSQC and HMBC) (see experimental for full assignment). 


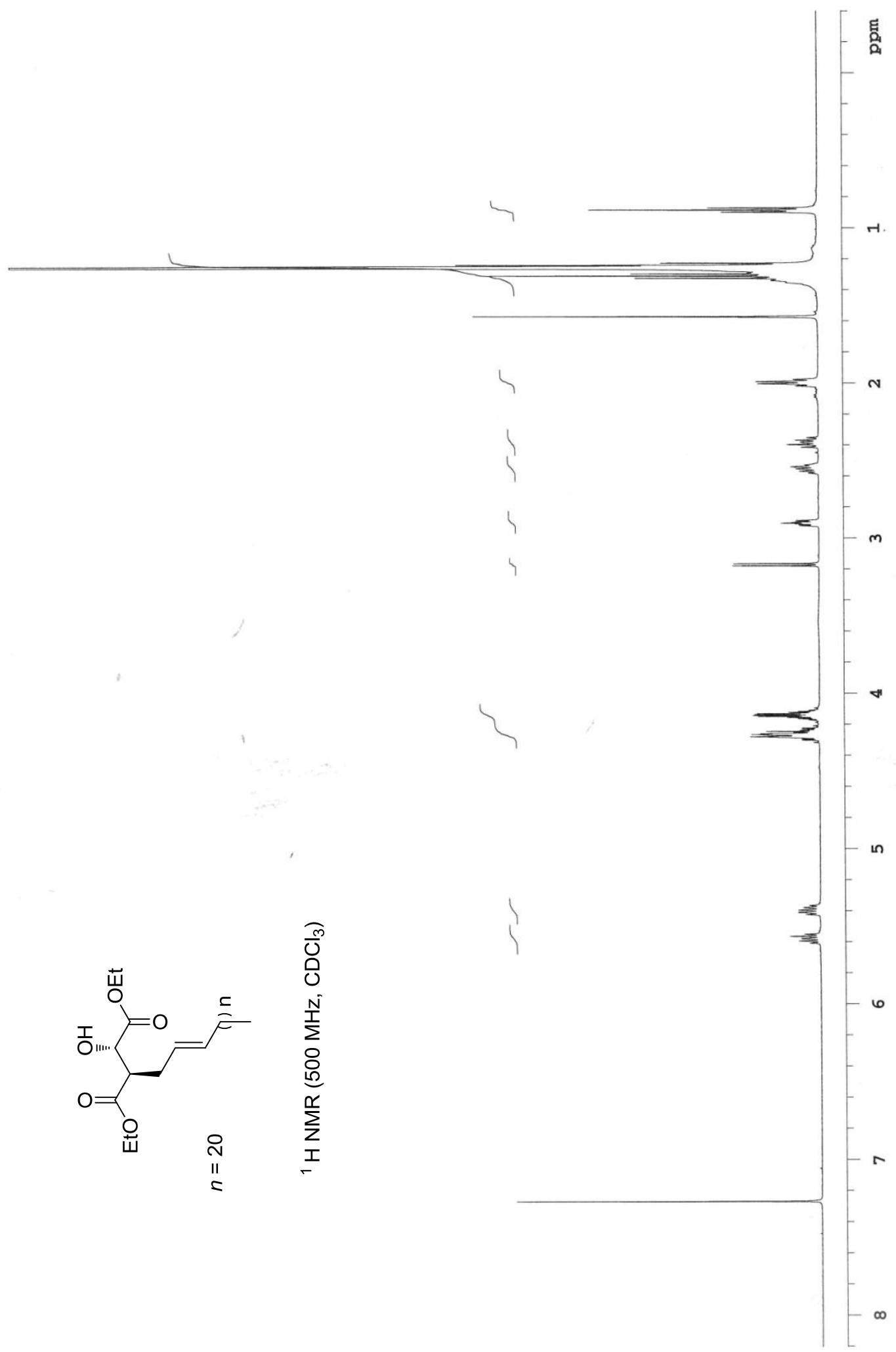

Figure 2. ${ }^{1} \mathrm{H}$ NMR spectrum of product $\mathbf{5 j}$ 


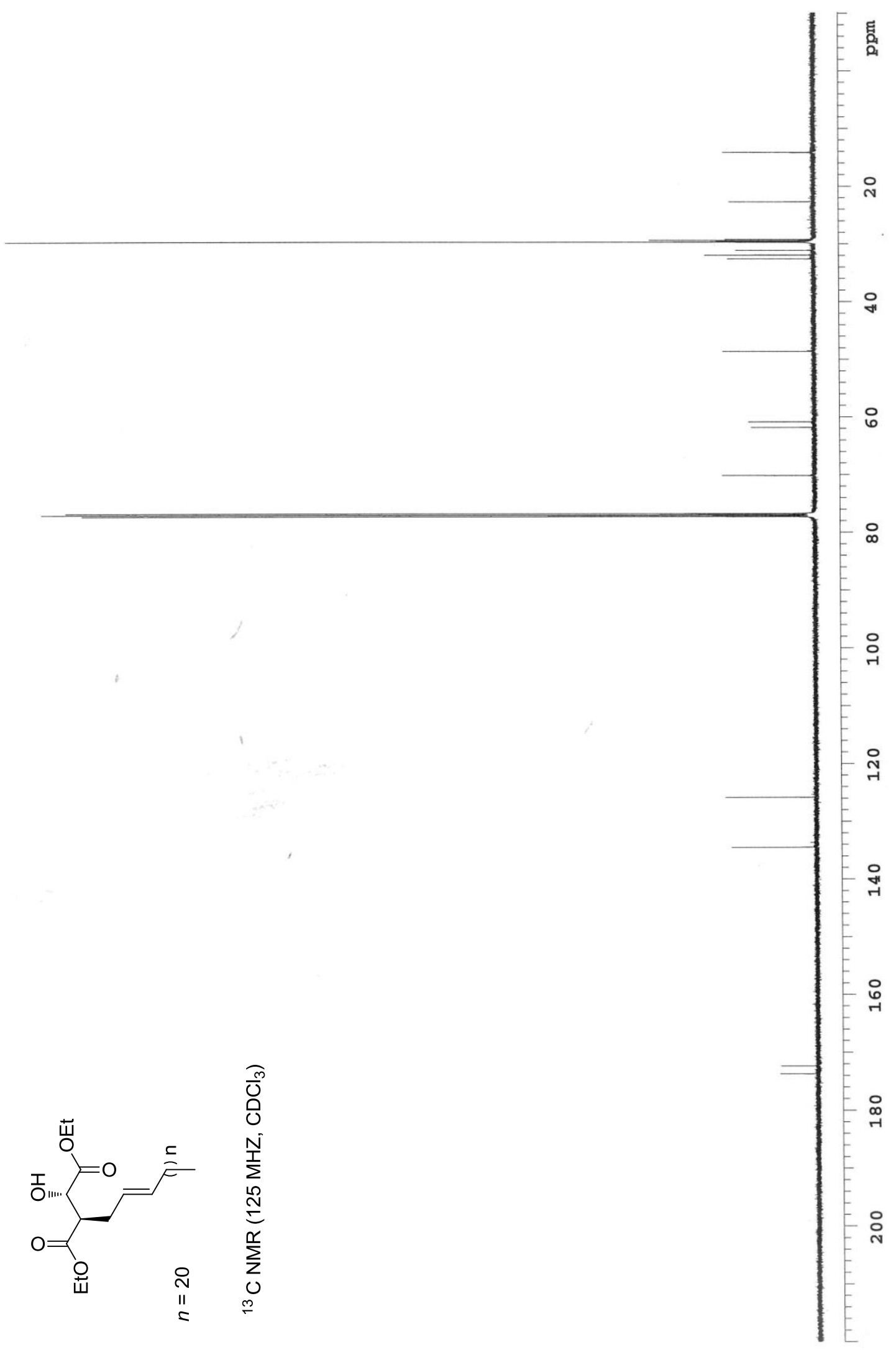

Figure 3. ${ }^{13} \mathrm{C}$ NMR spectrum for product $\mathbf{5 j}$ 


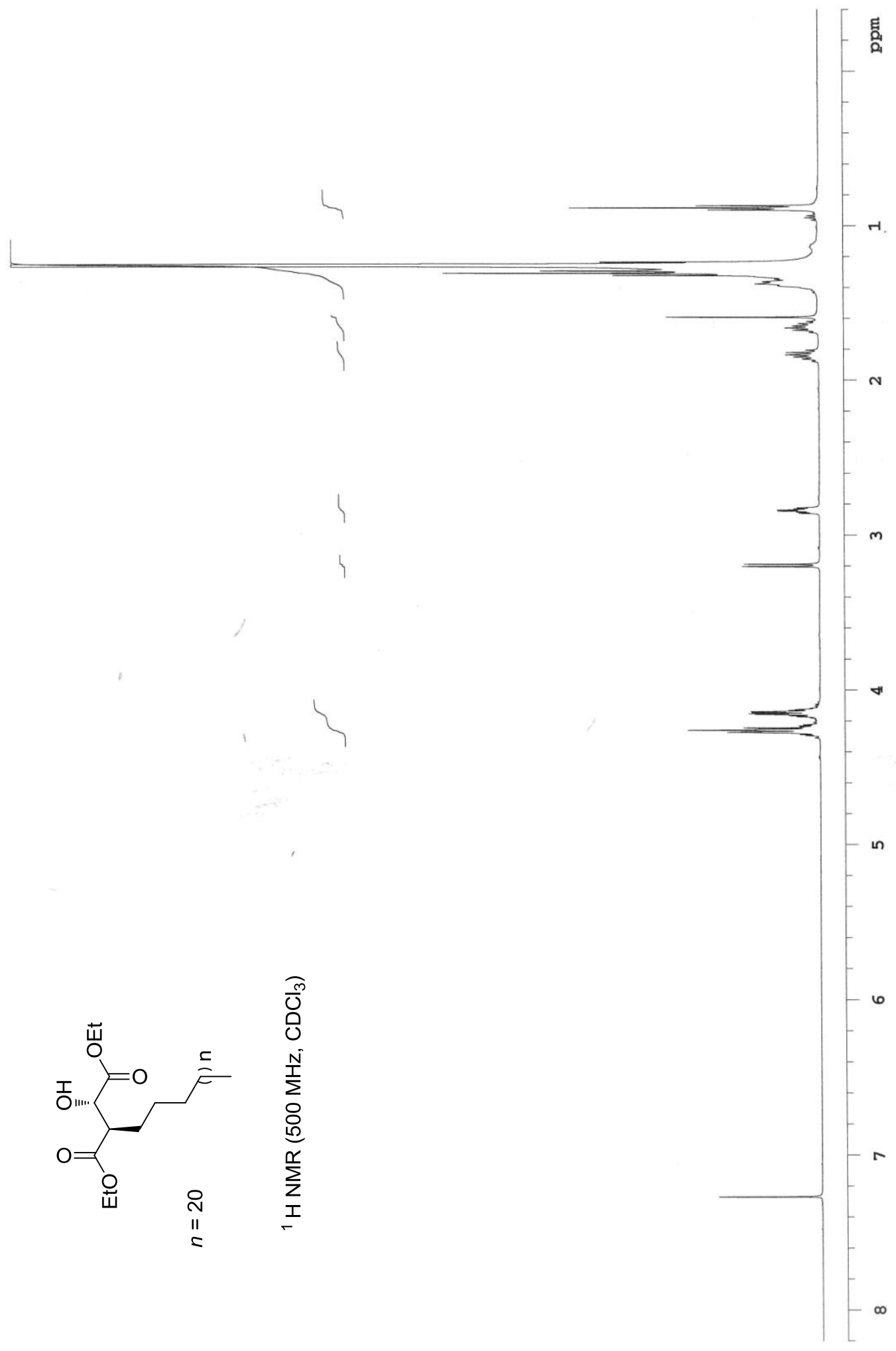

Figure 4. ${ }^{1} \mathrm{H}$ NMR spectrum of product $\mathbf{5 k}$ 


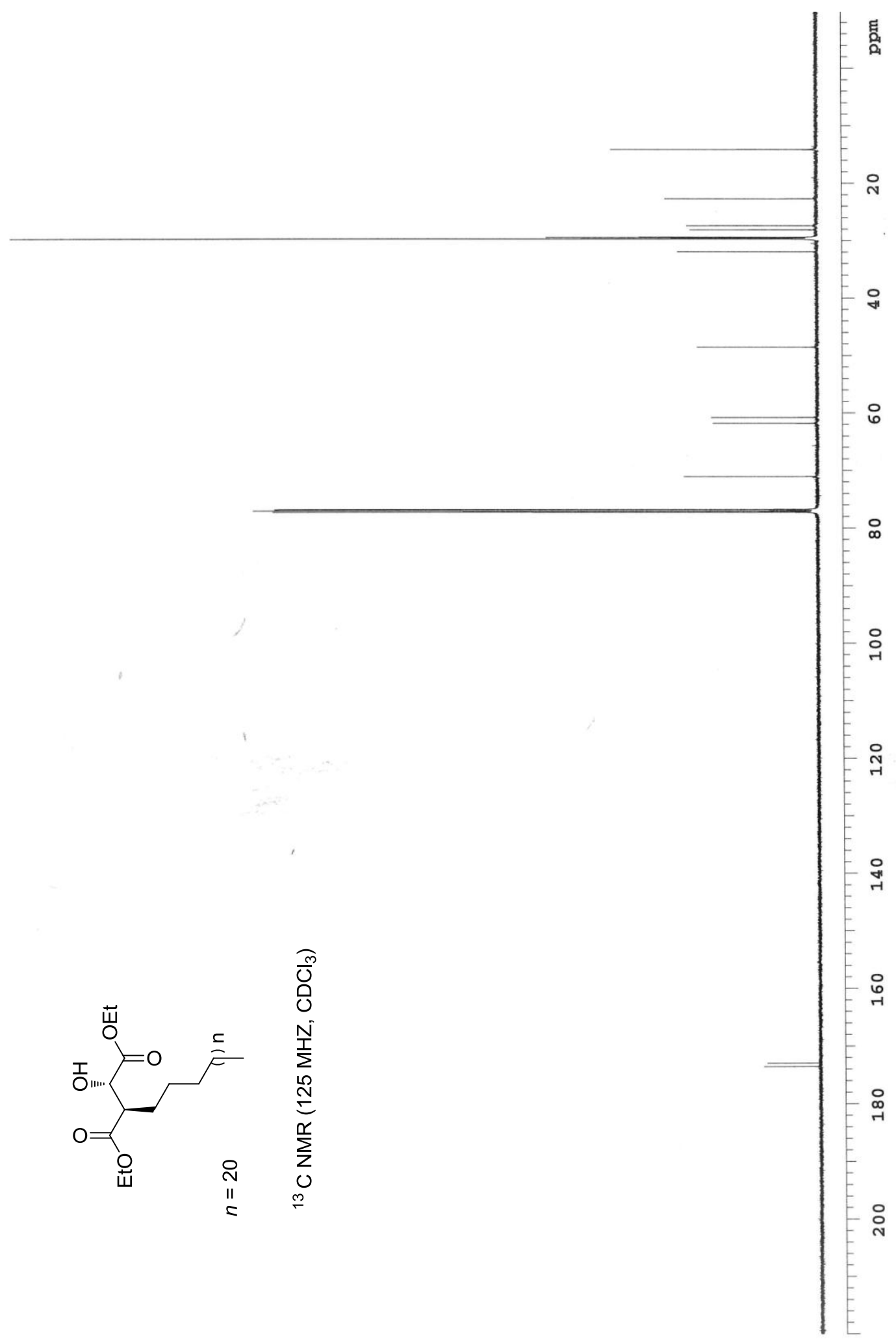

Figure 5. ${ }^{13} \mathrm{C}$ NMR spectrum of product 5k 


\subsection{Conclusion}

We have developed an improved methodology for the synthesis of long chain $\alpha$ alkylated $\beta$-hydroxy esters via the use of allylic halides in the Fráter-Seebach alkylation. This allylic alkylation is highly diastereoselective, and when compared to similar reactions using the corresponding saturated alkyl halides, gives superior yields. The prerequisite allylic iodides are themselves readily prepared in two steps and in good yield from the corresponding aldehydes, while the unsaturated $\alpha$ alkylated $\beta$-hydroxy esters can be readily hydrogenated in excellent yield. The final $\alpha$-alkylated $\beta$-hydroxy esters are, in turn, valuable synthetic intermediates for the preparation of a number of biologically important lipids.

\subsection{Experimental}

Unless stated otherwise all reactions were performed under $\mathrm{N}_{2}$. Prior to use, THF was distilled from $\mathrm{Na}$ wire and benzophenone, toluene was dried and stored under $\mathrm{Na}$ wire, $\mathrm{CH}_{2} \mathrm{Cl}_{2}$ was distilled from $\mathrm{P}_{2} \mathrm{O}_{5}$ and acetone was dried with $\mathrm{K}_{2} \mathrm{CO}_{3}$, distilled and stored over $4 \AA$ MS. HMPA was dried with $\mathrm{CaH}_{2}$, distilled and stored under nitrogen, di-isopropylamine was dried with $\mathrm{NaOH}$, distilled and stored under nitrogen, allyl bromide, allyl iodide and heptyl iodide were dried with $\mathrm{MgSO}_{4}$, distilled and stored under nitrogen. L-(-)-Malic acid (Sigma), bromotetradecane (Fluka), 1-docosanol (Aldrich), 1-eicosanol (Alfa Aesar), 1M vinylmagnesium bromide (Aldrich) pentanal (Koch-Light Laboratories), $n$-BuLi (Aldrich, 2M solution in hexanes), dodecanal (Aldrich), octadecanol (BDH), $\mathrm{PPh}_{3}$ (Merck), $\mathrm{I}_{2}$ (Unilab), $\mathrm{Pd} / \mathrm{C}$ (Aldrich), $\mathrm{H}_{2} \mathrm{SO}_{4}$ (Lab-Scan), ethanol (Pure Science), anhydrous $\mathrm{Et}_{2} \mathrm{O}$ (Biolab), EtOAc (Panreac), petroleum ether (Pure Science), $\mathrm{CHCl}_{3}$ (Panreac), $\mathrm{NaHCO}_{3}$ (Pure Science), $\mathrm{K}_{2} \mathrm{CO}_{3}$ (Pure Science), $\mathrm{Na}_{2} \mathrm{~S}_{2} \mathrm{O}_{3}$ (Panreac), $\mathrm{MgSO}_{4}$ (Pure Science), $\mathrm{NaCl}$ (Panreac) were used as received. 1-Iodotetradecane ${ }^{14}$ and L-diethyl malate ${ }^{8}$ were prepared using literature procedures. All solvents were removed via evaporation at reduced pressure. Reactions were monitored by TLC analysis on Macherey-Nagel silica gel coated plastic sheets $(0.20 \mathrm{~mm}$, Polygram SIL G/UV254) by coating with a solution of $5 \% \mathrm{KMnO}_{4}$ and $1 \% \mathrm{NaIO}_{4}$ in $\mathrm{H}_{2} \mathrm{O}$ followed by heating. Column chromatography was performed using Pure Science silica gel (40-63 $\mu \mathrm{m})$. High 
resolution mass spectra were recorded on a Waters Q-TOF Premier ${ }^{\mathrm{TM}}$ Tandem Mass Spectrometer using positive electro-spray ionisation and atmospheric-pressure chemical ionisation. Optical rotations were recorded on a Perkin-Elmer 241 polarimeter or Autopol II (Rudolph Research Analytical) at $589 \mathrm{~nm}$ (sodium D-line). Infrared spectra were recorded as thin films using a Bruker Tensor 27 FTIR spectrometer equipped with an Attenuated Total Reflectance (ATR) sampling accessory and are reported in wave numbers $\left(\mathrm{cm}^{-1}\right)$. Nuclear magnetic resonance spectra were recorded at $20{ }^{\circ} \mathrm{C}$ in $\mathrm{CDCl}_{3}$ using a Varian INOVA operating at 500 MHz. Chemical shifts are given in ppm $(\delta)$ relative to solvent residual peak. NMR peak assignments were made using COSY, HSQC and HMBC 2D experiments.

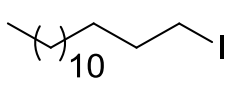

1-Iodotetradecane. ${ }^{15}$ Sodium iodide $(10.81 \mathrm{~g}, 90.1 \mathrm{mmol})$ was added to a stirring solution of 1-bromotetradecane (10.0 g, 36.1 $\mathrm{mmol})$ in acetone $(20 \mathrm{~mL})$. The reaction mixture was refluxed under nitrogen for $48 \mathrm{~h}$, after which the mixture was filtered and concentrated in vасио. The resulting residue was dissolved in diethyl ether and washed with sat. $\mathrm{Na}_{2} \mathrm{~S}_{2} \mathrm{O}_{3}$, brine dried $\left(\mathrm{MgSO}_{4}\right)$ and concentrated in vacuo. The product was obtained after silica gel flash chromatography (eluting in petroleum ether) as colourless oil (13.7g, $84.7 \mathrm{mmol}, 94 \%) . \mathrm{R}_{f}=0.82$ (PE/EA, 2/1, v/v); IR (film) 2921, 2852, 1176, $720 \mathrm{~cm}^{-1}$; ${ }^{1} \mathrm{H}$ NMR $\left(500 \mathrm{MHz}, \mathrm{CDCl}_{3}\right) \delta 3.19(\mathrm{t}, J=7.1 \mathrm{~Hz}, 2 \mathrm{H}, \mathrm{H}-1), 1.83$ (pentet, $\left.J_{\alpha, \beta}=J_{\beta, \gamma}=7.1 \mathrm{~Hz}, 2 \mathrm{H}, \mathrm{H}-2\right), 1.40-1.36(\mathrm{~m}, 2 \mathrm{H}, \mathrm{H}-3), 1.28-1.20(\mathrm{~m}, 20 \mathrm{H}, \mathrm{H}-4-\mathrm{H}-$ 13), 0.89 (t, $J=7.1 \mathrm{~Hz}, 3 \mathrm{H}, \mathrm{H}-14) ;{ }^{13} \mathrm{C} \mathrm{NMR}\left(125 \mathrm{MHz}, \mathrm{CDCl}_{3}\right) \delta 33.5$ (C-2), 31.9, 30.5, 29.70, 29.66, 29.63, 29.57, 29.44, 29.37, 28.56, 22.7 (C-3-C-13), 14.1 (C-14), $7.3(\mathrm{C}-1)$.

\section{General Procedure for the synthesis of alkyl iodides from the corresponding} alcohol. $\mathrm{PPh}_{3}$ (12 mmol, 1.2 equiv.) was added to a solution of the appropriate alcohol (10 mmol, 1 equiv.) in dry THF $(100 \mathrm{~mL})$, followed by imidazole $(18 \mathrm{mmol}$, 1.8 equiv.). The flask was then lowered into a water bath and $\mathrm{I}_{2}(13 \mathrm{mmol}, 1.3$ equiv.) was added slowly to maintain the temperature at $c a .25^{\circ} \mathrm{C}$. The resulting mixture was refluxed for $5 \mathrm{~h}$, after which water was added to quench the reaction and the mixture was extracted with DCM. The organic layer was washed with $\mathrm{Na}_{2} \mathrm{~S}_{2} \mathrm{O}_{3}$, water and 
brine, dried $\left(\mathrm{MgSO}_{4}\right)$ and concentrated in vacuo. The product was purified using silica gel column chromatography and the eluent given.

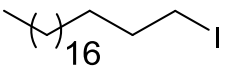

1-Iodoeicosane. By subjecting 1-eicosanol (1.0g, $3.35 \mathrm{mmol})$ to the general procedure for the synthesis of alkyl iodides, 1iodoeicosane was obtained (eluting in petroleum ether) as a white solid (0.95 g, $2.35 \mathrm{mmol}, 70 \%$ ). $\mathrm{R}_{f}=0.80$ (PE/EA, 2/1, v/v); IR (film) 2920, 2851, 917, $783 \mathrm{~cm}^{-1} ;{ }^{1} \mathrm{H}$ NMR (500 MHz, $\left.\mathrm{CDCl}_{3}\right) \delta 3.20(\mathrm{t}, J=7.1 \mathrm{~Hz}, 2 \mathrm{H}, \mathrm{H}-1), 1.83$ (pentet, $\left.J_{\alpha, \beta}=J_{\beta, \gamma}=7.1 \mathrm{~Hz}, 2 \mathrm{H}, \mathrm{H}-2\right), 1.44-1.37$ (m, 2H, H-3), 1.31-1.70 (m, 32H, H4-H-19), 0.90 (t, $J=6.9 \mathrm{~Hz}, 3 \mathrm{H}, \mathrm{H}-20) ;{ }^{13} \mathrm{C} \mathrm{NMR}\left(125 \mathrm{MHz}, \mathrm{CDCl}_{3}\right) \delta 33.6(\mathrm{C}-2)$, 32.0, 30.5, 29.73, 29.71, 29.69, 29.65, 29.58, 29.45, 29.40, 28.58, 22.7 (C-3-C-19), 14.2 (C-20), $7.3(\mathrm{C}-1)$.

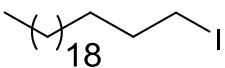

1-Iododocosane. By subjecting 1-docosanol (1.0 g, $3.06 \mathrm{mmol})$ to the general procedure for synthesis of alkyl iodides, 1iododocosane was obtained (eluting in petroleum ether) as a white solid (0.8 g, 1.84 mmol, 60\%). $\mathrm{R}_{f}=0.79$ (PE/EA, 2/1, v/v); IR (film): 2915, 2848, 1165, $740 \mathrm{~cm}^{-1} ;{ }^{1} \mathrm{H}$ $\operatorname{NMR}\left(500 \mathrm{MHz}, \mathrm{CDCl}_{3}\right) \delta 3.19(\mathrm{t}, J=7.1 \mathrm{~Hz}, 2 \mathrm{H}, \mathrm{H}-1), 1.83$ (pentet, $J_{\alpha \beta}=J_{\beta \gamma}=7.4$ $\mathrm{Hz}, 2 \mathrm{H}, \mathrm{H}-2), 1.40-1.36$ (m, 2H, H-3), 1.33-1.26 (m, 36H, H-4-H-21), 0.89 (t, $J=$ $6.8 \mathrm{~Hz}, 3 \mathrm{H}, \mathrm{H}-22) ;{ }^{13} \mathrm{C} \mathrm{NMR}\left(125 \mathrm{MHz}, \mathrm{CDCl}_{3}\right) \delta 33.6(\mathrm{C}-2), 31.9,30.5,29.70$, 29.67, 29.63, 29.56, 29.43, 29.37, 28.56, 26.06, 22.7 (C-3-C-21), 14.1 (C-22), 7.4 (C-1).<smiles>CCOC(=O)CC(O)C(=O)OCC</smiles>

Diethyl-L-malate (3). ${ }^{8}$ L-Malic acid (15 g, $\left.112 \mathrm{mmol}\right)$ was dissolved in ethanol and conc. $\mathrm{H}_{2} \mathrm{SO}_{4}(0.36 \mathrm{ml}, 89.9 \mathrm{mmol})$ was added. The reaction mixture was refluxed for $72 \mathrm{~h}$, after which the reaction was stopped and the solvent evaporated in vacuo. The light yellow residue was purified via silica gel column chromatography $(5: 1$, petroleum ether/EtOAc, v/v) to afford diethyl malate $\mathbf{3}$ as a colourless oil (20.2 g, $106 \mathrm{mmol}$, 94.9\%). $\left.\mathrm{R}_{f}=0.40 \mathrm{PE} / \mathrm{EA}, 5 / 1, \mathrm{v} / \mathrm{v}\right) ;[\alpha]_{\mathrm{D}}^{23}=-6.3\left(c=1.0, \mathrm{CHCl}_{3}\right)$; IR (film): 3481, 
2984, 2940, 1731, 1447, 1373, 1267, 1177, 1099, 1023, 859, $735 \mathrm{~cm}^{-1} ;{ }^{1} \mathrm{H}$ NMR (500 $\left.\mathrm{MHz}, \mathrm{CDCl}_{3}\right) \delta 4.49\left(\mathrm{ddd}, J_{2,3 \mathrm{a}}=J_{2,3 \mathrm{~b}}=J_{2, \mathrm{OH}}=5.3 \mathrm{~Hz}, 1 \mathrm{H}, \mathrm{H}-2\right), 4.32-4.25(\mathrm{~m}, 2 \mathrm{H}$, $\left.\mathrm{CH}_{2} \mathrm{O}-1\right), 4.18\left(\mathrm{q}, J=7.2 \mathrm{~Hz}, 2 \mathrm{H}, \mathrm{CH}_{2} \mathrm{O}-4\right), 3.21\left(\mathrm{~d}, J_{2, \mathrm{OH}}=5.3 \mathrm{~Hz}, 1 \mathrm{H}, \mathrm{OH}\right), 2.86$ $\left(\mathrm{dd}, J_{3 \mathrm{a}, 3 \mathrm{~b}}=16.3 \mathrm{~Hz}, J_{2,3 \mathrm{a}}=4.5 \mathrm{~Hz}, 1 \mathrm{H}, \mathrm{H}-3 \mathrm{a}\right), 2.79\left(\mathrm{dd}, J_{3 \mathrm{a}, 3 \mathrm{~b}}=16.3 \mathrm{~Hz}, J_{2,3 \mathrm{~b}}=6.0\right.$ $\mathrm{Hz}, 1 \mathrm{H}, \mathrm{H}-3 \mathrm{~b}), 1.31$ (t, $\left.J=7.2 \mathrm{~Hz}, 3 \mathrm{H}, \mathrm{CH}_{3}, 1-\mathrm{OEt}\right), 1.28$ (t, $J=7.2 \mathrm{~Hz}, 3 \mathrm{H}, \mathrm{CH}_{3}, 4$ $\mathrm{OEt}) ;{ }^{13} \mathrm{C}$ NMR $\left(125 \mathrm{MHz}, \mathrm{CDCl}_{3}\right) \delta 173.4(\mathrm{C}-1), 170.5$ (C-4), $67.3(\mathrm{C}-2), 62.1$ $\left(\mathrm{CH}_{2} \mathrm{O}, 1-\mathrm{OEt}\right), 61.0\left(\mathrm{CH}_{2} \mathrm{O}, 4-\mathrm{OEt}\right), 38.7(\mathrm{C}-3), 14.1\left(\mathrm{CH}_{3}, 1-\mathrm{OEt}\right), 14.1\left(\mathrm{CH}_{3}, 4-\right.$ $\mathrm{OEt}) ; \mathrm{HRMS}(\mathrm{ESI}) \mathrm{m} / \mathrm{z}$ calcd. for $\left[\mathrm{C}_{8} \mathrm{H}_{14} \mathrm{O}_{5}+\mathrm{Na}\right]^{+}:$213.0739, obsd.: 213.0737 .

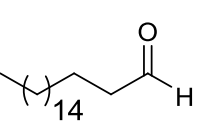

1-Octadecanal (6c). 1-Octadecanol (5.00 g, $18.5 \mathrm{mmol})$ was added to a solution of PCC (7.97 g, $37 \mathrm{mmol})$ and molecular sieves $\AA$ (5.6 g) in DCM $(90 \mathrm{~mL})$ under nitrogen and the reaction mixture stirred at r.t. for $6 \mathrm{~h}$. The mixture was then reduced in vacuo and the resulting oil subjected to silica gel flash chromatography with 1-octadecanal eluting in petroleum ether/EtOAc 20:1 (v/v) as white solid (4.86 g, $18.1 \mathrm{mmol}, 98 \%) . \mathrm{R}_{f}=0.78(\mathrm{PE} / \mathrm{EA}$, 2/1, v/v); IR (film) 2953, 2913, 2848, 1711, $1275 \mathrm{~cm}^{-1} ;{ }^{1} \mathrm{H}$ NMR (500 MHz, $\left.\mathrm{CDCl}_{3}\right)$ $\delta 9.75(\mathrm{t}, J=1.9 \mathrm{~Hz}, 1 \mathrm{H}, \mathrm{H}-1), 2.40\left(\mathrm{dt}, J_{2 \mathrm{a}, 2 \mathrm{~b}}=14.7 \mathrm{~Hz}, J_{2,3}=7.4 \mathrm{~Hz}, 2 \mathrm{H}, \mathrm{H}-2\right), 1.61$ (pentet, $\left.J_{\alpha, \beta}=J_{\beta, \gamma}=7.3 \mathrm{~Hz}, 2 \mathrm{H}, \mathrm{H}-3\right), 1.32-1.24$ (m, 28H, H-4-H-17), 0.86 (t, $J=7.2$ $\mathrm{Hz}, 3 \mathrm{H}, \mathrm{H}-18$ ); ${ }^{13} \mathrm{C}$ NMR (125 MHz, $\mathrm{CDCl}_{3}$ ) $\delta 202.9$ (C-1), 43.9 (C-2), 31.9 (C-3), 29.70, 29.69, 29.68, 29.66, 29.63, 29.60, 29.57, 29.42, 29.36, 29.35, 29.2, 22.7, 22.1 (C-4-C-17), 14.1 (C-18).

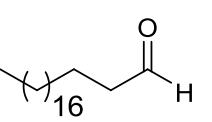

1-Eicosanal (6d). 1-Eicosanol (5.00 g, $16.7 \mathrm{mmol})$ was added to a solution of PCC (7.22 g, $33.5 \mathrm{mmol})$ and molecular sieves $4 \AA$ (5.0 g) in DCM $(80 \mathrm{~mL})$ under nitrogen and the reaction mixture stirred at r.t. for $6 \mathrm{~h}$. The reaction mixture was then reduced in vacuo and the resulting oil subjected to silica gel flash chromatography with 1-eicosanal eluting in petroleum ether/EtOAc, 20:1 (v/v) as white solid (4.45 g, $15.0 \mathrm{mmol}, 90 \%) . \mathrm{R}_{f}=0.82(\mathrm{PE} / \mathrm{EA}$, 2/1, v/v); IR (film): 2913, 2849, 1711, $1264 \mathrm{~cm}^{-1} ;{ }^{1} \mathrm{H}$ NMR (500 MHz, $\left.\mathrm{CDCl}_{3}\right) \delta 9.78$ $(\mathrm{t}, J=1.9 \mathrm{~Hz}, 1 \mathrm{H}, \mathrm{H}-1), 2.43\left(\mathrm{dt}, J_{2 \mathrm{a}, 2 \mathrm{~b}}=14.8 \mathrm{~Hz}, J_{2,3}=7.4 \mathrm{~Hz}, 2 \mathrm{H}, \mathrm{H}-2\right), 1.64$ (pentet, $\left.J_{\alpha, \beta}=J_{\beta, \gamma}=7.5 \mathrm{~Hz}, 2 \mathrm{H}, \mathrm{H}-3\right), 1.30-1.25(\mathrm{~m}, 32 \mathrm{H}, \mathrm{H}-4-\mathrm{H}-19), 0.89$ (t, $J=7.1$ 
$\mathrm{Hz}, 3 \mathrm{H}, \mathrm{H}-20) ;{ }^{13} \mathrm{C}$ NMR (125 MHz, $\left.\mathrm{CDCl}_{3}\right) \delta 203.0$ (C-1), 43.9 (C-2), 31.9 (C-3), 29.70, 29.68, 29.68, 29.66, 29.63, 29.58, 29.42, 29.36, 29.35, 29.2, 22.7, 22.1 (C-4C-19), 14.1 (C-20).

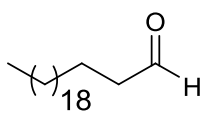

1-Docosanal (6e). 1-Docosanol (2.00 g, $6.12 \mathrm{mmol})$ was added to a solution of PCC (2.64 g, $12.2 \mathrm{mmol})$ and molecular sieves $4 \AA$ $(1.84 \mathrm{~g})$ in DCM $(40 \mathrm{~mL})$ under nitrogen and the reaction mixture stirred at r.t. for $6 \mathrm{~h}$. The reaction mixture was then reduced in vacuo and the resulting oil subjected to silica gel flash chromatography with 1-docosanal eluting in petroleum ether/EtOAc, 20:1 (v/v) as white solid (1.75 g, $5.38 \mathrm{mmol}, 88 \%) . \mathrm{R}_{f}=$ 0.66 (PE/EA, 2/1, v/v); IR (film): 2913, 2849, 1711, $1264 \mathrm{~cm}^{-1} ;{ }^{1} \mathrm{H}$ NMR (500 MHz, $\left.\mathrm{CDCl}_{3}\right) \delta 9.77(\mathrm{t}, J=1.7 \mathrm{~Hz}, 1 \mathrm{H}, \mathrm{H}-1), 2.43\left(\mathrm{dt}, J_{2 \mathrm{a}, 2 \mathrm{~b}}=13.2 \mathrm{~Hz}, J_{2,3}=7.6 \mathrm{~Hz}, 2 \mathrm{H}\right.$, H-2), 1.63 (pentet, $\left.J_{\alpha, \beta}=J_{\beta, \gamma}=7.1 \mathrm{~Hz}, 2 \mathrm{H}, \mathrm{H}-3\right), 1.30-1.26$ (m, 36H, H-4-H-21), 0.89 $(\mathrm{t}, J=6.8 \mathrm{~Hz}, 3 \mathrm{H}, \mathrm{H}-22) ;{ }^{13} \mathrm{C}$ NMR $\left(125 \mathrm{MHz}, \mathrm{CDCl}_{3}\right) \delta 203.0(\mathrm{C}-1), 44.0(\mathrm{C}-2)$, 31.8 (C-3), 29.70, 29.69, 29.68, 29.66, 29.63, 29.60, 29.42, 29.38, 29.35, 29.2, 22.7, 22.1 (C-4-C-21), 14.1 (C-22).

General procedure for the synthesis of allylic iodides. To a solution of aldehyde (10 mmol, 1.0 equiv.) in dry THF $(50 \mathrm{~mL}), 1 \mathrm{M}$ vinyl magnesium bromide in THF (15 mmol, 1.5 equiv.) was added dropwise at $0{ }^{\circ} \mathrm{C}$. For the longer lipids $(\mathbf{4 c}-\mathbf{4 e})$, freshly prepared vinyl magnesium bromide was used and the aldehyde was dissolved in toluene instead of THF. The mixture was stirred for 90 min at $0{ }^{\circ} \mathrm{C}$, followed by $1 \mathrm{~h}$ at room temperature. The reaction was then quenched by the addition of $\mathrm{NH}_{4} \mathrm{Cl}$, extracted with $\mathrm{Et}_{2} \mathrm{O}(3 \times 50 \mathrm{~mL})$ and the combined organic layers were dried over $\mathrm{MgSO}_{4}$, filtered and concentrated in vacuo to give the allylic alcohol as a viscous oil which was used without further purification. To a solution of $\mathrm{PPh}_{3}(15 \mathrm{mmol}, 1.5$ equiv.) in $\mathrm{CH}_{2} \mathrm{Cl}_{2}(15 \mathrm{~mL})$ was added iodine (15 mmol, 1.5 equiv.) and the mixture stirred at room temperature for $5 \mathrm{~min}$. A solution of the crude allylic alcohol (10 mmol, 1 equiv.) in $\mathrm{CH}_{2} \mathrm{Cl}_{2}(30 \mathrm{~mL})$ was then added and the mixture stirred at r.t. overnight. The reaction mixture was diluted with $\mathrm{Et}_{2} \mathrm{O}$ and successively washed with sat. $\mathrm{Na}_{2} \mathrm{~S}_{2} \mathrm{O}_{3}$, (3x until the organic layer was free of iodine), water, saturated sodium 
bicarbonate solution and brine. The organic layer was dried over $\mathrm{MgSO}_{4}$, filtered and concentrated in vacuo. Purification of the crude residue by silica gel flash column chromatography (petroleum ether) afforded the allylic iodide.

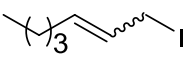

1-Iodo-hept-2-ene (4a). By subjecting pentanal (10.0 g, $116 \mathrm{mmol}$ ) to the general procedure for the synthesis of allylic iodides, iodoheptene 4a was obtained (eluting in petroleum ether) as a pale yellow oil (23.0 g, 103 mmol, 89\% over 2 steps). $\mathrm{R}_{f}=0.71$ (PE/EA, 2/1, v/v); IR (film): 2956, 2928, 2859, 1458, 970, $741 \mathrm{~cm}^{-1} ;{ }^{1} \mathrm{H}$ NMR (500 MHz, $\left.\mathrm{CDCl}_{3}\right) \delta 5.74$ $5.71\left(\mathrm{~m}, 2 \mathrm{H}, \mathrm{H}-2\right.$ and H-3), 3.91-3.88 (m, 2H, H-1a and H-1b), $2.04\left(\mathrm{dd}, J_{3,4}=J_{4,5}=\right.$ $7.0 \mathrm{~Hz}, 2 \mathrm{H}, \mathrm{H}-4 \mathrm{a}$ and H-4b), 1.39-1.24 (m, 4H, H-5 and H-6), 0.82 (t, $J_{6,7}=7.2 \mathrm{~Hz}$, $\left.3 \mathrm{H}, \mathrm{CH}_{3}-7\right) ;{ }^{13} \mathrm{C}$ NMR (125 MHz, $\left.\mathrm{CDCl}_{3}\right) \delta 135.3$ (C-2), 127.8 (C-3), 31.7, 30.9, 22.1 (C-4-C-6), 13.9 (C-7), 7.1 (C-1); HRMS(APCI) $\mathrm{m} / \mathrm{z}$ calcd. for $\left[\mathrm{C}_{7} \mathrm{H}_{13} \mathrm{I}+\mathrm{H}\right]^{+}$: 225.0140, obsd.: 225.0149 .<smiles>ICC=[14CH]CI</smiles>

1-Iodo-tetradec-2-ene (4b). By subjecting dodecanal (1.00 g, 5.42 mmol) to the general procedure for the synthesis of allylic iodides, iodo-tetradecene $\mathbf{4 b}$ was obtained (eluting in petroleum ether) as a pale yellow oil (1.40 g, $4.39 \mathrm{mmol}, 81 \%$ over 2 steps). $\mathrm{R}_{f}=0.76$ (PE/EA, 2/1, v/v); IR (film): 2955, 2922, 2852, 1464, 961, $721 \mathrm{~cm}^{-1} ;{ }^{1} \mathrm{H}$ NMR $\left(500 \mathrm{MHz}, \mathrm{CDCl}_{3}\right) \delta 5.73-5.71(\mathrm{~m}, 2 \mathrm{H}$, $\mathrm{H}-2$ and H-3), 3.90-3.88 (m, 2H, H-1a and H-1b), 2.03 (dd, $J_{3,4}=J_{4,5}=7.2 \mathrm{~Hz}, 2 \mathrm{H}$, H-4a and H-4b), 1.39-1.27 (m, 18H, H-5-H-13), 0.82 (t, J6,7 = 7.2 Hz, 3H, $\mathrm{CH}_{3}-14$ ); ${ }^{13} \mathrm{C}$ NMR (125 MHz, $\left.\mathrm{CDCl}_{3}\right) \delta 135.4$ (C-2), 127.7 (C-3), 32.0, 31.9, 29.65,29.62, 29.60, 29.4, 29.3, 29.1, 28.8, 22.731 .7 (C-4-C-13), 14.1 (C-14), 7.1 (C-1); HRMS(APCI) $m / z$ calcd. for $\left[\mathrm{C}_{14} \mathrm{H}_{27} \mathrm{I}+\mathrm{H}\right]^{+}: 323.1236$, obsd.: 323.1242 .

1-Iodo-eicos-2-ene (4c). By subjecting octadecanal (1.69 g, 6.32 $\mathrm{mmol}$ ) to the general procedure for the synthesis of allylic iodides, iodo-eicosene $\mathbf{4} \mathbf{c}$ was obtained (eluting in petroleum ether) as a white solid (1.80 g, $4.42 \mathrm{mmol}, 70 \%$ over 2 steps). $\mathrm{R}_{f}=0.86$ (PE/EA, 2/1, v/v); IR 
(film): 2924, 2853, 1464, 961, $738 \mathrm{~cm}^{-1} ;{ }^{1} \mathrm{H}$ NMR (500 MHz, $\mathrm{CDCl}_{3}$ ) $\delta$ 5.73-5.71 (m, 2H, H-2 and H-3), 3.89-3.87 (m, 2H, H-1a and H-1b), $2.03\left(\mathrm{dd}, J_{3,4}=J_{4,5}=7.2\right.$ $\mathrm{Hz}, 2 \mathrm{H}, \mathrm{H}-4 \mathrm{a}$ and H-4b), 1.44-1.22 (m, 30H, H-5-H-19), 0.89 (t, $J_{6,7}=6.7 \mathrm{~Hz}, 3 \mathrm{H}$, $\left.\mathrm{CH}_{3}-20\right) ;{ }^{13} \mathrm{C}$ NMR $\left(125 \mathrm{MHz}, \mathrm{CDCl}_{3}\right.$ ) $\delta 135.4$ (C-2), 127.8 (C-3), 32.1, 31.9, 29.71, 29.68, 29.67, 29.65, 29.6, 29.50, 29.45, 29.3, 29.1, 28.8, 28.7, 26.8, 22.7 (C-4-C-19), 14.1 (C-20), 7.1 (C-1); HRMS(APCI) $m / z$ calcd. for $\left[\mathrm{C}_{20} \mathrm{H}_{39} \mathrm{I}+\mathrm{H}\right]^{+}: 407.2175$, obsd.: 407.2168.

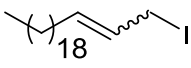

1-Iodo-docos-2-ene (4d). By subjecting eicosanal (1.20 g, 4.05 $\mathrm{mmol}$ ) to the general procedure for the synthesis of allylic iodides, iodo-docosene $\mathbf{4 d}$ was obtained (eluting in petroleum ether) as a white solid (1.25 g, $2.87 \mathrm{mmol}, 71 \%$ over 2 steps). $\mathrm{R}_{f}=0.95$ (PE/EA, 2/1, v/v); IR (film): 2922, 2852, 1464, 962, $740 \mathrm{~cm}^{-1} ;{ }^{1} \mathrm{H}$ NMR (500 MHz, $\left.\mathrm{CDCl}_{3}\right) \delta 5.72-5.71$ $\left(\mathrm{m}, 2 \mathrm{H}, \mathrm{H}-2\right.$ and H-3), 3.88-3.87 (m, 2H, H-1a and H-1b), $2.01\left(\mathrm{dd}, J_{3,4}=J_{4,5}=7.2\right.$ $\mathrm{Hz}, 2 \mathrm{H}, \mathrm{H}-4 \mathrm{a}$ and $\mathrm{H}-4 \mathrm{~b}), 1.43-1.28$ (m, 34H, H-5-H-21), 0.89 (t, $J_{6,7}=6.7 \mathrm{~Hz}, 3 \mathrm{H}$, $\left.\mathrm{CH}_{3}-22\right) ;{ }^{13} \mathrm{C}$ NMR $\left(125 \mathrm{MHz}, \mathrm{CDCl}_{3}\right) \delta 135.4$ (C-2), 127.7 (C-3), 32.0, 31.9, 29.70, 29.67, 29.66, 29.65, 29.58, 29.5, 29.44, 29.36, 29.3, 29.1, 28.8, 28.7, 26.9, 26.8, 22.7 (C-4-C-21), 14.1 (C-22), 7.1 (C-1); HRMS(APCI) $\mathrm{m} / \mathrm{z}$ calcd. for $\left[\mathrm{C}_{22} \mathrm{H}_{43} \mathrm{I}+\mathrm{H}\right]^{+}$: 435.2488, obsd.: 435.2494 .

1-Iodo-tetracos-2-ene (4e). By subjecting docosanal (3.50 g, 10.8 (to $\mathrm{H}_{20}$, $\mathrm{mmol}$ ) to the general procedure for the synthesis of allylic iodides, iodo-tetracosene $\mathbf{4 e}$ was obtained (eluting in petroleum ether) as a white solid (3.63 g, $7.87 \mathrm{mmol}, 73.2 \%$ over 2 steps). $\mathrm{R}_{f}=0.95$ (PE/EA, 2/1, v/v); IR (film): 2915, 2848, 1713, 1471, $739 \mathrm{~cm}^{-1}$; ${ }^{1} \mathrm{H}$ NMR (500 MHz, $\left.\mathrm{CDCl}_{3}\right) \delta 5.73-5.71$ $\left(\mathrm{m}, 2 \mathrm{H}, \mathrm{H}-2\right.$ and H-3), 3.89-3.88 (m, 2H, H-1a and H-1b), $2.02\left(\mathrm{dd}, J_{3,4}=J_{4,5}=6.8\right.$ $\mathrm{Hz}, 2 \mathrm{H}, \mathrm{H}-4 \mathrm{a}$ and H-4b), 1.37-1.26 (m, 38H, H-5-H-23), 0.89 (t, $J_{6,7}=7.1 \mathrm{~Hz}, 3 \mathrm{H}$, $\left.\mathrm{CH}_{3}-24\right) ;{ }^{13} \mathrm{C}$ NMR $\left(125 \mathrm{MHz}, \mathrm{CDCl}_{3}\right) \delta 135.4$ (C-2), 127.8 (C-3), 32.0, 31.9, 29.72, 29.69, 29.68, 29.67, 29.60, 29.47, 29.39, 29.1, 28.8, 22.7 (C-4-C-23), 14.1 (C-24), 7.1 (C-1); HRMS(APCI) $m / z$ calcd. for $\left[\mathrm{C}_{24} \mathrm{H}_{47} \mathrm{I}+\mathrm{H}\right]^{+}: 463.2801$, obsd.: 463.2805 . 
General Procedure for the Synthesis of $\alpha$-Alkenyl- $\beta$-Hydroxy-Diesters. $n$-BuLi $(11.5 \mathrm{~mL}, 2.0 \mathrm{~m}$ solution in hexanes, $23.0 \mathrm{mmol})$ was added to a solution of diisopropylamine $(3.6 \mathrm{~mL}, 25.0 \mathrm{mmol})$ in THF $(20 \mathrm{~mL})$ at $0{ }^{\circ} \mathrm{C}$. After $30 \mathrm{~min}$ the solution was cooled down to $-78^{\circ} \mathrm{C}$ and diethyl malate $5(1.9 \mathrm{~g}, 10 \mathrm{mmol})$ in THF (20 $\mathrm{mL}$ ) was added. The resulting mixture was stirred at $-78{ }^{\circ} \mathrm{C}$ for $1 \mathrm{~h}$, warmed up to $20{ }^{\circ} \mathrm{C}$ over $1 \mathrm{~h}$ and stirred at $-20{ }^{\circ} \mathrm{C}$ for $20 \mathrm{~min}$. After cooling down to $-78{ }^{\circ} \mathrm{C}$, the allylic iodide (15.0 mmol, 1.5 equiv.) in THF $(20 \mathrm{~mL})$ was added dropwise and the reaction was stirred for $1 \mathrm{~h}$ at $-50{ }^{\circ} \mathrm{C}$ and then a further $1 \mathrm{~h}$ during which time the temperature increased to $-20{ }^{\circ} \mathrm{C}$. The reaction was then quenched using $\mathrm{NH}_{4} \mathrm{Cl}$ (sat.) and extracted with EtOAc $(3 \times 100 \mathrm{~mL})$. The combined organic layers were washed with water $(30 \mathrm{~mL})$ and brine $(30 \mathrm{~mL})$, dried $\left(\mathrm{MgSO}_{4}\right)$, filtered and the solvent removed in vacuo to yield a crude yellow oil. Purification of the residue, using silica gel flash column chromatography and the eluent given, gave the alkylated product.

Ethyl $2 S$-hydroxy-3R-ethoxycarbonyl-hex-4-enoate (anti-

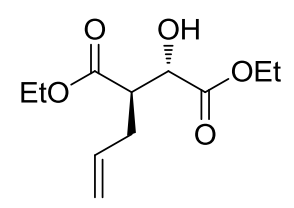

5a). By reacting diethyl malate 3 (3.96 g, $20.9 \mathrm{mmol})$ with allyl bromide $(2.64 \mathrm{~mL}, 31.25 \mathrm{mmol})$ according to the general procedure for the synthesis of $\alpha$-alkenyl- $\beta$-hydroxy-diesters, hexenoate 5a was obtained (eluting in 10:1, petroleum ether/EtOAc, v/v) as a colourless oil $(2.72 \mathrm{~g}, 11.9 \mathrm{mmol}, 57 \%$, anti:syn $=14: 1) . \mathrm{R}_{f}=$ $0.39(\mathrm{PE} / \mathrm{EA}, 2 / 1, \mathrm{v} / \mathrm{v}) ;[\alpha]_{\mathrm{D}}^{23}=+13.0\left(c=2.23, \mathrm{CHCl}_{3}\right), \mathrm{Lit}^{[34]}[\alpha]_{\mathrm{D}}{ }^{20}=+11.3(\mathrm{c}=$ 2.23, $\mathrm{CHCl}_{3}$ ); IR (film): 3079, 2982, 2961, 2924, 1733, 1643, 1132, 1099, 1031, 736, $703 \mathrm{~cm}^{-1} ;{ }^{1} \mathrm{H}$ NMR $\left(500 \mathrm{MHz}, \mathrm{CDCl}_{3}\right) \delta 5.75$ (ddt, $J_{5,6 \text {-trans }}=17.1 \mathrm{~Hz}, J_{5,6 \text {-cis }}=10.2$ $\left.\mathrm{Hz}, J_{4 \mathrm{a}, 5}=J_{4 \mathrm{~b}, 5}=7.5 \mathrm{~Hz}, 1 \mathrm{H}, \mathrm{H}-5\right), 5.11$ (d, $J_{5,6-\operatorname{trans}}=17.1 \mathrm{~Hz}, 1 \mathrm{H}, \mathrm{H}-6$-cis), 5.05 (d, $J_{5,6-\text { trans }}=10.2 \mathrm{~Hz}, 1 \mathrm{H}, \mathrm{H}-6$-trans), 4.25-4.14 (m, 3H, $\mathrm{CH}_{2} \mathrm{O}-1$ and $\mathrm{H}-2$ ), 4.12-4.01 $\left(\mathrm{m}, 2 \mathrm{H}, 3-\mathrm{CO}_{2} \mathrm{CH}_{2}\right), 2.90(\mathrm{~m}, 1 \mathrm{H}, \mathrm{H}-3), 2.56\left(\mathrm{ddd}, J_{4 \mathrm{a}, 4 \mathrm{~b}}=14.4 \mathrm{~Hz}, J_{3,4 \mathrm{a}}=J_{4 \mathrm{a}, 5}=7.5\right.$ $\mathrm{Hz}, 1 \mathrm{H}, \mathrm{H}-4 \mathrm{a}), 2.38\left(\mathrm{ddd}, J_{4 \mathrm{a}, 4 \mathrm{~b}}=14.4 \mathrm{~Hz}, J_{3,4 \mathrm{~b}}=J_{4 \mathrm{~b}, 5}=7.5 \mathrm{~Hz}, 1 \mathrm{H}, \mathrm{H}-4 \mathrm{~b}\right), 1.24(\mathrm{t}, J$ $\left.=7.1 \mathrm{~Hz}, 3 \mathrm{H}, \mathrm{CH}_{3}, 1-\mathrm{OEt}\right), 1.17\left(\mathrm{t}, J=7.0 \mathrm{~Hz}, 3 \mathrm{H}, \mathrm{CH}_{3}, 3-\mathrm{CO}_{2} \mathrm{Et}\right) ;{ }^{13} \mathrm{C} \mathrm{NMR}(125$ $\left.\mathrm{MHz}, \mathrm{CDCl}_{3}\right) \delta 173.6(\mathrm{C}-1), 172.0$ (3-CO ${ }_{2}$ ), 134.9 (C-5), 118.0 (C-6), 70.2 (C-2), $61.9\left(\mathrm{CH}_{2} \mathrm{O}, 1-\mathrm{OEt}\right), 61.0\left(\mathrm{CH}_{2} \mathrm{O}, 3-\mathrm{CO}_{2} \mathrm{CH}_{2}\right), 48.1(\mathrm{C}-3), 32.2(\mathrm{C}-4), 14.1\left(\mathrm{CH}_{3}, 1-\right.$ 
OEt), $14.1\left(\mathrm{CH}_{3}, 3-\mathrm{CO}_{2} \mathrm{Et}\right)$; HRMS(ESI) $\mathrm{m} / \mathrm{z}$ calcd. for $\left[\mathrm{C}_{11} \mathrm{H}_{18} \mathrm{O}_{5}+\mathrm{Na}\right]^{+}$: 253.1052, obsd.: 253.1055 .

\section{Ethyl $2 S$-hydroxy-3R-ethoxycarbonyl-decen-5-enoate (anti-}

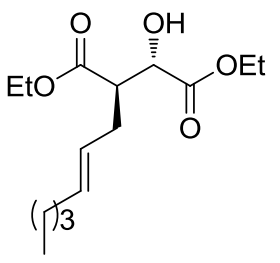

5c). By reacting diethyl malate 3 (3.98 g, $20.9 \mathrm{mmol})$ with 1iodo-hept-2-ene (7.03 g, $31.42 \mathrm{mmol})$ according to the general procedure for the synthesis of $\alpha$-alkenyl- $\beta$-hydroxy-diesters, decenoate 5c was obtained (eluting in 15:1, petroleum ether/EtOAc, v/v) as a colourless oil (3.28 g, $11.5 \mathrm{mmol}, 55 \%$, anti:syn $=9: 1) . \mathrm{R}_{f}=0.42(\mathrm{PE} / \mathrm{EA} 2 / 1, \mathrm{v} / \mathrm{v}) ;[\alpha]_{\mathrm{D}}^{23}=+19.0\left(c=1.0, \mathrm{CHCl}_{3}\right) ; \mathrm{IR}$ (film): 3234, 2983, 2960, 2929, 1734, 1466, 1374, 1198, 861, $736 \mathrm{~cm}^{-1}$; ${ }^{1} \mathrm{H}$ NMR $\left(500 \mathrm{MHz}, \mathrm{CDCl}_{3}\right) \delta 5.57\left(\mathrm{dt}, J_{5,6}=15.2 \mathrm{~Hz}, J_{6,7 \mathrm{a}}=J_{6,7 \mathrm{~b}}=6.6 \mathrm{~Hz}, 1 \mathrm{H}, \mathrm{H}-6\right), 5.39(\mathrm{dt}$, $\left.J_{5,6}=15.2 \mathrm{~Hz}, J_{4 \mathrm{a}, 5}=J_{4 \mathrm{~b}, 5}=6.2 \mathrm{~Hz}, 1 \mathrm{H}, \mathrm{H}-5\right), 4.21-4.31\left(\mathrm{~m}, 3 \mathrm{H}, \mathrm{CH}_{2} \mathrm{O}-1\right.$ and $\left.\mathrm{H}-2\right)$, 4.16-4.10 (m, 2H, 3- $\left.\mathrm{CO}_{2} \mathrm{CH}_{2}\right), 2.90\left(\mathrm{ddd}, J_{3,4 \mathrm{a}}=J_{3,4 \mathrm{~b}}=8.3 \mathrm{~Hz}, J_{2,3}=3.2 \mathrm{~Hz}, 1 \mathrm{H}, \mathrm{H}-\right.$ 3), 2.58-2.51 (m, $1 \mathrm{H}, \mathrm{H}-4 \mathrm{a}), 2.38\left(\mathrm{ddd}, J_{4 \mathrm{a}, 4 \mathrm{~b}}=14.4 \mathrm{~Hz}, J_{3,4 \mathrm{~b}}=8.3 \mathrm{~Hz}, J_{4 \mathrm{~b}, 5}=6.2 \mathrm{~Hz}\right.$, $1 \mathrm{H}, \mathrm{H}-4 \mathrm{~b}), 2.01\left(\mathrm{q}, J_{6,7}=J_{7,8}=6.6 \mathrm{~Hz}, 2 \mathrm{H}, \mathrm{H}-7\right), 1.33-1.27(\mathrm{~m}, 4 \mathrm{H}, \mathrm{H}-8$ and H-9), $1.24\left(\mathrm{t}, J=7.3 \mathrm{~Hz}, 6 \mathrm{H}, 2 \times \mathrm{CH}_{3}\right), 0.88$ (t, $\left.J=7.2 \mathrm{~Hz}, 3 \mathrm{H}, \mathrm{CH}_{3}-10\right) ;{ }^{13} \mathrm{C}$ NMR $(125$ $\left.\mathrm{MHz}, \mathrm{CDCl}_{3}\right) \delta 173.7(\mathrm{C}-1), 172.3\left(3-\mathrm{CO}_{2}\right), 134.4$ (C-6), 125.9 (C-5), 70.2 (C-2), $61.8\left(\mathrm{CH}_{2} \mathrm{O}, 1-\mathrm{OEt}\right), 60.8\left(\mathrm{CH}_{2} \mathrm{O}, 3-\mathrm{CO}_{2} \mathrm{CH}_{2}\right), 48.6(\mathrm{C}-3), 32.2(\mathrm{C}-4), 31.5(\mathrm{C}-7)$, 31.1 (C-8), 22.2 (C-9), 14.2 (C-10), $14.1\left(\mathrm{CH}_{3}, 1-\mathrm{OEt}\right), 14.1\left(\mathrm{CH}_{3}, 3-\mathrm{CO}_{2} \mathrm{Et}\right)$; HRMS(ESI) $m / z$ calcd. for $\left[\mathrm{C}_{15} \mathrm{H}_{26} \mathrm{O}_{5}+\mathrm{Na}\right]^{+}: 309.1678$, obsd.: 309.1682 .

\section{Ethyl $2 S$-hydroxy-3R-ethoxycarbonyl-heptadecen-5-enoate}<smiles>CCOC(=O)C(O)C(C/C=C/[In])C(=O)OCC</smiles>
(anti-5e). By reacting diethyl malate $3(3.99 \mathrm{~g}, 21.0 \mathrm{mmol})$ with 1-iodo-tetradec-2-ene (10.14 g, $31.5 \mathrm{mmol})$ according to the general procedure for the synthesis of $\alpha$-alkenyl- $\beta$-hydroxydiesters, heptadecenoate 5e was obtained (eluting in 15:1, petroleum ether/EtOAc, v/v) as a colourless oil (4.11 g, $10.7 \mathrm{mmol}, 51 \%$, anti:syn = 10:1). $\mathrm{R}_{f}=0.5(\mathrm{PE} / \mathrm{EA}, 2 / 1, \mathrm{v} / \mathrm{v}) ;[\alpha]_{\mathrm{D}}^{23}=+2.0\left(c=0.1, \mathrm{CHCl}_{3}\right)$; IR (film): 3522, 2924, 2853, 1737, 1219, 1032, $772 \mathrm{~cm}^{-1} ;{ }^{1} \mathrm{H}$ NMR (500 MHz, $\left.\mathrm{CDCl}_{3}\right) \delta 5.57\left(\mathrm{dt}, J_{5,6}\right.$ $\left.=15.1 \mathrm{~Hz}, J_{6,7 \mathrm{a}}=J_{6,7 \mathrm{~b}}=7.1 \mathrm{~Hz}, 1 \mathrm{H}, \mathrm{H}-6\right), 5.39\left(\mathrm{dt}, J_{5,6}=15.1 \mathrm{~Hz}, J_{4 \mathrm{a}, 5}=J_{4 \mathrm{~b}, 5}=7.2\right.$ 
$\mathrm{Hz}, 1 \mathrm{H}, \mathrm{H}-5), 4.31-4.20$ (m, 3H, $\mathrm{CH}_{2} \mathrm{O}-1$ and $\left.\mathrm{H}-2\right), 4.16-4.11\left(\mathrm{~m}, 2 \mathrm{H}, 3-\mathrm{CO}_{2} \mathrm{CH}_{2}\right.$ ), $3.18\left(\mathrm{~d}, J_{2, \mathrm{OH}}=7.4 \mathrm{~Hz}, 1 \mathrm{H}, \mathrm{OH}\right), 2.90\left(\mathrm{ddd}, J_{3,4 \mathrm{a}}=J_{3,4 \mathrm{~b}}=8.3 \mathrm{~Hz}, J_{2,3}=3.2 \mathrm{~Hz}, 1 \mathrm{H}, \mathrm{H}-\right.$ 3), 2.58-2.51 (m, 1H, H-4a), $2.38\left(\mathrm{ddd}, J_{4 \mathrm{a}, 4 \mathrm{~b}}=14.2 \mathrm{~Hz}, J_{3,4 \mathrm{~b}}=8.3 \mathrm{~Hz}, J_{4 \mathrm{~b}, 5}=7.2 \mathrm{~Hz}\right.$, $1 \mathrm{H}, \mathrm{H}-4 \mathrm{~b}$ ), 1.99 (q, $J_{6,7}=J_{7,8}=7.1 \mathrm{~Hz}, 2 \mathrm{H}, \mathrm{H}-7$ ), 1.32-1.23 (m, 24H, H-8-H-16 and $\left.2 \times \mathrm{CH}_{3}\right), 0.88\left(\mathrm{t}, J=7.2 \mathrm{~Hz}, 3 \mathrm{H}, \mathrm{CH}_{3}-17\right) ;{ }^{13} \mathrm{C} \mathrm{NMR}\left(125 \mathrm{MHz}, \mathrm{CDCl}_{3}\right) \delta 173.7(\mathrm{C}-$ 1), 172.3 (3- $\left.\mathrm{CO}_{2}\right), 134.4$ (C-6), 125.8 (C-5), 70.2 (C-2), $61.8\left(\mathrm{CH}_{2} \mathrm{O}, 1\right.$-OEt), 60.8 $\left(\mathrm{CH}_{2} \mathrm{O}, 3-\mathrm{CO}_{2} \mathrm{CH}_{2}\right), 48.6$ (C-3), 32.2 (C-4), 31.9 (C-7), 31.1 (C-8), 29.7, 29.6, 29.6, 29.5, 29.4, 29.3, 29.2, 22.68 (C-9-C-16), 14.1 (C-17), $14.1\left(\mathrm{CH}_{3}, 1-\mathrm{OEt}\right), 14.1\left(\mathrm{CH}_{3}\right.$, 3- $\mathrm{CO}_{2} \mathrm{Et}$ ); HRMS(ESI) $\mathrm{m} / z$ calcd. for $\left[\mathrm{C}_{22} \mathrm{H}_{40} \mathrm{O}_{5}+\mathrm{Na}\right]^{+}:$407.2773, obsd.: 407.2781 .

Ethyl $2 S$-hydroxy-3R-ethoxycarbonyl-tricos-5-enoate (anti-5g). By reacting diethyl malate $3(0.40 \mathrm{~g}, 2.11 \mathrm{mmol})$ with 1-iodo-eicos-2-ene<smiles>CCOC(=O)C(C/C=C/[13CH]C)[C@@H](O)C(=O)OCC</smiles>
$(1.28 \mathrm{~g}, 3.16 \mathrm{mmol})$ according to the general procedure for the synthesis of $\alpha$-alkenyl- $\beta$-hydroxy-diesters, tricosenoate $\mathbf{5 g}$ was obtained (eluting in 15:1, petroleum ether/EtOAc, v/v) as white solid (0.48 g, $1.03 \mathrm{mmol}, 49 \%$, anti:syn $=9: 1) . \mathrm{R}_{f}=$ $0.49(\mathrm{PE} / \mathrm{EA}, 2 / 1, \mathrm{v} / \mathrm{v}) ;[\alpha] \mathrm{D}^{22}=+6.0\left(c=1.0, \mathrm{CHCl}_{3}\right) ; \mathrm{IR}$ (film): 3517, 2924, 2853, 1737, 1219, 1032, 970, 772, $\mathrm{cm}^{-1} ;{ }^{1} \mathrm{H}$ NMR (500 MHz, $\left.\mathrm{CDCl}_{3}\right) \delta 5.56\left(\mathrm{dt}, J_{5,6}=15.4 \mathrm{~Hz}, J_{6,7 \mathrm{a}}=J_{6,7 \mathrm{~b}}=6.6 \mathrm{~Hz}, 1 \mathrm{H}, \mathrm{H}-6\right), 5.40\left(\mathrm{dt}, J_{5,6}=15.4\right.$ $\left.\mathrm{Hz}, J_{4 \mathrm{a}, 5}=J_{4 \mathrm{~b}, 5}=6.6 \mathrm{~Hz}, 1 \mathrm{H}, \mathrm{H}-5\right), 4.31-4.22\left(\mathrm{~m}, 3 \mathrm{H}, \mathrm{CH}_{2} \mathrm{O}-1\right.$ and $\left.\mathrm{H}-2\right), 4.19-4.10$ $\left(\mathrm{m}, 2 \mathrm{H}, 3-\mathrm{CO}_{2} \mathrm{CH}_{2}\right), 2.90\left(\mathrm{ddd}, J_{3,4 \mathrm{a}}=J_{3,4 \mathrm{~b}}=8.8 \mathrm{~Hz}, J_{2,3}=3.2 \mathrm{~Hz}, 1 \mathrm{H}, \mathrm{H}-3\right), 2.58-$ $2.52(\mathrm{~m}, 1 \mathrm{H}, \mathrm{H}-4 \mathrm{a}), 2.38\left(\mathrm{ddd}, J_{4 \mathrm{a}, 4 \mathrm{~b}}=15.2 \mathrm{~Hz}, J_{3,4 \mathrm{~b}}=J_{4 \mathrm{~b}, 5}=8.8 \mathrm{~Hz}, 1 \mathrm{H}, \mathrm{H}-4 \mathrm{~b}\right), 1.99$ $\left(\mathrm{q}, J_{6,7}=J_{7,8}=7.1 \mathrm{~Hz}, 2 \mathrm{H}, \mathrm{H}-7 \mathrm{a}, \mathrm{b}\right), 1.32-1.23\left(\mathrm{~m}, 36 \mathrm{H}, \mathrm{H}-8-\mathrm{H}-22\right.$ and $\left.2 \times \mathrm{CH}_{3}\right)$, 0.89 (t, $\left.J=7.1 \mathrm{~Hz}, 3 \mathrm{H}, \mathrm{CH}_{3}-23\right) ;{ }^{13} \mathrm{C} \mathrm{NMR}\left(125 \mathrm{MHz}, \mathrm{CDCl}_{3}\right) \delta 173.7$ (C-1), 172.3 (3- $\left.\mathrm{CO}_{2}\right), 134.4$ (C-6), 125.8 (C-5), 70.2 (C-2), $61.8\left(\mathrm{CH}_{2} \mathrm{O}, 1-\mathrm{OEt}\right), 60.8\left(\mathrm{CH}_{2} \mathrm{O}, 3-\right.$ $\mathrm{CO}_{2} \mathrm{CH}_{2}$ ), 48.6 (C-3), 32.2 (C-4), 31.9 (C-7), 31.1 (C-8), 29.7, 29.66, 29.65, 29.5, 29.4, 29.2, 22.7 (C-9-C-22), 14.1 (C-23), $14.1\left(\mathrm{CH}_{3}, 1-\mathrm{OEt}\right), 14.1\left(\mathrm{CH}_{3}, 3-\mathrm{CO}_{2} \mathrm{Et}\right)$; HRMS(ESI) $m / z$ calcd. for $\left[\mathrm{C}_{28} \mathrm{H}_{52} \mathrm{O}_{5}+\mathrm{Na}\right]^{+}:$491.3712, obsd.: 491.3706 . 


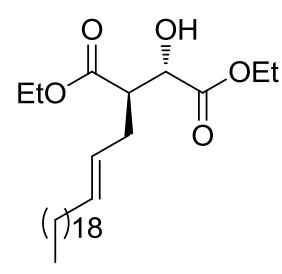

Ethyl $2 S$-hydroxy-3R-ethoxycarbonyl-pentacos-5-enoate (anti-5i). By reacting diethyl malate $3(0.53 \mathrm{~g}, 2.77 \mathrm{mmol})$ with 1-iodo-docos-2-ene (1.80 g, $4.15 \mathrm{mmol})$ according to the general procedure for the synthesis of $\alpha$-alkenyl- $\beta$-hydroxydiesters, pentacosenoate 5i was obtained (eluting in 15:1, petroleum ether/EtOAc, v/v) as a white solid (0.57 g, 1.16 mmol, 42\%, anti:syn = 9:1). $\mathrm{R}_{f}=0.6(\mathrm{PE} / \mathrm{EA}, 2 / 1, \mathrm{v} / \mathrm{v}) ;[\alpha] \mathrm{D}^{23}=+5.0(c=1.0$, $\mathrm{CHCl}_{3}$ ); IR (film): 3523, 2916, 2849, 1735, 1373, 1213, 1032, 969, 756 $\mathrm{cm}^{-1} ;{ }^{1} \mathrm{H}$ $\operatorname{NMR}\left(500 \mathrm{MHz}, \mathrm{CDCl}_{3}\right) \delta 5.56\left(\mathrm{dt}, J_{5,6}=15.1 \mathrm{~Hz}, J_{6,7 \mathrm{a}}=J_{6,7 \mathrm{~b}}=6.9 \mathrm{~Hz}, 1 \mathrm{H}, \mathrm{H}-6\right)$, $5.39\left(\mathrm{dt}, J_{5,6}=15.1 \mathrm{~Hz}, J_{4 \mathrm{a}, 5}=J_{4 \mathrm{~b}, 5}=7.3 \mathrm{~Hz}, 1 \mathrm{H}, \mathrm{H}-5\right), 4.30-4.22\left(\mathrm{~m}, 3 \mathrm{H}, \mathrm{CH}_{2} \mathrm{O}-1\right.$ and $\mathrm{H}-2), 4.14-4.10\left(\mathrm{~m}, 2 \mathrm{H}, 3-\mathrm{CO}_{2} \mathrm{CH}_{2}\right), 3.18\left(\mathrm{~d}, J_{2, \mathrm{OH}}=6.9 \mathrm{~Hz}, 1 \mathrm{H}, \mathrm{OH}\right), 2.90$ $\left(\right.$ ddd, $\left.J_{3,4 \mathrm{a}}=J_{3,4 \mathrm{~b}}=8.3 \mathrm{~Hz}, J_{2,3}=3.2 \mathrm{~Hz}, 1 \mathrm{H}, \mathrm{H}-3\right), 2.58-2.52(\mathrm{~m}, 1 \mathrm{H}, \mathrm{H}-4 \mathrm{a}), 2.38$ $\left(\mathrm{ddd}, J_{4 \mathrm{a}, 4 \mathrm{~b}}=14.1 \mathrm{~Hz}, J_{3,4 \mathrm{a}}=J_{4 \mathrm{a}, 5}=7.8 \mathrm{~Hz}, 1 \mathrm{H}, \mathrm{H}-4 \mathrm{~b}\right), 1.99\left(\mathrm{q}, J_{6,7}=J_{7,8}=7.1 \mathrm{~Hz}\right.$, $2 \mathrm{H}, \mathrm{H}-7 \mathrm{a}, \mathrm{b}), 1.33-1.21\left(\mathrm{~m}, 40 \mathrm{H}, \mathrm{H}-8-\mathrm{H}-24\right.$ and $\left.2 \mathrm{x} \mathrm{CH}_{3}\right), 0.88(\mathrm{t}, J=7.2 \mathrm{~Hz}, 3 \mathrm{H}$, $\left.\mathrm{CH}_{3}-25\right) ;{ }^{13} \mathrm{C}$ NMR (125 MHz, $\left.\mathrm{CDCl}_{3}\right) \delta 173.7(\mathrm{C}-1), 172.3\left(3-\mathrm{CO}_{2}\right), 134.5(\mathrm{C}-6)$, 125.8 (C-5), 70.2 (C-2), $61.8\left(\mathrm{CH}_{2} \mathrm{O}, 1-\mathrm{OEt}\right), 60.8\left(\mathrm{CH}_{2} \mathrm{O}, 3-\mathrm{CO}_{2} \mathrm{CH}_{2}\right), 48.6(\mathrm{C}-3)$, 32.5 (C-4), 31.9 (C-7), 31.1 (C-8), 29.7, 29.66, 29.64, 29.5, 29.4, 29.2, 22.7 (C-9-C24), 14.1 (C-25), 14.1 ( $\left.\mathrm{CH}_{3}, 1-\mathrm{OEt}\right), 14.1\left(\mathrm{CH}_{3}, 3-\mathrm{CO}_{2} \mathrm{Et}\right)$; HRMS(ESI) $\mathrm{m} / z$ calcd. for $\left[\mathrm{C}_{30} \mathrm{H}_{56} \mathrm{O}_{5}+\mathrm{Na}\right]^{+}:$519.4025, obsd.: 519.4029 .

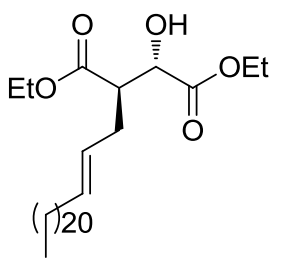

Ethyl 2S-hydroxy-3R-ethoxycarbonyl-heptacos-5-enoate (anti-5j). By reacting diethyl malate 3 (0.55 g, $2.89 \mathrm{mmol})$ with 1-iodo-tetracos-2-ene (2.0 g, $4.32 \mathrm{mmol})$ according to the general procedure for the synthesis of $\alpha$-alkenyl- $\beta$-hydroxydiesters, heptacosenoate $\mathbf{5 j}$ was obtained (eluting in 15:1, petroleum ether/EtOAc, v/v) as a white solid (0.62 g, $1.19 \mathrm{mmol}, 41 \%$, anti:syn = 9:1). $\mathrm{R}_{f}=0.58(\mathrm{PE} / \mathrm{EA}, 2 / 1, \mathrm{v} / \mathrm{v}) ;[\alpha] \mathrm{D}^{22}=+0.1\left(c=1.0, \mathrm{CHCl}_{3}\right) ; \mathrm{IR}($ film): 3351, 2922, 2852, 1736, 1376, 1215, 1042, $756 \mathrm{~cm}^{-1} ;{ }^{1} \mathrm{H}$ NMR $\left(500 \mathrm{MHz}, \mathrm{CDCl}_{3}\right) \delta 5.56$ $\left(\mathrm{dt}, J_{5,6}=15.1 \mathrm{~Hz}, J_{6,7 \mathrm{a}}=J_{6,7 \mathrm{~b}}=6.8 \mathrm{~Hz}, 1 \mathrm{H}, \mathrm{H}-6\right), 5.39\left(\mathrm{dt}, J_{5,6}=15.1 \mathrm{~Hz}, J_{4 \mathrm{a}, 5}=J_{4 \mathrm{~b}, 5}\right.$ $=6.5 \mathrm{~Hz}, 1 \mathrm{H}, \mathrm{H}-5), 4.30-4.22\left(\mathrm{~m}, 3 \mathrm{H}, \mathrm{CH}_{2} \mathrm{O}-1\right.$ and $\left.\mathrm{H}-2\right), 4.16-4.12(\mathrm{~m}, 2 \mathrm{H}, 3-$ $\left.\mathrm{CO}_{2} \mathrm{CH}_{2}\right), 3.17\left(\mathrm{~d}, J_{2, \mathrm{OH}}=7.3 \mathrm{~Hz}, 1 \mathrm{H}, \mathrm{OH}\right), 2.91\left(\mathrm{ddd}, J_{3,4 \mathrm{a}}=J_{3,4 \mathrm{~b}}=9.1 \mathrm{~Hz}, J_{2,3}=3.2\right.$ $\mathrm{Hz}, 1 \mathrm{H}, \mathrm{H}-3), 2.58-2.53(\mathrm{~m}, 1 \mathrm{H}, \mathrm{H}-4 \mathrm{a}), 2.38\left(\mathrm{ddd}, J_{4 \mathrm{a}, 4 \mathrm{~b}}=14.3 \mathrm{~Hz}, J_{3,4 \mathrm{a}}=J_{4 \mathrm{a}, 5}=8.3\right.$ 
$\mathrm{Hz}, 1 \mathrm{H}, \mathrm{H}-4 \mathrm{~b}$ ), 2.00 (q, $\left.J_{6,7}=J_{7,8}=7.1 \mathrm{~Hz}, 2 \mathrm{H}, \mathrm{H}-7 \mathrm{a}, \mathrm{b}\right), 1.37-1.18$ (m, 44H, H-8-H26 and $\left.2 \times \mathrm{CH}_{3}\right), 0.88\left(\mathrm{t}, J=6.8 \mathrm{~Hz}, 3 \mathrm{H}, \mathrm{CH}_{3}-27\right) ;{ }^{13} \mathrm{C} \mathrm{NMR}\left(125 \mathrm{MHz}, \mathrm{CDCl}_{3}\right) \delta$ 173.7 (C-1), 172.3 (3-CO $\left.{ }_{2}\right), 134.5$ (C-6), 125.8 (C-5), $70.2(\mathrm{C}-2), 61.8\left(\mathrm{CH}_{2} \mathrm{O}, 1\right.$ OEt), $60.8\left(\mathrm{CH}_{2} \mathrm{O}, 3-\mathrm{CO}_{2} \mathrm{CH}_{2}\right), 48.6$ (C-3), 32.6 (C-4), 31.9 (C-7), 31.1 (C-8), 29.71, 29.67, 29.65, 29.58, 29.52, 29.37, 29.2, 22.7 (C-9-C-26), 14.2 (C-27), $14.1\left(\mathrm{CH}_{3}, 1\right.$ OEt), $14.1\left(\mathrm{CH}_{3}, 3-\mathrm{CO}_{2} \mathrm{Et}\right)$; $\mathrm{HRMS}(\mathrm{ESI}) \mathrm{m} / \mathrm{z}$ calcd. for $\left[\mathrm{C}_{32} \mathrm{H}_{60} \mathrm{O}_{5}+\mathrm{Na}\right]^{+}: 547.4338$, obsd.: 547.4344 .

General Procedure for the Synthesis of $\alpha$-Alkyl- $\beta$-Hydroxy-Diesters. $n$-BuLi $(11.5 \mathrm{~mL}, 2.0 \mathrm{~m}$ solution in hexanes, $23.0 \mathrm{mmol})$ was added to a solution of diisoproplyamine $(3.6 \mathrm{~mL}, 25.0 \mathrm{mmol})$ in THF $(20 \mathrm{~mL})$ at $0{ }^{\circ} \mathrm{C}$. After $30 \mathrm{~min}$, the solution was cooled down to $-78^{\circ} \mathrm{C}$ and diethyl malate $5(1.9 \mathrm{~g}, 10 \mathrm{mmol})$ in THF (20 $\mathrm{mL}$ ) was added. The resulting mixture was stirred at $-78{ }^{\circ} \mathrm{C}$ for $1 \mathrm{~h}$, warmed up to $20{ }^{\circ} \mathrm{C}$ over $1 \mathrm{~h}$ and stirred at $-20^{\circ} \mathrm{C}$ for $20 \mathrm{~min}$. After cooling down to $-78{ }^{\circ} \mathrm{C}$, the alkyl iodide (15.0 mmol, 1 equiv.) in THF $(20 \mathrm{~mL})$ was added dropwise and the reaction stirred for $2 \mathrm{~h}$, during which time the temperature increased to $0^{\circ} \mathrm{C}$ and stirred for a further $2 \mathrm{~h}$ at room temperature. The reaction was quenched using $\mathrm{NH}_{4} \mathrm{Cl}$ (sat.) and extracted with EtOAc $(3 \times 100 \mathrm{~mL})$. The combined organic layers were washed with water $(30 \mathrm{~mL})$ and brine $(30 \mathrm{~mL})$, dried $\left(\mathrm{MgSO}_{4}\right)$, filtered and the solvent removed in vacuo to yield a crude yellow oil. Purification of the residue using silica gel flash column chromatography and the eluent given, gave the alkylated product.

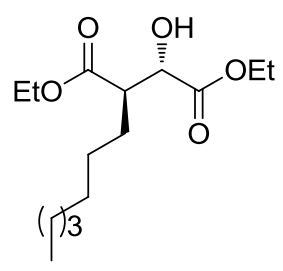

Ethyl $2 S$-hydroxy-3R-ethoxycarbonyl-decanoate (anti-5b). By reacting diethyl malate 3 (3.97 g, $20.9 \mathrm{mmol})$ with 1iodoheptane $(5.13 \mathrm{~mL}, 31.3 \mathrm{mmol})$ according to the general procedure for the synthesis of $\alpha$-alkylated- $\beta$-hydroxy-diesters, decanoate 5b was obtained (eluting in 15:1, petroleum ether/EtOAc, v/v) as a colourless oil (2.24 g, $7.4 \mathrm{mmol}, 37 \%$, anti:syn $=7: 1) . \mathrm{R}_{f}=$ $0.73(\mathrm{PE} / \mathrm{EA}, 2 / 1, \mathrm{v} / \mathrm{v}) ;[\alpha] \mathrm{D}^{23}=+0.7\left(c=0.1, \mathrm{CHCl}_{3}\right)$; IR (film): 3522, 3020, 2928, 2857, 1734, 1376, 1216, 1027, 754, $668 \mathrm{~cm}^{-1}$; ${ }^{1} \mathrm{H}$ NMR $\left(500 \mathrm{MHz}, \mathrm{CDCl}_{3}\right) \delta 4.31-$ $4.21\left(\mathrm{~m}, 3 \mathrm{H}, \mathrm{CH}_{2} \mathrm{O}-1\right.$ and $\left.\mathrm{H}-2\right), 4.14\left(\mathrm{q}, J_{\mathrm{a}, \mathrm{b}}=7.1 \mathrm{~Hz}, 2 \mathrm{H}, \mathrm{CH}_{2} \mathrm{O}, 3-\mathrm{CO}_{2} \mathrm{CH}_{2}\right), 3.19$ 
$\left(\mathrm{d}, J_{2, \mathrm{OH}}=7.6 \mathrm{~Hz}, 1 \mathrm{H}, \mathrm{OH}\right), 2.84\left(\mathrm{td}, J_{3,4}=7.1 \mathrm{~Hz}, J_{2,3}=3.7 \mathrm{~Hz}, 1 \mathrm{H}, \mathrm{H}-3\right), 1.85$ (ddt, $\left.J_{4 \mathrm{a}, 4 \mathrm{~b}}=14.9 \mathrm{~Hz}, J_{3,4 \mathrm{a}}=J_{4 \mathrm{a}, 5 \mathrm{a}}=J_{4 \mathrm{a}, 5 \mathrm{~b}}=7.1 \mathrm{~Hz}, 1 \mathrm{H}, \mathrm{H}-4 \mathrm{a}\right), 1.66\left(\mathrm{ddt}, J_{4 \mathrm{a}, 4 \mathrm{~b}}=14.9 \mathrm{~Hz}\right.$, $\left.J_{3,4 \mathrm{~b}}=J_{4 \mathrm{~b}, 5 \mathrm{a}}=J_{4 \mathrm{~b}, 5 \mathrm{~b}}=6.8 \mathrm{~Hz}, 1 \mathrm{H}, \mathrm{H}-4 \mathrm{~b}\right), 1.40-1.24\left(\mathrm{~m}, 16 \mathrm{H}, \mathrm{H}-5-\mathrm{H}-9,2 \times \mathrm{CH}_{3}\right), 0.89$ $\left(\mathrm{t}, J=6.9 \mathrm{~Hz}, 3 \mathrm{H}, \mathrm{CH}_{3}-10\right) ;{ }^{13} \mathrm{C} \mathrm{NMR}\left(125 \mathrm{MHz}, \mathrm{CDCl}_{3}\right) \delta 173.5(\mathrm{C}-1), 172.9$ (3$\left.\mathrm{CO}_{2}\right), 71.1(\mathrm{C}-2), 61.8\left(\mathrm{CH}_{2} \mathrm{O}, 1-\mathrm{OEt}\right), 60.8\left(\mathrm{CH}_{2} \mathrm{O}, 3-\mathrm{CO}_{2} \mathrm{CH}_{2}\right), 48.6(\mathrm{C}-3), 31.8(\mathrm{C}-$ 4), 29.4, 29.1, 28.1, 27.4, 22.6 (C-5-C-9), 14.1 (C-10), $14.1\left(\mathrm{CH}_{3}, 1-\mathrm{OEt}\right), 14.1$ $\left(\mathrm{CH}_{3}, 3-\mathrm{CO}_{2} \mathrm{Et}\right)$; HRMS(ESI) $\mathrm{m} / \mathrm{z}$ calcd. For $\left[\mathrm{C}_{15} \mathrm{H}_{28} \mathrm{O}_{5}+\mathrm{Na}\right]^{+}: 311.1833$, obsd.: 311.1834 .

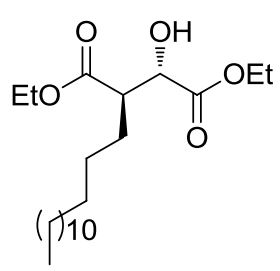

\section{Ethyl $2 S$-hydroxy-3R-ethoxycarbonyl-heptadecanoate (anti-} 5d). By reacting diethyl malate $3(0.44 \mathrm{~g}, 2.35 \mathrm{mmol})$ with 1 iodotetradecane $(1.14 \mathrm{~g}, 3.53 \mathrm{mmol})$ according to the general procedure for the synthesis of $\alpha$-alkyl- $\beta$-hydroxy-diesters, heptadecanoate 5d was obtained (eluting in 15:1, petroleum ether/EtOAc, v/v) as a colourless oil $(0.14 \mathrm{~g}, 0.34 \mathrm{mmol}, 15 \%$, anti:syn $=9: 1) . \mathrm{R}_{f}=$ $0.66(\mathrm{PE} / \mathrm{EA}, 2 / 1, \mathrm{v} / \mathrm{v}) ;[\alpha] \mathrm{D}^{23}=+4.0\left(c=1.0, \mathrm{CHCl}_{3}\right)$; IR (film): 3514, 3020, 2925 , 2584, 1735, 1466, 1369, 1216, $755 \mathrm{~cm}^{-1} ;{ }^{1} \mathrm{H}$ NMR (500 MHz, $\left.\mathrm{CDCl}_{3}\right) \delta 4.29-4.22$ $\left(\mathrm{m}, 3 \mathrm{H}, \mathrm{CH}_{2} \mathrm{O}-1\right.$ and $\left.\mathrm{H}-2\right), 4.14\left(\mathrm{q}, J=7.1 \mathrm{~Hz}, 2 \mathrm{H}, 3-\mathrm{CO}_{2} \mathrm{CH}_{3}\right), 3.19\left(\mathrm{~d}, J_{2, \mathrm{OH}}=7.6\right.$ $\mathrm{Hz}, 1 \mathrm{H}, \mathrm{OH}), 2.84\left(\mathrm{td}, J_{3,4}=7.3 \mathrm{~Hz}, J_{2,3}=3.5 \mathrm{~Hz}, 1 \mathrm{H}, \mathrm{H}-3\right), 1.83$ (ddt, $J_{4 \mathrm{a}, 4 \mathrm{~b}}=14.0$ $\left.\mathrm{Hz}, J_{3,4 \mathrm{a}}=J_{4 \mathrm{a}, 5 \mathrm{a}}=J_{4 \mathrm{a}, 5 \mathrm{~b}}=7.0 \mathrm{~Hz}, 1 \mathrm{H}, \mathrm{H}-4 \mathrm{a}\right), 1.66\left(\mathrm{ddt}, J_{4 \mathrm{a}, 4 \mathrm{~b}}=14.0 \mathrm{~Hz}, J_{3,4 \mathrm{~b}}=J_{4 \mathrm{~b}, 5 \mathrm{a}}=\right.$ $\left.J_{4 \mathrm{~b}, 5 \mathrm{~b}}=7.2 \mathrm{~Hz}, 1 \mathrm{H}, \mathrm{H}-4 \mathrm{~b}\right), 1.45-1.21\left(\mathrm{~m}, 30 \mathrm{H}, \mathrm{H}-5-\mathrm{H}-16\right.$ and $\left.2 \mathrm{x} \mathrm{CH}_{3}\right), 0.87(\mathrm{t}, J=$ $\left.6.4 \mathrm{~Hz}, 3 \mathrm{H}, \mathrm{CH}_{3}-17\right) ;{ }^{13} \mathrm{C} \mathrm{NMR}\left(125 \mathrm{MHz}, \mathrm{CDCl}_{3}\right) \delta 173.5(\mathrm{C}-1), 172.9\left(3-\mathrm{CO}_{2}\right)$, 71.1 (C-2), $61.8\left(\mathrm{CH}_{2} \mathrm{O}, 1-\mathrm{OEt}\right), 60.8\left(\mathrm{CH}_{2} \mathrm{O}, 3-\mathrm{CO}_{2} \mathrm{CH}_{2}\right), 48.6(\mathrm{C}-3), 31.9(\mathrm{C}-4)$, 29.7, 29.7, 29.7, 29.7, 29.6, 29.6, 29.4, 28.1, 27.4, 22.7 (C-5-C-16), 14.2 (C-17), $14.1\left(\mathrm{CH}_{3}, \quad 1-\mathrm{OEt}\right), \quad 14.1 \quad\left(\mathrm{CH}_{3}, \quad 3-\mathrm{CO}_{2} \mathrm{Et}\right) ; \quad \mathrm{HRMS}(\mathrm{ESI}) \mathrm{m} / \mathrm{z}$ calcd. For $\left[\mathrm{C}_{22} \mathrm{H}_{42} \mathrm{O}_{5}+\mathrm{Na}\right]^{+}:$409.2931, obsd.: 409.2928 .

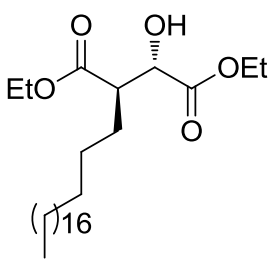

Ethyl $2 S$-hydroxy-3R-ethoxycarbonyl-tricosanoate (anti5f). By reacting diethyl malate $3(0.22 \mathrm{~g}, 1.15 \mathrm{mmol})$ with 1 iodoeicosane $(0.70 \mathrm{~g}, 1.72 \mathrm{mmol})$ according to the general procedure for the synthesis of $\alpha$-alkyl- $\beta$-hydroxy-diesters, 
tricosanoate $\mathbf{5 f}$ was obtained (eluting in 15:1, petroleum ether/EtOAc, v/v) as a white solid (0.02 g, $0.05 \mathrm{mmol}, 4 \%$, anti:syn $=6: 1) . \mathrm{R}_{f}=0.58(\mathrm{PE} / \mathrm{EA}, 2 / 1, \mathrm{v} / \mathrm{v}) ;[\alpha] \mathrm{D}^{22}=$ +2.0 ( $c=1.0, \mathrm{CHCl}_{3}$ ); IR (film): 2918, 2850, 1737, 1252, 1182, 1099, 1030, 837, $757, \mathrm{~cm}^{-1} ;{ }^{1} \mathrm{H}$ NMR (500 MHz, $\left.\mathrm{CDCl}_{3}\right) \delta 4.31-4.21\left(\mathrm{~m}, 3 \mathrm{H}, \mathrm{CH}_{2} \mathrm{O}-1\right.$ and $\left.\mathrm{H}-2\right)$, $4.18-4.12\left(\mathrm{~m}, 2 \mathrm{H}, 3-\mathrm{CO}_{2} \mathrm{CH}_{3}\right), 3.20\left(\mathrm{~d}, J_{2, \mathrm{OH}}=7.8 \mathrm{~Hz}, 1 \mathrm{H}, \mathrm{OH}\right), 2.84\left(\mathrm{td}, J_{3,4}=7.2\right.$ $\left.\mathrm{Hz}, J_{2,3}=3.7 \mathrm{~Hz}, 1 \mathrm{H}, \mathrm{H}-3\right), 1.83\left(\mathrm{ddt}, J_{4 \mathrm{a}, 4 \mathrm{~b}}=14.4 \mathrm{~Hz}, J_{3,4 \mathrm{a}}=J_{4 \mathrm{a}, 5 \mathrm{a}}=J_{4 \mathrm{a}, 5 \mathrm{~b}}=7.8 \mathrm{~Hz}\right.$, $1 \mathrm{H}, \mathrm{H}-4 \mathrm{a}), 1.66$ (ddt, $\left.J_{4 \mathrm{a}, 4 \mathrm{~b}}=14.4 \mathrm{~Hz}, J_{3,4 \mathrm{~b}}=J_{4 \mathrm{~b}, 5 \mathrm{a}}=J_{4 \mathrm{~b}, 5 \mathrm{~b}}=7.4 \mathrm{~Hz}, 1 \mathrm{H}, \mathrm{H}-4 \mathrm{~b}\right), 1.39$ $1.23\left(\mathrm{~m}, 42 \mathrm{H}, \mathrm{H}-5-\mathrm{H}-22\right.$ and $\left.2 \mathrm{x} \mathrm{CH}_{3}\right), 0.89\left(\mathrm{t}, J=6.9 \mathrm{~Hz}, 3 \mathrm{H}, \mathrm{CH}_{3}-23\right) ;{ }^{13} \mathrm{C} \mathrm{NMR}$ $\left(125 \mathrm{MHz}, \mathrm{CDCl}_{3}\right) \delta 173.5(\mathrm{C}-1), 172.9\left(3-\mathrm{CO}_{2}\right), 71.0(\mathrm{C}-2), 61.8\left(\mathrm{CH}_{2} \mathrm{O}, 1-\mathrm{OEt}\right)$, $60.8\left(\mathrm{CH}_{2} \mathrm{O}, 3-\mathrm{CO}_{2} \mathrm{CH}_{2}\right), 48.6(\mathrm{C}-3), 31.9(\mathrm{C}-4), 29.68,29.66,29.64,29.62,29.5$, 29.4, 29.3, 28.1, 27.4, 22.7 (C-5-C-22), 14.2 (C-23), $14.1\left(\mathrm{CH}_{3}, 1-\mathrm{OEt}\right), 14.1\left(\mathrm{CH}_{3}\right.$, 3- $\mathrm{CO}_{2} \mathrm{Et}$ ); HRMS(ESI) m/z calcd. For $\left[\mathrm{C}_{28} \mathrm{H}_{54} \mathrm{O}_{5}+\mathrm{Na}\right]^{+}: 493.3869$, obsd.: 493.3871.

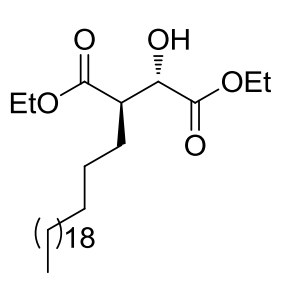

Ethyl 2S-hydroxy-3R-ethoxycarbonyl-pentacosanoate

(anti-5h). By reacting diethyl malate $3(0.22 \mathrm{~g}, 1.16 \mathrm{mmol})$ with 1-iododocosane $(0.78 \mathrm{~g}, 1.77 \mathrm{mmol})$ according to the general procedure for the synthesis of $\alpha$-alkyl- $\beta$-hydroxydiesters, pentacosanoate $\mathbf{5 h}$ was obtained (eluting in 15:1, petroleum ether/EtOAc, v/v) as a white solid (0.05 g, $0.096 \mathrm{mmol}, 8 \%$, anti:syn = 6:1). $\mathrm{R}_{f}=0.58(\mathrm{PE} / \mathrm{EA}, 2 / 1, \mathrm{v} / \mathrm{v}) ;[\alpha] \mathrm{D}^{22}=+3.0\left(c=0.1, \mathrm{CHCl}_{3}\right) ; \mathrm{IR}$ (film) 3473, 2917, 2850, 1737, 1599, 2032, 837, 758, 721, $668 \mathrm{~cm}^{-1} ;{ }^{1} \mathrm{H}$ NMR (500 MHz, $\left.\mathrm{CDCl}_{3}\right)$ $\delta 4.30-4.21\left(\mathrm{~m}, 3 \mathrm{H}, \mathrm{CH}_{2} \mathrm{O}-1\right.$ and $\left.\mathrm{H}-2\right), 4.14\left(\mathrm{~m}, 2 \mathrm{H}, 3-\mathrm{CO}_{2} \mathrm{CH}_{2}\right), 3.20\left(\mathrm{~d}, J_{2, \mathrm{OH}}=7.6\right.$ $\mathrm{Hz}, 1 \mathrm{H}, 2-\mathrm{OH}), 2.84\left(\mathrm{td}, J_{3,4}=7.6 \mathrm{~Hz}, J_{2,3}=3.7 \mathrm{~Hz}, 1 \mathrm{H}, \mathrm{H}-3\right), 1.83$ (ddt, $J_{4 \mathrm{a}, 4 \mathrm{~b}}=14.2$ $\left.\mathrm{Hz}, J_{3,4 \mathrm{a}}=J_{4 \mathrm{a}, 5 \mathrm{a}}=J_{4 \mathrm{a}, 5 \mathrm{~b}}=7.2 \mathrm{~Hz}, 1 \mathrm{H}, \mathrm{H}-4 \mathrm{a}\right), 1.66\left(\mathrm{ddt}, J_{4 \mathrm{a}, 4 \mathrm{~b}}=14.2 \mathrm{~Hz}, J_{3,4 \mathrm{~b}}=J_{4 \mathrm{~b}, 5 \mathrm{a}}=\right.$ $\left.J_{4 \mathrm{~b}, 5 \mathrm{~b}}=7.2 \mathrm{~Hz}, 1 \mathrm{H}, \mathrm{H}-4 \mathrm{~b}\right), 1.40-1.24$ (m, 46H, H-5-H-24, 2 х CH $\left.\mathrm{CH}_{3}\right), 0.89$ (t, $J=6.6$ $\left.\mathrm{Hz}, 3 \mathrm{H}, \mathrm{CH}_{3}-25\right) ;{ }^{13} \mathrm{C}$ NMR $\left(125 \mathrm{MHz}, \mathrm{CDCl}_{3}\right) \delta 173.5(\mathrm{C}-1), 172.9\left(3-\mathrm{CO}_{2}\right), 71.1$ (C-2), $61.8\left(\mathrm{CH}_{2} \mathrm{O}, 1-\mathrm{OEt}\right), 60.8\left(\mathrm{CH}_{2} \mathrm{O}, 3-\mathrm{CO}_{2} \mathrm{CH}_{2}\right), 48.6(\mathrm{C}-3), 31.9$ (C-4), 29.7, 29.7, 29.7, 29.6, 29.4, 29.4, 28.1, 27.4, 22.7 (C-5-C-24), 14.2 (C-25), $14.1\left(\mathrm{CH}_{3}, 1\right.$ OEt), $14.1\left(\mathrm{CH}_{3}, 3-\mathrm{CO}_{2} \mathrm{Et}\right)$; HRMS(ESI) m/z calcd. For $\left[\mathrm{C}_{30} \mathrm{H}_{58} \mathrm{O}_{5}+\mathrm{Na}\right]^{+}: 521.4182$, obsd.: 521.4180 . 
General Procedure for Hydrogenation. $\mathrm{Pd} / \mathrm{C}(5 \mathrm{wt} \%)$ was added to a solution of the allylic alkylated diester $(1 \mathrm{mmol})$ in a mixture of $\mathrm{CH}_{2} \mathrm{Cl}_{2} / \mathrm{MeOH}(10 \mathrm{~mL}, 1 / 1$, v/v) and stirred at room temperature under $\mathrm{H}_{2}$ (gas) overnight. The reaction mixture was filtered through Celite, the Celite washed thoroughly with $\mathrm{CH}_{2} \mathrm{Cl}_{2} / \mathrm{MeOH}$ (20 $\mathrm{mL}, 1 / 1, \mathrm{v} / \mathrm{v}$ ) and the filtrate concentrated in vacuo. The product was purified using silica gel flash chromatography and the eluent given.

Ethyl 2S-hydroxy-3R-ethoxycarbonyl-decanoate (anti-5b). By subjecting decenoate (anti:syn 9:1) 5c (2.01 g, $6.99 \mathrm{mmol})$ to the general procedure for hydrogenation pure anti- 5b was obtained (eluting in 15:1 petroleum ether/EtOAc, $\mathrm{v} / \mathrm{v})$ as a colourless oil $(1.81 \mathrm{~g}, 6.29 \mathrm{mmol}, 90 \%)$. The spectral data matched that reported earlier.

Ethyl $2 S$-hydroxy-3R-ethoxycarbonyl-heptadecanoate (anti-5d). By subjecting heptadecenoate (anti:syn 10:1) 5e (3.60 g, $9.38 \mathrm{mmol})$ to the general procedure for hydrogenation pure anti-5d was obtained (eluting in 15:1, petroleum ether/EtOAc, $\mathrm{v} / \mathrm{v})$ as a colourless oil $(3.29 \mathrm{~g}, 8.52 \mathrm{mmol}, 91 \%)$. The spectral data matched that reported earlier.

Ethyl 2S-hydroxy-3R-ethoxycarbonyl-tricosanoate (anti-5f). By subjecting tricosenoate (anti:syn 9:1) 5g $(0.40 \mathrm{~g}, 0.85 \mathrm{mmol})$ to the general procedure for hydrogenation pure anti-5f was obtained (eluting in 15:1, petroleum ether/EtOAc, $\mathrm{v} / \mathrm{v})$ as a white solid $(0.36 \mathrm{~g}, 0.77 \mathrm{mmol}, 90 \%)$. The spectral data matched that reported earlier.

Ethyl 2S-hydroxy-3R-ethoxycarbonyl-pentacosanoate (anti-5h). By subjecting pentacosenoate (anti:syn 9:1) $\mathbf{5 i}(0.80 \mathrm{~g}, 1.61 \mathrm{mmol})$ to the general procedure for hydrogenation pure anti-5h was obtained (eluting in 15:1, petroleum ether/EtOAc, $\mathrm{v} / \mathrm{v})$ as a white solid $(0.72 \mathrm{~g}, 1.45 \mathrm{mmol}, 90 \%)$. The spectral data matched that reported earlier.

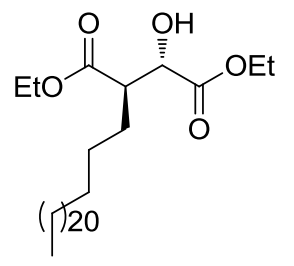

Ethyl 2S-hydroxy-3R-ethoxycarbonyl-heptacosanoate (anti5k). By subjecting heptacosenoate (anti:syn 9:1) 5j (0.11 g, $0.21 \mathrm{mmol}$ ) to the general procedure for hydrogenation pure 
anti-5k was obtained (eluting in 15:1, petroleum ether/EtOAc, v/v) as a white solid $(0.10 \mathrm{~g}, 0.19 \mathrm{mmol}, 90 \%) . \mathrm{R}_{f}=0.54(\mathrm{PE} / \mathrm{EA}, 2 / 1, \mathrm{v} / \mathrm{v}) ;[\alpha] \mathrm{D}^{22}=+2.0(c=0.1$, $\mathrm{CHCl}_{3}$ ); IR (film) 3473, 2917, 2850, 1737, 1208, 1029, 771, $668 \mathrm{~cm}^{-1} ;{ }^{1} \mathrm{H}$ NMR (500 $\left.\mathrm{MHz}, \mathrm{CDCl}_{3}\right) \delta 4.30-4.20\left(\mathrm{~m}, 3 \mathrm{H}, \mathrm{CH}_{2} \mathrm{O}-1\right.$ and $\left.\mathrm{H}-2\right), 4.18-4.12\left(\mathrm{~m}, 2 \mathrm{H}, 3-\mathrm{CO}_{2} \mathrm{CH}_{2}\right)$, $3.20\left(\mathrm{~d}, J_{2, \mathrm{OH}}=7.9 \mathrm{~Hz}, 1 \mathrm{H}, 2-\mathrm{OH}\right), 2.84\left(\mathrm{td}, J_{3,4}=7.3 \mathrm{~Hz}, J_{2,3}=3.7 \mathrm{~Hz}, 1 \mathrm{H}, \mathrm{H}-3\right)$, $1.83\left(\mathrm{ddt}, J_{4 \mathrm{a}, 4 \mathrm{~b}}=13.9 \mathrm{~Hz}, J_{3,4 \mathrm{a}}=J_{4 \mathrm{a}, 5 \mathrm{a}}=J_{4 \mathrm{a}, 5 \mathrm{~b}}=7.6 \mathrm{~Hz}, 1 \mathrm{H}, \mathrm{H}-4 \mathrm{a}\right), 1.66\left(\mathrm{ddt}, J_{4 \mathrm{a}, 4 \mathrm{~b}}=\right.$ $\left.13.9 \mathrm{~Hz}, J_{3,4 \mathrm{~b}}=J_{4 \mathrm{~b}, 5 \mathrm{a}}=J_{4 \mathrm{~b}, 5 \mathrm{~b}}=7.1 \mathrm{~Hz}, 1 \mathrm{H}, \mathrm{H}-4 \mathrm{~b}\right), 1.43-1.24(\mathrm{~m}, 50 \mathrm{H}, \mathrm{H}-5-\mathrm{H}-26,2 \mathrm{x}$ $\left.\mathrm{CH}_{3}\right), 0.89\left(\mathrm{t}, J=6.8 \mathrm{~Hz}, 3 \mathrm{H}, \mathrm{CH}_{3}-27\right) ;{ }^{13} \mathrm{C} \mathrm{NMR}\left(125 \mathrm{MHz}, \mathrm{CDCl}_{3}\right) \delta 173.5(\mathrm{C}-1)$, $172.9\left(3-\mathrm{CO}_{2}\right), 71.0(\mathrm{C}-2), 61.8\left(\mathrm{CH}_{2} \mathrm{O}, 1-\mathrm{OEt}\right), 60.8\left(\mathrm{CH}_{2} \mathrm{O}, 3-\mathrm{CO}_{2} \mathrm{CH}_{2}\right), 48.6(\mathrm{C}-3)$, 31.9 (C-4), 29.7, 29.68, 29.67, 29.65, 29.58, 29.45, 29.37, 28.1, 27.4, 22.7 (C-5-C26), 14.2 (C-27), $14.1\left(\mathrm{CH}_{3}, 1-\mathrm{OEt}\right.$ and $\left.\mathrm{CH}_{3}, 3-\mathrm{CO}_{2} \mathrm{Et}\right)$; HRMS(ESI) m/z calcd. For $\left[\mathrm{C}_{32} \mathrm{H}_{62} \mathrm{O}_{5}+\mathrm{Na}\right]^{+}:$549.4495, obsd.: 549.4490.

Cross metathesis for the preparation of ethyl-2S-hydroxy-3R-ethoxycarbonylheptadecanoate (anti-5d). To a solution of compound anti-5a (0.106 g, $0.46 \mathrm{mmol})$ in $\mathrm{CH}_{2} \mathrm{Cl}_{2}(2.5 \mathrm{~mL})$, was added Grubbs second generation catalyst $(0.02 \mathrm{~g}, 0.023$ mmol) followed by 1 -tridecene $(0.11 \mathrm{~mL}, 0.46 \mathrm{mmol})$ and the reaction mixture refluxed under nitrogen for 14 hours before being cooled down and reduced in vасио. The resulting crude product was columned yielding the heptadecenoate anti5e (eluting in 15:1, petroleum ether/EtOAc, v/v) as a colourless oil (0.07 g, 0.19 mmol, 41\%). Subsequent hydrogenation of anti-5e according to the above general procedure, then yielded pure anti-5d $(0.07 \mathrm{~g}, 0.18 \mathrm{mmol}, 99 \%)$ as a colourless oil. The spectral data matched that previously determined as reported herein.

General procedure for alkylation using HMPA as a solvent. $n$-BuLi $(11.5 \mathrm{~mL}$, $2.0 \mathrm{~m}$ solution in hexanes, $23.0 \mathrm{mmol}$ ) was added to a solution of di-isopropylamine (3.6 mL, $25.0 \mathrm{mmol})$ in THF $(20 \mathrm{~mL})$ at $0{ }^{\circ} \mathrm{C}$. After $30 \mathrm{~min}$ the solution was cooled down to $-78{ }^{\circ} \mathrm{C}$ and diethyl malate $3(1.9 \mathrm{~g}, 10 \mathrm{mmol})$ in THF $(20 \mathrm{~mL})$ was added. The resulting mixture was stirred at $-78^{\circ} \mathrm{C}$ for $1 \mathrm{~h}$, warmed up to $-20^{\circ} \mathrm{C}$ over $1 \mathrm{~h}$ and stirred at $-20{ }^{\circ} \mathrm{C}$ for $20 \mathrm{~min}$. After cooling down to $-78{ }^{\circ} \mathrm{C}$, the appropriate iodide (15.0 mmol, 1.5 equiv.) in HMPA $(20 \mathrm{~mL})$ was added dropwise and the reaction was stirred for $1 \mathrm{~h}$ at $-50{ }^{\circ} \mathrm{C}$ and then a further $1 \mathrm{~h}$ during which time the temperature 
increased to $0{ }^{\circ} \mathrm{C}$. The reaction was then quenched using $\mathrm{NH}_{4} \mathrm{Cl}$ (sat.) and extracted with EtOAc (3 x $100 \mathrm{~mL}$ ). The combined organic layers were washed with water (30 $\mathrm{mL})$ and brine $(30 \mathrm{~mL})$, dried $\left(\mathrm{MgSO}_{4}\right)$, filtered and the solvent removed in vacuo to yield a crude yellow oil. Purification of the residue, using silica gel flash column chromatography and the eluent given, gave the alkylated product.

Ethyl 2S-hydroxy-3R-ethoxycarbonyl-heptadecanoate (anti-5d). By reacting diethyl malate $3(0.47 \mathrm{~g}, 2.45 \mathrm{mmol})$ with 1-iodotetradecane $(1.19 \mathrm{~g}, 3.69 \mathrm{mmol})$ according to the general procedure for alkylation described above, heptadecanoate $\mathbf{5 d}$ was obtained (eluting in 15:1, petroleum ether/EtOAc, v/v) as a colourless oil (0.32 $\mathrm{g}, 0.83 \mathrm{mmol}, 35 \%$, anti:syn $=7: 1)$. The spectral data matched that reported earlier.

Ethyl $2 S$-hydroxy-3R-ethoxycarbonyl-heptadecen-5-enoate (anti-5e). By reacting diethyl malate 3 (0.45 g, $2.35 \mathrm{mmol})$ with 1-iodo-tetradec-2-ene (1.14 g, $3.53 \mathrm{mmol})$ according to the general procedure described above, heptadecenoate 5e was obtained (eluting in 15:1, petroleum ether/EtOAc, v/v) as a colourless oil (0.40 g, $1.05 \mathrm{mmol}$, $45 \%$, anti:syn =9:1). The spectral data matched that reported earlier. 


\section{References}

(1) Khan, A. A.; Chee, S. H.; Stocker, B. L.; Timmer, M. S. M. Eur. J. Org. Chem. 2012, 995-1002.

(2) Alexakis, A.; Malan, C.; Lea, L.; Tissot-Croset, K.; Polet, D.; Falciola, C. Chimica 2006, 60, 124-130.

(3) Magid, R. M. Tetrahedron 1980, 36, 1901-1930.

(4) Alvarez-Manzaneda, E. J.; Chahboun, R.; Cabrera Torres, E.; Alvarez, E.; Alvarez-Manzaneda, R.; Haidour, A.; Ramos López, J. M. Tetrahedron Lett. 2005, 46, $3755-3759$.

(5) Marukawa, K.; Takikawa, H.; Mori, K. Biosci. Biotechnol. Biochem. 2001, 65, 305-314.

(6) King, A. O.; Anderson, R. K.; Larsen, R. D.; Verhoeven, R.; Reider, P. J. J. Org. Chem. 1993, 58, 3731-3735.

(7) Fuson, R. C.; Mon, M. T. J. Org. Chem. 1960, 26, 756-758.

(8) Wipf, P.; Uto, Y.; Yoshimura, S. Chem. Eur. J. 2002, 8, 1670-1681.

(9) Utaka, M.; Higashi, H.; Takeda, A. J. Chem. Soc. Chem. Commun. 1987, 1368-1369.

(10) Fujisawa, T.; Fujimura, A.; Sato, T. Bull. Chem. Soc. Jpn. 1988, 61, 12731279.

(11) Seebach, D.; Aebi, J.; Wasmuth, D. Org. Synth. 1990, 7, 153-162.

(12) Chatterjee, A. K.; Choi, T.; Sanders, D. P.; Grubbs, R. H. J. Am. Chem. Soc. 2003, 125, 11360-11370.

(13) Seebach, D.; Wasmuth, D. Helv. Chim. Acta 1980, 63, 197-200.

(14) Pijper, D.; Bulten, E.; Šmisterová, J.; Wagenaar, A.; Hoekstra, D.; Engberts, J. B. F. N.; Hulst, R. Eur. J. Org. Chem. 2003, 4406-4412.

(15) Miyata, O.; Takahashi, S.; Tamura, A.; Ueda, M.; Naito, T. Tetrahedron 2008, 64, 1270-1284. 


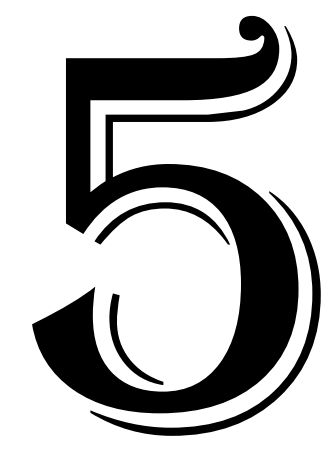

\section{TMCM}

\section{Synthesis}

\subsection{Introduction}

Trehalose dicorynomycolates (TDCMs, 1, Figure 1) are naturally occurring glycolipids found in Corynebacteria which exhibit important immunological properties such as adjuvant ${ }^{1,2}$ and tumor regression activities. ${ }^{3}$ With recent advances in the studies of the biological potential of trehalose glycolipids, interest in TDCMs has been renewed. Accordingly, there have been a number of synthetic routes reported in literature for accessing TDCMs and their analogues ${ }^{4,5,6}$ (see Chapter 1, Section 1.5.3b). We envisaged, however, that these routes could be improved and thus make this important class of compound more readily accessible. With the improved Fráter-Seebach methodology already developed (Chapter 4), it was proposed that the product from this alkylation could form a key intermediate en route to the synthesis of TDCM and analogues. For the purpose of the work presented herein, the synthesis of trehalose monocorynomycolate (TMCM, 2) was undertaken 
in order to determine other key methodologies that then may be used in the synthesis of further TDCMs. Attempts to prepare diester 3 will also be discussed.
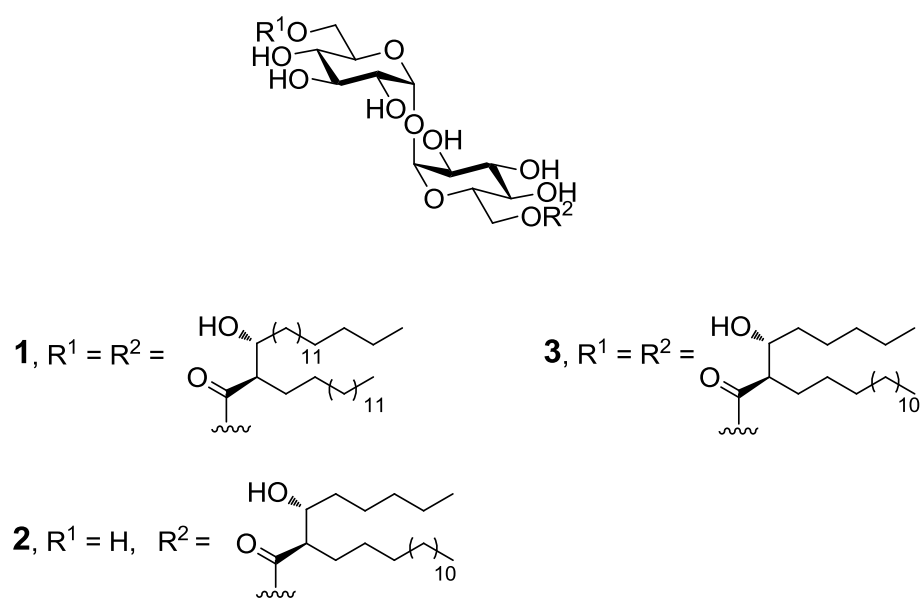

Figure 1. TDCM (1), TMCM analogue (2) and TDCM analogue (3)

\subsection{TMCM and TDCM Synthesis}

The retrosynthetic strategy for the synthesis of TDCMs $\mathbf{1}$ and $\mathbf{3}$ is presented (Scheme 1). Here, a convergent strategy was proposed whereby the two key intermediates, TMS trehalose $\mathbf{4}$ and tert-butyldimethylsilyl (TBS) protected corynomycolic acid 5a or $\mathbf{5 b}$ could be coupled to obtain the mono or diester as required. As previously illustrated (Chapter 2), it was envisioned that the stoichiometry of acid would determine whether the mono- or diester would be formed. TMS trehalose 4, in turn, could be synthesised through the previously reported one-pot two-step silylation process starting with commercially available $\alpha, \alpha$-trehalose $(\mathbf{6}) .^{7}$ To prepare TBS corynomycolic acids $\mathbf{5 a}$ and $\mathbf{5 b}$, a copper-mediated Grignard reaction could be

performed between epoxide 7 and either commercially available $n$-BuLi (8a) or readily synthesised tetradecylmagnesium bromide $(\mathbf{8 b})$. Epoxide 7 could be accessed in three steps from malic ester $\mathbf{9}$ according to our previously reported Fráter-Seebach alkylation methodology (see Chapter 4). 

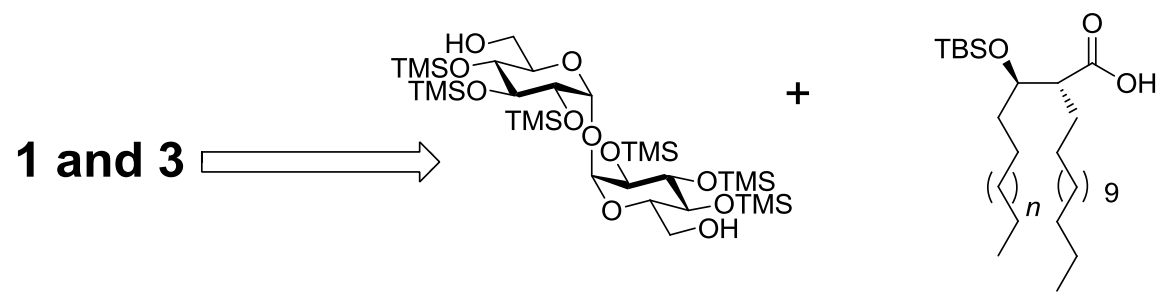

4

5a, $n=1$

$\mathbf{5 b}, n=11$
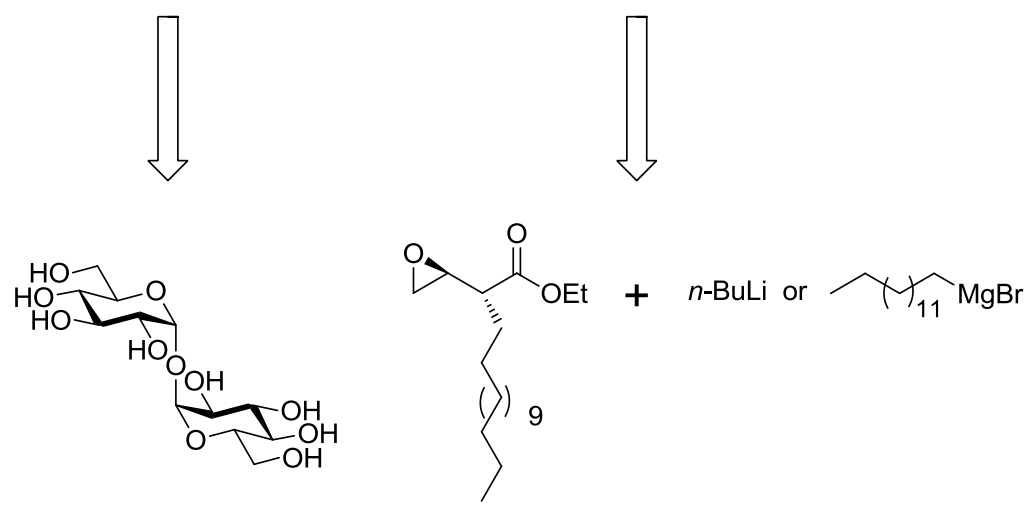

6

7

$8 a / 8 b$

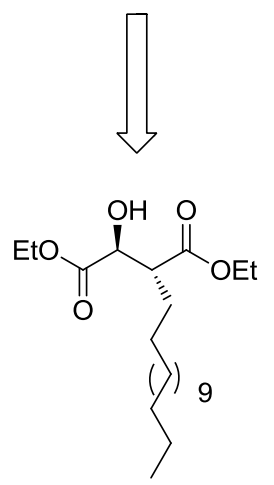

9

Scheme 1. Retrosynthesis for TDCMs 1 and 3.

To prepare the key TBS corynomycolic acid 5, our synthetic efforts commenced with the borane dimethylsulfide (BMS) reduction of malic ester 9 in order to selectively reduce the ethyl ester adjacent to the hydroxyl group. ${ }^{8}$ This reaction led to diol $\mathbf{1 0}$ in a respectable $60 \%$ yield and as the only observed product (Scheme 2). The primary hydroxyl in $\mathbf{1 0}$ was then transformed into a tosylate via reaction of $\mathbf{1 0}$ with $\mathrm{TsCl}$, $\mathrm{Et}_{3} \mathrm{~N}$ in the presence of catalytic dibutyltin oxide. Subjecting tosylate $\mathbf{1 1}$ to basic 
conditions then resulted in the formation of epoxide 7 in good $(81 \%)$ yield over two steps.
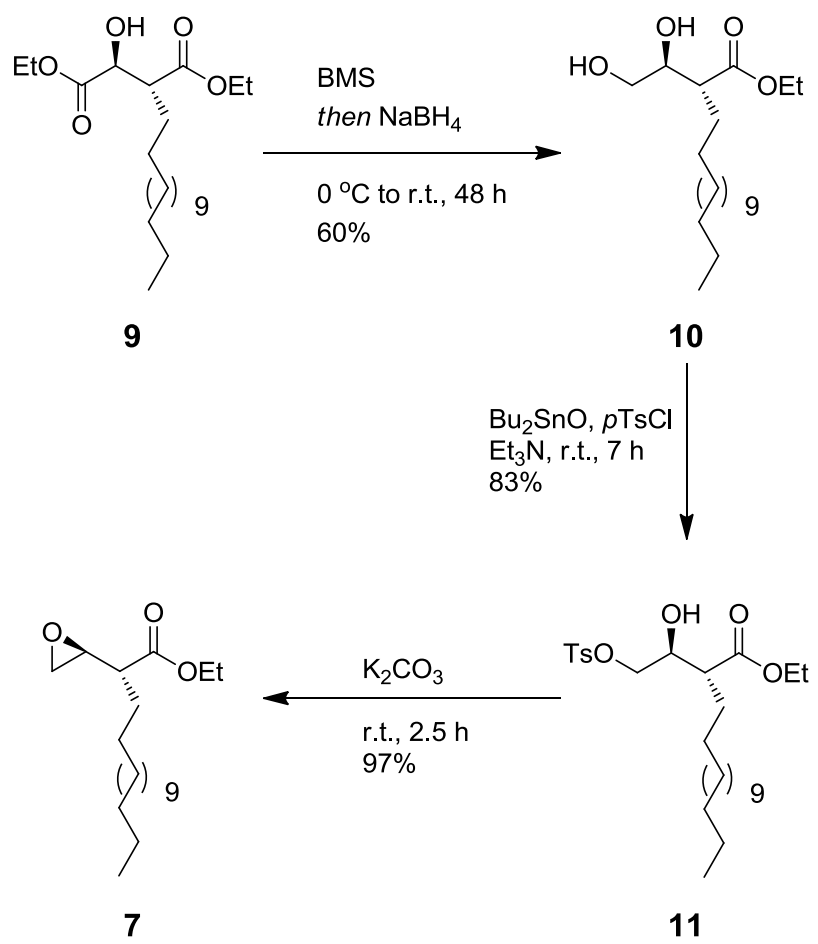

Scheme 2. Synthesis of epoxide 7

With epoxide $\mathbf{7}$ in hand, we next attempted to prepare corynomycolic ester $\mathbf{1 2}$ using a copper-mediated Grignard reaction to open the epoxide. ${ }^{9,10}$ Copper-mediated Grignard reactions are versatile tools for carbon-carbon bond formation ${ }^{11,12,13}$ and are carried out in the presence of copper salts such as $\mathrm{CuCN}, \mathrm{CuI}, \mathrm{CuCl}$ and $\mathrm{CuBr}$, of which $\mathrm{CuI}$ is most commonly used. ${ }^{14}$ Accordingly, epoxide 7 was first subjected to reaction with $\mathrm{CuI}$ (2.5 equiv.) and $n$-BuLi (5 equiv.) in THF (Table 1, Entry 1). Unfortunately, the major product from this reaction was halohydrin 13a with none of the desired corynomycolic ester 12a being obtained. This was not entirely unexpected as the formation of similar halo-products have been reported in literature. ${ }^{15}$ In an attempt to restrict formation of $\mathbf{1 3 a}$, the amount of $\mathrm{CuI}$ was reduced ( 0.15 equiv.), however, the halohydrin was still the only product obtained from the reaction mixture (Entry 2). Alexakis et al. had previously reported that use of a Lewis acid could reduce the formation of halohydrin products in the nucleophilic 
ring opening of epoxides. ${ }^{16}$ Thus, $\mathrm{BF}_{3} \cdot \mathrm{Et}_{2} \mathrm{O}$ was used in the reaction (Entry 3). Although, a faster reaction was observed, again only halohydrin 13a was isolated. In view of this, we then opted to use $\mathrm{CuCN}$ as the copper reagent (Entry 4). Fortunately, this reaction was successful with complete consumption of starting material seen after 4 hours and only the desired alkylated product 12a was observed (71\% yield).

Table 1. Copper mediated Grignard reaction

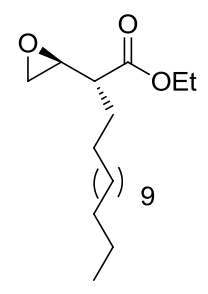

7

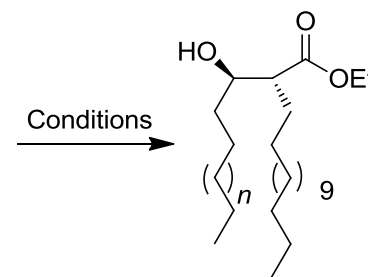

12a, $n=1$

12b, $n=11$

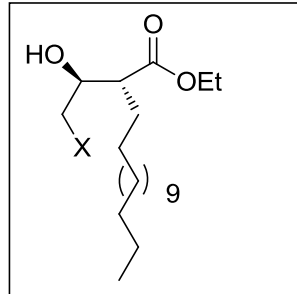

13a, $X=1$ 13b, $X=\mathrm{Br}$

\begin{tabular}{|c|c|c|c|}
\hline Entry & Conditions & Results & Yield $(\%)^{[a]}$ \\
\hline 1 & $\begin{array}{l}\text { CuI ( } 2.5 \text { equiv.), } n \text {-BuLi ( } 5 \text { equiv.), THF, } \\
-35^{\circ} \mathrm{C}, 4 \mathrm{~h}\end{array}$ & 13a only & $60 \%$ \\
\hline 2 & $\begin{array}{l}\mathrm{CuI}(0.1 \text { equiv. }), n \text {-BuLi ( } 2 \text { equiv.), THF, } \\
-35^{\circ} \mathrm{C}, 4 \mathrm{~h}\end{array}$ & 13a only & $10 \%$ \\
\hline 3 & $\begin{array}{l}\mathrm{CuI}(2.5 \text { equiv. }), \quad n-\mathrm{BuLi} \text { ( } 5 \text { equiv. }) \text {, } \\
\left.\mathrm{BF}_{3} \text {.OEt ( } 5 \text { equiv. }\right), \mathrm{THF},-35^{\circ} \mathrm{C}, 2 \mathrm{~h}\end{array}$ & 13a only & $60 \%$ \\
\hline 4 & $\begin{array}{l}\mathrm{CuCN} \text { ( } 2 \text { equiv.), } n \text {-BuLi ( } 4 \text { equiv.), THF, } \\
-50 \text { to }-20{ }^{\circ} \mathrm{C}, 4 \mathrm{~h}\end{array}$ & 12a only & $71 \%$ \\
\hline 5 & $\begin{array}{l}\mathrm{CuCN} \text { ( } 2 \text { equiv.), } \mathrm{C} 14 \mathrm{MgBr} \text { ( } 4 \text { equiv. in } \\
\mathrm{THF} \text { ), THF, }-50 \text { to } 0^{\circ} \mathrm{C}, 5 \mathrm{~h}\end{array}$ & 13b only & $60 \%$ \\
\hline 6 & $\begin{array}{l}\mathrm{CuCN} \text { ( } 2 \text { equiv.), } \mathrm{C} 14 \mathrm{Li} \text { (4 equiv. in } \\
\mathrm{THF}), \mathrm{THF},-50 \text { to } 0{ }^{\circ} \mathrm{C}, 8 \mathrm{~h}\end{array}$ & Starting material & $80 \%{ }^{[\mathrm{b}]}$ \\
\hline 7 & $\begin{array}{l}\mathrm{CuCN} \text { (2 equiv.), } \mathrm{C} 14 \mathrm{Li} \text { ( } 4 \text { equiv. in } \\
\left.\mathrm{Et}_{2} \mathrm{O}\right),-50 \text { to } 0{ }^{\circ} \mathrm{C}, 8 \mathrm{~h}\end{array}$ & $\begin{array}{l}\text { Starting material } \\
\text { unidentified by-product } \\
\text { (trace) }\end{array}$ & $80 \%^{[\mathrm{b}]}$ \\
\hline 8 & $\begin{array}{l}\mathrm{CuCN} \text { ( } 2 \text { equiv.), } \mathrm{C} 14 \mathrm{Li} \text { ( } 4 \text { equiv. in } \\
\text { toluene), THF, }-50 \text { to } 0{ }^{\circ} \mathrm{C}, 8 \mathrm{~h}\end{array}$ & Starting material & $80 \%^{[\mathrm{b}]}$ \\
\hline 9 & $\begin{array}{l}\mathrm{CuCN} \text { ( } 2 \text { equiv.), } \mathrm{C} 14 \mathrm{Li} \text { ( } 4 \text { equiv. in } \\
\text { cyclohexane), THF, }-50 \text { to } 0^{\circ} \mathrm{C}, 8 \mathrm{~h}\end{array}$ & Starting material & $80 \%{ }^{[b]}$ \\
\hline
\end{tabular}

[a] Isolated yields

[b] Yield of recovered starting material 
Having successfully synthesised the butylated product 12a, our attention then turned to the use of copper-mediated Grignard reaction to install the C14 lipid. Thus, tetradecylmagnesium bromide (prepared via reaction of bromo-tetredecane and magnesium) ${ }^{17}$ was subjected to Grignard reaction with epoxide 7 and $\mathrm{CuCN}$ (Entry 5). Unfortunately, the only product obtained from the reaction was halohydrin $\mathbf{1 3 b}$. We then opted to use tetradecyllithium (C14Li) in the alkylation so as to avoid formation of any halogenated by-products. To this end, C14Li was prepared as a solution in THF (via reaction of tetradecylbromide and $\mathrm{Li}$ ), ${ }^{18}$ and then added to a solution of expoxide 7 in THF (Entry 6). Unfortunately, no formation of $\mathbf{1 2 b}$ occured and only starting material was isolated. A change of reaction solvent (entries 7-9) faired no better, with only starting material recovered.

In the interest of time, we proceeded using the butylated adduct 12a in the synthesis of a short-chain TDCM. It is proposed, however, that the longer alkyl chains could be installed via the use of the more reactive alkyne lithium in this reaction. ${ }^{19}$ Though adding an additional step (reduction of the triple bond) following alkylation, this strategy could still allow for a highly competitive synthesis of the TDCMs.

Continuing on with the butylated adduct 12a, a TBS protection of the hydroxyl group in 12a (using TBSCl and imidiazole in DMF) was attempted. This reaction, however, was not successful with starting material and only minor amounts $(<10 \%)$ of the desired product formed. A change of solvent $\left(\mathrm{CH}_{2} \mathrm{Cl}_{2}\right)$, prolonged reaction times, heating the reaction mixture, or the addition of DMAP as a catalyst did not improve the product yield. As the hydroxyl is in a secondary position with adjacent lipid groups, steric hinderance could be a potential cause for the poor yield in the protection step. In order to improve the yield, 12a was subjected to the more reactive TBSOTf (prepared via reaction of TfOH and TBSCl) ${ }^{20}$ and 2,6-lutidine in $\mathrm{CH}_{2} \mathrm{Cl}_{2}$. Gratifyingly, the reaction was complete in $30 \mathrm{~min}$ and the silylated product obtained in high (90\%) yield (Scheme 3). Hydrolysis of the ethyl ester using LiOH was then attempted so as to generate protected corynomycolic acid 5. Unfortunately, this reaction was not chemo-selective and loss of the TBS group also occurred to give corynomycolic acid 14. 
Given this, we resorted to a different strategy whereby corynomycolic ester 12a would be first hydrolysed, then bis-silylated. ${ }^{21}$ The bis-silylated product could then be subjected to milder basic conditions in order to selectively remove the more labile TBS-ester leading to protected corynomyolic acid 5. To this end, corynomycolic ester 12a was treated with $\mathrm{LiOH}$ and acid $\mathbf{1 4}$ was obtained in quantitative yields (Scheme 3). Acid 14 was then treated with TBSOTf and 2,6-lutidine to give the bissilylated product which, upon treatment with $\mathrm{K}_{2} \mathrm{CO}_{3}$, resulted in the desired TBS corynomycolic acid 5 in good (89\%) yield over two steps.

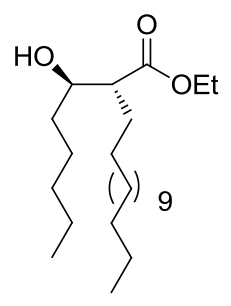

$12 a$

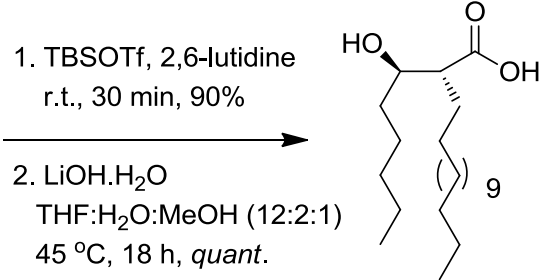

14

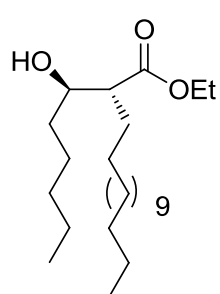

$12 \mathrm{a}$

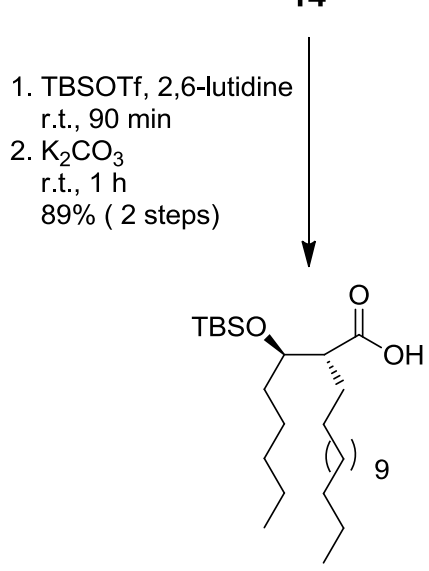

5

Scheme 3. Synthesis of TBS protected corynomycolic acid $\mathbf{5}$.

With the TBS corynomycolic acid $\mathbf{5}$ in hand, our attention turned to the coupling of this acid to the trehalose core. TMS trehalose $\mathbf{4}$ was synthesised using Johnson's $\operatorname{protocol}^{7}$ (see Chapter 2), and subjected to esterification with acid 5 (4.4 equiv.) in the presence of EDCI (6.6 equiv.) and DMAP (1.6 equiv.) (Scheme 4). It was proposed that these conditions would lead to the diester (as observed with the linear trehalose diesters (TDEs) series, Chapter 2). Indeed after stirring at $70{ }^{\circ} \mathrm{C}$ overnight, 
complete consumption of acid $\mathbf{5}$ was noted and two higher running spots (compared to TMS trehalose 4) were observed during TLC analysis of the reaction mixture, which were thought to be the mono and diesterified products. One of the products obtained was the protected TMCM 15 (30\% yield), unfortunately, the other product was not the expected diester but tentatively assigned corynomycolic anhydride $\mathbf{1 6}$. The structure of anhydride 16 was assigned based on ${ }^{1} \mathrm{H}$ NMR spectral data. In addition, treatment of product 16 with $\mathrm{K}_{2} \mathrm{CO}_{3}$, yielded acid $\mathbf{5}$, which is in agreement with the product expected from the reaction of an anhydride with a base. Time did not permit further optimisation of the reaction to increase yield of $\mathbf{1 5}$, or indeed, to investigate ways in which to synthesise the desired diester. It is envisioned that a change of solvent and prolonged reaction times could help to improve this reaction. Anhydrides are known to react with alcohols in the presence of EDCI and DMAP 22 and thus addition of further equivalents of these reagents could potentially drive the esterification further. In order to form the final TMCM compound 2, TMCM 15 would be deprotected using Dowex $-\mathrm{H}^{+}$.

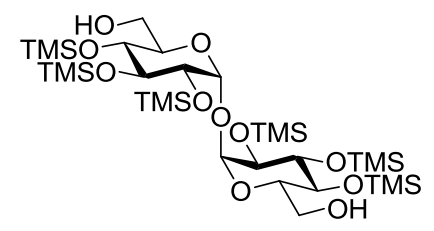

4
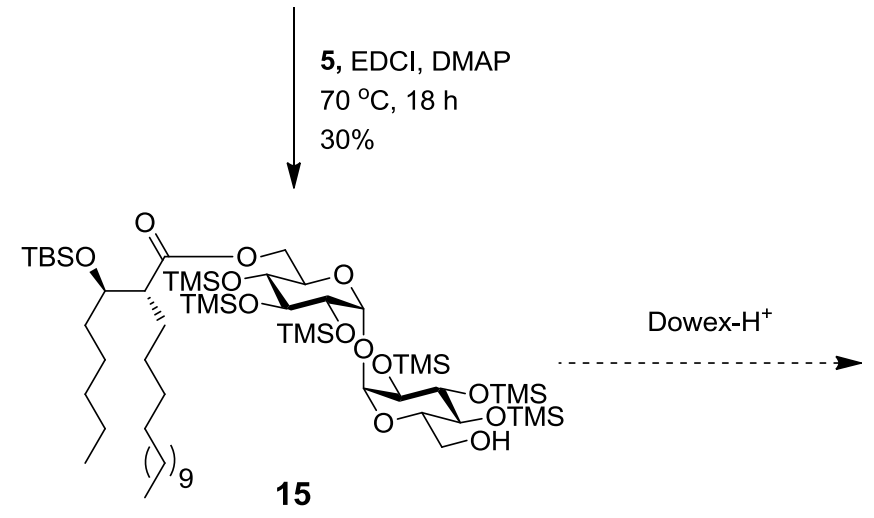
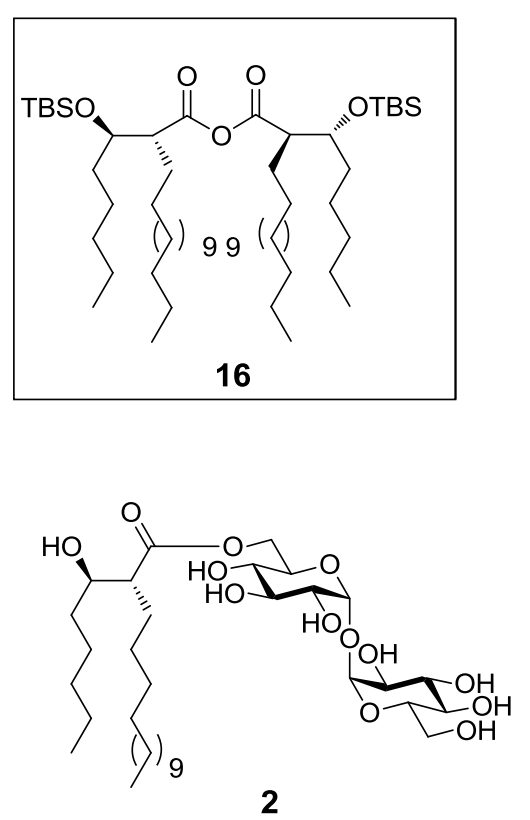

Scheme 4. Synthesis of protected TMCM analogue 15. 


\subsection{Conclusion and Future work}

The synthesis of a fully protected truncated TMCM has been achieved. One of the key steps in the synthesis was a copper mediated Grignard reaction for the formation of the corynomycolic acid moiety. Difficulties were observed when attempts were made to install a longer alkyl lipid chain $(\mathrm{C} 14)$ using this alkylation and one way to solve this would be via the use of the more reactive lithiated C14 alkyne in this reaction. Functional group manipulations were then performed and the desired silyl ether was obtained in good overall yields, however, esterification proved more difficult and only the protected TMCM along with the corynomycolic anhydride were isolated. To overcome this, it is proposed that prolonged reaction times and addition of further equivalents of EDCI and DMAP to the reaction mixture is required to drive the reaction further. Once these issues are resolved, it is then proposed that this general synthetic strategy can be used for the synthesis of a variety of TDCMs.

\subsection{Experimental}

Unless stated otherwise all reactions were performed under $\mathrm{N}_{2}$. Prior to use, THF was distilled from $\mathrm{Na}$ wire and benzophenone, toluene was dried and stored under $\mathrm{Na}$ wire and $\mathrm{TfOH}$ (flurochem) was distilled. $\mathrm{BH}_{3} \cdot \mathrm{Me}_{2} \mathrm{~S}$ (1M in THF, Acros), $\mathrm{NaBH}_{4}$ (Aldrich), dibutyltin oxide (Aldrich), tosyl chloride (Aldrich), $n$-BuLi (Aldrich, $2 \mathrm{M}$ solution in hexanes), imidiazole (Apollo), TBSCl (Apollo), 2,6-lutidine (Fluka), $\mathrm{CuCN}$ (Ajax chemicals), LiOH. $\mathrm{H}_{2} \mathrm{O}$ (Riedel-de-Haën), EDCI (Aldrich), DMAP (Merck), anhydrous DMF (Acros), 33\% HCl (Panreac), ethanol (Pure Science), methanol (Panreac), EtOAc (Panreac), petroleum ether (Pure Science), $\mathrm{NaHCO}_{3}$ (Pure Science), $\mathrm{K}_{2} \mathrm{CO}_{3}$ (Pure Science), $\mathrm{MgSO}_{4}$ (Pure Science), $\mathrm{NaCl}$ (Panreac) were used as received. All solvents were removed via evaporation at reduced pressure. Reactions were monitored by TLC analysis on Macherey-Nagel silica gel coated plastic sheets $(0.20 \mathrm{~mm}$, Polygram SIL G/UV254) by coating with a solution of $5 \%$ 
$\mathrm{KMnO}_{4}$ and $1 \% \mathrm{NaIO}_{4}$ in $\mathrm{H}_{2} \mathrm{O}$ followed by heating or by dipping in $10 \% \mathrm{H}_{2} \mathrm{SO}_{4}$ in EtOH followed by charring at $\sim 150{ }^{\circ} \mathrm{C}$. Column chromatography was performed using Pure Science silica gel $(40-63 \mu \mathrm{m})$. High resolution mass spectra were recorded on a Waters Q-TOF Premier ${ }^{\mathrm{TM}}$ Tandem Mass Spectrometer using positive electro-spray ionisation. Optical rotations were recorded on a Perkin-Elmer 241 polarimeter or Autopol II (Rudolph Research Analytical) at $589 \mathrm{~nm}$ (sodium D-line). Infrared spectra were recorded as thin films using a Bruker Tensor 27 FTIR spectrometer equipped with an Attenuated Total Reflectance (ATR) sampling accessory and are reported in wave numbers $\left(\mathrm{cm}^{-1}\right)$. Nuclear magnetic resonance spectra were recorded at $20{ }^{\circ} \mathrm{C}$ in $\mathrm{CDCl}_{3}$ using a Varian INOVA operating at 500 MHz. Chemical shifts are given in ppm $(\delta)$ relative to solvent residual peak. NMR peak assignments were made using COSY, HSQC and HMBC 2D experiments.

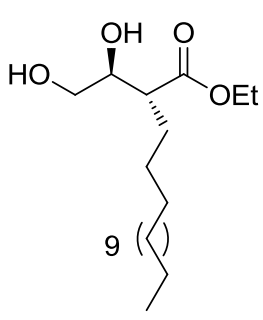

3R-Ethoxycarbonyl-2S-hydroxy-heptadecanol (10). Borane dimethylsulfide complex $(0.68 \mathrm{~mL}, 1 \mathrm{M}$ in THF, $0.68 \mathrm{mmol})$ was slowly added to a solution of malic ester $9(0.24 \mathrm{~g}, 0.62$ $\mathrm{mmol})$ in THF (2 mL). The reaction was stirred at r.t. overnight after which time it was cooled to $0{ }^{\circ} \mathrm{C}$ and $\mathrm{NaBH}_{4}(0.002 \mathrm{~g}$, $0.04 \mathrm{mmol}$ ) was added. The reaction was allowed to warm to room temperature overnight, before being quenched with Dowex $-\mathrm{H}^{+}(10 \%$ by weight $)$ and then ethanol (3 $\mathrm{mL})$ was added. The reaction mixture was filtered, washed (EtOH) and concentrated in vacuo. The residue was dissolved in toluene:ethanol $(1: 1,5 \mathrm{~mL})$ and concentrated (repeated $3 \mathrm{x}$ ) in order to remove ethanol and boron as $\mathrm{B}(\mathrm{OEt})_{3}$. The resulting crude oil was purified using silica gel flash column chromatography (eluting in 1:1, petroleum ether/EtOAc, v/v) to give the title compound $\mathbf{1 0}$ as a colourless oil $(0.13 \mathrm{~g}, 0.37 \mathrm{mmol}, 60 \%) . \mathrm{R}_{f}=0.30(\mathrm{PE} / \mathrm{EA}, 1 / 1, \mathrm{v} / \mathrm{v}) ;[\alpha] \mathrm{D}^{20}=4.0(c$ $\left.=0.1, \mathrm{CHCl}_{3}\right)$; IR (film) 2922, 2852, 1734, 1176, $756 \mathrm{~cm}^{-1} ;{ }^{1} \mathrm{H}$ NMR $(500 \mathrm{MHz}$, $\left.\mathrm{CDCl}_{3}\right) \delta 4.23-4.10\left(\mathrm{~m}, 2 \mathrm{H}, 3-\mathrm{CO}_{2} \mathrm{CH}_{2}\right), 3.83-3.80(\mathrm{~m}, 1 \mathrm{H}, \mathrm{H}-2), 3.69\left(\mathrm{dd}, J_{1 \mathrm{a}, 1 \mathrm{~b}}=\right.$ $\left.11.0 \mathrm{~Hz}, J_{1 \mathrm{a}, 2}=6.8 \mathrm{~Hz}, 1 \mathrm{H}, \mathrm{H}-1 \mathrm{a}\right), 3.55\left(\mathrm{dd}, J_{1 \mathrm{a}, 1 \mathrm{~b}}=11.0 \mathrm{~Hz}, J_{1 \mathrm{~b}, 2}=6.8 \mathrm{~Hz}, 1 \mathrm{H}, \mathrm{H}-\right.$ $1 \mathrm{~b}), 3.11\left(\mathrm{~d}, J_{2, \mathrm{OH}}=3.4 \mathrm{~Hz}, \mathrm{C} 2-\mathrm{OH}\right), 2.53\left(\mathrm{dt}, J_{2,3}=J_{3,4 \mathrm{a}}=J_{3,4 \mathrm{~b}}=8.0 \mathrm{~Hz}, 1 \mathrm{H}, \mathrm{H}-3\right)$, 2.13 (bs, 1H, C1-OH), 1.69-1.60 (m, 1H, H-4a), 1.59-1.55 (m, 1H, H-4b), 1.31-1.28 
(m, 27H, H-5-H-16 and $\left.\mathrm{OCH}_{2} \mathrm{CH}_{3}\right), 0.88\left(\mathrm{t}, J_{16,17}=7.1 \mathrm{~Hz}, 3 \mathrm{H}, \mathrm{CH}_{3}-17\right) ;{ }^{13} \mathrm{C} \mathrm{NMR}$ $\left(125 \mathrm{MHz}, \mathrm{CDCl}_{3}\right) \delta 175.5\left(3-\mathrm{CO}_{2}\right), 72.7(\mathrm{C}-2), 65.0(\mathrm{C}-1), 60.8\left(\mathrm{CH}_{2} \mathrm{O}, 3-\right.$ $\mathrm{CO}_{2} \mathrm{CH}_{2}$ ), 47.5 (C-3), 31.9, 29.68, 29.67, 29.65, 29.61, 29.5, 29.44, 29.39, 29.36, 29.34, 27.14, 22.69 (C-4-C-16), 14.2 (C-17), $14.1\left(\mathrm{CH}_{3}, 3-\mathrm{CO}_{2} \mathrm{Et}\right)$; HRMS(ESI) $\mathrm{m} / \mathrm{z}$ calcd. for $\left[\mathrm{C}_{20} \mathrm{H}_{40} \mathrm{O}_{4}+\mathrm{Na}\right]^{+}: 367.2824$, obsd.: 367.2820 .

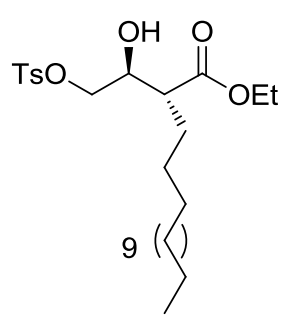

3R-Ethoxycarbonyl-2S-hydroxyheptadecanoyl $p$-toluenesulfonate (11). To a solution of diol 10 (0.29 g, $0.84 \mathrm{mmol})$ in $\mathrm{CH}_{2} \mathrm{Cl}_{2}(5 \mathrm{~mL}), \mathrm{Bu}_{2} \mathrm{SnO}(0.004$, $0.016 \mathrm{mmol}), \mathrm{TsCl}(0.18 \mathrm{~g}, 1.01 \mathrm{mmol})$, and $\mathrm{Et}_{3} \mathrm{~N}(0.14 \mathrm{~mL}$, $1.01 \mathrm{mmol}$ ) were added. The resulting reaction mixture was stirred at r.t. for $2.5 \mathrm{~h}$, after which time brine was added and the resulting solution extracted with $\mathrm{CH}_{2} \mathrm{Cl}_{2}(3 \times 30 \mathrm{~mL})$. The combined organic layers were dried with $\mathrm{MgSO}_{4}$ and concentrated in vacuo. The resulting crude solid was purified using silica gel flash column chromatography (eluting in 5:1, petroleum ether/EtOAc, v/v) to give the title compound as a white solid $(0.35 \mathrm{~g}, 0.70 \mathrm{mmol}, 84 \%) . \mathrm{R}_{f}=0.56$ $(\mathrm{PE} / \mathrm{EA}, 1 / 1, \mathrm{v} / \mathrm{v}) ;[\alpha] \mathrm{D}^{20}=2.0\left(c=1.0, \mathrm{CHCl}_{3}\right) ; \mathrm{IR}$ (film) 2925, 1539, 1265, 1176, $753 \mathrm{~cm}^{-1} ;{ }^{1} \mathrm{H}$ NMR $\left(500 \mathrm{MHz}, \mathrm{CDCl}_{3}\right) \delta 7.80\left(\mathrm{~d}, J=8.3 \mathrm{~Hz}, 2 \mathrm{H}, \mathrm{H}_{\text {arom }}\right), 7.35(\mathrm{~d}, J=$ $\left.8.1 \mathrm{~Hz}, 2 \mathrm{H}, \mathrm{H}_{\text {arom }}\right), 4.20-4.12\left(\mathrm{~m}, 2 \mathrm{H}, 3-\mathrm{CO}_{2} \mathrm{CH}_{2}\right), 4.05\left(\mathrm{~d}, J_{1,2}=4.9 \mathrm{~Hz}, 2 \mathrm{H}, \mathrm{H}-1\right)$, $3.9\left(\mathrm{dt}, J_{1,2}=J_{2,3}=4.9 \mathrm{~Hz}, 1 \mathrm{H}, \mathrm{H}-2\right), 2.55(\mathrm{~m}, 1 \mathrm{H}, \mathrm{H}-3), 2.46\left(\mathrm{~s}, 3 \mathrm{H}, \mathrm{C}_{\mathrm{ar}}-\mathrm{CH}_{3}\right), 1.70$ 1.64 (m, 1H, H-4a), 1.53-1.43 (m, 1H, H-4b), 1.30-1.25 (m, 27H, H-5-H-16, $\left.\mathrm{OCH}_{2} \mathrm{CH}_{3}\right), 0.88\left(\mathrm{t}, J_{16,17}=6.4 \mathrm{~Hz}, 3 \mathrm{H}, \mathrm{CH}_{3}-17\right) ;{ }^{13} \mathrm{C} \mathrm{NMR}\left(125 \mathrm{MHz}, \mathrm{CDCl}_{3}\right) \delta$ $174.8\left(3-\mathrm{CO}_{2}\right), 145.1\left(C_{\mathrm{ar}}-\mathrm{CH}_{3}\right), 132.5\left(C_{\mathrm{ar}}-\mathrm{SO}_{2}\right), 129.9\left(\mathrm{C}_{\mathrm{ar}}\right), 128.0\left(\mathrm{C}_{\mathrm{ar}}\right), 71.6(\mathrm{C}-1)$, 70.0 (C-2), $60.8\left(\mathrm{CH}_{2} \mathrm{O}, 3-\mathrm{CO}_{2} \mathrm{CH}_{2}\right), 47.0$ (C-3), 31.9, 29.69, 29.68, 29.66, 29.61, 29.53, 29.36, 29.27, 27.11, 22.69, 21.67 (C-4-C16, $\left.\mathrm{C}_{\mathrm{ar}}-\mathrm{CH}_{3}\right), 14.14$ (C-17), 14.10 $\left(\mathrm{CH}_{3}, 3-\mathrm{CO}_{2} \mathrm{Et}\right)$; HRMS(ESI) $\mathrm{m} / z$ calcd. for $\left[\mathrm{C}_{27} \mathrm{H}_{46} \mathrm{O}_{6} \mathrm{~S}+\mathrm{Na}\right]^{+}:$521.2913, obsd.: 521.2908. 


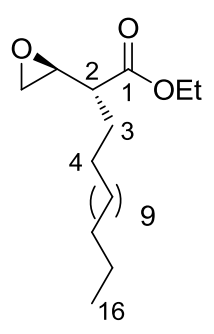

Ethyl (2R)-2-[(R)-oxiranyl]-hexadecanoate (7). To a solution of tosylate $11(0.32 \mathrm{~g}, 0.64 \mathrm{mmol})$ in $\mathrm{MeOH}(7 \mathrm{~mL})$ was added $\mathrm{K}_{2} \mathrm{CO}_{3}$ $(0.11 \mathrm{~g}, 0.76 \mathrm{mmol})$ and the reaction stirred at r.t. for $2 \mathrm{~h}$ after which time $\mathrm{NH}_{4} \mathrm{Cl}(20 \mathrm{~mL})$ was added. The resulting solution was extracted with EtOAc $(3 \times 30 \mathrm{~mL})$, the combined organic layers were dried with $\mathrm{MgSO}_{4}$, concentrated in vacuo and crude solid was purified using silica gel flash column chromatography (eluting in 20:1, petroleum ether/EtOAc, v/v) to give the title compound as a white solid $(0.20 \mathrm{~g}, 0.61 \mathrm{mmol}$, $97 \%) . \mathrm{R}_{f}=0.73(\mathrm{PE} / \mathrm{EA}, 1 / 1, \mathrm{v} / \mathrm{v}) ;[\alpha] \mathrm{D}^{20}=1.0\left(c=0.1, \mathrm{CHCl}_{3}\right) ; \mathrm{IR}($ film) 2825 , 1733, 1464, 1203, $668 \mathrm{~cm}^{-1} ;{ }^{1} \mathrm{H}$ NMR $\left(500 \mathrm{MHz}, \mathrm{CDCl}_{3}\right) \delta 4.20(\mathrm{q}, J=7.1 \mathrm{~Hz}, 2 \mathrm{H}$, $\left.1-\mathrm{OCH}_{2}\right), 3.17-3.10(\mathrm{~m}, 1 \mathrm{H}, 2-\mathrm{CH}), 2.83\left(\mathrm{dd}, J_{\mathrm{CHa}, \mathrm{CHb}}=8.8 \mathrm{~Hz}, J_{2-\mathrm{CH}, 2-\mathrm{CHCHa}}=4.1\right.$ $\mathrm{Hz}, 1 \mathrm{H}, 2-\mathrm{CHCHaHb}), 2.56\left(\mathrm{dd}, J_{\mathrm{CHa}, \mathrm{CHb}}=8.8 \mathrm{~Hz}, J_{2-\mathrm{CH}, 2-\mathrm{CHCHb}}=4.1 \mathrm{~Hz}, 1 \mathrm{H}, 2-\right.$ $\mathrm{CHCHaHb}), 2.13\left(\mathrm{dt}, J_{2,3}=J_{2,2-\mathrm{CH}}=8.0 \mathrm{~Hz}, 1 \mathrm{H}, \mathrm{H}-2\right), 1.75-1.69(\mathrm{~m}, 1 \mathrm{H}, \mathrm{H}-3 \mathrm{a})$, $1.62-1.55(\mathrm{~m}, 1 \mathrm{H}, \mathrm{H}-3 \mathrm{~b}), 1.30-1.25\left(\mathrm{~m}, 27 \mathrm{H}, \mathrm{H}-4-\mathrm{H}-15,1-\mathrm{OCH}_{2} \mathrm{CH}_{3}\right), 0.88$ (t, $J_{15,16}$ $\left.=6.6 \mathrm{~Hz}, 3 \mathrm{H}, \mathrm{CH}_{3}-16\right) ;{ }^{13} \mathrm{C} \mathrm{NMR}\left(125 \mathrm{MHz}, \mathrm{CDCl}_{3}\right) \delta 173.6(\mathrm{C}-1), 60.8\left(\mathrm{CH}_{2} \mathrm{O}, 1-\right.$ $\left.\mathrm{CO}_{2} \mathrm{CH}_{2}\right), 52.7\left(2-\mathrm{CHCH}_{2}\right), 49.0(\mathrm{C}-2), 46.4\left(2-\mathrm{CHCH}_{2}\right), 31.9,29.69,29.67,29.65$, 29.61, 29.53, 29.47, 29.37, 29.36, 29.08, 27.23, 22.69 (C-3-C-15), 14.3 (C-16), 14.1 $\left(\mathrm{CH}_{3}\right.$, 1-OEt); HRMS(ESI) $\mathrm{m} / z$ calcd. for $\left[\mathrm{C}_{20} \mathrm{H}_{38} \mathrm{O}_{3}+\mathrm{Na}\right]^{+}$: 349.2719 , obsd.: 349.2713 .

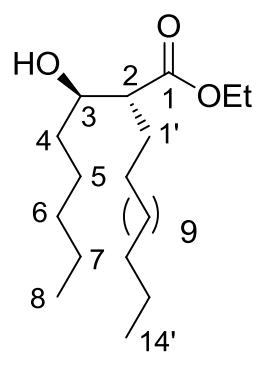

Ethyl-(2R,3R)-3-hydroxy-2-tetradecyl-octanoate (12a). A solution of $\mathrm{CuCN}(13 \mathrm{mg}, 0.14 \mathrm{mmol})$ in THF $(0.3 \mathrm{~mL})$ was cooled to $-50{ }^{\circ} \mathrm{C}$ and BuLi $(2 \mathrm{M}$ in cyclohexane, $0.14 \mathrm{~mL}, 0.28$ mmol) was added dropwise to the solution. The resulting reaction mixture was stirred for $30 \mathrm{~min}$ after which time the temperature increased to $-20{ }^{\circ} \mathrm{C}$. The reaction was then cooled to $-50{ }^{\circ} \mathrm{C}$ and epoxide 7 (23 $\left.\mathrm{mg}, 0.070 \mathrm{mmol}\right)$ in THF $(0.5 \mathrm{~mL})$ was added. The reaction mixture was stirred for a further $2 \mathrm{~h}$ during which time the temperature increased to $-20{ }^{\circ} \mathrm{C}$, then quenched with $\mathrm{NH}_{4} \mathrm{Cl}$, extracted with EtOAc $(3 \times 20 \mathrm{~mL})$, and the combined organic layers were washed with water, brine, dried with $\mathrm{MgSO}_{4}$ and concentrated in vacuo. The resulting crude solid was purified using silica gel flash 
column chromatography (eluting in 20:1, petroleum ether/EtOAc, v/v) to give the title compound as a white solid (19 mg, $0.050 \mathrm{mmol}, 71 \%) . \mathrm{R}_{f}=0.41$ (PE/EA, 5/1, $\mathrm{v} / \mathrm{v}) ;[\alpha] \mathrm{D}^{20}=8.0 \quad\left(c=1.0, \mathrm{CHCl}_{3}\right) ; \mathrm{IR}\left(\right.$ film) $2924,2854,1714,754,689 \mathrm{~cm}^{-1} ;{ }^{1} \mathrm{H}$ $\operatorname{NMR}\left(500 \mathrm{MHz}, \mathrm{CDCl}_{3}\right) \delta 4.18\left(\mathrm{q}, J=7.3 \mathrm{~Hz}, 2 \mathrm{H}, 3-\mathrm{CO}_{2} \mathrm{CH}_{2}\right), 3.72-3.61(\mathrm{~m}, 1 \mathrm{H}$, $\mathrm{H}-3), 2.51\left(\mathrm{~d}, J_{3, \mathrm{OH}}=8.5 \mathrm{~Hz}, 1 \mathrm{H}, 3-\mathrm{OH}\right), 2.41\left(\mathrm{ddd}, J_{2,3}=9.1 \mathrm{~Hz}, J_{1 \mathrm{a}^{\prime}, 2}=J_{1 \mathrm{~b}^{\prime}, 2}=5.1\right.$ $\mathrm{Hz}, 1 \mathrm{H}, \mathrm{H}-2), 1.72\left(\mathrm{ddt}, J_{1 \mathrm{a}^{\prime}, 1 \mathrm{~b}^{\prime}}=13.2 \mathrm{~Hz}, J_{1 \mathrm{a}^{\prime}, 2}=J_{1 \mathrm{a}^{\prime}, 2 \mathrm{a}^{\prime}}=J_{1 \mathrm{a}^{\prime}, 2 \mathrm{a}^{\prime}}=8.6 \mathrm{~Hz}, 1 \mathrm{H}, \mathrm{H}-1 \mathrm{a}^{\prime}\right)$, $1.58\left(\mathrm{ddt}, J_{1 \mathrm{a}^{\prime}, 1 \mathrm{~b}^{\prime}}=13.2 \mathrm{~Hz}, J_{1 \mathrm{~b}^{\prime}, 2}=J_{1 \mathrm{~b}^{\prime}, 2 \mathrm{a}^{\prime}}=J_{1 \mathrm{~b}^{\prime}, 2 \mathrm{a}^{\prime}}=8.2 \mathrm{~Hz}, 1 \mathrm{H}, \mathrm{H}-1 \mathrm{~b}^{\prime}\right), 1.46(\mathrm{~m}, 2 \mathrm{H}$, H-4), 1.39-1.16 (m, 33H, H-5-H-7, H-2'-H-13', $\left.\mathrm{OCH}_{2} \mathrm{CH}_{3}\right), 0.88$ (t, $J_{7,8}=J_{13^{\prime}, 14^{\prime}}=$ $7.1 \mathrm{~Hz}, 6 \mathrm{H}, \mathrm{CH}_{3}-8$ and 14 ); ${ }^{13} \mathrm{C} \mathrm{NMR}\left(125 \mathrm{MHz}, \mathrm{CDCl}_{3}\right) \delta 175.9(\mathrm{C}-1), 72.3(\mathrm{C}-3)$, $60.4\left(\mathrm{CH}_{2} \mathrm{O}, 1\right.$-OEt), 50.8 (C-2), 35.7 (C-4), 31.9, 31.7, 29.70, 29.69, 29.67, 29.63, 29.57, 29.50, 29.44, 29.37, 27.36, 25.43, 22.7, 22.60 (C-5-C-7 and C-1'-C-13'), 14.3, 14.1, 14.0 (C-8, C-14' and 1-OEt); HRMS(ESI) $m / z$ calcd. for $\left[\mathrm{C}_{24} \mathrm{H}_{48} \mathrm{O}_{3}+\mathrm{Na}\right]^{+}$: 407.3501, obsd.: 407.3508.

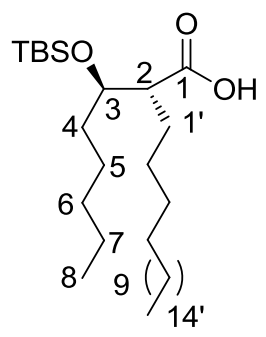

\section{(2R,3R)-3-Tert-butyldimethylsilyloxy-2-tetradecyl-octanoic}

acid (5). A solution of corynomycolic ester 12a (15 mg, 0.039 mmol) in THF:MeOH: $\mathrm{H}_{2} \mathrm{O}(12: 2: 1,2 \mathrm{~mL})$ was treated with LiOH. $\mathrm{H}_{2} \mathrm{O}(54 \mathrm{mg}, 1.28 \mathrm{mmol})$ and the resulting reaction mixture was heated at $45^{\circ} \mathrm{C}$ overnight $(18 \mathrm{~h})$ after which time it was acidified with $1 \mathrm{M} \mathrm{HCl}(\mathrm{pH}=3)$ and diluted with EtOAc $(10$

$\mathrm{mL}$ ). The organic layer was washed with water, brine, dried with $\mathrm{MgSO}_{4}$ and concentrated in vacuo. This gave corynomycolic acid $\mathbf{1 4}$ in quantitative yield, which was used without further purification.

TBSOTf $(0.09 \mathrm{~mL}, 0.39 \mathrm{mmol})$ and 2,6-lutidine $(0.07 \mathrm{~mL}, 0.59 \mathrm{mmol})$ was added to a solution of corynomycolic acid $14(14 \mathrm{mg}, 0.039 \mathrm{mmol})$ in $\mathrm{CH}_{2} \mathrm{Cl}_{2}(1 \mathrm{~mL})$ and the reaction was stirred at r.t. for 90 min after which time complete conversion of the starting material to the bis-silyl product was observed. The solvent was then removed in vacuo and the residue diluted with EtOAc $(10 \mathrm{~mL})$, washed with $0.1 \mathrm{M} \mathrm{HCl}(3 \mathrm{x}$ $10 \mathrm{~mL})$, water $(10 \mathrm{~mL})$, brine $(10 \mathrm{~mL})$, dried with $\mathrm{MgSO}_{4}$ and filtered. Following 
removal of the solvent in vacuo, the crude product was then dissolved in $\mathrm{CH}_{2} \mathrm{Cl}_{2}$ and treated with $10 \% \mathrm{~K}_{2} \mathrm{CO}_{3}$ in water $(0.05 \mathrm{~mL})$. The reaction mixture was stirred at r.t. for $1 \mathrm{~h}$ after which time it was neutralised with $1 \mathrm{M} \mathrm{HCl}(\mathrm{pH}=3)$ and extracted with EtOAc (3 x $20 \mathrm{~mL})$. The combined organic layer was washed with water, brine, dried with $\mathrm{MgSO}_{4}$ and concentrated in vacuo. The title compound was obtained after silica gel flash column chromatography (eluting in 50:1, petroleum ether/EtOAc, v/v) to give the title compound as a pale yellow oil $(16.4 \mathrm{mg}, 0.035 \mathrm{mmol}, 89 \%$ over 2 steps). $\mathrm{R}_{f}=0.38(\mathrm{PE} / \mathrm{EA}, 10 / 1, \mathrm{v} / \mathrm{v}) ;[\alpha] \mathrm{D}^{17}=20.0 \quad\left(c=0.1, \mathrm{CHCl}_{3}\right) ; \mathrm{IR}($ film) 2924, $2854,1708,1254,774 \mathrm{~cm}^{-1} ;{ }^{1} \mathrm{H} \mathrm{NMR}\left(500 \mathrm{MHz}, \mathrm{CDCl}_{3}\right) \delta 3.82\left(\mathrm{dt}, J_{2,3}=J_{3,4 \mathrm{a}}=J_{3,4 \mathrm{~b}}\right.$ $=7.3 \mathrm{~Hz}, 1 \mathrm{H}, \mathrm{H}-3), 2.56-2.46(\mathrm{~m}, 1 \mathrm{H}, \mathrm{H}-2), 1.72\left(\mathrm{ddt}, J_{1 \mathrm{a}^{\prime}, 1 \mathrm{~b}^{\prime}}=14.0 \mathrm{~Hz}, J_{1 \mathrm{a}^{\prime}, 2}=J_{1 \mathrm{a}^{\prime}, 2 \mathrm{a}^{\prime}}\right.$ $\left.=J_{1 \mathrm{a}^{\prime}, 2 \mathrm{~b}^{\prime}}=6.7 \mathrm{~Hz}, 1 \mathrm{H}, \mathrm{H}-1 \mathrm{a}^{\prime}\right), 1.59\left(\mathrm{ddt}, J_{4 \mathrm{a}, 4 \mathrm{~b}}=13.5 \mathrm{~Hz}, J_{3,4 \mathrm{a}}=J_{4 \mathrm{a}, 5}=6.6 \mathrm{~Hz}, 1 \mathrm{H}, \mathrm{H}-\right.$ $4 \mathrm{a}), 1.57\left(\mathrm{ddt}, J_{4 \mathrm{a}, 4 \mathrm{~b}}=13.5 \mathrm{~Hz}, J_{3,4 \mathrm{~b}}=J_{4 \mathrm{~b}, 5}=6.6 \mathrm{~Hz}, 1 \mathrm{H}, \mathrm{H}-4 \mathrm{~b}\right), 1.51$ (ddt, $J_{1 \mathrm{a}^{\prime}, 1 \mathrm{~b}^{\prime}}=$ $\left.14.0 \mathrm{~Hz}, J_{1 b^{\prime}, 2}=J_{1 b^{\prime}, 2 \mathrm{a}^{\prime}}=J_{1 \mathrm{~b}^{\prime}, 2 \mathrm{~b}^{\prime}}=6.7 \mathrm{~Hz}, 1 \mathrm{H}, \mathrm{H}-1 \mathrm{~b}^{\prime}\right), 1.34-1.26(\mathrm{~m}, 33 \mathrm{H}, \mathrm{H}-5-\mathrm{H}-7, \mathrm{H}-$ 2'-H-13', $\left.\mathrm{OCH}_{2} \mathrm{CH}_{3}\right), 0.92\left(\mathrm{~s}, 9 \mathrm{H}, \mathrm{Si}\left(\mathrm{CH}_{3}\right)_{3}\right), 0.87\left(\mathrm{t}, J_{7,8}=J_{13^{\prime}, 14^{\prime}}=7.1 \mathrm{~Hz}, 6 \mathrm{H}, \mathrm{CH}_{3}-\right.$ 8 and 14 '), 0.14 (s, 3H, $\left.\mathrm{Si}\left(\mathrm{CH}_{3}\right)\right), 0.13$ (s, 3H, Si $\left(\mathrm{CH}_{3}\right) ;{ }^{13} \mathrm{C} \mathrm{NMR}\left(125 \mathrm{MHz}, \mathrm{CDCl}_{3}\right)$ $\delta 175.8$ (C-1), 73.6 (C-3), 50.2 (C-2), 35.5 (C-4), 31.9, 31.8, 29.8, 29.70, 29.69, 29.66, 29.63, 29.55, 29.45, 29.40, 29.41, 29.37, 27.44, 25.85, 24.64, 22.70, 22.51 (C5-C-7 and C-1'-C-13'), $25.72\left(\mathrm{SiC}\left(\mathrm{CH}_{3}\right)_{3}\right), 17.9\left(\mathrm{SiC}\left(\mathrm{CH}_{3}\right)_{3}\right), 14.1,14.0(\mathrm{C}-8$ and $\mathrm{C}-$ 14'), -4.3, -4.9 $\left(\mathrm{SiCH}_{3}\right)$; HRMS(ESI) $\mathrm{m} / z$ calcd. for $\left[\mathrm{C}_{28} \mathrm{H}_{58} \mathrm{O}_{3} \mathrm{Si}+\mathrm{Na}\right]^{+}$: 493.4047, obsd.: 493.4059 .

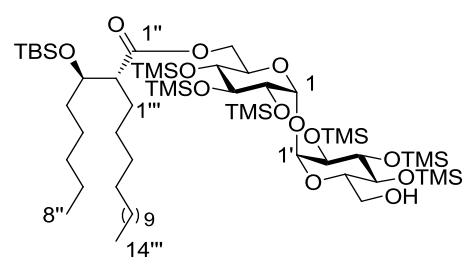

$2,2^{\prime}, 3,3$ ', $4,4^{\prime}$-Hexa$O$-trimethylsilyl-6-O-[(2R,3R)-3-tertbutyldimethylsilyloxy-2-tetradecyl-octanoyl]$\boldsymbol{\alpha}, \boldsymbol{\alpha}^{\prime}$-D-trehalose (15). To a solution of TMS trehalose $4(4.0 \mathrm{mg}, 0.005 \mathrm{mmol})$ and protected corynomycolic acid $5(10.3 \mathrm{mg}, 0.022 \mathrm{mmol})$ in toluene $(1.5 \mathrm{~mL})$, EDCI $(6.0 \mathrm{mg}$, $0.033 \mathrm{mmol})$ and DMAP $(1.0 \mathrm{mg}, 0.008 \mathrm{mmol})$ were added and the reaction was stirred at $70{ }^{\circ} \mathrm{C}$ overnight after which time the resulting precipitate was filtered off and washed with EtOAc ( $3 \times 10 \mathrm{~mL})$. The combined organic layers were washed with water $(10 \mathrm{~mL})$, brine $(10 \mathrm{~mL})$ and concentrated in vacuo. Silica gel flash 
chromatography of the crude product resulted in protected TMCM 15, (eluting in 30:1 (v/v) Pet. Ether/EtOAc), as a colourless oil (1.84 mg, $0.015 \mathrm{mmol}, 30 \%) . \mathrm{R}_{f}=$ $0.53(\mathrm{PE} / \mathrm{EA}, 5 / 1, \mathrm{v} / \mathrm{v}) ;[\alpha]^{18}{ }_{\mathrm{D}}=+60\left(c=0.05, \mathrm{CHCl}_{3}\right)$; IR (film): 3627, 3019, 2959, $1721,1463,1278,1070 \mathrm{~cm}^{-1} ;{ }^{1} \mathrm{H}$ NMR $\left(500 \mathrm{MHz}, \mathrm{CDCl}_{3}\right) \delta 4.90\left(\mathrm{~d}, J_{1,2 / 1^{\prime}, 2^{\prime}}=3.0 \mathrm{~Hz}\right.$, $\left.1 \mathrm{H}, \mathrm{H}-1 / 1^{\prime}\right), 4.83\left(\mathrm{~d}, J_{1,2 / 1^{\prime}, 2^{\prime}}=3.0 \mathrm{~Hz}, 1 \mathrm{H}, \mathrm{H}-1 / 1^{\prime}\right), 4.59\left(\mathrm{dd}, J_{6 \mathrm{a}, 6 \mathrm{~b}}=11.6 \mathrm{~Hz}, J_{5,6 \mathrm{a}}=\right.$ $2.3 \mathrm{~Hz}, 2 \mathrm{H}, \mathrm{H}-6 \mathrm{a}), 4.33$ (dd, $J_{6 \mathrm{a}, 6 \mathrm{~b}}=11.6 \mathrm{~Hz}, J_{5,6 \mathrm{~b}}=4.1 \mathrm{~Hz}, 2 \mathrm{H}, \mathrm{H}-6 \mathrm{~b}$ ), 3.97 (ddd, $J_{4,5}$ $\left.=9.0 \mathrm{~Hz}, J_{5,6 \mathrm{a}}=2.3 \mathrm{~Hz}, J_{5,6 \mathrm{~b}}=4.1 \mathrm{~Hz}, 1 \mathrm{H}, \mathrm{H}-5\right), 3.93\left(\mathrm{dt}, J_{2^{\prime \prime}, 3^{\prime \prime}}=J_{3^{\prime \prime}, 4^{\prime \prime}}=6.0 \mathrm{~Hz}, 1 \mathrm{H}\right.$, H-3"), $3.88\left(\mathrm{dd}, J_{2,3 / 2^{\prime}, 3^{\prime}}=J_{3,4 / 3^{\prime}, 4^{\prime}}=9.0 \mathrm{~Hz}, 1 \mathrm{H}, \mathrm{H}-3\right), 3.84-3.82$ (m, 1H, H-5'), 3.72$3.65\left(\mathrm{~m}, 2 \mathrm{H}, \mathrm{H}-6 \mathrm{a}^{\prime}\right.$ and $\left.6 \mathrm{~b}^{\prime}\right), 3.47\left(\mathrm{dd}, J_{3,4 / 3^{\prime}, 4^{\prime}}=J_{4,5 / 4^{\prime}, 5^{\prime}}=9.0 \mathrm{~Hz}, 2 \mathrm{H}, \mathrm{H}-4\right.$ and $\left.4^{\prime}\right), 3.42$ $\left(\mathrm{dd}, J_{1,2 / 1^{\prime}, 2^{\prime}}=3.0 \mathrm{~Hz}, J_{2,3 / 2^{\prime}, 3^{\prime}}=9.0 \mathrm{~Hz}, 1 \mathrm{H}, \mathrm{H}-2 / 2^{\prime}\right), 3.38\left(\mathrm{dd}, J_{1,2 / 1^{\prime}, 2^{\prime}}=3.0 \mathrm{~Hz}, J_{2,3 / 2^{\prime}, 3^{\prime}}=\right.$ $\left.9.0 \mathrm{~Hz}, 1 \mathrm{H}, \mathrm{H}-2 / 2^{\prime}\right), 2.55\left(\mathrm{ddd}, J_{2^{\prime \prime}, 3^{\prime \prime}}=9.4 \mathrm{~Hz}, J_{1 \mathrm{a}^{\prime \prime}, 2^{\prime \prime}}=J_{1 \mathrm{~b}^{\prime \prime}, 2^{\prime \prime}}=4.8 \mathrm{~Hz}, 1 \mathrm{H}, \mathrm{H}-2^{\prime \prime}\right)$, $1.72\left(\mathrm{dt}, J_{3^{\prime \prime}, 4^{\prime \prime}}=J_{4^{\prime \prime}, 5^{\prime \prime}}=5.3 \mathrm{~Hz}, 2 \mathrm{H}, \mathrm{H}-4^{\prime \prime}\right), 1.60-1.52$ (m, 2H, H-1"'), 1.33-1.26 (m, 30H, H-5"-H-7", H-2'"-H-13'"), 0.93 (s, 9H, Si( $\left.\left.\mathrm{CH}_{3}\right)_{3}\right), 0.167,0.154,0.149,0.120$, 0.059 (6 s, 60H, $\mathrm{CH}_{3}$, TMS and TBS); ${ }^{13} \mathrm{C} \mathrm{NMR}\left(125 \mathrm{MHz}, \mathrm{CDCl}_{3}\right) 174.1$ (C-1"), 94.5 (C-1/1'), 94.4 (C-1/1'), 73.40 (C-3/3'), 73.39 (C-3/3'), 72.72 (C-3"), 72.83 (C-5'), 72.76 (C-2/2'), 72.72 (C-2/2'), 71.9 (C-4/4'), 71.4 (C-4/4'), 70.7 (C-5), 62.42 (C-6), 61.65 (C-6'), 51.8 (C-2"), 33.30, 31.92, 31.43, 31.00, 30.17, 29.79, 29.70, 29.67, 29.53, 29.38, 28.12, 26.94, 26.30, 25.81, 24.50, 22.70, 22.63, 22.06 (C-4"-C-7" and C-1"'-C-13'") $25.81\left(\mathrm{SiC}\left(\mathrm{CH}_{3}\right)_{3}\right), 18.0\left(\mathrm{SiC}\left(\mathrm{CH}_{3}\right)_{3}\right), 14.14,14.04$ (C-8" and C-14"'), 1.05, 1.01, 0.92, 0.86, 0.17, $0.04\left(\mathrm{SiCH}_{3}, \mathrm{TMS}\right),-4.3,-4.9\left(\mathrm{SiCH}_{3}, \mathrm{TBS}\right)$; HRMS (ESI) $m / z$ calcd. for $\left[\mathrm{C}_{58} \mathrm{H}_{126} \mathrm{O}_{13} \mathrm{Si}_{7}+\mathrm{Na}\right]^{+}:$1249.7476, obsd.: 1249.7482 . 


\section{References}

(1) Ravindran, R.; Bhowmick, S.; Das, A.; Ali, N. BMC Microbiol. 2010, 10, 181-191.

(2) Hovav, A.-H.; Fishman, Y.; Bercovier, H. Infect. Immun. 2005, 73, 250-257.

(3) Yarkoni, E.; Rapp, H. J.; Polonsky, J.; Varenne, J.; Lederer, E. Infect. Immun. 1979, 26, 462- 466.

(4) Nishizawa, M.; Garcia, D. M.; Minagawa, R.; Noguchi, Y.; Imagawa, H.; Yamada, H.; Watanabe, R.; Yoo, Y. C.; Azuma, I. Synlett 1996, 452-454.

(5) Nishizawa, M.; Minagawa, R.; Garcia, D. M.; Hatakeyama, S.; Yamada, H. Tetrahedron Lett. 1994, 35, 5891-5894.

(6) Nishizawa, M.; Yamamoto, H.; Imagawa, H.; Barbier-Chassefiére, V.; Petit, E.; Azuma, I.; Papy-Garcia, D. J. Org. Chem. 2007, 72, 1627-1633.

(7) Johnson, D. Carbohydr. Res. 1992, 237, 313-318.

(8) Seiki, S.; Ishiiwa, T.; Kuroda, A.; Koga, K.; Moriwake, T. Tetrahedron 1992, 48, 4067-4086.

(9) Herr, R. W.; Wieland, D. M.; Johnson, C. R. J. Am. Chem. Soc. 1970, 92, 3813-3814.

(10) Lipshutz, B. H.; Kozlowski, J.; Wilhelm, R. S. J. Am. Chem. Soc. 1982, 104, 2305-2307.

(11) Lipshutz, B. H.; Wilhelm, R. S.; Kozlowski, J. A. Tetrahedron 1984, 40, 5005-5038.

(12) Lipshutz, B. H.; Wilhelm, R. S.; Floyd, D. M. J. Am. Chem. Soc. 1981, 103, $7672-7674$.

(13) Lipshutz, B. H.; Wilhelm, R. S.; Kozlowski, J. Tetrahedron Lett. 1982, 23, 3755-3758.

(14) Fujioka, H.; Ohba, Y.; Hirose, H.; Murai, K.; Kita, Y. Angew. Chem. Int. Ed. 2005, 44, 734-737.

(15) Allepuz, A. C.; Badorrey, R.; Díaz-de-Villegas, M. D.; Gálvez, J. A. Eur. J. Org. Chem. 2009, 6172-6178.

(16) Alexakis, A.; Jachiet, D.; Normant, J. F. Tetrahedron 1986, 42, 5607-5619.

(17) Ichikawa, Y.; Nishimura, T.; Hayashi, T. Organometallics 2011, 30, 23422348.

(18) Merten, H.; Gilman, H. J. Am. Chem. Soc. 1954, 76, 5798-5799.

(19) Herold, P. Helv. Chim. Acta 1988, 71, 354-362.

(20) Corey, E. J.; Hidetsura, C.; Rücker, C.; Hua, D. H. Tetrahedron Lett. 1981, 22, 3455-3458.

(21) Bennett, F.; Knight, D. W.; Fenton, G. J. Chem. Soc. Perkin Trans 1 1991, 133-140.

(22) Lienkamp, K.; Madkour, A. E.; Kumar, K.-N.; Nüsslein, K.; Tew, G. N. Chem. Eur. J. 2009, 15, 11715-11722. 


\section{AfBP Probe Synthesis and Biological Testing}

\subsection{Introduction}

To understand more about the manner in which trehalose dimycolates (TDMs) interact with cells of the immune system, we developed the Affinity Based Proteome (AfBP) probe 1, which is structurally similar to the parent TDMs whilst also containing a benzophenone trap and an alkyne tag group. This particular trap and tag system has been chosen due to its small size and hydrophobic character and thus its ability to best mimic the TDM lipid. Our probe has been developed so as to leave the bioactive carbohydrate portion of the TDM unfunctionalised.

Previous studies have shown that TDM, as well as its simpler synthetic analogue trehalose dibehenate (TDB), binds to macrophage inducible C-type lectin (Mincle) in order to induce an immune response, ${ }^{1,2}$ however, to date no other receptors for TDMs have been determined. Accordingly, by synthesising probe $\mathbf{1}$ and using it for Affinity Based Proteome Profiling (AfBPP), other proteins that TDMs bind to may be identified. The focus of this chapter is the synthesis of $\mathrm{A} f \mathrm{BP}$ probe $\mathbf{1}$. The probe 
binding and protein identification studies will be performed by our collaborator Dr. Faustin Kamena at a later date.

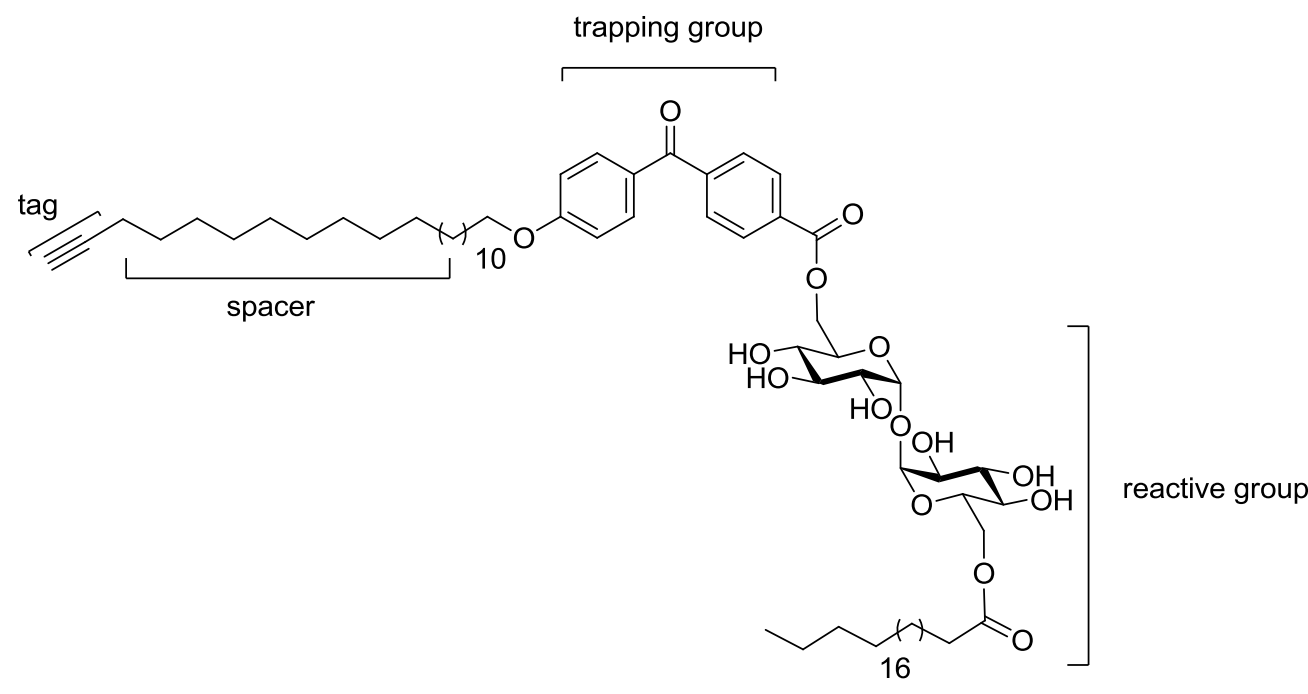

1

Figure 1. Proposed AfBP Probe 1

\subsection{TDM Probe Synthesis}

For the synthesis of probe 1, a convergent strategy was planned whereby the two intermediates, TMS mono-trehalose ester $\mathbf{2}$ and carboxylic acid $\mathbf{3}$ would be coupled followed by deprotection to obtain the final compound (Scheme 1). The TMS monotrehalose ester $\mathbf{2}$ could be obtained through esterification of diol $\mathbf{4}$ with behenic acid (5). Compound 4, in turn, could be synthesised via a one-pot two-step silylation process starting with commercially available $\alpha, \alpha$-D-trehalose. ${ }^{3}$ To prepare the trap and tag, carboxylic acid $\mathbf{3}$ could be accessed via the alkylation of benzophenone $\mathbf{6}$ with iodide 7, with compound $\mathbf{6}$ prepared in five steps from commercially available terephthalic acid (8) and iodide 7 synthesised in five steps from 1,4-butanediol (9). 


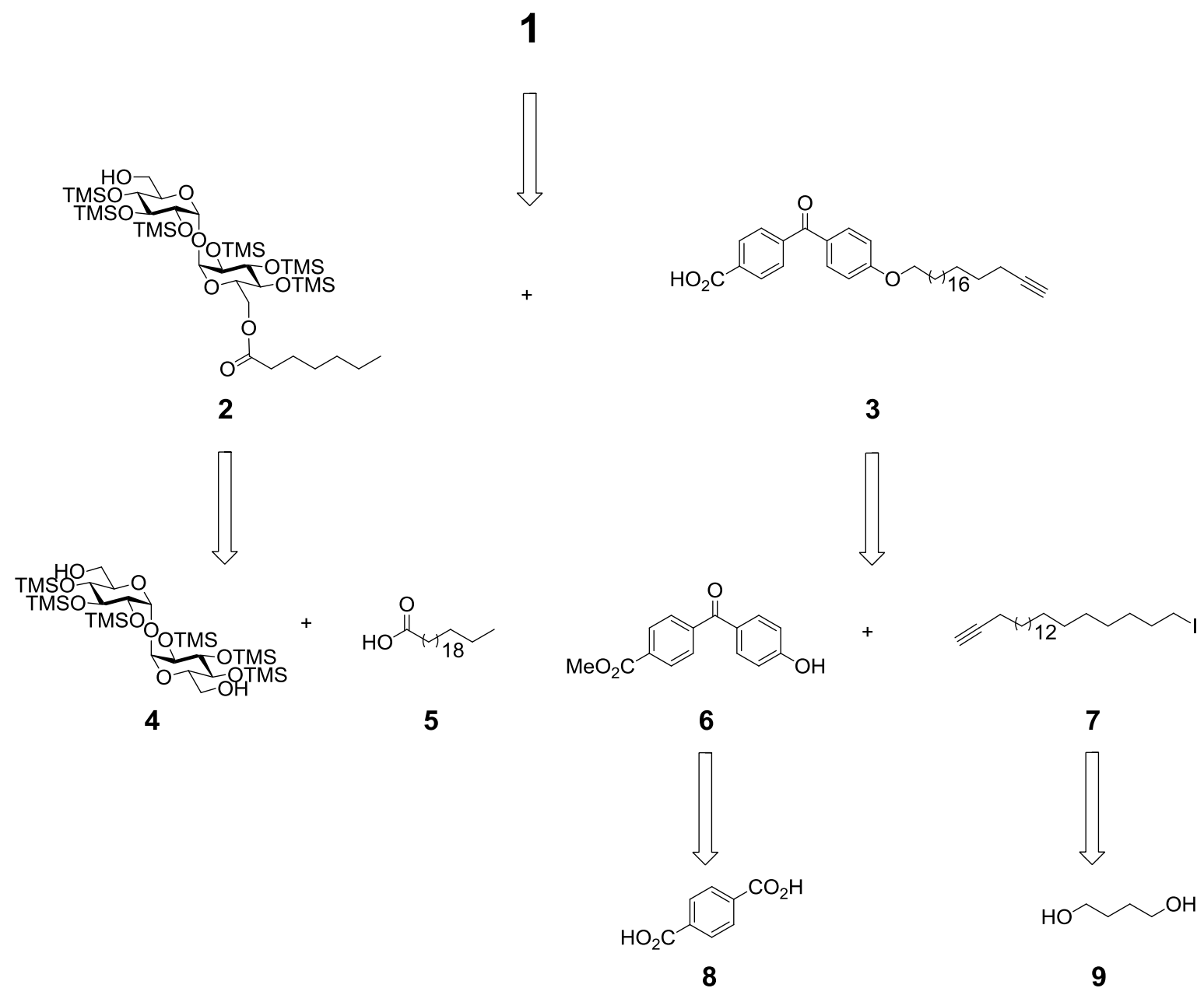

Scheme 1. Retrosynthesis of target AfBP probe 1

To prepare benzophenone $\mathbf{6}$, terephthalic acid $\mathbf{8}$ was first converted to dimethyl ester 10 via reaction with thionyl chloride and $\mathrm{MeOH}$ (Scheme 2). Hydrolysis of one of the methyl ester groups using potassium hydroxide (1.1 equiv.) gave monoacid 11 in good $(87 \%)$ yield over two steps. ${ }^{4}$ Acid $\mathbf{1 1}$ was then converted to acid chloride $\mathbf{1 2}$ by reacting it with $\mathrm{SOCl}_{2}$. Due to the instability of acid chloride 12, it was immediately subjected to Friedel-Crafts acylation with anisole in the presence of aluminium chloride in an attempt to form the para-substituted benzophenone compound 13. The literature procedure involved addition of $\mathrm{AlCl}_{3}$ in one portion and in our hand, this led to a yield of only $40 \%$ which was comparable to the reported yield of $42 \%$. $^{5}$ The yield of the product could be significantly increased to $70 \%$ by portion-wise addition 
of $\mathrm{AlCl}_{3}$ during the course of the reaction. About $5 \%$ of the expected orthosubstituted product was also formed which was inseparable from the para-substituted product. However, the para- and ortho-substituted products could be separated after demethylation of benzophenone 13 (vide infra). The major product was identified as para- substituted benzophenone $\mathbf{1 3}$ based on the proton, COSY, and HMBC spectral analysis. The four protons of the anisole moiety in the para-product are in two different chemical environments, and as expected only two distinguished resonances were observed for them, as opposed to four resonances which would be expected for the ortho-substituted product.

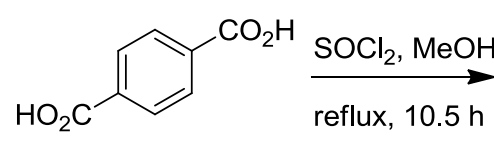

8

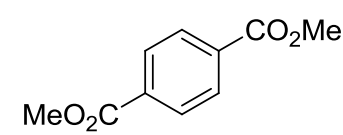

10

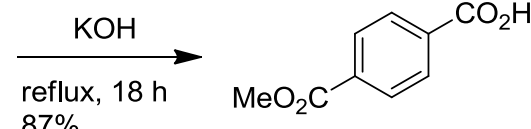

(2 steps)

11

$\mathrm{SOCl}_{2}$ reflux, $4 \mathrm{r}$<smiles>COc1ccc(C(=O)c2ccc(C(C)=O)cc2)cc1</smiles>

13

$\mathrm{AlCl}_{3}$ r.t. to reflux, $1 \mathrm{~h}$ $85 \%$<smiles>COC(=O)c1ccc(C(=O)c2ccc(O)cc2)cc1</smiles>

6<smiles>COC(=O)c1ccc(C(=O)Cl)cc1</smiles>
(2 steps)

Scheme 2. Synthesis of benzophenone 6

Having successfully prepared benzophenone ester 13, the next step in our strategy was demethylation to generate the target benzophenone $\mathbf{6}$, ready for coupling to the alkynyl iodide 7. To this end, benzophenone $\mathbf{1 3}$ was treated with trimethylsilyl iodide (1.1 equiv.), ${ }^{6}$ however, despite several attempts this strategy did not eventuate in 
product formation and only starting material was recovered from the reaction. Use of boron trichloride (4 equiv.) was also not successful with starting material retrieved from the reaction. Next, $\mathrm{AlCl}_{3}$ (4 equiv.) was used, according to the more recent procedure of Hartmann and co-workers. ${ }^{7}$ This resulted in c.a. $30 \%$ of the desired product along with unreacted starting material. Fortunately, by increasing the amount of $\mathrm{AlCl}_{3}$ (6 equiv.), and adding it in two portions during the reaction, greatly enhanced the yield, with benzophenone ester 6 obtained in good (85\%) yield. The ${ }^{1} \mathrm{H}$ NMR spectra of compound 6 (Figure 2), showed one singlet at $\delta 3.98 \mathrm{ppm}$ as compared to the two singlets at $\delta 3.98$ and $\delta 3.91 \mathrm{ppm}$ for the methyl ester precursor 13. ${ }^{13} \mathrm{C}$ NMR spectral analysis showed a downfield shift of $3.6 \mathrm{ppm}$ for the aromatic carbon attached to the hydroxyl group in compound $\mathbf{6}$ when compared to the same carbon in 13. A shift of $1.5 \mathrm{ppm}$ for the adjacent aromatic carbons also provided evidence that demethylation occurred. The chemical shifts of the other carbons in compounds 6 and 13 were within 0.5 ppm of each other. Mass spectral analysis of the product was in agreement of the expected mass, [HRMS calcd. for $\left[\mathrm{C}_{15} \mathrm{H}_{12} \mathrm{O}_{4}+\mathrm{Na}\right]^{+}:$279.0626, obsd.: 279.0633] and full assignment was made on the basis of 2D NMR (COSY, HSQC and HMBC) (see experimental for full assignment).

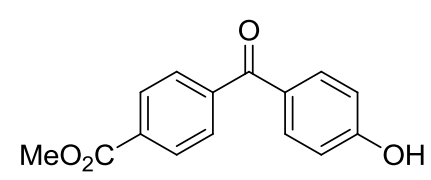

6

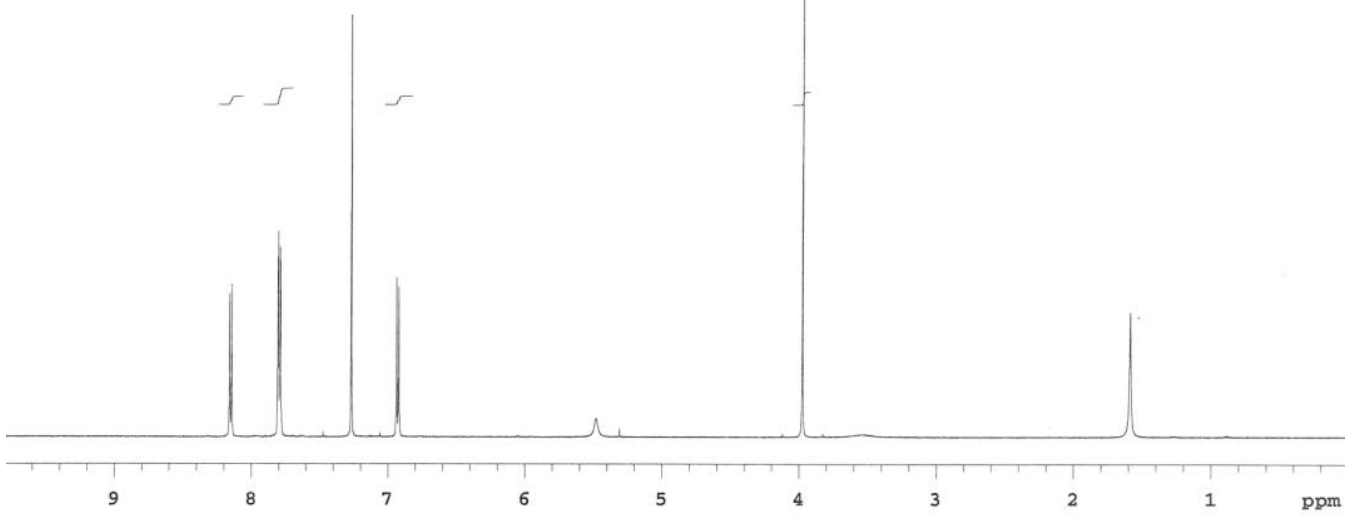

Figure 2. ${ }^{1} \mathrm{H}$ NMR spectrum of benzophenone 6 
To prepare the iodide 7, a convergent synthetic strategy was proposed (Scheme 3). First, bromo-hexadecane (14) was reacted with sodium acetylide in order to form 1octadecyne (15). The concentration of the reaction mixture proved critical in obtaining optimal yields for this reaction, with the use of either THF or DMF at 5 $\mathrm{mL} / \mathrm{mmol}$ resulting in no product formation and starting material being recovered from the reaction mixture. However, when the reaction was carried out in DMF at $1.1 \mathrm{~mL} / \mathrm{mmol}^{8}{ }^{8} 98 \%$ yield of alkyne 15 was achieved. The other key intermediate required for the synthesis of iodide 7 was the THP-protected bromide 16. To this end, 1,4-butanediol (9) was reacted with hydrogen bromide under Dean-Stark conditions to form corresponding mono-substituted bromide. ${ }^{9}$ Though this reaction was low yielding (c.a. 40\%) the amount of product obtained was comparable to literature when either toluene or benzene was used as a solvent. As TLC of the reaction mixture showed complete consumption of the starting material, one possible reason for this low yield could be due to further reaction of the mono-substituted bromide with $\mathrm{HBr}$ resulting in formation of THF, which could have been lost during work-up and subsequent removal of the solvent in vacuo. Treatment of the desired mono-brominated intermediate with 3,4-dihydropyran and pyridinium paratoluenesulfonate (PPTS), resulted in formation of tetrahydropyran (THP) ether 16 in excellent $(97 \%)$ yield. ${ }^{10}$ 


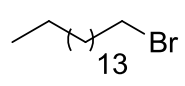

14

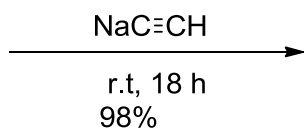

$98 \%$

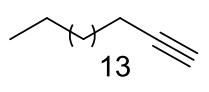

15
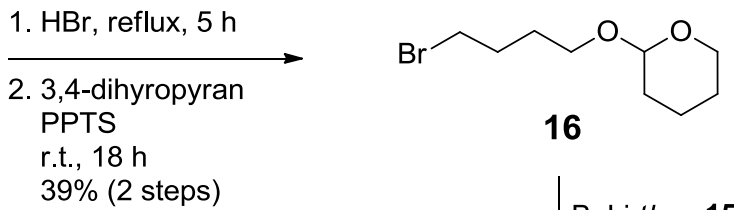

16

BuLi then 15

reflux, $24 \mathrm{~h}$

$\sqrt{83 \%}$

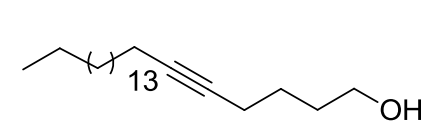

18

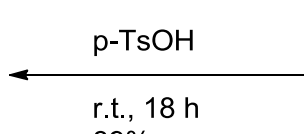

$89 \%$

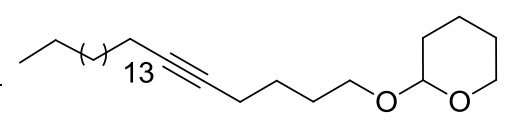

17

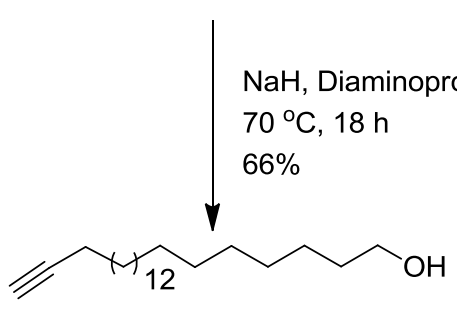

19

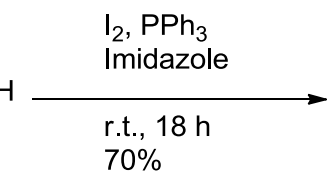

$70 \%$

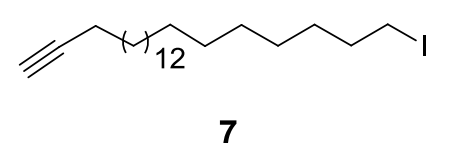

Scheme 3. Synthesis of iodide 7

With the required THP ether $\mathbf{1 6}$ in hand, a BuLi-mediated alkylation with octadecyne $\mathbf{1 5}$ was then attempted. This proceeded smoothly with alkyne $\mathbf{1 7}$ being formed in a high $(83 \%)$ yield. Subsequent removal of the THP protecting group in 17 using paratoluenesulfonic acid (PTSA) resulted in alcohol 18, which was then isomerised by way of a zipper reaction to form alcohol 19.

The mechanism of the zipper reaction can be explained by a series of allene/alkyne interconversions (Scheme 4). ${ }^{11}$ The first step in the process involves reacting a strong base (e.g. $\mathrm{NaH})$ with diaminopropane to form sodium 3-propylamide (I), which subsequently deprotonates the hydroxyl moiety in alcohol II. This deprotonation is followed by a concerted mechanism whereby the distal carbon adjacent to the alkyne is deprotonated, and allene III is formed. The reaction then goes through a series of allene/alkyne interconversions all of which are in equilibrium. The final product is 
trapped as a very stable alkyne anion (IV) which is protonated in the work-up to form the terminal alkyne product $(\mathbf{V})$. The stability of alkyne anion IV is attributed to the presence of the two negative charges on opposite end of the molecule, minimising charge repulsion and thus enhancing the stability of the anion.

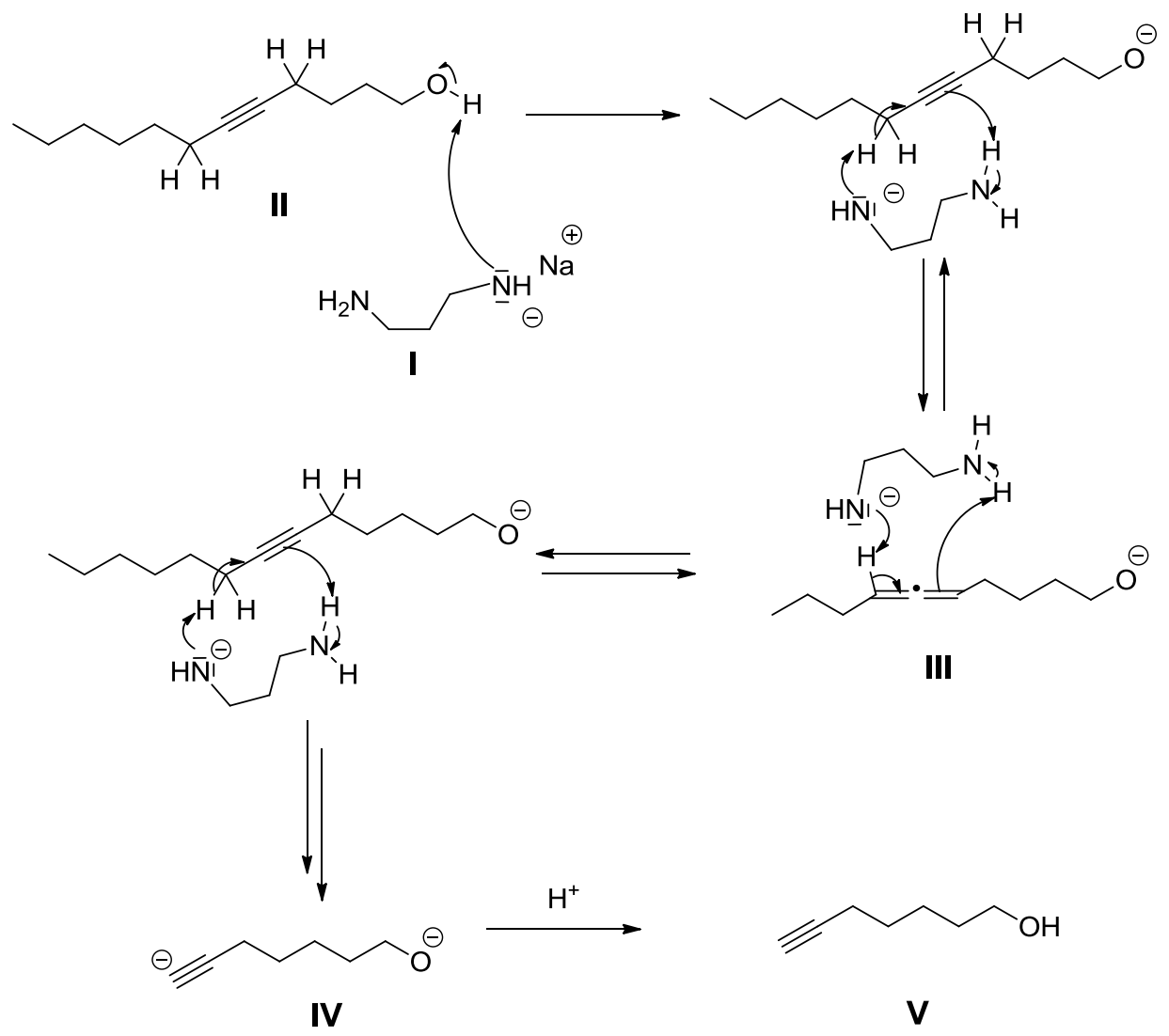

Scheme 4. Zipper reaction for isomerisation of triple bonds

Comparison of the ${ }^{1} \mathrm{H}$ NMR spectral data for alcohol 18 and 19 clearly illustrates the migration of the triple bond (Figure 3). In the ${ }^{1} \mathrm{H}$ NMR spectrum for alcohol 18, characteristic peaks include triplets at $3.68 \mathrm{ppm}(J=6.4 \mathrm{~Hz})$ for $\mathrm{H}-1$ and at $0.89 \mathrm{ppm}$ $(J=7.0 \mathrm{~Hz})$ for $\mathrm{H}-22$ and the two resonances at $2.20 \mathrm{ppm}\left(\mathrm{tt}, J=7.1 \mathrm{~Hz},{ }^{5} J=2.2 \mathrm{~Hz}\right)$ and $2.14 \mathrm{ppm}\left(\mathrm{tt}, J=6.9 \mathrm{~Hz},{ }^{5} J=2.2 \mathrm{~Hz}\right.$ ) for $\mathrm{H}-4$ and $\mathrm{H}-7$ corresponding to the two methyl protons flanking the triple bond. In the spectrum for alcohol 19, however, isomerisation of the triple bond is clearly evident by the presence of a triplet at 1.94 ppm $\left({ }^{4} J=2.6 \mathrm{~Hz}\right)$ accounting for the terminal alkyne proton and the absence of the peak at approximately $0.89 \mathrm{ppm}$, (correlating to $\mathrm{H}-22$ in 18). To complete the 
synthesis of target iodide 7, alcohol $\mathbf{1 9}$ was then treated with iodine, triphenylphosphine, and imidazole to give 7 in $70 \%$ yield.

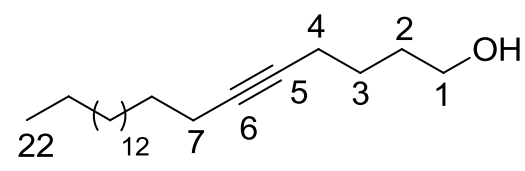

18
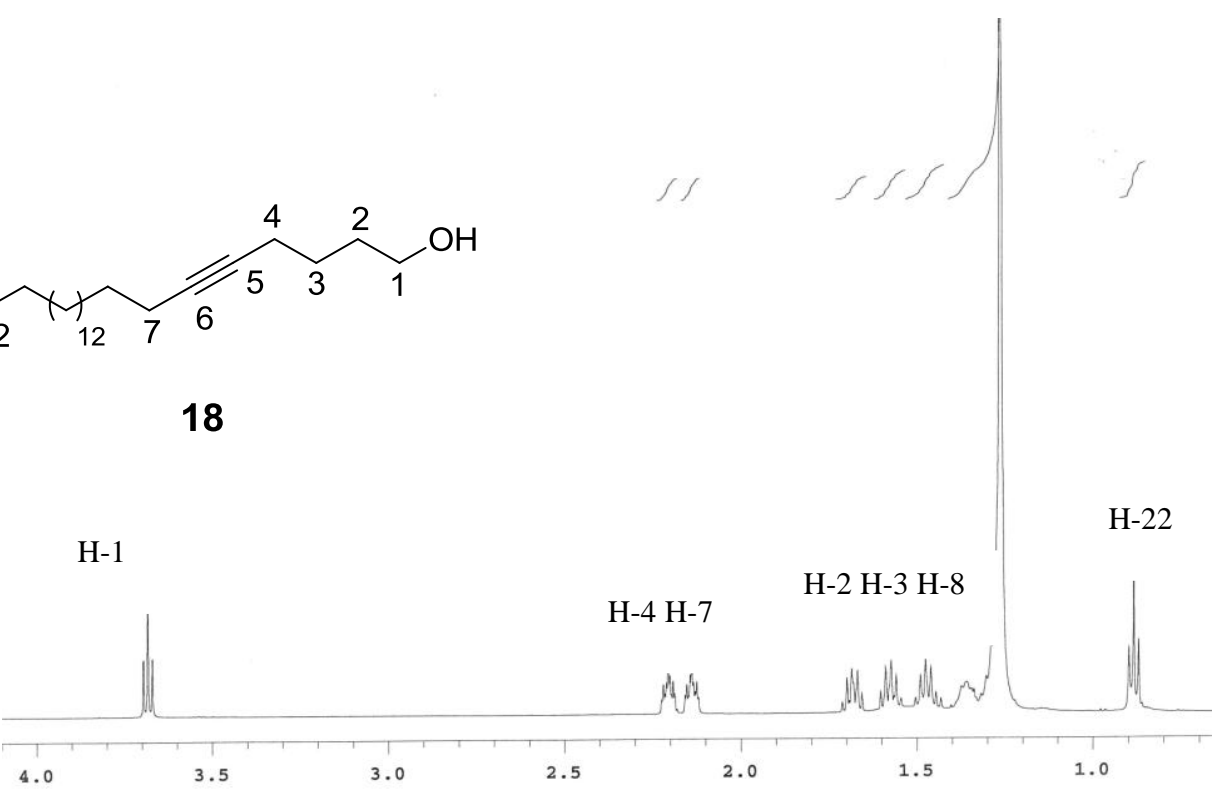

A

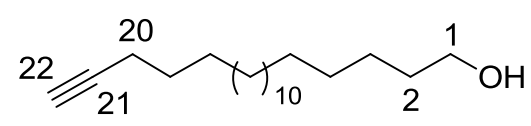

19

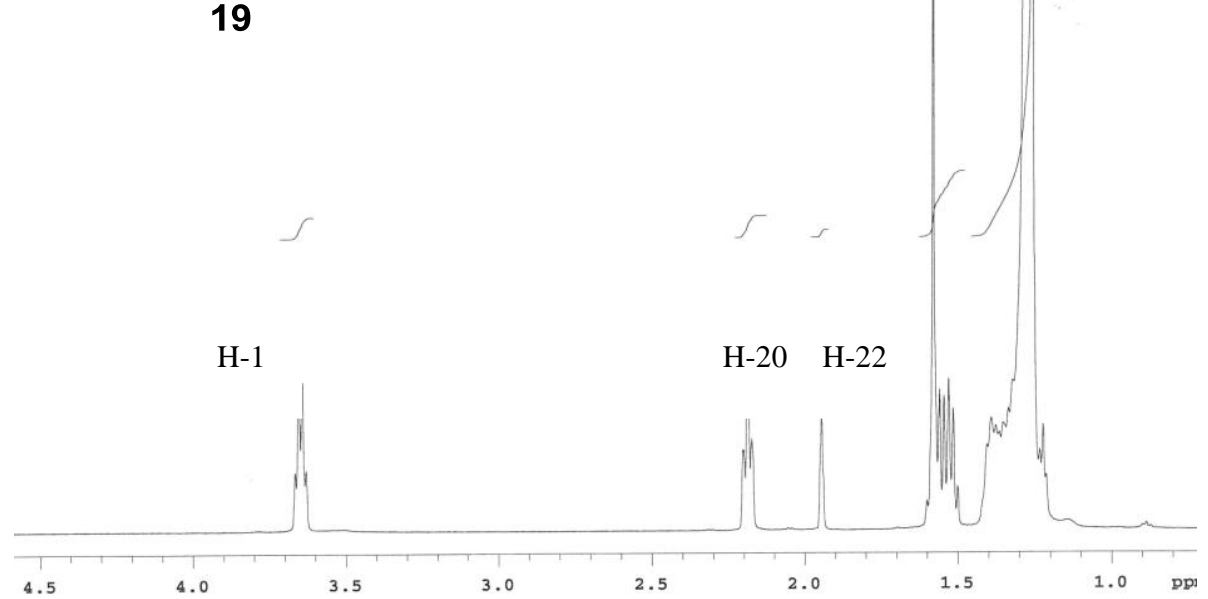

B

Figure 3. ${ }^{1} \mathrm{H}$ NMR spectra of compounds $\mathbf{1 8}$ and 19 
Having prepared iodide 7, coupling with benzophenone 6 was then attempted (Table 1). First, sodium hydride (1.1 equiv.) was used as a base and the reaction was carried out in toluene (entry 1). Unfortunately, this only gave $10 \%$ of the alkylated product 20, with mainly starting material being obtained from the reaction mixture. Increasing the amount of $\mathrm{NaH}$ (2.2 equiv.) did not lead to any significant improvement in the yield (entry 2) and in addition, degradation of the alkyl iodide 7 was observed. Use of $\mathrm{K}_{2} \mathrm{CO}_{3}$ along with 18-crown-6 ether also did not lead to any significant increase in yield (entry 3), however with caesium carbonate a small increase in product yield was achieved (entry 4). It was thought that one of the reasons for this low yield could be the low solubility of compound $\mathbf{6}$ in toluene, therefore the solvent system was changed to toluene:DMF (1:1) (entry 5). Indeed this led to an increased yield (24\%), though as the result was still modest we turned our attention to the use of a lipid containing a different leaving group.

Table 1. Alkylation conditions for coupling benzophenone $\mathbf{6}$ and iodide 7

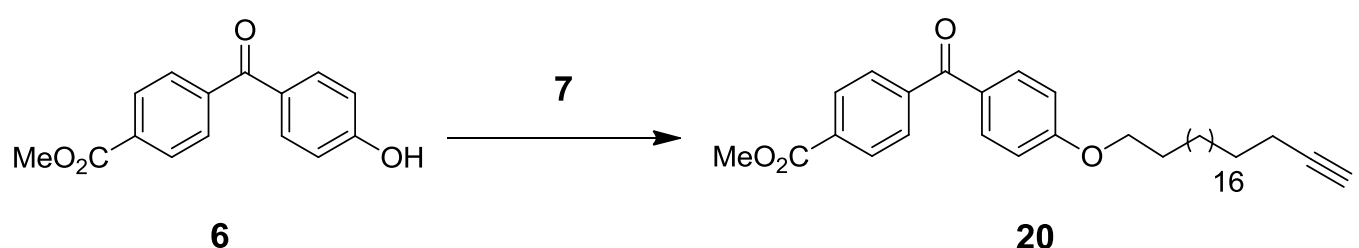

\begin{tabular}{lll}
\hline Entry & Conditions & Product yield (\%) \\
\hline 1 & $\mathrm{NaH}(1.1$ equiv.), toluene, r.t. & 10 \\
2 & $\mathrm{NaH}\left(2.2\right.$ equiv.), toluene, r.t to $70{ }^{\circ} \mathrm{C}$ & 12 \\
3 & $\mathrm{~K}_{2} \mathrm{CO}_{3}$ (1.1 equiv.), 18-crown-6, toluene, $70{ }^{\circ} \mathrm{C}$ & 12 \\
4 & $\mathrm{CsCO}_{3}$ (1.1 equiv.), 18-crown-6, toluene, $70{ }^{\circ} \mathrm{C}$ & 16 \\
5 & $\mathrm{CsCO}_{3}$ (1.1 equiv.), 18-crown-6, DMF:toluene 1:1, $50{ }^{\circ} \mathrm{C}$ & 24 \\
\hline
\end{tabular}


It was proposed that a triflate group, a good leaving group, would make the adjacent carbon electrophile 'hard' which is desired in this instance since in $O$-alkylation the nucleophile is an oxygen atom which is a 'hard' nucleophile. Accordingly, alcohol 19 was reacted with triflic anhydride and pyridine, with TLC analysis of the reaction mixture after 45 minutes indicating complete consumption of starting material. Unfortunately, the triflate product could not be purified with hydrolysis of the product to alcohol 19 observed after silica gel column chromatography. At this point the tosylate leaving group was chosen, as in addition to being a good leaving group, it is more stable than the triflate group. Thus alcohol $\mathbf{1 9}$ was reacted with tosyl chloride and pyridine ${ }^{12}$ providing tosylate 21 in $97 \%$ yield (Scheme 5). Tosylate 21 was then subjected to alkylation with benzophenone $\mathbf{6}$ in the presence of $\mathrm{NaH}(1.1$ equiv.). This resulted in slightly improved but still modest $30 \%$ yield of the alkylated product 20. However, a change of base to $\mathrm{CsCO}_{3}(1.1$ equiv.), along with the addition of 18-crown-6 ether, resulted in good (64\%) product yield, which was deemed sufficient to continue on with the synthesis. Subsequent hydrolysis of the methyl ester in product $\mathbf{2 0}$ with $\mathrm{LiOH}$, led to carboxylic acid $\mathbf{3}$ in good (80\%) yield. Here, it should be noted that the hydrolysis was performed under reflux to ensure complete solubilisation of the starting material. In addition, the reaction needed to be stopped following complete consumption of the starting material to prevent product degradation.
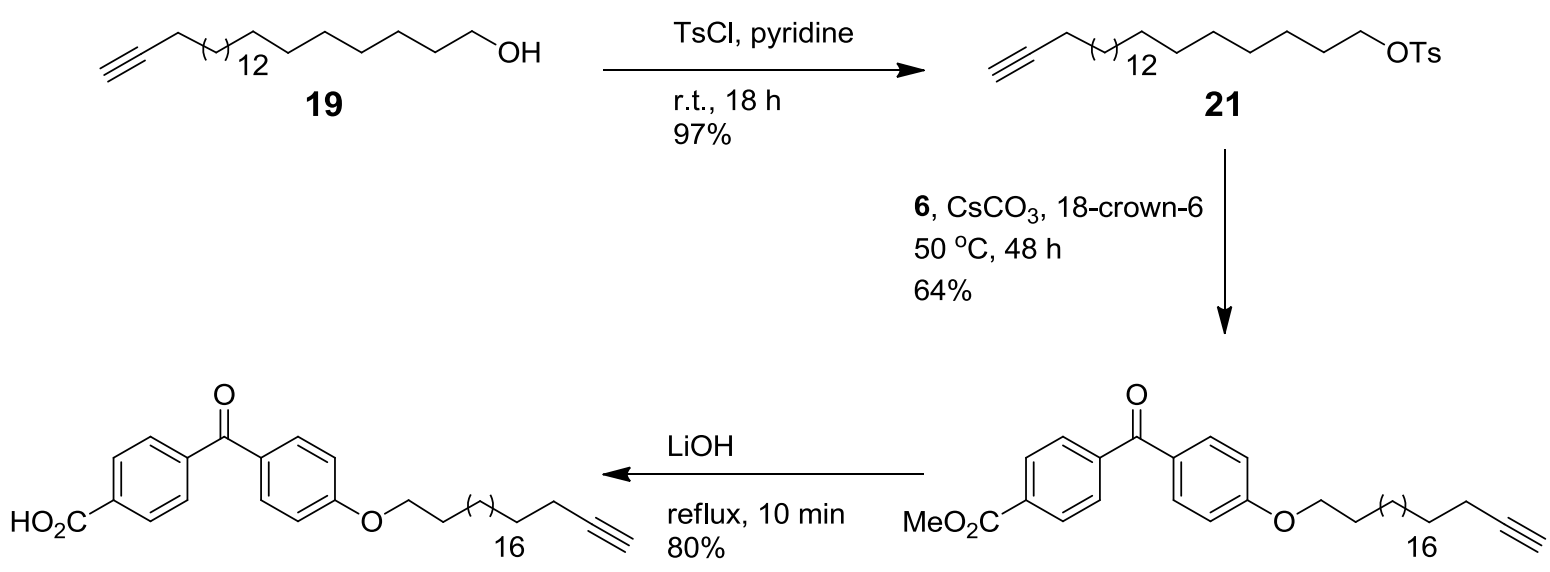

3

Scheme 5. Synthesis of benzophenone building block 3 
With the synthesis of the benzophenone building block $\mathbf{3}$ established, our focus then turned to the synthesis of the trehalose building block 2 . Using a protocol previously discussed (see Chapter 2), commercially available $\alpha, \alpha$-D-trehalose was per-silylated using $\mathrm{N}, \mathrm{O}$-bis-trimethylsilylacetamide (BSA) and catalytic tetra-butyl ammonium fluoride (TBAF), and the more labile primary trimethylsilyl (TMS) ethers were then selectively removed via the addition of $\mathrm{K}_{2} \mathrm{CO}_{3}$ to give the trehalose diol 4 (Scheme 6). Esterification of diol 4 with behenic acid 5 (obtained from Jones oxidation of 1docosanol), via the mediation of 1-ethyl-3-(3-dimethylaminopropyl)carbodiimide (EDCI) and 4-dimethylamino-pyridine (DMAP) led to the mono-trehalose ester $\mathbf{2}$ in $75 \%$ yield. Compound 2 was then subjected to a second esterification, this time using benzophenone 3. Here, it was interesting to note that this coupling was quite slow with the reaction only occurring when the mixture was refluxed in toluene over seven days. Even then, only a modest (30\%) yield of the protected probe $\mathbf{2 2}$ was obtained, which was then subjected to Dowex $-\mathrm{H}^{+}$in order to liberate target $\mathrm{A} f \mathrm{BP} \mathbf{1}$ in quantitative yield. 

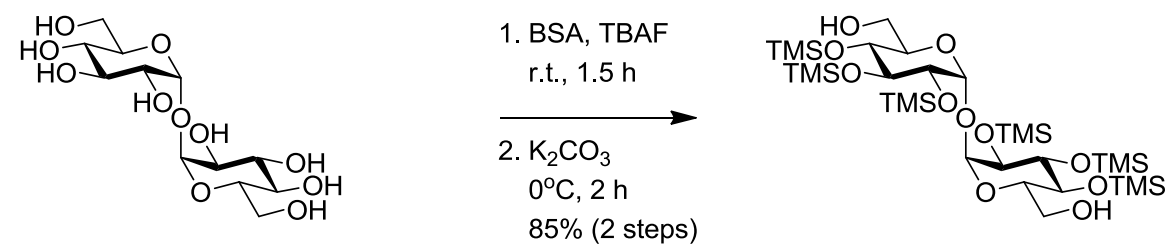

$\alpha, \alpha$-D-trehalose
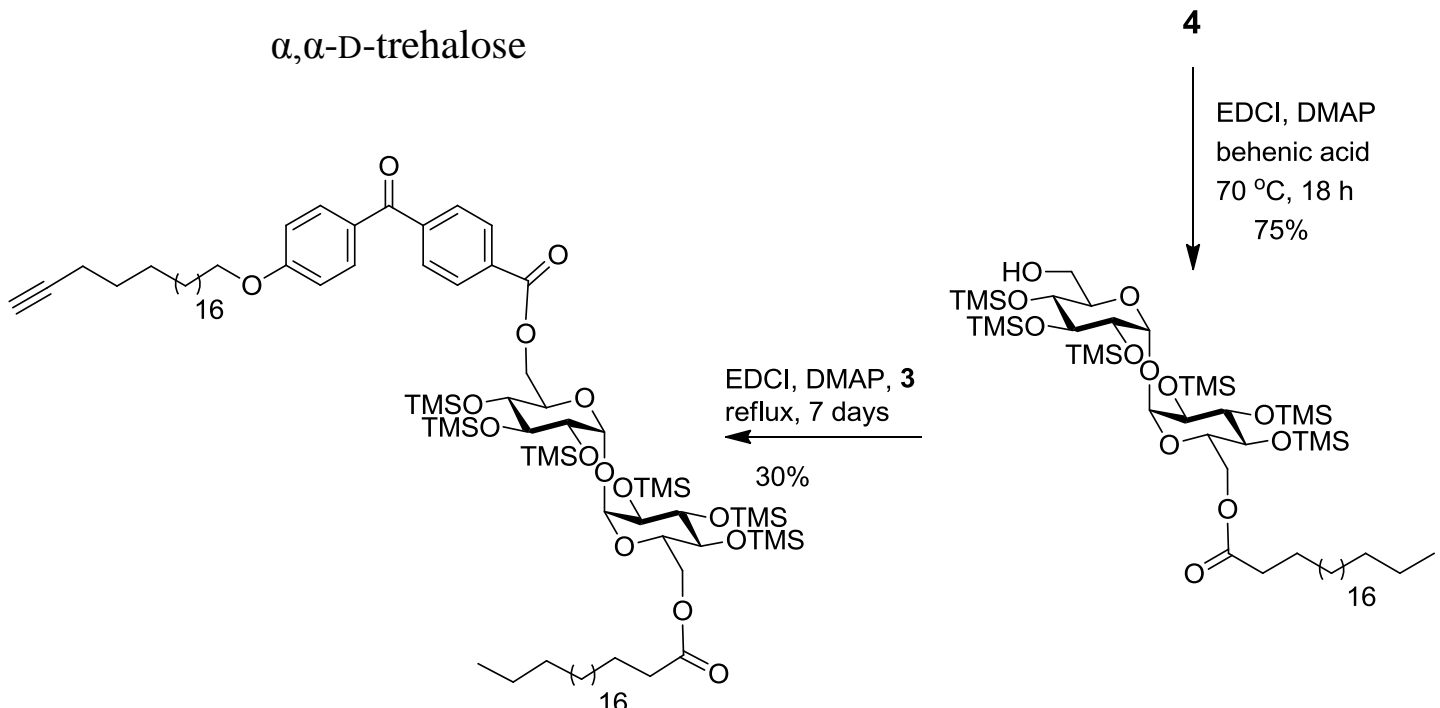

22

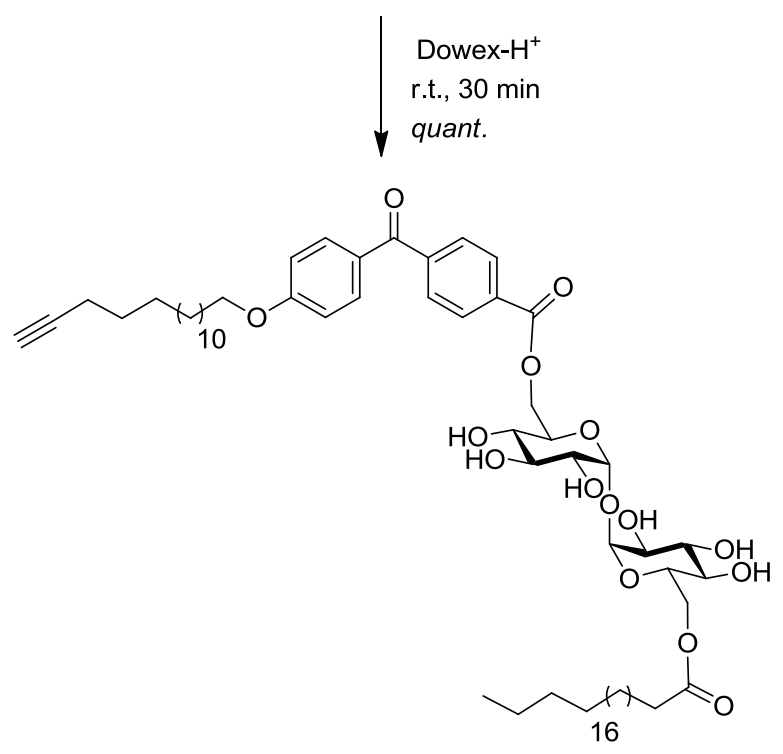

1

Scheme 6. Total synthesis of AfBP probe 1 
The ${ }^{1} \mathrm{H}$ NMR spectrum of AfBP probe $\mathbf{1}$ clearly displayed all the required resonances (Figure 4). The key peaks in this instance are the two anomeric signals which were present as doublets at $5.84(\mathrm{~d}, J=3.6 \mathrm{~Hz})$ and $5.83 \mathrm{ppm}(\mathrm{d}, J=3.6 \mathrm{~Hz})$ indicative of the asymmetrical nature of the trehalose moiety. The presence of the aromatic resonances for the benzophenone protons are clearly evident as doublets at $8.20(\mathrm{~J}=$ $8.2 \mathrm{~Hz}), 7.86(J=8.8 \mathrm{~Hz}), 7.68(J=8.2 \mathrm{~Hz})$ and $7.06 \mathrm{ppm}(J=8.8 \mathrm{~Hz})$. The terminal alkyne proton had a triplet resonance at $2.68 \mathrm{ppm}\left({ }^{4} J=2.7 \mathrm{~Hz}\right)$ with the ether protons present as a triplet at $3.96 \mathrm{ppm}(J=6.3 \mathrm{~Hz})$. Mass spectral analysis of the product was in agreement with the expected mass, [HRMS(ESI) $\mathrm{m} / \mathrm{z}$ calcd. for $\left[\mathrm{C}_{70} \mathrm{H}_{112} \mathrm{O}_{15}+\mathrm{Na}\right]^{+}: 1215.7893$, obsd.:1215.7897] and full assignment was made on the basis of 2D NMR (COSY, HSQC and HMBC) (see experimental for full assignment). The NMR analysis was carried out using deuterated pyridine as the solvent due to the amphiphilic nature of the molecule which made solubilisation of the compound difficult in any other solvent system. 


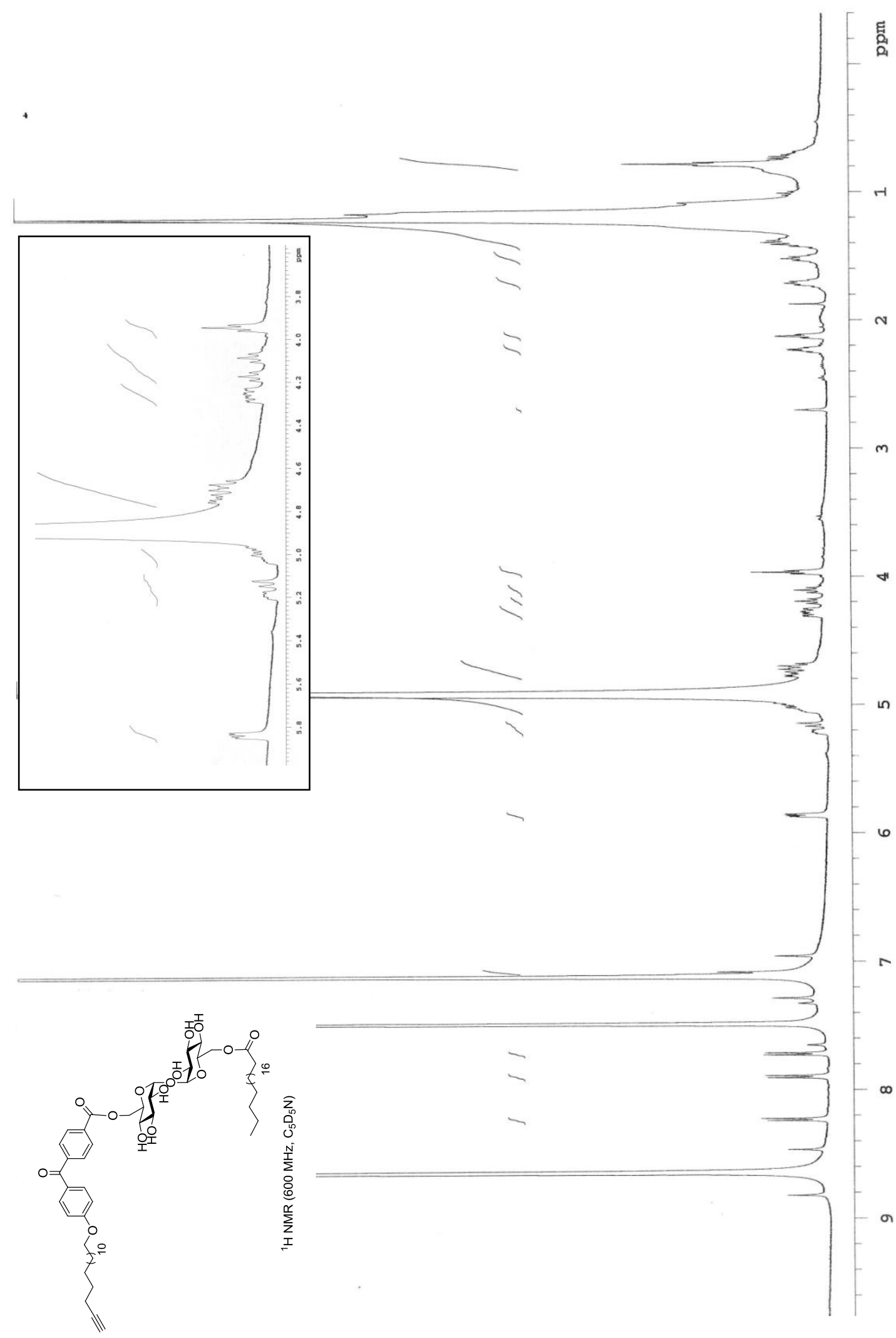

Figure 4. ${ }^{1} \mathrm{H}$ NMR spectrum of $\mathrm{A} f \mathrm{BP}$ probe 1 


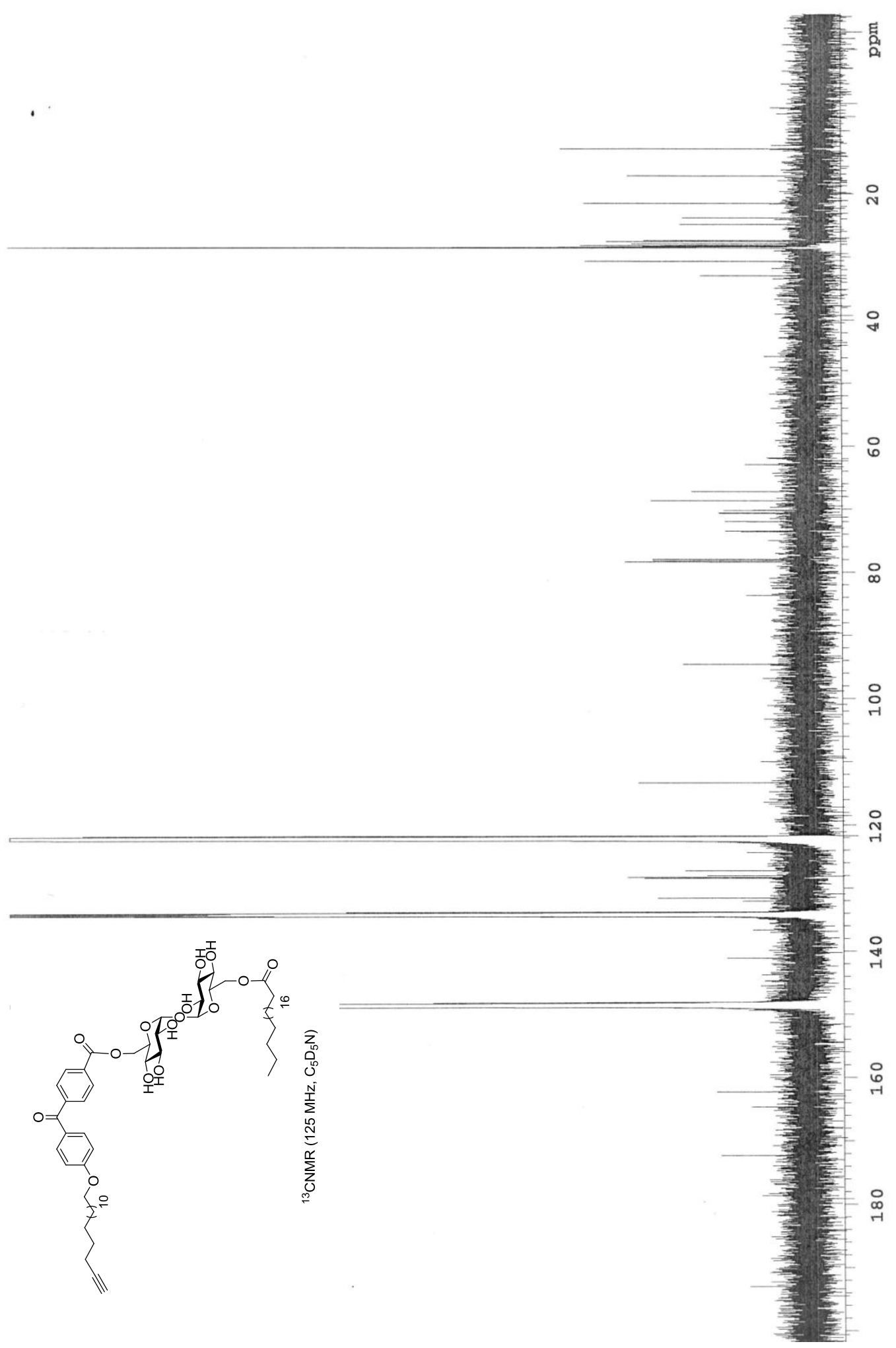

Figure 5. ${ }^{13} \mathrm{C}$ NMR spectrum of $\mathrm{A} f \mathrm{BP}$ probe $\mathbf{1}$ 


\subsection{Biological Testing}

With AfBP probe $\mathbf{1}$ in hand, the ability of the probe to activate bone marrow macrophages (BMM) was investigated. To this end, bone marrow cells were isolated from mice and plated out in 24 well plate at $2.5 \times 10^{5}$ cell $/ \mathrm{mL}$ to a total of $1 \mathrm{~mL}$ in each well and differentiated into macrophages over 10 days (see experimental section for more details). The macrophages were primed with $10 \mathrm{ng} / \mathrm{mL} \mathrm{IFN}-\gamma$ for 3 hours after which time they were stimulated with probe 1 or C22 trehalose diester (C22 TDE) at $20 \mu \mathrm{g} / \mathrm{mL}$ and $40 \mu \mathrm{g} / \mathrm{mL}$. LPS was used as a positive control in the experiments. The supernatants were analysed after 96 hours for nitric oxide (NO) production (Figure 6). As seen, the probe did activate macrophages in a concentration dependent manner. Although the activation by probe $\mathbf{1}$ was lower than that by the C22 TDE, it was still significant ( $p=0.005$ at $40 \mu \mathrm{g} / \mathrm{mL}$ ).

The reduced activity of probe $\mathbf{1}$ when compared to C22 TDE could be due to the presence of the benzophenone group next to the trehalose sugar unit in the probe. Since it is already known that Mincle is a carbohydrate recognising receptor, the presence of the benzophenone group next to trehalose could hinder the binding of the probe to this receptor on macrophages. However, probe $\mathbf{1}$ needs to be tested in proteome profiling experiments to deduce its potential as an $\mathrm{A} f \mathrm{BP}$ probe. 


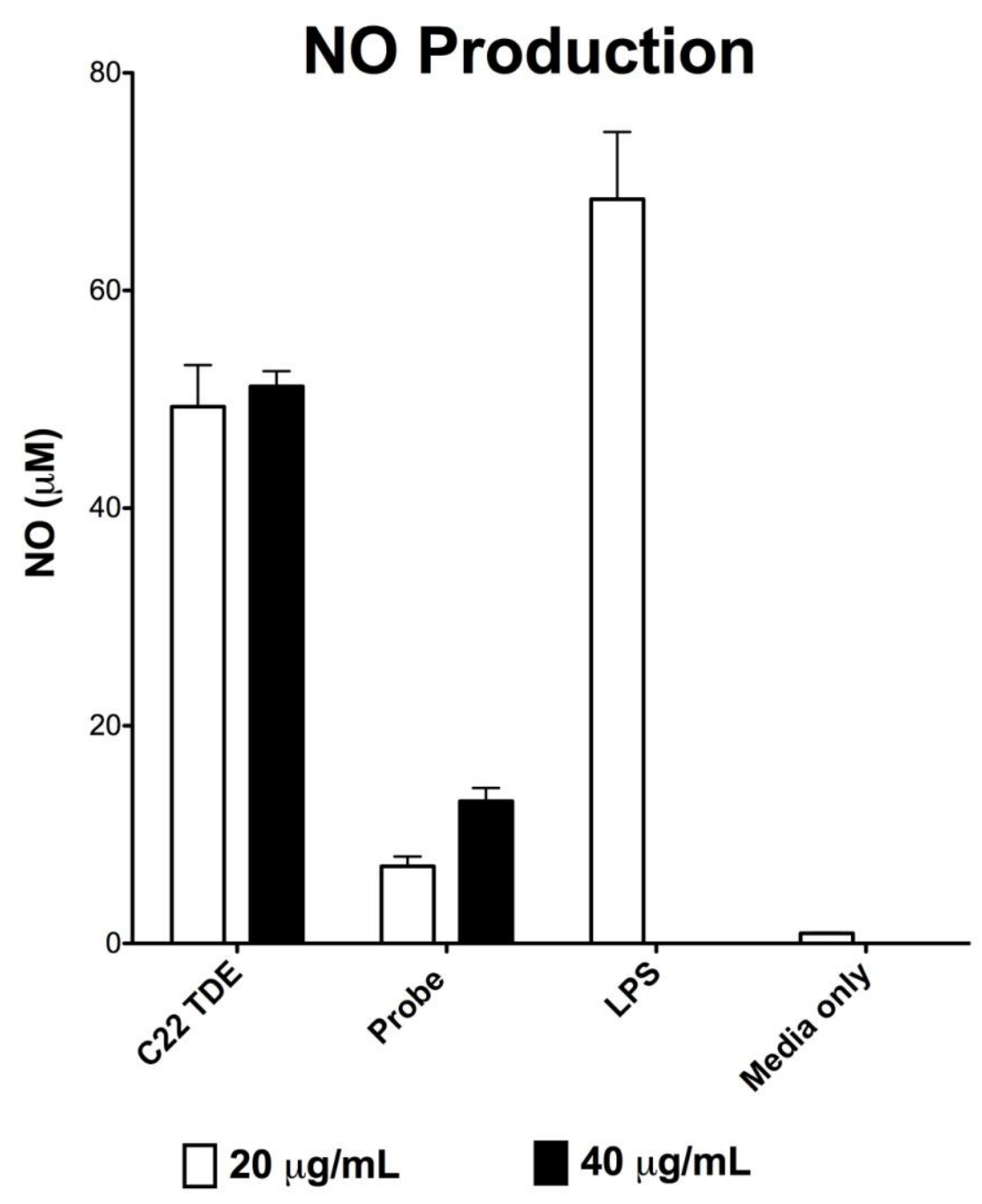

Figure 6. NO production by $\mathrm{BMM}$ treated with $\mathrm{A} f \mathrm{BP}$ probe 1. $\mathrm{BMM}$ were stimulated with 20 or $40 \mu \mathrm{g} / \mathrm{mL}$ of probe 1 or C22 TDE or with LPS (100 ng/mL). At $96 \mathrm{~h}$ the supernatants were analysed for NO using Griess assay. 


\subsection{Future Work}

With the initial macrophage assay completed, the next step is to test the probe in proteome profiling experiments in order to deduce its usefulness for identifying proteins that trehalose glycolipids bind to. These experiments will be done in vitro, whereby BMM will be stimulated using probe 1, followed by light mediated attachment of probe 1 to the protein/s it interacts with on macrophages (Figure 7). The alkyne functionality would be subjected to a click reaction with an azide linked biotin molecule. Following this, the probe-protein-azide-biotin complex would undergo streptavidin enrichment, trypsin digestion, and analysis with liquid chromatography/mass spectrometry (LC/MS) and sodium dodecyl sulfatepolyacrylamide gel electrophoresis (SDS-PAGE) analysis in order to elucidate the identity of the linked proteins. 


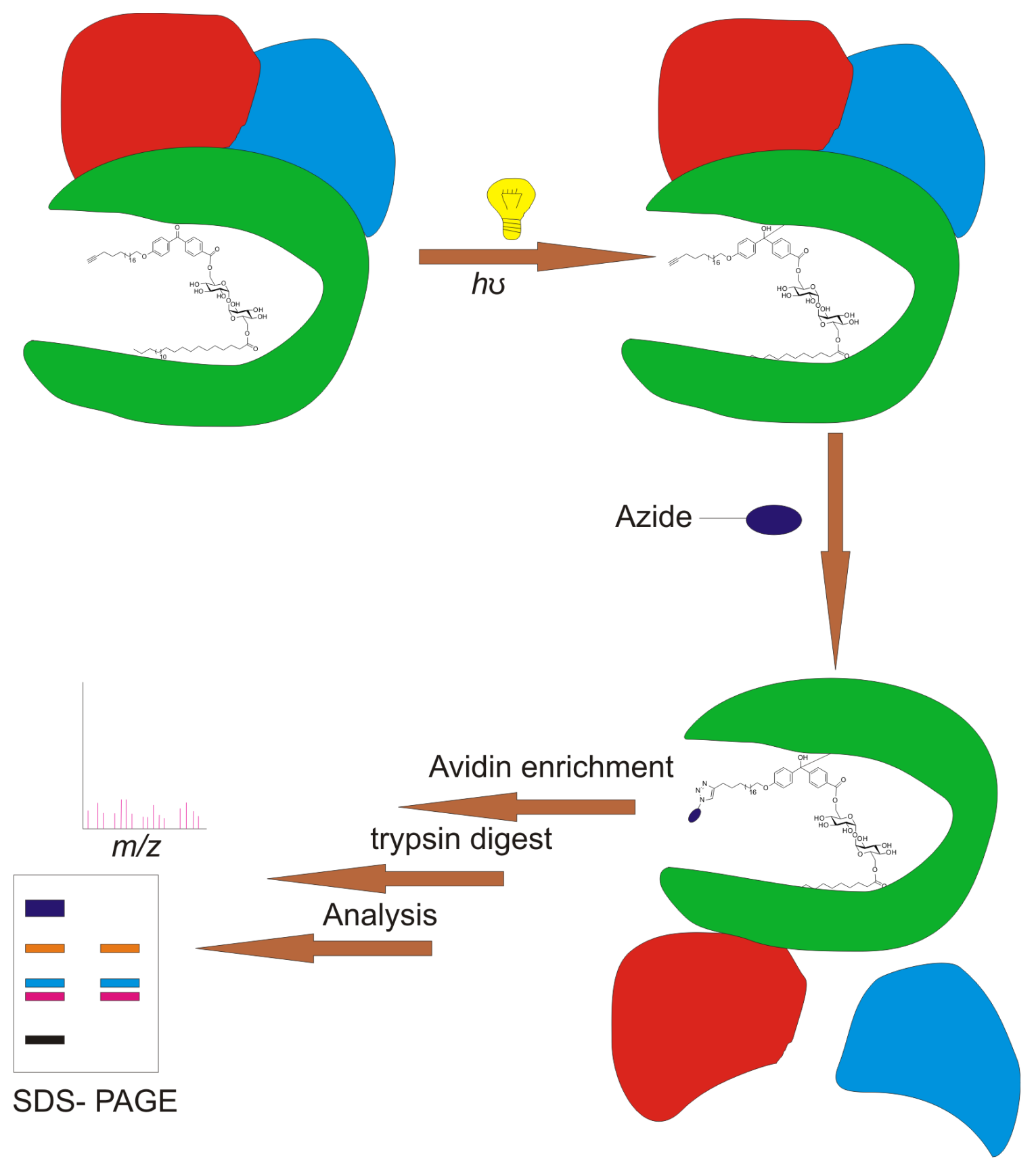

Figure 7. A $f \mathrm{BP}$ probe 1 in Affinity Based Profiling 


\subsection{Conclusion}

The synthesis of an affinity based probe has been achieved using a convergent synthetic strategy in an overall $1.4 \%$ yield. The key steps in the synthesis included a Friedel-Crafts acylation for the formation of the benzophenone building group, and a zipper reaction for formation of the terminal alkyne functionality. Final coupling was achieved by way of an EDCI, DMAP-mediated esterification of the C22 trehalose mono-ester with the benzophenone based carboxylic acid. The probe was able to activate BMM albeit at lower levels than the $\mathrm{C} 22$ trehalose diester.

\subsection{Experimental}

\subsubsection{Material and methods for Biological Assays}

C57BL/6 male mice were bred and housed in a conventional animal facility at the Malaghan Institute of Medical Research, Wellington, New Zealand. All animals used for the experiments were aged between 8-10 weeks. All experimental procedures were approved by the Victoria University Animal Ethics Committee in accordance with their guidelines for the care of animals. Synthesised TDEs were tested to be endotoxin-free $(\leq 0.125 \mathrm{EU} / \mathrm{mL})$ with an endotoxin kit (Pyrotell, Limulus Amebocyte Lysate).

Generation of bone marrow derived macrophages (BMMs): Bone marrow cells were collected from the tibia and femur of C57BL/6 mice and were cultured (250 000 cells/mL) in Iscove's Modified Dulbecco's Media (IMDM-Gibco) supplemented with 5\% FBS (Gibco), 1\% Penicillin streptomycin (Gibco) and $55 \mu \mathrm{M} 2$ mercaptoethanol (Invitrogen) containing $10 \mathrm{ng} / \mathrm{mL}$ GM-CSF (clone X63/GM-CSF murine cells). Cells were incubated at $37{ }^{\circ} \mathrm{C}\left(5 \% \mathrm{CO}_{2}\right)$ and the media changed on 
days 2, 5 and 7. On day 10, the media was removed and the BMM were primed with $10 \mathrm{ng} / \mathrm{mL}$ IFN- $\gamma$ (Peprotech) for $3 \mathrm{~h}$ prior to the addition of the compounds.

BMM Assay: C22 TDE and AfBP probe 1 stock solutions were prepared (2.5 $\mathrm{mg} / \mathrm{mL}$ in PBS containing 2\% DMSO), vortexed and warmed to $50{ }^{\circ} \mathrm{C}$ for $30 \mathrm{~min}$ (x 3) to ensure complete solubilisation of the compounds prior to administration to BMM cultures. BMM cultures were then treated with 20 or $40 \mu \mathrm{g} / \mathrm{mL}$ of C22 TDE, or TDM probe 1 with LPS (100 ng/mL) as a positive control and media only as a negative control for the times indicated. Supernatants were collected and tested immediately for NO levels.

NO analysis: NO levels in supernatants were determined using the Griess assay.

\subsubsection{Chemistry Experimental}

Unless stated otherwise, all reactions were performed under $\mathrm{N}_{2}$. Prior to use, THF was distilled from $\mathrm{Na}$ wire and benzophenone, pyridine was dried and stored over 4 $\AA$ molecular sieves (4 $\AA$ MS), toluene was dried and stored over Na wire and $\mathrm{CH}_{2} \mathrm{Cl}_{2}$ was distilled from $\mathrm{P}_{2} \mathrm{O}_{5}$. Terephthalic acid (BDH), thionyl chloride (Acros), $\mathrm{KOH}$ (Science), 33\% $\mathrm{HCl}$ (Panreac), $\mathrm{H}_{2} \mathrm{SO}_{4}$ (Panreac) $\mathrm{AlCl}_{3}$ (Sigma-Aldrich), sodium acetylide (Aldrich, $18 \%$ in xylene), bromohexadecane (BDH), 1,4-butanediol (BDH), HBr (Acros), PPTS (Aldrich), dihydropyran (Pfaltz and Bauer), n-BuLi (Aldrich, 2M solution in hexanes), PTSA (Sigma-Aldrich), diaminopropane (Aldrich), tosyl chloride (Aldrich), 18-crown-6 ether (Sigma-Aldrich), $\mathrm{CrO}_{3}(\mathrm{M} \& \mathrm{~B})$, $\mathrm{NaH}$ (Avocado Research Chemicals, 60\% dispersion in mineral oil), D-(+)-trehalose dihydrate (Sigma), TBAF (Aldrich), BSA (Fluka), Dowex $-\mathrm{H}^{+}$(Supelco), 1docosanol (Aldrich), EDCI (Aldrich), DMAP (Merck), anhydrous DMF (Acros), anhydrous $\mathrm{Et}_{2} \mathrm{O}$ (Biolab), EtOAc (Panreac), petroleum ether (Pure Science), $\mathrm{CHCl}_{3}$ (Panreac), anhydrous $\mathrm{MeOH}$ (Panreac), isopropanol (Pure Science), $\mathrm{NaHCO}_{3}$ (Pure Science), $\mathrm{K}_{2} \mathrm{CO}_{3}$ (Pure Science), $\mathrm{MgSO}_{4}$ (Pure Science) and $\mathrm{NaCl}$ (Panreac) were used as received. 
All solvents were removed via evaporation at reduced pressure. Reactions were monitored by TLC analysis on Macherey-Nagel silica gel coated plastic sheets $(0.20$ mm, Polygram SIL G/UV254) with detection by UV-absorption (short wave UV$254 \mathrm{~nm}$; long wave UV-366 nm); coating with a solution of $5 \% \mathrm{KMnO}_{4}$ and $1 \%$ $\mathrm{NaIO}_{4}$ in $\mathrm{H}_{2} \mathrm{O}$ followed by heating or by dipping in $10 \% \mathrm{H}_{2} \mathrm{SO}_{4}$ in EtOH followed by charring at $\sim 150{ }^{\circ} \mathrm{C}$. Column chromatography was performed using Pure Science silica gel $(40-63 \mu \mathrm{m})$. High resolution mass spectra were recorded on a Waters QTOF Premier ${ }^{\mathrm{TM}}$ Tandem Mass Spectrometer using positive electro-spray ionisation. Optical rotations were recorded on a Perkin-Elmer 241 polarimeter or Autopol II (Rudolph Research Analytical) at $589 \mathrm{~nm}$ (sodium D-line). Infrared spectra were recorded as thin films using a Brüker Tensor 27 FTIR spectrometer equipped with an Attenuated Total Reflectance (ATR) sampling accessory and are reported in wave numbers $\left(\mathrm{cm}^{-1}\right)$. Nuclear magnetic resonance spectra were recorded at $20{ }^{\circ} \mathrm{C}$ in $\mathrm{CDCl}_{3}$ or $\mathrm{C}_{5} \mathrm{D}_{5} \mathrm{~N}$ using a Varian INOVA operating at $500 \mathrm{MHz}$. Chemical shifts are given in ppm $(\delta)$ relative to residual solvent peak. NMR peak assignments were made using COSY, HSQC and HMBC 2D experiments.

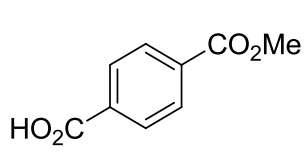

Monomethyl terephthalate (11). A solution of terephthalic acid (8) $(10 \mathrm{~g}, 60.2 \mathrm{mmol})$ in $\mathrm{MeOH}(250 \mathrm{~mL})$ was refluxed for $30 \mathrm{~min}$ after which time $\mathrm{SOCl}_{2}(87.2 \mathrm{~mL}, 1.20 \mathrm{~mol})$ was added and the reaction mixture was refluxed for a further $10 \mathrm{~h}$. The reaction mixture was then cooled and the solvent removed in vacuo. The product was extracted with $\mathrm{Et}_{2} \mathrm{O}$ (3 $\times 200 \mathrm{~mL})$ and washed with saturated $\mathrm{NaHCO}_{3}(3 \times 60 \mathrm{~mL})$ solution. The combined organic layers were dried with $\mathrm{MgSO}_{4}$ and concentrated in vacuo to yield dimethyl terephthalate (10) as white solid (quant.) and it was used in subsequent reaction without further purification.

Dimethyl terephthalate (10) $(9.77 \mathrm{~g}, 50.2 \mathrm{mmol})$ was dissolved in $\mathrm{MeOH}(165 \mathrm{~mL})$ and the reaction mixture was refluxed for $30 \mathrm{~min}$ after which time it was cooled to r.t. followed by $\mathrm{KOH}$ addition $(3.11 \mathrm{~g}, 55.4 \mathrm{mmol})$. The reaction was then heated at reflux overnight after which time the mixture was cooled and the solvent removed in vacuo. The resulting crude product was dissolved in water and washed with $\mathrm{CH}_{2} \mathrm{Cl}_{2}$ 
( $3 \times 100 \mathrm{~mL}$ ). The aqueous layer was then neutralised with concentrated $1 \mathrm{M} \mathrm{HCl}$ and the precipitate was extracted with $\mathrm{Et}_{2} \mathrm{O}$, dried with $\mathrm{MgSO}_{4}$, and concentrated to yield the title compound as a white solid (7.86 g, $43.7 \mathrm{mmol}, 87 \%$ over two steps). The spectral data obtained matched that reported in literature. ${ }^{4}$

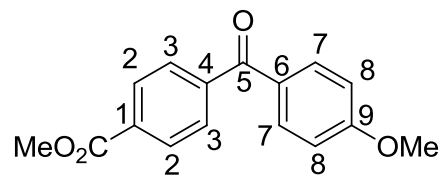

Methyl 4-(4-methoxybenzoyl)-benzoate (13). $\mathrm{SOCl}_{2}$ (3.92 $\mathrm{mL}, 53.9 \mathrm{mmol})$ was added to acid 11 (2.44 g, 13.9 mmol) and the reaction mixture was refluxed until a clear solution had formed (c.a. 4 h). The solvent was reduced in vacuo (under nitrogen), and the resulting acid chloride 12 (2.76 g, $13.9 \mathrm{mmol})$ was dissolved in $\mathrm{CHCl}_{3}(71 \mathrm{~mL})$ and anisole $(1.51 \mathrm{~mL}, 13.9 \mathrm{mmol})$ and $\mathrm{AlCl}_{3}(1.85 \mathrm{~g}, 13.9 \mathrm{mmol})$ were added. The reaction mixture was then refluxed for $10 \mathrm{~h}$, after which time another portion of $\mathrm{AlCl}_{3}(1.85 \mathrm{~g}, 13.9 \mathrm{mmol})$ was added and the mixture refluxed for a further 10 h. Following this, the solution was cooled, quenched with $\mathrm{H}_{2} \mathrm{O}$ (100 $\mathrm{mL})$, and extracted with EtOAc $(3 \times 80 \mathrm{~mL})$. The combined organic layers were washed with brine $(50 \mathrm{~mL})$, dried over $\mathrm{MgSO}_{4}$, and the solvent removed in vacuo to yield the crude product. The title compound was obtained after silica gel flash chromatography (eluting in 20:1, Pet. Ether/EtOAc, v/v) as a white solid (2.60 g, $9.62 \mathrm{mmol}, 70 \%) ; \mathrm{R}_{f}=0.76$ (EtOAc); IR (film): 2944, 2832, 1448, 1022, $737 \mathrm{~cm}^{-1}$; ${ }^{1} \mathrm{H} \mathrm{NMR}\left(500 \mathrm{MHz}, \mathrm{CDCl}_{3}\right) \delta 8.15\left(\mathrm{~d}, J_{2,3}=8.5 \mathrm{~Hz}, 2 \mathrm{H}, \mathrm{H}-2\right), 7.83\left(\mathrm{~d}, J_{7,8}=8.7 \mathrm{~Hz}\right.$, 2H, H-7), 7.79 (d, $\left.J_{2,3}=8.5 \mathrm{~Hz}, 2 \mathrm{H}, \mathrm{H}-3\right), 6.98$ (d, $\left.J_{7,8}=8.7 \mathrm{~Hz}, 2 \mathrm{H}, \mathrm{H}-8\right), 3.98$ (s, 3H, $\mathrm{CO}_{2} \mathrm{Me}$ ), 3.91 (s, 3H, OMe); ${ }^{13} \mathrm{C}$ NMR (125 MHz, $\mathrm{CDCl}_{3}$ ) $\delta 194.8(\mathrm{C}-5), 166.4$ $\left(\mathrm{CO}_{2} \mathrm{Me}\right), 163.6$ (C-9), 142.2 (C-4), 132.8 (C-1), 132.6 (C-7), 129.6 (C-6), 129.4 (C2 and C-3), $113.8(\mathrm{C}-8), 55.6\left(-\mathrm{OCH}_{3}\right), 52.4\left(\mathrm{CO}_{2} \mathrm{Me}\right)$; HRMS(ESI) $\mathrm{m} / z$ calcd. for $\left[\mathrm{C}_{16} \mathrm{H}_{14} \mathrm{O}_{4}+\mathrm{Na}\right]^{+}:$293.0790, obsd.: 293.0790.

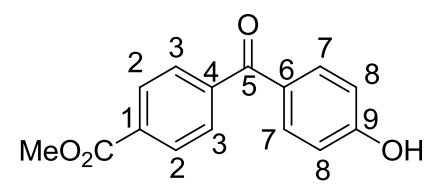

Methyl 4-(4-hydroxybenzoyl)-benzoate (6). $\mathrm{AlCl}_{3}$ $(1.46 \mathrm{~g}, 11.0 \mathrm{mmol})$ was added to a solution of benzophenone $13(0.99 \mathrm{~g}, 3.66 \mathrm{mmol})$ in toluene $(15 \mathrm{~mL})$ 
and the reaction mixture was stirred at r.t. for $30 \mathrm{~min}$ followed by $30 \mathrm{~min}$ at reflux. The reaction was then cooled to r.t., followed by further addition of $\mathrm{AlCl}_{3}((1.46 \mathrm{~g}$, $11.0 \mathrm{mmol}$ ) and $30 \mathrm{~min}$ at reflux. The reaction mixture was then poured into 1:1 ice $/ \mathrm{H}_{2} \mathrm{O}$ mixture, stirred for a further $30 \mathrm{~min}$ and extracted with EtOAc $(3 \times 50 \mathrm{~mL})$. The combined organic layers were washed with brine, dried $\left(\mathrm{MgSO}_{4}\right)$, and concentrated in vacuo. The title compound was obtained after silica gel flash chromatography (eluting in 10:1, Pet. Ether/EtOAc, v/v) as a white solid (0.80 g, 3.13 mmol, 85\%). $\mathrm{R}_{f}=0.24$ (2/1, PE/EA, v/v); IR (film): 3317, 2944, 2832, 1448, 1022, $741 \mathrm{~cm}^{-1} ;{ }^{1} \mathrm{H}$ NMR (500 MHz, $\left.\mathrm{CDCl}_{3}\right) \delta 8.15\left(\mathrm{~d}, J_{2,3}=8.3 \mathrm{~Hz}, 2 \mathrm{H}, \mathrm{H}-2\right), 7.79$ $\left(\mathrm{d}, J_{2,3}=8.3 \mathrm{~Hz}, 2 \mathrm{H}, \mathrm{H}-3\right), 7.79\left(\mathrm{~d}, J_{7,8}=8.5 \mathrm{~Hz}, 2 \mathrm{H}, \mathrm{H}-7\right), 6.93\left(\mathrm{~d}, J_{7,8}=8.5 \mathrm{~Hz}, 2 \mathrm{H}\right.$, $\mathrm{H}-8), 3.98$ (s, 3H, $\left.\mathrm{CO}_{2} \mathrm{Me}\right) ;{ }^{13} \mathrm{C}$ NMR (125 MHz, $\left.\mathrm{CDCl}_{3}\right) \delta 194.8(\mathrm{C}-5), 166.4$ ( $\mathrm{CO}_{2} \mathrm{Me}$ ), 160.0 (C-9), 142.0 (C-4), 133.0 (C-7), 132.8 (C-1), 129.8 (C-6), 129.47 (C-2), 129.46 (C-3), 115.3 (C-8), $52.4\left(\mathrm{CO}_{2} \mathrm{Me}\right)$; HRMS(ESI) $\mathrm{m} / \mathrm{z}$ calcd. for $\left[\mathrm{C}_{15} \mathrm{H}_{12} \mathrm{O}_{4}+\mathrm{Na}\right]^{+}:$279.0626, obsd.: 279.0633 .

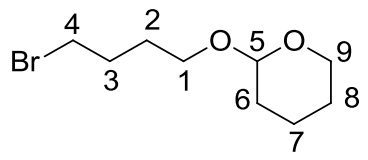

2-(4-Bromobutyloxyl)-tetrahydropyran (16). To a solution of 1,4-butanediol $(4.46 \mathrm{~mL}, 50.3 \mathrm{mmol})$ in toluene $(70 \mathrm{~mL})$ was added a $48 \% \mathrm{HBr}$ solution $(6.25 \mathrm{~mL}, 55.2 \mathrm{mmol})$ and the reaction mixture was refluxed using a Dean-Stark apparatus, until all the starting material had been consumed (as determined from TLC analysis). The solution was then cooled, extracted with $\mathrm{CH}_{2} \mathrm{Cl}_{2}(3 \times 60 \mathrm{~mL})$, washed with water, dried with $\mathrm{MgSO}_{4}$, and the solvent removed in vacuo to yield 4-bromo-1-butanol (3.06 g, 20.1 mmol, 40\%), which was used in the consecutive reaction without further purification. To a solution of 4-bromo-1-butanol (2.0 g, $13.0 \mathrm{mmol})$ in $\mathrm{CH}_{2} \mathrm{Cl}_{2}(30 \mathrm{~mL})$ was added pyridinium para-toluenesulfonate (PPTS) (0.65 g, $2.61 \mathrm{mmol})$ and 3,4-dihydropyran $(2.77 \mathrm{~mL}, 30.4 \mathrm{mmol})$ and the reaction was stirred at r.t. overnight. The reaction mixture was then quenched with $\mathrm{H}_{2} \mathrm{O}(20 \mathrm{~mL})$ and extracted with EtOAc $(3$ x 40 $\mathrm{mL})$. The combined organic layers were washed with brine $(30 \mathrm{~mL})$, dried with $\mathrm{MgSO}_{4}$, and the solvent reduced in vacuo. The title compound was obtained after silica gel flash chromatography (eluting in 50:1, Pet. Ether/EtOAc, v/v) as a white solid (3.03 g, $12.7 \mathrm{mmol}, 97 \%) . \mathrm{R}_{f}=0.83$ (1/1, PE/EA, v/v); IR (film): 2940, 2860, 
1133, 1075, 904, $668 \mathrm{~cm}^{-1} ;{ }^{1} \mathrm{H}$ NMR $\left(500 \mathrm{MHz}, \mathrm{CDCl}_{3}\right) \delta 4.57\left(\mathrm{t}, J_{5,6 \mathrm{a}}=J_{5,6 \mathrm{~b}}=2.5\right.$ $\mathrm{Hz}, 1 \mathrm{H}, \mathrm{H}-5), 3.84\left(\mathrm{ddd}, J_{9 \mathrm{a}, 9 \mathrm{~b}}=11.0 \mathrm{~Hz}, J_{8 \mathrm{a}, 9 \mathrm{a}}=J_{8 \mathrm{~b}, 9 \mathrm{a}}=2.4 \mathrm{~Hz}, 1 \mathrm{H}, \mathrm{H}-9 \mathrm{a}\right), 3.76(\mathrm{dt}$, $\left.J_{1 \mathrm{a}, 1 \mathrm{~b}}=9.8 \mathrm{~Hz}, J_{1 \mathrm{a}, 2 \mathrm{a}}=J_{1 \mathrm{a}, 2 \mathrm{~b}}=6.6 \mathrm{~Hz}, \mathrm{H}-1 \mathrm{a}\right), 3.52-3.48(\mathrm{~m}, 1 \mathrm{H}, \mathrm{H}-9 \mathrm{~b}), 3.45\left(\mathrm{t}, J_{3,4}=\right.$ $7.1 \mathrm{~Hz}, 2 \mathrm{H}, \mathrm{H}-4), 3.41\left(\mathrm{dt}, J_{1 \mathrm{a}, 1 \mathrm{~b}}=9.8 \mathrm{~Hz}, J_{1 \mathrm{~b}, 2 \mathrm{a}}=J_{1 \mathrm{~b}, 2 \mathrm{~b}}=6.1 \mathrm{~Hz}, 1 \mathrm{H}, \mathrm{H}-1 \mathrm{~b}\right), 1.97$ (pentet, $\left.J_{\alpha, \beta}=J_{\beta, \gamma}=7.1 \mathrm{~Hz}, 2 \mathrm{H}, \mathrm{H}-3\right), 1.83-1.78(\mathrm{~m}, 1 \mathrm{H}, \mathrm{H}-7 \mathrm{a}), 1.76-1.71(\mathrm{~m}, 1 \mathrm{H}, \mathrm{H}-$ 2), 1.71-1.68 (m, 1H, H-6a), 1.60-1.50 (m, 4H, H-6b, H-7b, H-8); ${ }^{13} \mathrm{C}$ NMR (125 $\mathrm{MHz}, \mathrm{CDCl}_{3}$ ) $\delta 98.8$ (C-5), 66.5 (C-1), 62.3 (C-9), 33.8 (C-4), 30.7 (C-6), 29.8 (C3), 28.4 (C-2), 25.4 (C-8), 19.6 (C-7); HRMS(ESI) $m / z$ calcd. for $\left[\mathrm{C}_{9} \mathrm{H}_{17} \mathrm{O}_{2} \mathrm{Br}+\mathrm{Na}\right]^{+}$: 259.0304, obsd.: 259.0318 .

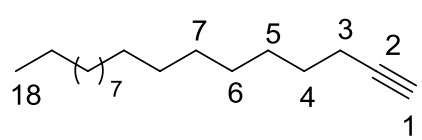

Octadecyne (15). A solution of bromo-hexadecane (14) $(4.54 \mathrm{~g}, 14.9 \mathrm{mmol})$ in DMF $(20 \mathrm{~mL})$ was cooled to $0{ }^{\circ} \mathrm{C}$ and sodium acetylide (18\% in xylene, $5.95 \mathrm{~mL}, 22.3$

mmol) was added to it. The reaction mixture was stirred at r.t. overnight after which time it was diluted with $\mathrm{Et}_{2} \mathrm{O}(100 \mathrm{~mL})$, washed with water $(50 \mathrm{~mL}), 1 \mathrm{M} \mathrm{HCl}(50$ $\mathrm{mL})$, brine $(25 \mathrm{~mL})$ dried with $\mathrm{MgSO}_{4}$, and the solvent reduced in vacuo. Octadecyne (15) was obtained after silica gel flash chromatography (eluting in Pet. Ether), as a white solid (3.62 g, $14.5 \mathrm{mmol}, 98 \%) . \mathrm{R}_{f}=0.50$ (Pet. Ether); IR (film): 3314, 2922, 2853, 2341, 1236, $668 \mathrm{~cm}^{-1} ;{ }^{1} \mathrm{H}$ NMR (500 MHz, $\left.\mathrm{CDCl}_{3}\right) \delta 2.19$ (dt, $\left.J_{3 \mathrm{a}, 3 \mathrm{~b}}=9.8 \mathrm{~Hz}, J_{3 \mathrm{a}, 4}=7.1 \mathrm{~Hz}, 1 \mathrm{H}, \mathrm{H}-3 \mathrm{a}\right), 2.18\left(\mathrm{dt}, J_{3 \mathrm{a}, 3 \mathrm{~b}}=9.8 \mathrm{~Hz}, J_{3 \mathrm{~b}, 4}=7.1 \mathrm{~Hz}, 1 \mathrm{H}\right.$, $\mathrm{H}-3 \mathrm{~b}), 1.94$ (t, ${ }^{4} J_{1,3}=2.6 \mathrm{~Hz}, 1 \mathrm{H}, \mathrm{H}-1$ ), 1.55 (pentet, $J_{\alpha, \beta}=J_{\beta \gamma}=7.1 \mathrm{~Hz}, 2 \mathrm{H}, \mathrm{H}-4$ ), $1.44-1.36$ (m, 2H, H-5) 1.32-1.26 (m, 24H, H-6-H-17), 0.89 (t, $J_{17,18}=6.8 \mathrm{~Hz}, \mathrm{H}-$ 18); ${ }^{13} \mathrm{C} \mathrm{NMR}\left(125 \mathrm{MHz}, \mathrm{CDCl}_{3}\right) \delta 84.8$ (C-2), 68.0 (C-1), 31.9, 29.70, 29.68, 29.66, 29.62, 29.52, 29.37, 29.12, 28.77, 28.50, 22.70 (C-4-C-17), 18.4 (C-3), 14.1 (C-18); HRMS(ESI) $m / z$ calcd. for $\left[\mathrm{C}_{18} \mathrm{H}_{34}+\mathrm{Na}\right]^{+}: 273.2558$, obsd.: 273.2550 .

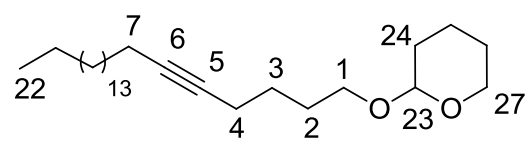

2-(5-Docosynyloxy)-tetrahydropyran (17). nBuLi $(8.28 \mathrm{~mL}, 2.0 \mathrm{M}$ solution in hexanes, 16.6 mmol) was added to a solution of octadecyne (15) $(2.07 \mathrm{~g}, 8.28 \mathrm{mmol})$ in THF $(30 \mathrm{~mL})$ at $0{ }^{\circ} \mathrm{C}$ and the reaction mixture was refluxed 
for $10 \mathrm{~h}$, after which time it was cooled to r.t. and THP ether 16 (4.97 g, $20.7 \mathrm{mmol})$ in THF (30 mL) was added. The reaction was refluxed for a further $24 \mathrm{~h}$ then quenched with $\mathrm{H}_{2} \mathrm{O}(50 \mathrm{~mL})$, extracted with Pet. Ether $(3 \times 60 \mathrm{~mL})$, washed with brine $(40 \mathrm{~mL})$, dried with $\mathrm{MgSO}_{4}$ and reduced in vacuo. The title compound was obtained after silica gel flash chromatography (eluting in 75:1, Pet. Ether/EtOAc, $\mathrm{v} / \mathrm{v})$ as colourless oil (2.8 g, $6.84 \mathrm{mmol}, 83 \%) . \mathrm{R}_{f}=0.69$ (2/1, PE/EA, v/v); IR (film): 2922, 2852, 1363, 1186, 738, $704 \mathrm{~cm}^{-1} ;{ }^{1} \mathrm{H}$ NMR (500 MHz, $\left.\mathrm{CDCl}_{3}\right) \delta 4.58\left(\mathrm{t}, J_{23,24 \mathrm{a}}\right.$ $\left.=J_{23,24 \mathrm{~b}}=2.9 \mathrm{~Hz}, 1 \mathrm{H}, \mathrm{H}-23\right), 3.86\left(\mathrm{ddd}, J_{27 \mathrm{a}, 27 \mathrm{~b}}=11.1 \mathrm{~Hz}, J_{26 \mathrm{a}, 27 \mathrm{a}}=J_{26 \mathrm{~b}, 27 \mathrm{a}}=3.0 \mathrm{~Hz}\right.$, $1 \mathrm{H}, \mathrm{H}-27 \mathrm{a}), 3.75\left(\mathrm{dt}, J_{1 \mathrm{a}, 1 \mathrm{~b}}=9.7 \mathrm{~Hz}, J_{1 \mathrm{a}, 2 \mathrm{a}}=J_{1 \mathrm{a}, 2 \mathrm{~b}}=3.9 \mathrm{~Hz}, 1 \mathrm{H}, \mathrm{H}-1 \mathrm{a}\right), 3.51-3.48$ $(\mathrm{m}, 1 \mathrm{H}, \mathrm{H}-27 \mathrm{~b}), 3.40\left(\mathrm{dt}, J_{1 \mathrm{a}, 1 \mathrm{~b}}=9.7 \mathrm{~Hz}, J_{1 \mathrm{~b}, 2 \mathrm{a}}=J_{1 \mathrm{~b}, 2 \mathrm{~b}}=3.1 \mathrm{~Hz}, 1 \mathrm{H}, \mathrm{H}-1 \mathrm{~b}\right), 2.19$ (tt, $\left.J_{3,4}=7.1 \mathrm{~Hz},{ }^{5} J_{4,7}=2.2 \mathrm{~Hz}, 2 \mathrm{H}, \mathrm{H}-4\right), 2.13\left(\mathrm{tt}, J_{7,8}=7.0 \mathrm{~Hz},{ }^{5} J_{4,7}=2.2 \mathrm{~Hz}, 2 \mathrm{H}, \mathrm{H}-7\right)$, 1.86-1.77 (m, 1H, H-25a), 1.75-1.62 (m, 3H, H-24a and H-26), 1.61-1.50 (m, 6H, $\mathrm{H}-2, \mathrm{H}-3, \mathrm{H}-24 \mathrm{~b}$ and H-25b), 1.47 (pentet, $J_{7,8}=J_{8,9}=7.3 \mathrm{~Hz}, 2 \mathrm{H}, \mathrm{H}-8$ ), $1.37-1.31$ (m, 2H, H-9), 1.30-1.25 (m, 24H, H-10-H-21), 0.88 (t, $\left.J_{1,2}=6.8 \mathrm{~Hz}, 2 \mathrm{H}, \mathrm{H}-22\right) ;{ }^{13} \mathrm{C}$ NMR (125 MHz, $\mathrm{CDCl}_{3}$ ) $\delta 98.8$ (C-23), 80.5 (C-6), 79.8 (C-5), 67.1 (C-1), 62.3 (C27), 31.9, 30.7, 29.70, 29.68, 29.66, 29.65, 29.57, 29.4, 29.19, 29.16, 28.9, 28.9, 25.9, 25.5, 22.7 (C-2, C-3, C-8-C-21, C-24, C-26), 19.6 (C-25), 18.8 (C-7), 18.6 (C4), 14.1 (C-22); HRMS(ESI) $\mathrm{m} / z$ calcd. for $\left[\mathrm{C}_{27} \mathrm{H}_{50} \mathrm{O}_{2}+\mathrm{Na}\right]^{+}$: 429.3709, obsd.: 429.3713 .

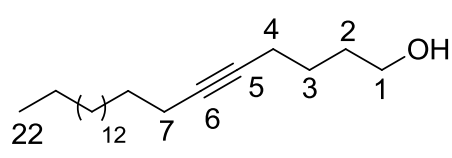

5-Docosyn-1-ol (18). To a solution of alkyne 17 (2.01 $\mathrm{g}, 4.91 \mathrm{mmol})$ in $\mathrm{MeOH}(20 \mathrm{~mL})$ was added PTSA $(0.28 \mathrm{~g}, 1.47 \mathrm{mmol})$ and the reaction mixture was stirred at r.t. overnight before being quenched with $\mathrm{H}_{2} \mathrm{O}$ and extracted with EtOAc (3 x $50 \mathrm{~mL})$. The combined organic layers were washed with $\mathrm{H}_{2} \mathrm{O}(30 \mathrm{~mL})$, brine $(30$ $\mathrm{mL}$ ), dried with $\mathrm{MgSO}_{4}$ and reduced in vacuo. The title compound was obtained after silica gel flash chromatography (eluting in 20:1, Pet. Ether/EtOAc, v/v) as a white solid (1.40 g, $4.34 \mathrm{mmol}, 89 \%) \mathrm{R}_{f}=0.33$ (5/1, PE/EA, v/v); IR (film): 2984, 1738, 1447, 1234, $1044 \mathrm{~cm}^{-1} ;{ }^{1} \mathrm{H}$ NMR $\left(500 \mathrm{MHz} \mathrm{CDCl}_{3}\right) \delta 3.68\left(\mathrm{t}, J_{1,2}=6.4 \mathrm{~Hz}, 2 \mathrm{H}, \mathrm{H}-\right.$ 1), $2.20\left(\mathrm{tt}, J_{3,4}=7.1 \mathrm{~Hz},{ }^{5} J_{4,7}=2.2 \mathrm{~Hz}, 2 \mathrm{H}, \mathrm{H}-4\right), 2.14\left(\mathrm{tt}, J_{7,8}=6.9 \mathrm{~Hz},{ }^{5} J_{4,7}=2.2\right.$ $\mathrm{Hz}, 2 \mathrm{H}, \mathrm{H}-7$ ), 1.69 (pentet, $J_{\alpha, \beta}=J_{\beta, \gamma}=6.8 \mathrm{~Hz}, 2 \mathrm{H}, \mathrm{H}-2$ ), 1.57 (pentet, $J_{\alpha, \beta}=J_{\beta, \gamma}=6.9$ 
$\mathrm{Hz}, 2 \mathrm{H}, \mathrm{H}-3$ ), 1.47 (pentet, $J_{\alpha, \beta}=J_{\beta, \gamma}=7.2 \mathrm{~Hz}, 2 \mathrm{H}, \mathrm{H}-8$ ), 1.40-1.32 (m, 2H, H-9), 1.29-1.22 (m, 24H, H-10-H-21), 0.89 (t, $\left.J_{21,22}=7.0 \mathrm{~Hz}, 2 \mathrm{H}, \mathrm{H}-22\right) ;{ }^{13} \mathrm{C}$ NMR (125 $\mathrm{MHz}, \mathrm{CDCl}_{3}$ ) $\delta 80.8$ (C-6), 79.7 (C-5), 62.6 (C-1), 31.93 (C-2), 31.88, 29.71, 29.68, 29.66, 29.65, 29.57, 29.37, 29.18, 29.15, 28.90, 25.35, 22.70 (C-3, C-8-C-21), 18.7 (C-7), 18.5 (C-4), 14.1 (C-22); HRMS(ESI) $\mathrm{m} / z$ calcd. for $\left[\mathrm{C}_{22} \mathrm{H}_{42} \mathrm{O}+\mathrm{Na}\right]^{+}:$345.3133, obsd.: 345.3134 .

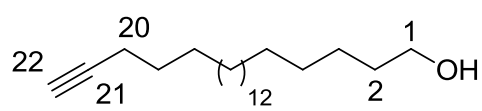

21-Docosyn-1-ol (19). Diaminopropane (10 mL) was added to $\mathrm{NaH}(0.88 \mathrm{~g}, 22.0 \mathrm{mmol}, 60 \%$ dispersion in mineral oil) and the resulting mixture was stirred at $70{ }^{\circ} \mathrm{C}$ until gas evolution ceased (c.a. $1 \mathrm{~h})$, after which time the mixture was cooled, and alcohol $18(0.36 \mathrm{~g}, 1.10$ $\mathrm{mmol})$ dissolved in diaminopropane $(5 \mathrm{~mL})$, was added dropwise. The reaction was stirred at $70{ }^{\circ} \mathrm{C}$ overnight after which time it was quenched with $\mathrm{H}_{2} \mathrm{O}$ and extracted with EtOAc ( $3 \times 35 \mathrm{~mL})$. The combined organic layer was then washed with water $(25 \mathrm{~mL})$, brine $(25 \mathrm{~mL})$, dried $\left(\mathrm{MgSO}_{4}\right)$ and the solvent reduced in vacuo. The title compound was obtained after silica gel flash chromatography (eluting in 20:1, Pet. Ether/EtOAc, v/v) as a white solid (3.1 g, $0.74 \mathrm{mmol}, 66 \%) \mathrm{R}_{f}=0.32(5 / 1, \mathrm{PE} / \mathrm{EA}$, v/v); IR (film): 3287, 2917, 2849, $1122 \mathrm{~cm}^{-1} ;{ }^{1} \mathrm{H}$ NMR $\left(500 \mathrm{MHz}, \mathrm{CDCl}_{3}\right) \delta 3.65$ (t, $\left.J_{1,2}=6.6 \mathrm{~Hz}, 2 \mathrm{H}, \mathrm{H}-1\right), 2.19\left(\mathrm{dt}, J_{20 \mathrm{a}, 20 \mathrm{~b}}=11.5 \mathrm{~Hz}, J_{19,20 \mathrm{a}}=7.1 \mathrm{~Hz}, 1 \mathrm{H}, \mathrm{H}-20 \mathrm{a}\right), 2.18$ $\left(\mathrm{dt}, J_{20 \mathrm{a}, 20 \mathrm{~b}}=11.5 \mathrm{~Hz}, J_{19,20 \mathrm{~b}}=7.1 \mathrm{~Hz}, 1 \mathrm{H}, \mathrm{H}-20 \mathrm{~b}\right), 1.94\left(\mathrm{t},{ }^{4} J_{20,22}=2.6 \mathrm{~Hz}, 1 \mathrm{H}, \mathrm{H}-\right.$ 22), 1.54 (pentet, $J_{\alpha, \beta}=J_{\beta, \gamma}=6.8 \mathrm{~Hz}, 2 \mathrm{H}, \mathrm{H}-2$ ), 1.51 (pentet, $J_{\alpha, \beta}=J_{\beta, \gamma}=7.3 \mathrm{~Hz}, 2 \mathrm{H}$, H-19), 1.41-1.14 (m, 32H, H-3-H-18); $\left.{ }^{13} \mathrm{C} \mathrm{NMR} \mathrm{(125} \mathrm{MHz,} \mathrm{CDCl}_{3}\right) \delta 84.8$ (C-21), 68.0 (C-22), 63.1 (C-1), 32.8 (C-2) 29.70, 29.69, 29.66, 29.62, 29.51, 29.44, 29.12, 28.77, 28.50 (C-3-C-19), $22.74(\mathrm{C}-20)$; $\mathrm{HRMS}(\mathrm{ESI}) \mathrm{m} / \mathrm{z}$ calcd. for $\left[\mathrm{C}_{22} \mathrm{H}_{42} \mathrm{O}+\mathrm{H}\right]^{+}$: 323.3314, obsd.: 323.3309 .

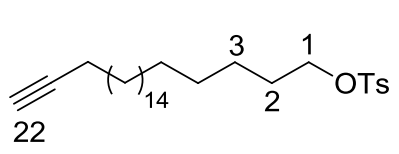

21-Docosynyl $p$-toluenesulfonate (21). To a solution of alcohol 19 (0.20 g, $0.63 \mathrm{mmol})$ in $\mathrm{CH}_{2} \mathrm{Cl}_{2}(3 \mathrm{~mL})$ at $0{ }^{\circ} \mathrm{C}$ was added pyridine $(0.10 \mathrm{~mL}, 1.25 \mathrm{mmol})$ then $\mathrm{TsCl}(0.18$ $\mathrm{g}, 0.94 \mathrm{mmol})$ and the reaction stirred at r.t. overnight. $\mathrm{Et}_{2} \mathrm{O}(30 \mathrm{~mL})$ and water $(20$ 
$\mathrm{mL}$ ) were added to the reaction mixture and the organic layer was washed with $2 \mathrm{M}$ $\mathrm{HCl}(30 \mathrm{~mL})$, followed by $5 \% \mathrm{NaHCO}_{3}(20 \mathrm{~mL})$, water $(30 \mathrm{~mL})$, brine $(30 \mathrm{~mL})$ and then dried with $\mathrm{MgSO}_{4}$. The solvent was removed in vacuo and the title compound obtained after silica gel flash chromatography (eluting in 50:1, Pet. Ether/EtOAc, $\mathrm{v} / \mathrm{v})$ as a white solid (0.28 g, $0.61 \mathrm{mmol}, 97 \%) . \mathrm{R}_{f}=0.46(5 / 1, \mathrm{PE} / \mathrm{EA}, \mathrm{v} / \mathrm{v}) ; \mathrm{IR}$ (film): 2917, 2850, 1472, 1173, $668 \mathrm{~cm}^{-1} ;{ }^{1} \mathrm{H}$ NMR (500 MHz, $\left.\mathrm{CDCl}_{3}\right) \delta 7.80$ (d, $J$ $\left.=8.3 \mathrm{~Hz}, 2 \mathrm{H}, \mathrm{H}_{\text {arom }}\right), 7.35\left(\mathrm{~d}, J=8.1 \mathrm{~Hz}, 2 \mathrm{H}, \mathrm{H}_{\text {arom }}\right), 4.03\left(\mathrm{t}, J_{1,2}=6.6 \mathrm{~Hz}, 2 \mathrm{H}, \mathrm{H}-1\right)$, $2.46\left(\mathrm{~s}, 3 \mathrm{H}, \mathrm{CH}_{3}\right), 2.19\left(\mathrm{dt}, J_{20 \mathrm{a}, 20 \mathrm{~b}}=13.1 \mathrm{~Hz}, J_{19,20 \mathrm{a}}=7.1 \mathrm{~Hz}, 1 \mathrm{H}, \mathrm{H}-20 \mathrm{a}\right), 2.18(\mathrm{dt}$, $\left.J_{20 \mathrm{a}, 20 \mathrm{~b}}=13.1 \mathrm{~Hz}, J_{19,20 \mathrm{~b}}=7.1 \mathrm{~Hz}, 1 \mathrm{H}, \mathrm{H}-20 \mathrm{~b}\right), 1.95\left(\mathrm{t},{ }^{4} J_{20,22}=2.6 \mathrm{~Hz}, 1 \mathrm{H}, \mathrm{H}-22\right)$, 1.64 (pentet, $J_{\alpha, \beta}=J_{\beta, \gamma}=6.8 \mathrm{~Hz}, 2 \mathrm{H}, \mathrm{H}-2$ ), 1.52 (pentet, $J_{\alpha, \beta}=J_{\beta, \gamma}=6.6 \mathrm{~Hz}, 2 \mathrm{H}, \mathrm{H}$ 19), 1.40-1.38 (m, 2H, H-3), 1.34-1.22 (m, 30H, H-4-H-18); ${ }^{13} \mathrm{C}$ NMR (125 MHz, $\left.\mathrm{CDCl}_{3}\right) \delta 144.6\left(\mathrm{C}_{\mathrm{ar}}-\mathrm{CH}_{3}\right), 129.8\left(\mathrm{C}_{\mathrm{ar}}\right), 127.9\left(\mathrm{C}_{\mathrm{ar}}\right), 84.8(\mathrm{C}-21), 70.7(\mathrm{C}-1), 68.0(\mathrm{C}-$ 22), 29.70, 29.68, 29.65, 29.61, 29.50, 29.39, 29.11, 28.92, 28.81, 28.77, 28.50, 25.32 (C-2-C-19), $21.63\left(\mathrm{CH}_{3}\right), 18.4$ (C-20); HRMS(ESI) $\mathrm{m} / z$ calcd. for $\left[\mathrm{C}_{29} \mathrm{H}_{48} \mathrm{O}_{3} \mathrm{~S}+\mathrm{Na}\right]^{+}:$499.3222, obsd.: 499.3222 .

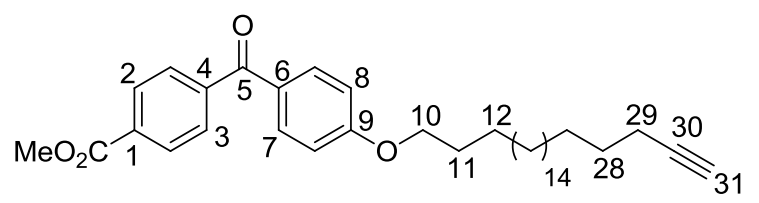

Methyl 4-[4-(21docosynyloxy)benzoyl]-benzoate (30.5 mg, $0.12 \mathrm{mmol}$ ) in $2 \mathrm{~mL}$ DMF was added $\mathrm{Cs}_{2} \mathrm{CO}_{3}$ (42.9 mg, $0.13 \mathrm{mmol}$ ), 18 crown-6-ether $(37.8 \mathrm{mg}, 0.14 \mathrm{mmol})$ and tosylate $21(83.0 \mathrm{mg}, 0.18 \mathrm{mmol})$ in toluene $(2 \mathrm{~mL})$ and the reaction was stirred at r.t. for $30 \mathrm{~min}$ and then heated to $50{ }^{\circ} \mathrm{C}$ over 2 nights. The reaction mixture was then cooled down, diluted with $\mathrm{CH}_{2} \mathrm{Cl}_{2}$ and water $(20 \mathrm{~mL})$. The aqueous layer was extracted with $\mathrm{CH}_{2} \mathrm{Cl}_{2}(2 \times 30 \mathrm{~mL})$ and the combined organic layers were dried with $\mathrm{MgSO}_{4}$, and the solvent removed in vacuo. The title compound was obtained after silica gel flash chromatography (eluting in 30:1, Pet. Ether/EtOAc, v/v) as a white solid (43.0 mg, $0.08 \mathrm{mmol}, 64 \%) ; \mathrm{R}_{f}=0.63$ (2/1, PE/EA, v/v); IR (film): 2916, 2848, 1638, 1604, 1256, $1107 \mathrm{~cm}^{-1} ;{ }^{1} \mathrm{H}$ NMR $\left(500 \mathrm{MHz}, \mathrm{CDCl}_{3}\right) \delta 8.14\left(\mathrm{~d}, J_{2,3}=8.0 \mathrm{~Hz}, 2 \mathrm{H}, \mathrm{H}-2\right), 7.81\left(\mathrm{~d}, J_{7,8}=8.8 \mathrm{~Hz}, 2 \mathrm{H}, \mathrm{H}-7\right)$, $7.79\left(\mathrm{~d}, J_{2,3}=8.0 \mathrm{~Hz}, 2 \mathrm{H}, \mathrm{H}-3\right), 6.96\left(\mathrm{~d}, J_{7,8}=8.8 \mathrm{~Hz}, 2 \mathrm{H}, \mathrm{H}-8\right), 4.04\left(\mathrm{t}, J_{10,11}=6.6\right.$ $\mathrm{Hz}, 2 \mathrm{H}, \mathrm{H}-10), 3.97\left(\mathrm{~s}, 3 \mathrm{H}, \mathrm{CO}_{2} \mathrm{Me}\right), 2.19\left(\mathrm{tt}, J_{28,29 \mathrm{a}}=7.3 \mathrm{~Hz},{ }^{4} J_{29,31}=2.4 \mathrm{~Hz}, 1 \mathrm{H}\right.$, 
H-29a), 2.18 (tt, $\left.J_{28,29 \mathrm{~b}}=7.1 \mathrm{~Hz},{ }^{4} J_{29,31}=2.4 \mathrm{~Hz}, 1 \mathrm{H}, \mathrm{H}-29 \mathrm{~b}\right), 1.94\left(\mathrm{t},{ }^{4} J_{29,31}=2.4 \mathrm{~Hz}\right.$, $1 \mathrm{H}, \mathrm{H}-31$ ), 1.82 (pentet, $J_{9,10}=J_{10,11}=7.1 \mathrm{~Hz}, 2 \mathrm{H}, \mathrm{H}-11$ ), $1.58-1.50(\mathrm{~m}, 2 \mathrm{H}, \mathrm{H}-28)$, 1.50-1.42 (m, 2H, H-12), 1.40-1.22 (m, 30H, H-13-H-27); ${ }^{13} \mathrm{C}$ NMR (125 MHz, $\left.\mathrm{CDCl}_{3}\right) \delta 194.8(\mathrm{C}-5), 166.4\left(\mathrm{CO}_{2} \mathrm{Me}\right), 163.6$ (C-9), 142.2 (C-4), 132.7 (C-1), 132.6 (C-7), 129.4 (C-3), 129.4 (C-2), 129.3 (C-6), 114.2 (C-8), 84.8 (C-30), 68.4 (C-31), 68.0 (C-10), $52.4\left(\mathrm{CO}_{2} \mathrm{Me}\right), 29.70,29.68,29.66,29.62,29.60,29.57,29.51,29.36$, 29.12, 29.09, 28.77, 28.50, 25.98 (C-11-C-28), 18.40 (C-29); HRMS(ESI) $m / z$ calcd. for $\left[\mathrm{C}_{37} \mathrm{H}_{52} \mathrm{O}_{4}+\mathrm{Na}\right]^{+}:$583.3763, obsd.: 583.3763 .

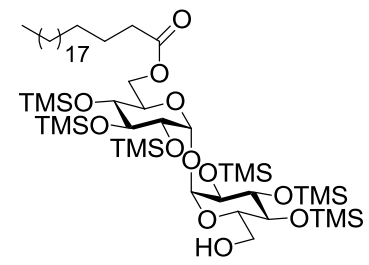

\section{2,2',3,3',4,4'-Hexa-O-trimethylsilyl-6-docosanoyl-6'-} hydroxyl, $\alpha, \alpha^{\prime}$-D-trehalose (2). To a solution of diol 4 $(48.9 \mathrm{mg}, 0.063 \mathrm{mmol})$ and behenic acid $(\mathbf{5}, 28.0 \mathrm{mg}$, $0.082 \mathrm{mmol})$ in dry toluene $(2 \mathrm{~mL})$ was added EDCI (30.2 $\mathrm{mg}, 0.16 \mathrm{mmol}$ ) and DMAP (1.1 mg, $0.01 \mathrm{mmol})$. The reaction was stirred at $70{ }^{\circ} \mathrm{C}$ until analysis by TLC showed no further formation of product. The resulting precipitate was removed by filtration and the precipitate washed thoroughly with EtOAc $(2 \times 20 \mathrm{~mL})$. The combined organic layers were washed with water $(20 \mathrm{~mL})$ and brine $(20 \mathrm{~mL})$, dried $\left(\mathrm{MgSO}_{4}\right)$, filtered and concentrated in vacuo. The title compound was obtained after silica gel flash chromatography eluting in 20:1 (v/v) Pet. Ether/EtOAc, as colourless oil $(52.0 \mathrm{mg}, 0.047 \mathrm{mmol}, 75 \%) . \mathrm{R}_{f}=0.55(\mathrm{PE} / \mathrm{EA}$, $5 / 1, \mathrm{v} / \mathrm{v}) ;[\alpha]_{\mathrm{D}}{ }^{18}=+20.2\left(c=1.0, \mathrm{CHCl}_{3}\right)$; IR (film): 3017, 2923, 2852, 2360, 2341, 1737, 1372, 1250, 1229, 1166, 1110, 1076, 1007, 965, 896, $872 \mathrm{~cm}^{-1} ;{ }^{1} \mathrm{H}$ NMR $(500$ $\left.\mathrm{MHz}, \mathrm{CDCl}_{3}\right) \delta 4.94\left(\mathrm{~d}, J_{1,2}=3.5 \mathrm{~Hz}, 1 \mathrm{H}, \mathrm{H}-1\right), 4.92\left(\mathrm{~d}, J_{1^{\prime}, 2^{\prime}}=3.6 \mathrm{~Hz}, 1 \mathrm{H}, \mathrm{H}-1^{\prime}\right)$, $4.30\left(\mathrm{dd}, J_{6 \mathrm{a}, 6 \mathrm{~b}}=12.0 \mathrm{~Hz}, J_{5,6 \mathrm{a}}=2.2 \mathrm{~Hz}, 1 \mathrm{H}, \mathrm{H}-6 \mathrm{a}\right), 4.07\left(\mathrm{dd}, J_{6 \mathrm{a}, 6 \mathrm{~b}}=12.0 \mathrm{~Hz}, J_{5,6 \mathrm{~b}}=\right.$ $4.6 \mathrm{~Hz}, 1 \mathrm{H}, \mathrm{H}-6 \mathrm{~b}), 4.03-4.00(\mathrm{~m}, 1 \mathrm{H}, \mathrm{H}-5), 3.92\left(\mathrm{t}, J_{2 / 2^{\prime}, 3 / 3^{\prime}}=J_{3 / 3^{\prime}, 4 / 4^{\prime}}=8.8 \mathrm{~Hz}, 1 \mathrm{H}, \mathrm{H}-\right.$ $\left.3 / 3^{\prime}\right), 3.91\left(\mathrm{t}, J_{2 / 2^{\prime}, 3 / 3^{\prime}}=J_{3 / 3^{\prime}, 4 / 4^{\prime}}=9.0 \mathrm{~Hz}, 1 \mathrm{H}, \mathrm{H}-3 / 3^{\prime}\right), 3.85\left(\mathrm{dt}, J_{4^{\prime}, 5^{\prime}}=9.5 \mathrm{~Hz}, J_{5^{\prime}, 6 \mathrm{a}^{\prime}}=\right.$ $\left.J_{5^{\prime}, 6 \mathrm{~b}^{\prime}}=3.5 \mathrm{~Hz}, 1 \mathrm{H}, \mathrm{H}-5^{\prime}\right), 3.86-3.83\left(\mathrm{~m}, 2 \mathrm{H}, \mathrm{H}-6 \mathrm{a}^{\prime}\right.$ and H-6b'), 3.49 (t, $J_{3,4}=J_{4,5}=9.0$ $\mathrm{Hz}, 1 \mathrm{H}, \mathrm{H}-4), 3.47\left(\mathrm{t}, J_{3^{\prime}, 4^{\prime}}=J_{4^{\prime}, 5^{\prime}}=9.0 \mathrm{~Hz}, 1 \mathrm{H}, \mathrm{H}-4^{\prime}\right), 3.44\left(\mathrm{dd}, J_{1,2 / 1^{\prime}, 2^{\prime}}=3.6 \mathrm{~Hz}\right.$, $\left.J_{2,3 / 2^{\prime}, 3^{\prime}}=9.0 \mathrm{~Hz}, 1 \mathrm{H}, \mathrm{H}-2 / 2^{\prime}\right), 3.43\left(\mathrm{dd}, J_{1,2 / 1^{\prime}, 2^{\prime}}=3.5 \mathrm{~Hz}, J_{2,3 / 2^{\prime}, 3^{\prime}}=9.0 \mathrm{~Hz}, 1 \mathrm{H}, \mathrm{H}-2 / 2^{\prime}\right)$, $2.35\left(\mathrm{dt}, J_{8 \mathrm{a}, 8 \mathrm{~b}}=13.2, J_{8 \mathrm{a}, 9}=7.3 \mathrm{~Hz}, 1 \mathrm{H}, \mathrm{H}-8 \mathrm{a}\right), 2.34\left(\mathrm{dd}, J_{8 \mathrm{a}, 8 \mathrm{~b}}=13.2, J_{8 \mathrm{~b}, 9}=7.4 \mathrm{~Hz}\right.$, 
1H, H-8b), 1.66-1.57 (m, 2H, H-9), 1.34-1.26 (m, 36H, H-10-H-27), 0.89 (t, J = 7.1 $\mathrm{Hz}, 3 \mathrm{H}, \mathrm{H}-28), 0.17,0.16,0.15,0.14,0.13$ (6 s, 54H, $\left.\mathrm{CH}_{3}, \mathrm{TMS}\right) ;{ }^{13} \mathrm{C}$ NMR (125 $\mathrm{MHz}, \mathrm{CDCl}_{3}$ ) $\delta 173.8$ (C-7), 94.5 (C-1/1'), 94.4 (C-1/1'), 73.5 (C-3/3'), 73.3 (C-3/3'), 72.9 (C-2/2'), 72.8 (C-5'), 72.6 (C-2/2'), 71.9 (C-4), 71.4 (C-4'), 70.8 (C-5), 63.3 (C6), 61.7 (C-6'), 34.2 (C-8), 31.9, 29.70, 29.66, 29.60, 29.5, 29.4, 29.3, 29.2, 24.8, 22.7 (C-9-C-27), 14.1 (C-28), 1.04, 1.00, 0.89, 0.85, 0.14, 0.10 (TMS) HRMS (ESI) $m / z$ calcd. for $\left[\mathrm{C}_{52} \mathrm{H}_{112} \mathrm{O}_{12} \mathrm{Si}_{6}+\mathrm{Na}\right]^{+}: 1119.6769$, obsd.: 1119.6667 .

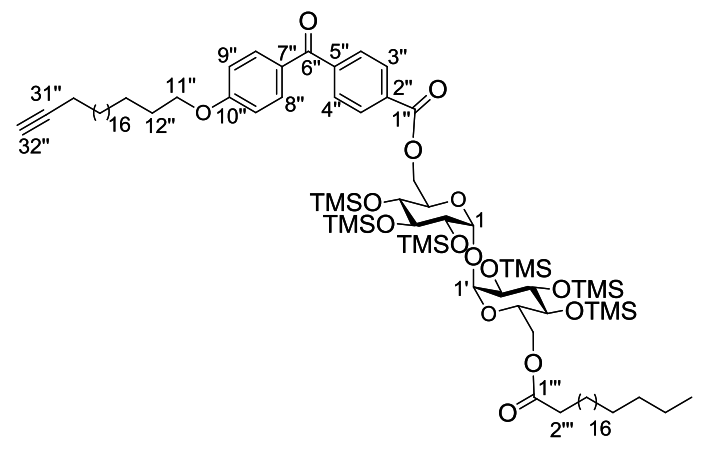

6'-O-docosanoyl-6-O-4-[4-(21docosynyloxy)benzoyl]benzoyl$2,2^{\prime}, 3,3^{\prime}, 4,4^{\prime}$-hexa- $O$-trimethylsilyl- $\alpha, \alpha^{\prime}-$ D-trehalose (22). $\mathrm{LiOH}_{2} \mathrm{H}_{2} \mathrm{O}(15 \mathrm{mg}, 0.36$ mmol) was added to a solution of $\mathbf{2 0}$ (20 $\mathrm{mg}, \quad 0.04 \mathrm{mmol})$ in $\quad 0.5 \quad \mathrm{~mL}$

THF: $\mathrm{H}_{2} \mathrm{O}: \mathrm{MeOH}(3: 1: 1)$ and the reaction mixture was refluxed for $10 \mathrm{~min}$ after which it was neutralised with $0.1 \mathrm{M} \mathrm{HCl}(\mathrm{pH}=3)$ and extracted with EtOAc $(3 \mathrm{x} 10$ $\mathrm{mL})$. The combined organic layers were washed with water, brine, dried $\left(\mathrm{MgSO}_{4}\right)$, filtered and concentrated in vacuo to yield carboxylic acid $\mathbf{3}$ as a white solid (15 mg, $0.03 \mathrm{mmol}, 80 \%$ ) which was used without further purification.

To a solution of mono-trehalose ester $2(8.5 \mathrm{mg}, 0.008 \mathrm{mmol})$ and carboxylic acid 3 $(14 \mathrm{mg}, 0.03 \mathrm{mmol})$ in dry toluene $(1 \mathrm{~mL})$ was added EDCI $(6.5 \mathrm{mg}, 0.034 \mathrm{mmol})$ and DMAP (0.2 mg, $0.001 \mathrm{mmol})$ and the reaction was refluxed for 7 days after which time the resulting precipitate was removed by filtration and the precipitate washed thoroughly with EtOAc ( 3 x $10 \mathrm{~mL}$ ). The combined organic layers were washed with water $(10 \mathrm{~mL})$, brine $(10 \mathrm{~mL})$ dried with $\mathrm{MgSO}_{4}$, filtered and concentrated in vacuo. The title compound was obtained after silica gel flash chromatography (eluting in 25:1, Pet. Ether/EtOAc, v/v) as colourless oil (3.5 mg, $0.002 \mathrm{mmol}, 30 \%) . \mathrm{R}_{f}=0.54(\mathrm{PE} / \mathrm{EA}, 5 / 1, \mathrm{v} / \mathrm{v}) ;[\alpha]^{22}{ }_{\mathrm{D}}=+0.06\left(c=0.1 \mathrm{CHCl}_{3}\right) ; \mathrm{IR}$ (film): 3628, 2920, 1457, 720, $677 \mathrm{~cm}^{-1} ;{ }^{1} \mathrm{H} \mathrm{NMR}\left(500 \mathrm{MHz}, \mathrm{CDCl}_{3}\right) \delta 8.14$ (d, $J_{3^{\prime \prime}, 4 "}$ $\left.=8.5 \mathrm{~Hz}, 2 \mathrm{H}, \mathrm{H}-3^{\prime \prime}\right), 7.81$ (d, $\left.J_{8^{\prime \prime}, 9^{\prime \prime}}=8.8 \mathrm{~Hz}, 2 \mathrm{H}, \mathrm{H}-8^{\prime \prime}\right), 7.79$ (d, $J_{3^{\prime \prime}} 4^{\prime \prime}=8.5 \mathrm{~Hz}, 2 \mathrm{H}, \mathrm{H}-$ 4"), $6.96\left(\mathrm{~d}, J_{8^{\prime \prime}, 9^{\prime \prime}}=8.8 \mathrm{~Hz}, 2 \mathrm{H}, \mathrm{H}-9 "\right), 4.95\left(\mathrm{~d}, J_{1,2 / 1^{\prime}, 2^{\prime}}=3.2 \mathrm{~Hz}, 1 \mathrm{H}, \mathrm{H}-1 / 1^{\prime}\right), 4.94$ (d, 
$\left.J_{1,2 / 1^{\prime}, 2^{\prime}}=3.2 \mathrm{~Hz}, 1 \mathrm{H}, \mathrm{H}-1 / 1^{\prime}\right), 4.59\left(\mathrm{dd}, J_{6 \mathrm{a}, 6 \mathrm{~b}}=12.0 \mathrm{~Hz}, J_{5,6 \mathrm{a}}=2.3 \mathrm{~Hz}, 1 \mathrm{H}, \mathrm{H}-6 \mathrm{a}\right), 4.33$ $\left(\mathrm{dd}, J_{6 \mathrm{a}, 6 \mathrm{~b}}=12.0 \mathrm{~Hz}, J_{5,6 \mathrm{~b}}=3.5 \mathrm{~Hz}, 1 \mathrm{H}, \mathrm{H}-6 \mathrm{~b}\right), 4.27\left(\mathrm{dd}, J_{6 \mathrm{a}^{\prime}, 6 \mathrm{~b}^{\prime}}=12.0 \mathrm{~Hz}, J_{5^{\prime}, 6 \mathrm{a}^{\prime}}=2.3\right.$ $\mathrm{Hz}, 1 \mathrm{H}, \mathrm{H}-6 \mathrm{a}), 4.13$ (ddd, $J_{4,5}=9.0 \mathrm{~Hz}, J_{5,6 \mathrm{a}}=2.3 \mathrm{~Hz}, J_{5,6 \mathrm{~b}}=3.5 \mathrm{~Hz}, 1 \mathrm{H}, \mathrm{H}-5$ ), 4.09 $\left(\mathrm{dd}, J_{6 \mathrm{a}^{\prime}, 6 \mathrm{~b}^{\prime}}=12.0 \mathrm{~Hz}, J_{5^{\prime}, 6 \mathrm{~b}^{\prime}}=3.5 \mathrm{~Hz}, 1 \mathrm{H}, \mathrm{H}-6 \mathrm{~b}^{\prime}\right), 4.04$ (t, $\left.J_{11^{\prime \prime}, 12^{\prime \prime}}=6.4 \mathrm{~Hz}, 2 \mathrm{H}, \mathrm{H}-11^{\prime \prime}\right)$, 4.02-3.97 (m, 1H, H-5'), $3.96\left(\mathrm{dd}, J_{2,3}=J_{3,4}=9.0 \mathrm{~Hz}, 1 \mathrm{H}, \mathrm{H}-3\right), 3.92\left(\mathrm{dd}, J_{2^{\prime}, 3^{\prime}}=J_{3^{\prime}, 4^{\prime}}=\right.$ $\left.9.0 \mathrm{~Hz}, 1 \mathrm{H}, \mathrm{H}-3^{\prime}\right), 3.64\left(\mathrm{dd}, J_{3,4}=J_{4,5}=9.0 \mathrm{~Hz}, 1 \mathrm{H}, \mathrm{H}-4\right), 3.49\left(\mathrm{dd}, J_{2,3 / 2^{\prime}, 3^{\prime}}=9.0 \mathrm{~Hz}\right.$, $\left.J_{1,2 / 1^{\prime}, 2^{\prime}}=3.2 \mathrm{~Hz}, 1 \mathrm{H}, \mathrm{H}-2 / 2^{\prime}\right) 3.48\left(\mathrm{dd}, J_{3^{\prime}, 4^{\prime}}=J_{4^{\prime}, 5^{\prime}}=9.0 \mathrm{~Hz}, 1 \mathrm{H}, \mathrm{H}-4^{\prime}\right), 3.47\left(\mathrm{dd}, J_{2,3 / 2^{\prime}, 3^{\prime}}\right.$ $\left.=9.0 \mathrm{~Hz}, J_{1,2 / 1^{\prime}, 2^{\prime}}=3.2 \mathrm{~Hz}, 1 \mathrm{H}, \mathrm{H}-2 / 2^{\prime}\right), 2.34\left(\mathrm{dt}, J_{2 \mathrm{a}^{\prime \prime}, 2 \mathrm{~b}^{\prime \prime \prime}}=11.4 \mathrm{~Hz}, J_{2 \mathrm{a}^{\prime \prime}, 3^{\prime \prime \prime}}=7.3 \mathrm{~Hz}\right.$, $\left.1 \mathrm{H}, \mathrm{H}-2 \mathrm{a} \mathrm{a}^{\prime \prime}\right), 2.33$ (dt, $\left.J_{2 \mathrm{a} " ', 2 \mathrm{~b}^{\prime \prime}}=11.4 \mathrm{~Hz}, J_{2 \mathrm{~b}^{\prime \prime}, 33^{\prime \prime}}=7.3 \mathrm{~Hz}, 1 \mathrm{H}, \mathrm{H}-2 \mathrm{~b}^{\prime \prime \prime}\right) 2.19$ (dtt, $\left.J_{30 \mathrm{a}^{\prime}, 30 \mathrm{~b}}=9.9 \mathrm{~Hz}, J_{29 ", 30 \mathrm{a}}=7.3 \mathrm{~Hz},{ }^{4} J_{30 \mathrm{a} ", 32^{\prime \prime}}=2.6 \mathrm{~Hz}, 1 \mathrm{H}, \mathrm{H}-30 \mathrm{a} "\right), 2.17$ (ddt, $J_{30 \mathrm{a} ", 30 \mathrm{~b}^{\prime \prime}}$ $\left.=9.9 \mathrm{~Hz}, J_{29^{\prime \prime}, 30 \mathrm{~b}^{\prime \prime}}=7.3 \mathrm{~Hz},{ }^{4} J_{30 \mathrm{~b}^{\prime \prime}, 32^{\prime \prime}}=2.6 \mathrm{~Hz}, 1 \mathrm{H}, \mathrm{H}-30 \mathrm{~b} "\right), 1.94\left(\mathrm{t},{ }^{4} J_{30 ", 32 "}=2.6 \mathrm{~Hz}\right.$, $1 \mathrm{H}, \mathrm{H}-32$ ), 1.82 (pentet, $\left.J_{11^{\prime \prime}, 12^{\prime \prime}}=J_{12^{\prime \prime} 13^{\prime \prime}}=6.7 \mathrm{~Hz}, 2 \mathrm{H}, \mathrm{H}-12^{\prime \prime}\right), 1.64-1.52$ (m, 4H, H3"' and H-13"), 1.50-1.22 (m, 68H, H-14"-H-29" and H-4"'-H-21"'), 0.88 (t, $J_{21}{ }^{\prime \prime}, 222^{\prime \prime}=$ $7.0 \mathrm{~Hz}, \mathrm{H}-22$ '"), 0.17, 0.16, 0.15, 0.14, 0.13 (6 s, 54H, $\left.\mathrm{CH}_{3}, \mathrm{TMS}\right) ;{ }^{13} \mathrm{C}$ NMR (125 $\left.\mathrm{MHz}, \mathrm{CDCl}_{3}\right) \delta 194.5$ (C-6"), 173.8 (C-1"'), 165.5 (C-1"), 163.1 (C-10"), 142.2 (C5"), 132.4 (C-4"), 132.3 (C-2"), 129.3 (C-3"), 129.2 (C-8"), 128.7 (C-7"), 114.0 (C9"), 94.29 (C-1/1'), 94.25 (C-1/1'), 84.6 (C-31"), 73.4 (C-3), 73.2 (C-3'), 72.44 (C2/2'), 72.40 (C-2/2'), 71.66 (C-4), 71.60 (C-4'), 70.53 (C-5'), 70.50 (C-5), 68.2 (C11"), 67.8 (C-32"), 63.8 (C-6), 63.0 (C-6'), 33.9 (C-2"'), 31.7, 31.2, 29.9, 29.8, 29.5, 29.43, 29.38, 29.34, 29.35, 29.27, 29.24, 29.20, 29.14, 29.1, 28.9, 28.88, 28.54, 28.26, 25.76, 24.78, 24.54, 22.47, 21.85, (C-3"'-C21"' and C-12"-C-29"), 18.17 (C30"), 13.9 (C-22"'), 0.86, 0.83, 0.70, 0.65, 0.01, 0.00 (TMS); HRMS (ESI) $\mathrm{m} / \mathrm{z}$ calcd. for $\left[\mathrm{C}_{88} \mathrm{H}_{160} \mathrm{O}_{15} \mathrm{Si}_{6}+\mathrm{Na}\right]^{+}$: 1648.0265 , obsd.: 1648.0280 .

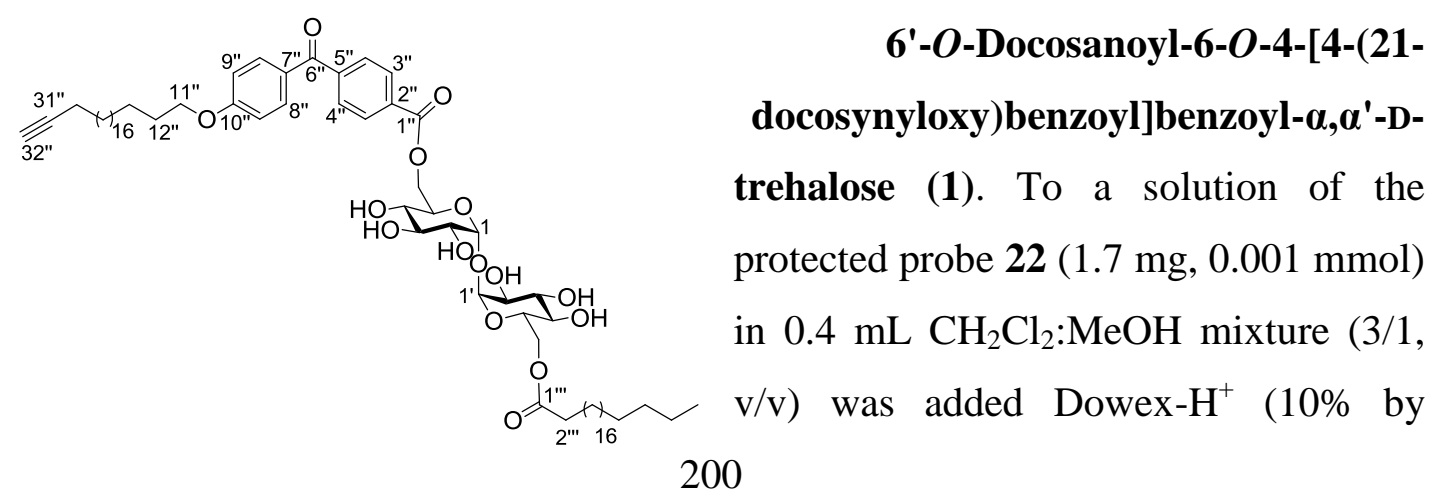


weight) and the reaction stirred at room temperature. After $30 \mathrm{~min}$, the reaction mixture was filtered and concentrated in vacuo. AfBP probe 1 was obtained after silica gel flash column chromatography (eluting in 97:3, EtOAc/MeOH, v/v) as a white solid (1.25 mg, $0.001 \mathrm{mmol}$, quant.). $\mathrm{R}_{f}=0.31$ (EtOAc); $[\alpha]^{18}{ }_{\mathrm{D}}=+0.6(c=0.1$, $\mathrm{C}_{5} \mathrm{H}_{5} \mathrm{~N}$ ); IR (film); 3567, 2970, 1739, 1365, 1217, $651 \mathrm{~cm}^{-1} ;{ }^{1} \mathrm{H}$ NMR (500 MHz, $\left.\mathrm{C}_{5} \mathrm{D}_{5} \mathrm{~N}\right) \delta 8.20\left(\mathrm{~d}, J_{3^{\prime \prime}, 4^{\prime \prime}}=8.2 \mathrm{~Hz}, 2 \mathrm{H}, \mathrm{H}-3^{\prime \prime}\right), 7.86\left(\mathrm{~d}, J_{8^{\prime \prime}, 9^{\prime \prime}}=8.8 \mathrm{~Hz}, 2 \mathrm{H}, \mathrm{H}-8^{\prime \prime}\right), 7.68$ $\left(\mathrm{d}, J_{3^{\prime \prime}, 4^{\prime \prime}}=8.2 \mathrm{~Hz}, 2 \mathrm{H}, \mathrm{H}-4^{\prime \prime}\right), 7.06$ (d, $\left.J_{8^{\prime \prime}, 9^{\prime \prime}}=8.8 \mathrm{~Hz}, 2 \mathrm{H}, \mathrm{H}-9 "\right), 5.84$ (d, $J_{1,2 / 1^{\prime}, 2^{\prime}}=3.6$ $\left.\mathrm{Hz}, 1 \mathrm{H}, \mathrm{H}-1 / 1^{\prime}\right), 5.83$ (d, $\left.J_{1,2 / 1^{\prime}, 2^{\prime}}=3.6 \mathrm{~Hz}, 1 \mathrm{H}, \mathrm{H}-1 / 1^{\prime}\right), 5.20-5.17$ (m, 1H, H-5), 5.154.94 (m, 5H, H-5, H-6a,b and H-6'a,b), 4.70 (dd, $J_{2,3}=J_{3,4}=9.6 \mathrm{~Hz}, 1 \mathrm{H}, \mathrm{H}-3$ ), 4.68 $\left(\mathrm{dd}, J_{2^{\prime}, 3^{\prime}}=J_{3^{\prime}, 4^{\prime}}=9.6 \mathrm{~Hz}, 1 \mathrm{H}, \mathrm{H}-3^{\prime}\right), 4.28\left(\mathrm{dd}, J_{2,3 / 2^{\prime}, 3^{\prime}}=9.6 \mathrm{~Hz}, J_{1,2 / 1^{\prime}, 2^{\prime}}=3.6 \mathrm{~Hz}, 1 \mathrm{H}, \mathrm{H}-\right.$ $\left.2 / 2^{\prime}\right), 4.24\left(\mathrm{dd}, J_{2,3 / 2^{\prime}, 3^{\prime}}=9.6 \mathrm{~Hz}, J_{1,2 / 1^{\prime}, 2^{\prime}}=3.6 \mathrm{~Hz}, 1 \mathrm{H}, \mathrm{H}-2 / 2^{\prime}\right), 4.09\left(\mathrm{dd}, J_{3,4}=J_{4,5}=\right.$ $9.6 \mathrm{~Hz}, 1 \mathrm{H}, \mathrm{H}-4), 4.09\left(\mathrm{dd}, J_{3^{\prime}, 4^{\prime}}=J_{4^{\prime}, 5^{\prime}}=9.6 \mathrm{~Hz}, 1 \mathrm{H}, \mathrm{H}-4^{\prime}\right), 3.96\left(\mathrm{t}, J_{11^{\prime \prime}, 12^{\prime \prime}}=6.3 \mathrm{~Hz}\right.$,

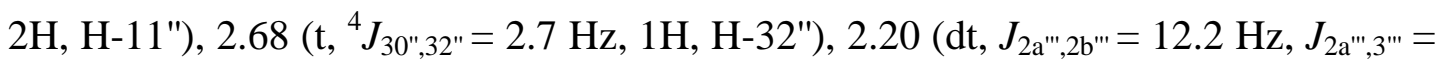
$\left.7.9 \mathrm{~Hz}, 2 \mathrm{H}, \mathrm{H}-2 \mathrm{a} \mathrm{a}^{\prime \prime}\right), 2.19$ (dt, $\left.J_{2 \mathrm{a}^{\prime \prime}, 2 \mathrm{~b} \mathrm{~b}^{\prime \prime}}=12.2 \mathrm{~Hz}, J_{2 \mathrm{~b}^{\prime \prime}, 33^{\prime \prime \prime}}=7.9 \mathrm{~Hz}, 1 \mathrm{H}, \mathrm{H}-2 \mathrm{~b} " '\right), 2.12$ $\left(\mathrm{dtt}, J_{30 \mathrm{a} ", 30 \mathrm{~b}^{\prime}}=9.9 \mathrm{~Hz}, J_{29 ", 30 \mathrm{a}^{\prime \prime}}=7.0 \mathrm{~Hz},{ }^{4} J_{30 \mathrm{a} ", 32 "}=2.7 \mathrm{~Hz}, 1 \mathrm{H}, \mathrm{H}-30 \mathrm{a} "\right), 2.10$ (dtt, $\left.J_{30 \mathrm{a}^{\prime \prime}, 30 \mathrm{~b}}=9.9 \mathrm{~Hz}, J_{29 ", 30 \mathrm{~b}^{\prime}}=7.0 \mathrm{~Hz},{ }^{4} J_{30 \mathrm{~b}}, 32^{\prime \prime}=2.7 \mathrm{~Hz} 1 \mathrm{H}, \mathrm{H}-30 \mathrm{~b} "\right), 1.69$ (pentet, $\left.J_{11^{\prime \prime}, 12^{\prime \prime}}=J_{12^{\prime \prime} 13^{\prime \prime}}=6.3 \mathrm{~Hz}, 2 \mathrm{H}, \mathrm{H}-12^{\prime \prime}\right), 1.50$ (pentet, $J_{2^{\prime \prime}, 3^{\prime \prime \prime}}=J_{3^{\prime \prime}, 4^{\prime \prime \prime}}=6.1 \mathrm{~Hz}, 2 \mathrm{H}, \mathrm{H}-3^{\prime \prime \prime}$ ), 1.39-1.35 (m, 2H, H-13"), 1.20-1.06 (m, 68H, H-14"-H-29" and H-4"'-H-21"'), 0.77 (t, $\left.J_{21 " ', 22^{\prime \prime}}=6.6 \mathrm{~Hz}, \mathrm{H}-22 " '\right) ;{ }^{13} \mathrm{C}$ NMR $\left(125 \mathrm{MHz}, \mathrm{C}_{5} \mathrm{D}_{5} \mathrm{~N}\right) \delta 193.0(\mathrm{C}-6 "), 172.3(\mathrm{C}-$ 1"'), 164.6 (C-1"), 162.2 (C-10"), 133.8 (C-5"), 131.7 (C-4"), 128.4 (C-2"), 128.3 (C3"), 128.0 (C-8"), 127.3 (C-7"), 113.3 (C-9"), 94.6 (C-1 and C-1'), 83.7 (C-31"), 73.6 (C-3), 73.5 (C-3'), 72.0 (C-2/2'), 72.40 (C-2/2'), 70.70 (C-4), 70.60 (C-4'), 70.23 (C5'), 70.16 (C-5), 68.7 (C-32") 67.2 (C-11"), 64.3 (C-6), 62.9 (C-6'), 33.0 (C-2'"), 30.7, 28.62, 28.60, 28.54, 28.52, 28.51, 28.48, 28.38, 28.34, 28.25, 28.21, 28.16, 28.0, 27.96, 27.94, 27.58, 27.41, 24.87, 23.85, 21.54 (C-3"'-C21"' and C-12"-C-29"), $17.18 \quad(\mathrm{C}-30 "), \quad 12.9 \quad$ (C-22'"); $\operatorname{HRMS}(\mathrm{ESI}) \mathrm{m} / \mathrm{z}$ calcd. for $\left[\mathrm{C}_{70} \mathrm{H}_{112} \mathrm{O}_{15}+\mathrm{Na}\right]^{+}: 1215.7893$, obsd.:1215.7897. 


\section{References}

(1) Schoenen, H.; Bodendorfer, B.; Hitchens, K.; Manzanero, S.; Werninghaus, K.; Nimmerjahn, F.; Agger, E. M.; Stenger, S.; Andersen, P.; Ruland, J.; Brown, G. D.; Wells, C.; Lang, R. J. Immunol. 2010, 184, 2756- 2760.

(2) Ishikawa, E.; Ishikawa, T.; Morita, Y. S.; Toyonaga, K.; Yamada, H.; Takeuchi, O.; Kinoshita, T.; Akira, S.; Yoshikai, Y.; Yamasaki, S. J. Exp. Med. 2009, 206, 2879-2888.

(3) Johnson, D. Carbohydr. Res. 1992, 237, 313-318.

(4) Chenot, E.-D.; Bernardi, D.; Comel, A.; Kirsch, G. Synth.Commun. 2007, 37, 483-490.

(5) Chappell, M. D.; Conner, S. E.; Gonzalez Valcarcel, I. C.; Lamar, J. C.; Li, J.; Moyers, J. S.; Owens, R. A.; Tripp, A. E.; Zhu, G. GLUCAGON RECEPTOR ANTAGONISTS, PREPARATION AND THERAPEUTIC USES 2005, PCT Int. Appl., 2005118542.

(6) Jung, M. E.; Lyster, M. A. J. Org. Chem. 1977, 42, 3761-3764.

(7) Salem, O. I. A.; Frotscher, M.; Scherer, C.; Neugebauer, A.; Biemel, K.; Streiber, M.; Maas, R.; Hartmann, R. W. J. Med. Chem. 2006, 49, 748-759.

(8) Li, C.; Xu, W.; Vadivel, S. K.; Fan, P.; Makriyannis, A. J. Med. Chem. 2005, $48,6423-6429$.

(9) Jonsson, S.; Liljefors, T.; Hansson, B. S. J. Chem. Ecol. 1991, 17, 102-122.

(10) Csuk, R.; Niesen, A.; Tschuch, G.; Moritz, G. Tetrahedron 2004, 60, 60016004.

(11) Brown, C. A.; Yamashita, A. J. Am. Chem. Soc. 1975, 97, 891-892.

(12) Kabalka, George, W.; Varma, M.; Varma, Rajendra, S. J. Org. Chem. 1986, $51,2386-2388$. 


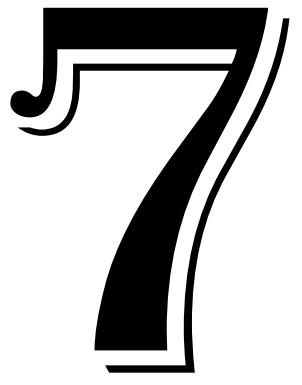

\section{Summary and}

\section{Future Prospects}

\subsection{Summary}

The use of bacteria in the treatment of disease was first illustrated by Coley who treated a number of cancer patients in the late 1800s using a concoction known as 'Coley's Toxin' (Streptococcal pyogenes and Serratia marcescens). Following this seminal work, there has been much interest in the potential of bacterial cell wall components in the treatment of disease, as highlighted in the introduction to this thesis (Chapter 1). In particular, Chapter 1 focuses on the trehalose glycolipids and outlines their synthesis, biological activities, and how such glycolipids can be used to understand cellular processes [e.g. via Affinity Based Proteome Profiling (AfBPP)].

In Chapter 2, the synthesis of linear fatty acid trehalose diesters (TDEs) is reported. The different synthetic strategies used to obtain a range of TDEs and the isolation of linear fatty acid trehalose monoesters (TMEs) is described. Initial methodology involved using benzyl protecting groups in the synthesis of these glycolipids, however, with long lipid chains, the removal of the benzyl protecting groups proved 
difficult. A switch to using trimethylsilyl (TMS) protecting groups yielded better results. In summary, nine TDEs and two TMEs were synthesised in good overall yields.

Chapter 3 focuses on the biological activities of the synthesised TDEs and TMEs. The importance of lipid length in inducing macrophage activation was studied along with investigations into the importance of having two lipid chains on the trehalose moiety for recognition by macrophages. It was observed that a lipid length of C18 or more is required to induce macrophage activation and one long lipid chain $(\geq \mathrm{C} 22)$ on trehalose is sufficient for activation. This is the first time that it has been shown that TMEs are also able to activate macrophages. The synthesised TMEs and TDEs were also tested for their cytotoxicity and, interestingly, no appreciable cytotoxicity was noted. Using knock-out models, it was shown that both TDEs and TMEs are ligands for Macrophage Inducible C-type Lectin (Mincle).

In Chapter 4, Fráter-Seebach alkylation methodology for the synthesis of $\alpha$-alkyl- $\beta$ hydroxy esters is presented. Here it was shown that allylic iodides were more effective alkylating reagents and gave better product yields as compared to their saturated alkyl halide counterparts. This was attributed to the delocalisation of the electron density over the allylic carbons in the transition state which leads to a lower transition state energy relative to the transition state of the corresponding saturated halides.

Use of the improved Fráter-Seebach alkylation for the synthesis of a fully protected trehalose monocorynomycolate (TMCM) is described in Chapter 5. Key steps in the synthetic route were a copper-mediated Grignard reaction for the synthesis of the corynomycolic acid moiety, selective formation of the silyl-ether and esterification to give the trehalose monoester. Problems were noted when a longer lipid chain $(\mathrm{C} 14)$ was used for the Grignard reaction and also during the esterification reaction, whereby formation of corynomycolic anhydride was noted with no diester observed. It is envisioned that these problems, however, can be solved and that the general synthetic strategy can be used for the subsequent syntheses of a variety of TDCMs. 
In Chapter 6, the design of an affinity based proteome (AfBP) probe for understanding the protein interactions of trehalose glycolipids is described. Incorporation of a benzophenone trap group and an alkyne tag to prepare a C22 trehalose probe was undertaken. Key synthetic steps included Friedel-Craft acylation for the formation of the benzophenone moiety and a Zipper reaction to prepare the terminal alkyne functionality. Initial biological testing of the AfBP probe was performed and it was observed that the probe led to macrophage activation (as determined by NO production) albeit at lower levels than the corresponding dibehenate derivative.

\subsection{Future Prospects}

\subsubsection{TDEs and TMEs and associated biological activities}

With our finding that long chain TMEs and TDEs are required to activate macrophages, our next step would be to understand more about the mechanism of this activation. For example, all macrophage experiments should be repeated using knock-out mice (e.g. Mincle ${ }^{-/-}, \mathrm{TLR}^{-/-}$and $\mathrm{Myd} 88^{-/-} \mathrm{BMMs}$ ) so that potential receptors can be identified. The ability of the trehalose esters to form aggregates (e.g. micelles) and the effect that this has on macrophage activation also needs to be determined, as does the ability of the compounds to switch the macrophage phenotype from M2 (e.g. TAMs) to M1. The ability of these compounds to be used as priming agents should also be further explored. Such experiments, along with the appropriate references, were described in more detail in Chapter 3.

\subsubsection{TMCM and TDCM Synthesis}

Having developed an improved Fráter-Seebach alkylation methodology, the next step is to apply this to the synthesis of more complex TDCMs. Problems encountered during the synthesis of the TDCMs included the copper-mediated Grignard alkylation when longer alkyl lipids were used and difficulties in the esterification 
reaction to form diesters. The use of lithiated alkyne lipids in the Grignard reaction could solve this problem and allow for the synthesis of longer chain TDCM analogues. For the esterification reaction a change of solvent, prolonged reaction times and further addition of EDCI and DMAP in order to form the diesters would be investigated as highlighted in Chapter 5. The TDCMs should also be tested for their biological activities - first in a macrophage activation assay, and then, for their potential as adjuvants and anti-tumour agents. By doing so, greater insight into the effects of trehalose glycolipid structure on biological function can be determined.

\subsubsection{AfBP}

The C22-trehalose AfBP probe (Chapter 6) is to be used in subsequent proteomic experiments to elucidate other receptors that the TDMs may bind to upon interaction with macrophages in the host cell. This work is to be undertaken by Dr. Faustin Kamena (Max-Plank Institute, Berlin). Depending on the results from these studies, other probes with varying trap and tag groups could then be designed and tested. 


\section{List of Publications}

1. Ashna A. Khan, Janice M.H. Cheng, Bridget L. Stocker, Mattie S.M. Timmer. "Glycolipids and CD1: The Crossroad between Chemistry and Immunology" Chemistry in NZ, 2010, 74, 57-62.

2. Janice M.H. Cheng, Ashna A. Khan, Bridget L. Stocker and Mattie S.M. Timmer. "Endogenous and Exogenous CD1- Binding Glycolipids" International Journal of Carbohydrate Chemistry, 2011, Volume 2011 (2011), Article ID 749591.

3. Ashna A. Khan, Stephanie H. Chee, Rene J. McLaughlin, Jacquie L. Harper, Faustin Kamena, Mattie S.M. Timmer, Bridget L. Stocker. "Long-Chain Lipids are Required for the Innate Immune Recognition of Trehalose Diesters by Macrophages" ChemBioChem, 2011, 12, 2572-2576.

4. Ashna A. Khan, Stephanie H. Chee, Bridget L. Stocker, Mattie S.M. Timmer. "The Synthesis of Long-Chain $\alpha$-Alkyl- $\beta$-Hydroxy-Esters using Allylic Halide in a Fráter-Seebach Alkylation" Eur. J. Org. Chem, 2012, 995-1002.

5. Ashna A. Khan, Bridget L. Stocker, Mattie S.M. Timmer. "Trehalose glycolipids - synthesis and biological activities" Carbohydr. Res. 2012, 356, 2536.

6. Janelle Sauvageau, Amy J. Foster, Ashna A. Khan, Stephanie H. Chee, Ian M. Sims, Mattie S.M. Timmer, Bridget L. Stocker. "Synthesis and Biological Activity of the Lipoteichoic Acid Anchor from Streptococcus sp. DSM 8747" ChemBioChem, 2012, 13, 2416-2424. 



\section{Appendix}

\section{${ }^{1} \mathrm{H}$ and ${ }^{13} \mathrm{C}$ NMR spectra of synthesised compounds}



Chapter 2 

2,2',3,3',4,4'-Hexa- $O$-benzyl-6,6'-di- $O$-trityl- $\alpha, \alpha^{\prime}$-D-trehalose (3) ${ }^{1} \mathrm{H} \mathrm{NMR}\left(500 \mathrm{MHz}, \mathrm{CDCl}_{3}\right)$
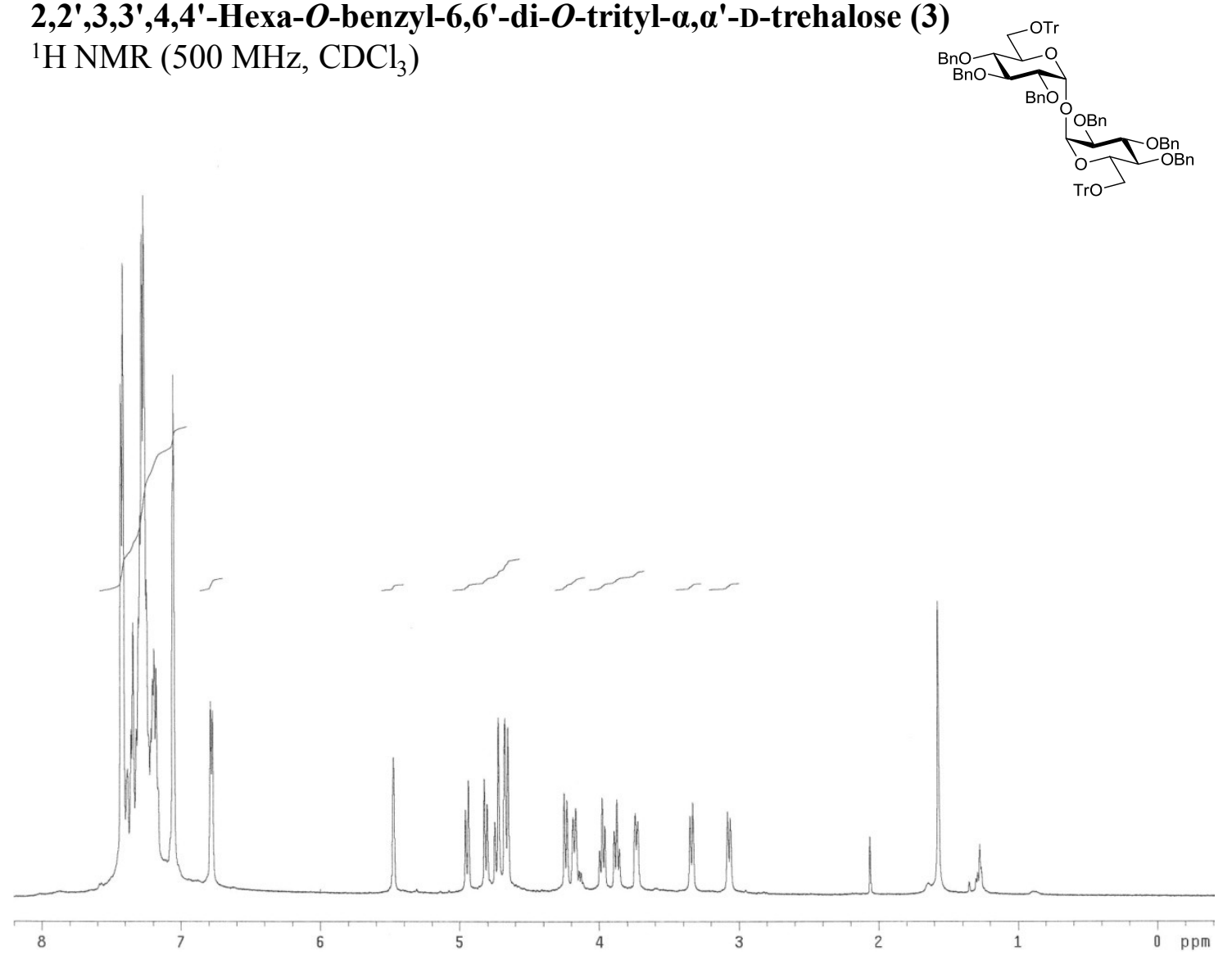

2,2',3,3',4,4'-Hexa- $O$-benzyl-6,6'-di- $O$-trityl- $\alpha, \alpha^{\prime}$-D-trehalose (3)

${ }^{13} \mathrm{C} \mathrm{NMR}\left(125 \mathrm{MHz}, \mathrm{CDCl}_{3}\right)$

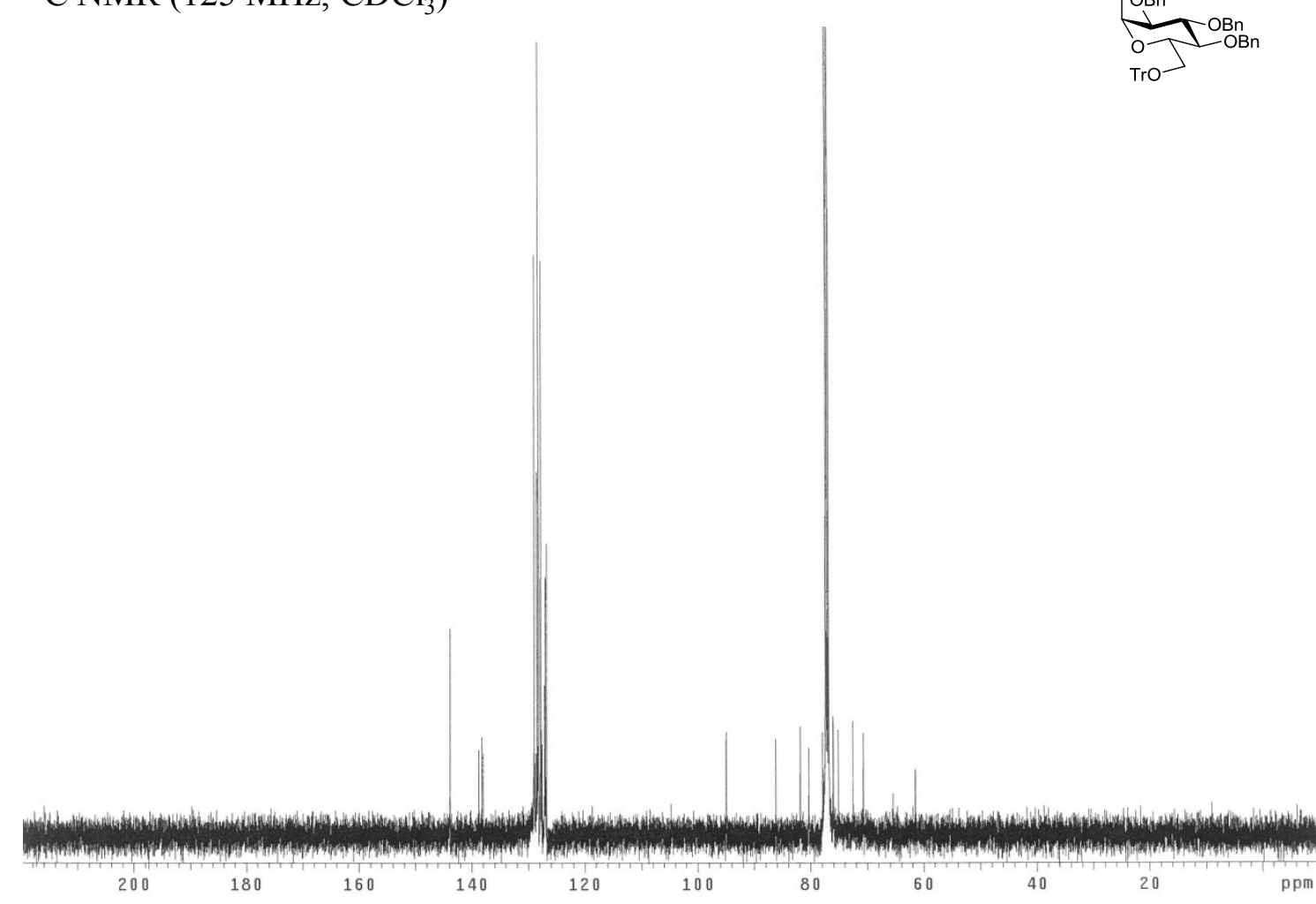


2,2',3,3',4,4'-Hexa-O-benzyl- $\alpha, \alpha^{\prime}$-D-trehalose (4) ${ }^{1} \mathrm{H} \mathrm{NMR}\left(500 \mathrm{MHz}, \mathrm{CDCl}_{3}\right)$
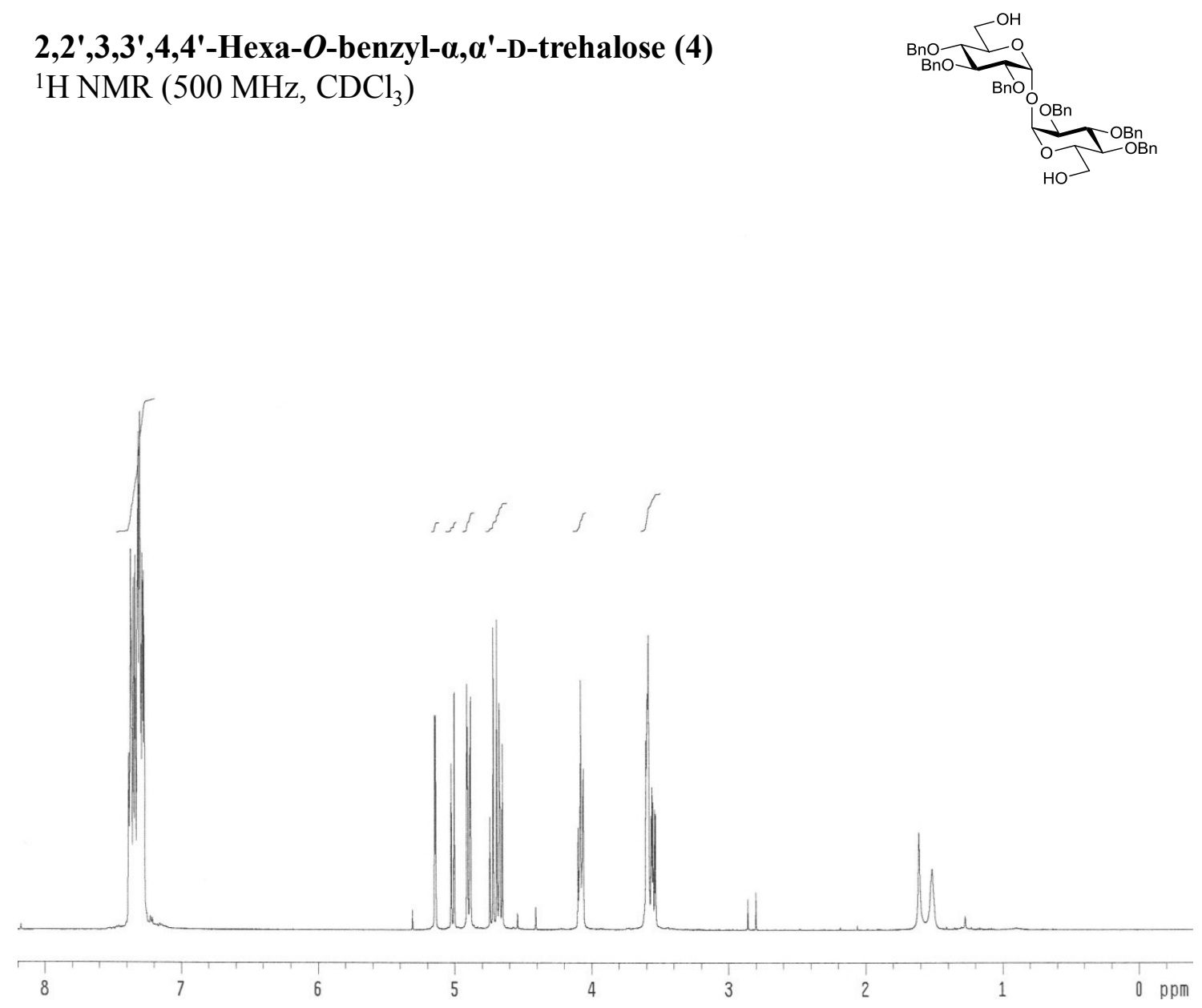

2,2',3,3',4,4'-Hexa-O-benzyl- $\alpha, \alpha^{\prime}$-D-trehalose (4) ${ }^{13} \mathrm{C} \mathrm{NMR}\left(125 \mathrm{MHz}, \mathrm{CDCl}_{3}\right)$
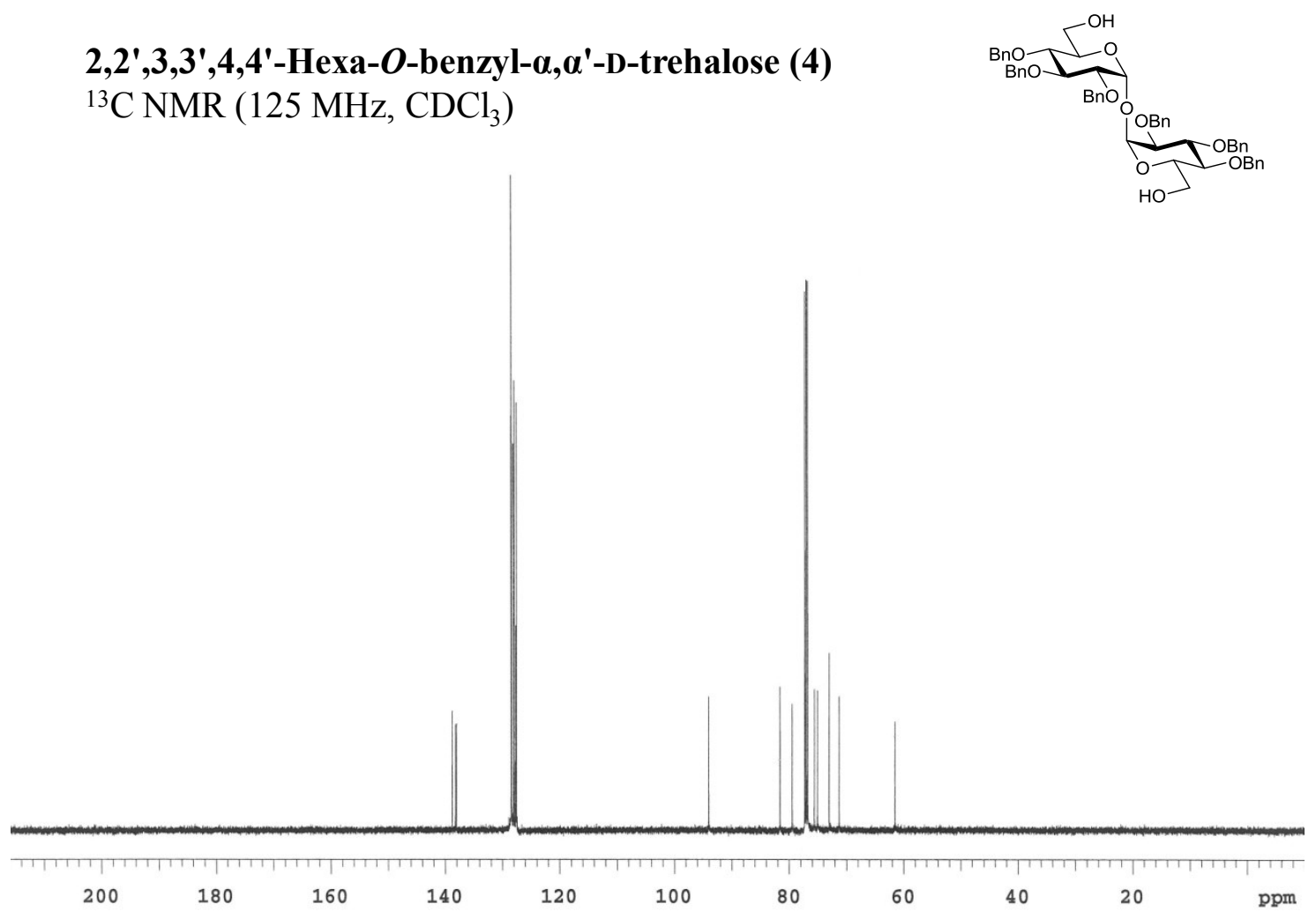
$2,2^{\prime}, 3,3^{\prime}, 4,4^{\prime}$-Hexa- $O$-benzyl-6,6'-di- $O$-butanoyl- $\alpha, \alpha^{\prime}$-Dtrehalose (5a)

${ }^{1} \mathrm{H} \mathrm{NMR}\left(500 \mathrm{MHz}, \mathrm{CDCl}_{3}\right)$
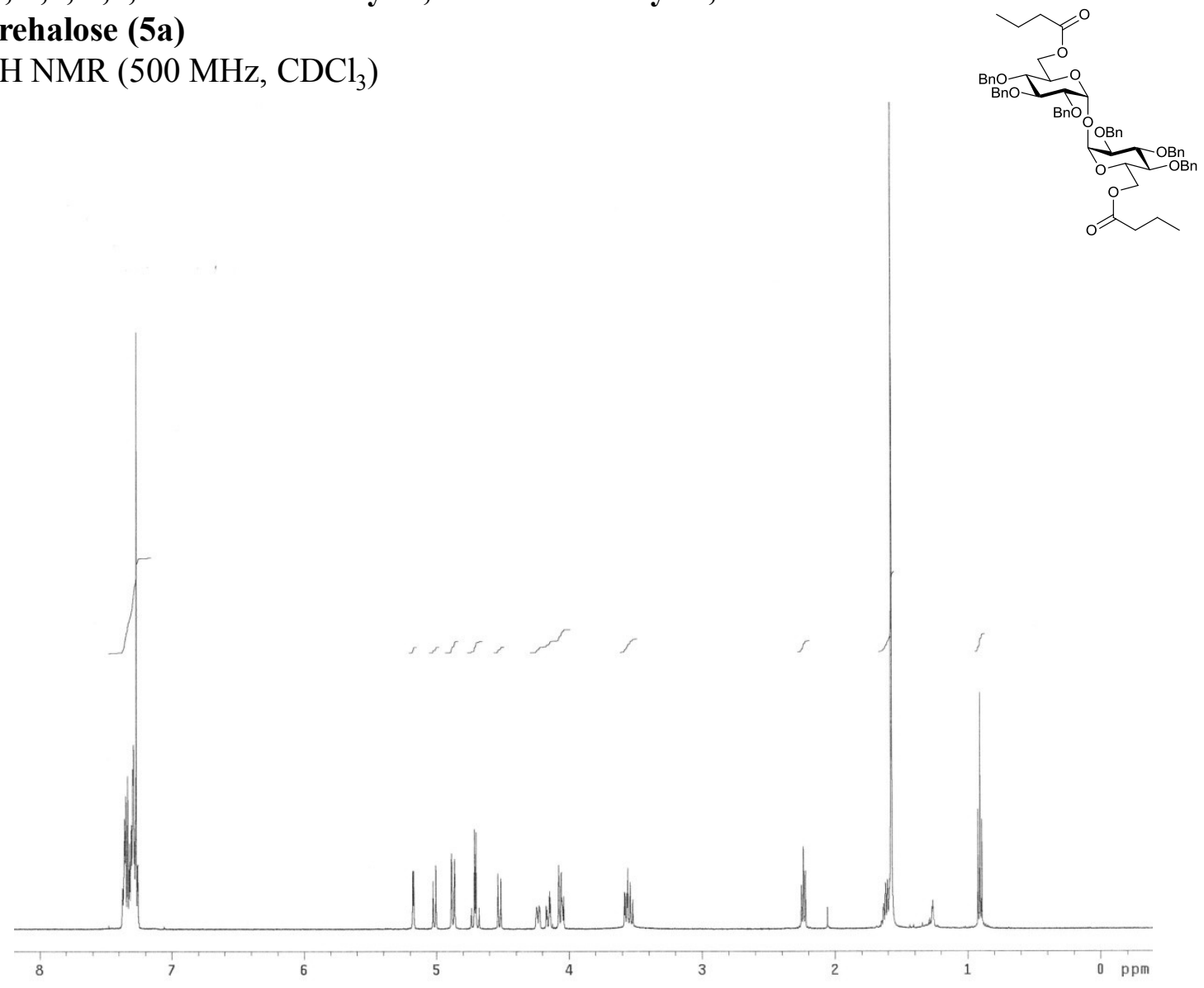

$2,2^{\prime}, 3,3 ', 4,4^{\prime}$-Hexa-O-benzyl-6,6'-di- $O$-butanoyl- $\alpha, \alpha^{\prime}$-Dtrehalose (5a)

${ }^{13} \mathrm{C} \mathrm{NMR}\left(125 \mathrm{MHz}, \mathrm{CDCl}_{3}\right)$
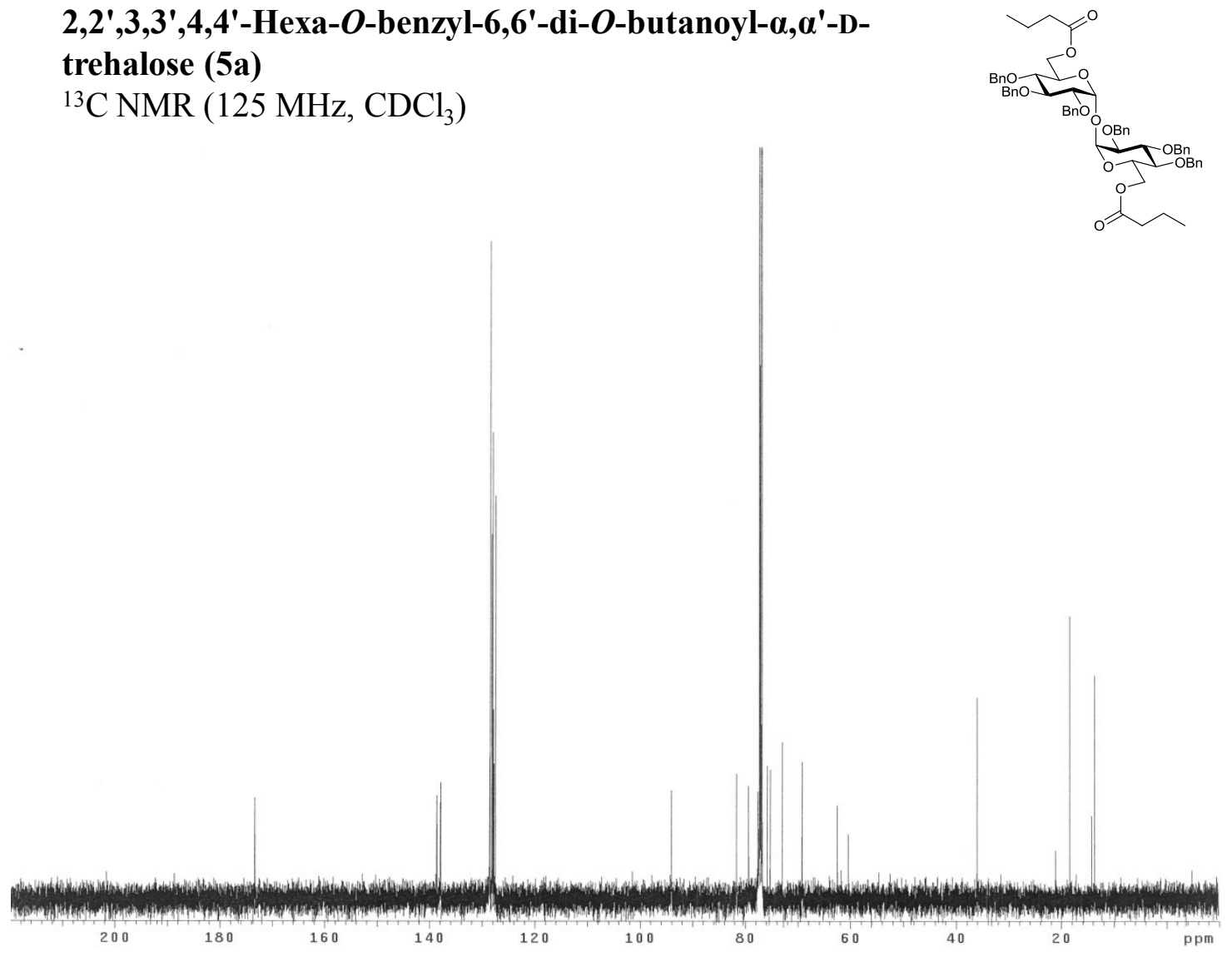

210 
$2,2^{\prime}, 3,33^{\prime}, 4,4^{\prime}$-Hexa-O-benzyl-6,6'-di- $O$-heptanoyl- $\alpha, \alpha^{\prime}$-Dtrehalose (5b)

${ }^{1} \mathrm{H}$ NMR (500 MHz, $\mathrm{CDCl}_{3}$ )
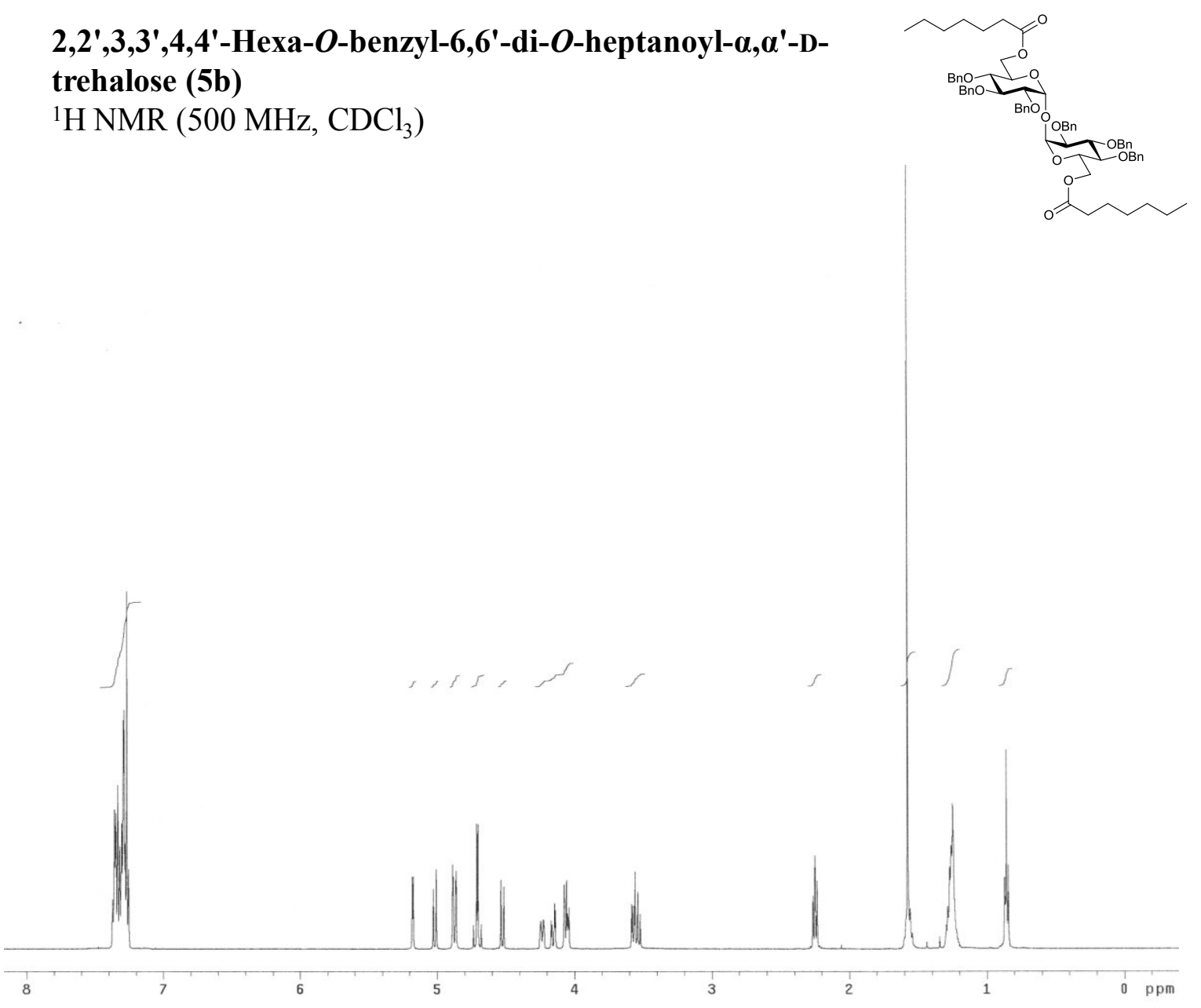

$2,2^{\prime}, 3,3^{\prime}, 4,4^{\prime}$-Hexa- $O$-benzyl-6,6'-di- $O$-heptanoyl- $\alpha, \alpha^{\prime}$-Dtrehalose (5b)

${ }^{13} \mathrm{C}$ NMR $\left(125 \mathrm{MHz}, \mathrm{CDCl}_{3}\right.$ )

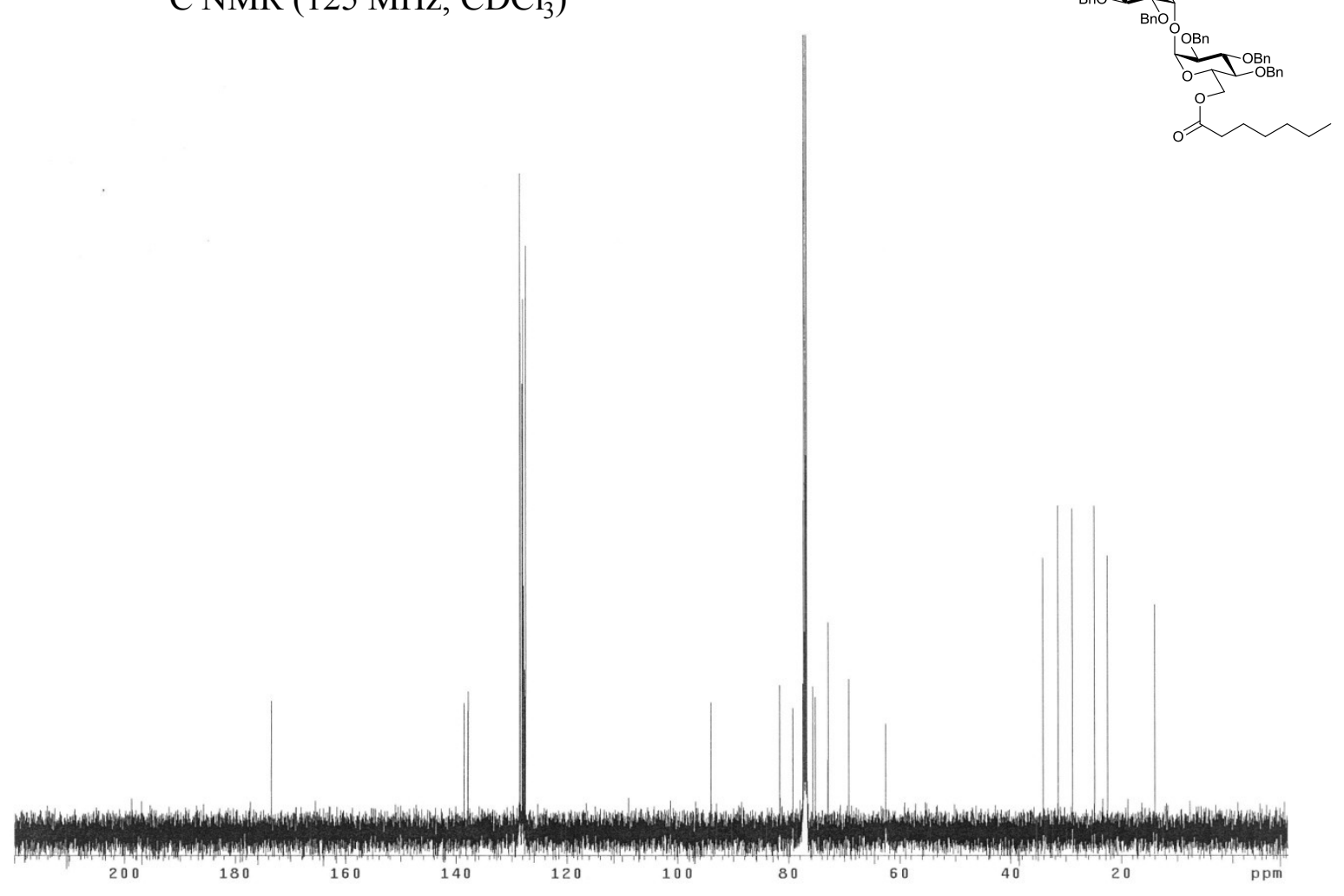


$2,2^{\prime}, 3,3^{\prime}, 4,4^{\prime}$-hexa- $O$-benzyl-6,6'-di- $O$-decanoyl- $\alpha, \alpha^{\prime}$-Dtrehalose (5c)

${ }^{1} \mathrm{H} \mathrm{NMR}\left(500 \mathrm{MHz}, \mathrm{CDCl}_{3}\right)$
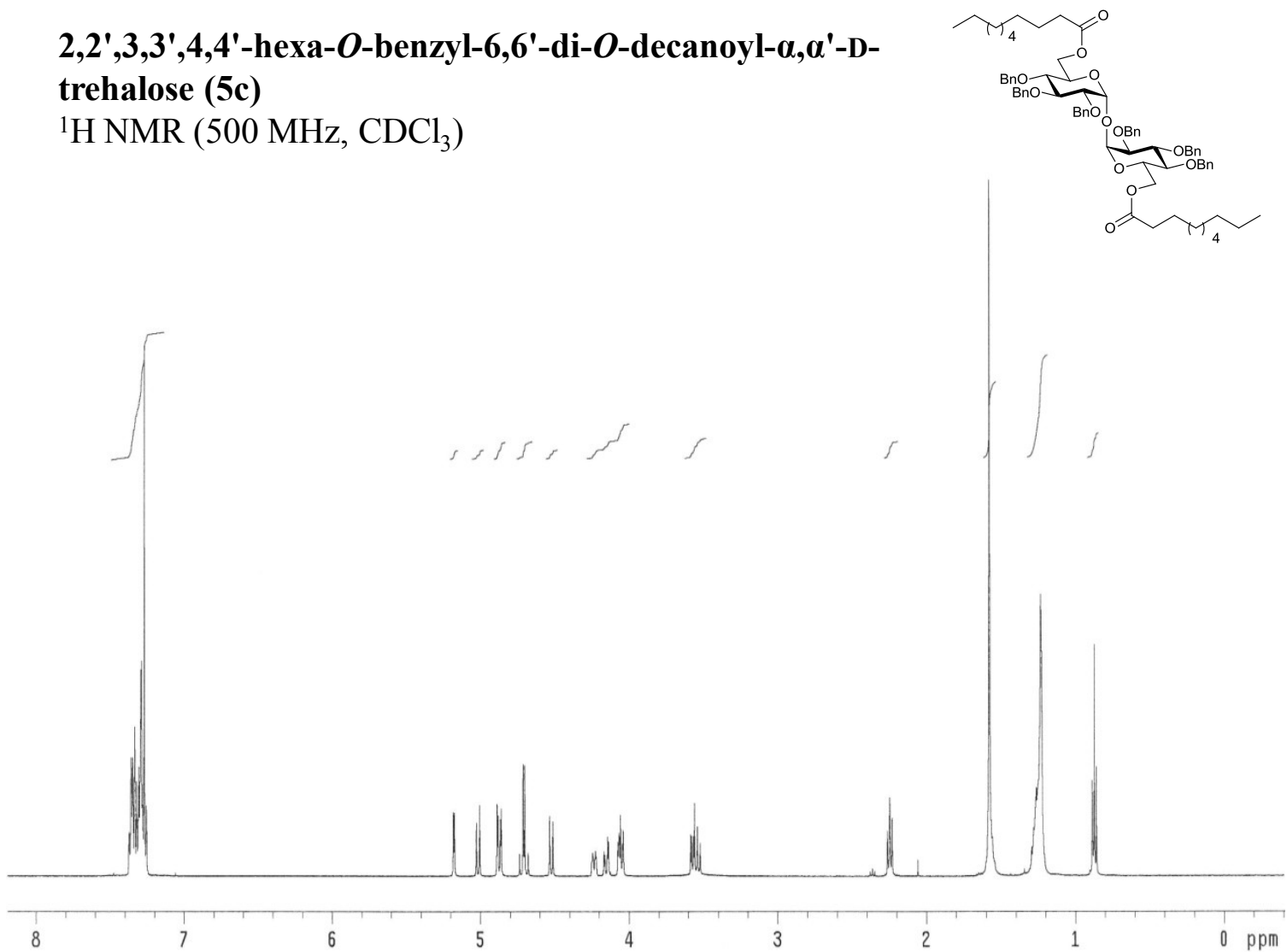

$2,2^{\prime}, 3,3^{\prime}, 4,4^{\prime}$-hexa- $O$-benzyl-6,6'-di- $O$-decanoyl-a, $\alpha^{\prime}$-Dtrehalose (5c)

${ }^{13} \mathrm{C} \mathrm{NMR}\left(125 \mathrm{MHz}, \mathrm{CDCl}_{3}\right)$
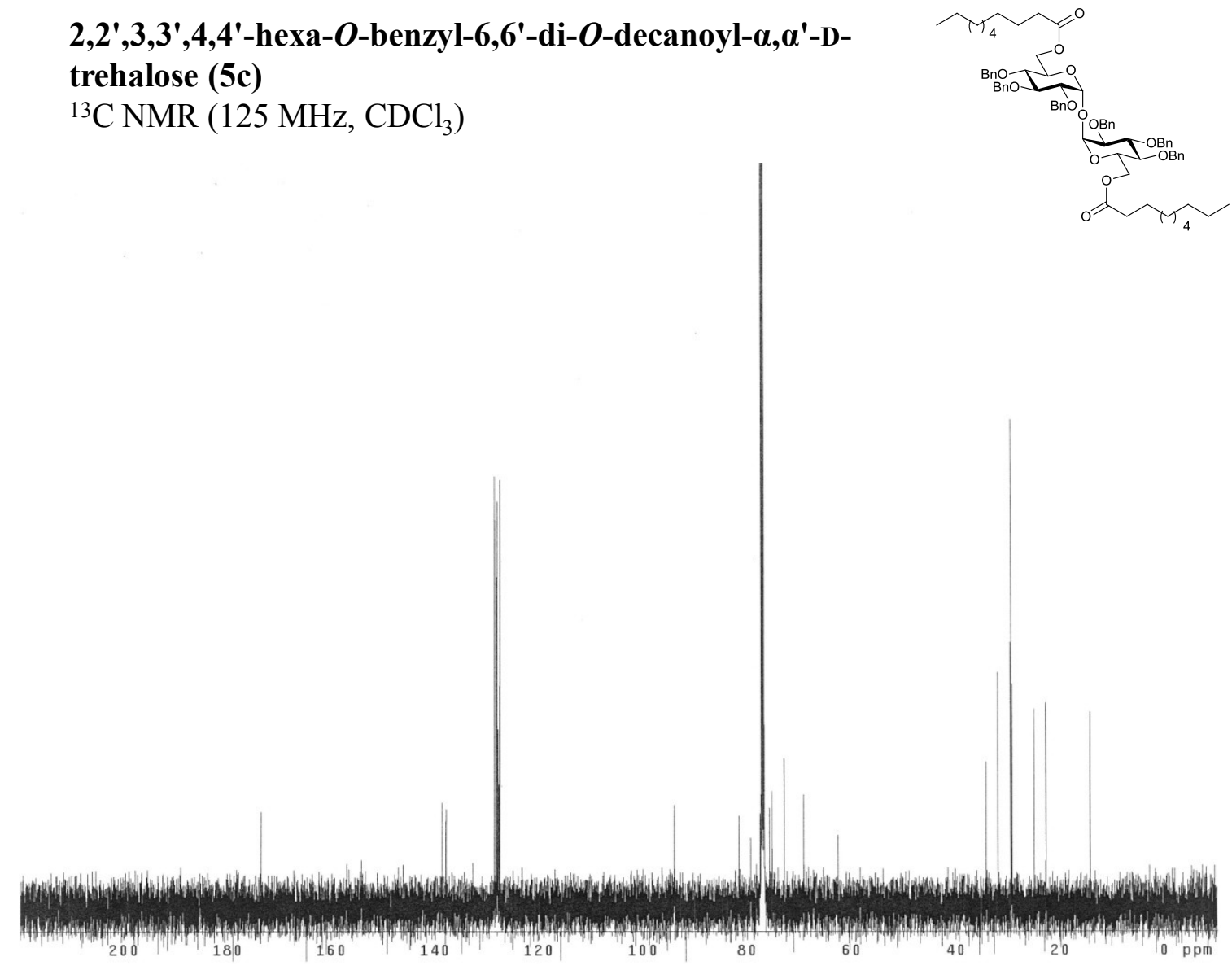
$2,2^{\prime}, 3,3^{\prime}, 4,4^{\prime}$-Hexa-O-benzyl-6,6'-di- $O$-stearoyl- $\alpha, \alpha^{\prime}$-Dtrehalose (5d)

${ }^{1} \mathrm{H} \mathrm{NMR}\left(500 \mathrm{MHz}, \mathrm{CDCl}_{3}\right)$

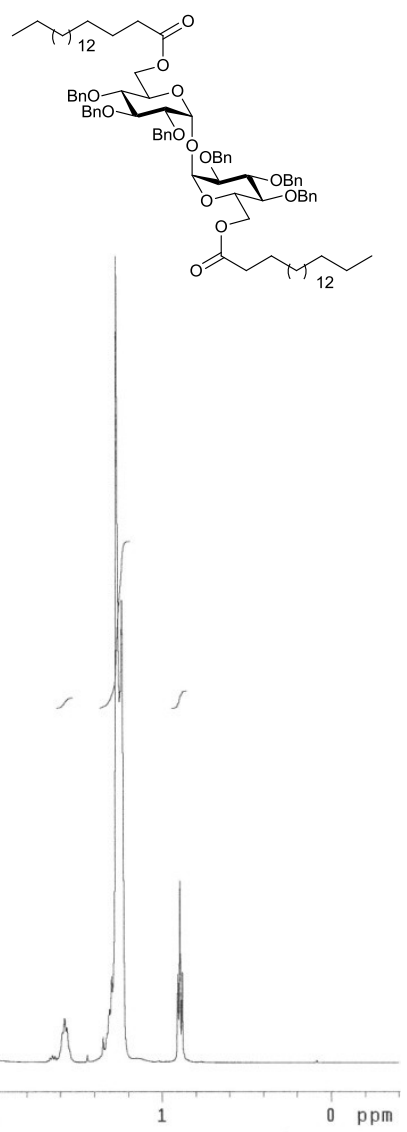

$2,2^{\prime}, 3,3^{\prime}, 4,4^{\prime}-$ Hexa-O-benzyl-6, $6^{\prime}$-di- $O$-stearoyl- $\alpha, \alpha^{\prime}$-Dtrehalose (5d)

${ }^{13} \mathrm{C} \mathrm{NMR}\left(125 \mathrm{MHz}, \mathrm{CDCl}_{3}\right)$

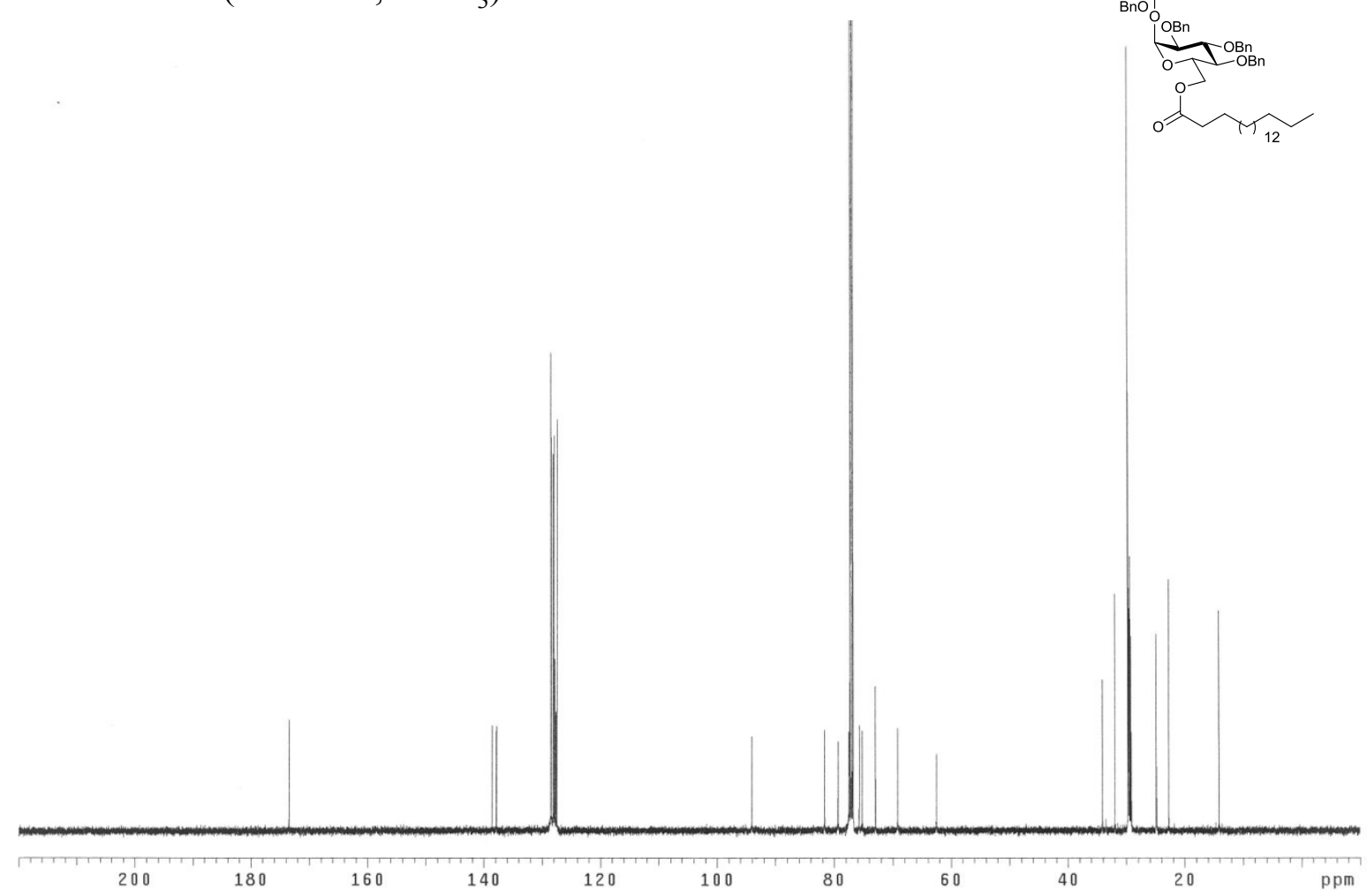


2,2',3,3',4,4'-hexa- $O$-trimethylsilyl- $\alpha, \alpha^{\prime}$-D-trehalose (6) ${ }^{1} \mathrm{H} \mathrm{NMR}\left(500 \mathrm{MHz}, \mathrm{CDCl}_{3}\right)$
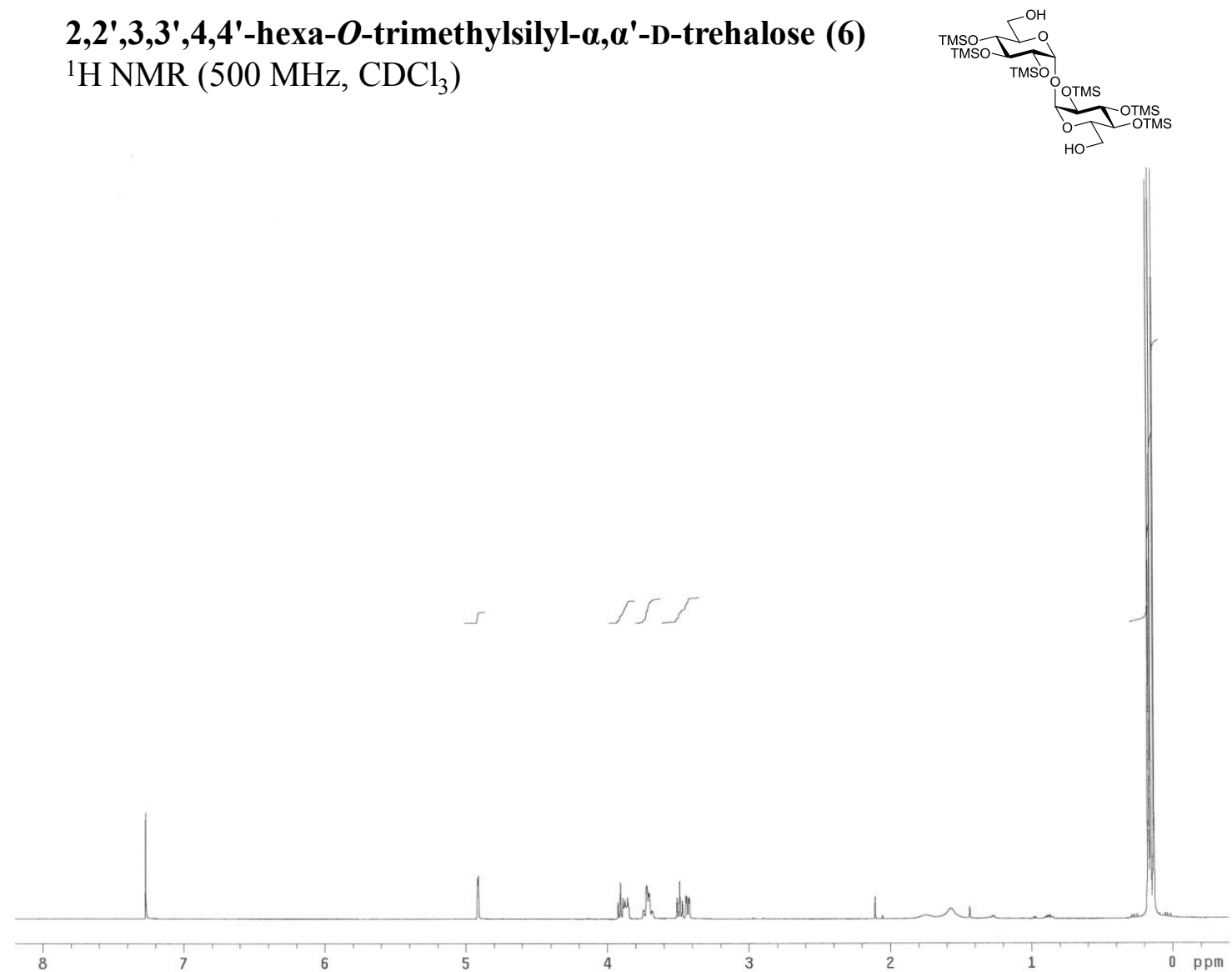

$2,2^{\prime}, 3,3^{\prime}, 4,4^{\prime}$-hexa- $O$-trimethylsilyl- $\alpha, \alpha^{\prime}$-D-trehalose (6) ${ }^{13} \mathrm{C} \mathrm{NMR}\left(125 \mathrm{MHz}, \mathrm{CDCl}_{3}\right)$

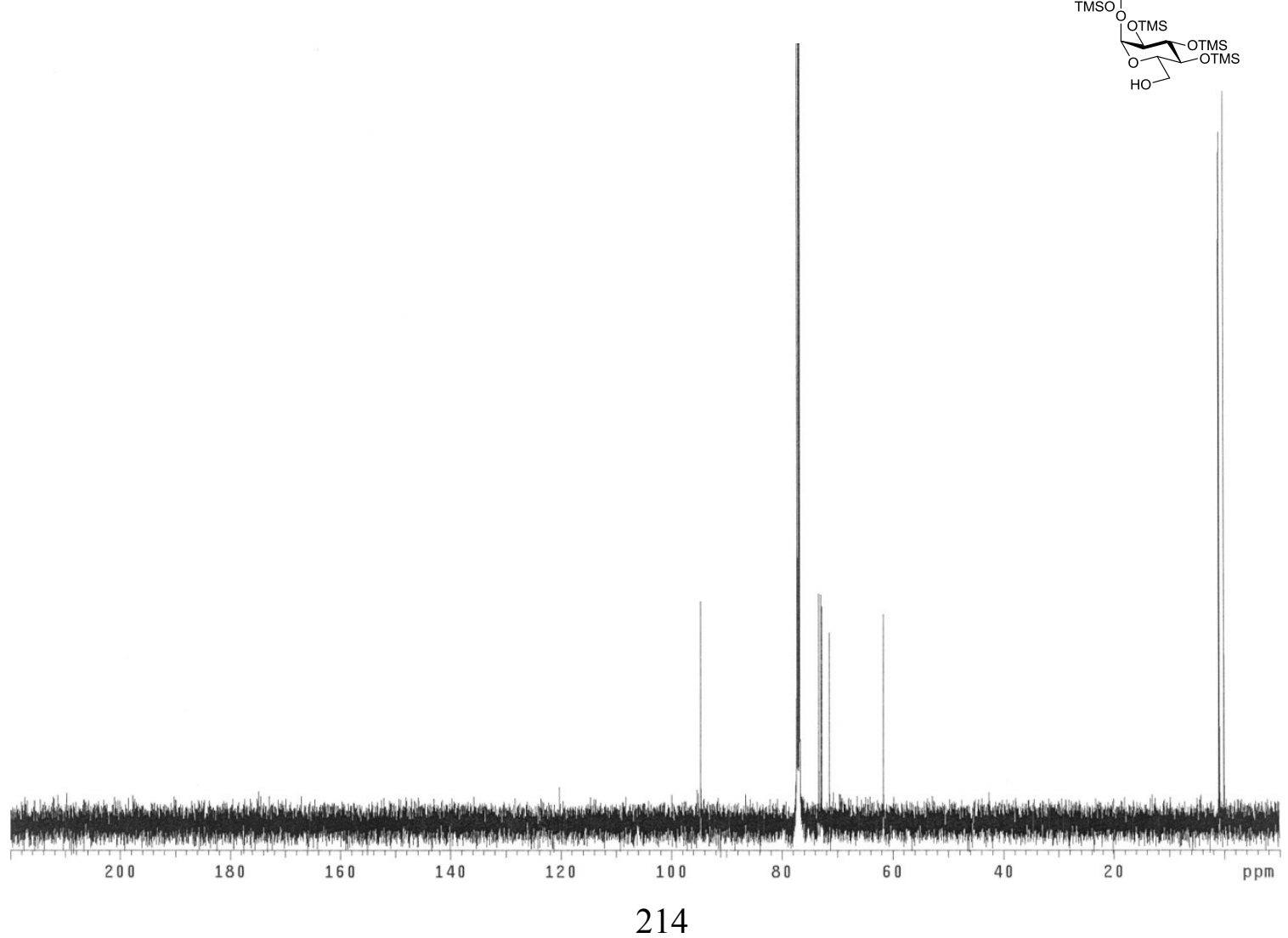


2,2',3,3',4,4'-Hexa-O-trimethylsilyl-6,6'-di-eicosanoyl$\alpha, \alpha^{\prime}$-D-trehalose (7e)

${ }^{1} \mathrm{H} \mathrm{NMR}\left(500 \mathrm{MHz}, \mathrm{CDCl}_{3}\right)$

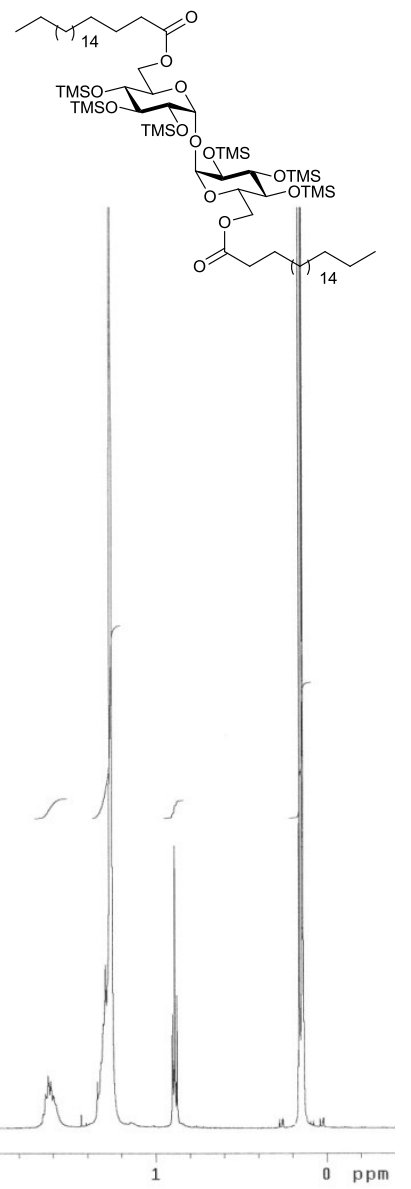

$2,2^{\prime}, 3,3^{\prime}, 4,4^{\prime}$-Hexa-O-trimethylsilyl-6,6'-di-eicosanoyl$\alpha, \alpha^{\prime}$-D-trehalose (7e)

${ }^{13} \mathrm{C} \mathrm{NMR}\left(125 \mathrm{MHz}, \mathrm{CDCl}_{3}\right)$

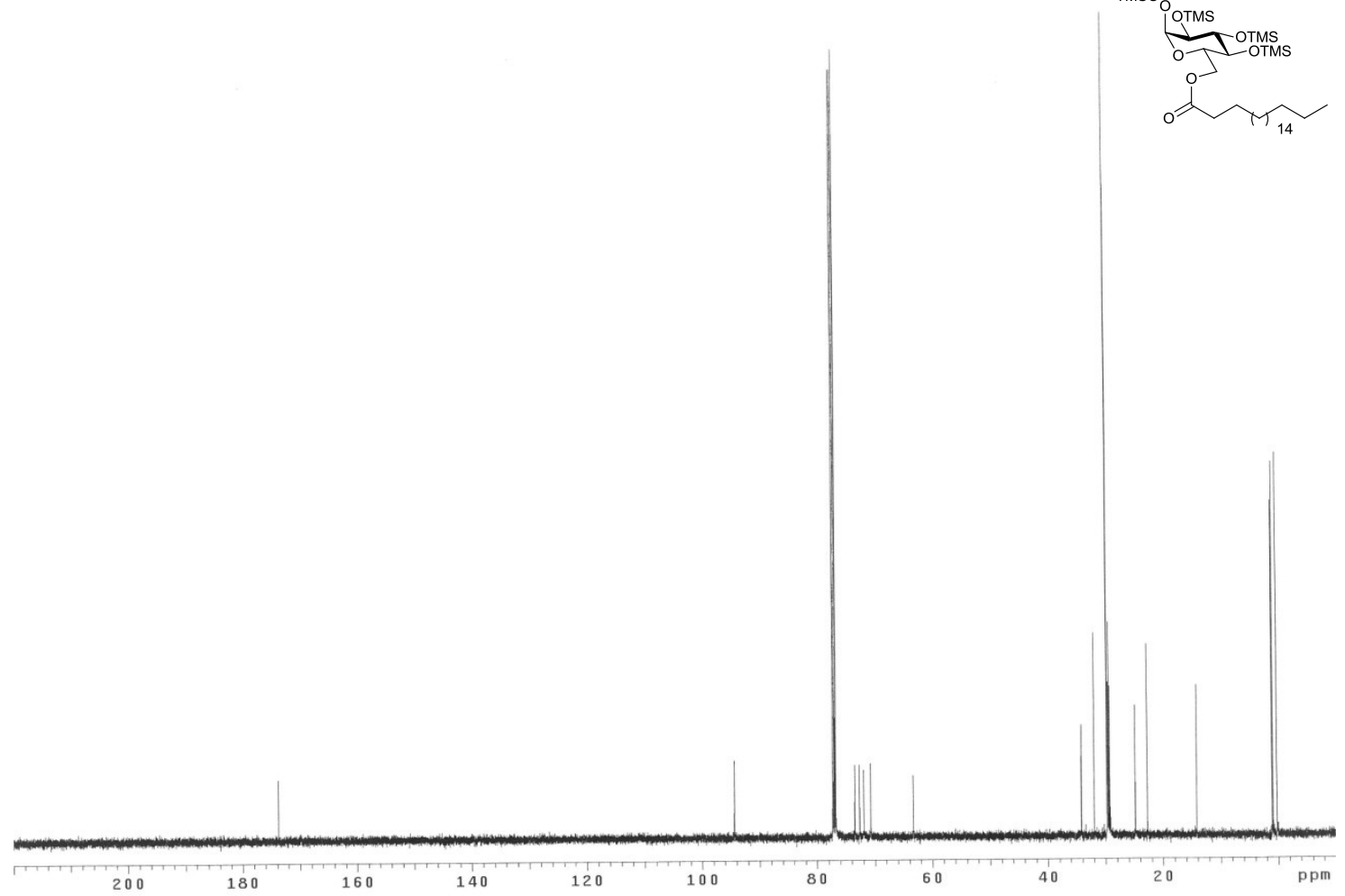


2,2',3,3',4,4'-Hexa-O-trimethylsilyl-6,6'-di-docosanoyl$\alpha, \alpha^{\prime}$-D-trehalose (7f)

${ }^{1} \mathrm{H}$ NMR $\left(500 \mathrm{MHz}, \mathrm{CDCl}_{3}\right)$

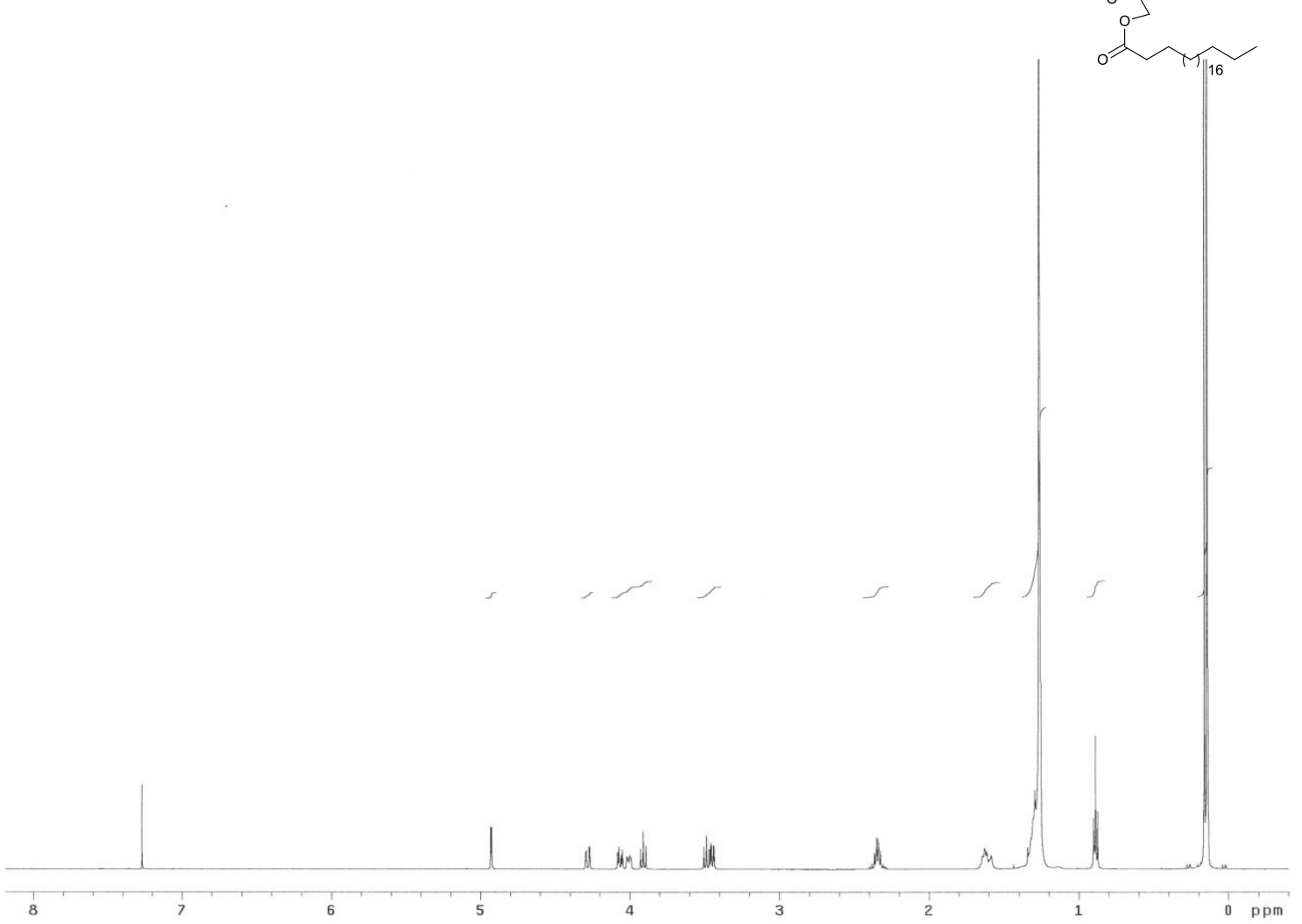

$2,2^{\prime}, 3,3^{\prime}, 4,4^{\prime}$-Hexa-O-trimethylsilyl-6,6'-di-docosanoyl$\alpha, \alpha^{\prime}$-D-trehalose (7f)

${ }^{13} \mathrm{C}$ NMR $\left(125 \mathrm{MHz}, \mathrm{CDCl}_{3}\right)$

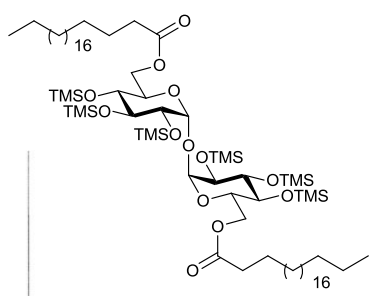


2,2',3,3',4,4'-Hexa-O-trimethylsilyl-6,6'-di-hexacosanoyl$\alpha, \alpha^{\prime}$-D-trehalose (7g)

${ }^{1} \mathrm{H} \mathrm{NMR}\left(500 \mathrm{MHz}, \mathrm{CDCl}_{3}\right)$
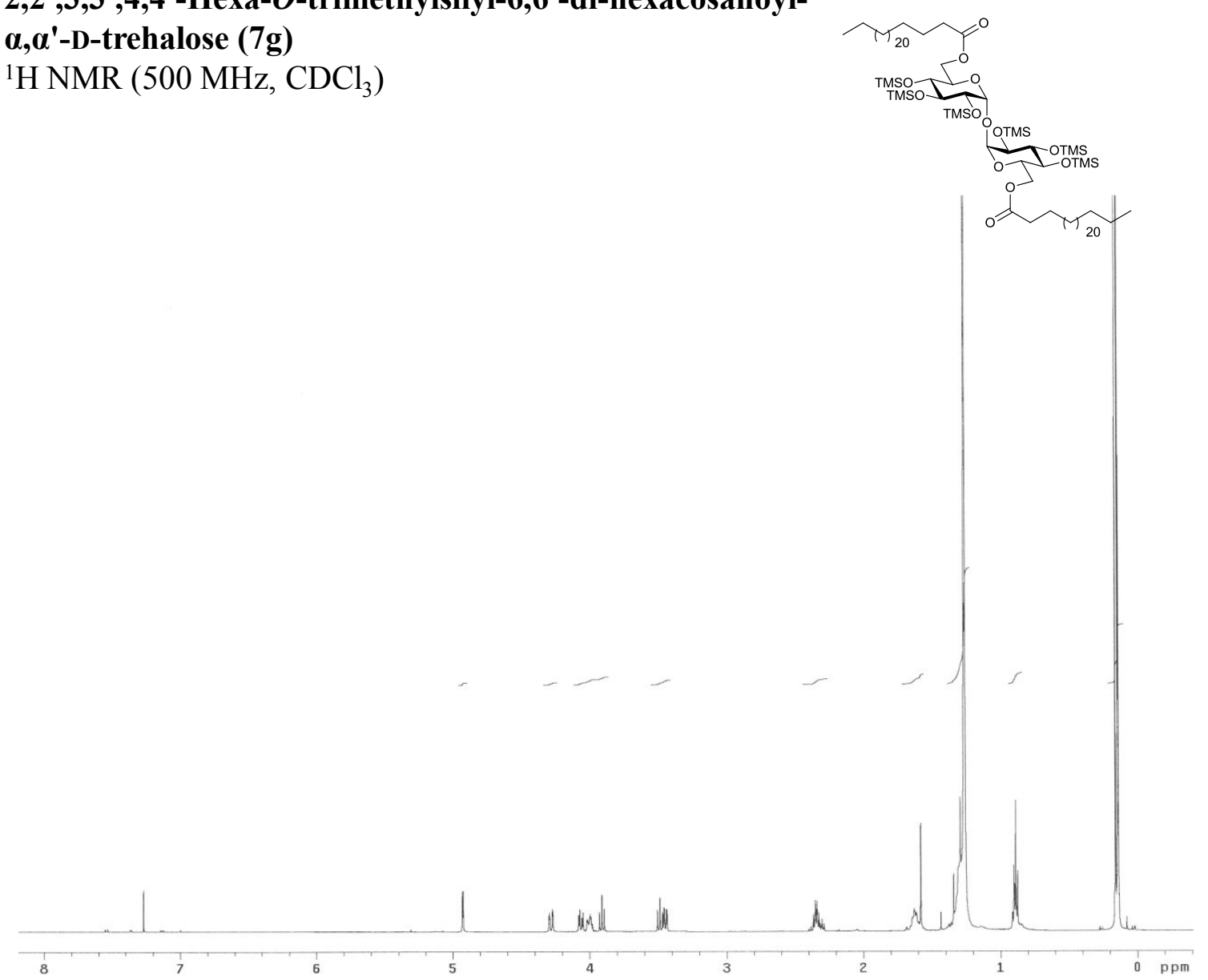

$2,2^{\prime}, 3,3^{\prime}, 4,4^{\prime}$-Hexa-O-trimethylsilyl-6,6'-dihexacosanoyl- $\alpha, \alpha^{\prime}$-D-trehalose (7g)

${ }^{13} \mathrm{C} \mathrm{NMR}\left(125 \mathrm{MHz}, \mathrm{CDCl}_{3}\right)$

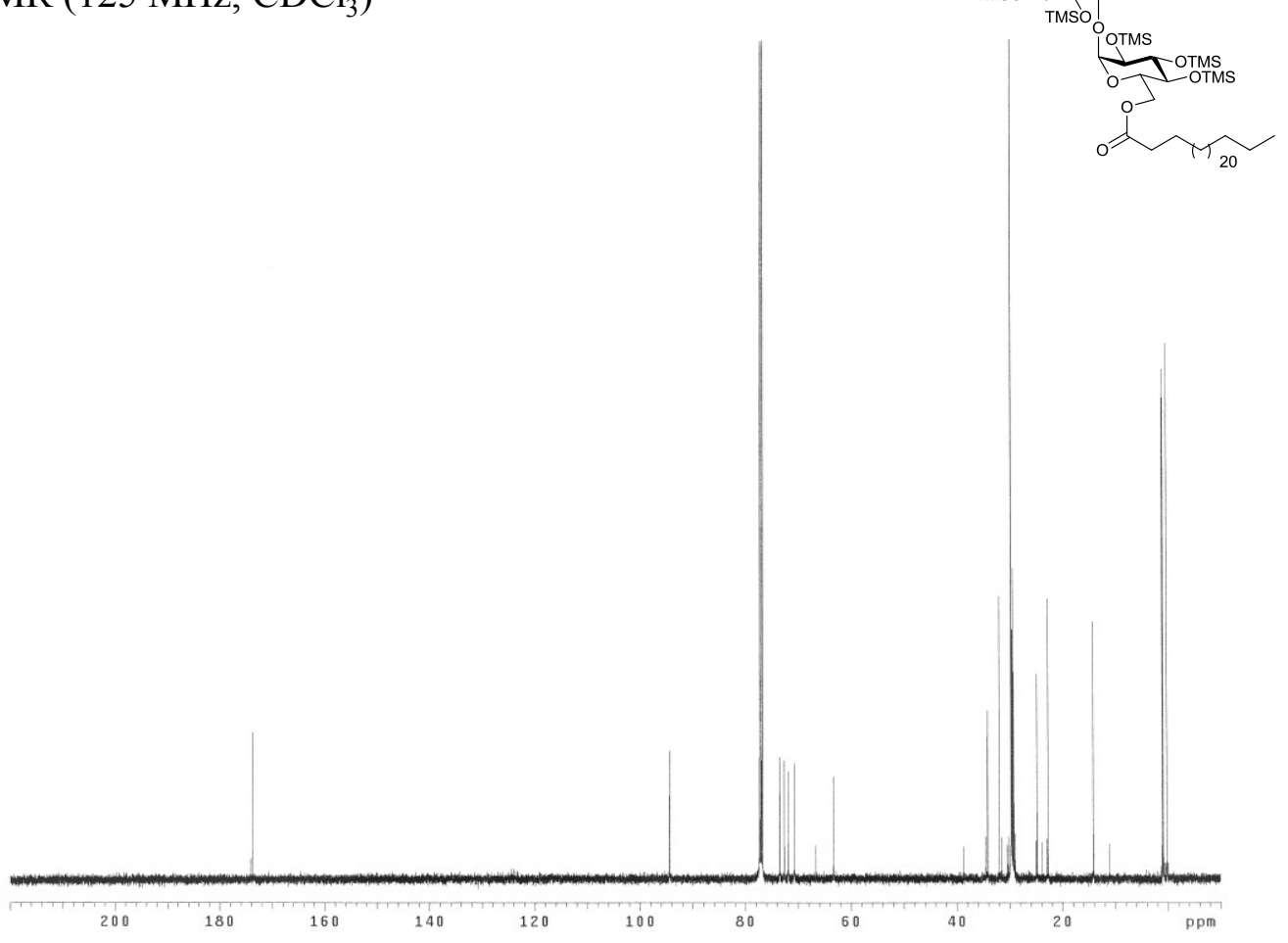


6,6'-Di- $O$-butanoyl- $\alpha, \alpha^{\prime}$-D-trehalose (1a)

${ }^{1} \mathrm{H} \mathrm{NMR}\left(500 \mathrm{MHz}, \mathrm{CD}_{3} \mathrm{OD}\right)$
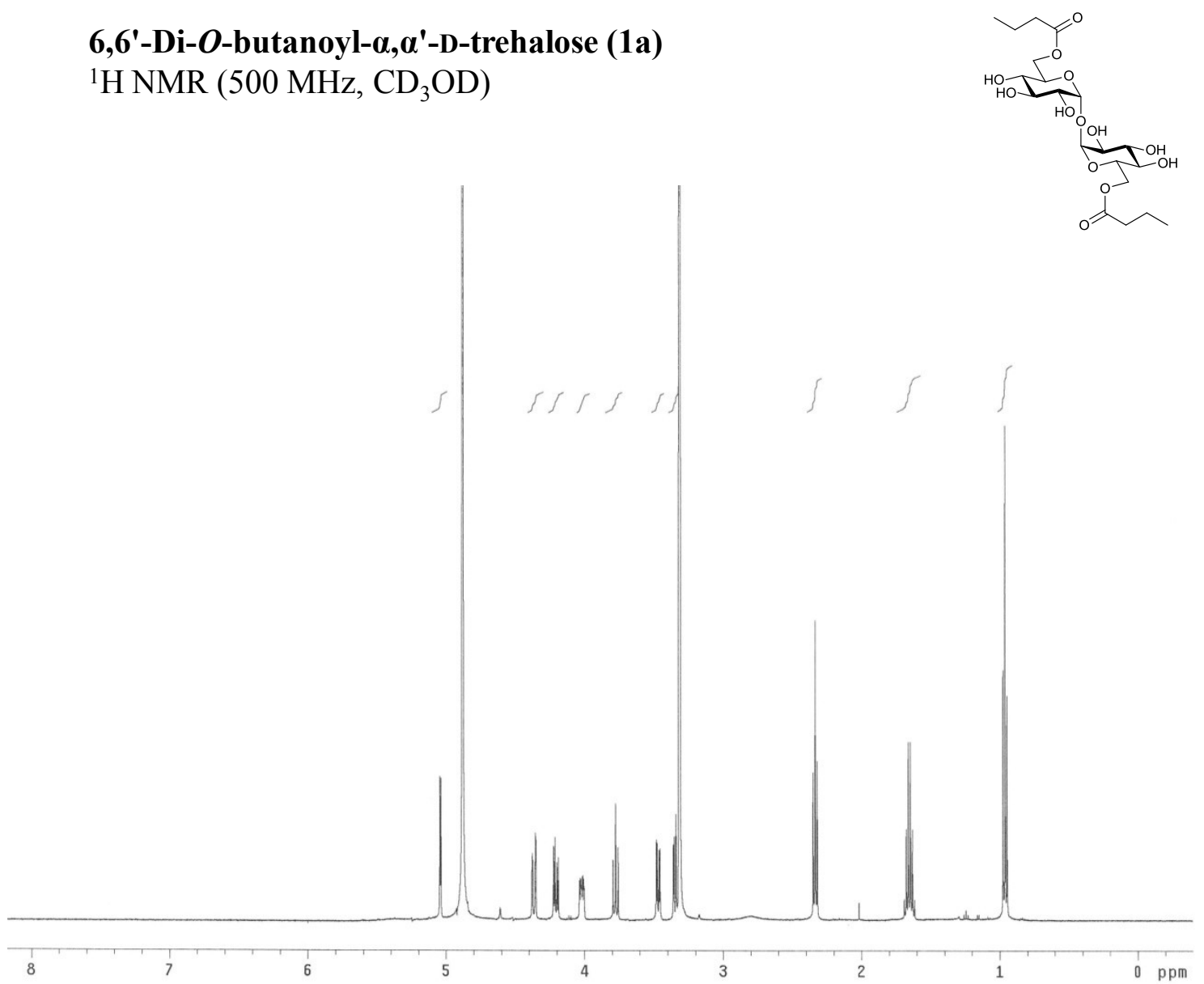

6,6'-Di- $O$-butanoyl- $\alpha, \alpha^{\prime}$-D-trehalose (1a)

${ }^{13} \mathrm{C}$ NMR (125 MHz, $\left.\mathrm{CD}_{3} \mathrm{OD}\right)$

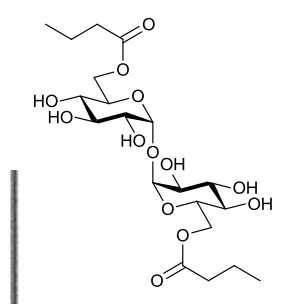


6,6'-Di- $O$-heptanoyl- $\alpha, \alpha^{\prime}-D$-trehalose (1b)

${ }^{1} \mathrm{H} \mathrm{NMR}\left(500 \mathrm{MHz}, \mathrm{CD}_{3} \mathrm{OD}\right)$
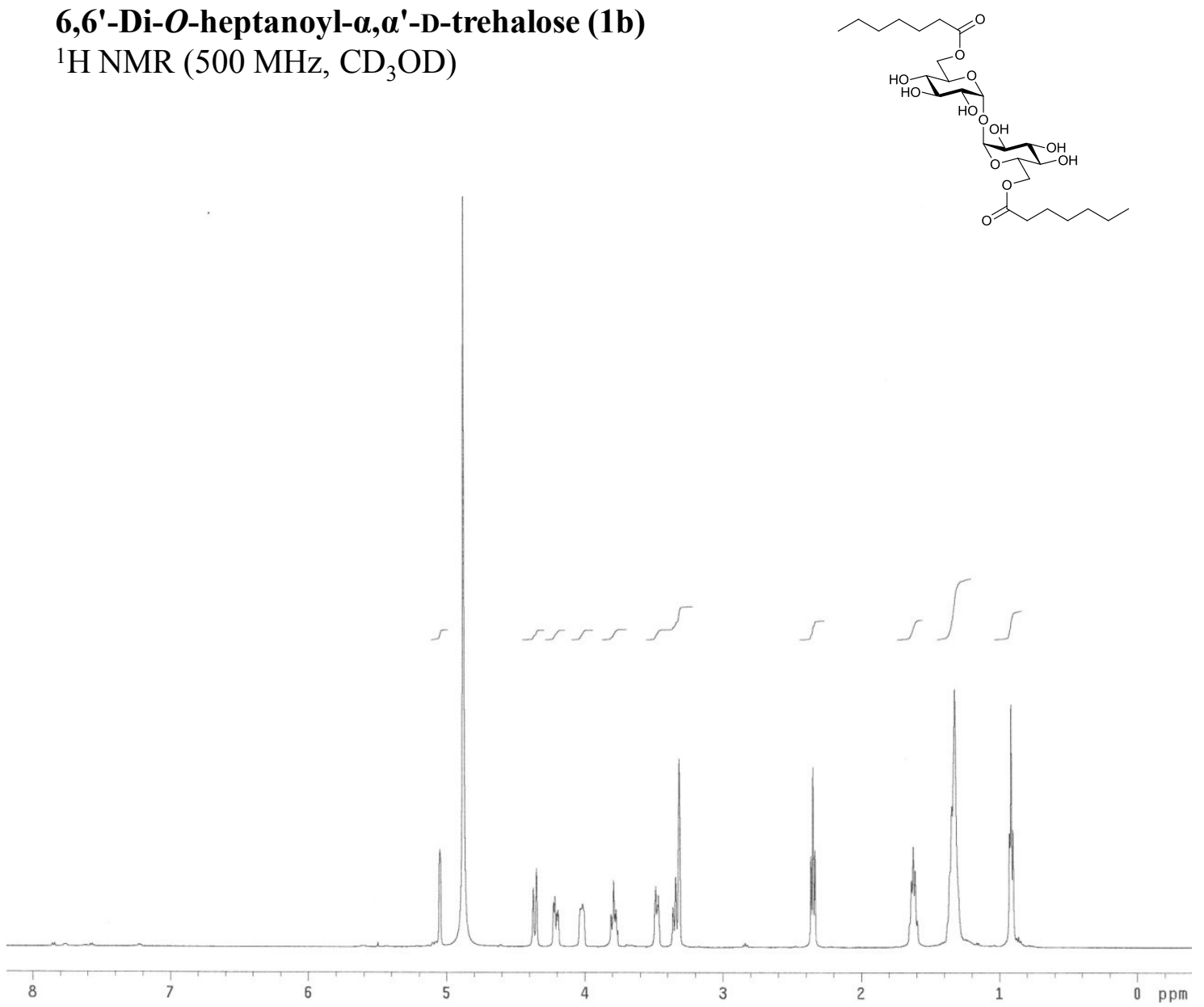

6,6'-Di- $O$-heptanoyl- $\alpha, \alpha^{\prime}$-D-trehalose (1b)

${ }^{13} \mathrm{C}$ NMR (125 MHz, CD $\left.3 \mathrm{OD}\right)$ 
6,6'-Di- $O$-decanoyl- $\alpha, \alpha^{\prime}$-D-trehalose (1c)

${ }^{1} \mathrm{H}$ NMR (500 MHz, $\mathrm{CD}_{3} \mathrm{OD}$ )
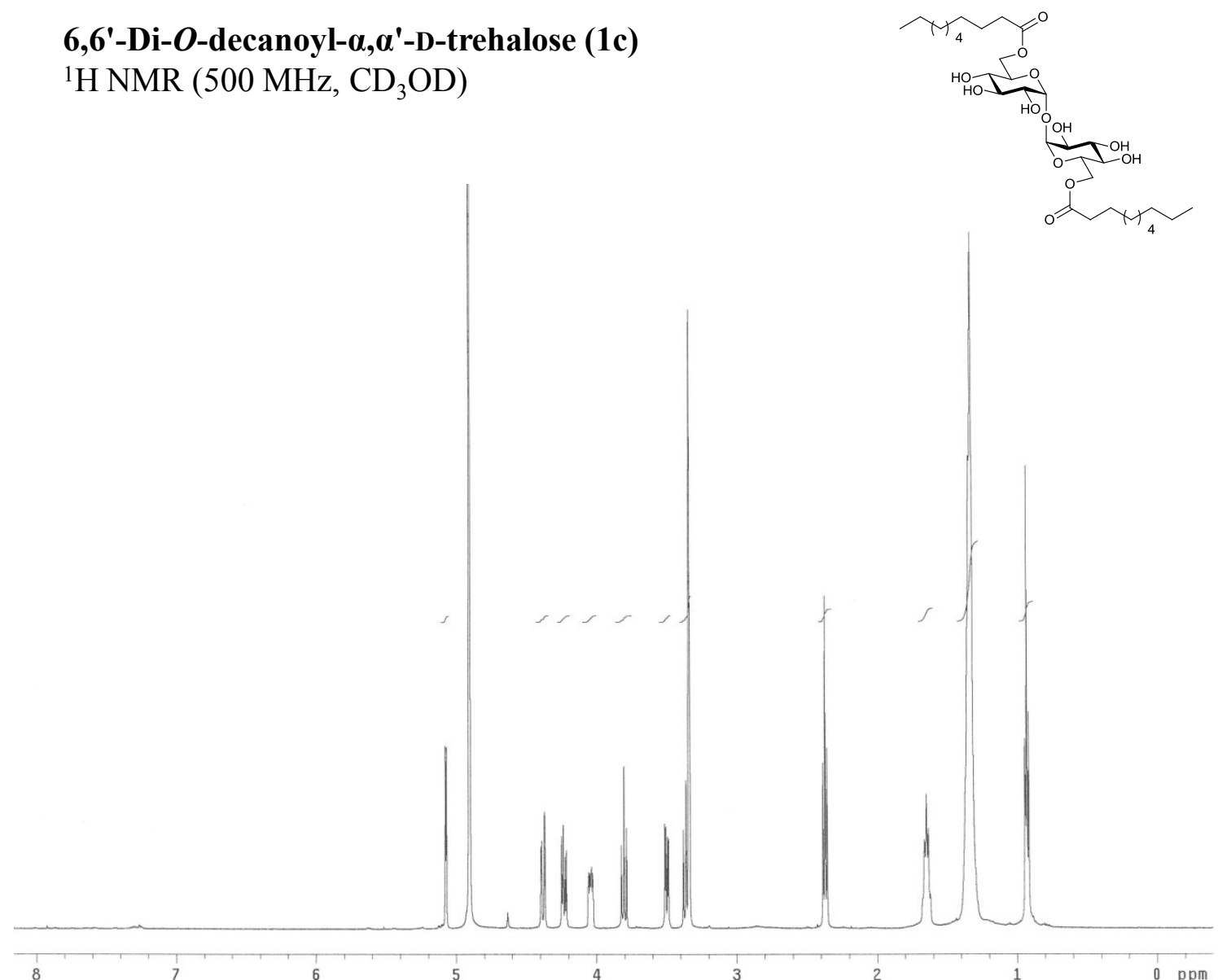

6,6'-Di- $O$-decanoyl- $\alpha, \alpha^{\prime}$-D-trehalose (1c)

${ }^{13} \mathrm{C}$ NMR (125 MHz, $\left.\mathrm{CD}_{3} \mathrm{OD}\right)$

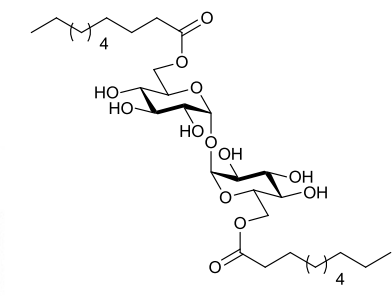


6,6'-Di- $\boldsymbol{O}$-stearoyl- $\alpha, \boldsymbol{\alpha}^{\prime}$-D-trehalose (1d)

${ }^{1} \mathrm{H} \mathrm{NMR}\left(500 \mathrm{MHz}, \mathrm{CD}_{3} \mathrm{OD}\right)$
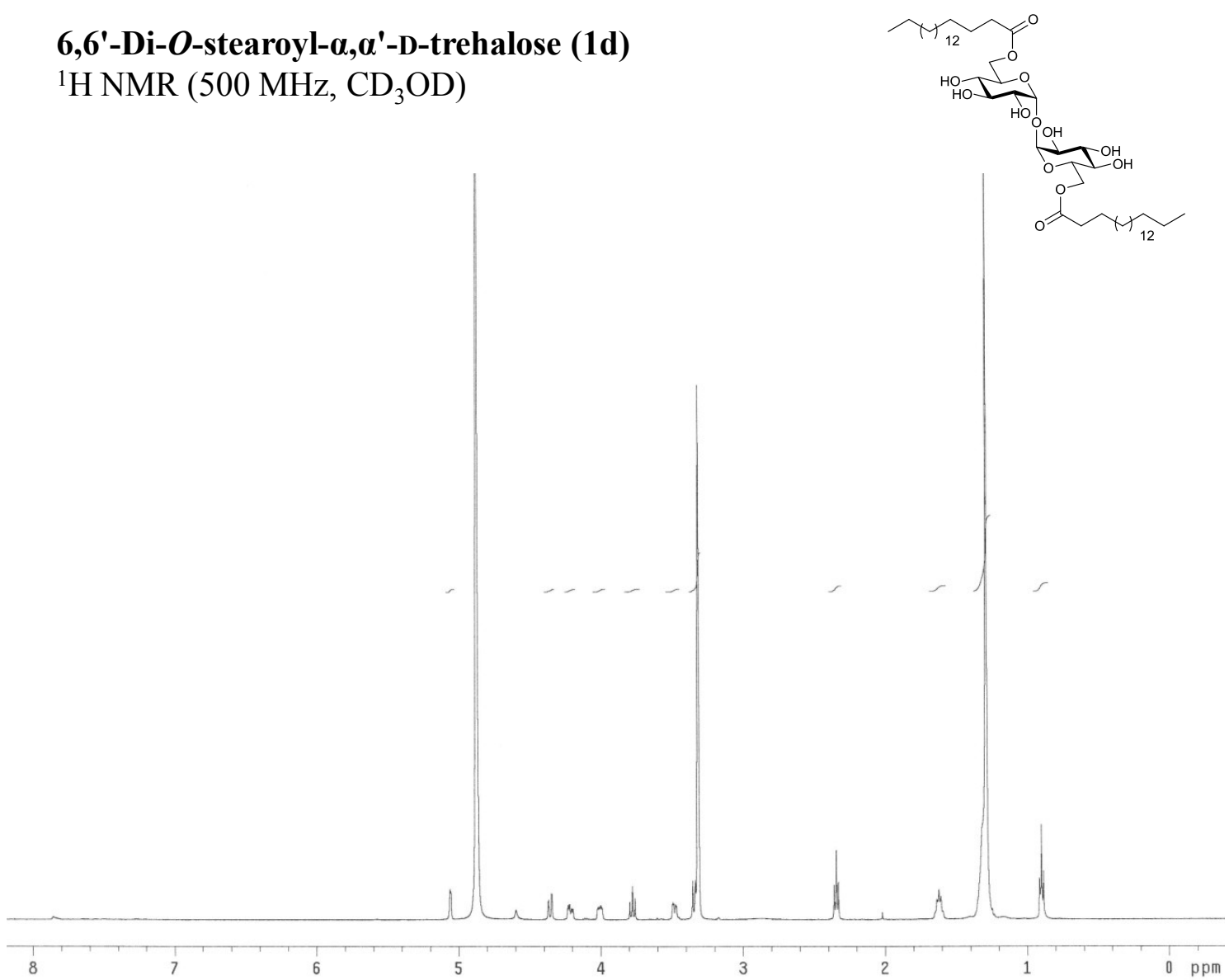

6,6'-Di- $O$-stearoyl- $\alpha, \alpha^{\prime}$-D-trehalose (1d)

${ }^{13} \mathrm{C}$ NMR (125 MHz, $\left.\mathrm{CD}_{3} \mathrm{OD}\right)$

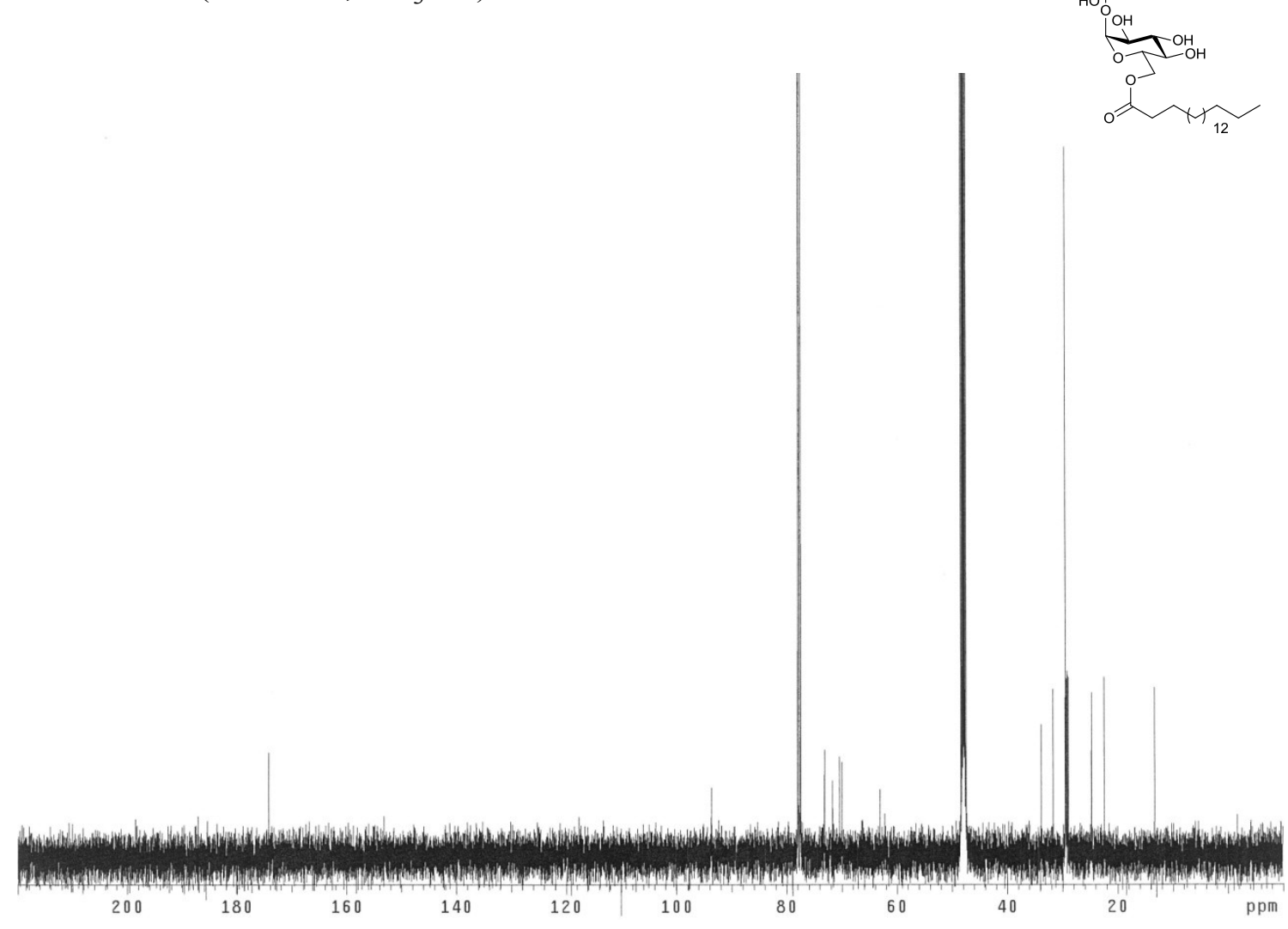


6,6'-Di- $O$-eicosanoyl- $\alpha, \alpha^{\prime}$-D-trehalose (1e)

${ }^{1} \mathrm{H} \mathrm{NMR}\left(500 \mathrm{MHz}, \mathrm{C}_{5} \mathrm{D}_{5} \mathrm{~N}\right)$
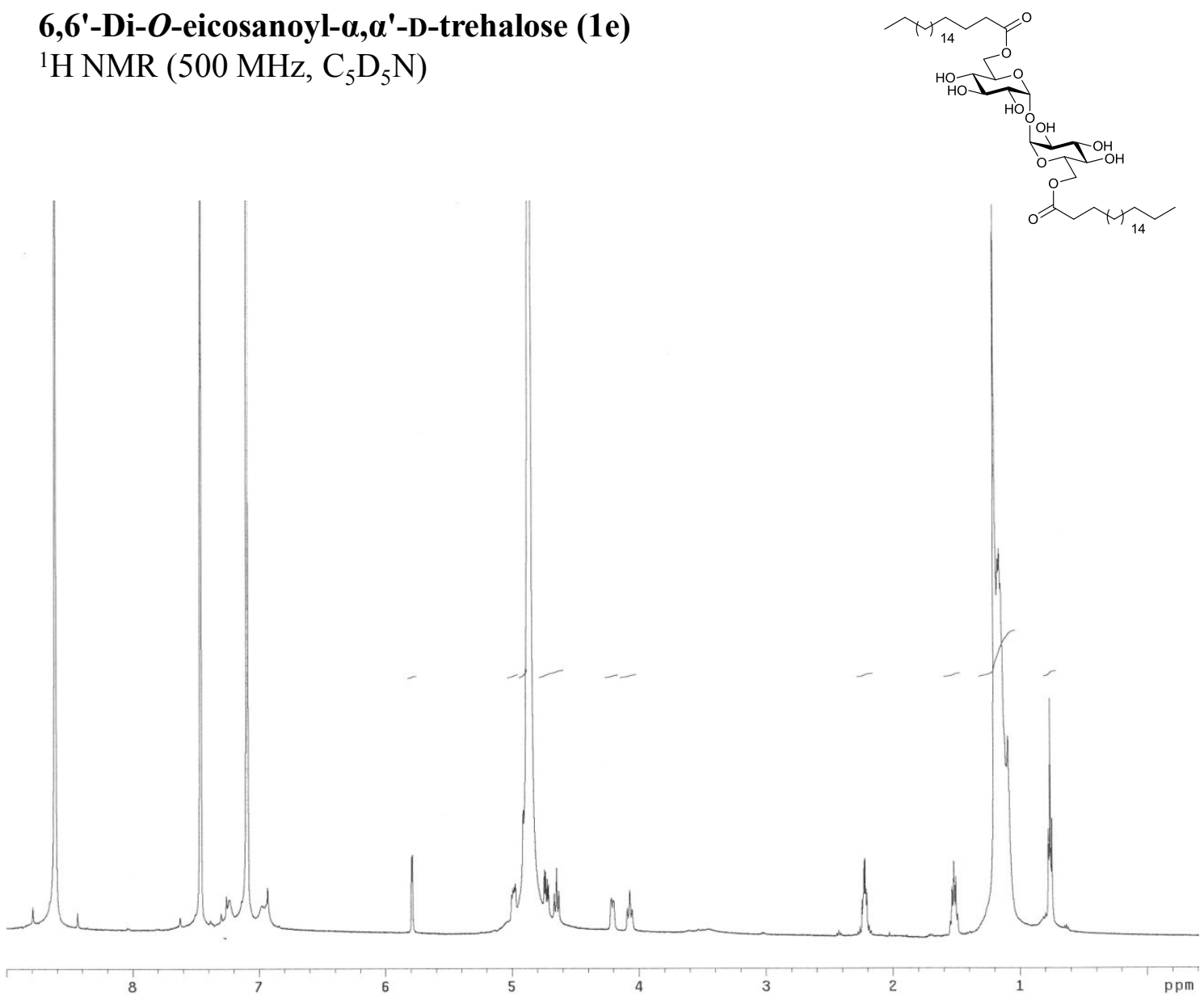

6,6'-Di-O-eicosanoyl- $\alpha, \alpha^{\prime}$-D-trehalose (1e)

${ }^{13} \mathrm{C}$ NMR (125 MHz, $\left.\mathrm{C}_{5} \mathrm{D}_{5} \mathrm{~N}\right)$
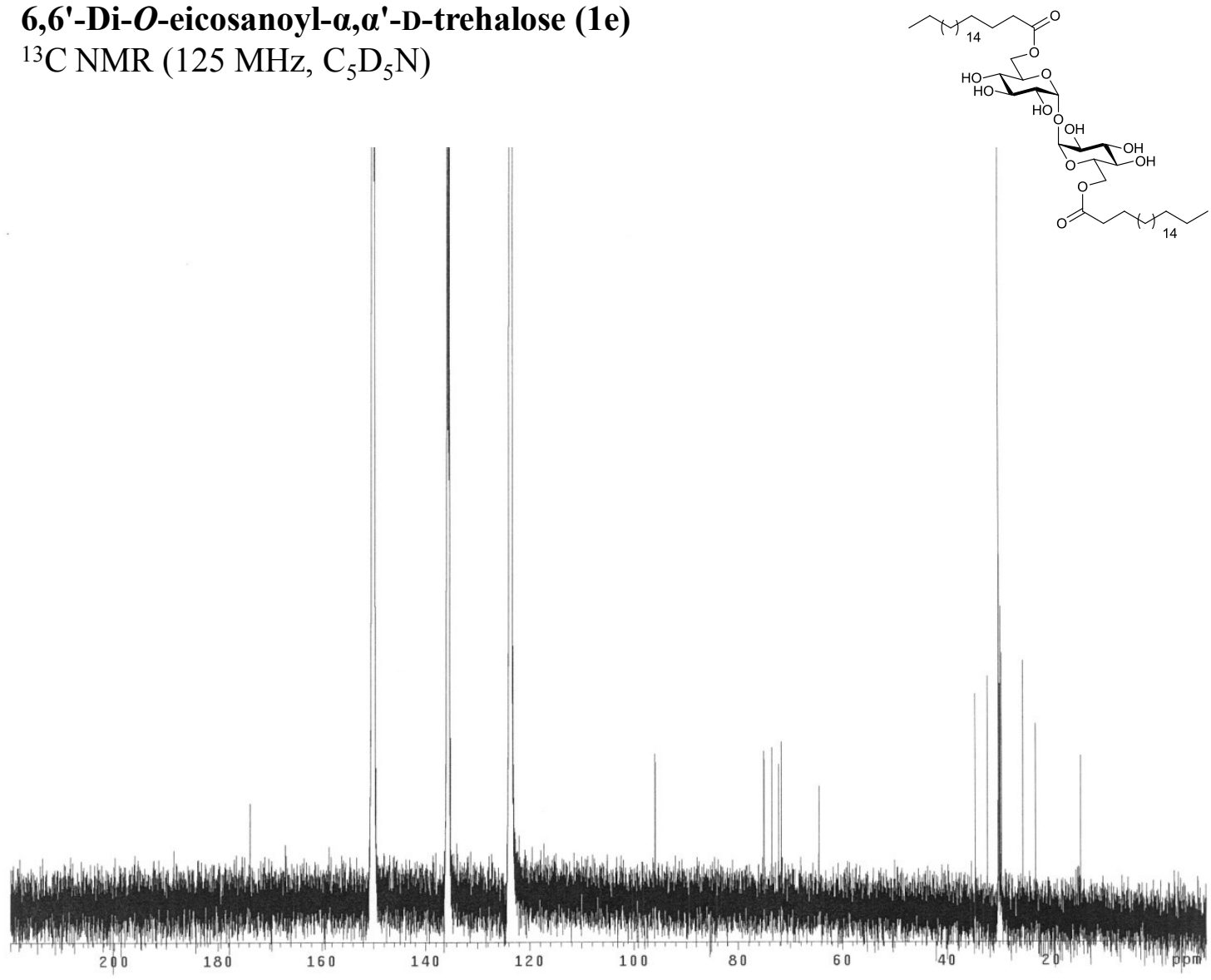
6,6'-Di-O-docosanoyl- $\alpha, \alpha^{\prime}$-D-trehalose (1f)

${ }^{1} \mathrm{H}$ NMR $\left(500 \mathrm{MHz}, \mathrm{C}_{5} \mathrm{D}_{5} \mathrm{~N}\right)$

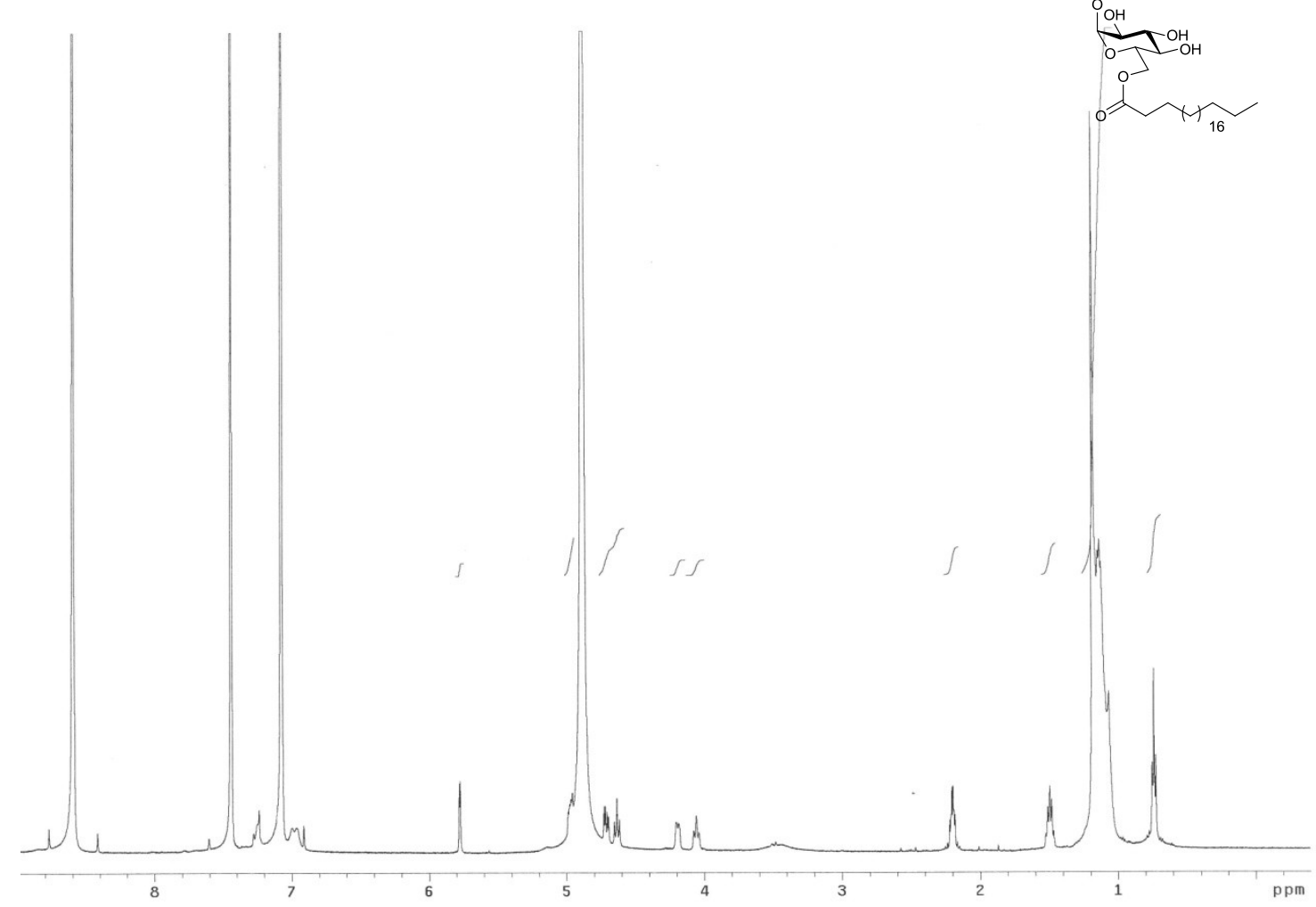

6,6'-Di-O-docosanoyl- $\alpha, \alpha^{\prime}$-D-trehalose (1f) ${ }^{13} \mathrm{C}$ NMR $\left(125 \mathrm{MHz}, \mathrm{C}_{5} \mathrm{D}_{5} \mathrm{~N}\right)$

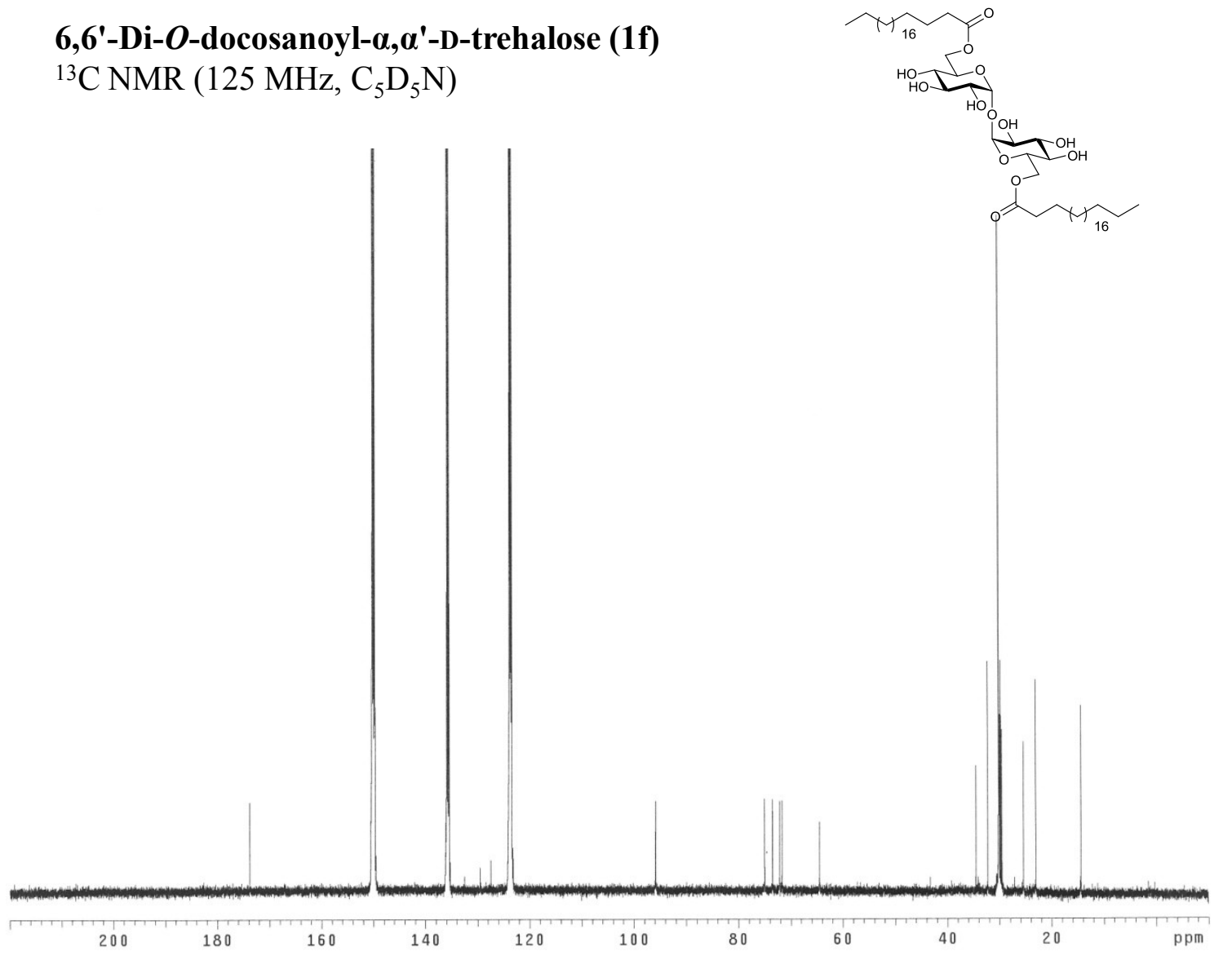

223 
6,6'-Di- $O$-hexacosanoyl- $\alpha, \alpha^{\prime}$-D-trehalose (1g)

${ }^{1} \mathrm{H} \mathrm{NMR}\left(500 \mathrm{MHz}, \mathrm{C}_{5} \mathrm{D}_{5} \mathrm{~N}\right)$
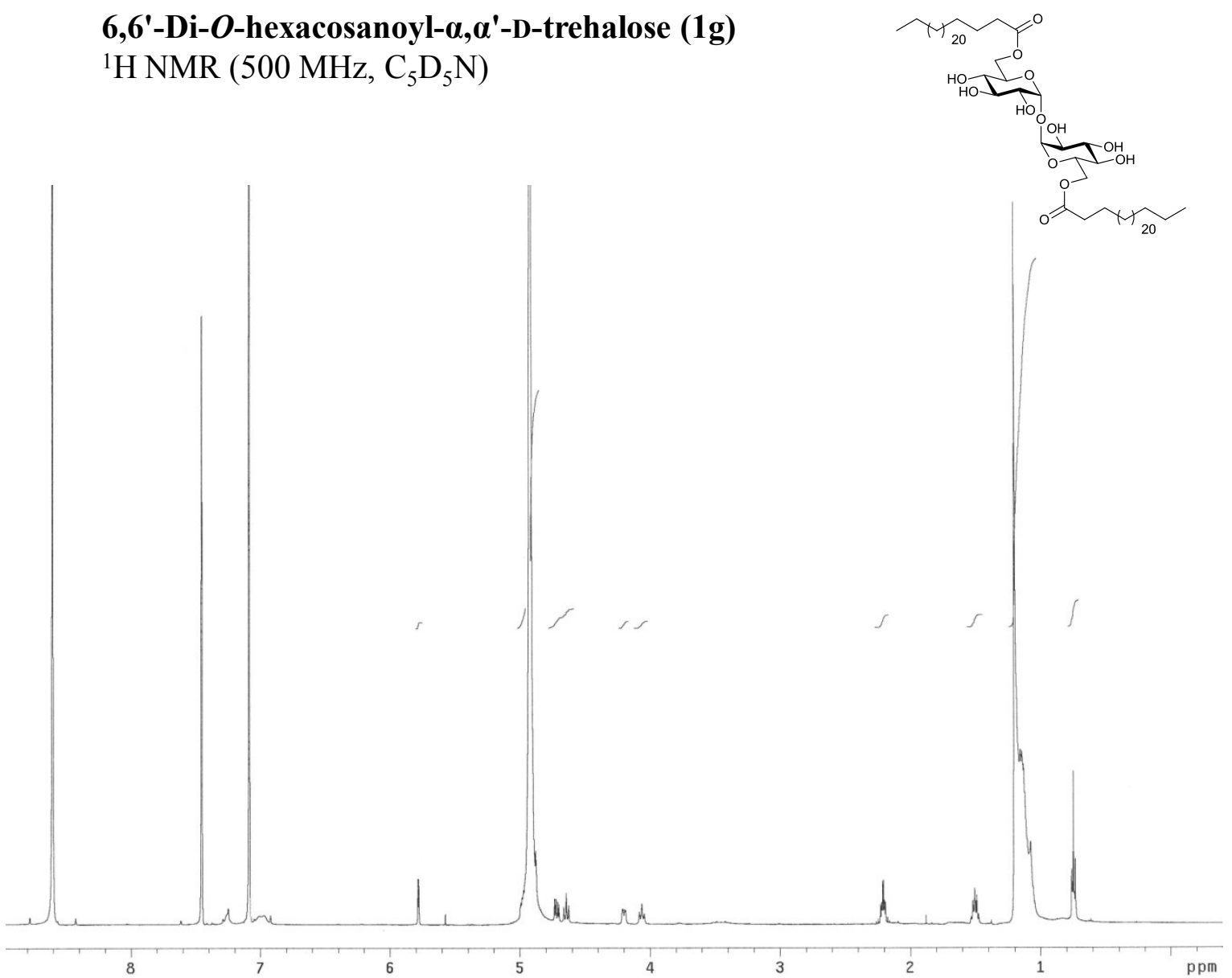

6,6'-Di- $O$-hexacosanoyl- $\alpha, \alpha^{\prime}$-D-trehalose (1g)

${ }^{13} \mathrm{C}$ NMR (125 MHz, $\left.\mathrm{C}_{5} \mathrm{D}_{5} \mathrm{~N}\right)$ )
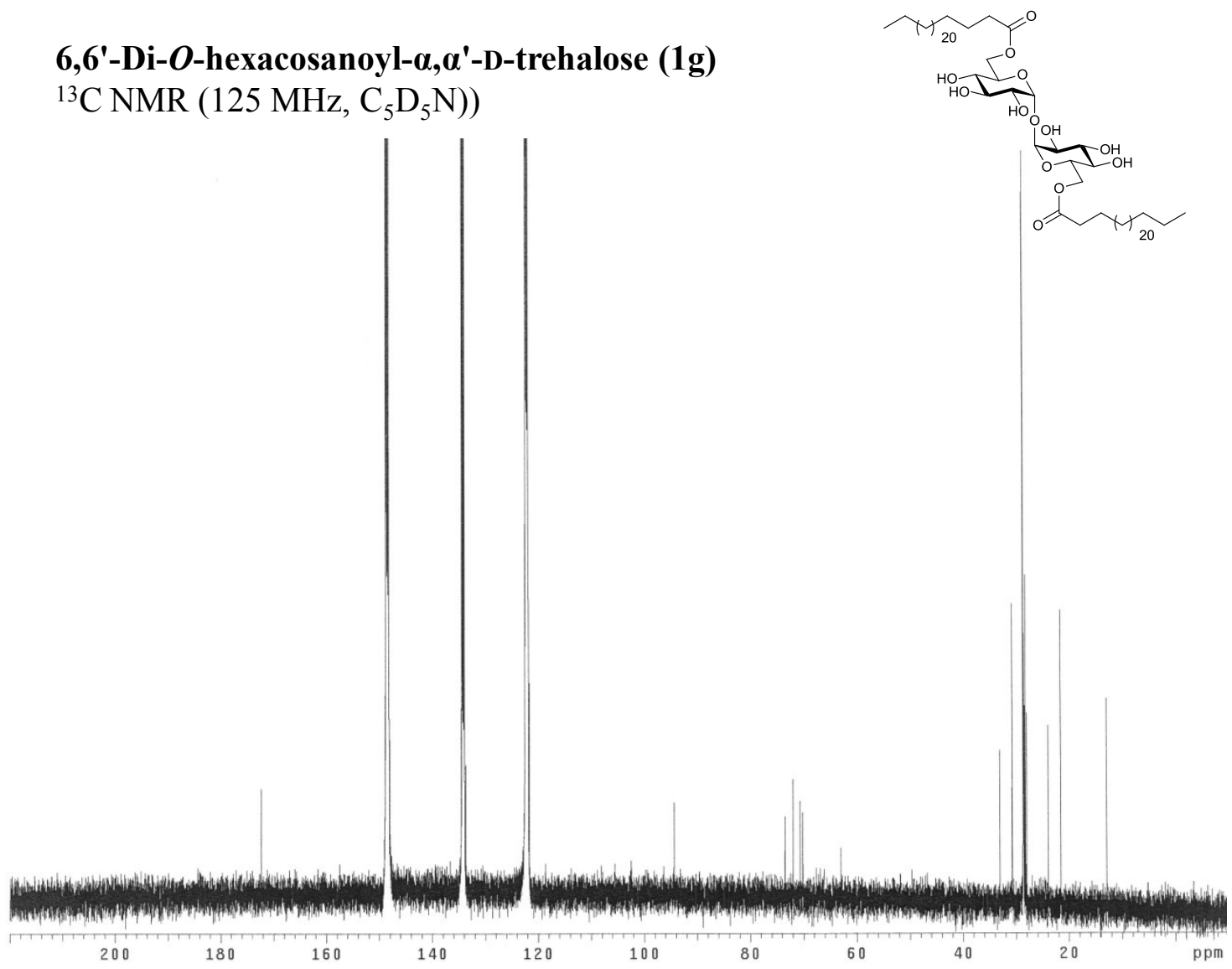

Chapter 4 

1-Octadecanal (6c)

${ }^{1} \mathrm{H}$ NMR $\left(500 \mathrm{MHz}, \mathrm{CDCl}_{3}\right)$
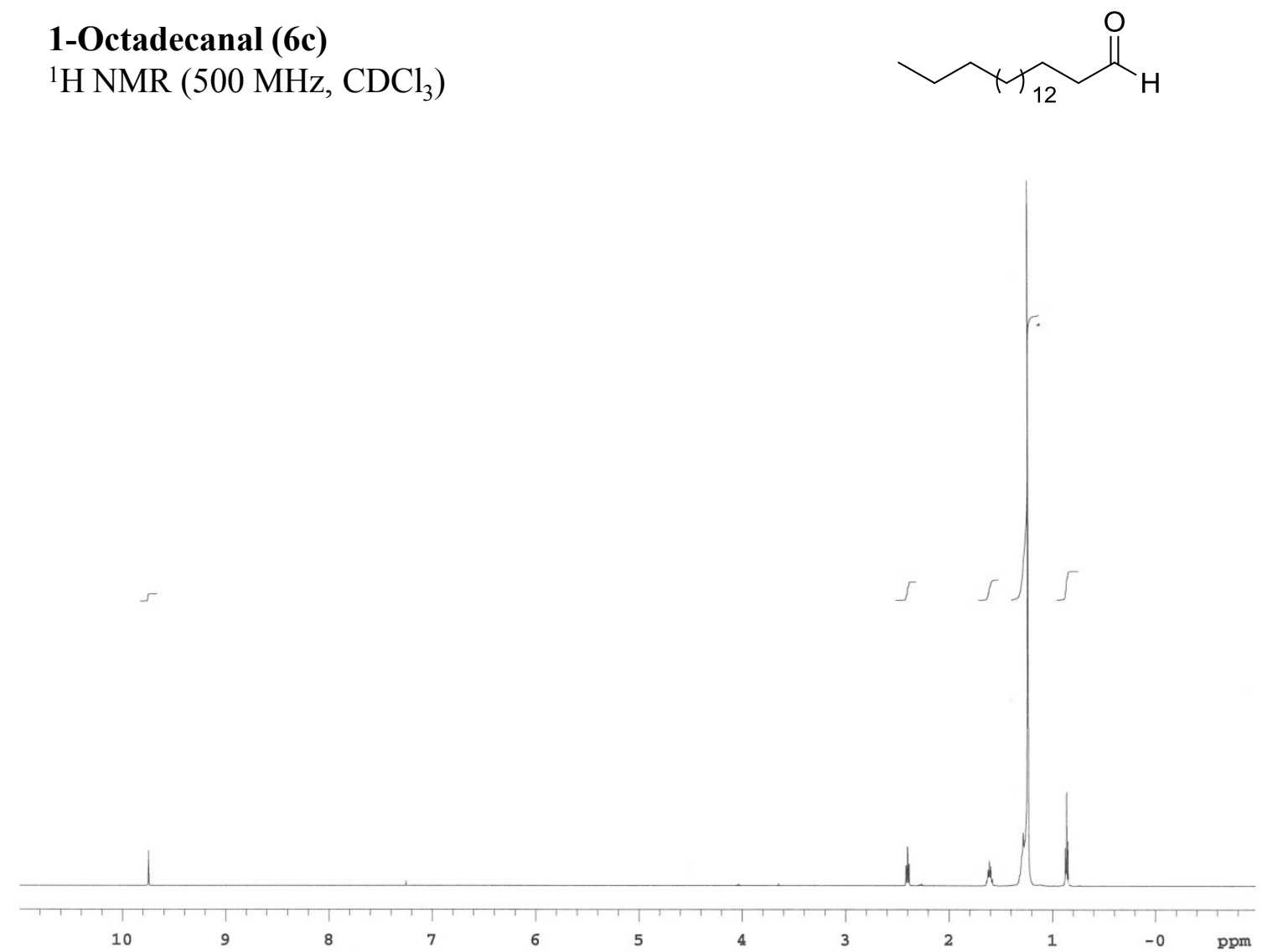

1-Octadecanal (6c)

${ }^{13} \mathrm{C}$ NMR $\left(125 \mathrm{MHz}, \mathrm{CDCl}_{3}\right)$
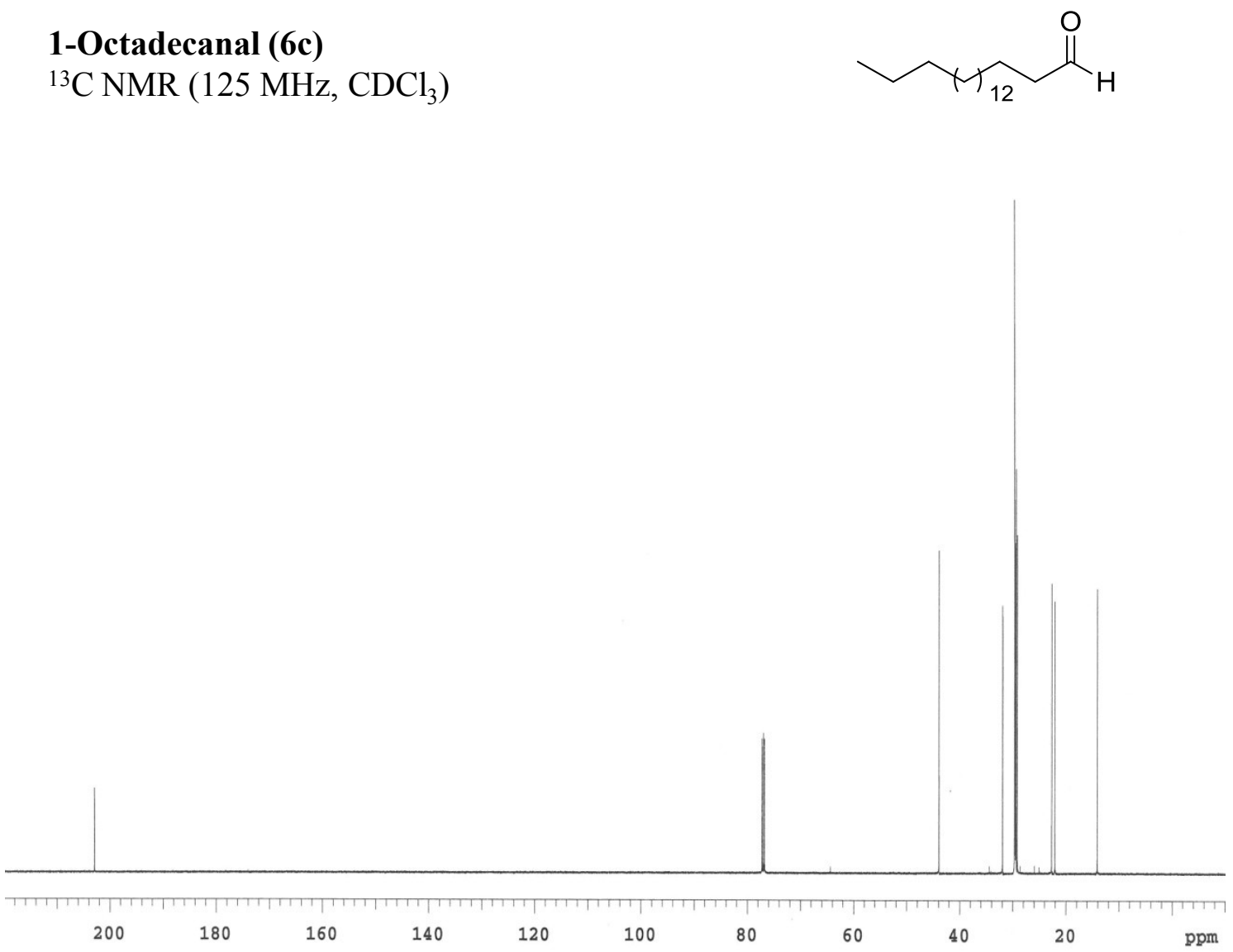
1-Eicosanal (6d)

${ }^{1} \mathrm{H} \mathrm{NMR}\left(500 \mathrm{MHz}, \mathrm{CDCl}_{3}\right.$ )<smiles>CCCCCCC=O</smiles>

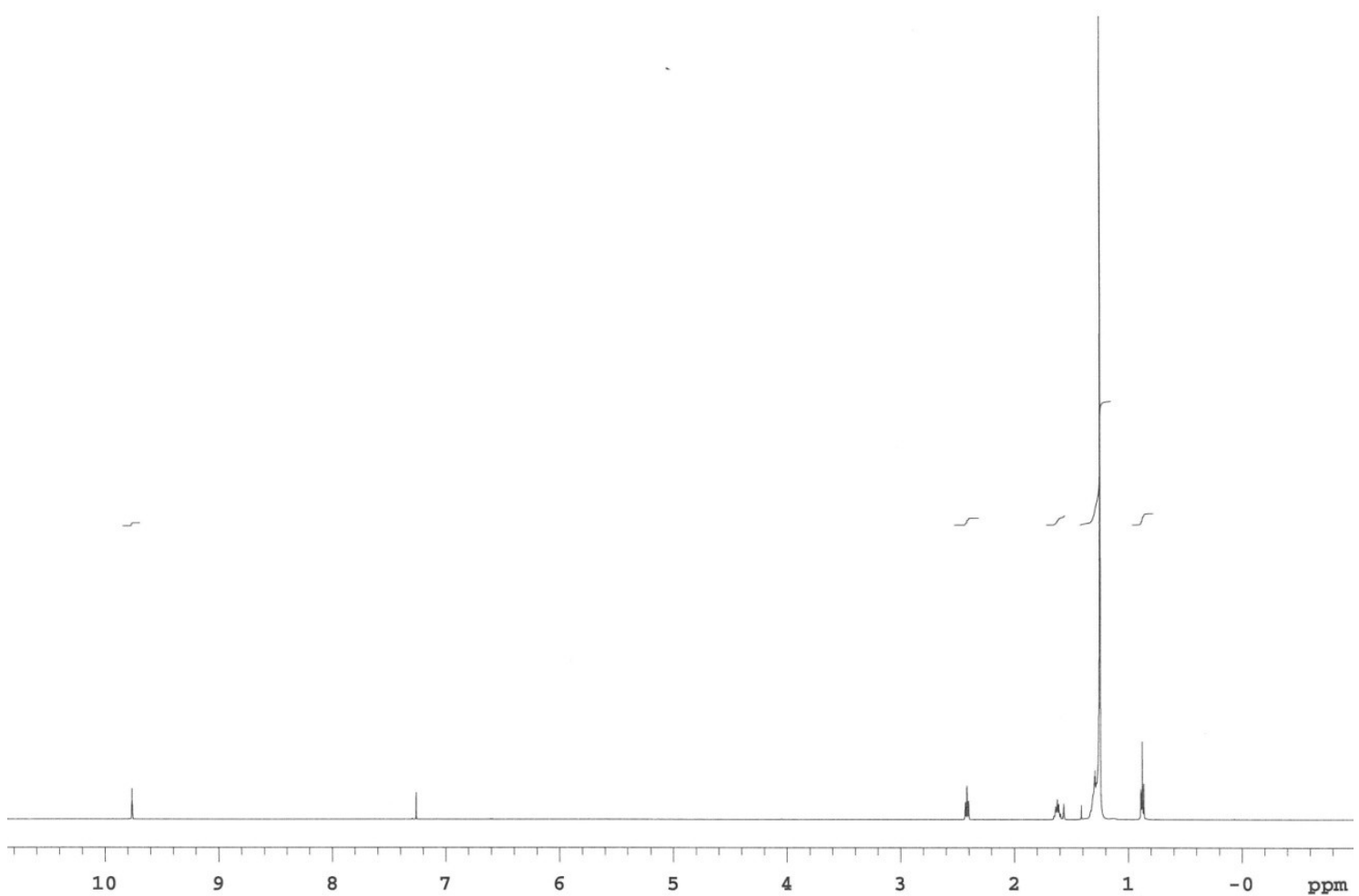

1-Eicosanal (6d)

${ }^{13} \mathrm{C} \mathrm{NMR}\left(125 \mathrm{MHz}, \mathrm{CDCl}_{3}\right.$ )
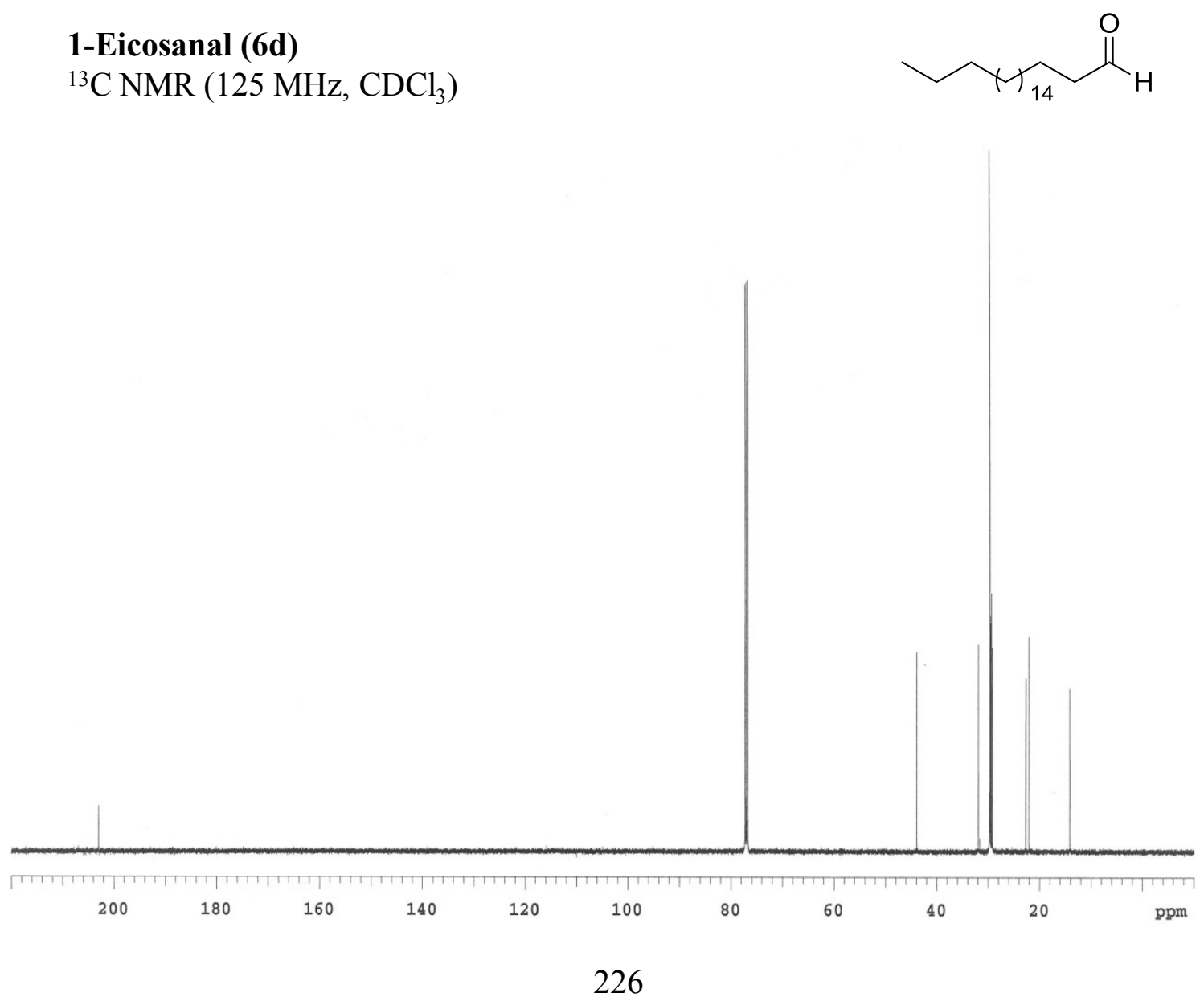
1-Iodotetradecane

${ }^{1} \mathrm{H} \mathrm{NMR}\left(500 \mathrm{MHz}, \mathrm{CDCl}_{3}\right.$ )
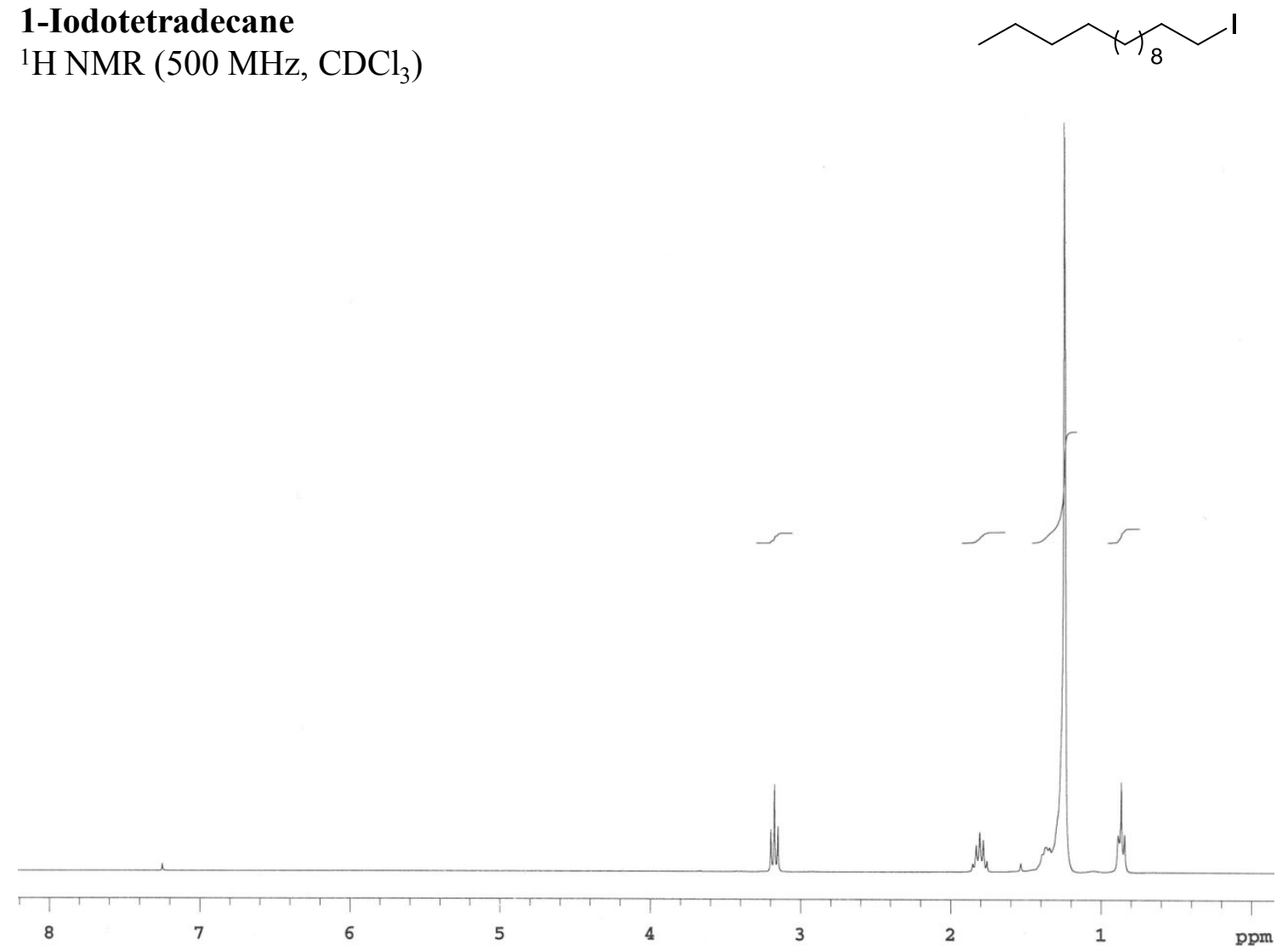

\section{1-Iodotetradecane}

${ }^{13} \mathrm{C} \mathrm{NMR}$ (125 MHz, $\mathrm{CDCl}_{3}$ )
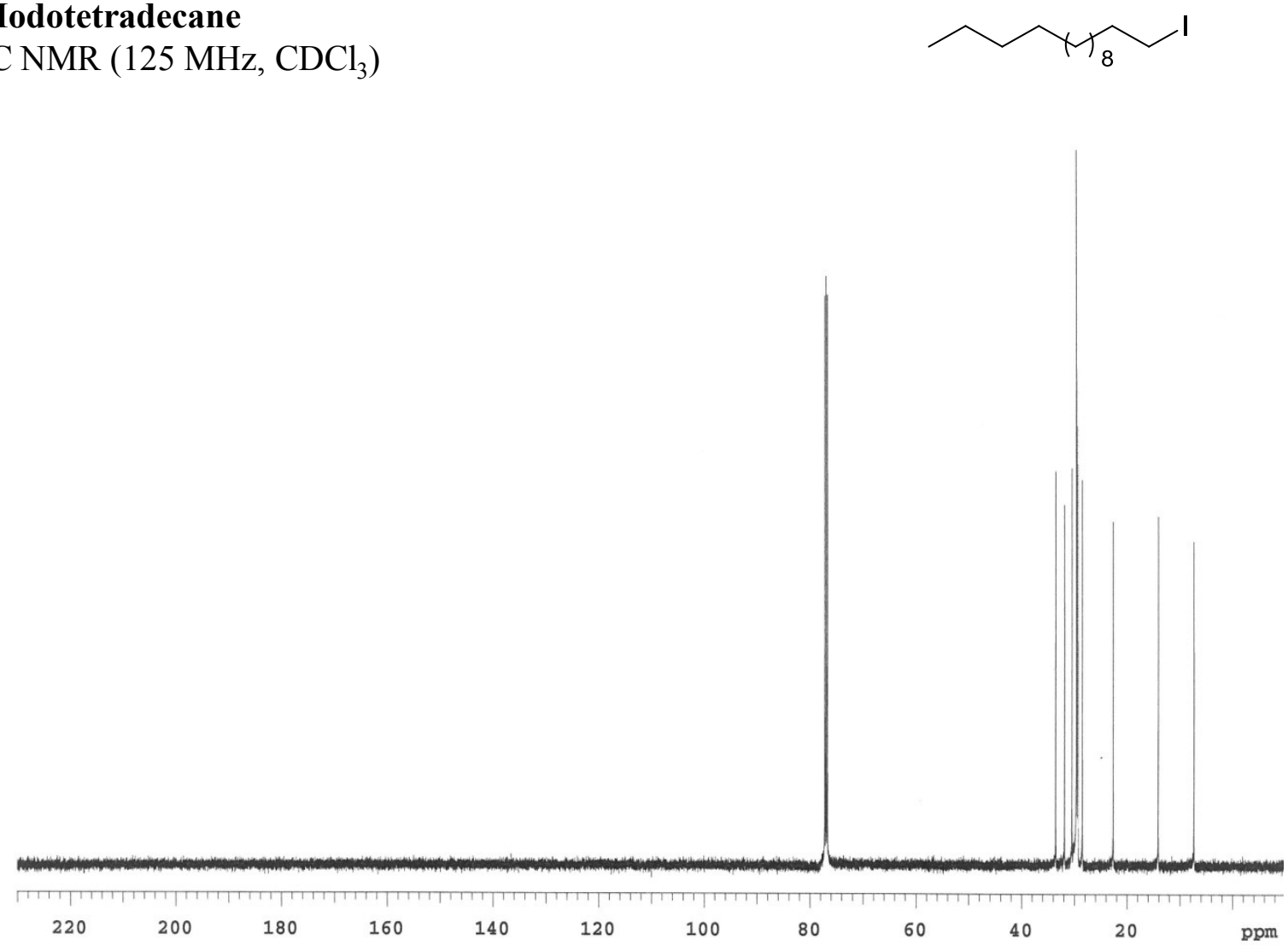
${ }^{1} \mathrm{H}$ NMR (500 MHz, $\mathrm{CDCl}_{3}$ )<smiles>CCCCCCCCI</smiles>

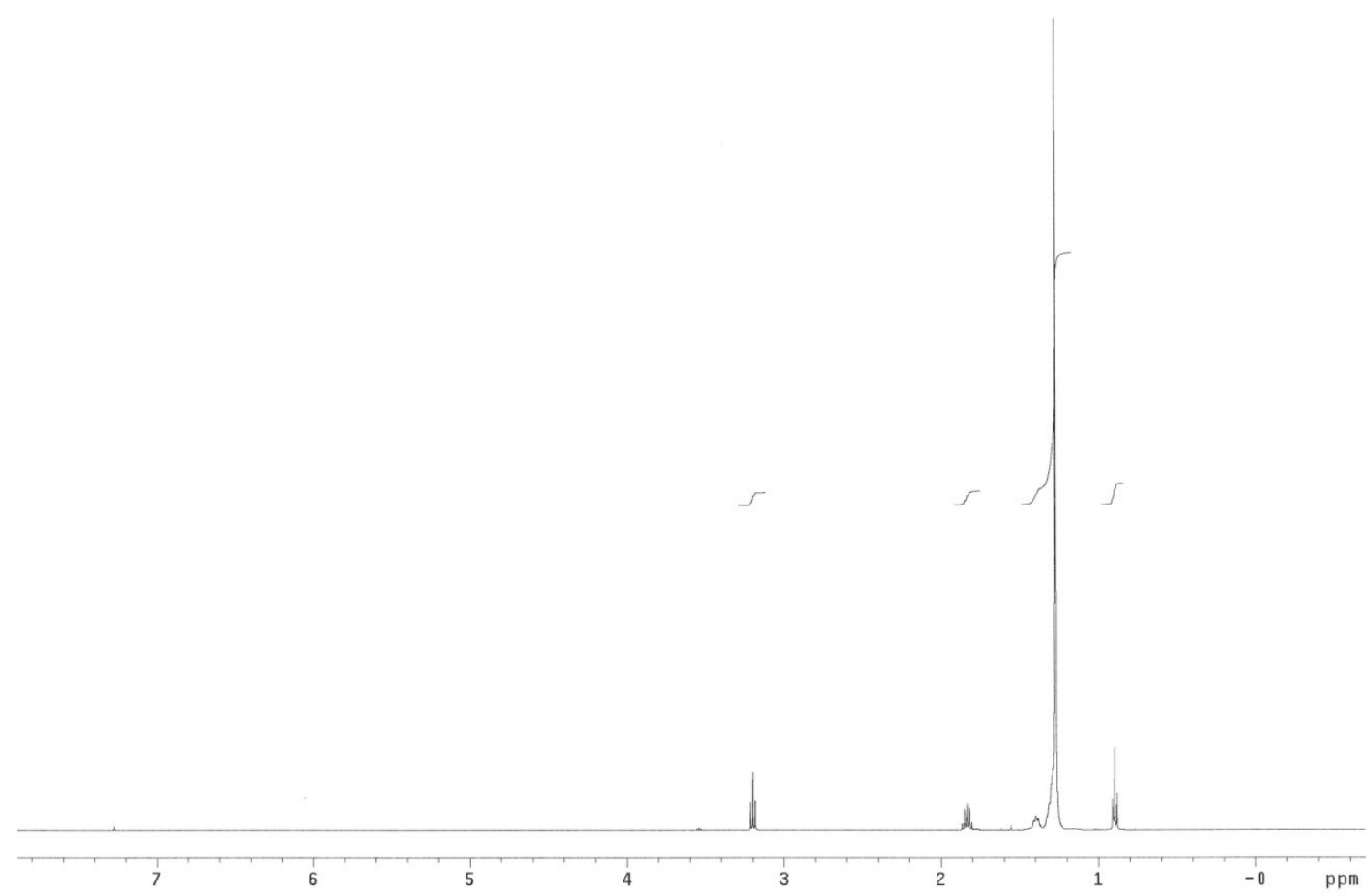

\section{1-Iodoeicosane}

${ }^{13} \mathrm{C} \mathrm{NMR}\left(125 \mathrm{MHz}, \mathrm{CDCl}_{3}\right)$
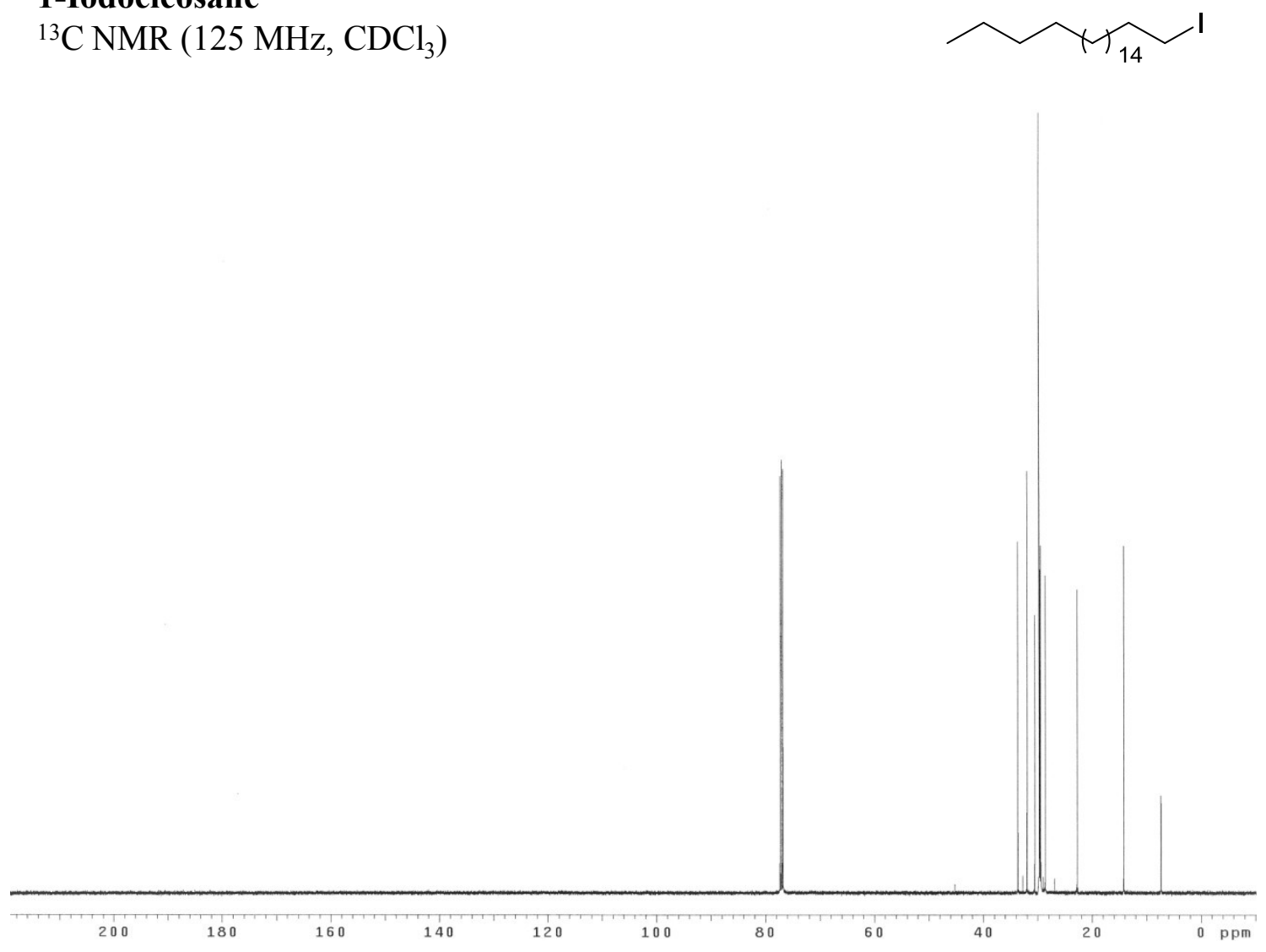


\section{1-Iododocosane}

${ }^{1} \mathrm{H}$ NMR (500 MHz, $\mathrm{CDCl}_{3}$ )

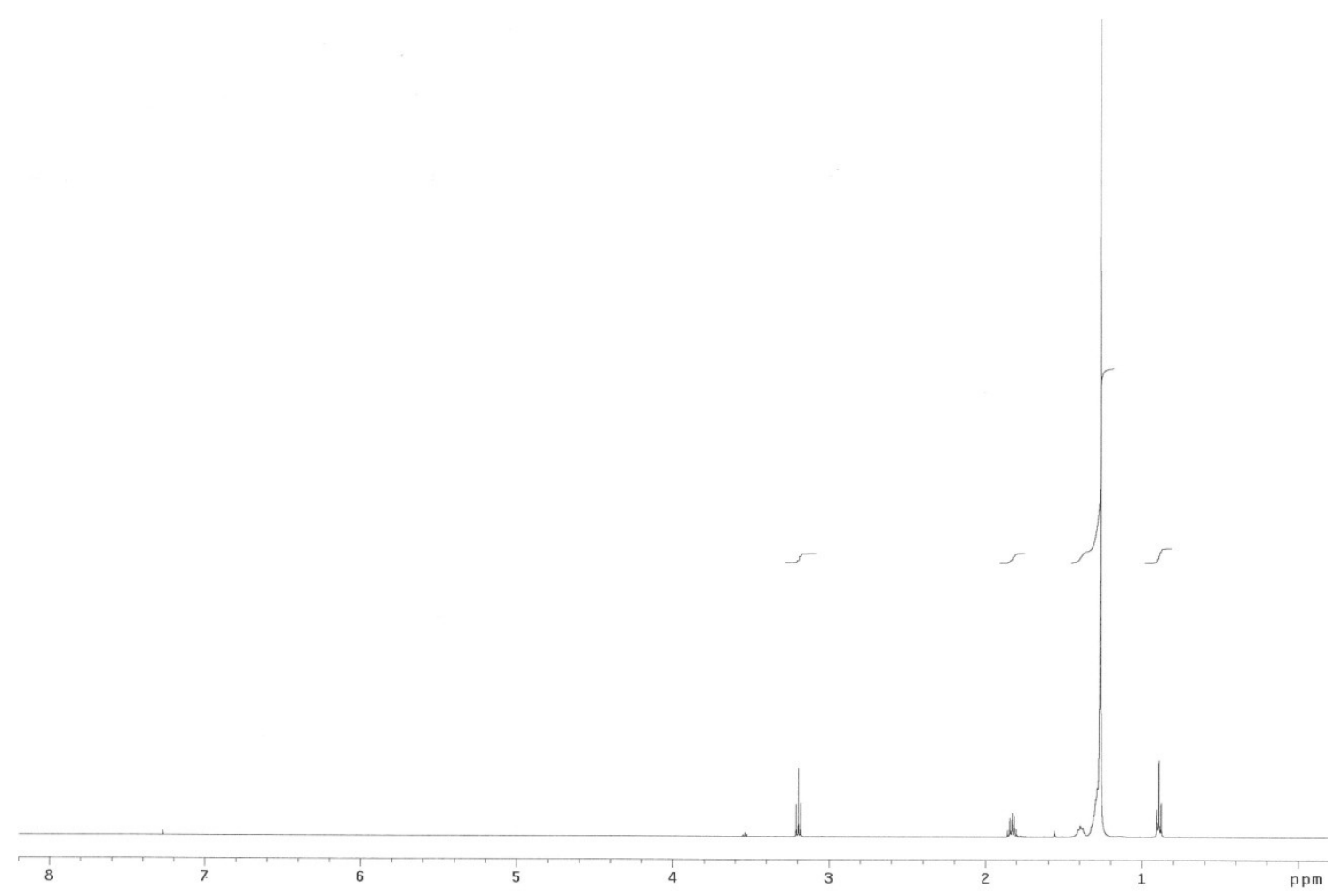

\section{1-Iododocosane}

${ }^{13} \mathrm{C} \mathrm{NMR}$ (125 MHz, $\mathrm{CDCl}_{3}$ )
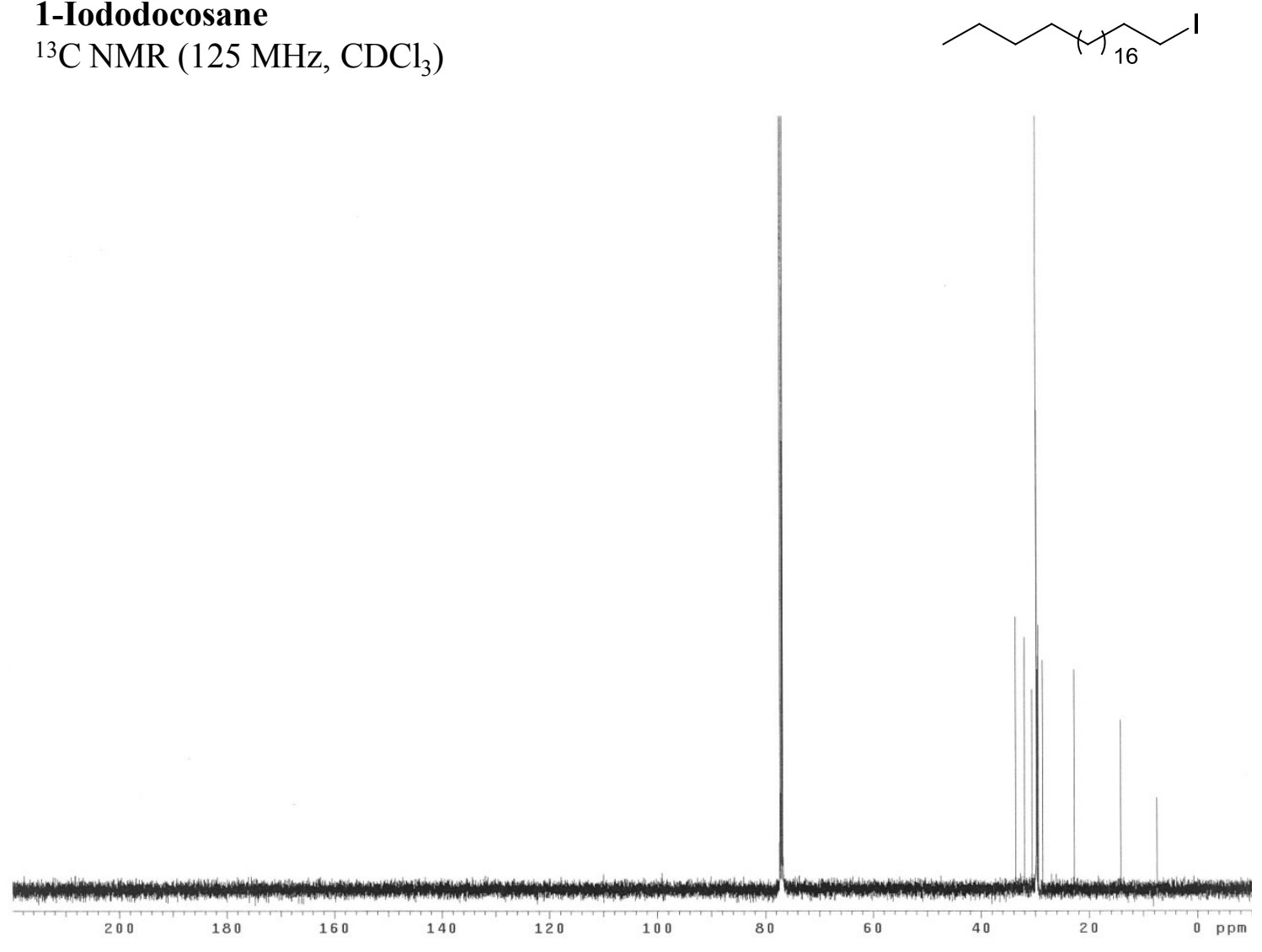
1-Iodo-hept-2-ene (4a)

${ }^{1} \mathrm{H} \mathrm{NMR}\left(500 \mathrm{MHz}, \mathrm{CDCl}_{3}\right.$ )<smiles>CCCC/C=C/CI</smiles>
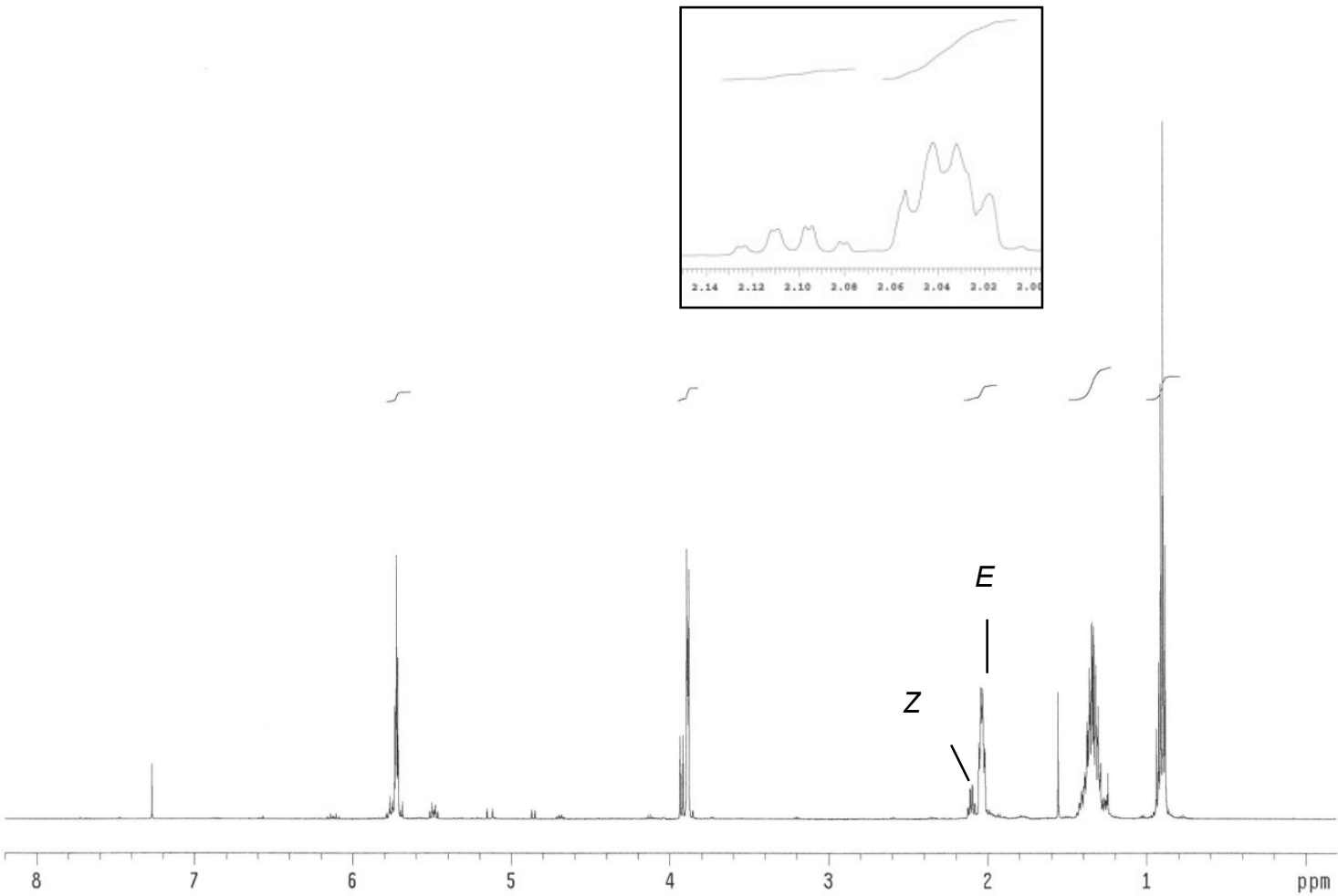

1-Iodo-hept-2-ene (4a)

${ }^{13} \mathrm{C} \mathrm{NMR}\left(125 \mathrm{MHz}, \mathrm{CDCl}_{3}\right.$ )<smiles>CCCCC=CCCI</smiles>

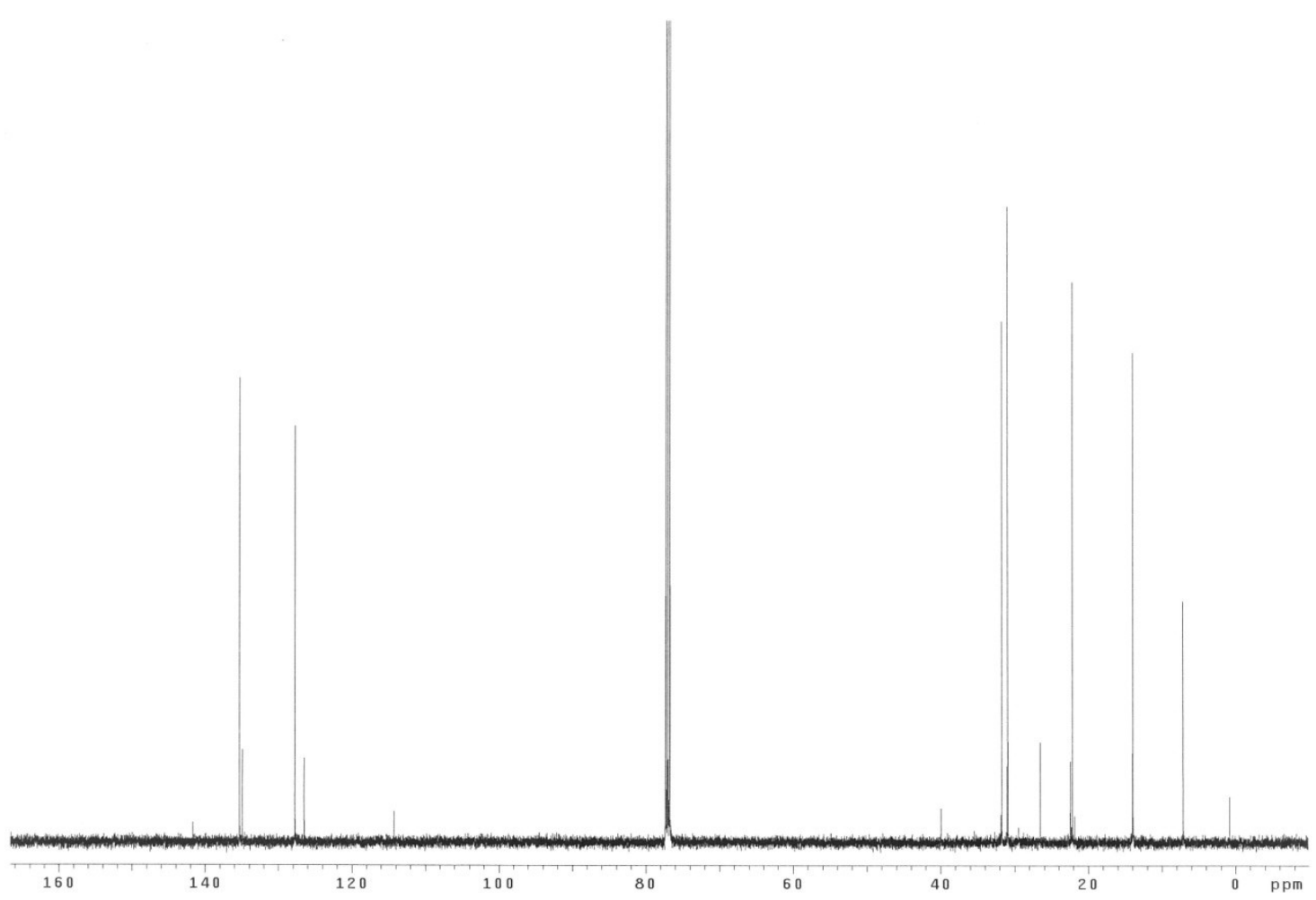


1-Iodo-tetradec-2-ene (4b)

${ }^{1} \mathrm{H}$ NMR (500 MHz, $\mathrm{CDCl}_{3}$ )
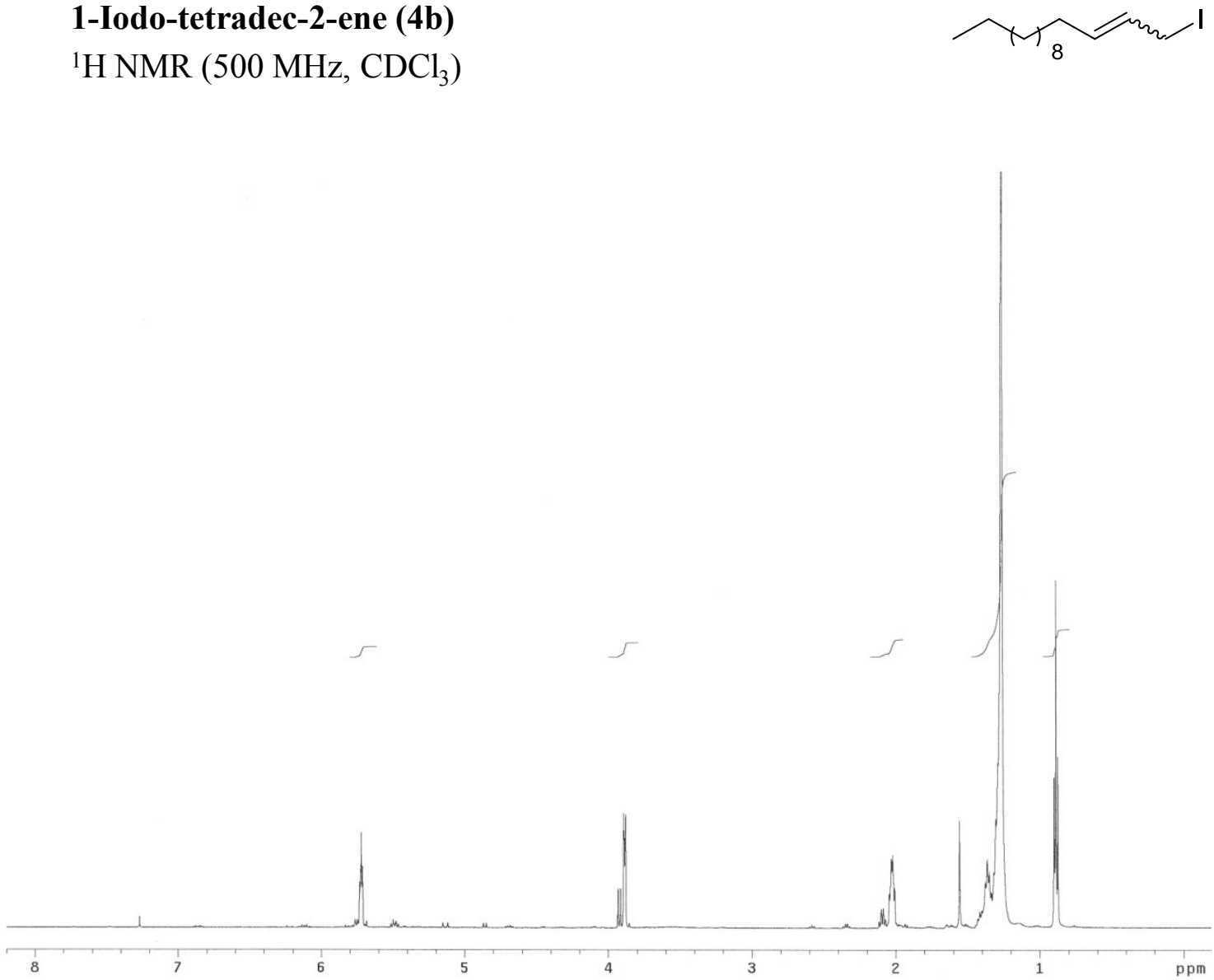

1-Iodo-tetradec-2-ene (4b)

${ }^{13} \mathrm{C} \mathrm{NMR}\left(125 \mathrm{MHz}, \mathrm{CDCl}_{3}\right)$
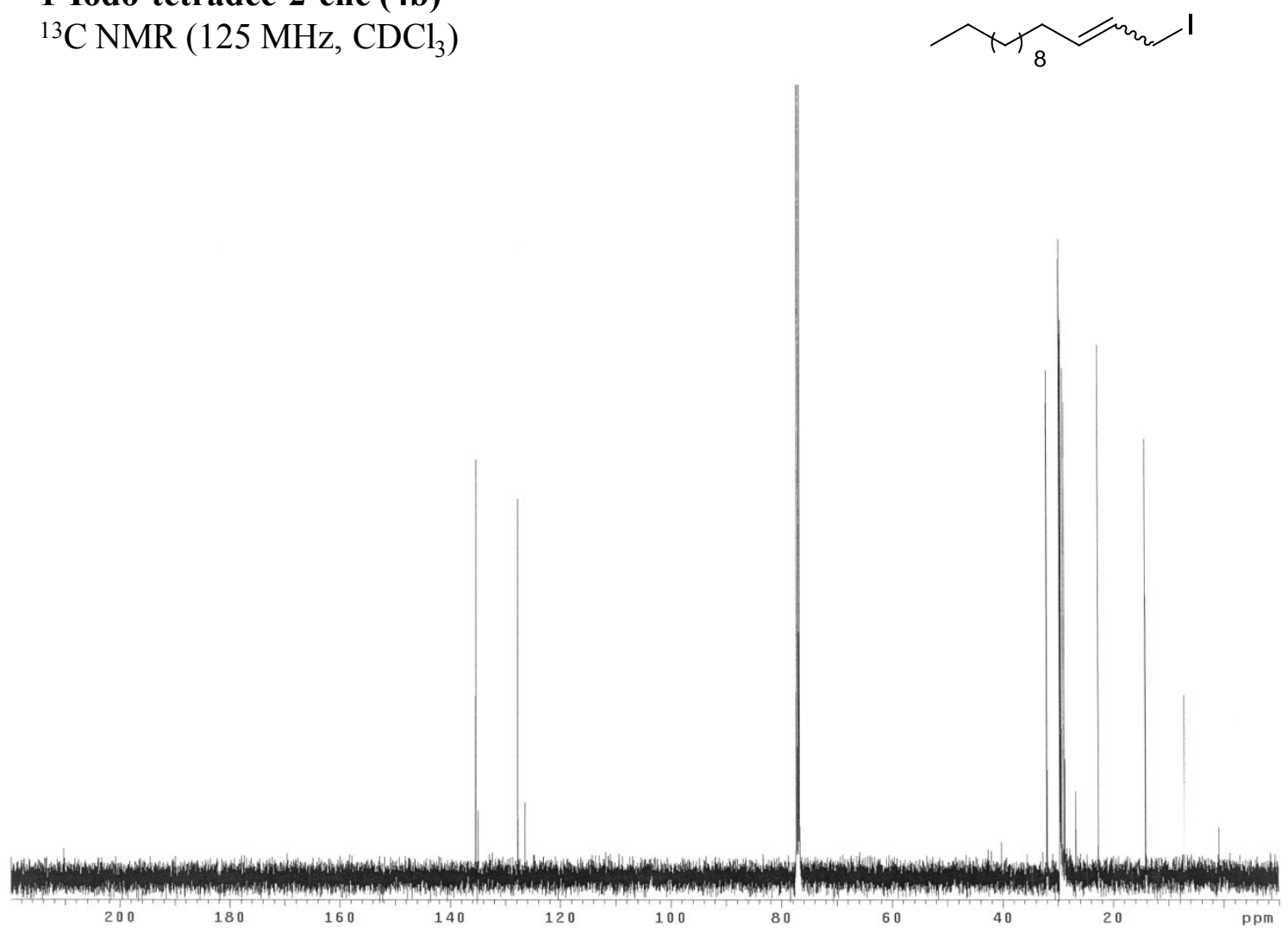
1-Iodo-eicos-2-ene (4c)

${ }^{1} \mathrm{H}$ NMR $\left(500 \mathrm{MHz}, \mathrm{CDCl}_{3}\right.$ )
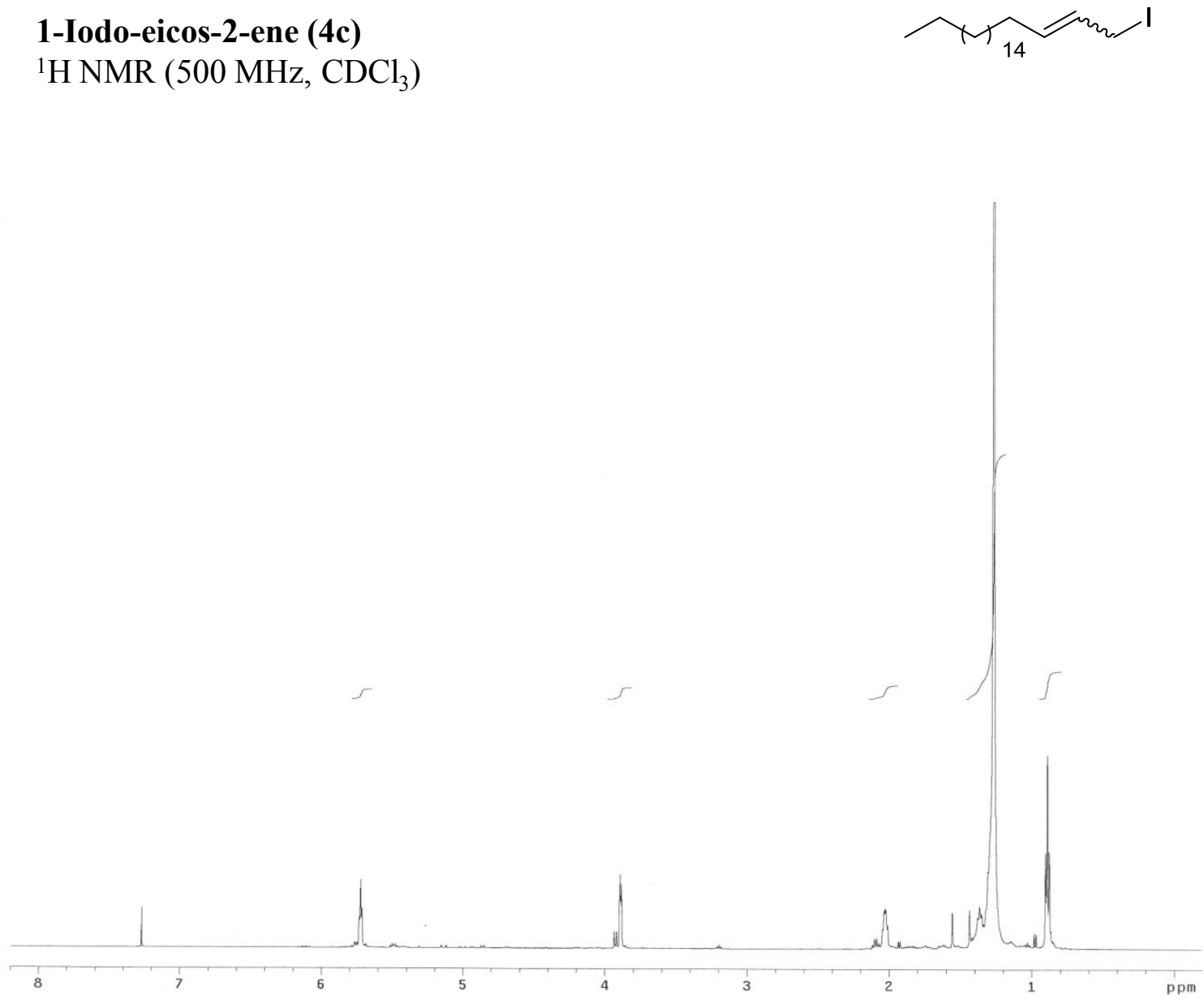

1-Iodo-eicos-2-ene (4c)

${ }^{13} \mathrm{C}$ NMR $\left(125 \mathrm{MHz}, \mathrm{CDCl}_{3}\right)$
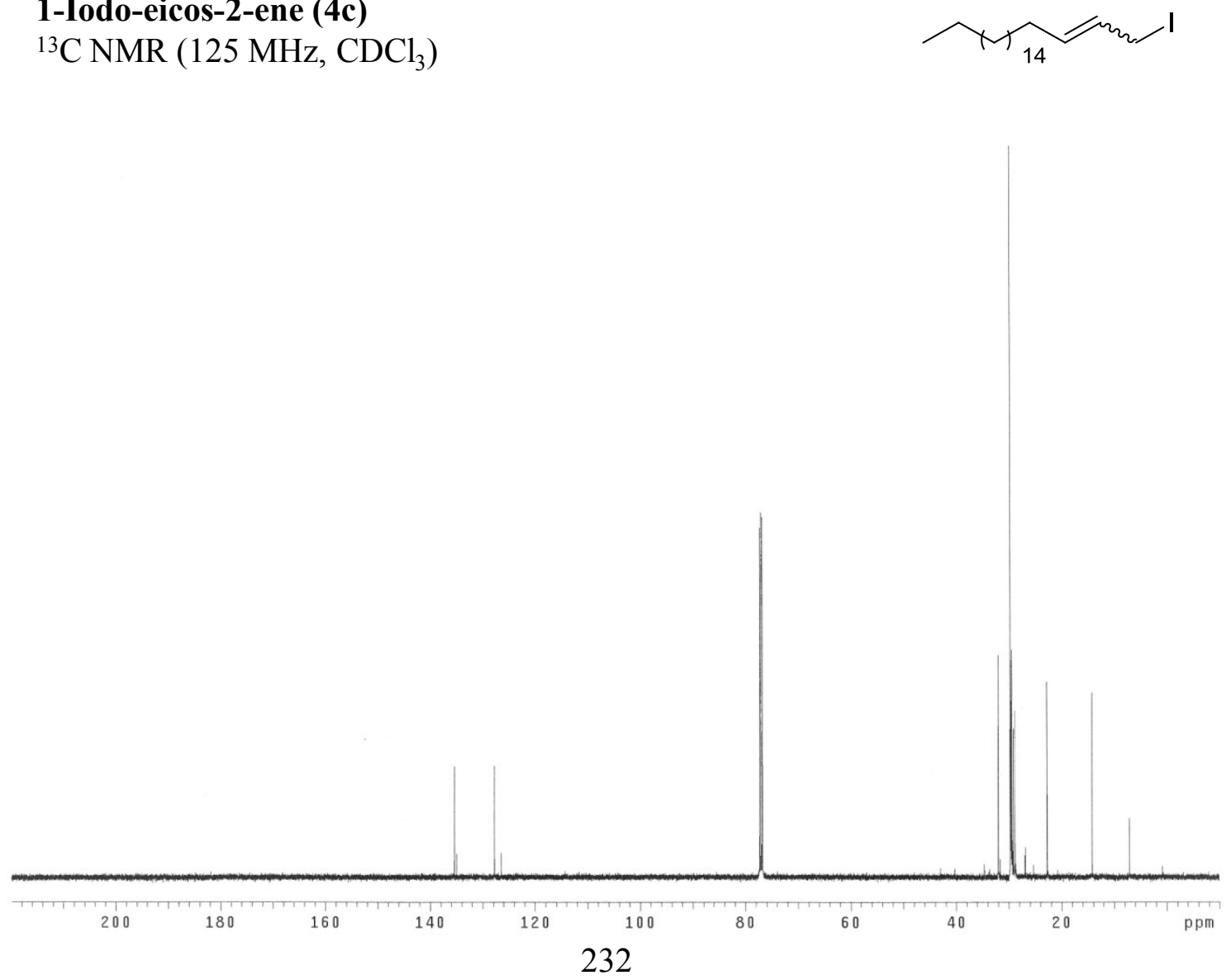
1-Iodo-docos-2-ene (4d)

${ }^{1} \mathrm{H}$ NMR (500 MHz, $\mathrm{CDCl}_{3}$ )
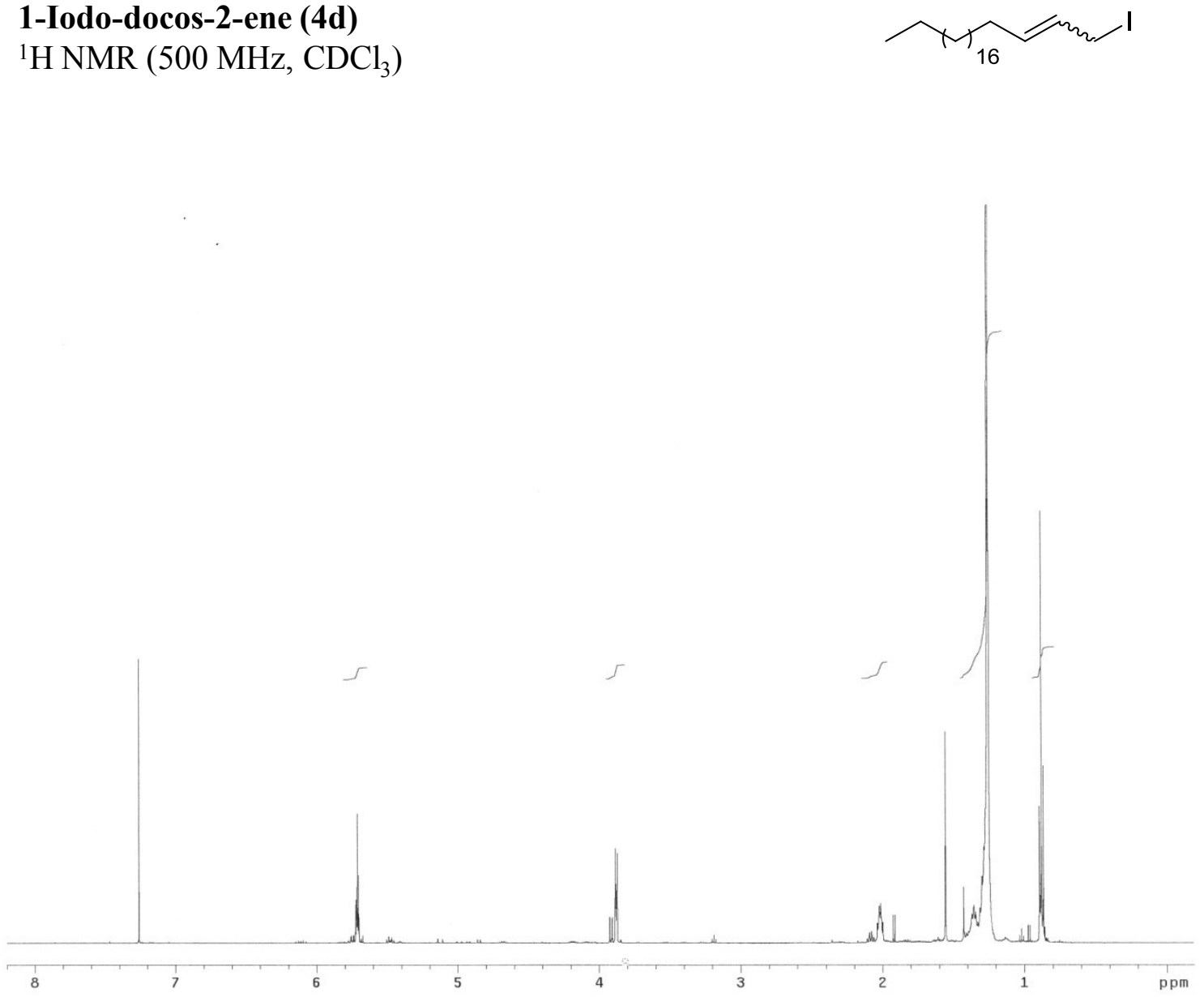

1-Iodo-docos-2-ene (4d)

${ }^{13} \mathrm{C}$ NMR $\left(125 \mathrm{MHz}, \mathrm{CDCl}_{3}\right)$
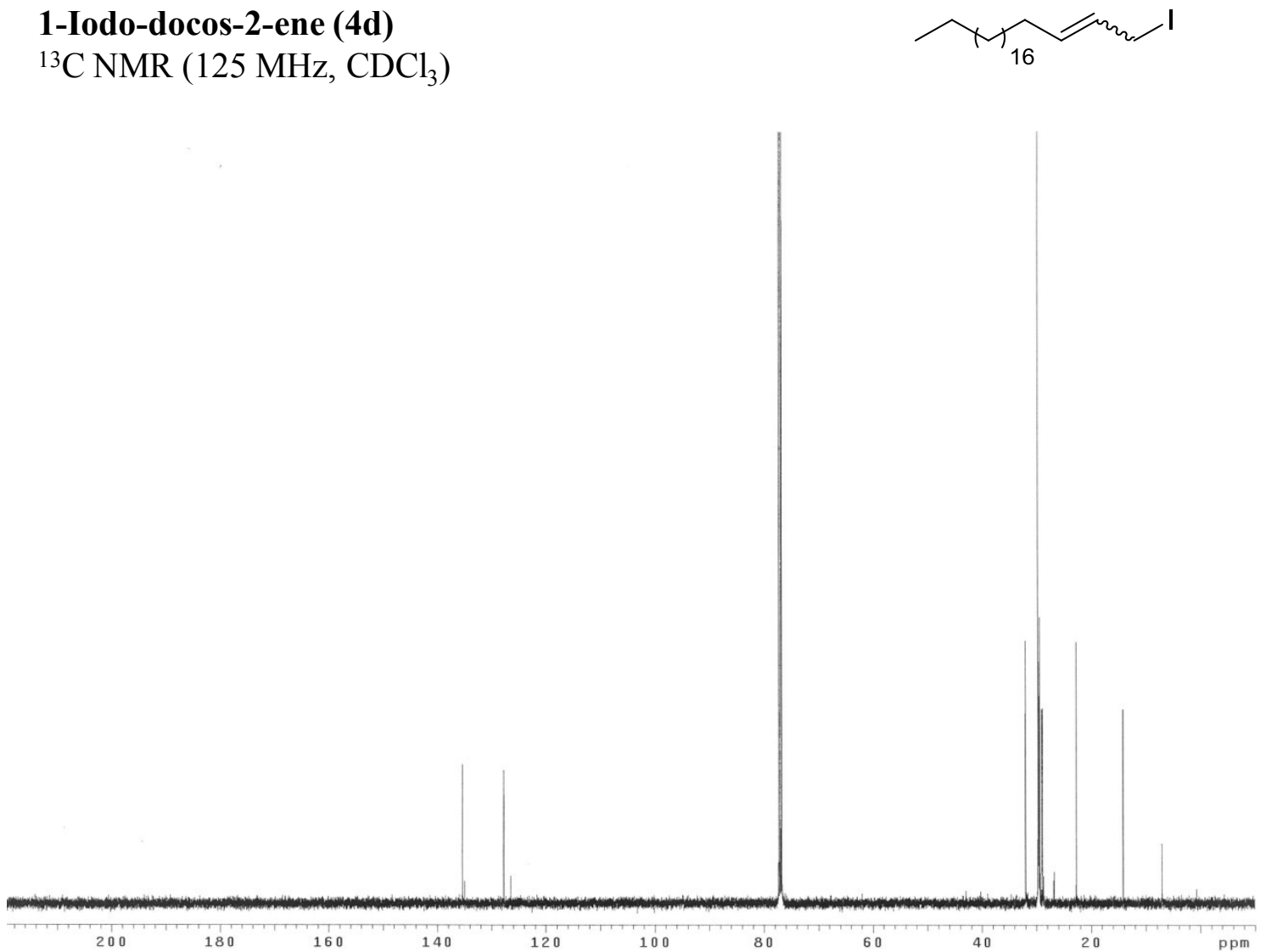
Diethyl L-malate (3)

${ }^{1} \mathrm{H}$ NMR $\left(500 \mathrm{MHz}, \mathrm{CDCl}_{3}\right.$ )<smiles>CCOC(=O)C[C@H](O)C(=O)OCC</smiles>

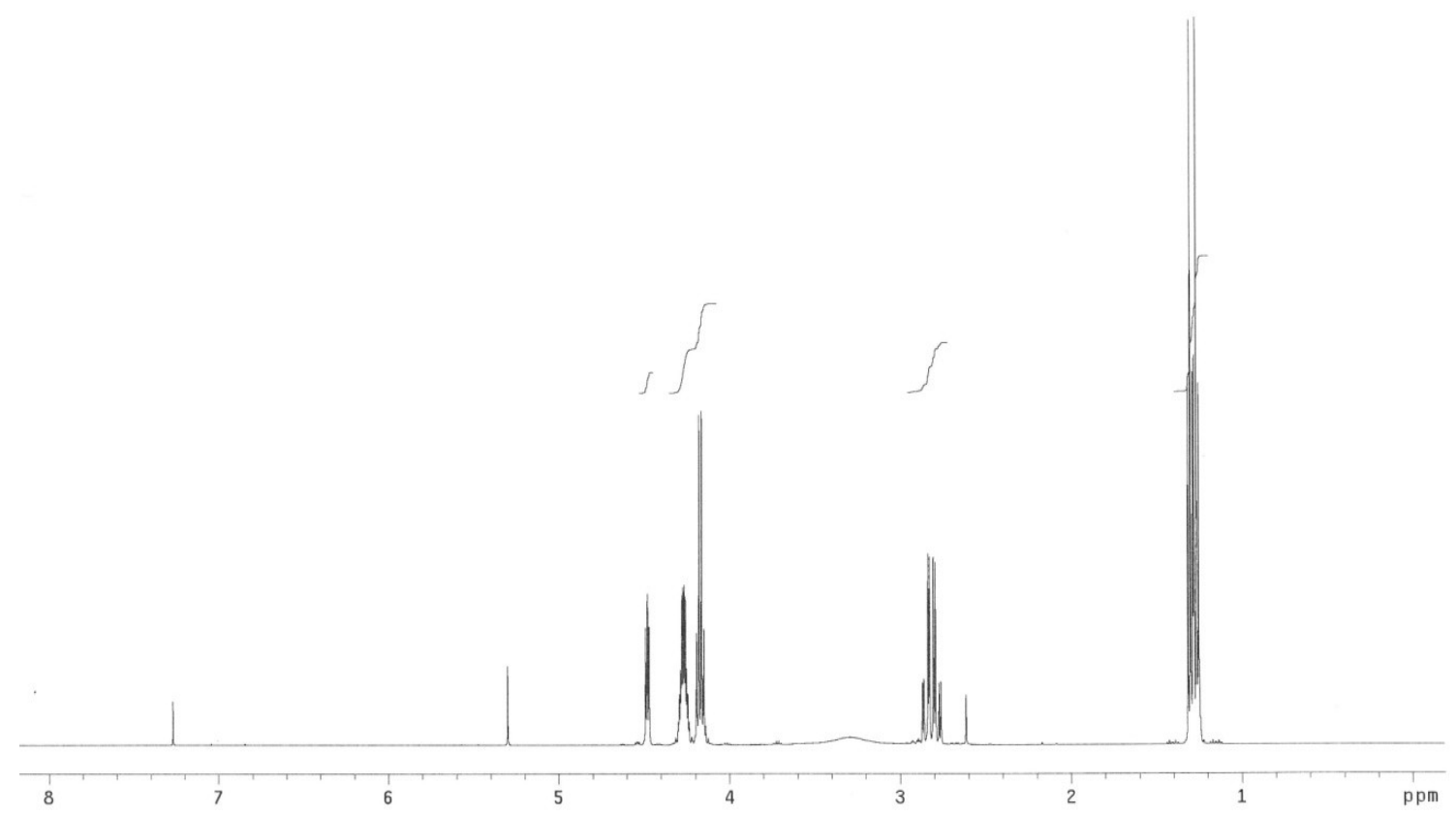

Diethyl L-malate (3)

${ }^{13} \mathrm{C}$ NMR (125 MHz, $\mathrm{CDCl}_{3}$ )

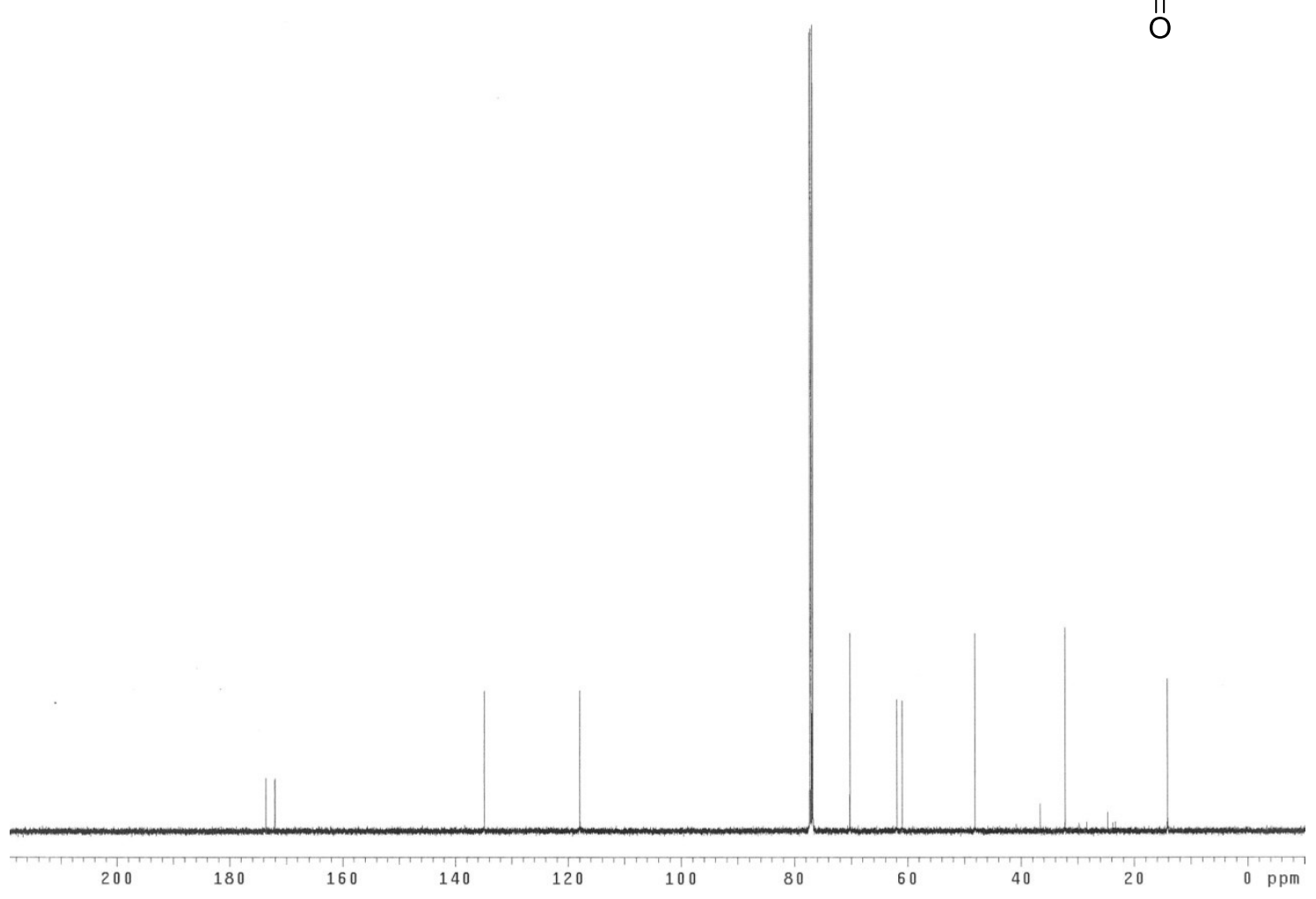


Ethyl $2 S$-hydroxy-3R-ethoxycarbonyl-hex-4-enoate (5a) ${ }^{1} \mathrm{H} \mathrm{NMR}\left(500 \mathrm{MHz}, \mathrm{CDCl}_{3}\right)$<smiles>C=CC[C@@H](C(=O)OCC)[C@@H](O)C(=O)OCC</smiles>

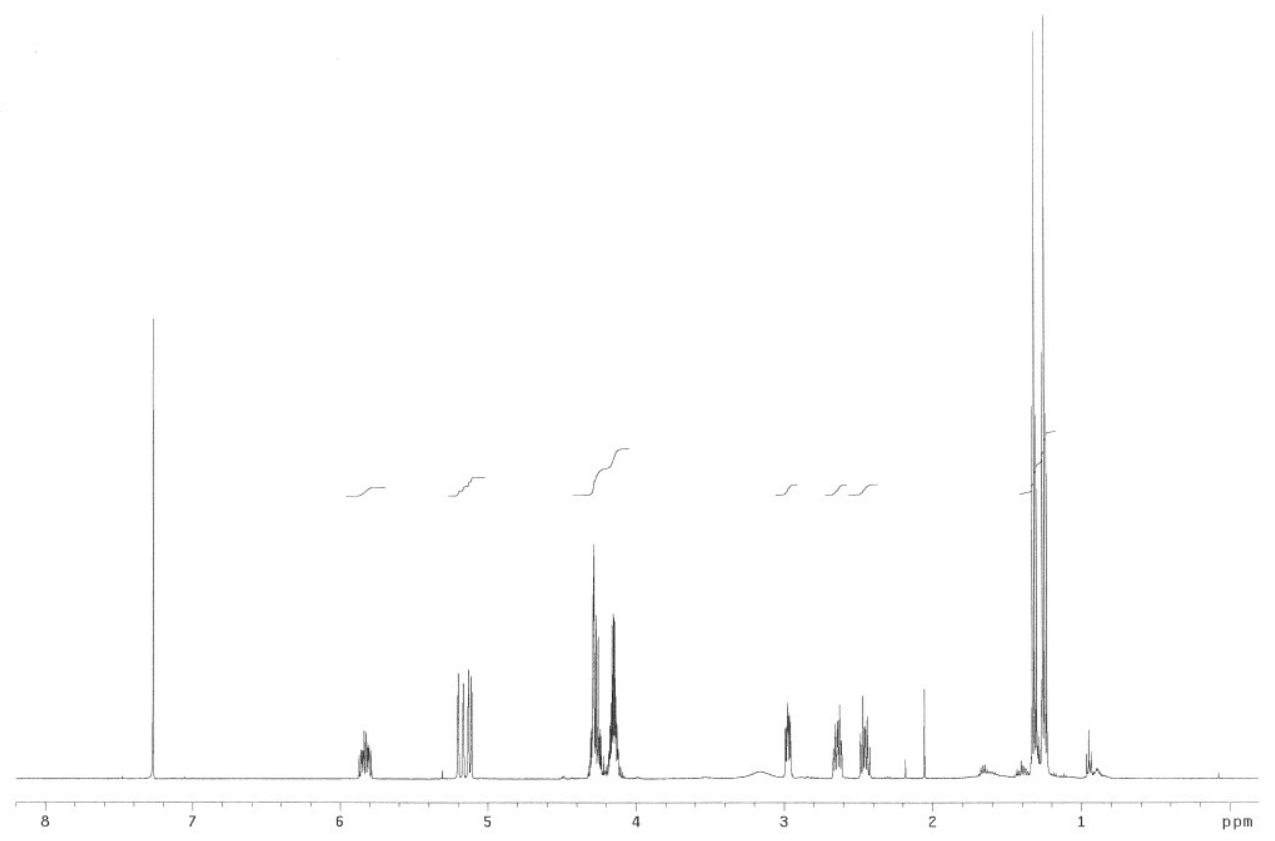

Ethyl 2S-hydroxy-3R-ethoxycarbonyl-hex-4-enoate (5a) ${ }^{13} \mathrm{C} \mathrm{NMR}\left(125 \mathrm{MHz}, \mathrm{CDCl}_{3}\right)$<smiles>C=CC[C@@H](C(=O)OCC)[C@@H](O)C(=O)OCC</smiles> 
Ethyl $2 S$-hydroxy-3R-ethoxycarbonyl-decanoate (5b) ${ }^{1} \mathrm{H}$ NMR $\left(500 \mathrm{MHz}, \mathrm{CDCl}_{3}\right)$<smiles>CCCCC(C(=O)OCC)C(O)C(=O)OCC</smiles>

From the reduction of $5 \mathrm{c}$

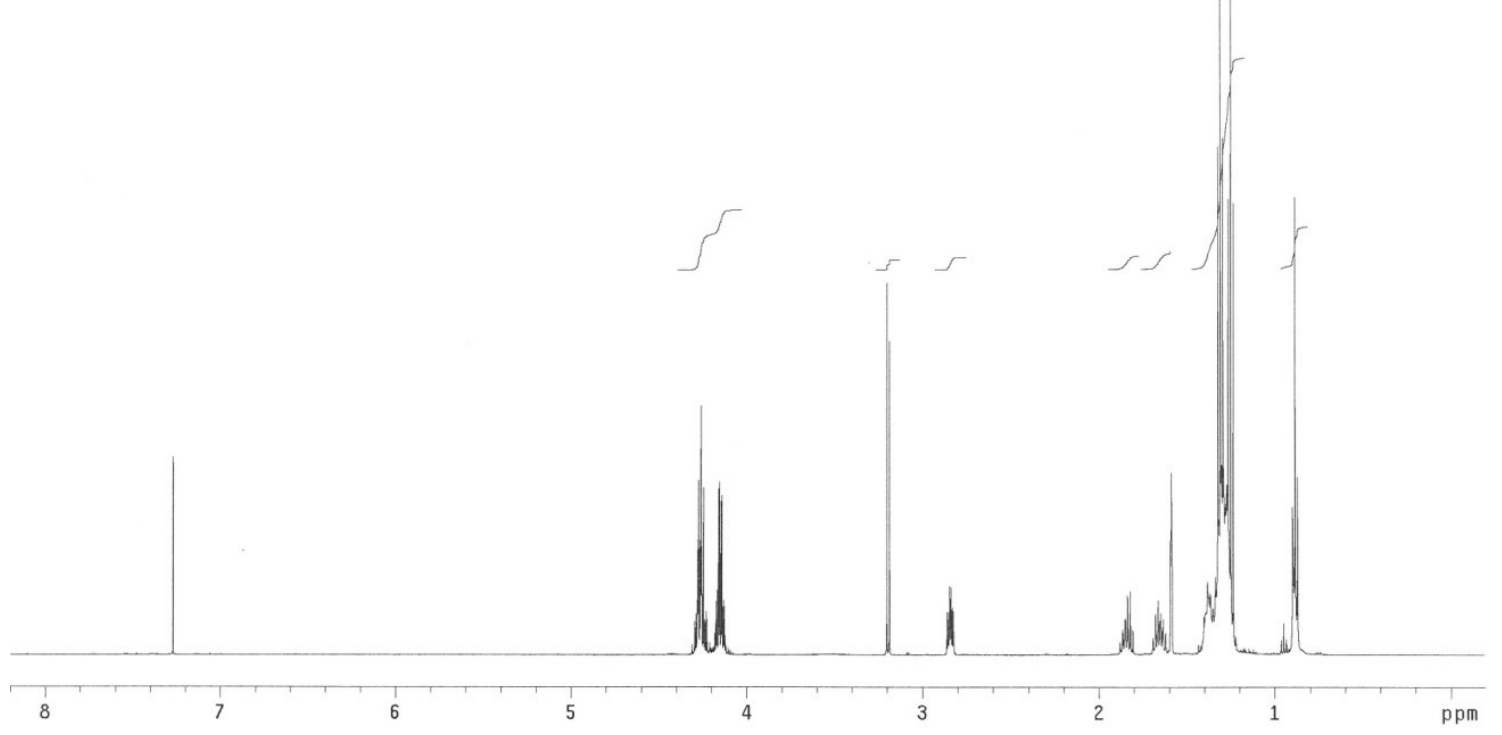

Ethyl 2S-hydroxy-3R-ethoxycarbonyl-decanoate (5b) ${ }^{13} \mathrm{C} \mathrm{NMR}\left(125 \mathrm{MHz}, \mathrm{CDCl}_{3}\right)$

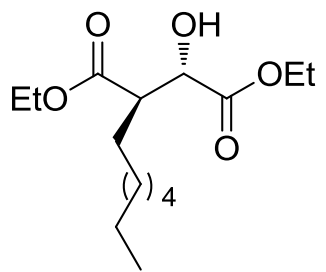


Ethyl $2 S$-hydroxy-3R-ethoxycarbonyl-decen-5-enoate (5c)

${ }^{1} \mathrm{H} \mathrm{NMR}\left(500 \mathrm{MHz}, \mathrm{CDCl}_{3}\right)$
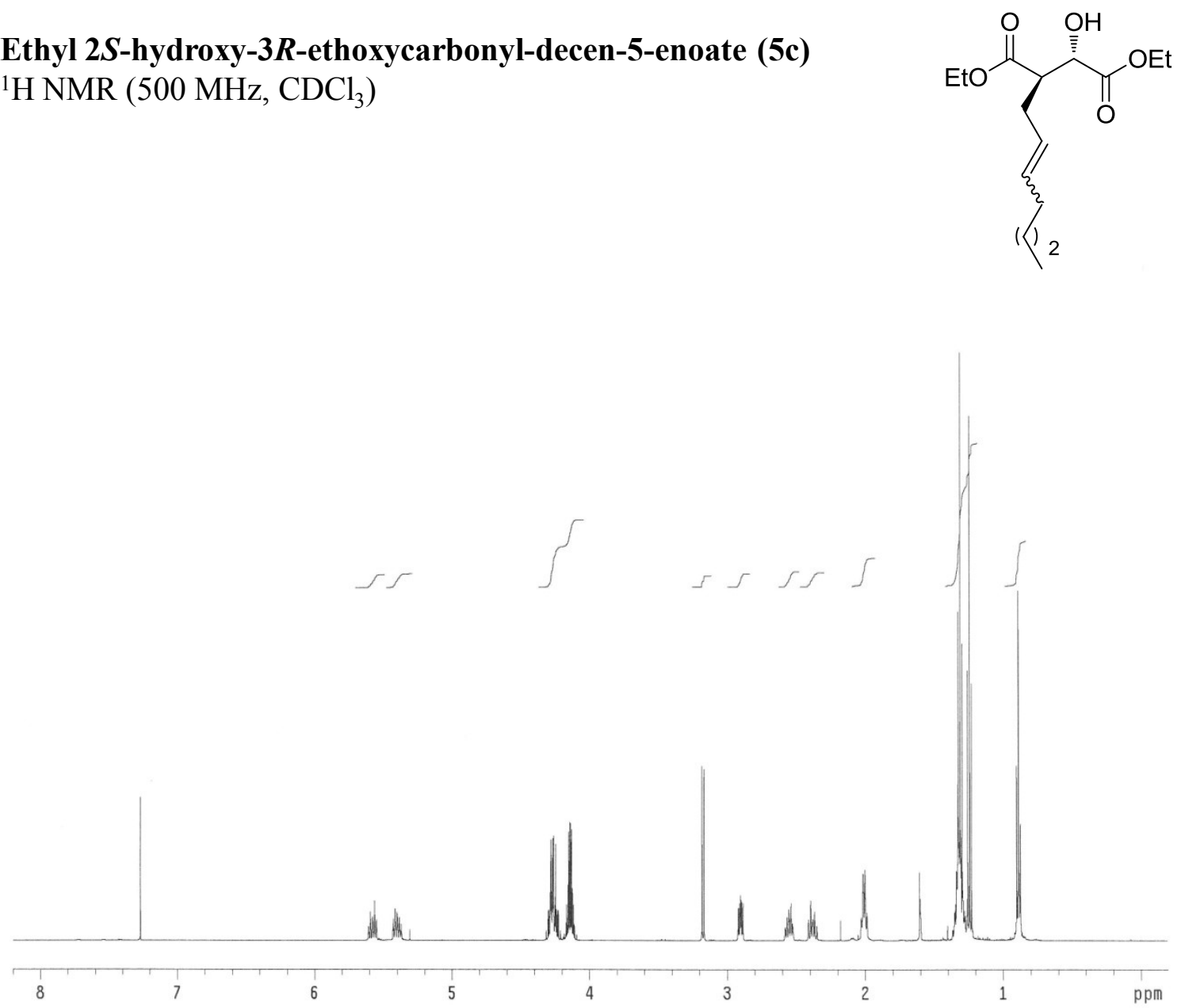

Ethyl 2S-hydroxy-3R-ethoxycarbonyl-decen-5-enoate (5c) ${ }^{13} \mathrm{C}$ NMR (125 MHz, $\mathrm{CDCl}_{3}$ )

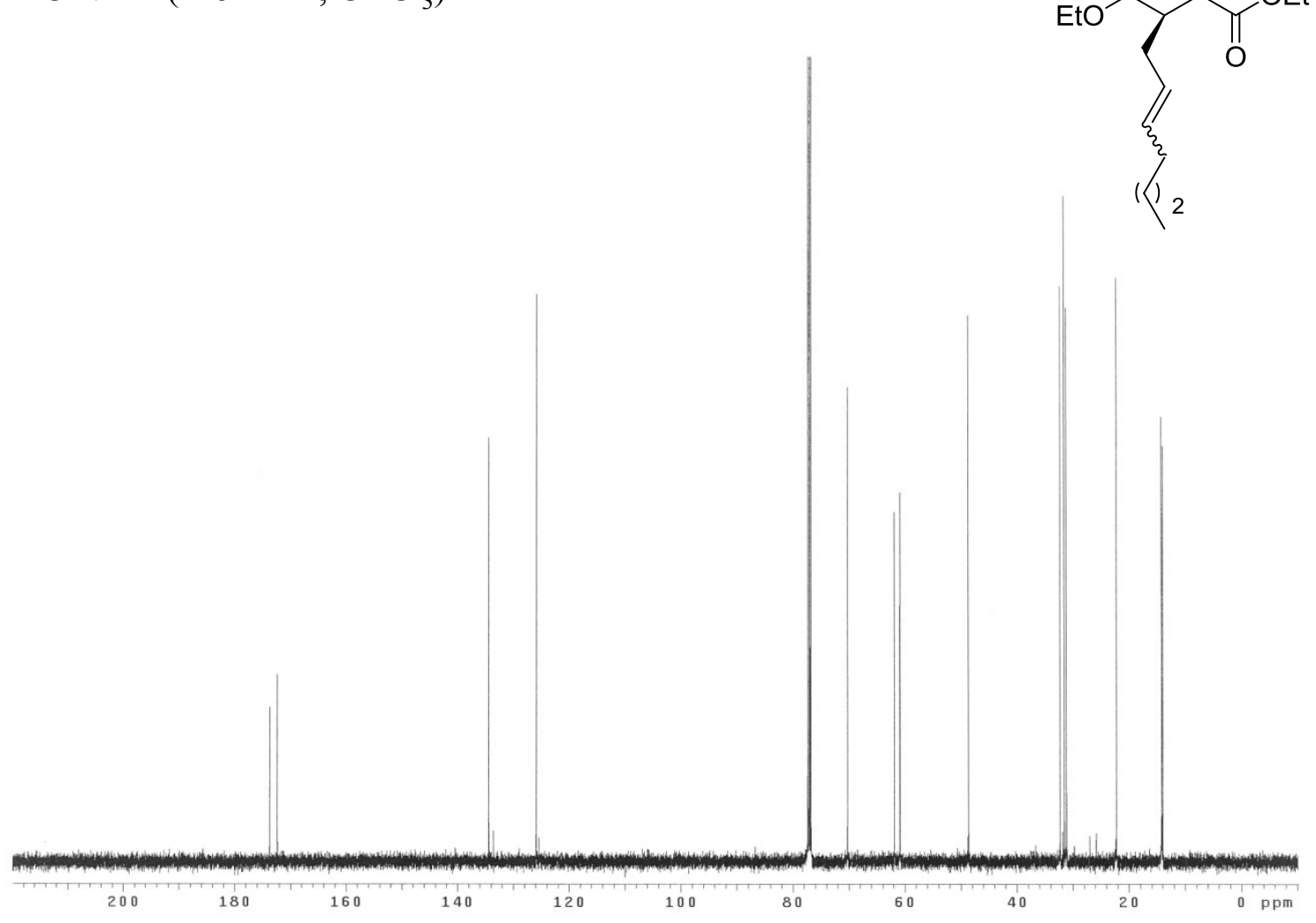


Ethyl $2 S$-hydroxy-3R-ethoxycarbonyl-heptadecanoate (5d) ${ }^{1} \mathrm{H} \mathrm{NMR}\left(500 \mathrm{MHz}, \mathrm{CDCl}_{3}\right)$<smiles>CCOC(=O)[C@H](O)[C@@H](C[14CH2][14CH3])C(=O)OCC</smiles>

From the reduction of $5 \mathrm{e}$

Ethyl 2S-hydroxy-3R-ethoxycarbonyl-heptadecanoate (5d) ${ }^{13} \mathrm{C} \mathrm{NMR}\left(125 \mathrm{MHz}, \mathrm{CDCl}_{3}\right)$

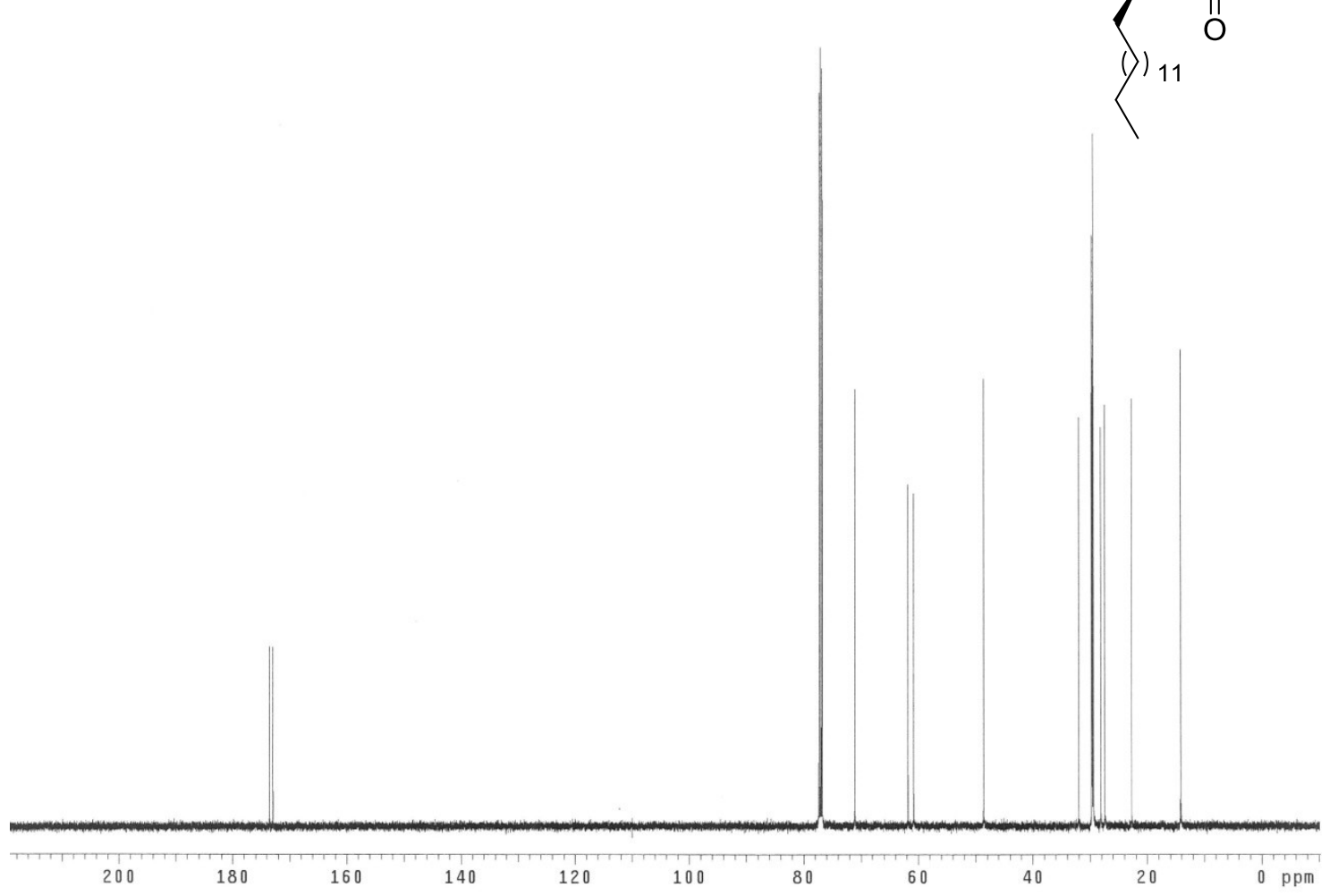


Ethyl $2 S$-hydroxy-3R-ethoxycarbonyl-heptadecen-5-enoate (5e) ${ }^{1} \mathrm{H} \mathrm{NMR}\left(500 \mathrm{MHz}, \mathrm{CDCl}_{3}\right)$

Ethyl $2 S$-hydroxy-3R-ethoxycarbonyl-heptadecen-5-enoate (5e) ${ }^{13} \mathrm{C} \mathrm{NMR}\left(125 \mathrm{MHz}, \mathrm{CDCl}_{3}\right)$

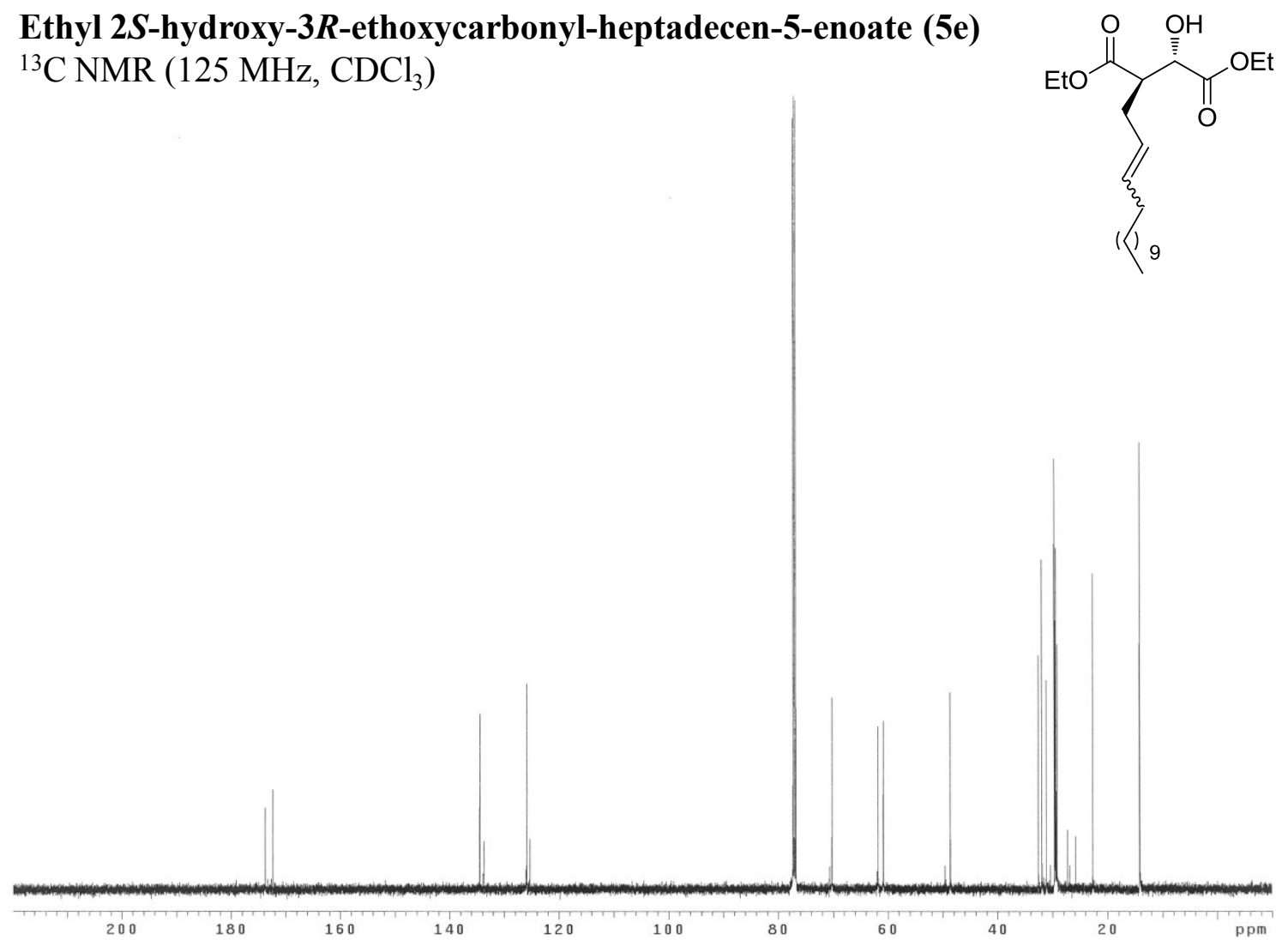


Ethyl 2S-hydroxy-3R-ethoxycarbonyl-tricosanoate (5f)

${ }^{1} \mathrm{H} \mathrm{NMR}\left(500 \mathrm{MHz}, \mathrm{CDCl}_{3}\right)$

From the reduction of $5 \mathrm{~g}$

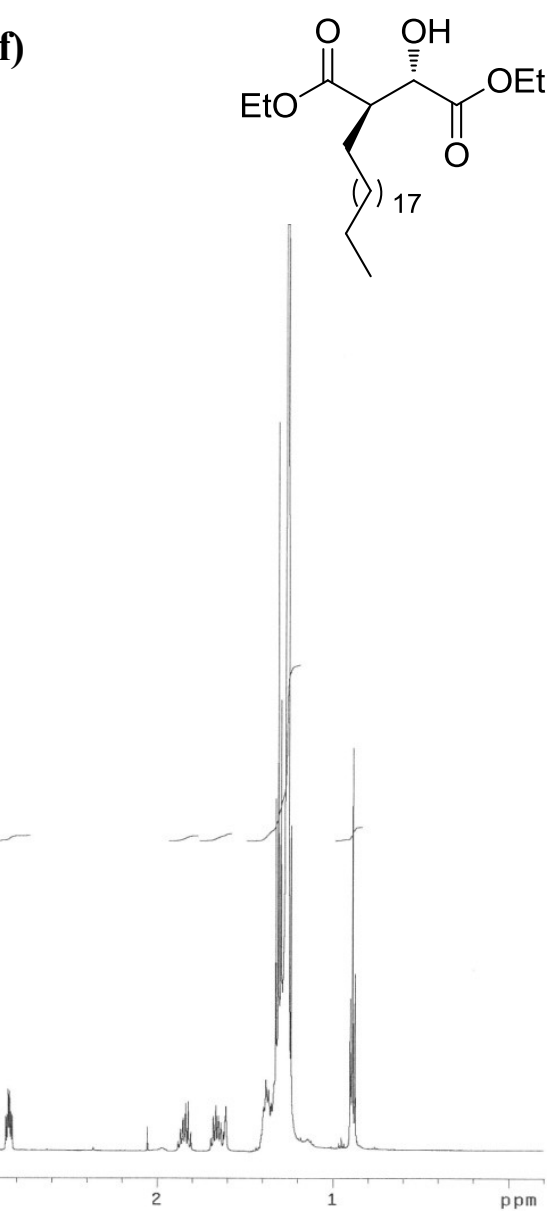

Ethyl 2S-hydroxy-3R-ethoxycarbonyl-tricosanoate (5f) ${ }^{13} \mathrm{C}$ NMR $\left(125 \mathrm{MHz}, \mathrm{CDCl}_{3}\right)$

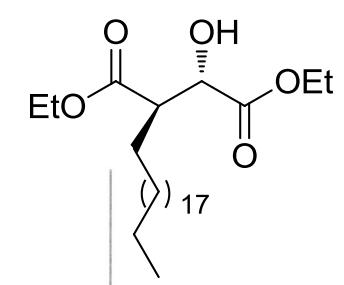


Ethyl $2 S$-hydroxy-3R-ethoxycarbonyl-tricos-5-enoate (5g)

${ }^{1} \mathrm{H} \mathrm{NMR}\left(500 \mathrm{MHz}, \mathrm{CDCl}_{3}\right)$
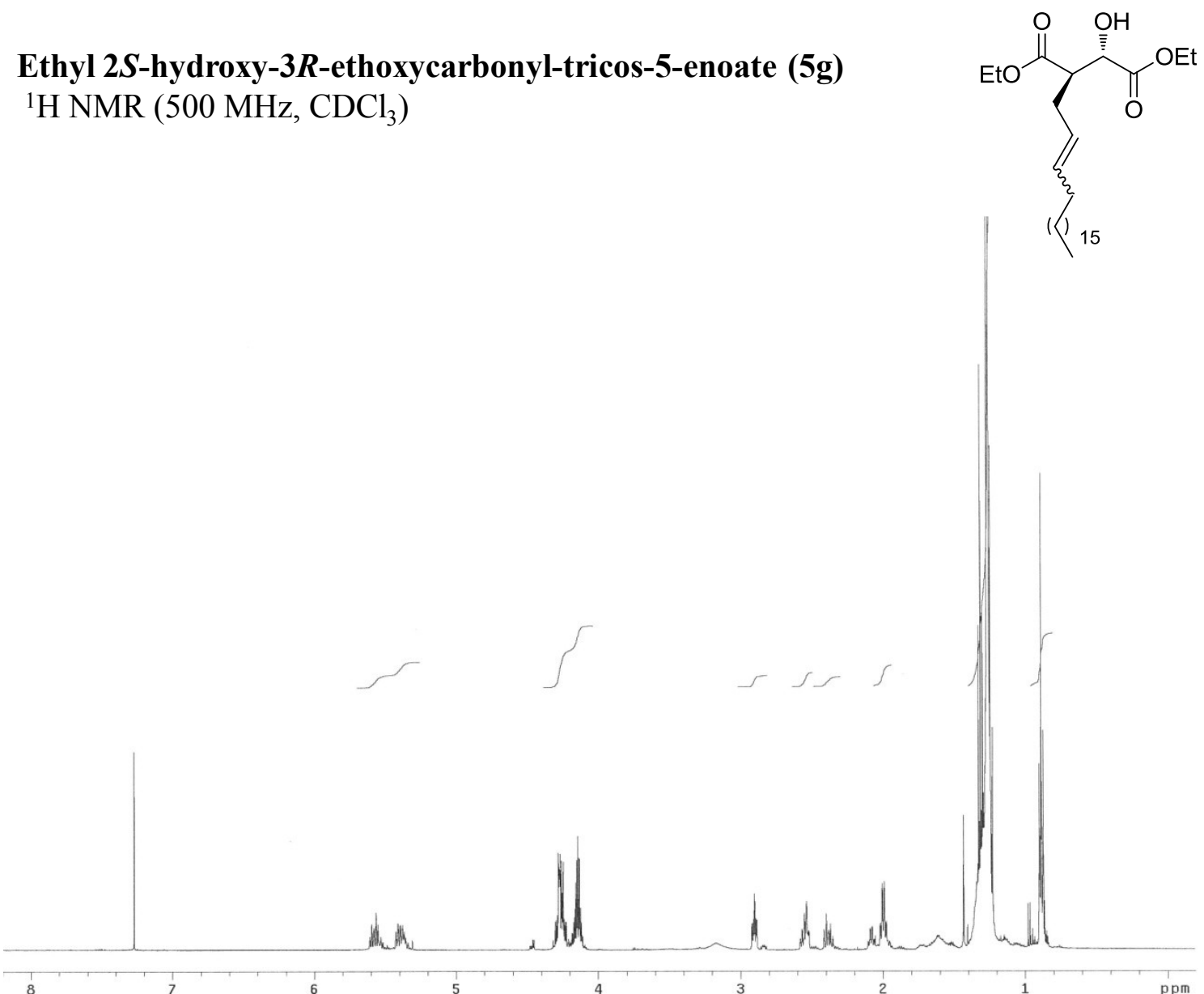

Ethyl $2 S$-hydroxy-3R-ethoxycarbonyl-tricos-5-enoate (5g) ${ }^{13} \mathrm{C}$ NMR $\left(125 \mathrm{MHz}, \mathrm{CDCl}_{3}\right)$

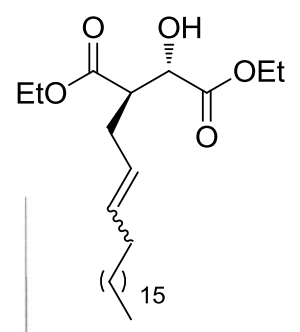


Ethyl $2 S$-hydroxy-3R-ethoxycarbonyl-pentacosanoate (5h) ${ }^{1} \mathrm{H}$ NMR $\left(500 \mathrm{MHz}, \mathrm{CDCl}_{3}\right.$ )<smiles>CCCCC(C(=O)OCC)C(O)C(=O)OCC</smiles>

From the reduction of $5 \mathrm{i}$

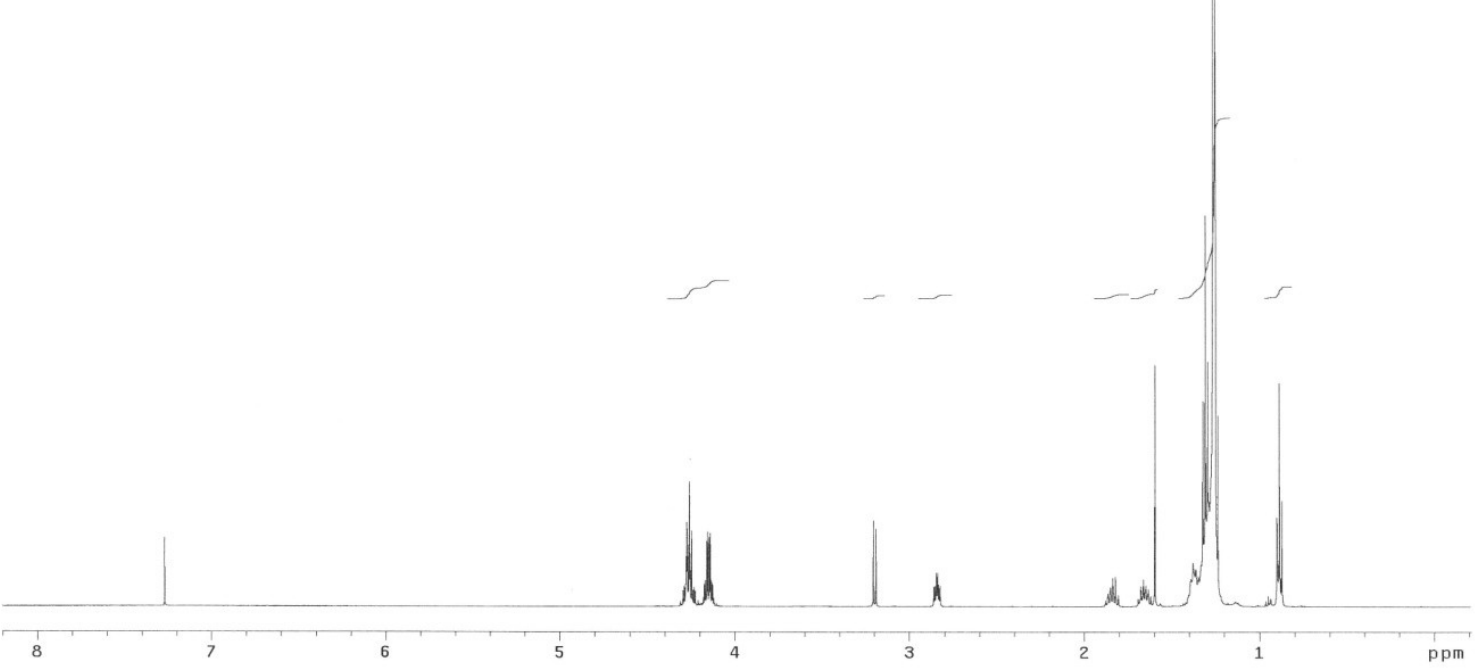

Ethyl $2 S$-hydroxy-3R-ethoxycarbonyl-pentacosanoate (5h) ${ }^{13} \mathrm{C} \mathrm{NMR}\left(125 \mathrm{MHz}, \mathrm{CDCl}_{3}\right)$

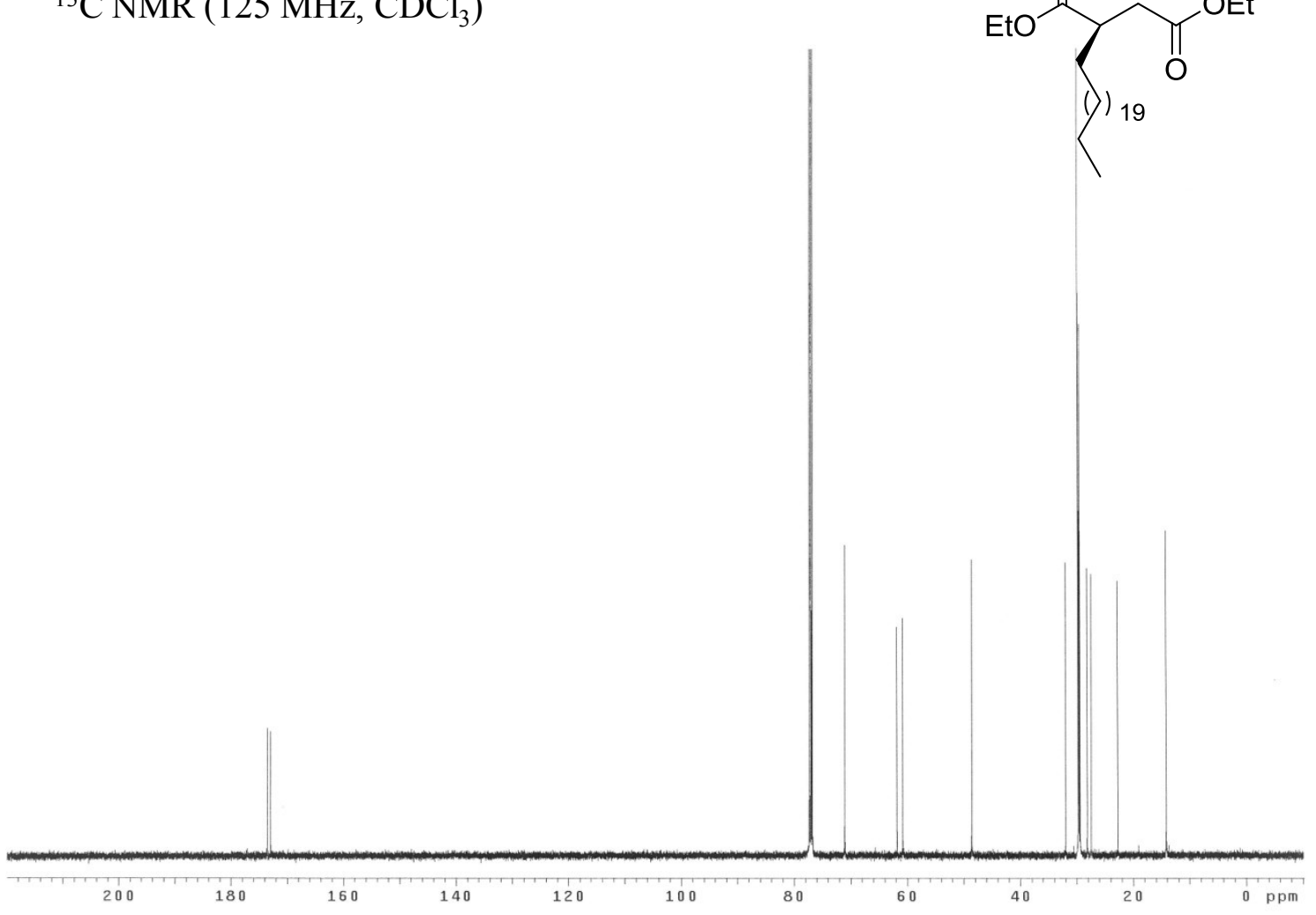


Ethyl $2 S$-hydroxy-3R-ethoxycarbonyl-pentacos-5-enoate (5i)

${ }^{1} \mathrm{H} \mathrm{NMR}\left(500 \mathrm{MHz}, \mathrm{CDCl}_{3}\right)$
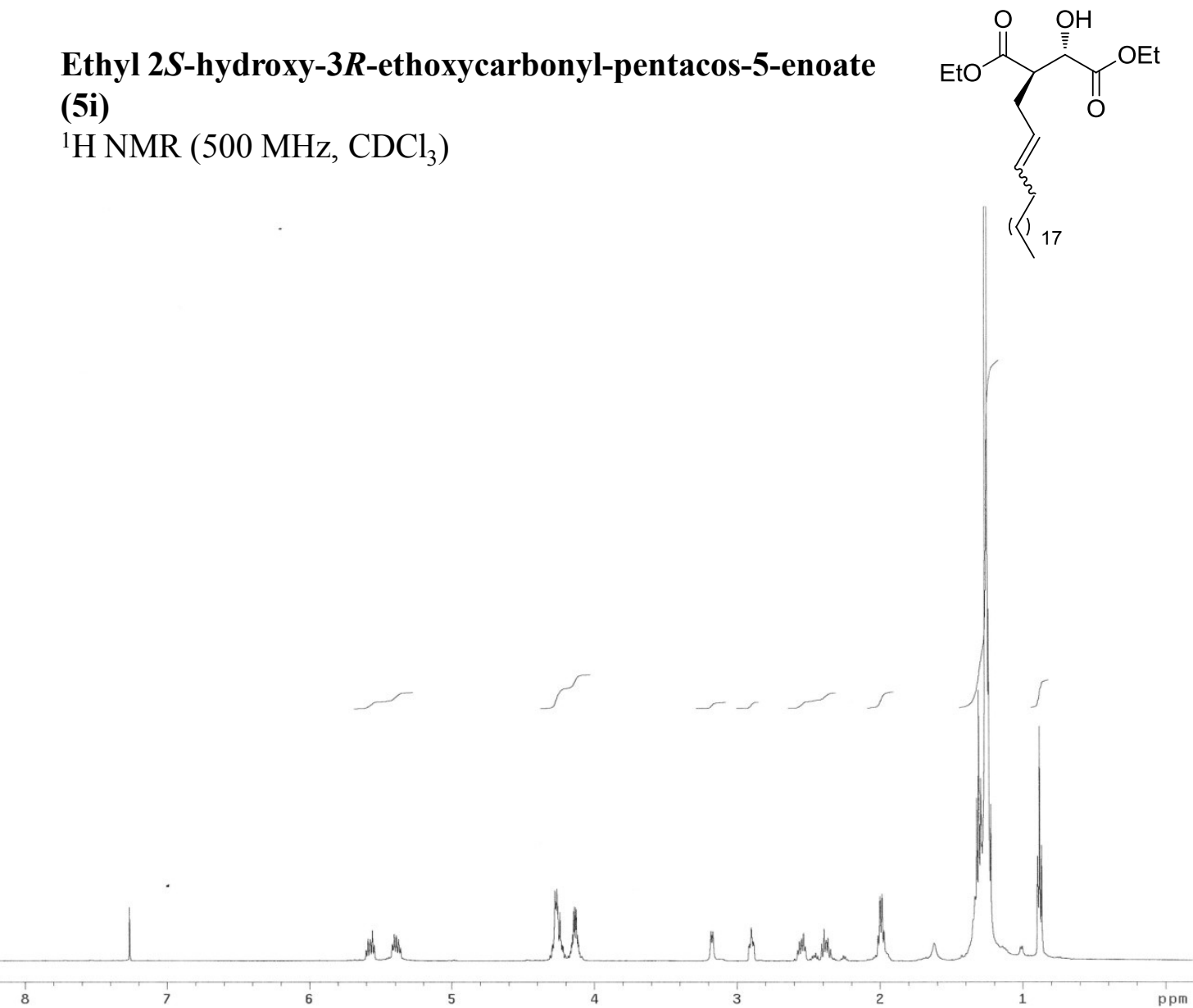

Ethyl $2 S$-hydroxy-3R-ethoxycarbonyl-pentacos-5-enoate (5i)

${ }^{13} \mathrm{C}$ NMR (125 MHz. $\left.\mathrm{CDCl}_{2}\right)$

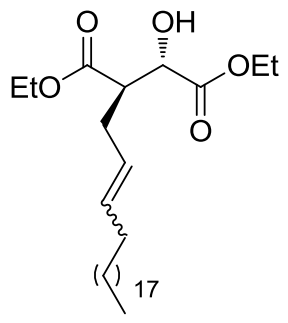



Chapter 5 

3R-Ethoxycarbonyl-2S-hydroxy-heptadecanol (10) ${ }^{1} \mathrm{H}$ NMR (500 MHz, $\mathrm{CDCl}_{3}$ )

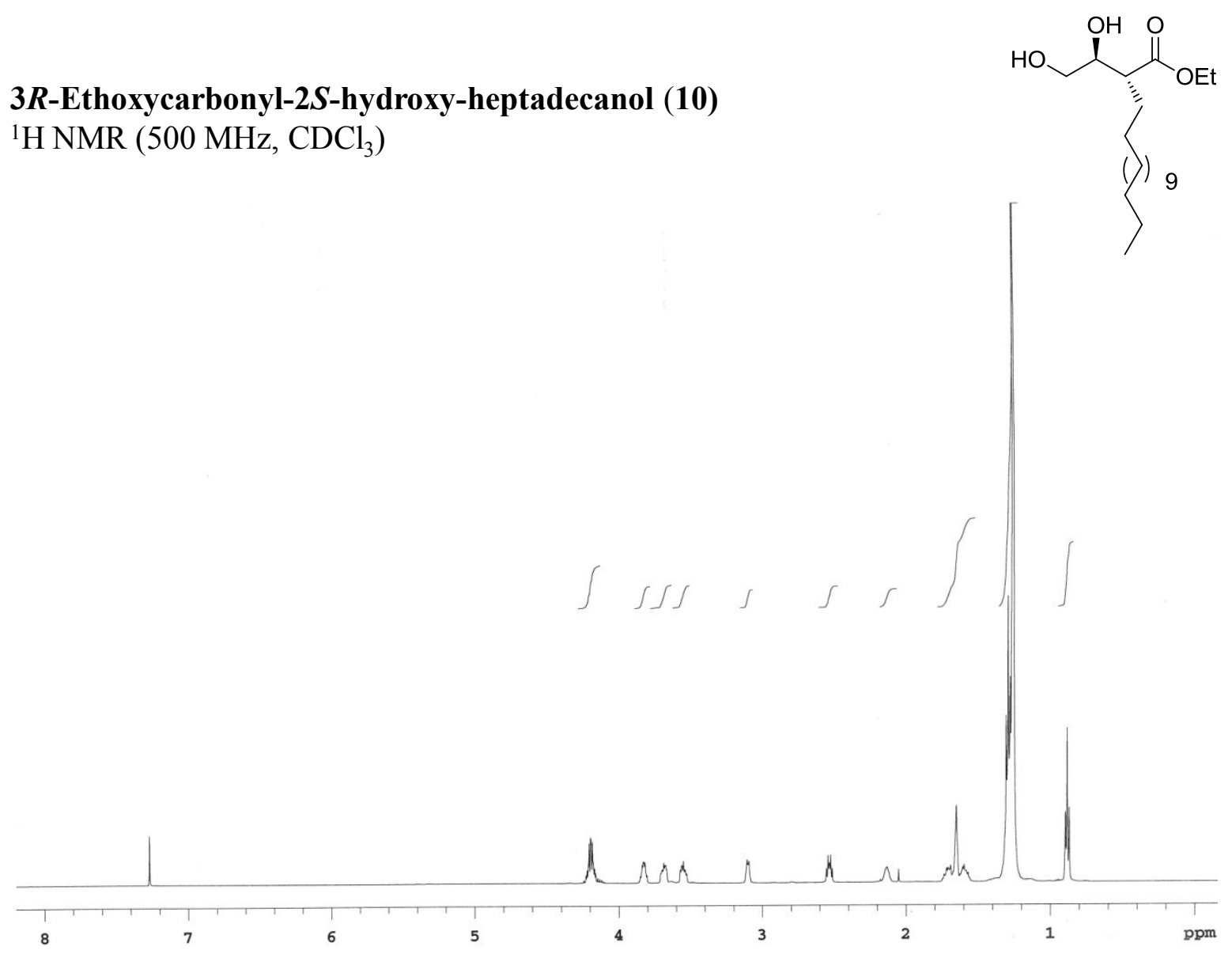

3R-Ethoxycarbonyl-2S-hydroxy-heptadecanol (10) ${ }^{13} \mathrm{C} \mathrm{NMR}\left(125 \mathrm{MHz}, \mathrm{CDCl}_{3}\right)$

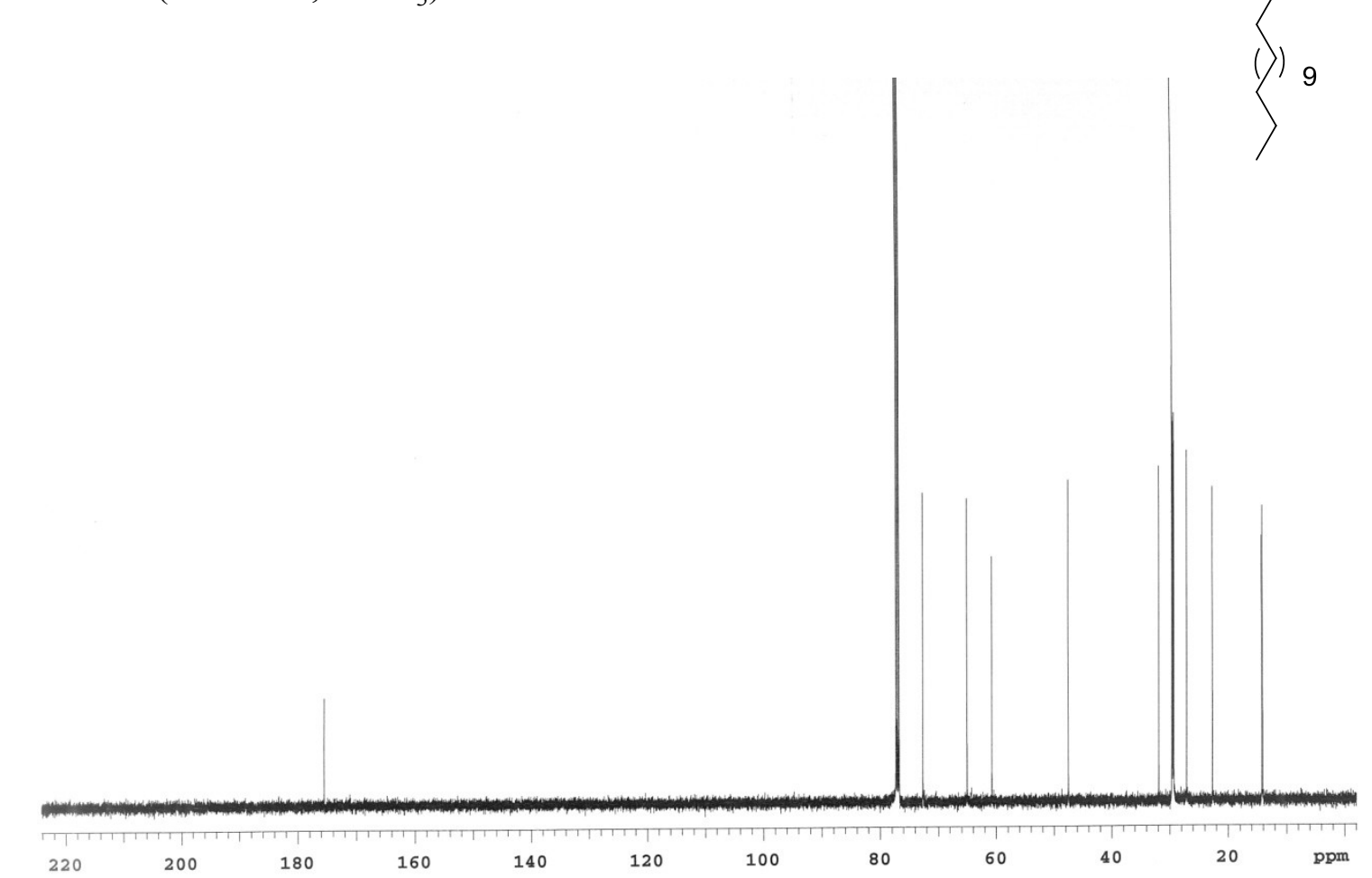


Ethyl (2R)-2-[(R)-oxiranyl]-hexadecanoate (7)

${ }^{1} \mathrm{H}$ NMR $\left(500 \mathrm{MHz}, \mathrm{CDCl}_{3}\right)$

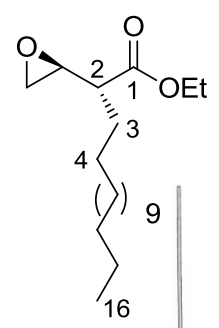

Ethyl (2R)-2-[(R)-oxiranyl]-hexadecanoate (7)

${ }^{13} \mathrm{C}$ NMR (125 MHz, $\mathrm{CDCl}_{3}$ )
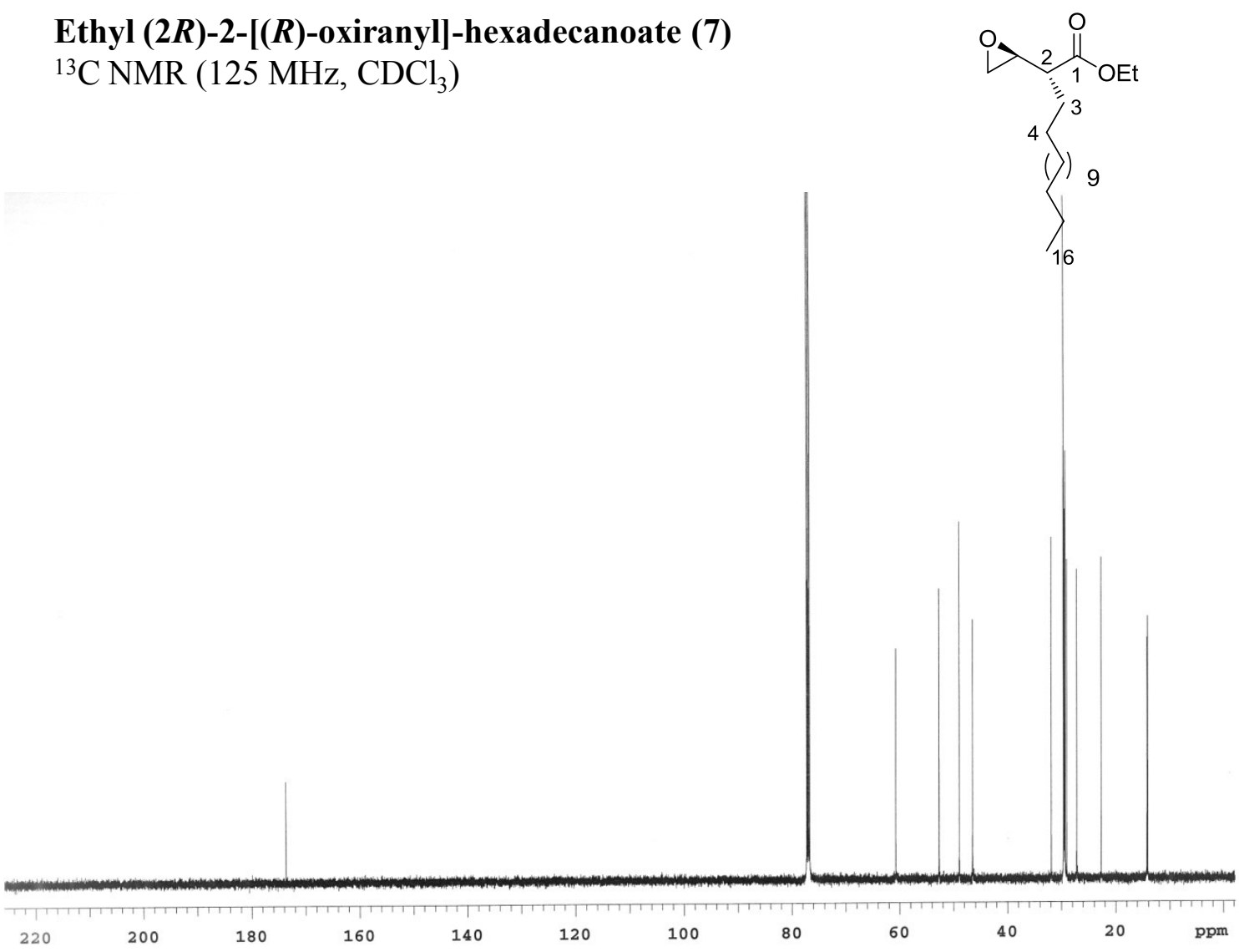
Ethyl -(2R,3R)-3-hydroxy-2-tetradecyl-octanoate (12a)

${ }^{1} \mathrm{H}$ NMR $\left(500 \mathrm{MHz}, \mathrm{CDCl}_{3}\right)$

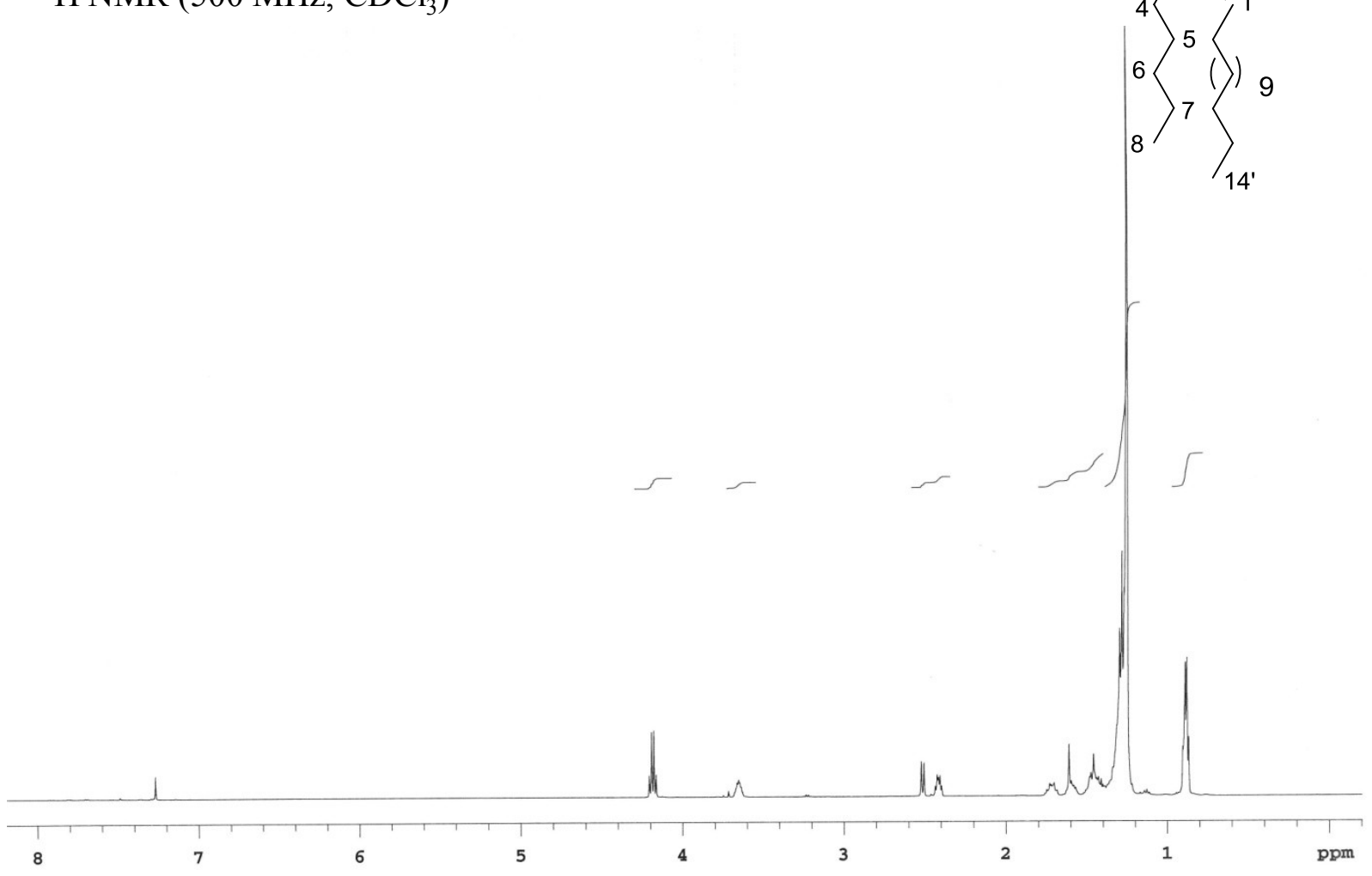

Ethyl -(2R,3R)-3-hydroxy-2-tetradecyl-octanoate (12a)

${ }^{13} \mathrm{C}$ NMR $\left(125 \mathrm{MHz}, \mathrm{CDCl}_{3}\right)$

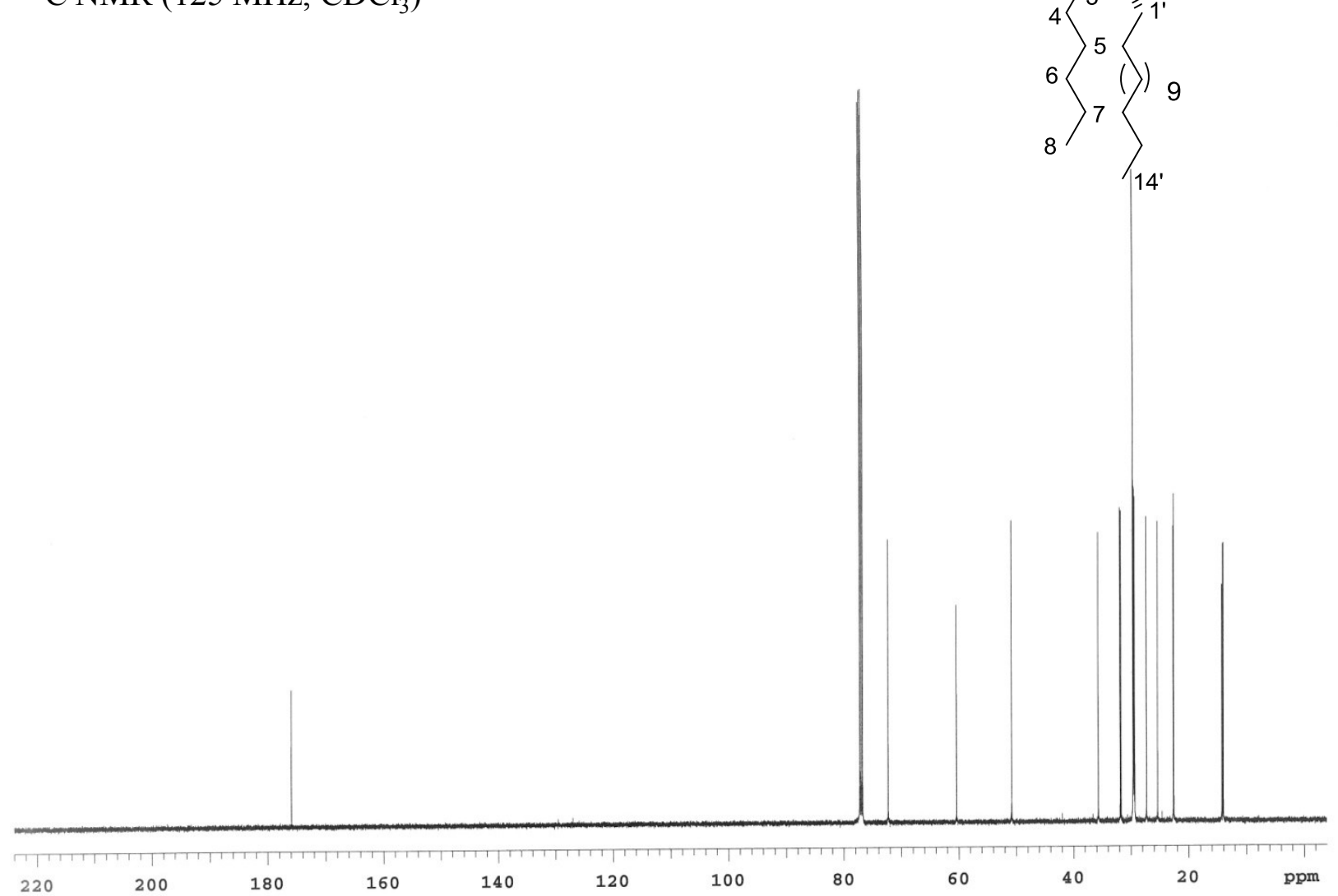


(2R,3R)-3-Tert-butyldimethylsilyloxy-2-tetradecyloctanoic acid (5)

${ }^{1} \mathrm{H} \mathrm{NMR}\left(500 \mathrm{MHz}, \mathrm{CDCl}_{\imath}\right.$ )

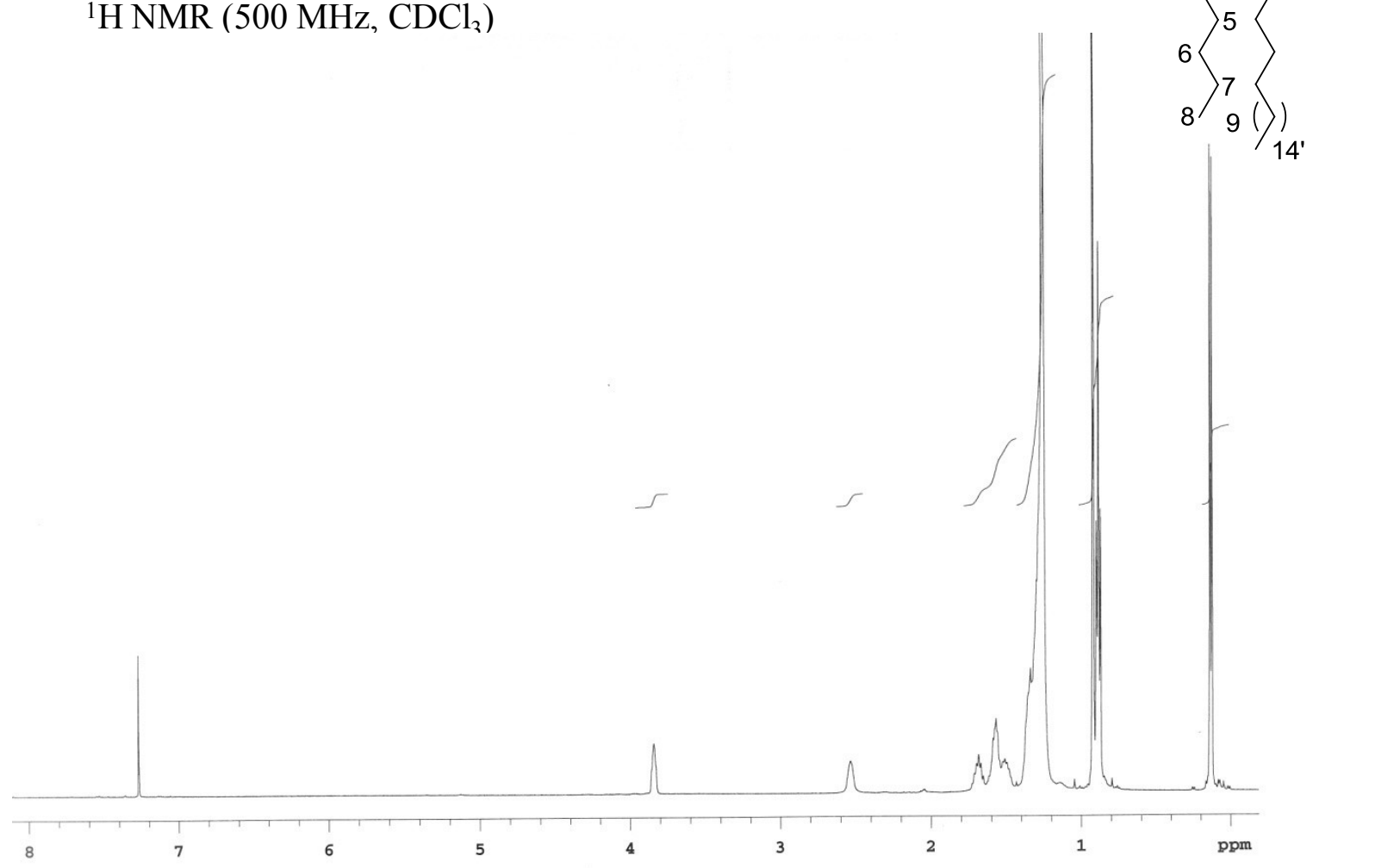

(2R,3R)-3-Tert-butyldimethylsilyloxy-2-tetradecyloctanoic acid (5)

${ }^{13} \mathrm{C} \mathrm{NMR}\left(125 \mathrm{MHz}, \mathrm{CDCl}_{3}\right)$

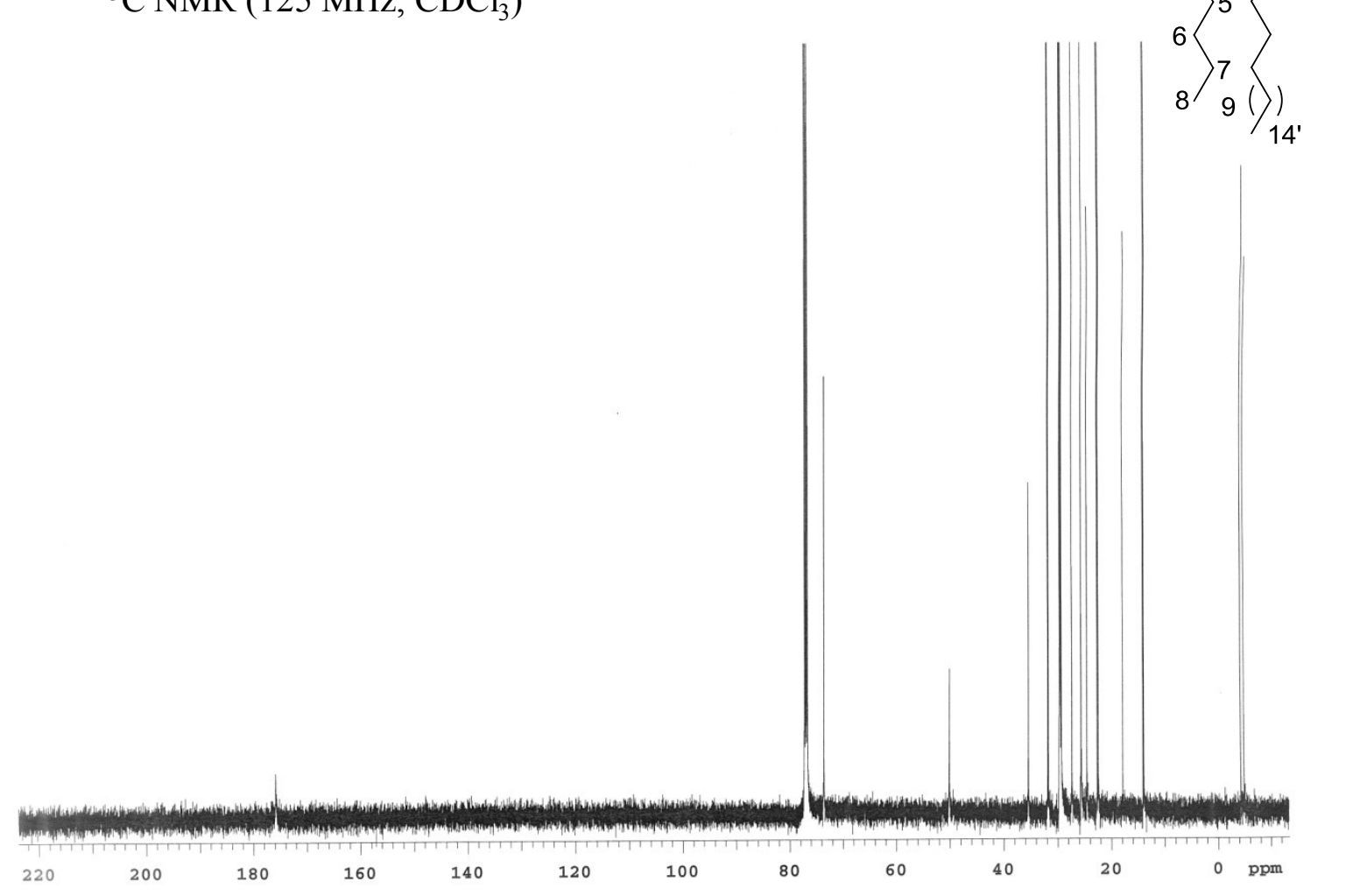


$2,2^{\prime}, 3,3 ', 4,4^{\prime}$-Hexa-O-trimethylsilyl-6- $O$-[(2R,3R)-3-tert-

butyldimethylsilyloxy-2-tetradecyl-octanoyl]-a, $\alpha^{\prime}$-D-trehalose (15)

${ }^{1} \mathrm{H} \mathrm{NMR} \mathrm{(500} \mathrm{MHz,} \mathrm{CDCl}_{3}$ )

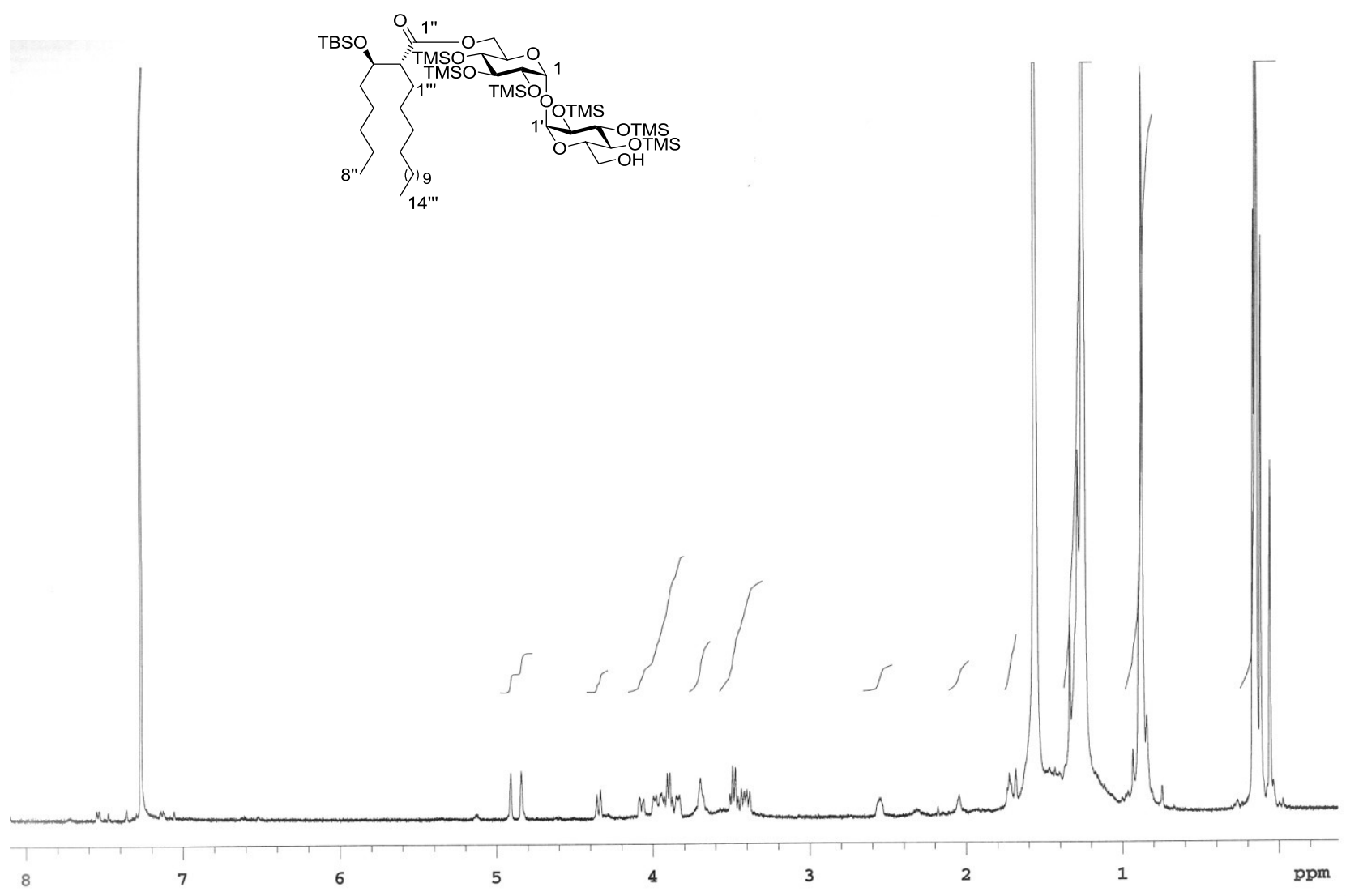





\section{Chapter 6}



2-(4-Bromobutyloxy)-tetrahydropyran (16)

${ }^{1} \mathrm{H} \mathrm{NMR}\left(500 \mathrm{MHz}, \mathrm{CDCl}_{3}\right.$ )
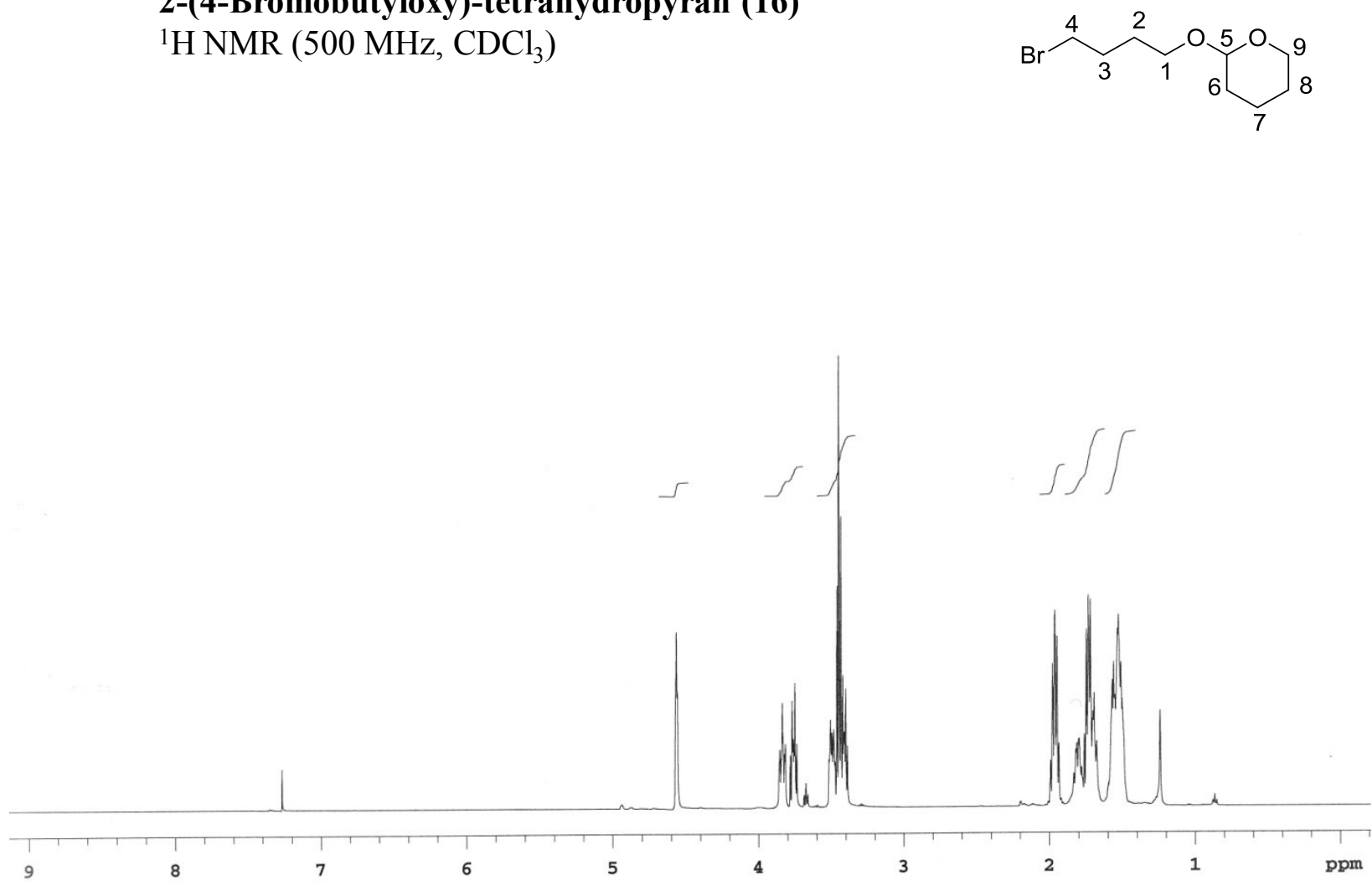

2-(4-Bromobutyloxy)-tetrahydropyran (16)

${ }^{13} \mathrm{C} \mathrm{NMR}\left(125 \mathrm{MHz}, \mathrm{CDCl}_{3}\right)$
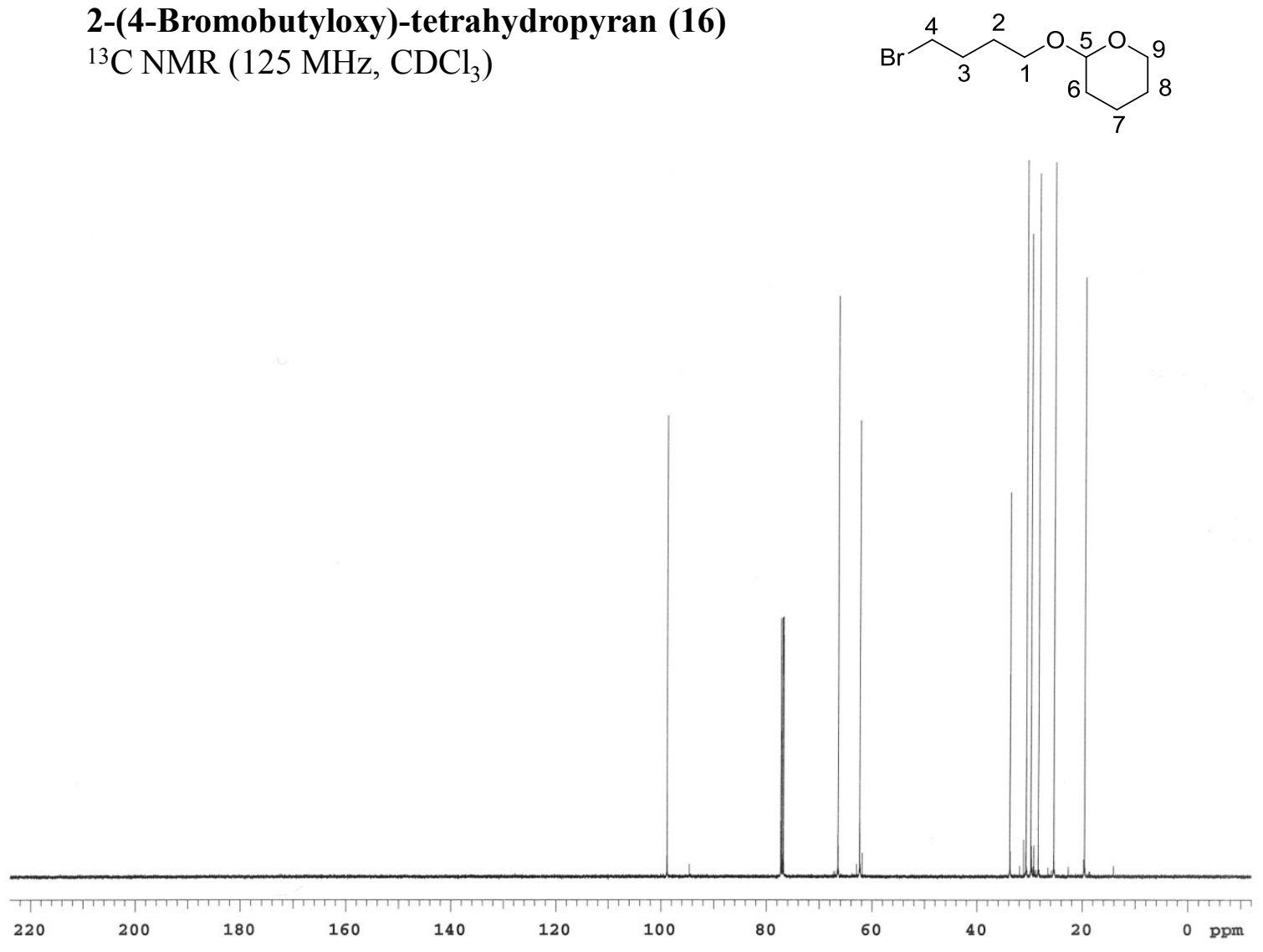
Octadecyne (15)

${ }^{1} \mathrm{H}$ NMR (500 MHz, $\mathrm{CDCl}_{3}$ )
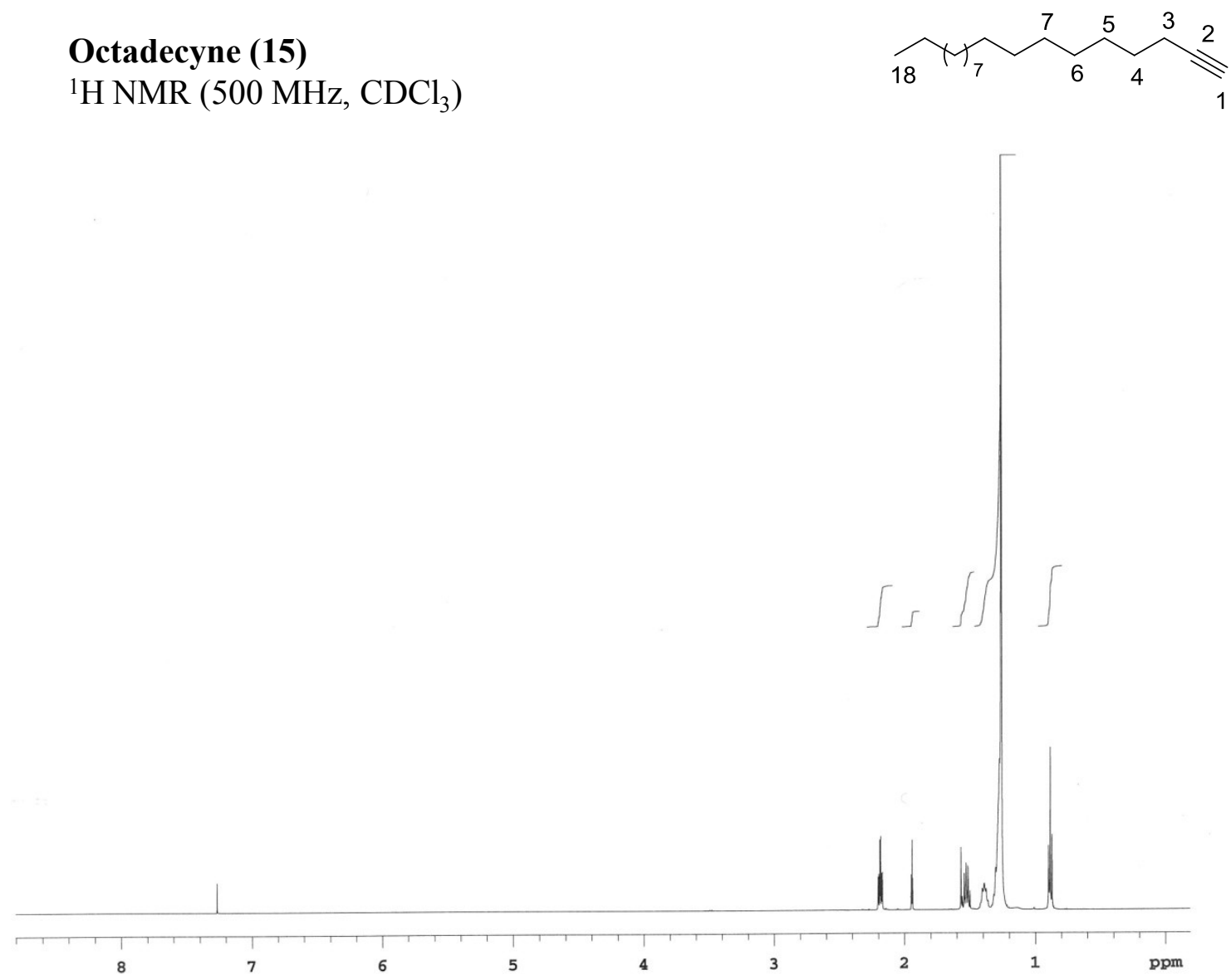

Octadecyne (15)

${ }^{13} \mathrm{C}$ NMR $\left(125 \mathrm{MHz}, \mathrm{CDCl}_{3}\right)$
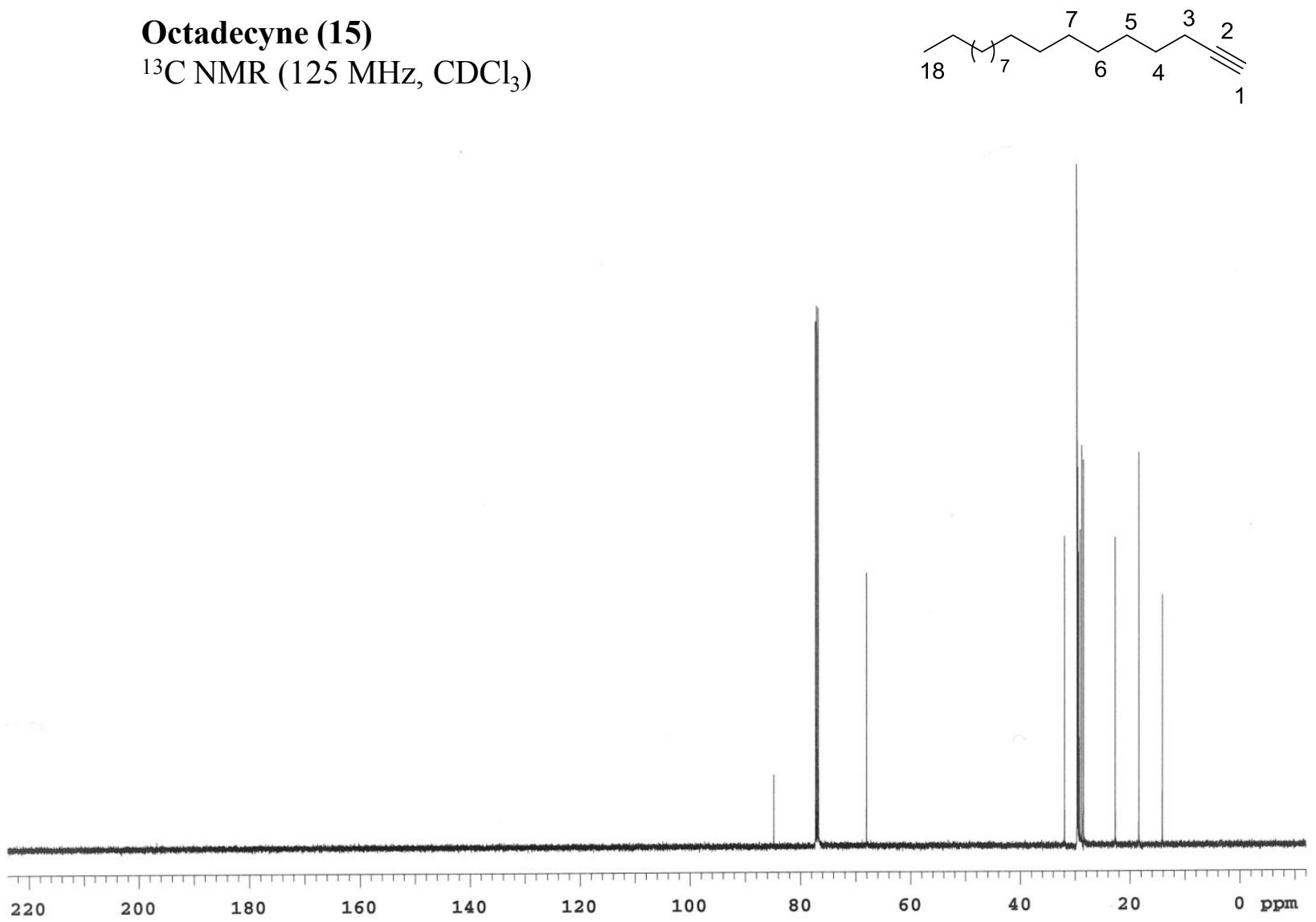
2-(5-Docosynyloxy)-tetrahydropyran (17)

${ }^{1} \mathrm{H} \mathrm{NMR} \mathrm{(500} \mathrm{MHz,} \mathrm{CDCl}_{3}$ )
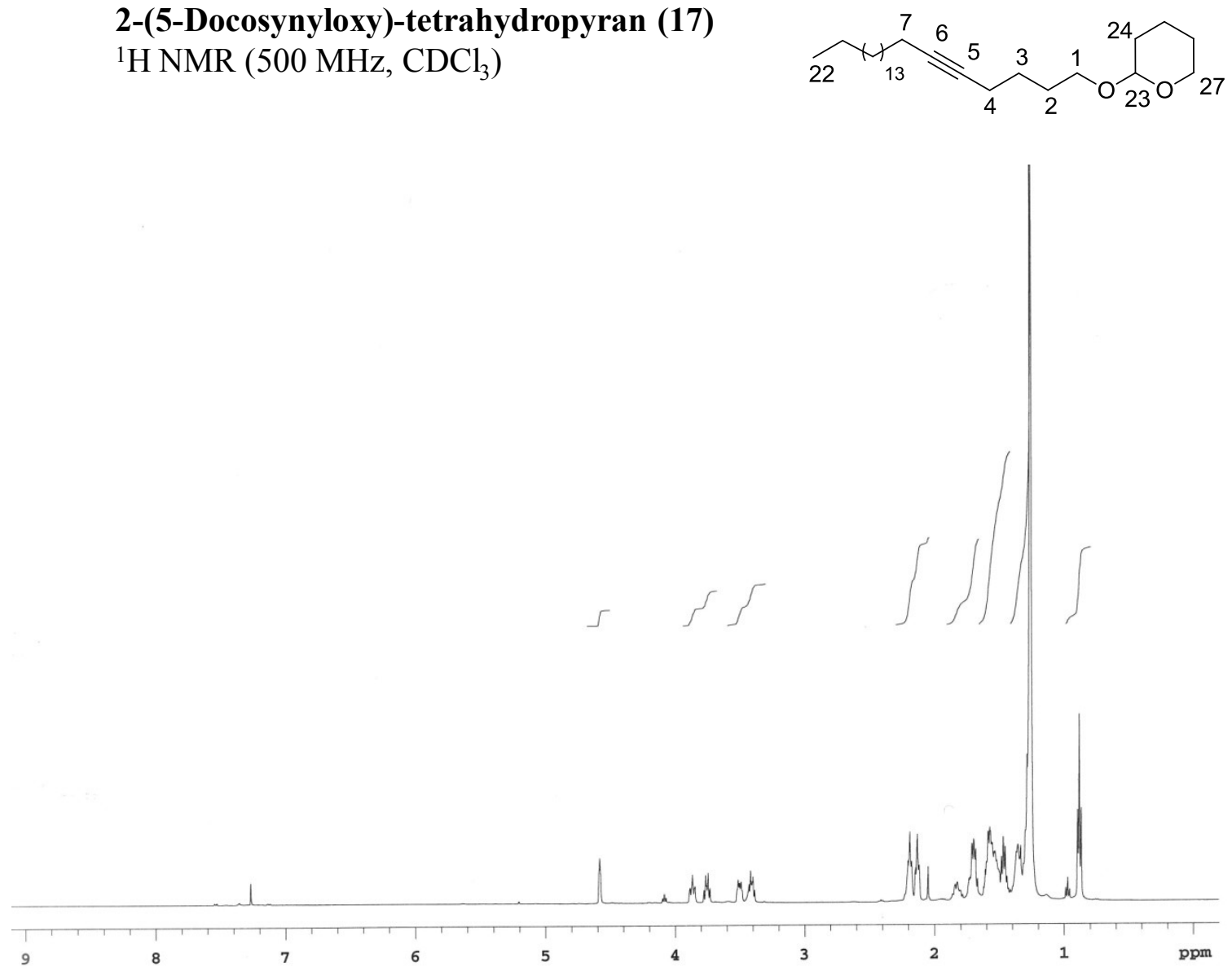

2-(5-Docosynyloxy)-tetrahydropyran (17)

${ }^{13} \mathrm{C} \mathrm{NMR}\left(125 \mathrm{MHz}, \mathrm{CDCl}_{3}\right)$
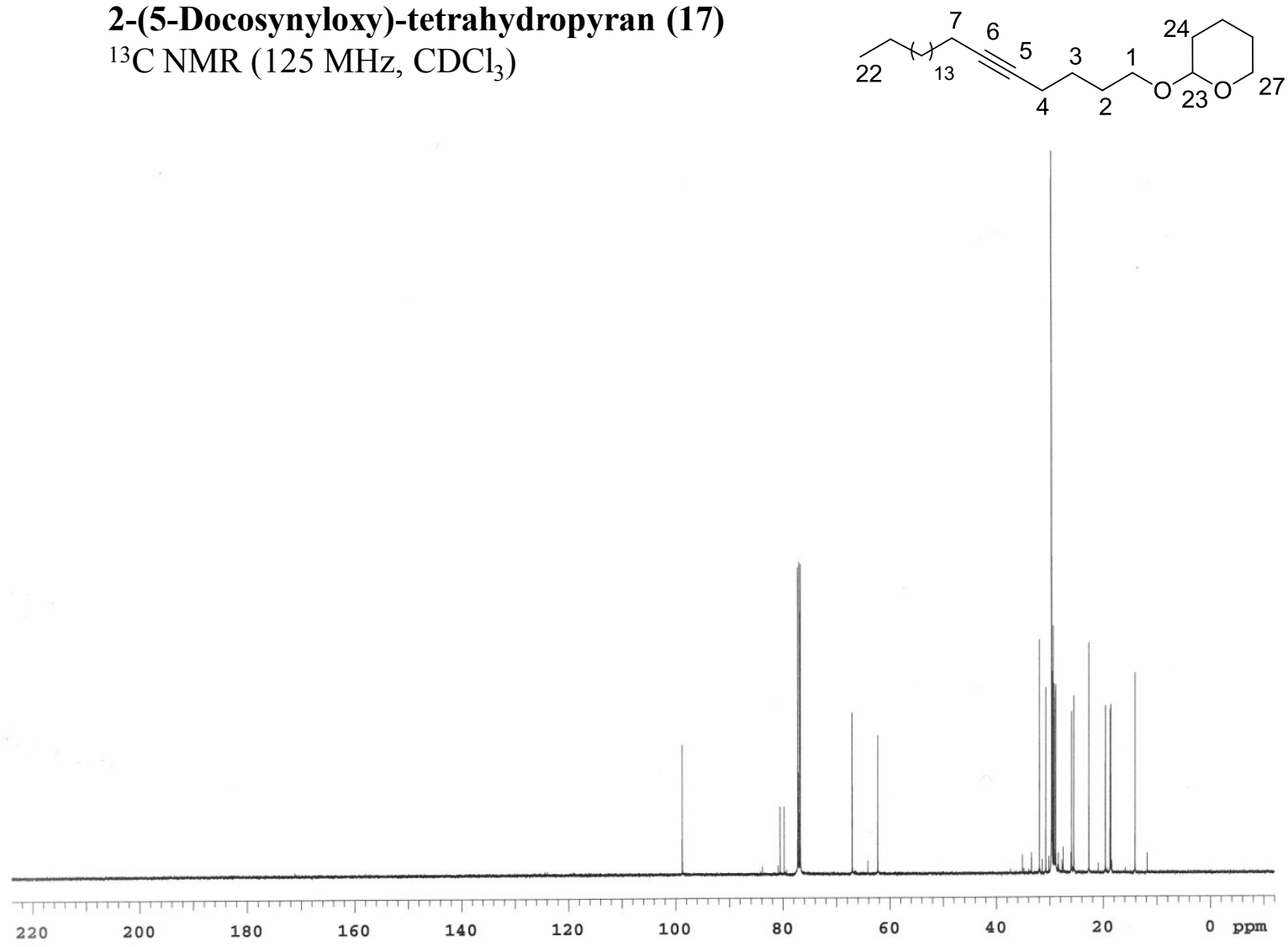
5-Docosyn-1-ol (18)

${ }^{1} \mathrm{H} \mathrm{NMR}\left(500 \mathrm{MHz}, \mathrm{CDCl}_{3}\right.$ )
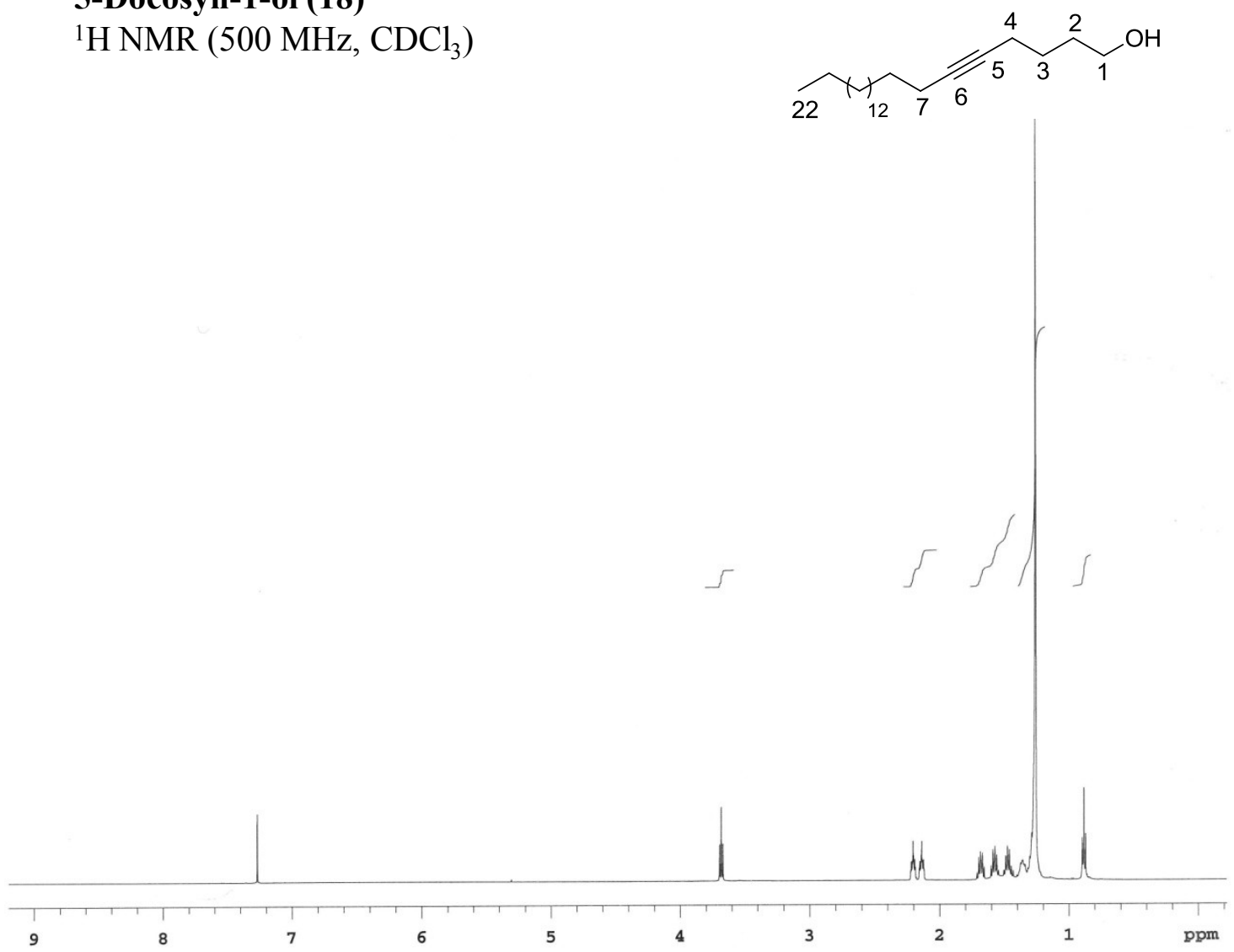

5-Docosyn-1-ol (18)

${ }^{13} \mathrm{C}$ NMR (125 MHz, $\mathrm{CDCl}_{3}$ )

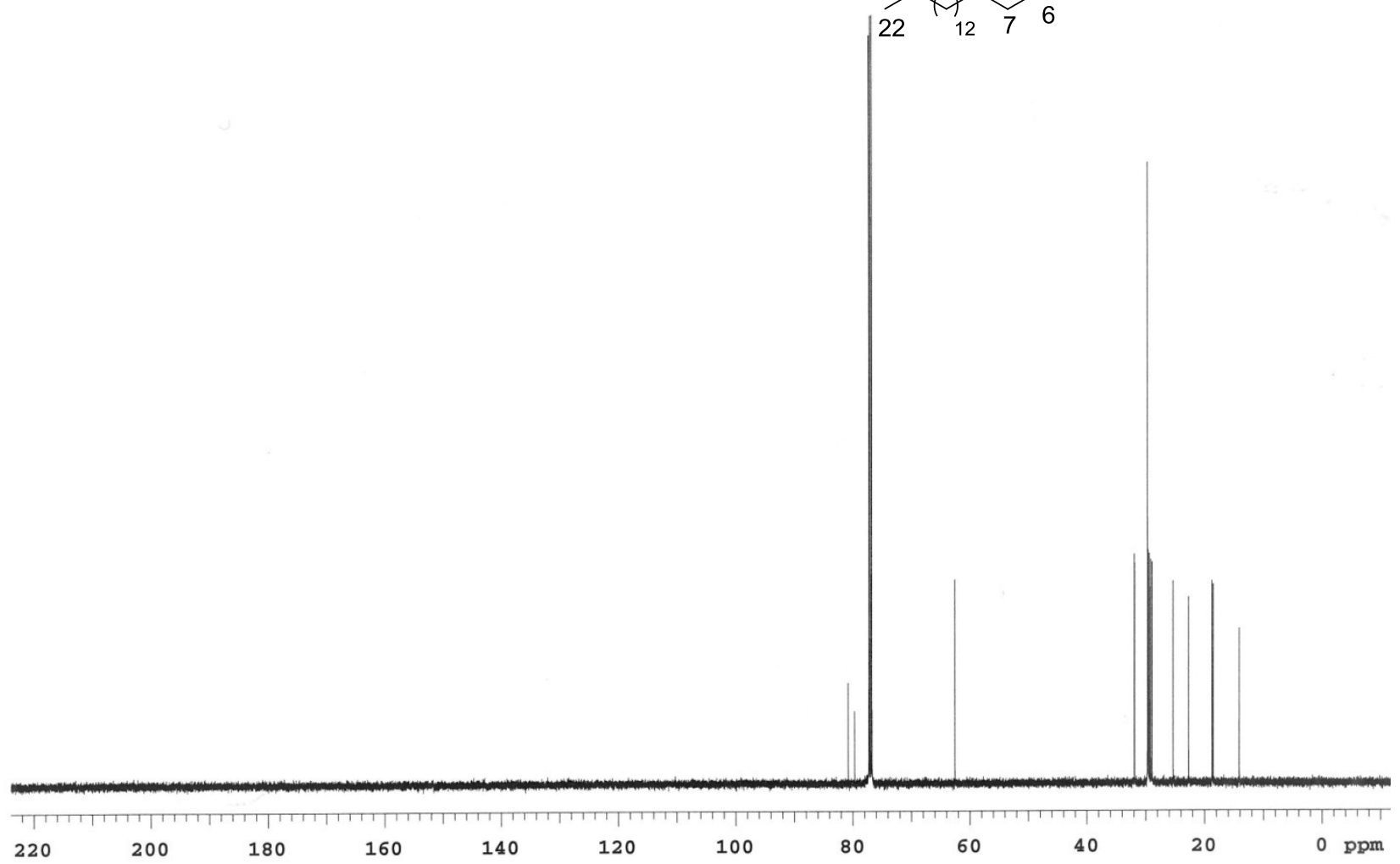


21-Docosyn-1-ol (19)

${ }^{1} \mathrm{H}$ NMR $\left(500 \mathrm{MHz}, \mathrm{CDCl}_{3}\right.$ )
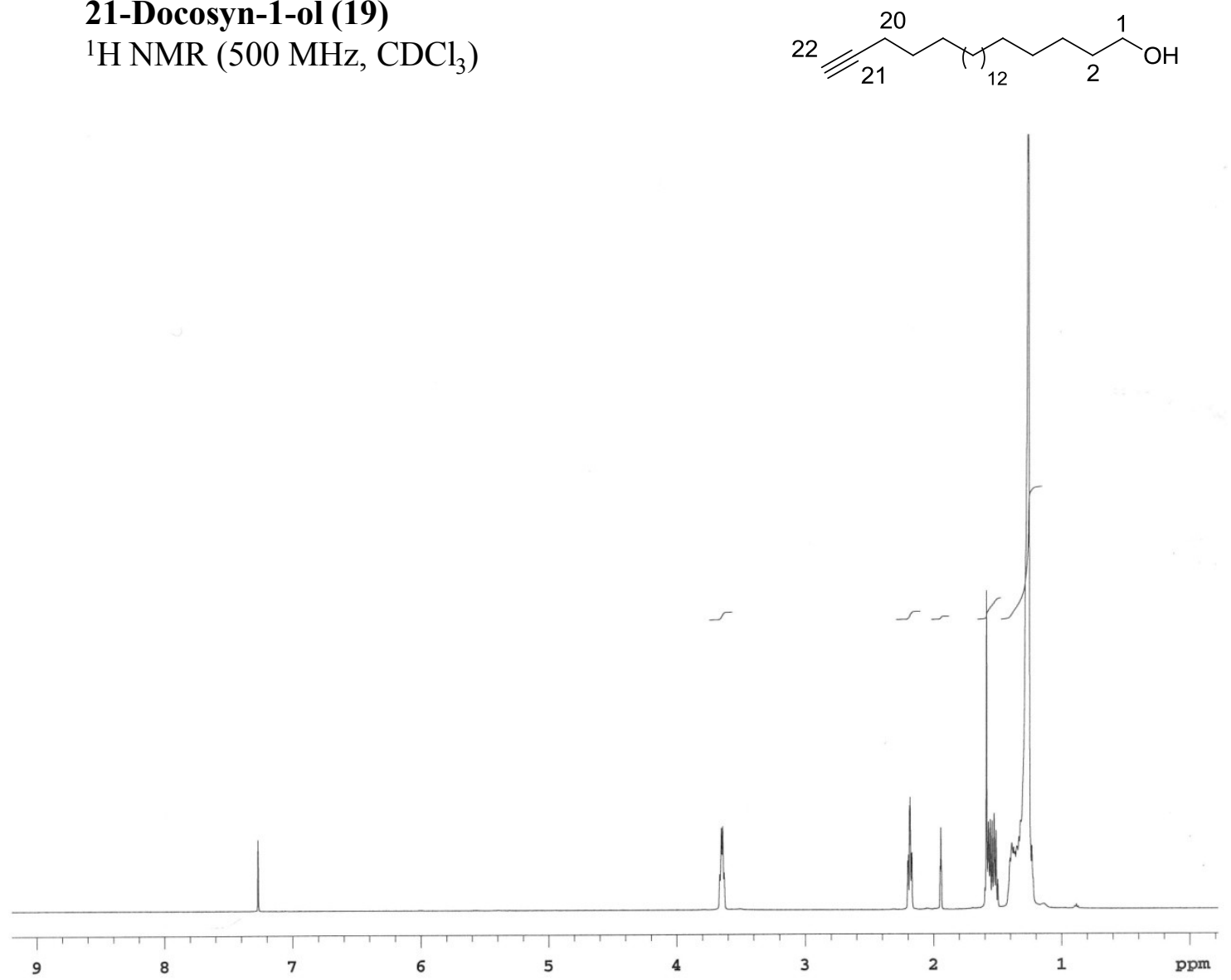

21-Docosyn-1-ol (19)

${ }^{13} \mathrm{C}$ NMR $\left(125 \mathrm{MHz}, \mathrm{CDCl}_{3}\right.$ )
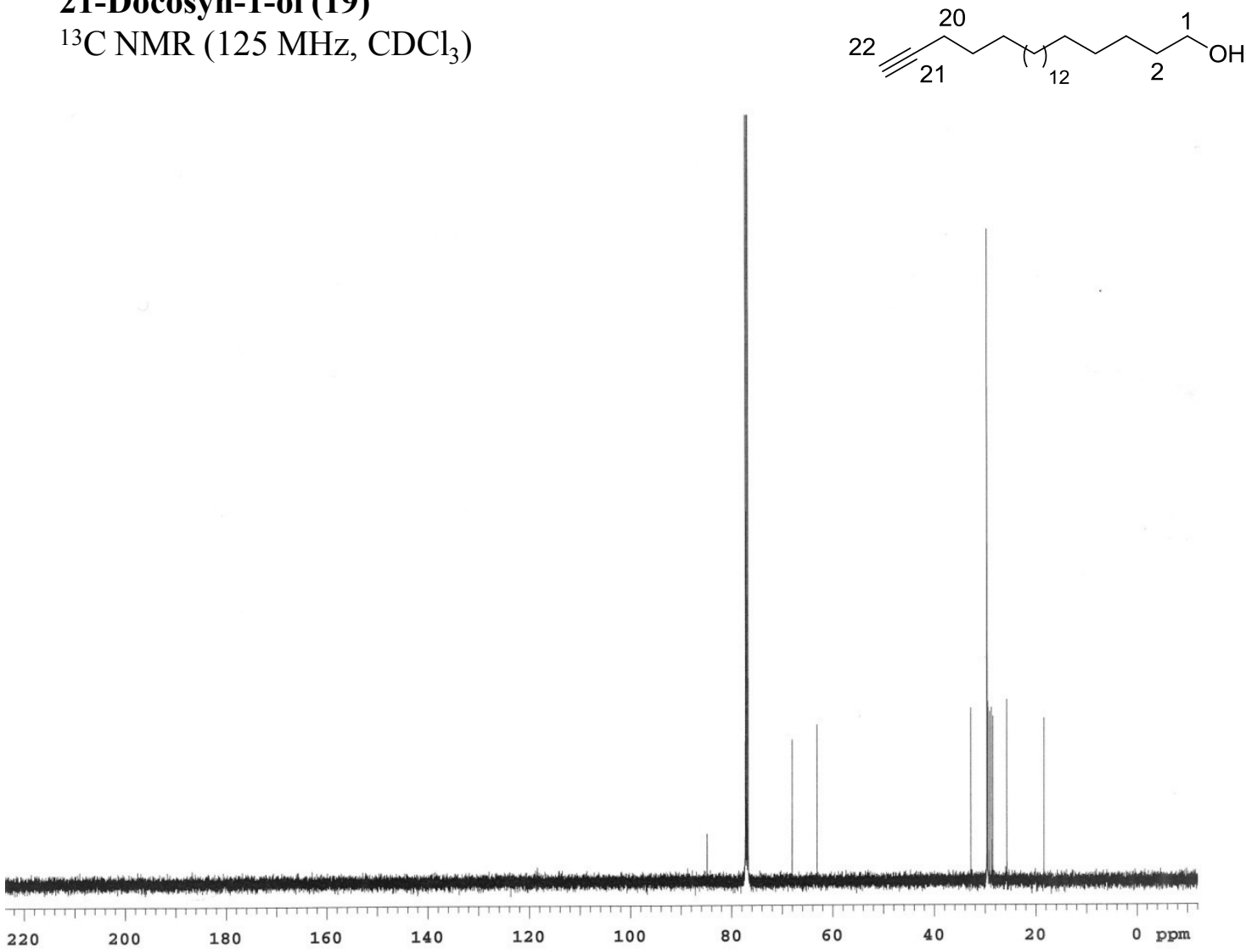
21-Docosynyl $p$-toluenesulfonate (21)

${ }^{1} \mathrm{H} \mathrm{NMR}\left(500 \mathrm{MHz}, \mathrm{CDCl}_{3}\right.$ )
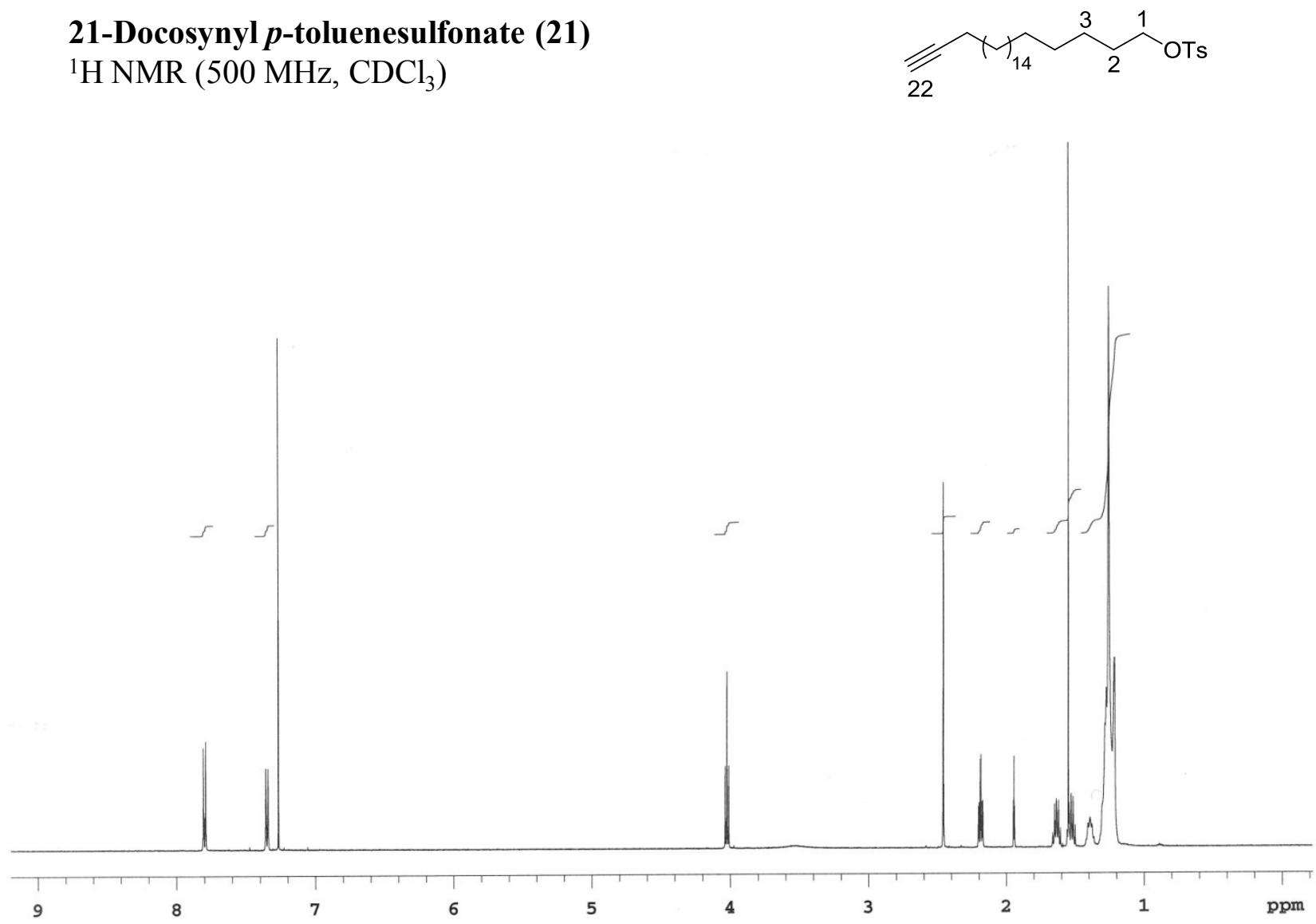

21-Docosynyl $p$-toluenesulfonate (21)

${ }^{13} \mathrm{C} \mathrm{NMR}\left(125 \mathrm{MHz}, \mathrm{CDCl}_{3}\right.$ )
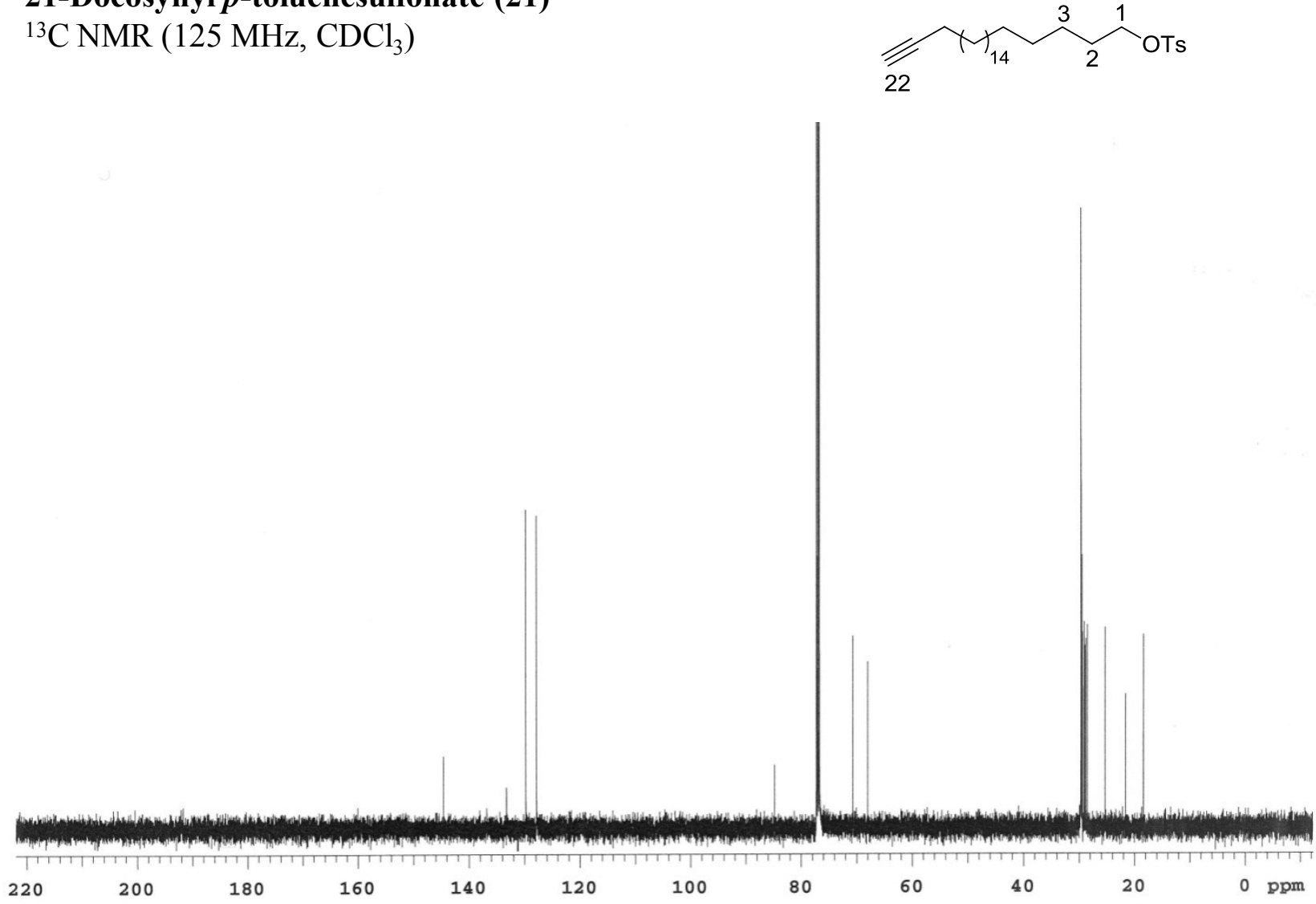
Methyl 4-[4-(21-

docosynyloxy)benzoyl]-benzoate (20)

${ }^{1} \mathrm{H} \mathrm{NMR}\left(500 \mathrm{MHz}, \mathrm{CDCl}_{3}\right)$
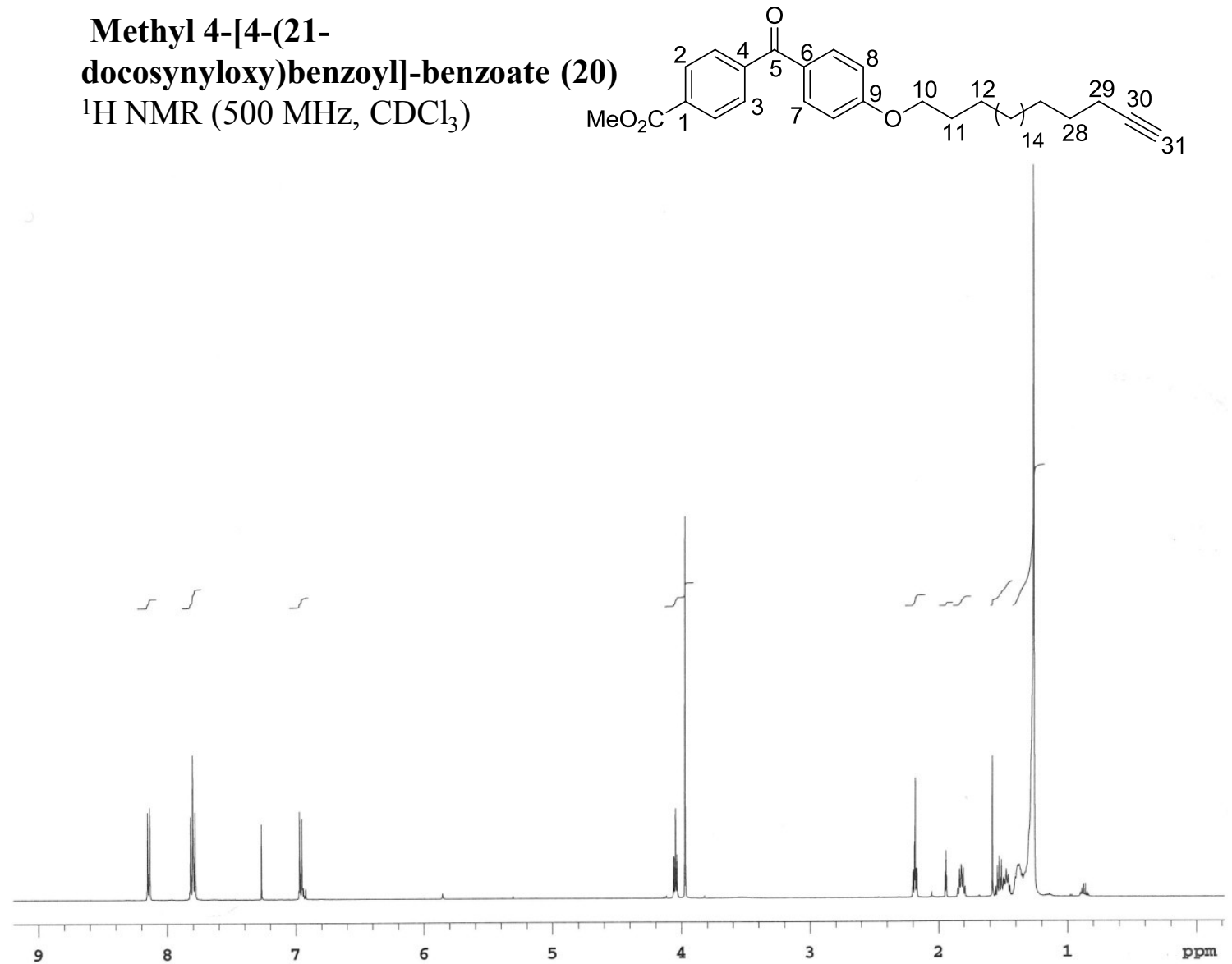

Methyl 4-[4-(21-

docosynyloxy)benzoyl]-benzoate (20)

${ }^{13} \mathrm{C}$ NMR (125 MHz, $\mathrm{CDCl}_{3}$ )
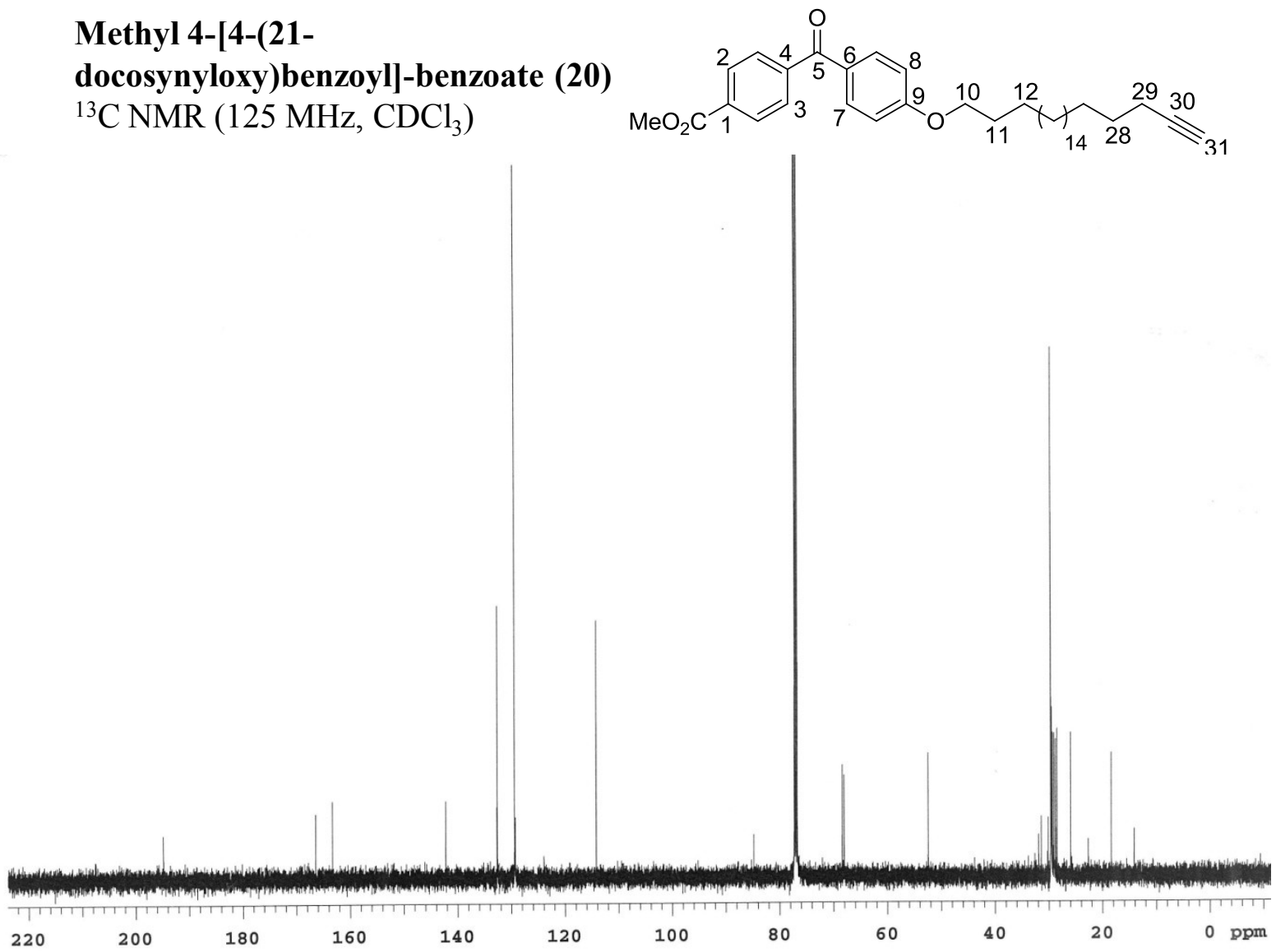
2,2',3,3',4,4'-Hexa-O-trimethylsilyl-6-

docosanoyl-6'-hydroxyl, $\alpha, \alpha^{\prime}$-D-trehalose (2)

${ }^{1} \mathrm{H}$ NMR $\left(500 \mathrm{MHz}, \mathrm{CDCl}_{3}\right)$
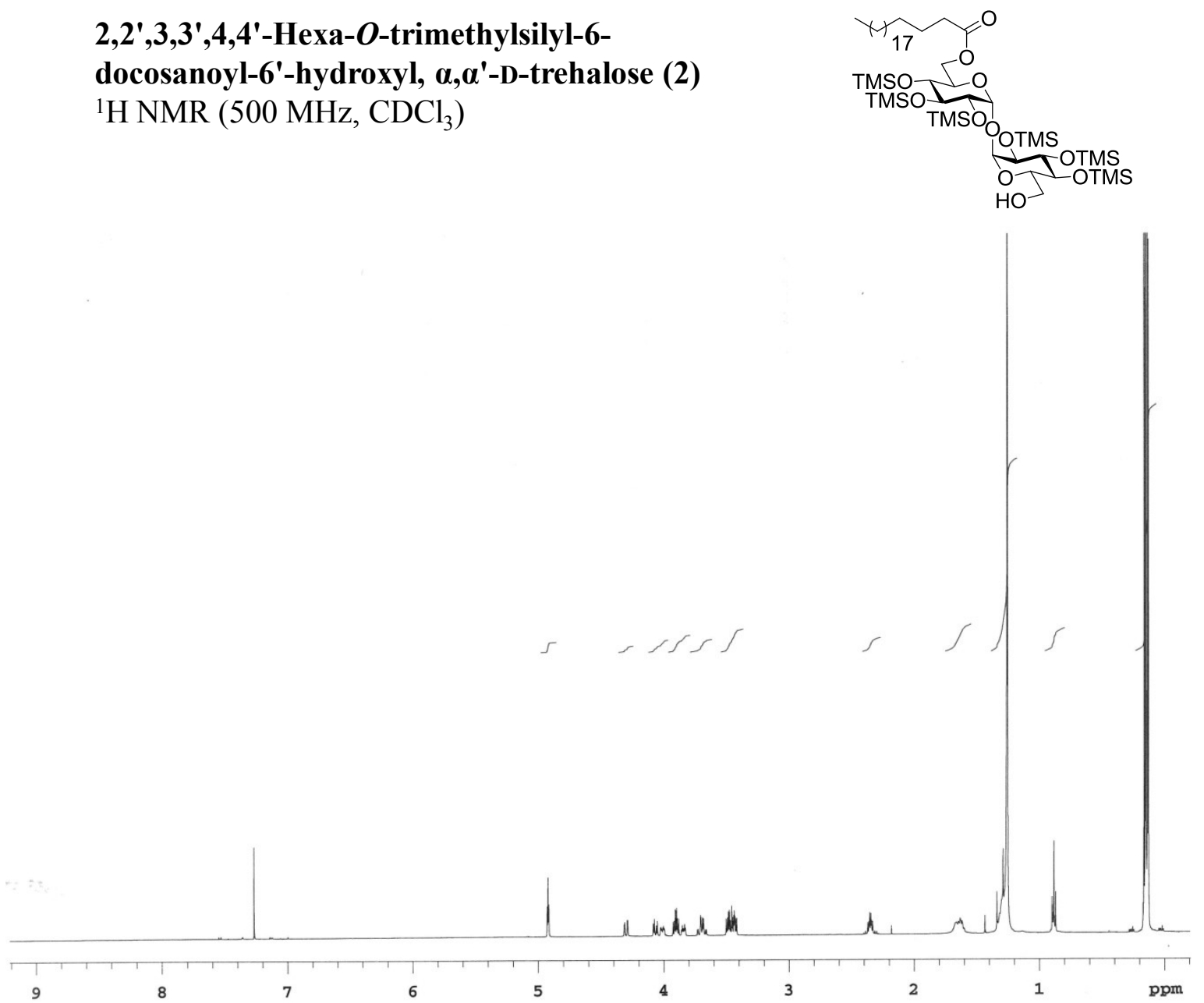

$2,2^{\prime}, 3,3^{\prime}, 4,4^{\prime}$-Hexa-O-trimethylsilyl-6-

docosanoyl-6'-hydroxyl, $\alpha, \alpha^{\prime}$-D-trehalose (2).

${ }^{13} \mathrm{C}$ NMR (125 MHz, $\left.\mathrm{CD}_{3} \mathrm{OD}\right)$

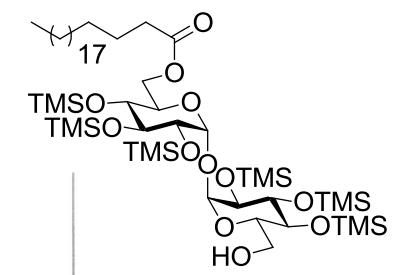


$2,2^{\prime}, 3,3^{\prime}, 4,4^{\prime}$-Hexa-O-trimethylsilyl-6'- $O$ docosanoyl-6-O-4-[4-(21-

docosynyloxy)benzoyl]benzoyl- $\alpha, \alpha^{\prime}-\mathrm{D}-$ trehalose (22) ${ }^{1} \mathrm{H}$ NMR (500 MHz,
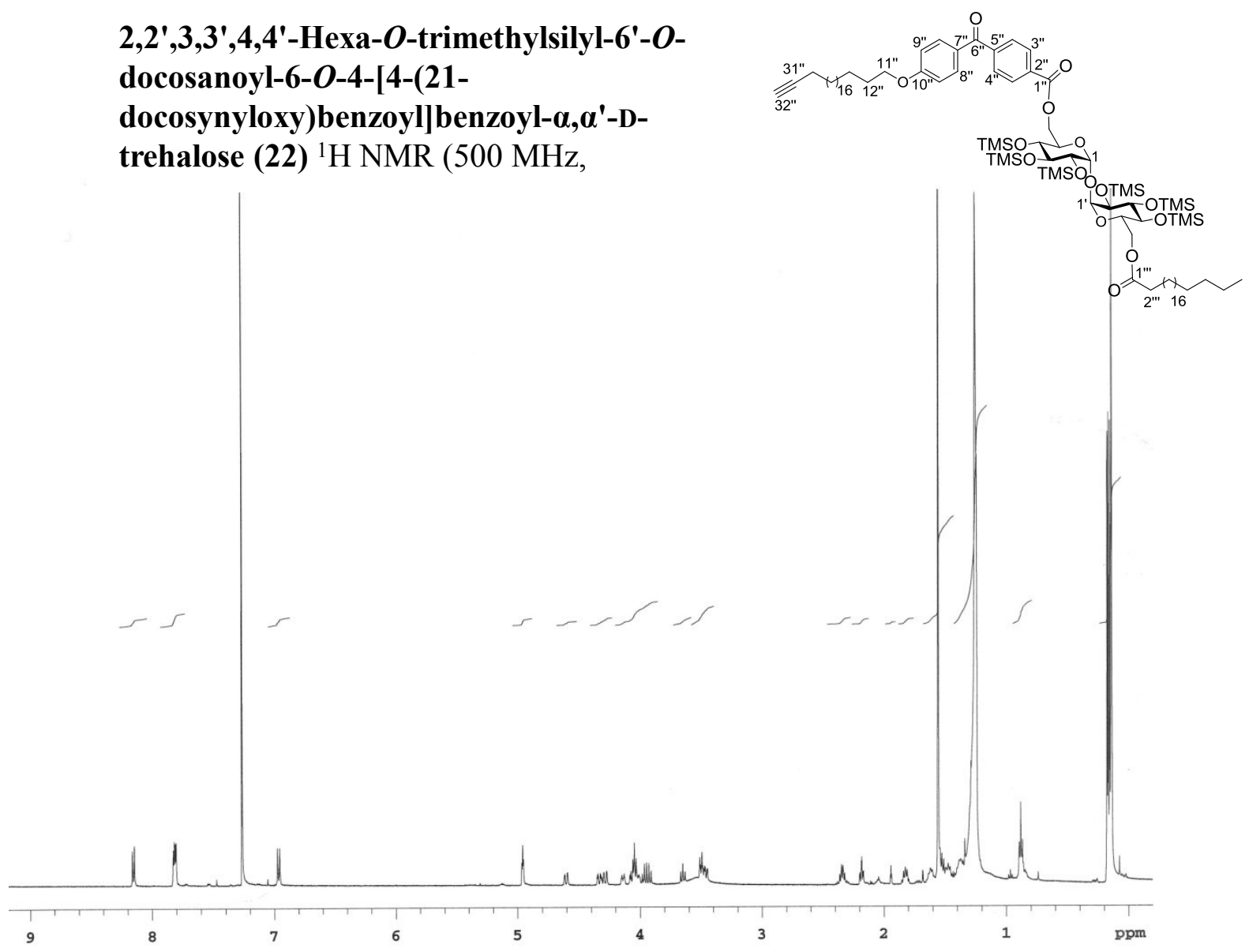

$2,2^{\prime}, 3,3^{\prime}, 4,4^{\prime}$-Hexa-O-trimethylsilyl-6'-Odocosanoyl-6-O-4-[4-(21docosynyloxy)benzoyl]benzoyl- $\alpha, \alpha^{\prime}-\mathrm{D}-$ trehalose (22).

${ }^{13} \mathrm{C} \mathrm{NMR}\left(125 \mathrm{MHz}, \mathrm{CDCl}_{3}\right)$
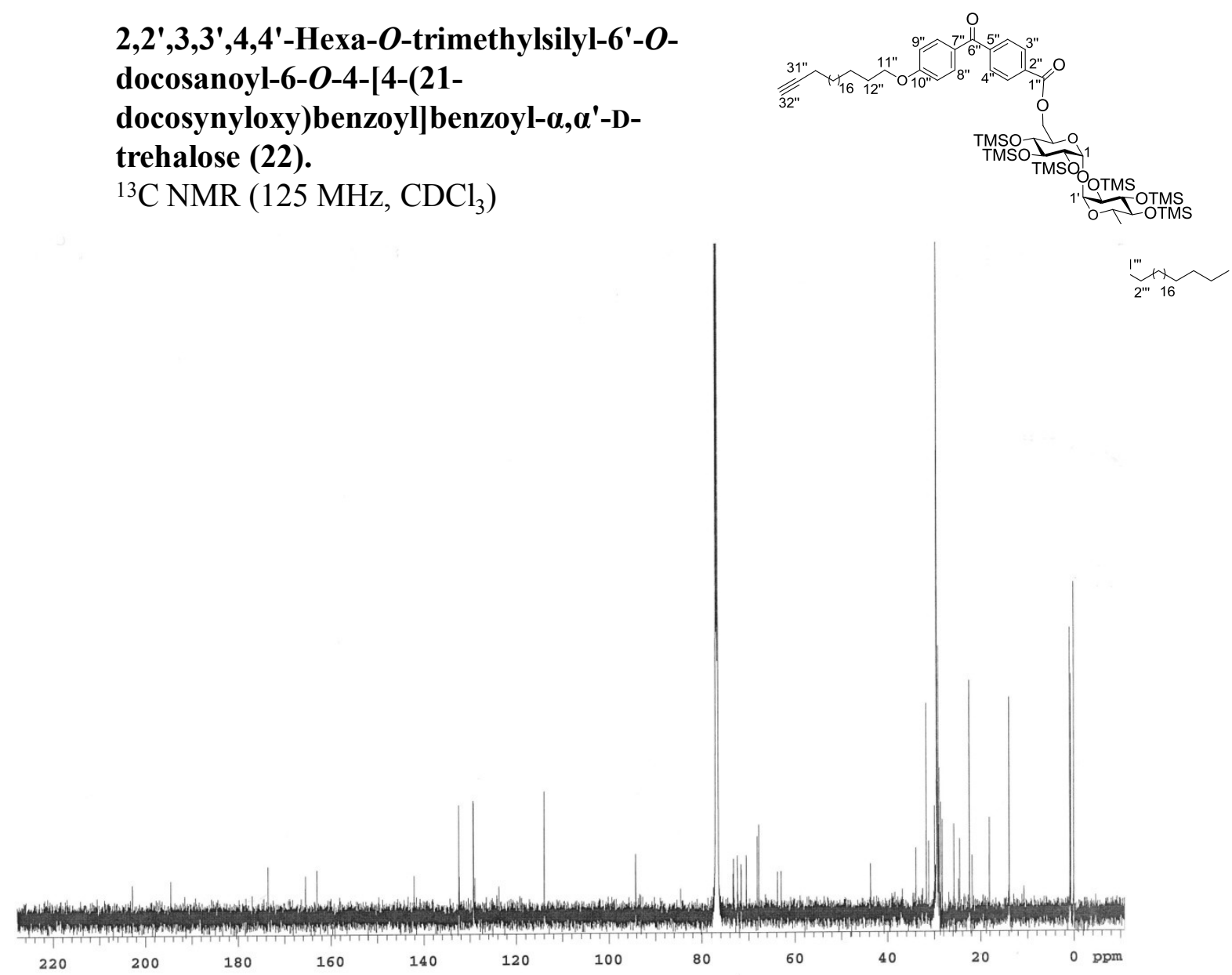
6'-O-Docosanoyl-6-O-4-[4-(21docosynyloxy)benzoyl]benzoyl- $\alpha, \alpha^{\prime}-$ D-trehalose (1)

${ }^{1} \mathrm{H}$ NMR (500 MHz, $\mathrm{C}_{5} \mathrm{D}_{5} \mathrm{~N}$ )
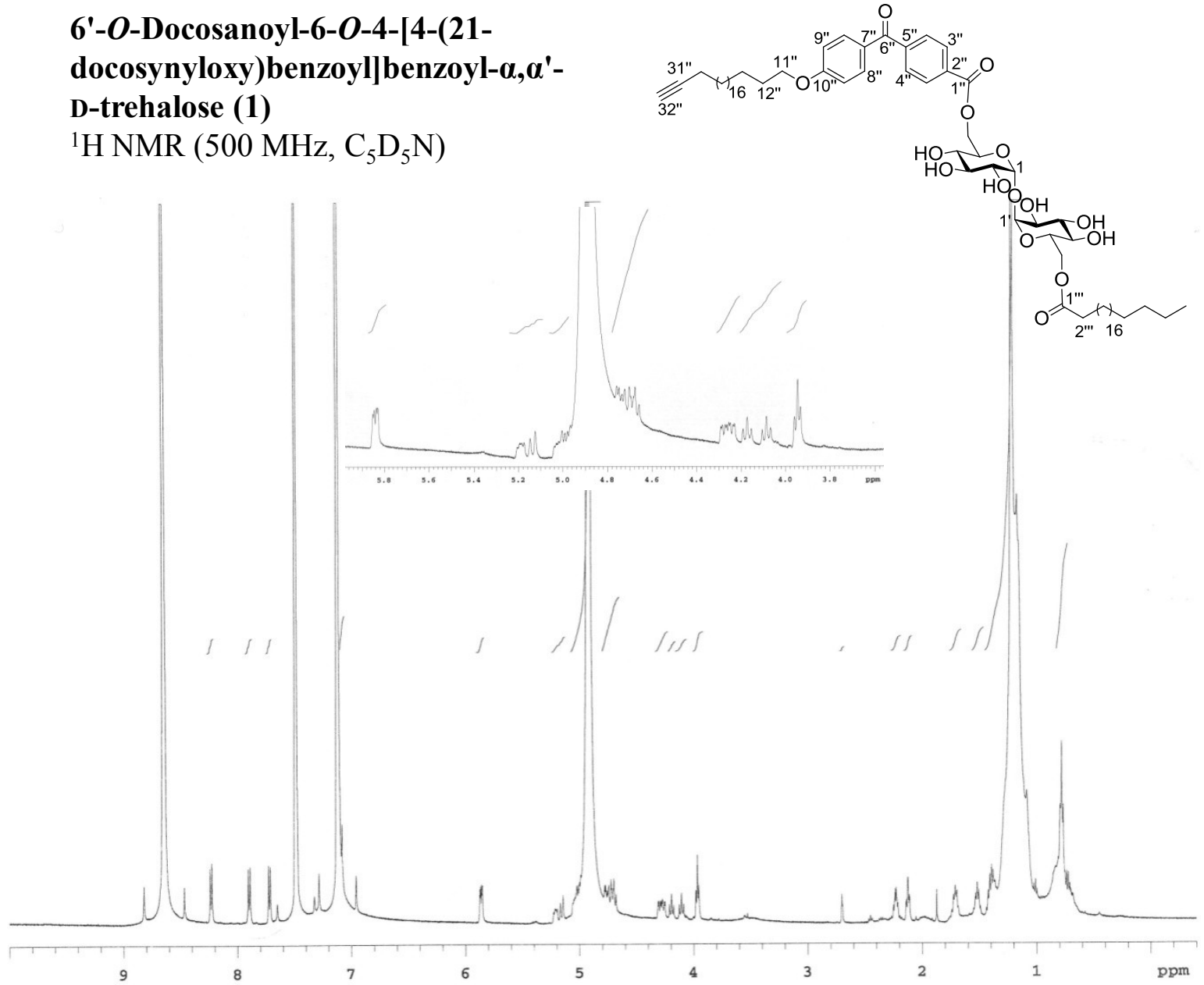

6'-O-Docosanoyl-6-O-4-[4-(21docosynyloxy)benzoyl]benzoyl- $\alpha, \alpha^{\prime}-$ D-trehalose (1)

${ }^{13} \mathrm{C}$ NMR $\left(125 \mathrm{MHz}, \mathrm{C}_{5} \mathrm{D}_{5} \mathrm{~N}\right)$

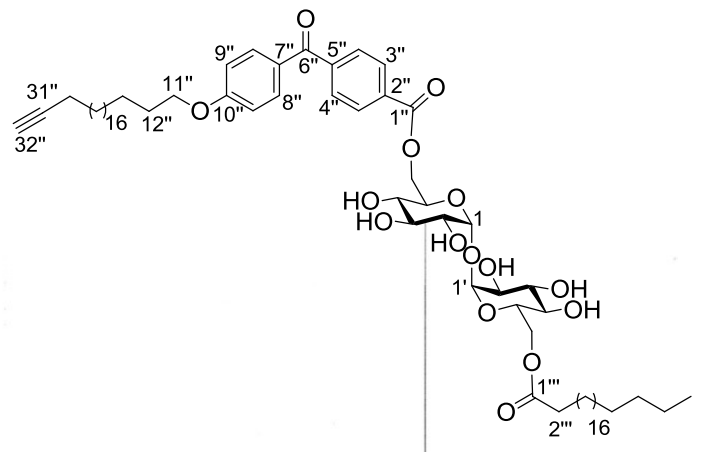

